Pac, David Frank

F2mdpo Mule deer

1991 population organization? behavior and dynamics in a northern Rocky

\title{
MULE DEER POPULATION ORGANIZATION, BEHAVIOR AND DYNAMICS IN A NORTHERN ROCKY MOUNTAIN ENVIRONMENT
}

David F. Pac

Richard J. Mackie Henry E. Jorgensen

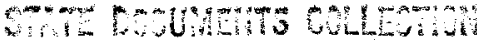

PED 1.1902

WANTAY STATE LERATY

ISI E. GW AVE.

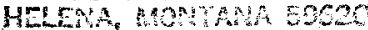

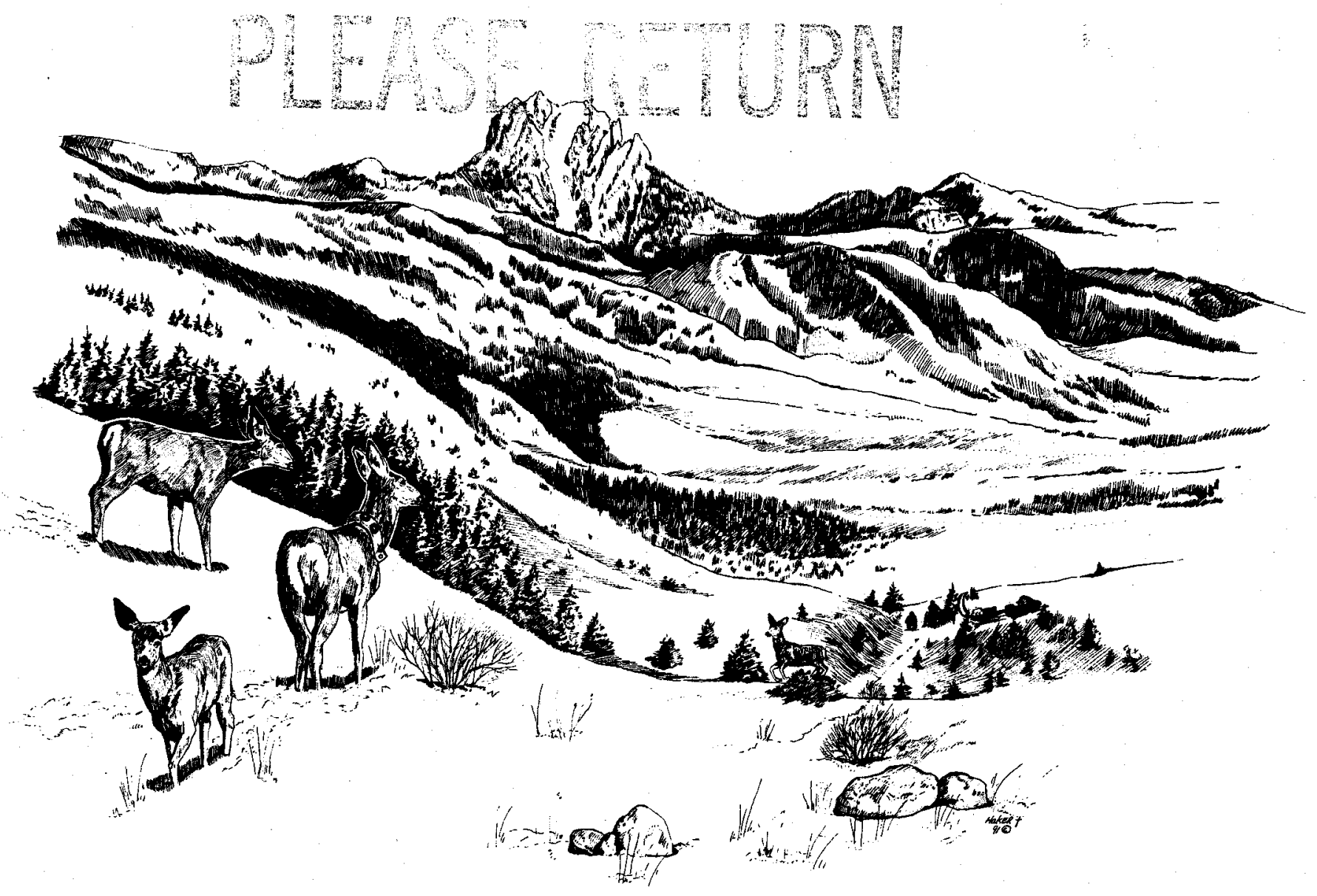


2) $\quad$ का

新舀 9

HA. -21003
MONTANA STATE LIBRARY S599.7357 F2mdpo 1991 c.1 Pac

Mule deer population organization, behav

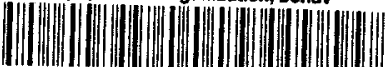

30864000761984 
FINAL REPORT

\section{RESEARCH PROJECT}

STATE: Montana

\begin{tabular}{|c|c|c|c|}
\hline PROJECT NO: & W-120-R-7-18 & TITLE: & Statewide Wildlife Research \\
\hline PROGRAM NO: & I & TITLE: & Statewide Big Game Research \\
\hline STUDY NO: & BG-1.2 & TITLE: & $\begin{array}{l}\text { Statewide Mule Deer Ecology } \\
\text { Studies }\end{array}$ \\
\hline \multirow[t]{2}{*}{ JOB NO: } & 1 & TITLE: & $\begin{array}{l}\text { Population ecology and habitat } \\
\text { relationships of mule deer in the } \\
\text { - Bridger Mountains, Montana }\end{array}$ \\
\hline & & & $\begin{array}{l}\text { Mule deer population } \\
\text { organization, behavior and } \\
\text { dynamics in a northern Rocky } \\
\text { Mountain environment }\end{array}$ \\
\hline
\end{tabular}

Period Covered: July 1, 1975 - June 30, 1987

Prepared by: $\quad$ David F. Pac

Richard J. Mackie

Henry E. Jorgensen
Approved by: Donald A. Childress

John P. Weigand

Date: October 31, 1991 


\section{ACKNOWLEDGEMENTS}

Although compiled and written by the three of us, this report represents a compendium of our studies and the work of many others who completed graduate research theses or participated in studies in the Bridger Mountains. These include Bruce T. Wilkins, who conducted the first studies of mule deer in the Bridger Mountains during 1955-1956 (Wilkins 1957), and subsequently established and measured transects and exclosures on winter range during 1957-1959. Later, thesis studies were completed by William F. Schwarzkoph (1973), Richard A. Bucsis (1974), Kenneth L. Hamlin (1974), Mary A. Morton (1976), David F. Pac (1976), William F. Steerey (1979), Heidi B. Youmans (1979), Harvey E. Nyberg (1980), and Alfred I. Rosgaard, Jr. (1981). Kenneth L. Hamlin and John G. Mundinger participated in studies during 1975, Shawn T. Stewart in 1976, and Craig J. Knowles in 1977. Special thanks are extended to Ken Hamlin, Terry Lonner, Gary Dusek, John Mundinger, Rich DeSimone, Alan Wood, Phil Schladweiler, Ken Greer, Shawn Riley, Fred King, Harry Whitney, Mike Ross, and the late Dan Palmisciano for their technical assistance, encouragement, and friendship. Numerous other Montana State University students and personnel of the Montana Department of Fish, Wildlife and Parks provided assistance in trapping, mortality surveys, and vegetation measurements throughout the study. Ray Mule', William Hoskins, and Steve Martin assisted in data compilation and statistical analyses.

Other Fish, Wildlife and Parks personnel contributed significantly through direction and general support, especially Research Bureau Chiefs Eugene O. Allen and John P. Weigand. Arnold J. Foss, Regional Wildlife Manager, Bozeman, provided assistance and unending support for population surveys and other efforts from inception of the study through his untimely death in March 1988.

The assistance and skills of Super Cub pilots Roger and David Stradley and the late James D. Stradley, Gallatin Flying Service, Belgrade and helicopter pilots Murray and Mark Duffy, Central Helicopters, Bozeman, and Larry Schweitzer, Larry's Flying Service, Denton, also contributed greatly to the study and results achieved.

This study could not have been conducted without the cooperation and support of many landowners, especially Lloyd and Sandy Maher, Elsie Armstrong, Horace Morgan, Dick Morgan, Dick Scott, Lee Eblen, George Eblen, Frank Norman Jr., Buck Anderson, Dave Irish, Hank, George and Mary Leffingwell, Charlie Papke, Lester Warwood, Dave Warwood, O. F. Peckinpaugh, Chuck Callatine, "Bud" Miles, "Frosty" Rall, James Taylor, Tom LaProwse, Ken Goering, Helen Walker, Jack Dunne, Orville Johns, Pehr Anderson, Mike Lee, and Park Swandal. 
We thank Martha A. Lonner and Marsha Leritz of Media Works, Bozeman, for their efforts in producing high quality figure graphics and Diana Haker for the cover drawing. Margaret Morelli, Erin Hooten, Tami Fuller, and Kay Coquyt demonstrated unending patience in typing and proofreading the final manuscript and the many revisions. Finally, we would like to especially thank our wives, Helga, Barb, and Dorothy, and our families for their sacrifices during this long endeavor.

The study was conducted with funding provided by Federal Aid in Wildlife Restoration, Montana Department of Fish, Wildlife and Parks Projects W-98-R, W-100$\mathrm{R}$, and $\mathrm{W}-120-\mathrm{R}$. Additional support was provided by the Department of Biology and the Montana Agricultural Experiment Station, Montana State University. 


\section{TABLE OF CONTENTS}

CHAPTER 1 - INTRODUCTION $\ldots \ldots \ldots \ldots \ldots \ldots \ldots \ldots \ldots$

CHAPTER 2 - APPROACH AND METHODS $\ldots \ldots \ldots \ldots \ldots \ldots$

Deer Distribution and Home Range $\ldots \ldots \ldots \ldots \ldots \ldots . \ldots$

Environmental Description and Deer Habitat Use ... . . . . . 5

Population Characteristics and Dynamics $\ldots \ldots \ldots \ldots \ldots \ldots$

CHAPTER 3 - THE BRIDGER MOUNTAIN STUDY AREA $\ldots \ldots$. . 12

Location and Topography $\ldots \ldots \ldots \ldots \ldots \ldots \ldots \ldots$

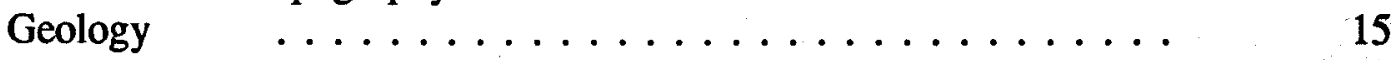

Climate and Weather $\ldots \ldots \ldots \ldots \ldots \ldots \ldots \ldots$

Vegetation $\quad \ldots \ldots \ldots \ldots \ldots \ldots \ldots \ldots \ldots \ldots$

Land Use and Other Animals $\ldots \ldots \ldots \ldots \ldots \ldots \ldots . \ldots . \ldots . \ldots 22$

CHAPTER 4 - SPATIAL ORGANIZATION $\ldots \ldots \ldots \ldots \ldots \ldots . \ldots 24$

PHU.1 - Northwest Slope . . . . . . . . . . . . . 27

PHU 2 - Southwest Slope . . . . . . . . . . . . . 29

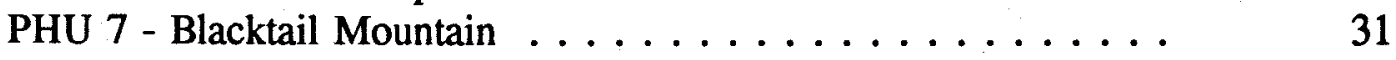

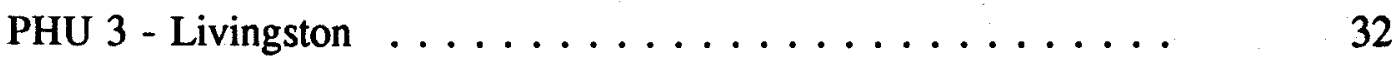

PHU 4 - Brackett Creek ................ 33

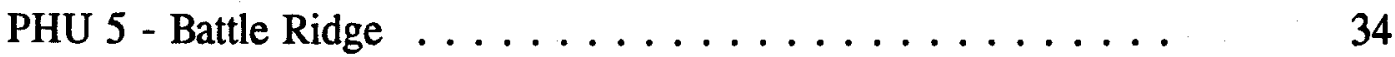

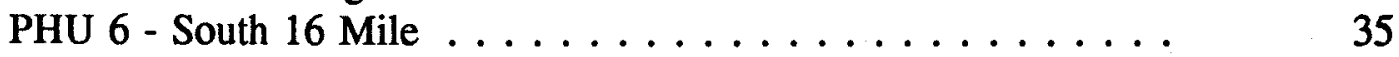

Population Subunits within PHUs $\ldots \ldots \ldots \ldots \ldots \ldots$

Behavioral Foundations for Population-Habitat Units . . . . . . . 40

Home Range Fidelity . . . . . . . . . . . $\quad 40$

Distribution and Use of Space by Related Deer . . . . . . 42

Genetic Composition of Population-Habitat Units . . . . . . . 48

Summary $\quad \ldots \ldots \ldots \ldots \ldots \ldots \ldots \ldots \ldots \ldots \ldots$

CHAPTER 5 - DEER DISTRIBUTION AND HABITAT USE IN

RELATION TO ENVIRONMENTAL FACTORS . . . . . . . . $\quad 50$

Topography and Climate $\ldots \ldots \ldots \ldots \ldots \ldots \ldots \ldots$

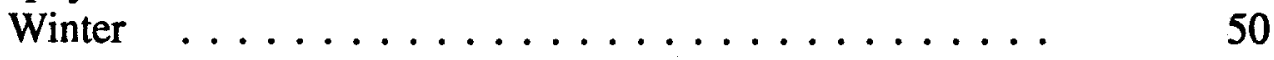

Spring, Summer, and Autumn $\ldots \ldots \ldots \ldots \ldots \ldots$ 
Seasonal Elevational Relationships $\ldots \ldots \ldots \ldots \ldots \ldots \ldots \ldots$

Winter $\ldots \ldots \ldots \ldots \ldots \ldots \ldots \ldots \ldots \ldots$

Summer ................. 62

Influence of Barrier Ridges $\ldots \ldots \ldots \ldots \ldots \ldots \ldots$. . . . . . 64

Deer Distribution and Habitat Use in Relation to Vegetation ... 73

General Patterns ................. 73

Seasonal Deer Distribution and Habitat Use in Relation to

Vegetation Characteristics in PHUs 1 and $4 \ldots \ldots \ldots .74$

Winter ................ 74

Spring $\ldots \ldots \ldots \ldots \ldots \ldots \ldots \ldots$

Summer $\ldots \ldots \ldots \ldots \ldots \ldots \ldots \ldots \ldots$

Autumn .................. $\quad 89$

Food Habits and Forage Relationships . . . . . . . . . . 90

Summary

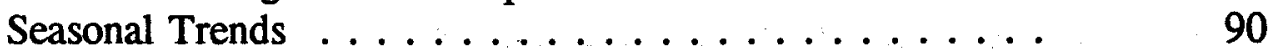

94

CHAPTER 6 - DEER MOVEMENTS AND BEHAVIORAL

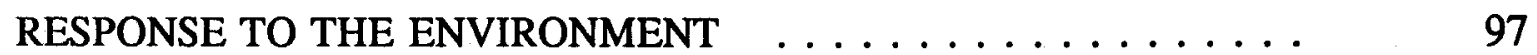

Individual Movement Patterns . . . . . . . . . . . . . . 97

Seasonal Use of Accessory Areas $\ldots \ldots \ldots \ldots \ldots . \ldots . \ldots 1$

Winter Accessory Areas . . . . . . . . . . . . . 103

Spring and Autumn Accessory Areas . . . . . . . . 106

Early Summer Accessory Areas . . . . . . . . . . . . . 115

Late Summer Accessory Areas . . . . . . . . . . . . . 121

Spatial Relationships Between Males and Females . . . . . . . 123

Monthly Mobility . . . . . . . . . . . . . . . . . . 124

Variation in Mobility Between Sexes . . . . . . . . . . 128

Seasonal Home Range Size and Mobility . . . . . . . . . . . 131

Distance and Timing of Movements Between Seasonal Ranges .. 137

Emigration $\quad \ldots \ldots \ldots \ldots \ldots \ldots \ldots \ldots \ldots \ldots \ldots$

Summary $\quad \ldots \ldots \ldots \ldots \ldots \ldots \ldots \ldots \ldots \ldots \ldots \ldots$

CHAPTER 7 - SOCIAL STRUCTURE $\ldots \ldots \ldots \ldots \ldots \ldots \ldots$

Maternal Doe Groups $\ldots \ldots \ldots \ldots \ldots \ldots \ldots \ldots$

Mature Buck Groups $\ldots \ldots \ldots \ldots \ldots \ldots \ldots \ldots$

Mixed Groups $\ldots \ldots \ldots \ldots \ldots \ldots \ldots \ldots \ldots \ldots$

Yearling Male Groups $\ldots \ldots \ldots \ldots \ldots \ldots \ldots \ldots$

Monthly and Seasonal Changes in Group Size .......... 156

Habitat Factors Influencing Group Size and Distribution $\ldots \ldots$.

Summary $\ldots \ldots \ldots \ldots \ldots \ldots \ldots \ldots \ldots \ldots \ldots \ldots$

CHAPTER 8 - REPRODUCTION AND MORTALITY $\ldots \ldots \ldots \ldots$

Reproduction, Fawn Mortality, and Recruitment $\ldots \ldots \ldots \ldots$

Conception and Birthdates $\ldots \ldots \ldots \ldots \ldots \ldots$ 
Pregnancy, Ovulation, and Fetal Rates . . . . . . . . 165

Litter Size . . . . . . . . . . . . . . . . . . . . 168

Fawn Mortality . . . . . . . . . . . . . . . . 169

Fawn Recruitment . . . . . . . . . . . . . 178

Fawn Sex Ratios . . . . . . . . . . . . . . . . . . . 185

Fawn Mortality in Relation to Adult Density . . . . . . . . . 189

Adult Mortality . . . . . . . . . . . . . . . . 191

Annual and Seasonal Mortality Rates . . . . . . . . . 192

Adult Mortality/Recruitment Relationships . . . . . . . . 198

Age-Specific Survival Rates . . . . . . . . . . . . . 199

Adult females . . . . . . . . . . . . . 199

Adult males . . . . . . . . . . . . . . $\quad 202$

Adult Mortality-Winter Severity Relationships . . . . . . 203

Adult Mortality-Density Relationships . . . . . . . . . . . 205

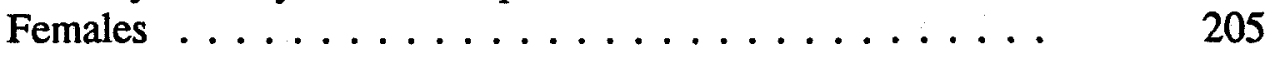

Males .................... 207

Summary $\quad \ldots \ldots \ldots \ldots \ldots \ldots \ldots \ldots \ldots \ldots \ldots \ldots$

CHAPTER 9 - POPULATION COMPOSITION, SIZE, AND TREND

Sex and Age Composition $\ldots \ldots \ldots \ldots \ldots \ldots \ldots$

Adult Age Structure .................... 214

Population Size and Trend . . . . . . . . . . . 223

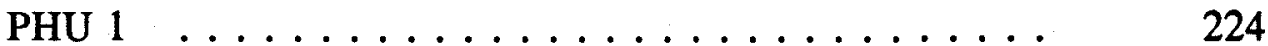

PHU 4 . . . . . . . . . . . . . . . . . . 227

Total Deer Numbers and Density in the Bridger Range . . . . . 230

Population Growth Rate . . . . . . . . . . . . . 234

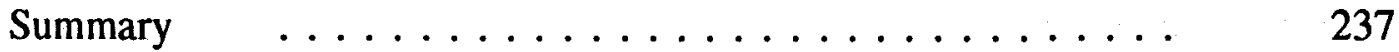

CHAPTER 10 - POPULATION-HABITAT RELATIONSHIPS . . . . . 239

Definition of Population and Habitat . . . . . . . . . . . 239

The Population-Habitat Unit (PHU) Concept . . . . . . . . . 240

Development of PHUs ... . . . . . . . . . . . . 242

Deer Behavior and Habitat Use Among Established PHUs . . . $\quad 245$

Influence of Behavior . . . . . . . . . . . . . 245

Influence of Stable Habitat Characteristics . . . . . . . 246

Influence of Variable Habitat Characteristics $\ldots \ldots \ldots .252$

CHAPTER 11 - POPULATION DYNAMICS . . . . . . . . . 258

Habitat Factors Affecting Population Size and Composition . . . . 258

Reproduction and Juvenile Mortality in Mountain Environments . 261

Adult Mortality in Mountain Environments . . . . . . . . . 266

Adult Females . . . . . . . . . . . . . . . . 267

Adult Males . . . . . . . . . . . . . . . 269 
Population Regulation $\ldots \ldots \ldots \ldots \ldots \ldots \ldots$

CHAPTER 12 - MANAGEMENT RECOMMENDATIONS _ . . . . 274

Population Management $\ldots \ldots \ldots \ldots \ldots . \ldots \ldots 274$

Habitat Management ................... 276

APPENDIX A - ENVIRONMENTAL CHARACTERISTICS OF

MULE DEER POPULATION-HABITAT UNITS IN THE

BRIDGER MOUNTAINS, MONTANA ..............

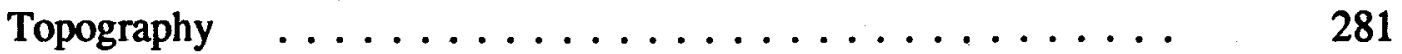

Climate and Weather $\ldots \ldots \ldots \ldots \ldots \ldots \ldots \ldots \ldots$

Temperature ................. 283

Precipitation ................ 286

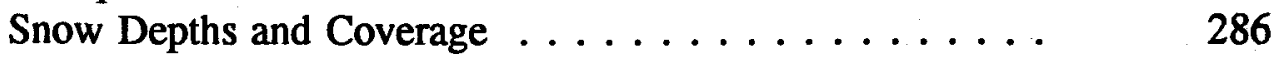

Wind ....................... 289

General Vegetational Characteristics of PHUs . . . . . . . . 291

Specific Vegetation Characteristics in PHUs 1 and $4 \ldots \ldots$. . 292

APPENDIX B $\quad \ldots \ldots \ldots \ldots \ldots \ldots \ldots \ldots \ldots \ldots . \ldots . \ldots . \ldots 295$

Appendix Table B1. Estimated number of mule deer bucks, does

and fawns harvested annually in each of three west slope

population/habitat units by year, 1975-1986. . . . . . . . . 295

Appendix Table B2. Estimated number of mule deer bucks, does, and fawns harvested annually in each of four east slope

population/habitat units by year, 1975-1986. . . . . . . . .

APPENDIX C $\quad \ldots \ldots \ldots \ldots \ldots \ldots$

Appendix Table C1. Mark-recapture (Lincoln indexes) population estimates for mule deer on the Armstrong segment of PHU 1 during April, 1973-1987. . . . . . . . . . . . . . .

Appendix Table C2. Mark-recapture (Lincoln indexes) population estimates and counting efficiencies for helicopter surveys of mule deer on winter ranges along the west slope of the Bridger Mountains, late winter 1979-1987. . . . . . . . . . . . . . Appendix Table C3. Mark-recapture (Lincoln indexes) population estimates and counting efficiencies for helicopter surveys of mule deer on winter ranges along the east slope of the Bridger Mountains, late winter 1979-1987. 


\section{CHAPTER 1}

\section{INTRODUCTION}

Mule deer (Odocoileus hemionus) occupy a broad spectrum of habitats throughout their range. Although biologists have long recognized that life history and demography of deer vary among populations along this spectrum, documentation was generally lacking. Recently completed studies of mule and white-tailed deer $(O$. virginianus) in several northern plains habitats in Montana (Hamlin and Mackie 1989, Wood et al. 1989, Dusek et al. 1989) have provided new knowledge concerning deer-habitat relationships and the role of environmental and behavioral factors on population ecology.

Our study focused on mule deer in Rocky Mountain habitat which may constitute the stronghold of the species throughout its range. This effort was initiated in 1975 by the Montana Fish and Game Department as part of a long-term investigation that included the three studies discussed above (Mackie et al. 1976). Because of the large size and complexity of our mountainous study area, we were particularly interested in studying variation in habitat use and population characteristics among different local environments. Perhaps, as suggested by Geist (1981), habitat selection, food habits, reproduction, and population dynamics are all closely linked to behavioral adaptions to individual habitats.

Objectives were to: 1) inter-relate environmental characteristics with patterns of mule deer habitat use and population parameters, 2) relate our results to studies in other major habitats and the prevailing concepts of population ecology, 3) develop new methods for improving deer management in Northern Rocky Mountain habitat.

The effort was initiated at a time when deer managers and scientists were perplexed by the failure of existing ecological concepts to explain widespread declines in mule deer populations in Montana and elsewhere in western North America. Because of this, the study was conducted specifically for deer management, and our data analyses and this report are directed substantially to that end. Management practice and theory are not mutually exclusive, however, and studies and data relative to one may address questions important to the other.

Few biologists would deny that serious gaps exist in current knowledge of population ecology. There is, for example, lack of agreement on such fundamental issues as definition of the term population. Yet, knowledge of how individuals of a species occupying natural environments are organized and integrated into populations is basic to understanding their ecology. 
Other questions exist with respect to definition of habitat and its relationship to members of the population. What are the mechanisms of adaptation to diverse environments? What factors determine distribution, movements, and habitat selection? What factors influence population size, structure, and dynamics?

Answers to questions such as these are vital to management. They can also be vital to population theory and construction of ecological models that attempt to increase our understanding about processes operating in nature or to predict future behavior of populations. However, even among species so widely studied as deer, knowledge is lacking or incomplete. This has led to much confusion about population-habitat relationships and the processes of population regulation (Hamlin and Mackie 1989).

The limited understanding of population ecology may have resulted from the short-term approach and limited scope of most studies. Many of these efforts have focused on obtaining only enough information to solve a specific management problem. Also, they usually were directed toward either habitat use or population characteristics. Long-term studies inter-relating habitat and population characteristics are rare.

Our 15-year study attempted to relate environmental characteristics to habitat use by deer and population dynamics. This perspective was especially advantageous when it became evident that the mule deer "population" in the Bridger Mountains actually consisted of seven discrete populations. Together with the environment in which it occurred, each of these populations comprised a distinct population-habitat unit.

In this report, Chapters 1 through 3 describe the study and study area. Chapters 4 through 9 present our results relative to population organization, habitat use, behavior, and dynamics. Chapters 10 through 12 discuss our results in terms of population-habitat relationships, population dynamics, and regulation and their implications for management. 


\section{CHAPTER 2}

\section{APPROACH AND METHODS}

Our studies, consisting of a combination of intensive and extensive field research, spanned more than 15 years. Like most long-term investigations, different approaches and methods were used.

Initially, the studies centered on habitat relationships and population dynamics of mule deer on the Armstrong study area along the northwest slope of the main Bridger Range. Wilkins $(1956,1957)$ had previously studied mule deer range use and food habits on this area during 1954-1955. Research on key browse utilization and condition trend survey techniques during 1957-1958 (Wilkins 1958) and 1970-1975 (Mackie 1975) provided additional background and baseline data.

During 1971-1975, five graduate thesis studies relating to mule deer habitat relationships were conducted on the Armstrong study area (Schwarzkoph 1973, Hamlin 1974, Bucsis 1974, Pac 1976, Morton 1976). These studies were supplemented by helicopter surveys to determine mule deer distribution and population characteristics along the west slope in early and late winter (Mackie et al. 1976).

With development of the Montana Statewide Deer Research Project in 1975, fulltime personnel were assigned to the study and investigations were gradually expanded to include all mule deer habitats within the entire Bridger Mountains. By 1978, it was evident that the mule deer "population" in this area consisted of several relatively distinct units that occupied a variety of environmental types (Mackie et al. 1978). Expanded helicopter surveys of all winter ranges in the Bridgers and additional graduate studies on the northwest slope (Youmans 1979), the southwest slope (Steerey 1979), and the Brackett Creek area on the east slope (Nyberg 1980, Rosgaard 1981), also indicated behavioral and demographic differences among deer in the units. This led us to expand data collection to test hypotheses that mule deer associated with individual winter ranges comprised distinct population-habitat units.

Funding and personnel constraints required that emphasis center in two intensive study units. These included our original core study area representing environments and conditions characteristic of the west slope and the Brackett Creek area representing the broadly different east slope. These two units provided the best opportunity to quantitatively describe the environment and deer population. Studies in other units were viewed and conducted as general, comparative, or supporting efforts. 
The different approaches, together with improvements in equipment and techniques, resulted in use of a variety of methods. The remainder of this chapter gives an overview of methodology employed to gather and analyze the major data sets. Further details are provided in results.

\section{Deer Distribution and Home Range}

A total of 968 mule deer (691F, $277 \mathrm{M}$ ) was captured and marked during 19721986. Sixty-nine of these were recaptured and recollared once, 21 were recollared twice, 3 were recollared three times, and 1 was recollared five times. The marked sample included 181 deer (155 F, 26M) equipped with radio transmitter collars. Some individual transmitter collars operated for no more than a few days in the early years of the study. Later, some transmitted for more than six years. All transmittered deer wore colored collars with individually recognizable symbols so they continued to provide some useful data even after failure of the transmitter. All other deer were marked with $10 \mathrm{~cm}$-wide individually recognizable neck bands constructed of Armortite (a nylon impregnated fabric) or Ritchey (vinyl) material. A numbered metal ear tag was attached to each ear of all deer.

Seven techniques were used to capture deer. Helicopter-drive traps (Beasom et al. 1980), Clover traps (Clover 1954), Cannon nets (Hawkins et al. 1968), and corral traps accounted for 57,21,13, and 7\% of all deer captured. Oregon style panel traps accounted for $2 \%$ of the total. One percent (12 deer) were captured by darting or netgunning (Barrett et al. 1982) from a helicopter. Captured deer were manually restrained. Sex, age determined by tooth replacement and wear (Robinette et al. 1957a), and general condition were noted for each.

We generally relocated radio-collared deer two to four times per month using a PA-18 Piper SuperCub aircraft. Most relocations were made during the first four hours after sunrise, although some flights occurred in the afternoon and early evening hours. No relocations were made during periods of darkness. A visual search was made for each individual located with radio telemetry. Overall, we recorded 6,889 telemetry and 13,059 visual locations of 784 marked deer. All locations of marked deer were plotted on $1: 15,840$ or $1: 24,000$ air photos.

Marked deer relocations were assigned Universal Transverse Mercator (UTM) coordinates and elevation to the nearest 30 meters. Seasonal home ranges expressed as minimum convex polygons (Mohr 1947) and average activity radii (AAR) (Hayne 1949) were calculated using the TELDAY software (T.N. Lonner and D.E. Burkhalter, User's Manual for the Computer Program TELDAY, Mont. Dept. Fish, Wildl. and Parks, unpubl.). These parameters were calculated for annual samples of relocations and aggregated samples of relocations gathered during all years for an individual while it occupied a particular seasonal home range. An index to monthly mobility was calculated according to procedures described by Dusek and Wood (1986). 
We also recorded social group characteristics and associations, numbers of fawns with marked females, calendar date, and other pertinent data. Group characteristics of unmarked deer were also recorded though locations were not always plotted on aerial photographs. Numerous other SuperCub flights were conducted to determine the summer distribution of neck-banded deer or to read and verify the number of marked individuals present on winter ranges before winter helicopter census flights.

In addition to data on seasonal distribution, home range, social structure, and behavior, relocations of marked deer also provided information on reproduction, recruitment, and mortality rates specific to sex and age classes.

Throughout this manuscript we used standardized definitions of sex/age class terminology: Adult doe and adult female refer to deer $\geq 1$ year of age. We did not routinely attempt to distinguish yearling females from those $\geq 2$ years. Adult bucks/adult males included individuals $\geq 1$ year; mature bucks were $\geq 2$ years. Yearlings were individuals between their first and second birthdays. Fawns were deer between birth and their first birthday on 1 June.

\section{Environmental Description and Deer Habitat Use}

Environmental measurements were conducted to characterize the Bridger Mountain Range (and population-habitat units included) as habitat for mule deer and to relate habitat selection and population characteristics to spatial and temporal variation in environmental conditions. Special emphasis was given to topography, climate/weather, and vegetation.

Topographic characteristics were measured using USGS topographic quadrangle maps. Mean, minimum, and maximum elevations were calculated from values recorded at $1-\mathrm{km}$ grid intervals across population-habitat units. Elevation data was summarized as frequency distributions of eight 200-meter elevational classes (from 1,300 to 2,900 m) for both winter range and total yearlong range. Topographic relief class (TRC) was calculated as the relative amount of elevational change between the $1-\mathrm{km}$ grid points in an east-west orientation. For winter ranges, the amount of area in steep $\left(20-30^{\circ}\right)$ and very steep $\left(>30^{\circ}\right)$ slopes of southerly (SSE-WSW) aspect was also determined.

Climatic differences and weather patterns, including seasonal temperature, precipitation, snow, and wind, were measured across the area (and compared among population-habitat units) using data from the National Weather Service Cooperative Reporting Stations at Montana State University (Bozeman), the Livingston Airport (NOAA 1978-1983), and weather recording stations maintained on five winter ranges (three on the west slope and two on the east slope of the Bridger Mountains) during October-May from 1978-79 through 1982-83. At these stations, temperature data were collected continuously using hygrothermographs, an anemometer and counter recorded wind speed, and snow depth and coverage was measured weekly along snow courses. 
For periods prior to 1978 and after 1983, winter weather data for these winter ranges were estimated by extrapolation from nearby U.S. Climatological stations. Calculation of annual winter severity indexes followed Leckenby (1986) except that wind and snow depth used weekly rather than hourly data.

Mean monthly temperatures across the study during summer were estimated from data for the official reporting station with conditions most similar to the area or population-habitat unit. Mean temperatures for autumn, winter, and spring months were estimated using data from our recording stations on winter ranges and/or the official reporting stations. For summer and autumn, we calculated an estimate of mean temperature at mean and high elevation within each population-habitat unit using the normal lapse rate of $6.5^{\circ} \mathrm{C} / 1,000 \mathrm{~m}$ (Lutgens and Tarbuck 1982). Estimates for winter and spring were similarly calculated for mean and low elevations within each winter range.

Precipitation characteristics across the entire area and within population-habitat units were estimated from a statewide precipitation map on which annual precipitation $<500 \mathrm{~mm}$ was mapped in $50 \mathrm{~mm}$ classes and precipitation $>500 \mathrm{~mm}$ was mapped in $250 \mathrm{~mm}$ classes. Mean annual precipitation was calculated by averaging the proportions of occurrence of midpoints of the precipitation class over the total area of each unit.

Snow depths, measured approximately four times monthly from November through May at weather stations on winter ranges, were extrapolated to estimate mean daily snow depths. Calculations utilized daily temperatures, estimated rate of snow melt, snow compaction at different temperatures, and data on daily snowfall and snowdepth at the Bozeman and Livingston weather stations.

General vegetation patterns and differences among population-habitat units were determined by mapping and measuring relative occurrence of major vegetation zones. These were: steppe, open canopy montane forest, closed canopy montane forest, and subalpine-alpine.

Initially, forest canopy coverage classes were:

1) scattered - individual trees widely separated with few if any crowns in contact;

2) open - some tree crowns in contact but numerous openings in stand;

3) medium - most crowns in contact but relatively large and dissimilar in size;

4) dense - nearly all crowns in contact, mostly small (narrow) and of similar size.

For analytical purposes, these classes were combined in two groups, open (classes 1 and 2) and closed (classes 3 and 4).

Detailed vegetation cover type maps $(1: 24,000)$ were constructed for the intensively studied Northwest Slope and Brackett Creek areas and computer digitized using the GEOSCAN software program (Lonner and Pexton 1983). Individual cover types (CTs) generally described species composition and structural characteristics of the 
overstory and understory. Cover types were, in essence, seral communities of habitat (climax) types described by Pfister et al. (1977) and Mueggler and Stewart (1980). Cover types were initially designated by aerial photo interpretation and modified as necessary by field reconnaissance and ground checking representative sites. Dominant plant species in the overstory and understory were listed in addition to other associated species. Elevation, slope, aspect, tree canopy coverage, and substrate type were recorded for each site.

Computer generated sampling plots or "scan circles" were employed in the analysis of deer use of vegetation types. The conceptual basis for this method was that an animal location was related not only to the single vegetation cover type at that precise location, but may also have been significantly influenced by the mosaic of types within a prescribed area around the relocation point. We used a scan circle radius of $100 \mathrm{~m}$ to reflect the limited mobility within small seasonal home ranges. A software package (Geocalc, William Hoskins, Unpubl.) was used to calculate cover type areas within deer and randomly located scan circles.

For analysis of deer use of vegetation, 53 individual cover types were combined into a hierarchical system of classification. The primary stratum described major vegetation zones along an elevation gradient including steppe, montane forest, and subalpine/alpine. Secondary strata were categorized according to major structural differences in the overstory layer. The tertiary strata in the hierarchy categorized forest cover types according to the dominant tree species in the overstory layer. This terminology generally follows standardized definitions (Hann and Jensen 1987). Statistical comparisons of observed and expected use of cover types followed the technique described by Neu et al. (1974) that employed a Bonferroni Z statistic.

Trends in production of understory vegetation on forested summer range along the Northwest Slope were measured from 1980 through 1984 on nine permanent transects. The transects were selected to sample a spectrum of cover types and site characteristics. Each consisted of 10-20 permanently marked sampling points on which production was measured with a capacitance meter. An additional 4-5 sampling points were similarly measured and then clipped for calibration of capacitance meter readings at each site. Measurements were made annually in early August when vegetation development peaked.

Three separate data sets, two dating back to 1955 and one to 1972, provided basis for evaluation of trends in density, canopy coverage, and canopy volume of important shrubs on winter range along the Northwest Slope during the past 30 years. These included:

1) chart-map measurements of three exclosures and adjacent check plots established in 1955 during studies by Wilkins (1957). Remeasurements were completed in 1973 and 1983. Two of the exclosures and check plots were mapped during all three periods. 
2) measurements of shrub intercept on 20 fifty-foot line intercept transects also established by Wilkins in 1955. Similar transects were established in the same general area and remeasured in 1983.

3) measurements of point-centered-quarter transects established in 1972 by Buscis (1974) and remeasured in 1983.

Population Characteristics and Dynamics

Complete-coverage helicopter surveys designed for census (Mackie et al, 1981) were conducted on some or all mule deer winter ranges during 1971-1987. During most years, early (late December-early January) and late (late March-early April) winter surveys were completed annually on principle study area units. Other winter ranges were flown according to annual budget constraints. During all surveys, numbers, sex, age, group size and composition, elevation, general location, and other data were recorded for mule deer and most other important species observed. We also attempted to ascertain the identity of all marked deer observed. All deer were classified as fawns, adult females, yearling males, and mature males. During early winter, yearling and mature males were distinguished by gross differences in antler size. Deer were classified only as adults or fawns in late winter.

McCullough and Hirth (1988) recommended that population census and marking be restricted to periods when catchability and observability biases are minimized or at least consistent from year to year. Early studies in the Bridger Mountains indicated that the annual life cycle of mule deer provided a "window" of opportunity for both marking and censusing populations. We confined marking operations to January-March when deer were dependably concentrated on winter ranges and population census to late MarchApril when deer were highly observable while seeking new, green forage on open footslopes.

During early years of the study when aerial census techniques were being developed, efforts to obtain reasonable annual estimates of population size and trend concentrated on the relatively small Armstrong segment of the Northwest Slope. Beginning in 1973, marked deer were available for mark-recapture Lincoln index estimates (Davis and Winstead 1980) derived from replicate survey counts conducted from a vehicle on the entire winter range. Personnel changes precluded population estimation in spring 1974. However, the counts were resumed and intensified in early spring 1975 and continued annually through 1987 . An average of $8.3 \pm 2.5$ complete counts were conducted annually during that period. Marked samples constituted 30-69\% of the estimated total populations from 1975-1983 and 12-22\% during 1984-1987. The mean of all estimates was listed as the best indicator of total deer numbers during spring of each year. Deviation around mean estimates was not large, particularly after 1978 when we perfected the vehicle route technique and could utilize large samples of marked deer during most years. All individual surveys met the assumption that a valid estimate 
required that the product of $\mathbf{M}$ (total marked) and $\mathbf{C}$ (total observed) exceed four times the population size (Robson and Regier 1964).

Lincoln index estimates of population size were also derived annually from full coverage helicopter census (Mackie et al. 1981) in late March or early April 1979-1987 on the Northwest Slope and Brackett Creek winter ranges. Although full coverage surveys were flown on these and other winter ranges during some or all years from 19711987, comprehensive efforts to derive population estimates were not initiated until 1979. Marking efforts in other populations permitted calculation of late winter Lincoln estimates only during 1981-1983. In these units, an average of 5\% (range $=2-10 \%$ ) of each population was marked in late winter. Rice and Harder (1977) reported that aerial census increased the ability to sample a large proportion of the population which permitted reductions in the required numbers of marked individuals.

According to McCullough and Hirth (1988), error in population estimates may be attributed primarily to catchability and observability bias, and sample size of $\mathbf{m}$ (marked observed), in that order. For $m \geq 30$, virtually all error was restricted to catchability and observability bias. For our estimates, $\mathrm{m}$ approached or exceeded 30 during most surveys. We attempted to minimize catchability bias by trapping intensively throughout the zone of winter concentration using a variety of capture methods. Observability bias was minimized by basing Lincoln estimates only on data collected in late March-April when all sex/age classes utilized the "early greenup" in open habitats at low elevation. More than half of the estimated total population was observed on most surveys.

Use of complete coverage aerial surveys minimized possible bias associated with partial or quadrat sampling systems. Observability bias related to differential distribution by sex and age class should also be reduced in full coverage counts. All aerial sampling methods in a particular habitat are subject to visibility bias because any census technique results in fewer animals seen than actually occur (Caughley and Goddard 1972). Total coverage counts always represented a minimum estimate of deer numbers on the area. Therefore, we had only to measure our aerial counting efficiency to develop a total population estimate.

We do not report Lincoln estimates for early winter aerial surveys. These were less reliable because of difficulty in assessing the number and distribution of marked samples available at the time surveys were conducted. Differential timing of movement between winter and summer ranges by individual deer precluded determination of marked deer that occurred on the area surveyed or had died on summer range. However, arithmetic modeling that included reconciliation of successive population estimates, population composition and available data on annual recruitment, and mortality rates permitted a reconstruction of early winter population size and composition for the Armstrong segment of the Northwest Slope. In this approach, population size, structure, and dynamics during any one season or year had to be reconcilable with estimates and 
data for previous and subsequent seasons and years before being acceptable. Arithmetic models were also developed for the Brackett Creek population. These models provided the best and final estimates of population size although they seldom varied significantly from the Lincoln estimates for late winter.

Another method was used to estimate relative numbers of deer associated with all populations in late winter. This involved application of an index of observability (or accuracy of counting) to numbers of deer counted on each winter range. On west and east slope winter ranges, aerial counting efficiency was measured during 12 and 16 full coverage helicopter surveys, respectively, in late winter. All surveys were flown parallel to drainages which maximized counting efficiency (Bartmann et al. 1986). Mackie et al. (1981) indicated that the proportion of marked deer counted during full coverage aerial surveys was generally consistent for similar sets of conditions in a particular habitat. Only marked deer known to be on the areas just prior to the census were used to calculate aerial counting efficiencies. This was established by verifying the presence of radio-collared deer and reading individually color-coded neckbands during surveys from a Piper SuperCub and from vehicle routes. This approach minimized problems associated with mark-recapture techniques (Kufeld et al. 1987). For particular winter ranges or years when marked samples were unavailable, we derived approximations of the number of deer on the area surveyed by referring to a three-point range expressed by the mean \pm 1 standard deviation of the aerial counting efficiencies measured from marked samples in other years in that habitat or a similar adjacent unit.

Seasonal and annual estimates of mortality were calculated from models of the two intensively studied populations. In addition, winter mortality patterns on the Armstrong area were monitored annually by carcass surveys on the winter range in early May 1974-1987.

Annual hunter harvest of adult bucks on the entire study area was estimated from statewide harvest surveys that sampled the two hunting units in the Bridger complex. In addition, during 1978-1987 a mail questionnaire was sent to all recipients of special antlerless permits for mule deer in both hunting districts together with a request for return of lower jaws from harvested deer. Determination of losses of marked deer permitted calculation of age-specific rates of mortality.

Biological materials and physical measurements were obtained from deer found dead of natural causes, hunter kills, trap mortalities, and from special collections. When possible, sex, age, location, and cause of death were recorded. Age was initially assigned on the basis of tooth replacement and wear with cementum analysis (Gilbert 1966) used to confirm or adjust ages of all deer $\geq 2$ years of age. Incidence of ovulation, corpora lutea of pregnancy, and fertilization rates (Cheatum 1949) were determined from collections of reproductive tracts. Fetal ages were assigned from crown-rump measurements following Hudson and Browman (1959). Age-specific fawn production and survival was determined from individually marked females of known or 
assigned age. Approximately one liter of the contents of the rumen of 228 mule deer that died of all causes during 1971-1987 was collected for analysis of food habits following methods of Wilkins (1957).

Statistical procedures followed Zar (1984). Analyses were conducted using the Montana State University computing services and a Zenith Data Systems 241 microcomputer. Statistical packages included the Statistical Analysis System (SAS) (Ray 1982) and MSUSTAT (Lund 1983). 


\section{CHAPTER 3}

\section{THE BRIDGER MOUNTAIN STUDY AREA}

The study area encompassed the entire Bridger Mountain Range, a representative, semi-isolated frontal range on the eastern flank of the northern Rocky Mountains. The area includes most of the topographic, climatic, and vegetational types that characterize the interface between the Rocky Mountains and Great Plains. This chapter generally describes the area and the physical and biotic features associated with its use by mule deer. Additional details concerning topography, climate/weather, and vegetation of the area and differences among population-habitat units are presented in Chapters 4,5 , and 6 and Appendix A.

Location and Topography

The Bridger Mountains are located at $45^{\circ} 53^{\prime}$ north latitude, $110^{\circ} 53^{\prime}$ west longitude in southwestern Montana. The study area encompassed approximately 2,000 $\mathrm{km}^{2}$ and included the main Bridger Range, three attending ridge formations, and footslopes extending to the Shields River to the east, 16-Mile Creek to the north, and the East Gallatin River or Dry Creek on the west (Fig. 3.1). Maximum distance north-south was $70 \mathrm{~km}$; the greatest distance east-west was about $35 \mathrm{~km}$.

Topographically, the area is dominated by the main Bridger Range -- a single, north-south trending ridge extending $40 \mathrm{~km}$ in an arcuate pattern along the west flank of the complex (Fig. 3.2). The highest elevations and steepest topography within the study area occur in the Bridger Range. Maximum elevations vary from $2,400 \mathrm{~m}$ on the southern and northern ends of the range to $2,947 \mathrm{~m}$ on Sacajawea and Hardscrabble Peaks near the center. The continuity of the ridge is broken by Ross Pass and Flathead Pass which separates Blacktail Mountain from the remainder of the range. Both have elevations about $2,130 \mathrm{~m}$. A few other minor "passes" exist, but all are high and steep.

The steepest slopes occur at the heads of glacial cirques carved into the eastern flanks of the main Bridger ridge. Some drop $40^{\circ}$ over a distance of $340 \mathrm{~m}$ while others drop near vertically over shorter distances. Most of the western flank is inclined over $20^{\circ}$ with many slopes of $30^{\circ}$ or more. The steeper slopes along the east flank become more gently sloping ridges, drainages, and valleys below 2,000-2,100 m elevation. Slopes along the west flank meet the Gallatin Valley at $1,700-1,800 \mathrm{~m}$. 


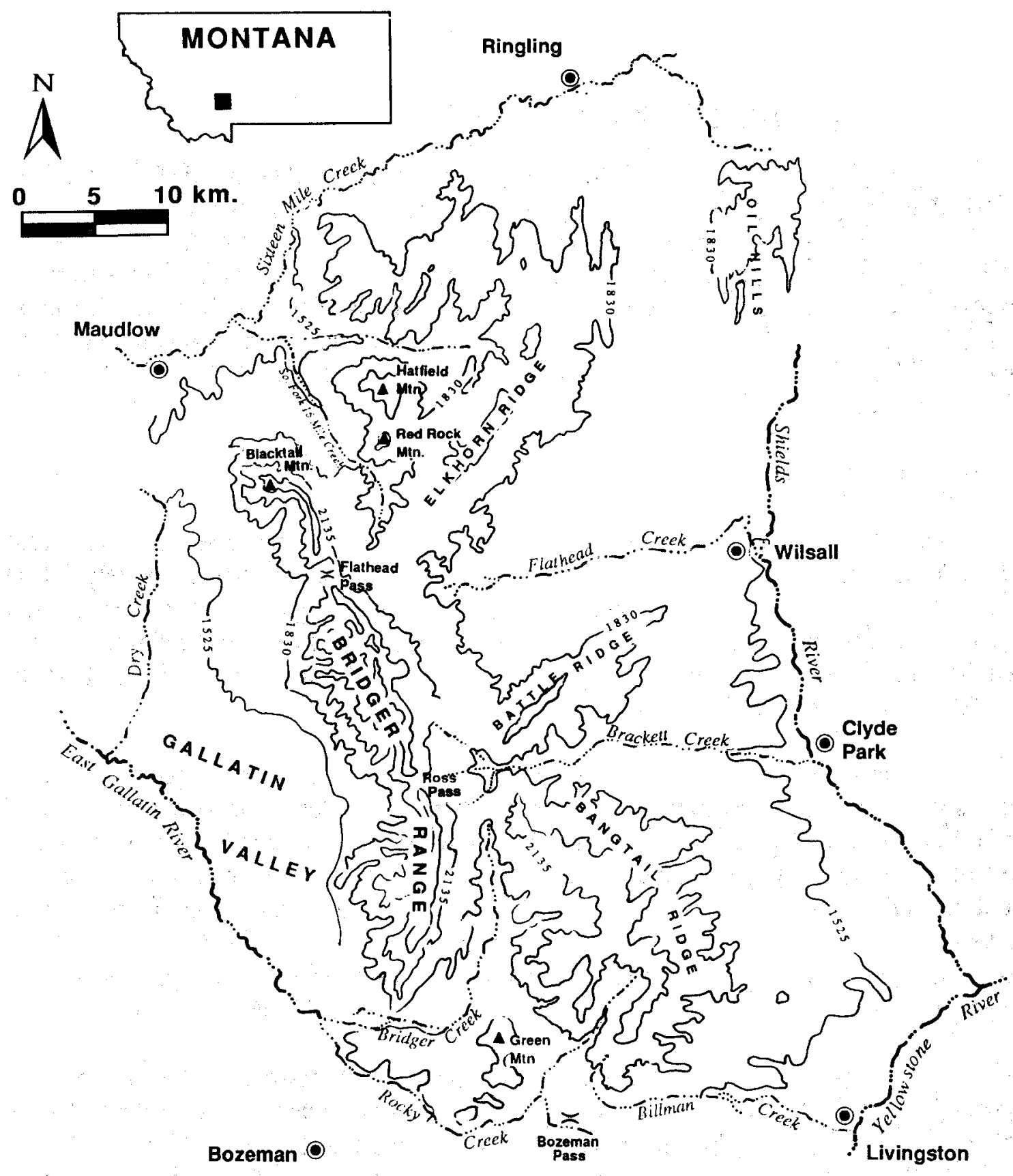

Figure 3.1. The Bridger Mountain study area. Contour interval is $305 \mathrm{~m}$. 


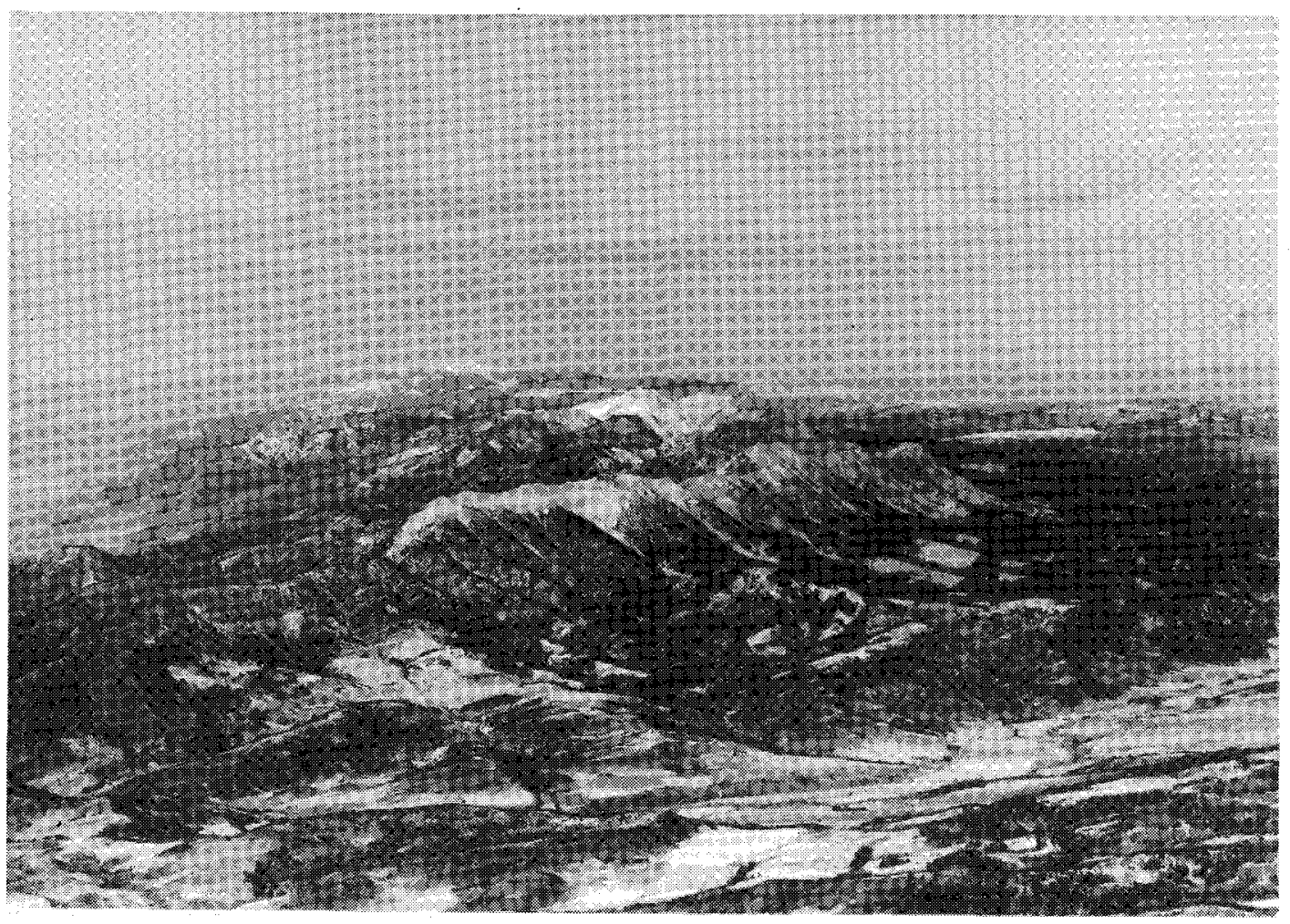

Figure 3.2. A view of the Bridger Mountain Range from the south.

Topography of the eastern two-thirds of the Bridger Mountain complex is dominated by the relatively low Bangtail, Battle, and Elkhorn Ridges. Bangtail Ridge, extending southeast, is the highest $(2,400 \mathrm{~m})$ and most prominent. Both Battle Ridge and Elkhorn Ridge have maximum elevations of 2,100-2,300 m. Green Mountain (2,093 m), Red Rock Mountain $(2,225 \mathrm{~m})$, and Hatfield Mountain $(2,321 \mathrm{~m})$ are smaller, semi-isolated ridges in the south-central and north-central portions of the study area, respectively.

The eastern flanks of Bangtail and Battle Ridges consist of mildly dissected footslopes descending gradually from about $1,830 \mathrm{~m}$ to $1,370-1,530 \mathrm{~m}$ along the Shields River. North of Flathead Creek, gently undulating lands extended as a broad, shallow valley from the footslopes of Elkhorn Ridge to the Shields River and Oil Hills. The latter, included in the study area as a result of summer use by mule deer wintering on the east flank of Battle Ridge, are an isolated escarpment near the headwaters of the Shields River.

To the north, the Bridger Mountain complex is bounded by moderately dissected benchlands and undulating foothills comprising the southern portion of the 16-Mile Creek Basin. To the south, the Bridger Mountains interface with the Gallatin Range along Rocky and Billman Creeks and Bozeman Pass. 
Four major stream drainages dissect the Bridger Complex. These include the South Fork of 16-Mile Creek, which drains northwesterly between Blacktail Mountain and the Elkhorn Ridge-Red Rock Hatfield Mountain complex; Flathead Creek that flows easterly separating Elkhorn and Battle Ridges; Brackett Creek running easterly between Battle and Bangtail Ridge; and Bridger Creek separating the southern portion of the main Bridger Range from Bangtail Ridge and Green Mountain. Other minor streams occur throughout the area but serve largely to promote topographic diversity.

The lowest elevations within the study area $(1,365 \mathrm{~m})$ occur at the confluence of the Shields and Yellowstone Rivers in the southeastern corner, the confluence of Dry Creek and the East Gallatin River on the western periphery, and along 16-Mile Creek at Maudlow in the northwestern corner. Ringling, in the northeastern corner, has an elevation of $1,630 \mathrm{~m}$.

\section{Geology}

The topography of the study area reflects a history of geologic change as complex as anywhere in western North America (Lageson 1989). Six major events were involved. Collectively, these events represent a microcosm of all the geological forces that influenced the Northern Rocky Mountain region. They served to shape other physical and biotic characteristics of the area, including climate and weather patterns, soils, vegetation, land use, and wildlife distribution and demographics. They included:

1. Development of the western North American crust comprising igneous and metamorphic rocks occurred some 2.5-3.5 billion years before present (BP). These rocks are presently exposed along low ridges on the southwest flank of the main Bridger Range.

2. Crustal deformation (rifting) of northwestern and west-central Montana approximately 1.4 billion years BP resulted in deposition of rocks now found along the northwest slopes of the range. The southern boundary of this rift was located along a line through the present Ross Pass.

3. Transgression and regression of shallow marine seas that periodically covered Montana resulted in deposition and formation of shales, sandstones, and limestones from around 570-65 million years BP. These strata presently crop out along the northern crest of the Bridger Range and on major ridges to the east.

4. Compressional folding and faulting uplifted and tilted those strata to a near-vertical attitude during the "Laramide orogeny" that created the Rocky Mountains about 60-55 million years BP. Upended and/or overturned strata (Madison limestones) formed the crest of the Bridger Range while less tilted and less resistant sandstones and shales formed lower ridges and valleys to the east. 
5. Extension of the crust of western North America occurred during the past 20 million years. This resulted in basin and range topography from the Bridger Range west and formation of the present Gallatin Valley through down-dropping of the western limb of the old Laramide Bridger Uplift. This process resulted in the steep slopes characteristic of the west side of the present day Bridger Range.

6. Differential erosion since the Laramide orogeny, plus local glaciation during the last 2 million years, carved the topography of the present Bridger Mountain complex. The presence of highly resistant vertical limestones resulted in the knife-like crest of the main Bridger Range while glaciers locally carved out cirque basins and valleys along slopes immediately east of the crest. Glaciation was more extensive along the eastern slope because of prevailing westerly winds that drifted snow across the crest onto the upper east flank. The occurrence of interspersed strata of relatively resistant sandstones and unresistant shales similarly resulted in differential erosion that carved Bangtail, Battle, Elkhorn, and other minor ridges and intervening valleys east of the Bridger Range.

\section{Climate and Weather}

The climate of the area generally resembles that of a middle latitude steppe (Lutgens and Tarbuck 1982). Conditions are semiarid with relatively long cold winters and short cool summers. This results from the combined effect of distance and rain-blocking mountain ranges between the Pacific Ocean and the study area on precipitation and domination of the area by cool dry air masses originating over the continent. There are, however, some important modifications of the basic steppe pattern within the study area.

First, there is considerably more maritime modification of the continental air mass over the area than over the northern plains to the east. For example, cyclonic (low pressure) storms originating over the Pacific Ocean frequently pass west to east through the area and increase precipitation during spring-early summer and autumn-early winter. In summer, heating of the continental air mass over the area produces low pressure which draws additional moisture from the ocean. In winter, a cold high pressure ridge within the air mass tends to push Pacific storm systems and moisture to the south. Although seasonal variation in temperature is greater than in areas to the west, the extremes are not nearly as great and periods of exceptional temperatures are shorter than in the central United States and Canada where the continental air mass is more dominant.

Secondly, because the study area comprises a mountain complex within a region of steppe, orographic effects produce a variety of local, cooler and wetter climates with characteristics similar to other macroclimates. Thus, the climate of the mid-elevation forest zone resembles a warm subarctic macroclimate (Lutgens and Tarbuck 1982). However, winters are shorter and lack the bitterly cold temperatures of the subarctic, while summers are only relatively cool. Also, the overall seasonal distribution of 
precipitation is not significantly different from warm subarctic, though somewhat greater amounts occur during summer than during winter. Forests at higher elevations $(>2,100$ $\mathrm{m}$ ) have a climate similar to the cool subarctic macroclimate, and areas above timberline correspond to a tundra climate. The principal differences are longer day length and greater solar radiation in winter, shorter days in summer, and greater precipitation yearlong at high elevations in the Bridgers.

Patterns of variation in seasonal precipitation and temperature within the study area, as exemplified by data from the Bozeman, Belgrade, and Livingston weather stations, are shown in Fig. 3.3. Precipitation typically is lowest during mid winter and mid summer when the continental air masses hold most strongly over the area. Precipitation is greatest in spring-early summer and autumn-early winter when the influence of those air masses subsides and Pacific storms move through. Although the convection storms of mid summer generally carry greater amounts of moisture than the storm systems of mid winter, overall precipitation in summer is less than in spring and autumn. This results in a general annual pattern of increasing precipitation from March to a peak in June, a decline through mid summer, another increase in late August to a second, smaller peak in September, followed by a general decline to the yearly low in February.

Despite the general winter "drought," snowfall constitutes a significant proportion $(>30 \%)$ of the total annual precipitation in the area. Snow may occur at any time of the year but usually begins in September and almost always is the dominant form of precipitation from November through April. Average annual snowfall in Bozeman is 213 $\mathrm{cm}$. It might also be noted that although precipitation in winter is much less than in summer, evaporation is low such that a net accumulation of moisture occurs during the period. During summer, evaporation occurs at a greater rate than precipitation and results in a net soil moisture deficit in most areas by mid to late summer (Fig. 3.3).

As indicated earlier, the annual temperature regime of the study area is generally characterized by considerable seasonal variation. Winters typically are long and cold with subfreezing average temperatures from November to March (Fig. 3.3). At Bozeman, the lowest average monthly temperature, $-6^{\circ} \mathrm{C}$, occurs in January; the highest, $19.4^{\circ} \mathrm{C}$, occurs in July.

Within these general patterns, orographic and elevational factors cause significant local variation in climate and weather conditions across the area. Both Bozeman and Belgrade, located west of the Bridger Range, receive higher annual precipitation than other lowland locations in the region.

Average annual precipitation increases sharply with elevation from $40-45 \mathrm{~cm}$ annually along the western footslopes to an estimated $127 \mathrm{~cm}$ along the main Bridger ridge, then declines progressively along the east and north flanks. Overall, precipitation is lower along the eastern foothills than in the Gallatin Valley to the west. Although this 

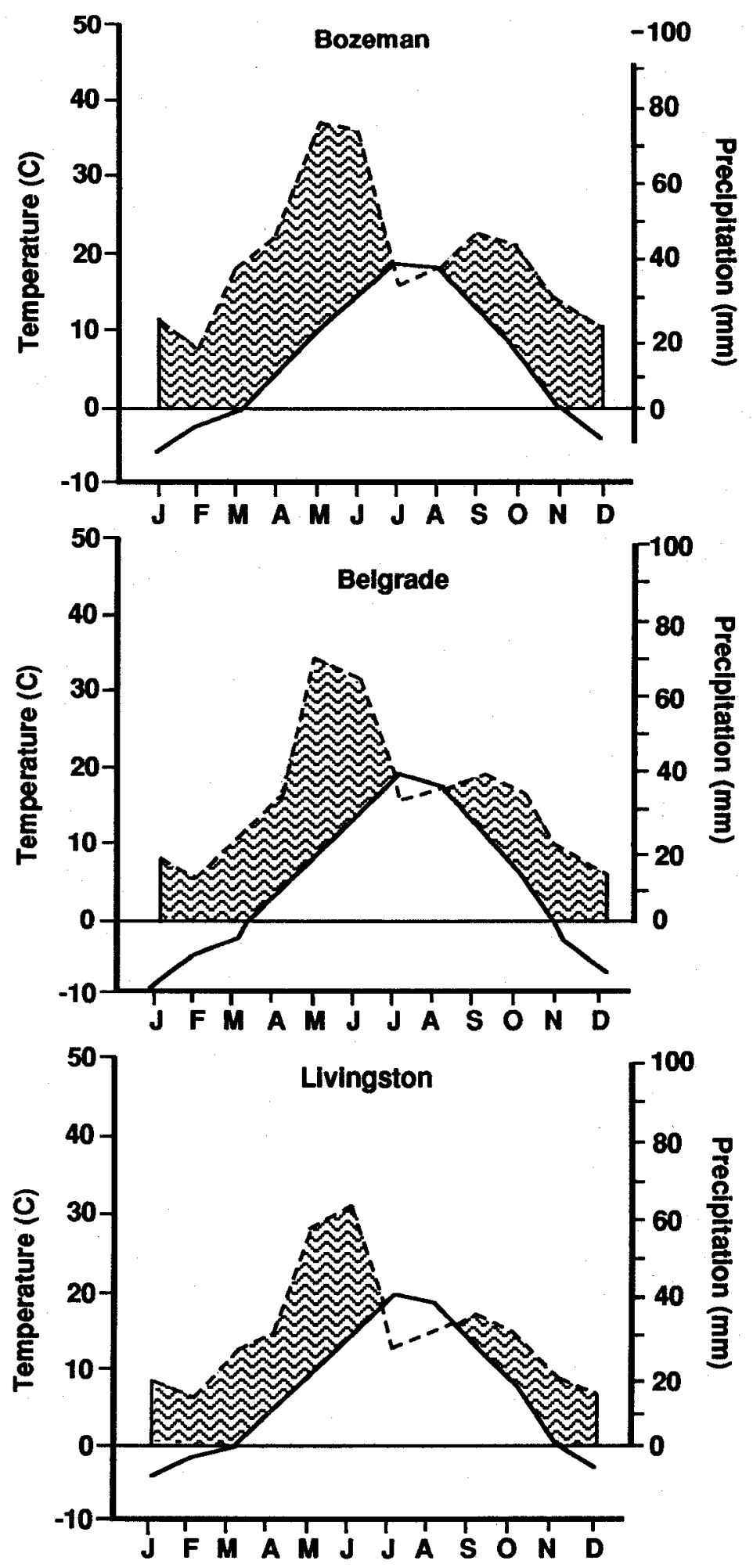

Figure 3.3. Mean monthly temperatures and precipitation at three weather stations near the Bridger Mountains. Shaded areas represent periods of net moisture accumulation. 
appears as a "rain-shadow" effect of the Bridger Range, it is also possible that the decrease simply reflects a return to "normal" precipitation typical of relatively level, low elevation areas in the region.

Temperature decreases with increasing elevation in a linear relationship at an average rate of $6.5^{\circ} \mathrm{C} / \mathrm{km}$ worldwide (Lutgens and Tarbuck 1982). Based on this, the estimated mean annual temperature on Sacajawea Peak, the highest point on the study area, is $9.5^{\circ} \mathrm{C}$ lower than the annual mean for Bozeman.

The mountains also cause other local variation in temperatures through and around the area. During winter, lower average temperatures prevail in the Gallatin Valley along the west flank of the Bridger Range than on eastern footslope and valley areas. This results, in part, because cold air often collects within the Gallatin Valley during periods of high pressure in winter and dissipation is hindered by the Bridger Range to the east and the Gallatin Range to the south. Under those conditions, temperatures on the eastern periphery may also be increased by relatively warm, westerly or southwesterly air flowing over the colder air trapped in intermountain valleys and subsiding along the east front of the mountains and valleys opening to the plains. This effect is strongest in the southeast portion of the study area near Livingston and diminishes northward. During other seasons, when cyclonic storms or other conditions prevent cold air inversions, there is little difference in average temperatures from west to east. Also, extensive cold air masses will occasionally become entrenched over the area and result in uniformly cold temperatures throughout.

The Bridger Range influences wind patterns and speeds across the study area in much the same manner as temperatures, impeding air flow along the west slope and enhancing flows on the east side. During autumn, winter, and spring, wind speeds generally average $4.8 \mathrm{~km} / \mathrm{hr}$ or less in the Gallatin Valley and along the lower west slope of the Bridger Range; they average $9.2 \mathrm{~km} / \mathrm{hr}$ or more near Livingston, but diminish northward along the Shields River Valley.

Variations in precipitation, temperature, and wind strongly affect the distribution and duration of snow cover across the study area. In general, snow depths and duration of snow cover increase with elevation with some modification due to slope and aspect. Greatest accumulations occur at high elevations on the east flank of the Bridger Range. Total snowfall relative to elevation is considerably greater in the Gallatin Valley and along western footslopes than on footslopes along the eastern and northern flanks of the area. Because high winds rarely occur on the west slope, snow coverage is more uniform on footslope and valley areas.

Vegetation

The Bridger Range and attending ridges and foothills comprise an "island" of forest within a "sea" of lowland steppe (Fig. 3.4). 


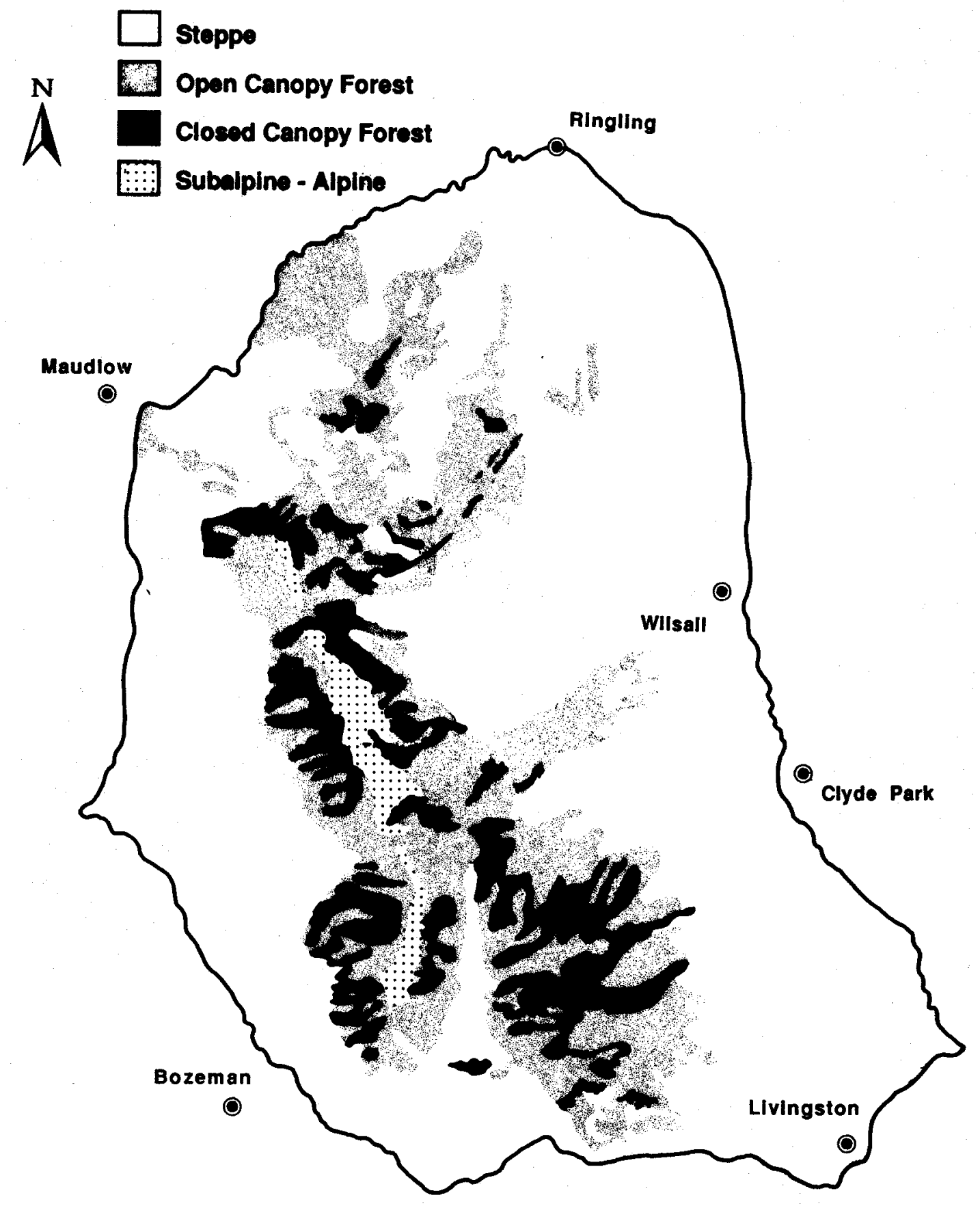

Figure 3.4. Vegetation zones within the study area. 
Three major vegetation zones occur. These include:

1) steppe dominated by open grassland and shrub-grassland communities covering $60 \%$ of the study area;

2) a montane forest zone dominated largely by Douglas fir (Pseudotsuga menziesii) and/or lodgepole pine (Pinus contorta), white-bark pine ( $P$. albicaulus), limber pine (Pinus flexilis), subalpine fir (Abies lasiocarpa), or spruce (Picea engelmanni) communities covering $38 \%$ of the area;

3 ) a subalpine-alpine zone covering $2 \%$ of the area at elevations above $2,400-2,700 \mathrm{~m}$ along the main Bridger Divide.

The three zones include approximately 35 habitat types that characterized the climax vegetation of the region (Pfister et al. 1977, Mueggler and Stewart 1980). Fourteen of those types cover the bulk of the study area. Because most of the area has been subject to disturbance, most habitat types are now represented by seral communities classified as existing vegetation cover types.

Despite grazing and other disturbance, most of the steppe vegetation appears to have retained floral composition similar to site potential. Generally, areas of steppe at lowest elevations are dominated by bluebunch wheatgrass (Agropyron spicatum) and/or bluebunch wheatgrass-Wyoming big sagebrush (Artemisia tridentata wyomingensis). At increasing elevations, Idaho fescue (Festuca idahoensis) becomes common while Wyoming big sagebrush varies in abundance by site and is ultimately replaced by mountain big sagebrush (A. $t$. vaseyana). Forbs such as arrowleaf balsamroot (Balsamorrhiza sagittata), silky lupine (Lupinus sericeus), and sticky geranium (Geranium viscossissimum) are common in the Idaho fescue and big sagebrush-Idaho fescue types. An antelope bitterbrush (Purshia tridentata)-Idaho fescue habitat type occupies some steep, west and southwesterly-facing slopes at lower elevations along the west flank of the Bridger Range.

Coniferous trees first appear at about $1,830 \mathrm{~m}$ elevation with canopy coverage increasing gradually or sharply depending on aspect. Scattered to open forest stands on southerly and westerly aspects immediately above the steppe might be considered an upward extension of steppe habitats to which a few trees have been added. Douglas fir is the dominant species in such stands to about $2,400 \mathrm{~m}$. On noncalcareous substrates between $2,400 \mathrm{~m}$ and timberline $( \pm 2,700 \mathrm{~m})$, whitebark pine and/or subalpine fir predominate. On calcerous substrates, whitebark pine is replaced by limber pine, and timberline occurs at about $2400 \mathrm{~m}$.

Although tree density and composition on south to west aspects changes only gradually with elevation, understories change considerably, usually from dominance by combinations of bluebunch wheatgrass, Idaho fescue, arrowleaf balsamroot, and heartleaf arnica (Arnica cordifolia) to predominance of elk sedge (Carex geyeri). Forbs tend to increase. Six forb species each have $1 \%$ or greater coverage in the Douglas fir-Idaho 
fescue type whereas each of 13 have $1 \%$ or greater coverage in the higher elevation Douglas fir-elk sedge habitat type (Pfister 1977).

Steep, northerly to easterly slopes throughout the Bridgers are normally covered by medium-dense forest stands with very different understory vegetation than occurs on adjacent steppe or scattered forest. Under near-climax to climax conditions, Douglas fir is the dominant tree on moist aspects at elevations below about $2,100 \mathrm{~m}$. Subalpine fir then predominates to at least $2,400 \mathrm{~m}$ where whitebark pine becomes dominant or co-dominant with fir on non-calcareous substrates. On relatively moist, gently-sloping ridges immediately east of the main Bridger Divide, Engelmann spruce also occurs as a climax dominant. However, as a result of fire and other past disturbances, many sites that would normally support medium to dense stands of Douglas fir, subalpine fir, and/or Engelmann spruce are currently dominated by extremely dense, even-aged stands of lodgepole pine.

At low elevations, understories of medium to dense forest stands are typically dominated by western snowberry (Symphoricarpos occidentalis) or by ninebark (Physocarpus malvaceous) along the southern flank of the study area. With increasing elevation, pinegrass (Calamagrostis rubescens) and blue huckleberry (Vaccinium globulare), successively, become understory dominants. Grouse whortleberry ( $V$. scoparium) usually dominates under high elevation stands of whitebark pine on northerly aspects.

Alpine vegetation occurs only on calcareous substrate along the main Bridger ridge north of Ross Pass. There, excessive drainage induced by the porous limestone, generally cold temperatures, and a short growing season combine to limit growth of trees and most other plants above $2,400 \mathrm{~m}$. Vegetation is extremely variable and difficult to classify in terms of communities. Common species include Hayden clover (Trifolium haydenii), mountain lomatium (Lomatium montanum), Gordon's ivesia (Ivesia gordonii), and sheep fescue (Festuca ovina). Below 2,740 m, common juniper (Juniperus communis) occurs on "Krumholz" and may ameliorate the severe topoedaphic conditions to allow growth of a few, stunted subalpine fir trees.

Vegetation along stream courses in the steppe zone includes variable communities dominated by riparian shrubs and cottonwood trees. Common shrubs include willows (Salix sp.), black hawthorn (Crataegus douglasii), chokecherry (Prunus virginiana), and woods rose (Rosa woodsii). Some of these shrubs and western snowberry also occur in small patches on moist upland sites adjacent to the lower timberline. Aspen (Populus tremuloides) also occurs locally in small clumps or stands on moist footslopes adjacent to streamcourses. 
Most of the study area, including nearly all of the steppe zone and about one-half of the foothill area, is privately owned. Lands above the lower limits of forest are predominantly national forest administered by the U.S. Forest Service, Gallatin National Forest. National Forest lands along the east flank of the main Bridger Range and on major ridges to the east generally occur in a checkerboard pattern with alternating sections $\left(2.59 \mathrm{~km}^{2}\right)$ in private and/or state ownership.

Private land uses include two basic classes: agriculture and rural residential development. The primary use is agriculture, largely grazing but including some dryland grain and hay production on gentle footslopes within the steppe zone. Much of the private land within the forest zone has been or is being logged. Rural residential development has been most extensive along footslopes and drainages in the southwestern, southern, and southeast portions near Bozeman and Livingston. Extensive development has also occurred along Bridger Creek in the interior and along portions of Brackett Creek west of Clyde Park.

Major uses of National Forest lands include timber management, livestock grazing, and recreation. Intensive logging has occurred in recent years on areas east of the Bridger Range Divide. On the west flank, logging has been limited largely to drainages immediately south and north of Flathead Pass.

Most mountain grasslands east of the Bridger Divide were subject to widespread and intensive grazing by domestic sheep in the past. Although some use by sheep continues, cattle grazing now predominates on most lands within the steppe zone as well as on mountain grasslands throughout the area. Grazing seasons, systems, and intensities vary widely.

Most of the area receives a variety of recreational uses. Hunting pressure is generally high during autumn (September-November), especially on National Forest lands. Access to private lands varies but is generally limited. Hiking, skiing, snowmobiling, and other off-road-vehicle use are other major activities on forest lands. A major ski area development is located along the east slope of the Bridger Range near the headwaters of Bridger Creek.

Major wildlife species in addition to mule deer include elk (Cervus elaphus), mountain goat (Oreamnos americanus), moose (Alces alces), black bear (Ursus americanus), mountain lion (Felis concolor), bobcat (Felix rufus), wolverine (Gulo gulo), and coyotes (Canis latrans), which occur throughout forest and foothill areas. White-tailed deer are abundant peripherally and along most major drainages. Pronghorn antelope (Antilocapra americana) occur in limited numbers in the northeastern portion of the study area. 


\section{CHAPTER 4}

\section{SPATIAL ORGANIZATION}

Plots of summer activity centers of deer marked on winter ranges documented that mule deer were distributed in seven population-habitat units (PHUs) within the Bridger Mountain complex (Figs. 4.1 and 4.2). Each PHU represented a rather distinct association of individual deer bonded together by traditional use of individual home ranges within a definable unit of yearlong habitat.

Each of the seven winter ranges around the periphery of the Bridger Mountains apparently acted as a "nucleus" for formation of a PHU. The boundaries of a PHU enclosed the yearlong distribution and movements of all adult females marked on that winter range (Fig. 4.1.). We used females to define boundaries because they demonstrated greater long-term fidelity to seasonal ranges and comprised the population segment most likely to reveal differences in population characteristics. Differences in the numbers of activity centers among PHUs reflected variation in the number of deer marked in each unit, though numbers were generally sufficient to represent distribution patterns within and between units.

Overlap between adjacent PHUs involved only $9 \%$ of the total area covered by the seven units. Zones of overlap occurred exclusively on summer range, along the contiguous perimeters of two or three adjacent PHUs, at points most distant from the respective winter ranges, and were usually associated with a major topographic feature. Summer home ranges of individuals from up to three widely separated winter ranges overlapped within this zone as indicated for PHUs 1, 6, and 7 (Fig. 4.1).

Marked samples were insufficient to delineate summer distribution of males in at least three of the seven PHUs (Fig. 4.2). However, general patterns of distribution of males were similar to those for females except that some males in PHUs 1, 4, 5, and 6 occupied summer/autumn ranges outside of the PHU defined on the basis of female distribution. This was consistent with other differences in distribution, movements, and habitat selection between the sexes and could result in increased association and greater opportunity for some genetic interchange between adjacent units than occurred with females. 


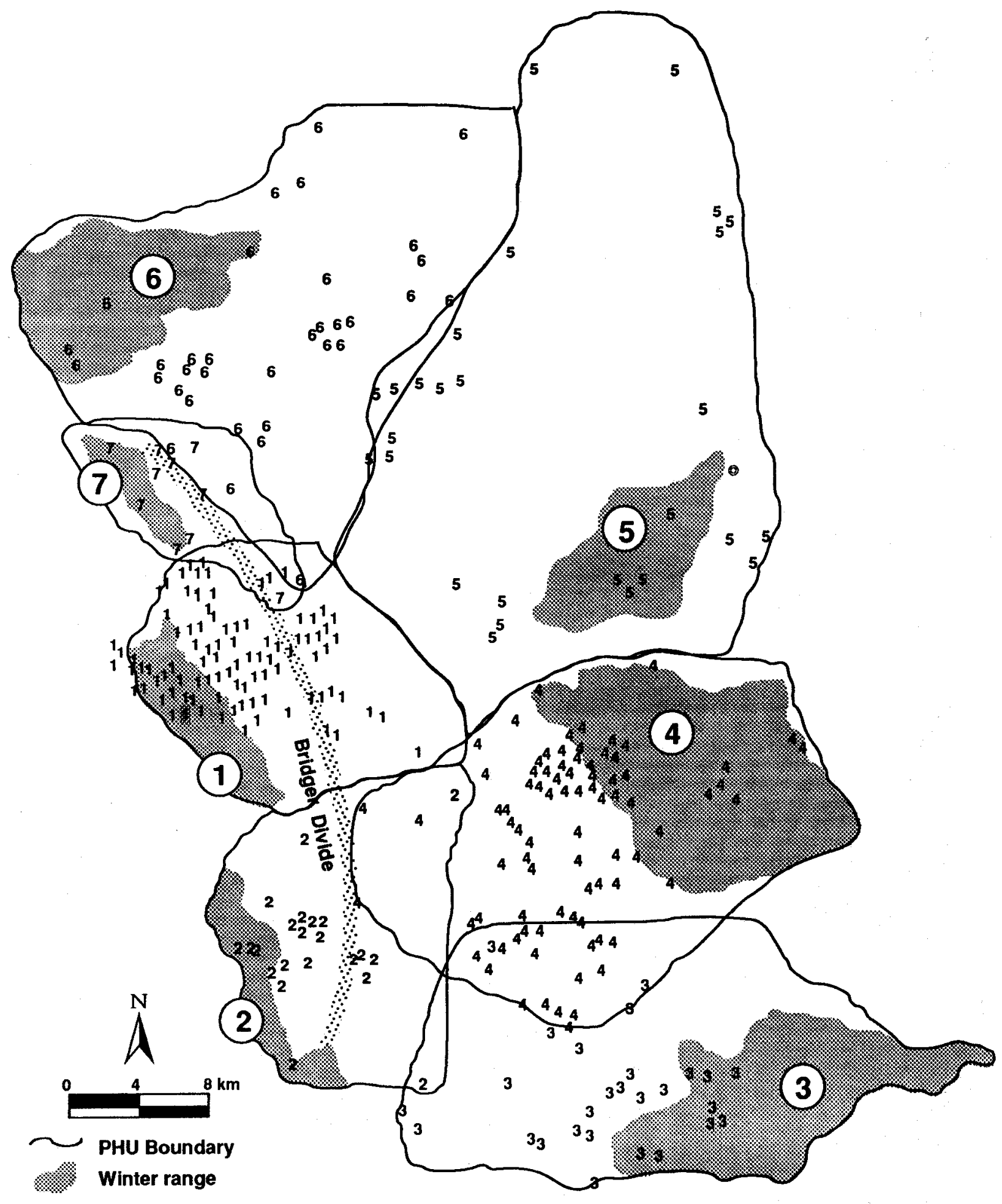

Figure 4.1. Distribution of seven mule deer population-habitat units (PHUs) in the Bridger Mountains. Small numbers show summer activity centers of 297 adult females associated with seven individual winter ranges indicated by large, circled numbers. 


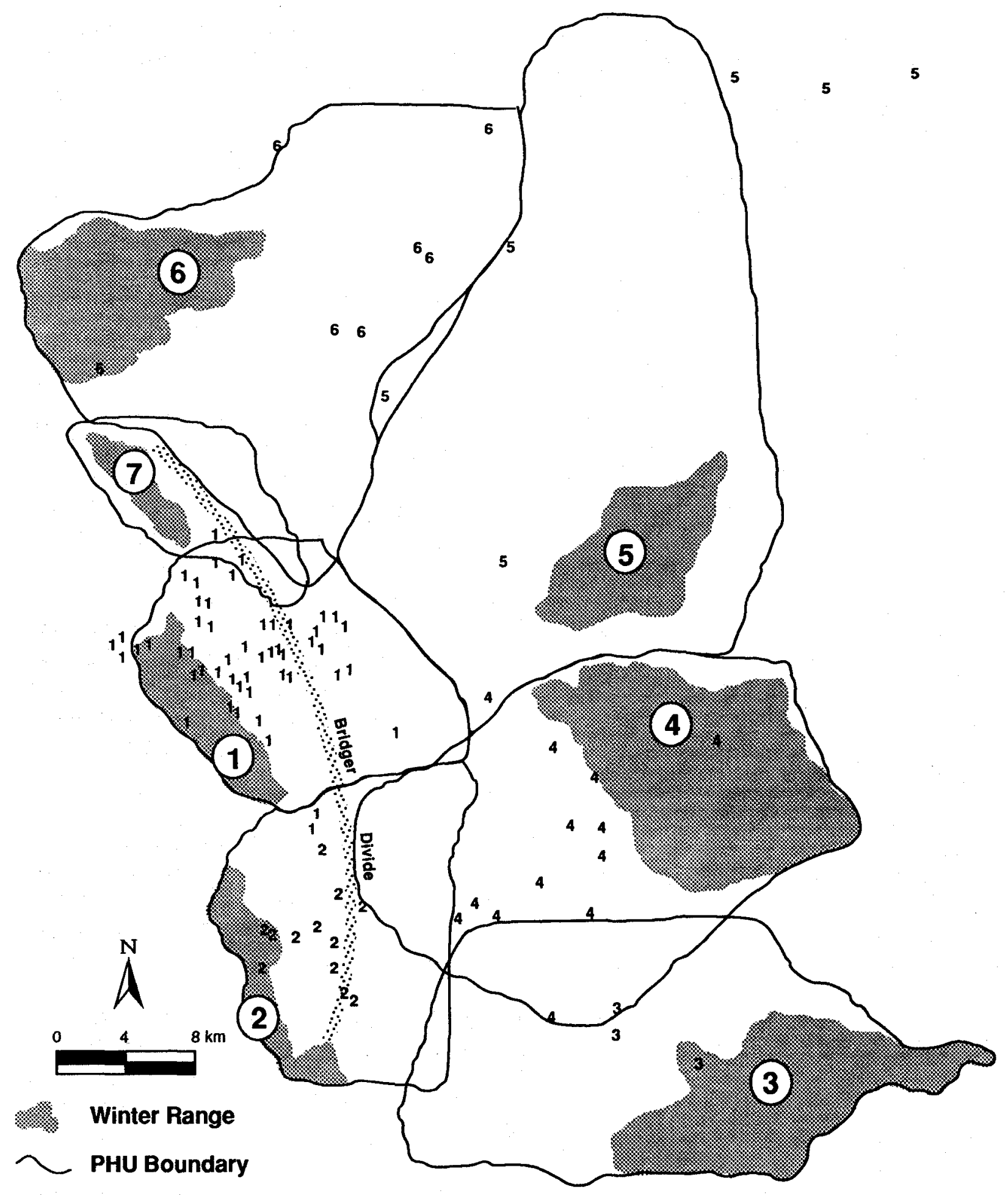

Figure 4.2. Summer distribution of 92 marked adult male mule deer in relation to seven PHUs. Small numbers show summer activity centers of bucks associated with individual winter ranges indicated by large, circled numbers. 
Following are brief, summary descriptions of the location, size, and major environmental characteristics of the seven PHUs. More detailed data and discussion of differences in topographic, climatic, and vegetative characteristics among units is presented in Appendix A.

\section{PHU 1 - Northwest Slope}

PHU 1 was located in the west-central portion of the study area (Fig. 4.3). It spanned the Bridger Divide and encompassed $186 \mathrm{~km}^{2}$ between Flathead Pass and Ross Pass. The northern half of the unit, called the Armstrong Range, was the site of early research efforts (Wilkins 1957) that ultimately provided impetus for long-term mule deer population studies presented in this report.

The highest elevations and greatest topographic relief found on the entire study area occurred within this unit (Fig. 4.4). Deep, rugged canyons extended westerly from the Bridger Divide and intersected the Gallatin Valley along a steep mountain front. East of the Divide, drainages originated in glacial cirque basins with nearly vertical rock walls. However, topographic characteristics were much more moderate in the middlelower reaches of these drainages.

Precipitation varied from $46 \mathrm{~cm}$ along footslopes to $127 \mathrm{~cm}$ on the crest of the Bridger Divide. Winter snowfall and minimum temperatures exhibited substantial annual variation. However, during most years, winter severity was sufficient to restrict mule deer to lower foothills along the west slopes. The summer growing season generally offered relatively predictable conditions for plant growth throughout summer and early autumn.

Corresponding to the marked changes in topography and local climate, a diversity of vegetation types occurred across the unit. Foothill areas along the west slope consisted of shrub-grasslands predominating on steep southerly aspects interspersed with "stringers" of Douglas fir forest on northerly aspects. These habitats were used as winter range $\left(32 \mathrm{~km}^{2}\right)$ by the entire mule deer population associated with PHU 1.

An extensive montane forest of Douglas fir, lodgepole pine, subalpine fir, and white-bark pine occurred at middle elevations along both sides of the Bridger Divide. Above the forest, subalpine and alpine zones occurred. These consist of clumps of stunted subalpine fir and spruce scattered throughout large grass-forb meadows. All of these habitats were important to mule deer during summer.

Because of the rugged topography, land uses were of relatively low intensity. Livestock grazing occurred in the foothill zone and along drainage bottoms at higher elevations during summer. Timber harvest was generally associated with the more productive forest stands found on moderate terrain east of the Bridger Divide. Logging 


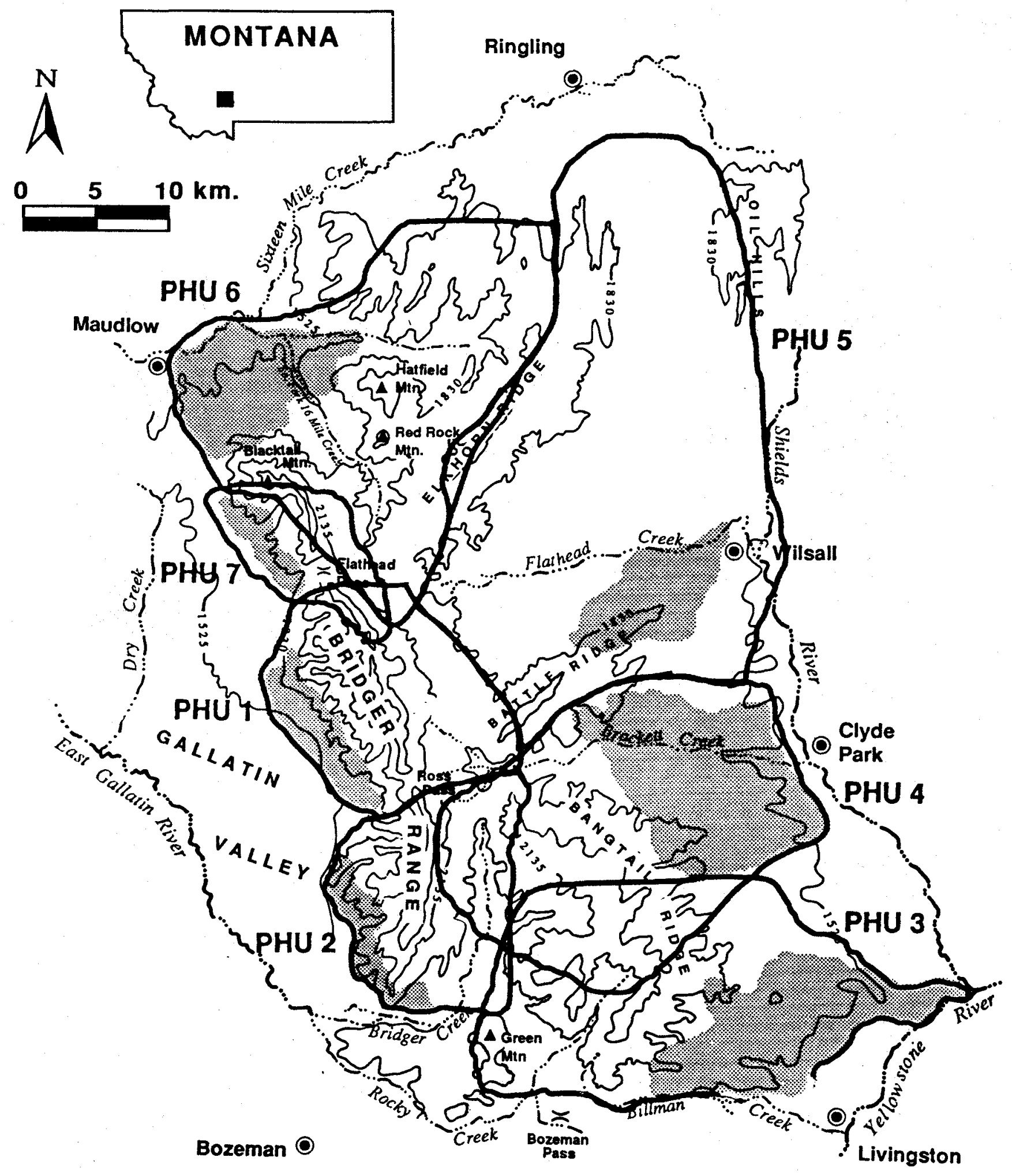

Figure 4.3. Location of seven mule deer PHUs in the Bridger Mountains, Montana. Shaded areas are winter ranges. 


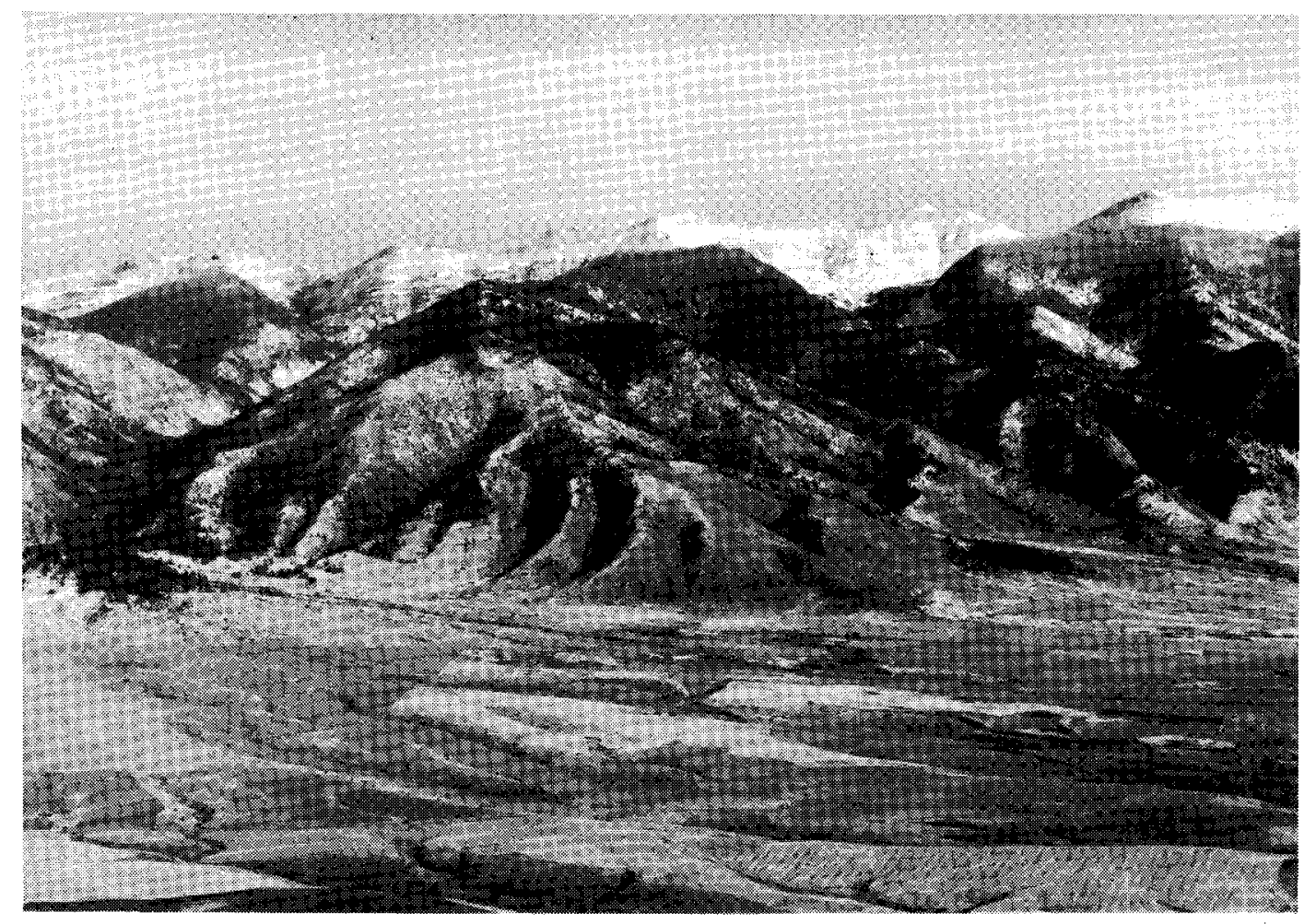

Figure 4.4. The Northwest Slope population/habitat unit (PHU 1) from the west.

on private and public land has intensified in recent years on these areas. However, many drainages remain in roadless condition.

\section{PHU 2 - Southwest Slope}

This unit $\left(187 \mathrm{~km}^{2}\right)$ encompassed the southwest portion of the study area (Fig. 4.3). It included the west and east slopes of the main Bridger Divide between Ross Pass and the southerly tip of the main Bridger Range.

Topographic characteristics were very similar to PHU 1 except that maximum elevations were slightly lower and the crest of the divide was less rugged (Fig. 4.5). Annual precipitation and snowfall patterns were also similar such that deer winter range $\left(25 \mathrm{~km}^{2}\right)$ occurred along the steep mountain footslope along the western edge of the unit. Vegetation types occurring in the footslope zone included a typical interspersion of shrubgrassland and conifer timber stands, although the overall density and diversity of shrub 


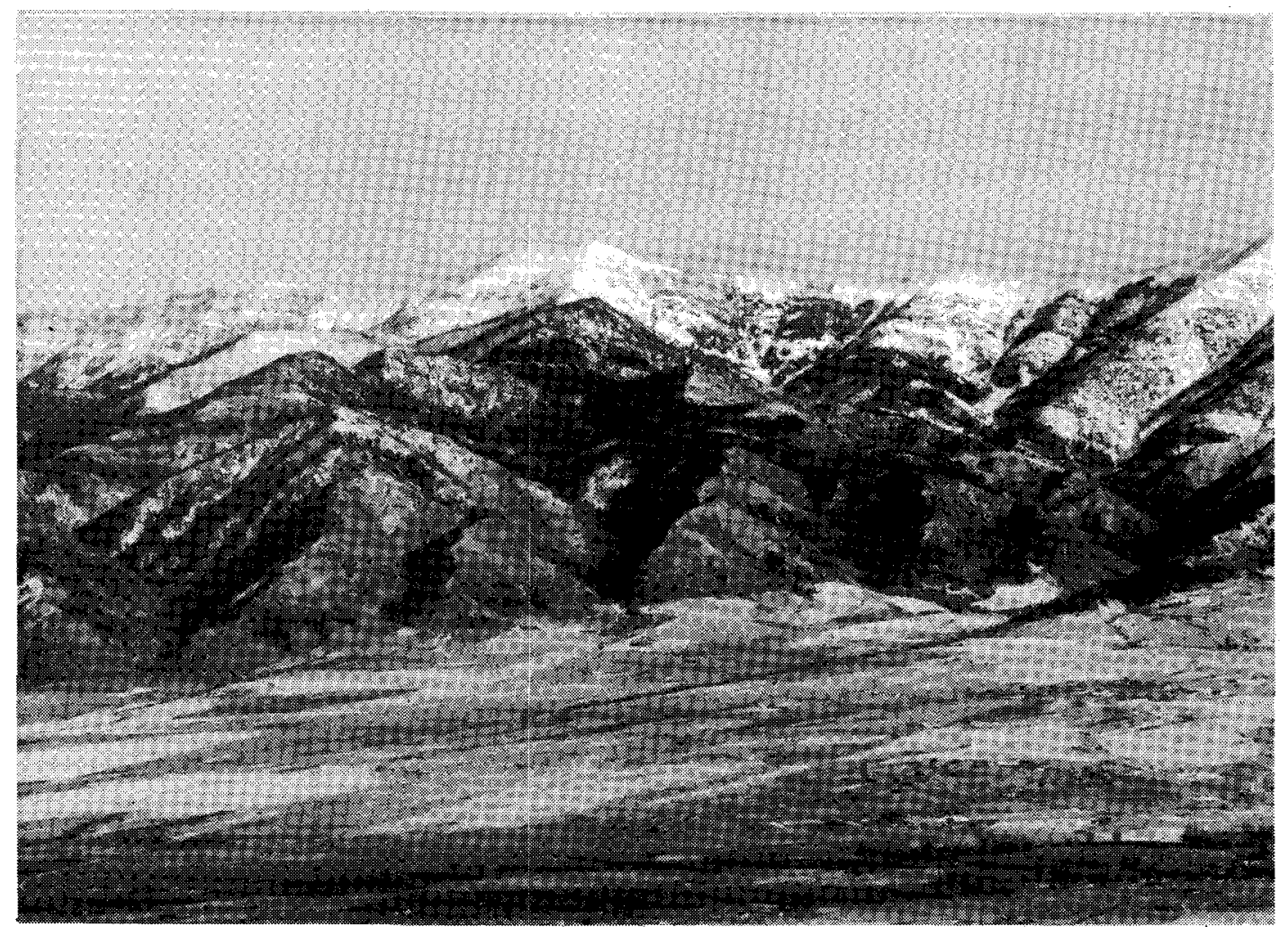

Figure 4.5. The Southwest Slope population/habitat unit (PHU 2) from the west.

species was lower than recorded in PHU 1. Notably, antelope bitterbrush, a major winter deer forage on the Armstrong Range, was absent on winter range in PHU 2.

Deer summer range in PHU 2 was characterized by an extensive montane forest dominated by Douglas fir and subalpine fir along both sides of the Bridger Divide. Grass-forb meadows within the montane forest were especially common on sites with limestone substrates. Subalpine vegetation was restricted to the highest elevations; the alpine zone was absent.

Land uses were similar to PHU 1 except that timber harvest has been more intensive on the east flanks of PHU 2. Additionally, high density home development has occurred across a substantial portion of the winter range and on lower summer range along Bridger Creek. Few roads penetrate many of the drainages on the west slope of this unit. 
This unit also spanned the main Bridger Divide. In the remainder of this report, PHUs 1, 2, and 7 are often collectively referred to as the three west slope PHUs or simply "the west slope". Located in the northern portion of the Bridger Mountain range (Fig. 4.3), the Blacktail Mountain unit was the smallest of the seven PHUs, occupying only $74 \mathrm{~km}^{2}$ between Blacktail Mountain and Flathead Pass (Fig. 4.6).

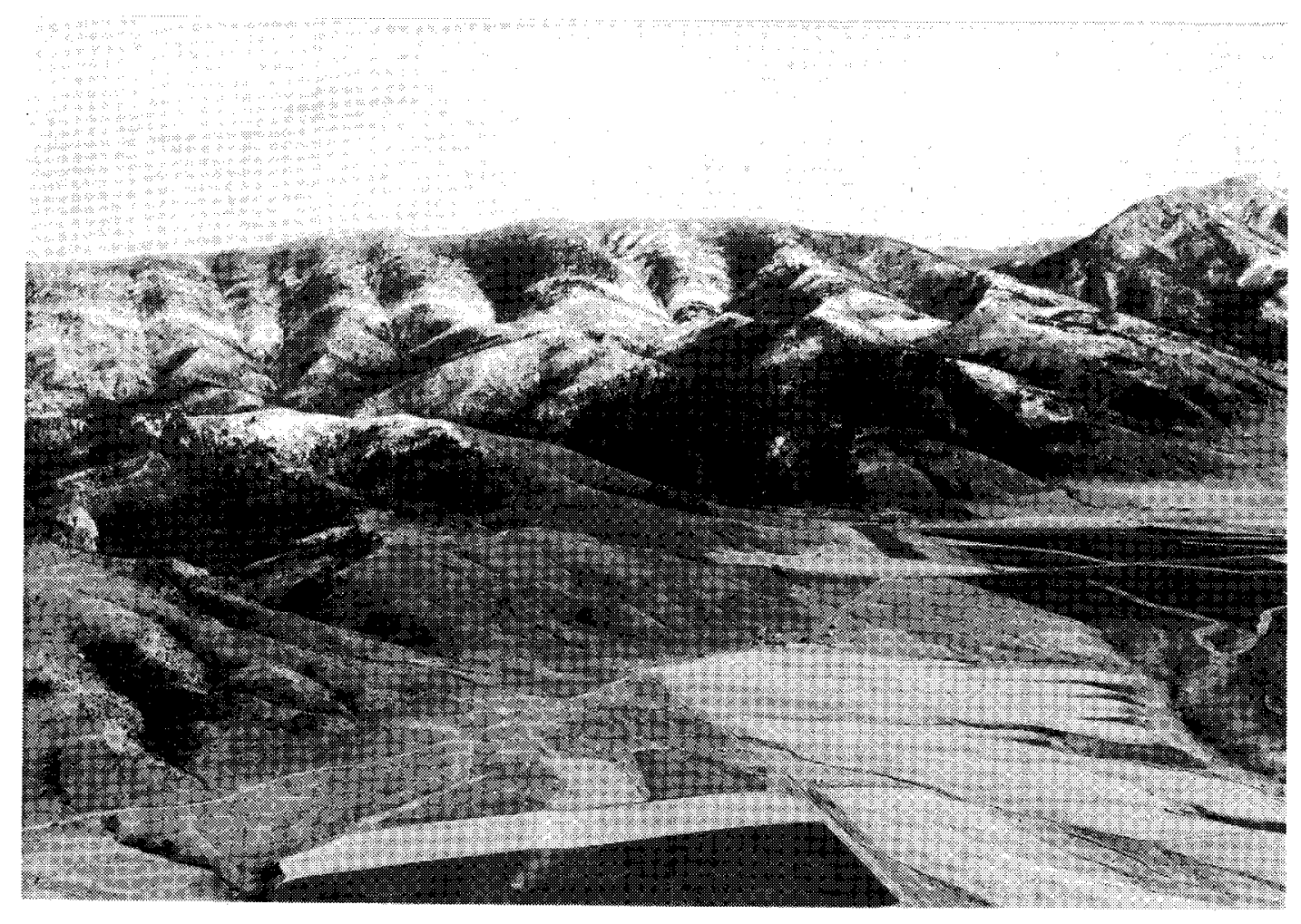

Figure 4.6. The Blacktail Mountain population/habitat unit (PHU 7) from the northwest.

Topographic characteristics were similar to PHUs 1 and 2 except that the crest of the Bridger Divide was lower in elevation and substantially less rugged. Local climatic patterns were similar to PHUs 1 and 2.

The winter range $\left(11 \mathrm{~km}^{2}\right)$ was located on the mountain footslope along the west edge of the unit. Average elevation of the winter range was higher than all other PHUs. Consequently, snow accumulation and persistence was greater than recorded in other units. 
Vegetation on winter range was structurally similar to other west slope PHUs, but diversity of shrub species was greater. Vegetative characteristics on summer range were also generally similar to PHUs 1 and 2, except that Douglas fir and limber pine forests were proportionally more common and whitebark pine and lodgepole pine forests less common. Also, headwater basins in PHU 7 were more densely timbered.

Intensive timber harvest has occurred in the southerly portion of this unit. Housing was limited to one ranch within the winter range boundary. Livestock grazing patterns were similar to other west slope units.

PHU 3 - Livingston

The Livingston PHU was one of four units (PHUs 3, 4, 5 and 6) collectively called the east slope PHUs or simply "the east slope". Each of these units was substantially larger than individual PHUs on the west slope.

PHU 3 spanned $316 \mathrm{~km}^{2}$ in the southeastern portion of the study area extending easterly from Green Mountain across the southern half of Bangtail Ridge (Fig. 4.3).

Compared to west slope PHUs, PHU 3 was lower in elevation and characterized by more gentle topographic relief across both winter and summer ranges. The landform might best be described as a moderately dissected plateau (Fig. 4.7). Total annual precipitation was less and snowfall on winter range was relatively sparse.

Vegetation on the large, open winter range $\left(95 \mathrm{~km}^{2}\right)$ consisted predominately of sagebrush-grassland interspersed with Rocky Mountain juniper. Conifer forest was much less common on winter range in PHU 3 than on west slope ranges. As was the case with all seven PHUs, most of the winter range was privately owned rangeland.

Vegetation on deer summer range was characterized by a predominantly opencanopy Douglas fir forest that included many sagebrush-grassland "parks". Lodgepole pine stands were limited to some northerly aspects. Lower elevation and relief limited the diversity of vegetation types and, to some extent, the length of the growing or "green" season over large portions of the unit.

Land ownership on summer range comprised a checkerboard of public and private holdings. Intensive timber harvest has occurred in all but one of the drainages. Consequently, much of the area was accessible by road and received recreational use throughout the year. Livestock grazing occurred more uniformly across this PHU than west slope units. Agricultural land was restricted in distribution to a small portion of the winter range. Low density housing developments are relatively common along the southern and eastern boundaries. 


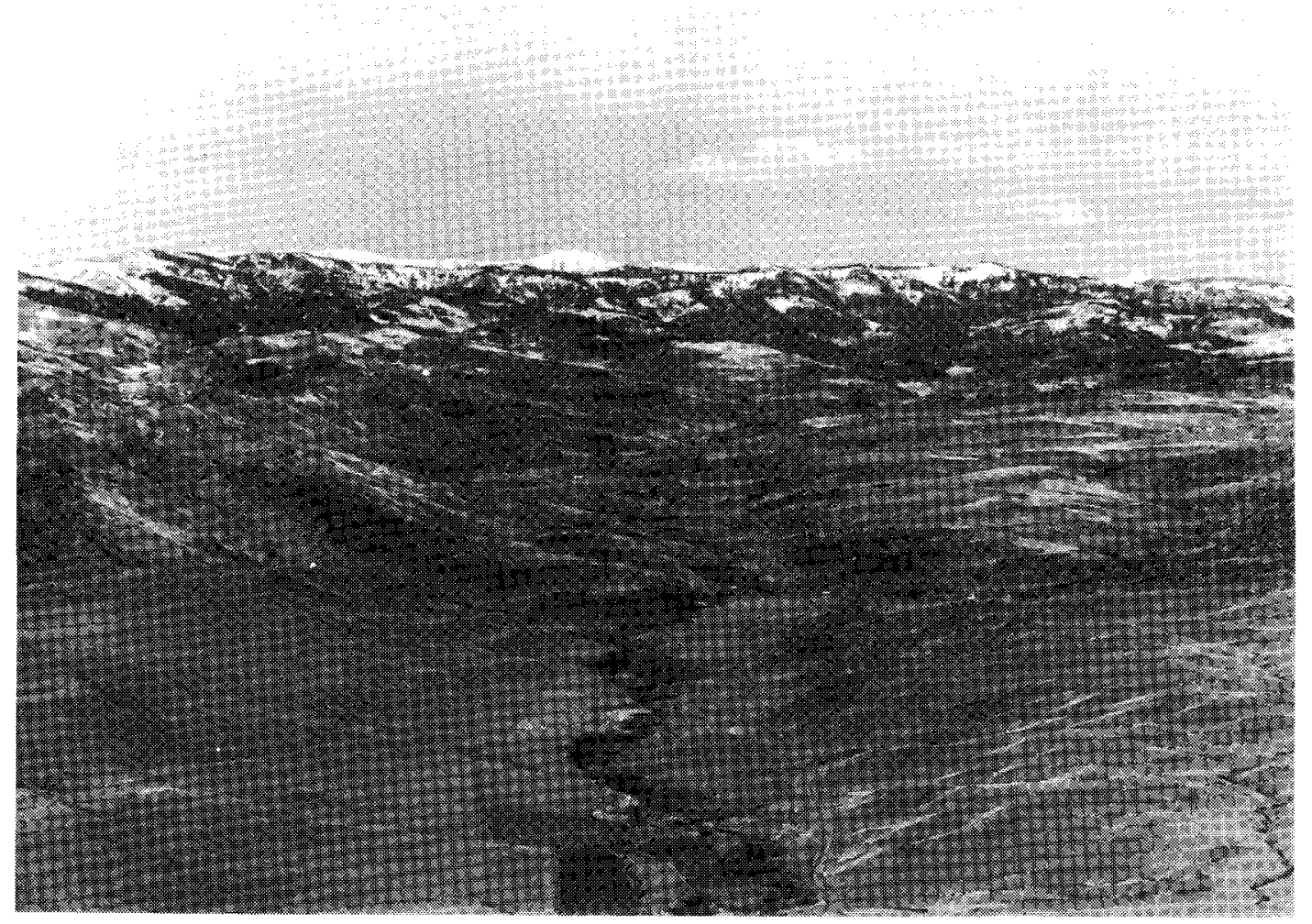

Figure 4.7. The Livingston population/habitat unit (PHU 3) from the southeast.

\section{PHU 4 - Brackett Creek}

The Brackett Creek unit was located in the east-central portion of the study area (Fig. 4.3). It occupied $371 \mathrm{~km}^{2}$ extending easterly from Bridger Creek across the northern half of Bangtail Ridge to the Shields River. Studies were more intensive in this unit compared to other east slope PHUs. Concurrently, PHU 4 was frequently used in comparison with PHU 1. PHU 4 contained the largest winter range $\left(135 \mathrm{~km}^{2}\right)$ among the seven PHUs.

Topographic, climatic, and vegetative characteristics (Fig. 4.8) were similar to PHU 3. During most of the study, timber harvest and roading were limited to a few drainages, though both activities accelerated rapidly in recent years. A few low density housing developments were scattered along Brackett Creek which bisects the northern portion of the PHU. Livestock grazing occurred seasonally throughout the area. Dryland alfalfa and grain fields accounted for about $17 \%$ of the winter range area. 


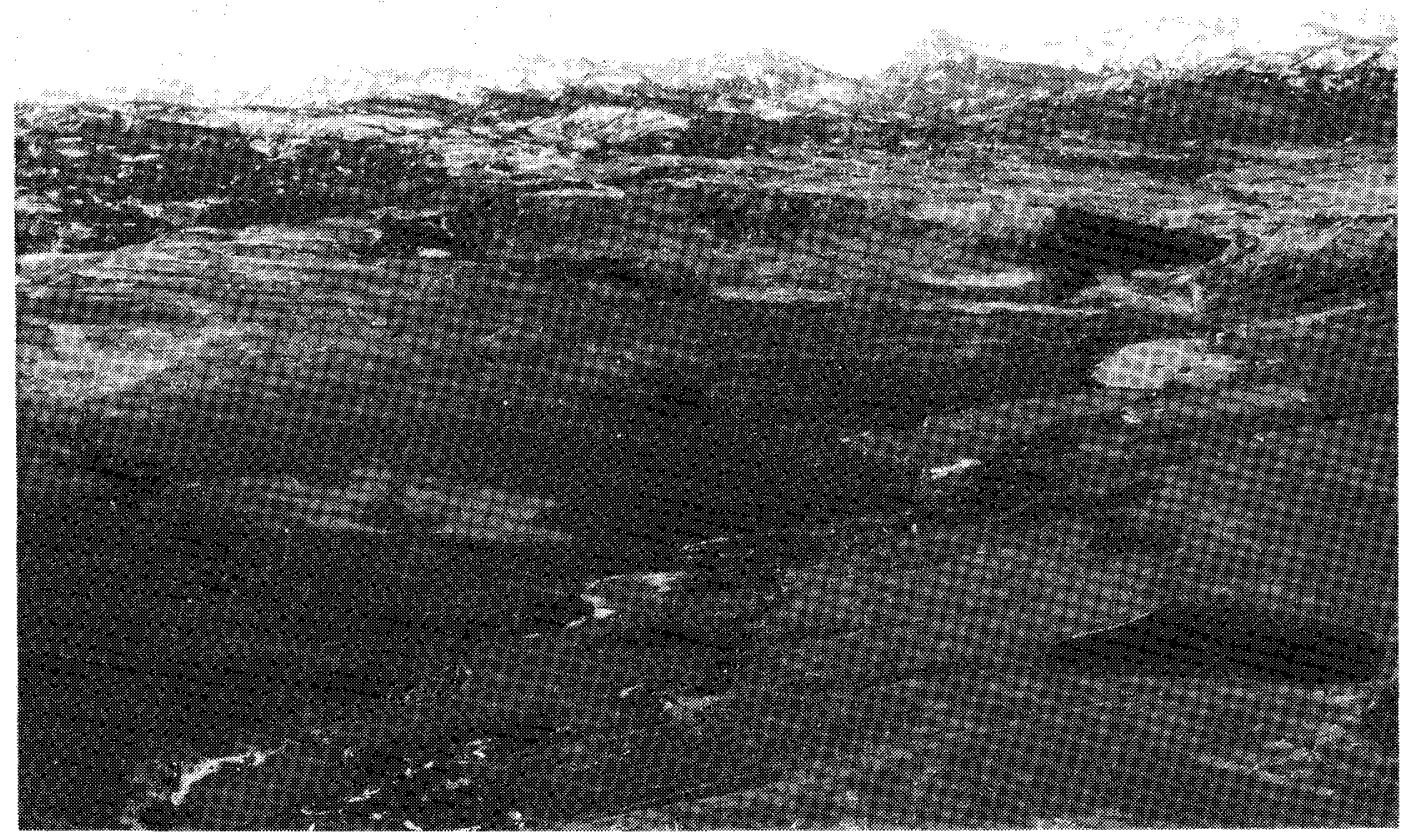

Figure 4.8. The Brackett Creek population/habitat unit (PHU 4) from the east.

\section{PHU 5 - Battle Ridge}

The Battle Ridge unit in the northeastern portion of the study area was the largest $\left(602 \mathrm{~km}^{2}\right)$ of the seven PHUs (Fig. 4.3). It was characterized by very gentle topography (Fig. 4.9). Mean elevations of the winter and summer range were very similar. Annual precipitation $(\overline{\mathrm{X}}=45 \mathrm{~cm})$ was the lowest of any PHU.

The winter range $\left(51 \mathrm{~km}^{2}\right)$ was located at the eastern end of Battle Ridge which formed the southern boundary of the unit. Here, moderate slopes and secondary drainages offered some topographic complexity. Vegetation consisted primarily of sagebrush-grasslands and scattered stands of juniper and Douglas fir along the western and higher reaches.

Summer range was primarily associated with scattered stands of Douglas fir forest and patches of aspen along the southern and northwestern borders of the PHU. Some deer also used riparian areas widely distributed across an expanse of monotypic rangelands and dryland agricultural fields that formed the remainder of this PHU.

Livestock grazing was the dominant land use because most of the unit consisted of large, privately owned ranches. Timber harvest was limited to a few small areas along the north and south boundaries. 


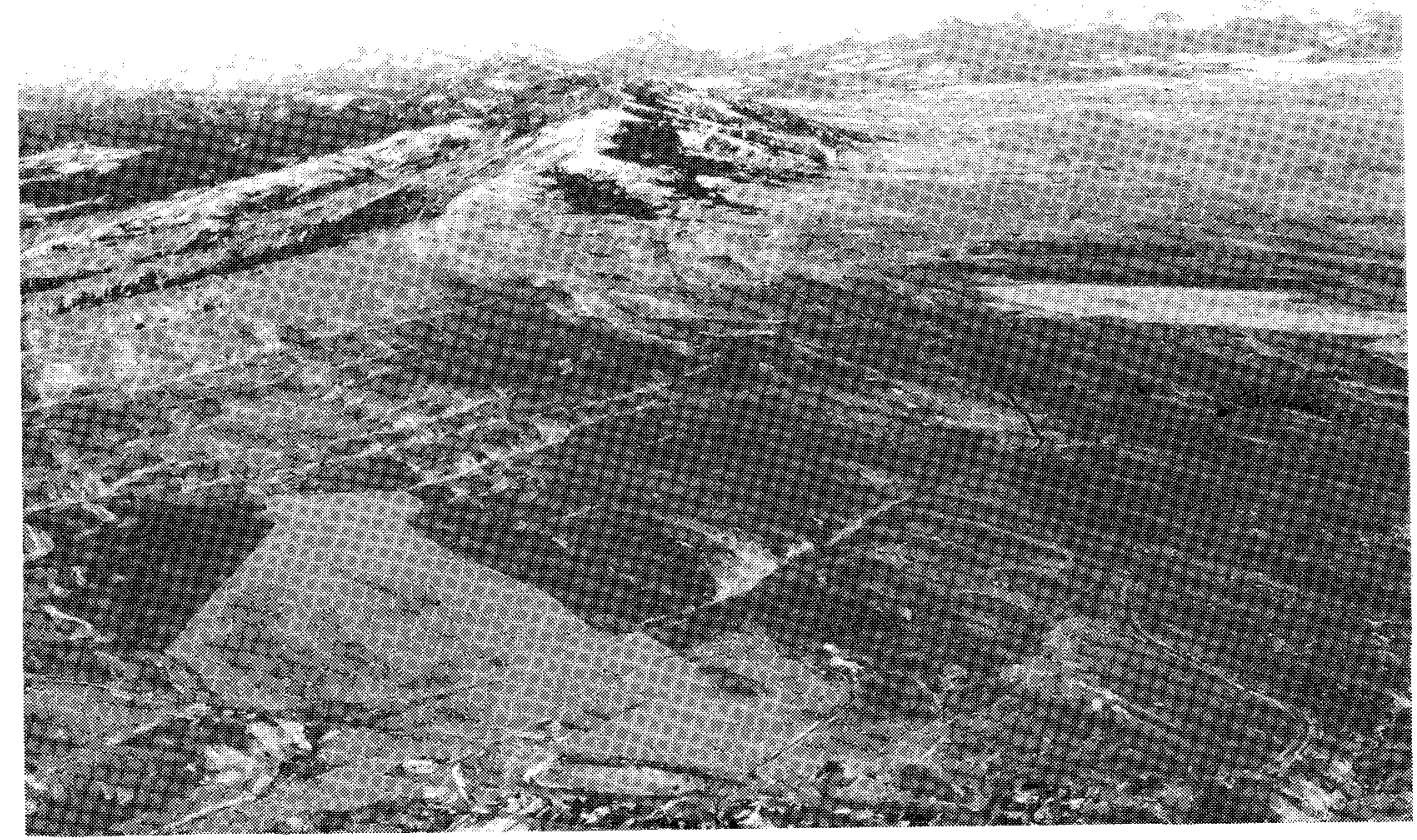

Figure 4.9. The Battle Ridge population/habitat unit (PHU 5) from the northeast.

PHU 6 - South 16 Mile

This PHU was second only to Battle Ridge in size, occupying $406 \mathrm{~km}^{2}$ along the northern tier of the study area (Fig. 4.3). It was situated in the southern half of a large intermountain basin separating the Bridger Range from the Big Belt Mountains (Fig. 4.10). Elkhorn Ridge and Hatfield Mountain contributed to the topographic complexity of the unit. Mean annual precipitation was $57 \mathrm{~cm}$, more than in PHU 5 but less than other east slope units.

The winter range encompassed $72 \mathrm{~km}^{2}$ in the northwestern part of the unit. Average elevation of the winter range was the lowest of any PHU. Consequently, snow accumulation and persistence were also comparatively low. Vegetative characteristics of the winter range were generally similar to other east slope units except that shrub (sagebrush and juniper) dominated habitats were comparatively more prevalent than open grasslands. Stands of Douglas fir were generally restricted to the upper boundary of the winter range.

On summer range, individual vegetation types occurred as large units loosely interspersed across the broadly undulating topography. Large stands of Douglas fir were found on northerly aspects while grasslands and shrub-grasslands occurred on southerly and westerly slopes. East aspects often included mesic, seep areas with isolated stands of aspen and other riparian vegetation. 


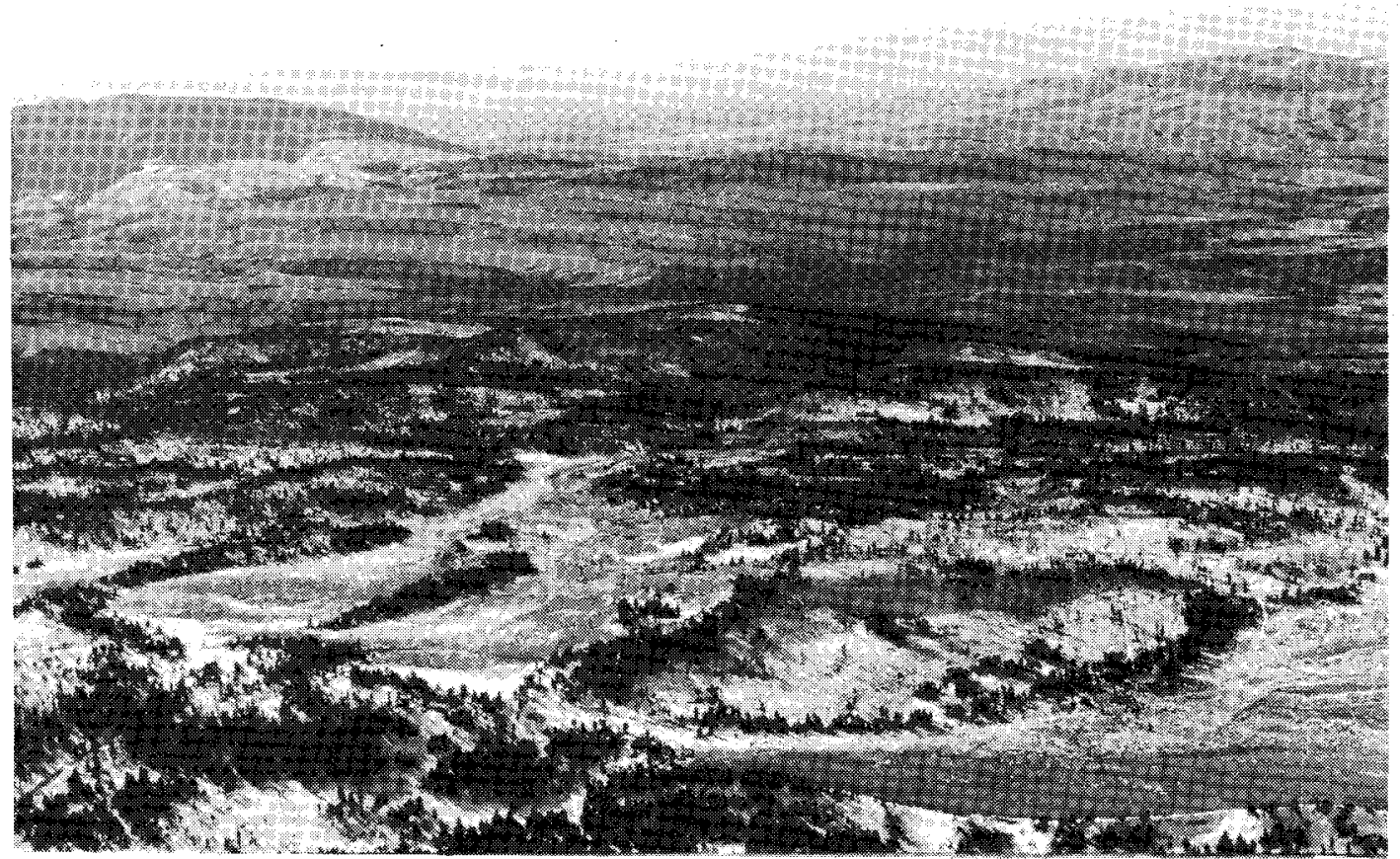

Figure 4.10. The South 16 Mile population/habitat unit (PHU 6) from the northeast.

Livestock grazing was the dominant land use. A few large, private ranches covered a high percentage of this PHU. Public land was limited to scattered tracts at higher elevations. Some low intensity timber harvest has occurred at a few sites widely distributed across the unit. A few dryland hay or grain fields were distributed across the northern perimeter of the winter range. Housing developments were limited to one small, low-density development on summer range in the southwestern part of the unit. A few ranch houses were scattered across the lower limits of the winter range.

Population Subunits within PHUs

Winter observations $(\mathrm{N}=8,451)$ of 253 marked deer in the Armstrong segment of PHU 1 during 1972-1986 indicated that individuals and their associated matrilineal groups were generally distributed within one of three population subunits (Fig. 4.11, Youmans 1979). It appeared that each subunit comprised an aggregation or loose band of matrilineal groups that were more closely related to one another than to groups in adjacent subunits. The identity of subunits was reinforced by strong individual and group fidelity to small winter home ranges within a limited amount of winter habitat.

During winter, individuals within a particular subunit were frequently loosely associated with one another in large groups that shared common foraging areas and choice bedding sites. Although the specific individuals comprising these large groups 
almost constantly changed, they seldom contained individuals from adjacent subunits. Mixing of individuals between subunits occurred only within the overlap zones delineated in Fig. 4.11. When groups from one subunit occasionally penetrated the interior of an adjacent unit, they attempted to avoid contact with resident groups. When such contact occurred, aggressive behavior by residents assured that intermingling was brief. Contact between females in the northern and southern subunits was never recorded during winter although separated by only $1.0 \mathrm{~km}$.

On PHU 1, adult males appeared to occur in and use subunits similar to females. However, some individual males frequently traveled between adjacent subunits and a few used all three.

Observations of marked individuals on PHU 4 indicated that deer distribution, movements, and habitat use were less compartmentalized than on west slope winter ranges. This was consistent with the larger area of winter habitat, more homogeneous topography and vegetation, and generally less specialization in habitat usage. Deer mobility and home range size were greater on PHU 4. However, the large size of the winter range obviously limited association of individuals occupying widely separated portions of the area.

Although adult females associated with separate subpopulation units on the Armstrong winter range tended to have somewhat different distributions during summer, subunits in summer were less distinct than those of winter (Fig. 4.12). Deer from the south subunit maintained the most striking "group" identity in that they almost exclusively used one drainage on the east slope of the Bridger Divide. Their movement patterns, however, appeared to be superimposed over middle subunit deer. Females from the middle subunit manifest the widest summer distribution, radiating outward from winter to summer home ranges located throughout the entire PHU. Adult females from the north winter range subunit generally used summer ranges in the northern portion of PHU 1, though some also moved into the interior of summer range used generally by middle subunit deer.

Summer distribution of mule deer in PHU 4 showed no obvious segmentation (Fig. 4.12). That is, greater numbers of individual movement patterns ran tangential to the majority. Two females moved to distant summer ranges up to $127 \mathrm{~km}$ away. As in winter, this somewhat more diffuse pattern on PHU 4 may have been related to less specialized movements over a larger area in more gentle terrain.

Patterns of use of summer range by adult males $(\mathrm{N}=46)$ from winter subunits on PHU 1 were similar to those of females except that males radiated outward in a wider arc. Sample size for males in PHU 4 precluded assessment of subunits. 


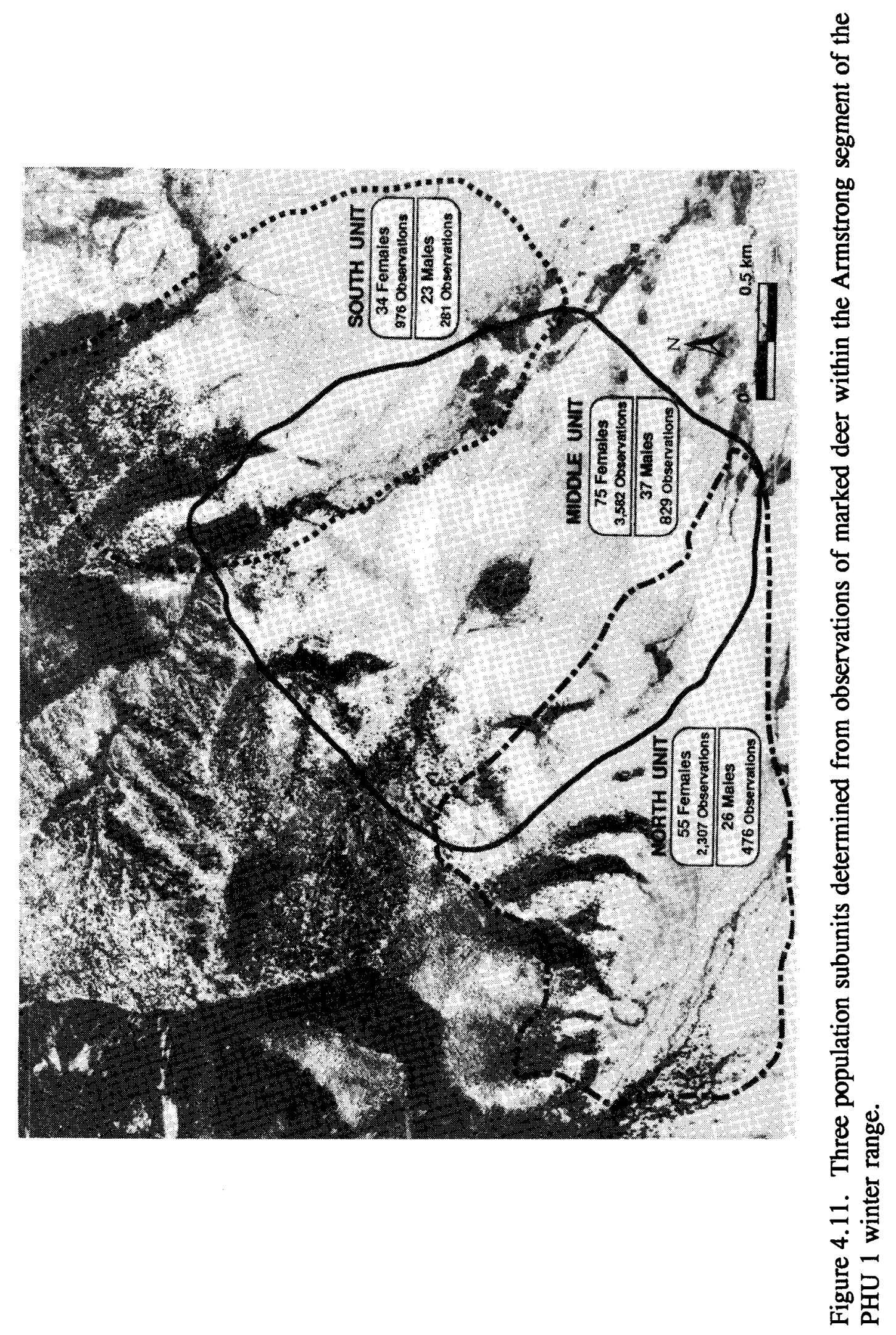



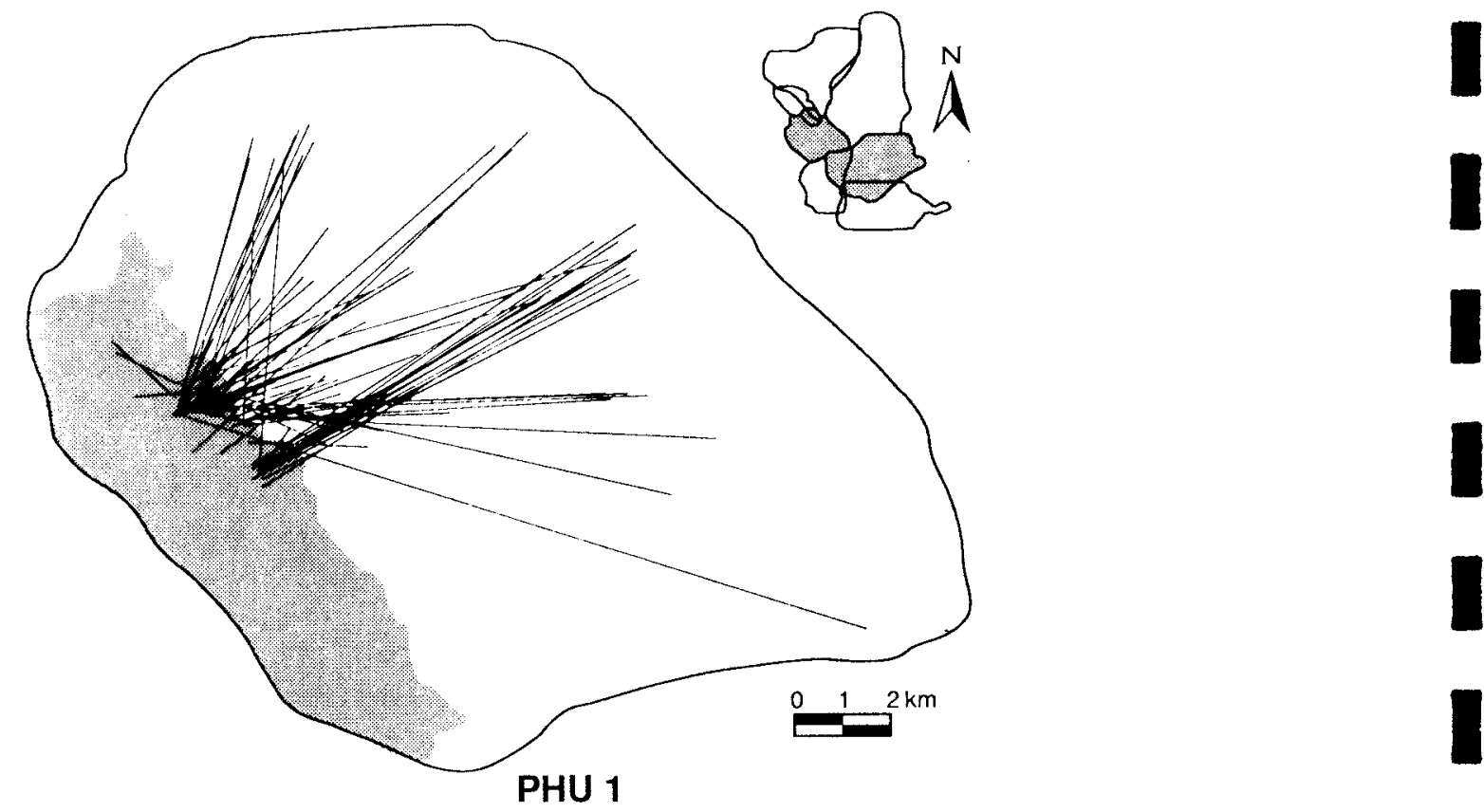

I

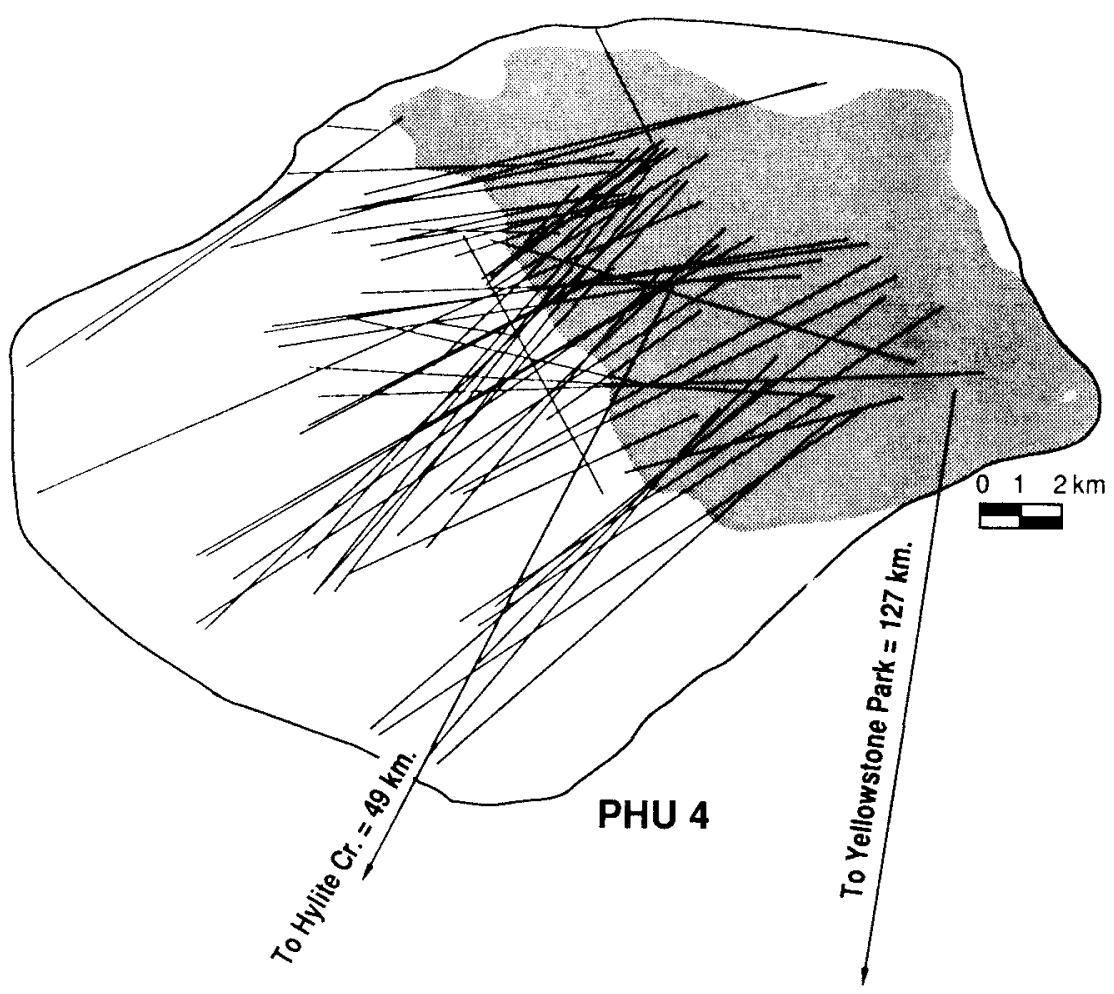

I

1

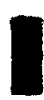

I

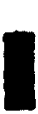

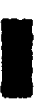

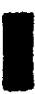

Figure 4.12. Juxtaposition of summer and winter activity centers for marked adult females in PHUs 1 and 4. 
Behavioral Foundations for Population-Habitat Units

Behavioral bonding of individuals to specific areas and home ranges within PHUs was fundamental to population organization and many aspects of distribution, movements, and habitat use. High fidelity to such areas was characteristic of both individuals and groups of maternally related deer. The latter indicated that patterns of distribution were formed and transmitted through social behavior.

\section{Home Range Fidelity}

A total of 581 females and 155 males were observed periodically for at least one year, providing opportunity to evaluate fidelity to seasonal home ranges (Table 4.1). Only $3 \%$ of females and $16 \%$ of males were known to have violated the basic pattern of high fidelity. Not more than $1 \%$ of either sex relocated their home range while remaining within the PHU where marked.

Overall, fidelity to winter home ranges was documented during a total of 1,389 and 166 consecutive deer-years for females and males, respectively. Females were known to use the same winter range for up to 12 years and males for at least five years. Traditional use of the same summer home range was verified for 104 females over 218 consecutive deer-years and 12 males over 18 deer-years. Individual females were documented using the same summer home range for up to 11 years while males were known to use the same range for at least four years.

Females associated with west slope PHUs generally exhibited higher fidelity to a given home range area than females on the east slope. Fidelity indices, calculated as the mean distance $(\mathrm{km})$ between geographic activity centers for consecutive years and computed for each radioed individual for each season, are listed in Table 4.2. During winter, average indices for adult females in west slope PHUs varied from 0.17 to 0.37 $(\overline{\mathrm{X}}=0.29)$ as compared to $0.30-0.92(\overline{\mathrm{X}}=0.66)$ for females associated with PHUs along the east side. These values were not directly comparable because females in east slope PHUs also had larger seasonal AARs. To correct this, indices were expressed as a percentage of the seasonal AAR. These values were 0.67 for the west slope and 0.81 for the east. A smaller fidelity index:AAR ratio would indicate relatively greater fidelity.

For summer range, fidelity indices $(\mathrm{km})$ varied from 0.16 to 0.28 among females in west slope PHUs compared to 0.23-0.49 for females in east slope units (Table 4.2). As in winter, the overall mean for west slope females was smaller $(0.20)$ than the mean for females in east slope units (0.42). Expressed as percentages of the respective mean seasonal AARs, the index for west slope females was 0.35 and that for east slope females was 0.61 . 


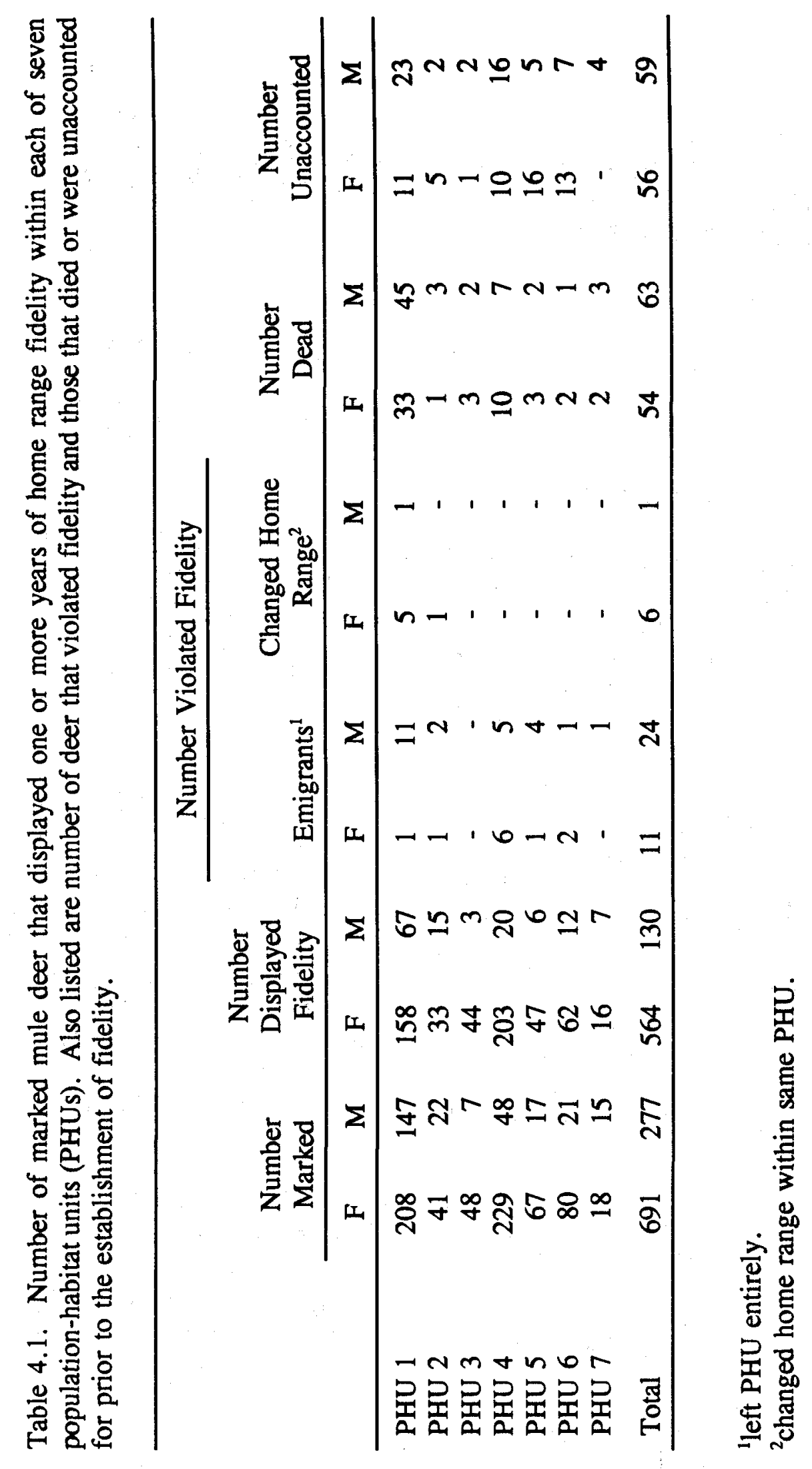


Table 4.2. Fidelity indices for radio-collared female and male mule deer in seven PHUs in the Bridger Mountains. Data are mean distance $(\mathrm{km})$ between the geographic activity centers of clusters of winter and summer telemetry relocations made in consecutive years.

\begin{tabular}{lrcc|ccc}
\hline & \multicolumn{3}{c|}{ WINTER } & \multicolumn{4}{c}{ SUMMER } \\
\hline & No. Deer & $\begin{array}{c}\text { No. Deer } \\
\text { Years }\end{array}$ & $\begin{array}{c}\text { Fidelity } \\
\text { Index }\end{array}$ & $\begin{array}{c}\text { No. } \\
\text { Deer }\end{array}$ & $\begin{array}{c}\text { No. Deer } \\
\text { Years }\end{array}$ & $\begin{array}{c}\text { Fidelity } \\
\text { Index }\end{array}$ \\
\hline ADULT FEMALE & & & & & \\
\hline PHU 1 & 17 & 43 & $0.34 \pm 0.17$ & 12 & 28 & $0.19 \pm 0.17$ \\
PHU 2 & 11 & 30 & $0.17 \pm 0.10$ & 7 & 21 & $0.16 \pm 0.09$ \\
PHU 7 & 8 & 16 & $0.37 \pm 0.13$ & 8 & 16 & $0.28 \pm 0.20$ \\
WEST & 36 & 89 & $0.29 \pm 0.16$ & 27 & 65 & $0.20 \pm 0.16$ \\
PHU 3 & 5 & 11 & $0.30 \pm 0.10$ & 8 & 16 & $0.23 \pm 0.19$ \\
PHU 4 & 7 & 15 & $0.61 \pm 0.39$ & 8 & 21 & $0.49 \pm 0.22$ \\
PHU 5 & 5 & 12 & $0.92 \pm 0.55$ & 5 & 11 & $0.45 \pm 0.22$ \\
PHU 6 & 10 & 20 & $0.77 \pm 0.47$ & 13 & 26 & $0.46 \pm 0.20$ \\
EAST & 27 & 58 & $0.66 \pm 0.45$ & 34 & 74 & $0.42 \pm 0.22$ \\
\hline \multicolumn{2}{l}{ ADULT MALE } & & & & & \\
\hline PHU 1 & 4 & 8 & $1.08 \pm 1.00$ & 4 & 9 & $0.36 \pm 0.12$ \\
\hline
\end{tabular}

The fact that average distances between consecutive GACs never exceeded $1.0 \mathrm{~km}$ for either seasonal range on either the west or east slope indicated that adult females generally displayed high site-specific fidelity to both winter and summer home ranges irrespective of location. Analysis of fidelity of adult males to individual home ranges was limited to a small sample in PHU 1. Here, average fidelity indices for winter and summer were $1.08 \pm 1.00$ and $0.36 \pm 0.12$, respectively.

\section{Distribution and Use of Space by Related Deer}

Lent (1974) indicated that mother-daughter relationships apparently extend well beyond weaning in several species of ungulates. Long-lasting social bonds resulting in cohesive matrilineal groups that include several generations apparently occur among red deer (Cervus elaphus) (Clutton-Brock et al. 1982, Guinness et al. 1979, Darling 1937), Siberian ibex (Capra ibex siberica) (Horwich et al. 1982), and white-tailed deer (Ozoga et al. 1982). This also appears to be the case in mule deer (Hamlin and Mackie 1989) and may represent the mechanism by which successful habitat use strategies are transmitted in a given environment. 
Our studies provided numerous observations of doe-fawn relationships extending from weaning into adult life. These included 15 doe-fawn pairs in PHU 1. In seven pairs, one member was radio collared and the other wore a neckband; in three, both members were radio collared; and five pairs were neckbanded only. Indices of association between mother/matriarch and offspring were calculated by dividing the number of observations in which both occurred in the same social group by the total number of observations of the matriarch during a given time period. This approach consistently designated the matriarch as the standard reference point and made comparisons between individuals and time periods more meaningful.

Nine marked pairs included female fawns for which we obtained 20-291 observations per deer on winter range over 2-11 consecutive years. In each case, the daughter as an adult occupied a winter range that overlapped that of the mother. None of the daughters was known to move to a different winter range over 45 deer-years of observation.

Seven of the daughters when $\geq 1$ year of age were observed (1-30 locations/deer) exclusively either within or in close proximity to their mothers' summer home range. The other two daughters were never seen during summer. None of the seven was known to change its summer home range location over 16 deer-years of monitoring (1-3 years/deer).

Among seven pairs of marked does and male fawns, six sons (8-35 observations/deer) returned as yearlings to winter home ranges that overlapped those of their mothers. The other emigrated $14 \mathrm{~km}$ north to winter within PHU 7. Only two of the seven were alive as 2-year olds, and both used their traditional winter home range.

Summer home range locations were determined for only four of the seven mother-son pairs (2-12 observations/deer). Two of the six sons that had winter home ranges overlapping those of their mothers were also observed within the maternal summer ranges -- one as a radioed yearling, the other as a neckbanded 2-year old. The lone known emigrant moved as a yearling to a summer range in PHU 7, $11 \mathrm{~km}$ north of its maternal summer range in PHU 1. Another neckbanded yearling used a summer range $6 \mathrm{~km}$ away from its mother's range but within PHU 1.

Association indices between does and their female offspring declined from an average $81 \%$ (range $56-100 \%, N=9$ ) during the offspring's first winter-spring to $69 \%$ $(29-94 \%, N=7)$ in winter-spring of the following (yearling) year. By their third winter, these daughters were seen with their mothers $50 \%$ of the time (range $0-75 \%, N$ $=6$ ). When observed in subsequent winters, these mother-daughter pairs were together an average of $56 \%$ (range $0-100 \%, N=5$ ) of the times the mother was seen. Although these data indicate that direct association between mother and daughter declined over time, they continued to use overlapping winter home ranges as described above. 
Male fawns were associated with their mothers on an average $85 \%$ of the time (range $67-100 \%, N=6)$ in winter/spring. This declined to $46 \%(13-71 \%, N=4)$ among yearling males and their mothers. Only two instances of association between mothers and their 2.5-year-old male offspring were recorded; winter-spring indices of association were 14 and $50 \%$.

Three mother-yearling daughter pairs were observed during summer. In each pair, both mother and daughter were radio collared. In one case, the maternal female successfully reared one fawn through summer, and the yearling daughter occurred in the same social group during only one (5\%) of 19 relocations between 15 June and 20 October. In a second case, mother and yearling daughter were relocated together on summer range on 2 May and 31 May. On 20 June, there were $2 \mathrm{~km}$ apart and alone. They were very close together ( $<150 \mathrm{~m}$ apart) though not seen on 13 July and 31 July. Subsequently, on 21 August and 22 September, they were together as a group with two other adults. The mother was not observed with a fawn during that year. In the third case, a doe and yearling daughter were observed in the same group on winter range on 1 June. On 27 June, both had moved to summer range and were radio-located about 150 $\mathrm{m}$ apart in separate social groups (the maternal doe was alone). Four subsequent relocations of mother and daughter from mid July through mid September indicated that the two remained apart in separate social groups through this period. The reproductive status of the mother was not known.

Association between related females with overlapping home ranges was documented during three generations within one matrilineal group (Fig. 4.13). The original matriarch (\#1021) was first marked with a neckband as a 2-year old on winter range in PHU 1 in 1973. She continued to use the same winter home range during 1973-1975; the location of her summer range was not determined. During late February 1975, her female fawn (\#1062) was marked with a neckband. The pair was seen together six times through 29 March when the doe was accidentally killed. During the remainder of the winter and spring, 1062 continued to use the maternal home range.

Female 1062 was next seen in February 1976 within the maternal winter home range where she was recaptured in early March and fitted with a radio collar (the first of five by which she was monitored for nearly 11 years). Between 17 May and 30 May, she moved east of the main Bridger Range Divide to summer range on Flathead Creek. That area was used through 7 October 1976 when she returned to the same winter range used the previous two years. She continued to follow this pattern of movement and use of the same two seasonal ranges throughout her life.

This "Flathead" doe (\#1062) was not observed with a fawn until summer 1978 when she was 4 years old. We captured and neckbanded her female fawn (\#1166) in January 1979 and observed the pair together on 7 of 10 observations of 1062 through May. Subsequently, 1062 was seen with one fawn on summer range in early August and with twin fawns plus yearling female 1166 in mid September 1979. 

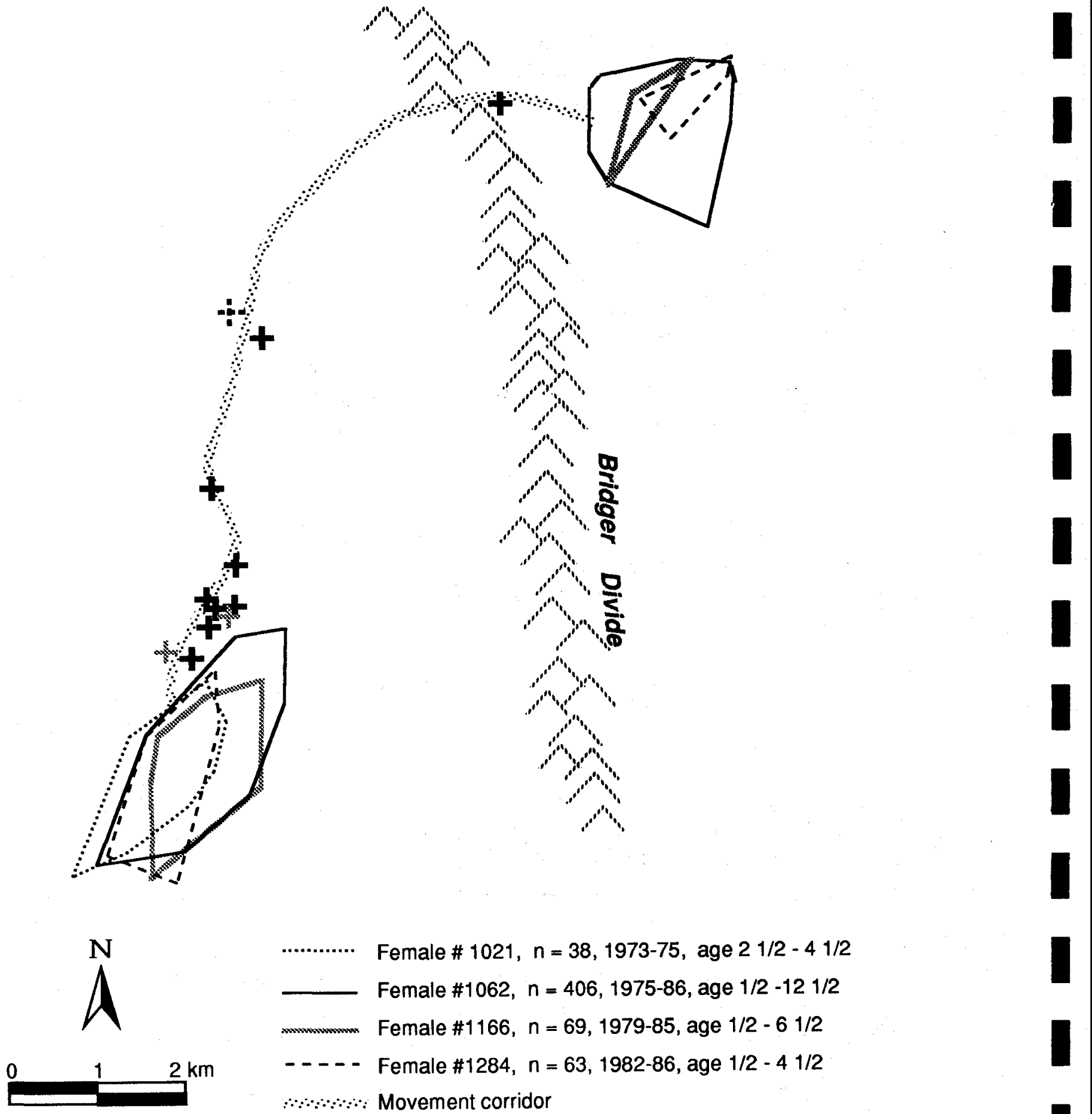

Female \# 1021, $n=38,1973-75$, age 2 1/2 - 4 1/2

Female \#1062, $n=406,1975-86$, age $1 / 2-12$ 1/2

Female \#1166, $n=69,1979-85$, age $1 / 2$ - $61 / 2$

- - - - Female \#1284, $n=63,1982-86$, age 1/2 - $41 / 2$

$\therefore \cdots$ Movement corridor

Figure 4.13. Seasonal home ranges and interseasonal movement of three generations of related female mule deer. Individual relocations indicate a shared movement corridor. 
The family of four shared the same home range during winter 1980 . However, mother and yearling daughter were seen together during only $4(31 \%)$ of 13 sightings of 1062. All four were seen together on winter range in late April. Subsequent relocation and tracking during mid May indicated that they moved as a group through rugged terrain along the movement corridor shown in Fig. 4.13 to summer range.

During summer 1980, the Flathead doe (age 6 years) was seen alone on two occasions in late summer. In late autumn, she and 2-year old daughter, 1166, were together in three of five observations on or near the winter range. The group included a fawn belonging to either 1062 or 1166 . They occurred together on their winter home range on four of seven relocations between January and May 1981.

In early June 1981, the 7-year old 1062 and 3-year old daughter 1166 were seen on their summer range with another adult doe and two yearlings. Thereafter, 1062 was seen with only a newborn fawn on three occasions through 9 August. On the latter, daughter 1166 was also seen about $0.5 \mathrm{~km}$ from her mother and in company with another adult female. In autumn, however, 1062 and 1166 were together on four of five sightings of either. Similarly, from January to May 1982 they were together on eight of nine observations. A female fawn of 1062 was captured and radio collared as \#1284 in early January. From then until departure from the winter range, 1284 was with her mother on seven $(\mathbf{7 8 \%})$ of nine sightings. In each case, 1166 was also in the group.

Yearling 1284 was seen on her mother's summer home range on Flathead Creek in late June 1982, but the two were about $150 \mathrm{~m}$ apart and apparently not in the same group. Four sets of relocations between mid July and mid September were also 0.3-1.3 $\mathrm{km}$ apart. In late September, 1284 cast her radio collar and was not seen again until she returned to the winter range. The 4-year old 1166 was not observed during summer 1982 but was seen on the winter range with a fawn through 1983. The Flathead doe apparently arrived on the winter range without a fawn.

During winter-spring 1983, yearling 1284 and her 8-year old mother were together on $15(94 \%)$ of 16 sightings. The 4-year old 1166 was with the mother on 10 (63\%) of 16 sightings, and all 3 were together on $9(57 \%)$ of the 16 observations. In May, 1062, 1284, and a fawn were seen along their movement corridor $3.0 \mathrm{~km}$ north of the winter home ranges (Fig. 4.13). The presence of the fawn indicated that 1166 was probably also in the group but hidden by dense timber.

The Flathead doe was seen on four occasions, each with one or two fawns, during summer 1983; daughters 1166 and 1284 were not seen that summer or autumn although both returned to winter range where 1166 was accompanied by a single fawn. This was the first time that mother 1062 and daughter 1166 were both accompanied by fawns on winter range. Coincidentally, they occurred together in only $2(17 \%)$ of 12 sightings during winter-spring; the lowest in seven years of coexistence. At the same time, 1284, which did not have a fawn, was present in 9 of the 12 sightings of the Flathead doe. 
None of the three related does was visually relocated during summer and autumn 1984. The reproductive status of 1062 could not be ascertained, while 1166 did not have a fawn and 1284 (age 3 years) was seen on winter range with a fawn for the first time. During winter-spring 1985, 1284 was seen with 1062 on five of eight sightings and 1166 (age 6 years) in four of four observations of the matriarch before 1166 was accidentally killed in mid-April 1985. All three were together in two of the four sightings to mid April.

Neither the Flathead doe or daughter 1284 was seen in summer 1985. Reproductive status of the matriarch was not determined, but 1284 apparently was accompanied by one fawn through early April 1986 . The two occurred together in all eight sightings of 1062 during winter and early spring 1986 . Observations were subsequently terminated with death of the Flathead doe at age 12 years on her summer home range in September 1986.

In summary, the Flathead doe and her offspring formed a matrilineal group that, over 12 years, shared the same or overlapping seasonal home ranges and moved together, at least from winter to summer ranges. This winter home range was essentially the same as that used by the Flathead doe's mother. During her first four years of life, daughter 1166 was observed with her mother in $58 \%$ of all observations $(N=45)$ of the latter during winter and spring. In contrast, during her first four years, the second daughter, 1284 , occurred with the matriarch $84 \%$ of the time (44 observations) during the same seasons. Reproductive output within the matrilineal group apparently affected the degree of association between these adult females. In winter, association was lowest when both mother and daughter had fawns and was generally highest when neither had fawns.

Degree of association between matriarch and daughter(s) also varied seasonally. For all summers combined, 1166 was seen with her mother on only 3 of 11 sightings of the latter. This increased to 7 of 15 sightings in fall and 32 of 61 observations in winter.

The long-lasting social bond between mother and female offspring played a significant role in forming and perpetuating successful habitat use patterns. This may be particularly important in high elevation mountain habitats like the Bridger Range where use of disjunct seasonal home ranges often requires specialized movement patterns. For example, the Flathead group (Fig. 4.13) crossed the precipitous Bridger Divide at an elevation of $2550 \mathrm{~m}$ through one of only three passes in PHU 1. The proper timing of movement with respect to snow conditions along the high divide and spring forage plant development on the summer range had to be learned or passed on from matriarch to offspring.

Horwich et al. (1982) and Lent (1974) described seasonal oscillation in the strength of the mother-daughter bond in Siberian ibex. We also noted seasonal oscillation in mother-daughter bonds in mule deer. The principle regressive period occurred during fawning and continued through much of the summer when other social 
forces and resource needs took precedence over maintenance of the mother-adult daughter bond. This period was characterized by parturition territoriality (Ozoga et al. 1982, Hamlin and Mackie 1989) by maternal does and periodic emigration of young adults. A high level of association occurred in autumn, winter, and spring. This maintained the matrilineal bonds and compensated for disruption during fawning.

Clutton-Brock et al. (1982) indicated that red deer matriarchs allowed their female offspring to set up overlapping home ranges. Consequently, resources within the home range, although somewhat diminished for the matriarch, were more likely to benefit their heirs rather than unrelated individuals. It may also result in the most effective utilization of habitat resources available to deer in a particular area.

\section{Genetic Composition of Population-Habitat Units}

In mammals, mitochondrial DNA (mtDNA) is maternally inherited without recombination. Thus, mtDNA can be useful in assessing genetic divergence, cytoplasmic gene flow, and subdivision of populations on a large and small geographic scale (Avise et al. 1979, Kessler and Avise 1985). The fact that males will not spread heritable mtDNA variation between areas may allow identification of population subdivision when predominantly male dispersal keeps nuclear gene frequencies homogeneous across a population. Birky et al. (1983) predicted that population subdivision will be approximately four times greater for mitochondrial than nuclear genomes, especially in species with predominantly male dispersal. This occurs because haploid, maternally inherited mtDNA has a smaller effective gene number than nuclear genes. Dispersing males will contribute mtDNA haplotypes to a new subpopulation only transiently until death. Unless dispersal rates are very high, the representation of foreign mtDNA types brought into a subpopulation by immigrants will be negligible.

Cronin et al. (1991) identified three mtDNA haplotypes (A, B, and D) from tissue collected from 134 mule deer in the Bridger Mountains. These occurred at significantly different frequencies between populations on the west and east slope. Frequencies of haplotypes A, B, and D in west slope deer were 8,85 , and $8 \%$, respectively, compared to 27,63 , and $8 \%$ for deer on the east slope.

The degree of differentiation of mtDNA haplotype frequencies between populations on the east and west slopes is only of low-moderate magnitude. However, it is generally consistent with other data indicating that west and east slope PHUs represent relatively distinct groups of interacting individuals. Cronin et al. (1991) further stated that a lack of differentiation of alleles at protein loci encoded by the nuclear genomes suggest maternal gene flow is more restricted than male gene flow. 


\section{Summary}

1. Mule deer in the Bridger Mountain complex were distributed in seven populationhabitat units (PHUs). Each PHU represented a distinct association of individual deer bonded together by traditional use of individual home ranges within a definable unit of yearlong habitat.

2. A topographic, climatic, and vegetative profile was given for each PHU. Although the environment of each was somewhat unique, west slope units (PHUs 1, 2, and 7) spanned the high Bridger Divide and were characterized by greater precipitation and a diversity of vegetation zones. East slope units (PHUs 3, 4, 5 , and 6 ) shared more gentle topographic relief, lower average precipitation, and fewer vegetation zones.

3. Deer occupying the Armstrong segment of PHU 1 were distributed within three population subunits that consisted of a definable aggregation of closely related individuals. Each subunit was associated with a particular segment of the winter range. This pattern was less evident on summer range. In PHU 4 on the east slope, subunitization was much less evident during both winter and summer.

4. Patterns of spatial distribution were formed and transmitted through social behavior. Among females, these long lasting social bonds result in cohesive matrilineal groups that include several generations.

5. Analysis of mitochondrial DNA (mtDNA) provided additional evidence that west and east slope PHUs represent distinct groups of individuals. 


\section{CHAPTER 5}

\section{DEER DISTRIBUTION AND HABITAT USE IN RELATION TO ENVIRONMENTAL FACTORS}

Mule deer distribution patterns and the location, size, and shape of populationhabitat units were fundamentally influenced by environmental characteristics across the Bridger Mountain Range and adjacent valley areas. Among these, topography, climate or weather, and vegetation were of major importance. This chapter generally describes the role of these factors in determining distribution patterns and habitat use.

Topography and Climate

\section{Winter}

High topographic relief along the west slope of the Bridger Mountains created an orographic gradient of precipitation across the study area. This relationship directly influenced the location, size, and shape of the seven mule deer winter ranges located around the mountain range (Fig. 5.1).

As a consequence of the steep precipitation gradient on the windward slope, the three west slope winter ranges were small, linear, and oriented along the mountain footslope on a north-south axis. They occurred predominantly within the 508-762 $\mathrm{mm}$ precipitation zone although the lower winter range boundary projected into the 457-508 $\mathrm{mm}$ zone and the upper boundary of the Northwest Slope and Southwest Slope winter ranges intersected a small portion of the $762-1016 \mathrm{~mm}$ zone.

At any given elevation, precipitation on the east, or leeward slope of the study area was lower than on the west slope. Also, gentle and rolling terrain resulted in a widening of precipitation zones on the east slope. Thus, the Livingston, Brackett Creek, and Battle Ridge winter ranges were larger, less linear, and tended to be oriented along an east-west axis. In contrast to the west slope, only a very small percentage of the total area of winter range occurred within the $508-762 \mathrm{~mm}$ precipitation zone. The 457-508 $\mathrm{mm}$ precipitation zone generally prevailed along the upper boundaries while the 356-406 and 406-457 $\mathrm{mm}$ zones occupied the remainder.

Environmental patterns on the South 16-Mile winter range differed somewhat from both east and west slopes. The South 16-Mile winter range comprised a low elevation basin separating the Bridger Mountains from the Big Belt Mountains to the 


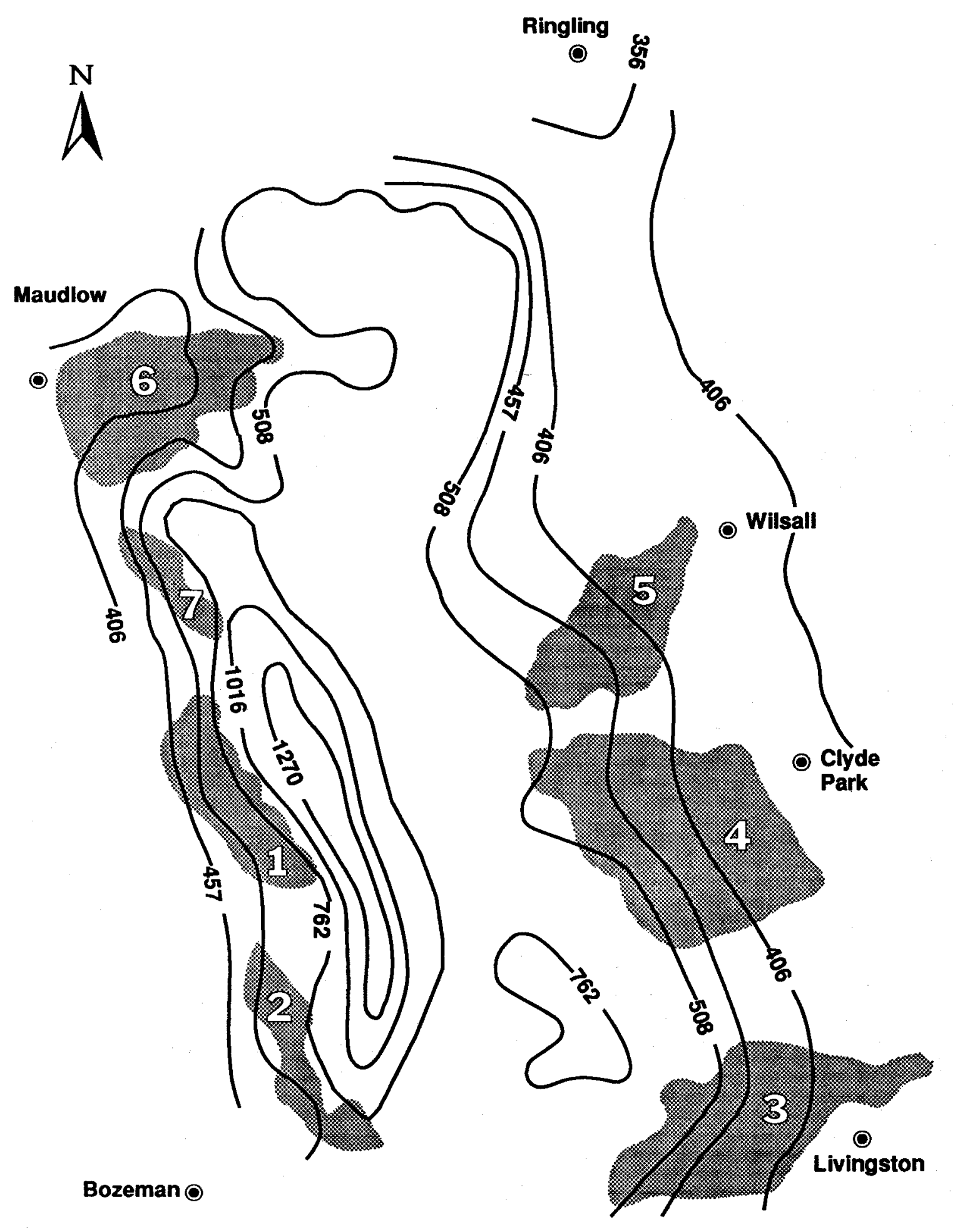

I

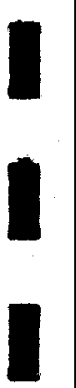

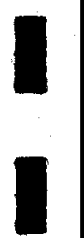

I

I

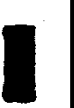

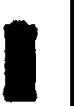

I

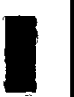

Figure 5.1. Distribution of precipitation zones $(\mathrm{mm})$ in the Bridger Mountains. Winter ranges are shaded. Winter ranges are: $1=$ Northwest Slope, $2=$ Southwest Slope, 3 = Livingston, $4=$ Brackett Creek, $5=$ Battle Ridge, $6=$ South 16 Mile, and $7=$ Blacktail Mountain. 
north. Because of gentle relief and distance from adjacent mountain ranges, precipitation patterns were not orographically influenced. Therefore, a greater percentage of the area occurred within the relatively dry $356-406 \mathrm{~mm}$ precipitation zone than the other two areas.

West slope winter ranges included much more area of steep $\left(20^{\circ}-30^{\circ}\right)$ and very steep $\left(>30^{\circ}\right)$ south-facing (SSE-WSW) slopes than other winter ranges (Appendix Table A2). These steep, southerly aspects greatly reduced snow accumulation and duration by 1) increasing inherent surface area (Fig. 5.2) and 2) increased absorption of solar radiation compared to level ground (Table 5.1). On most extreme $\left(45^{\circ}\right)$ slopes, snowfall may be reduced as much as $29 \%$, and about $85 \%$ more solar radiation was absorbed. The resulting reduced snow depth and duration permitted deer to successfully winter at higher elevations in zones of greater precipitation and snowfall than areas used by deer on the east side and north end.

Table 5.1. Solar radiation flux (calories $/ \mathrm{cm}^{2} /$ day) on primary aspects and level ground at $45^{\circ}$ north latitude. Values represent the mean of three readings taken on the first, middle, and last day of winter.

\begin{tabular}{crrrr}
\hline & North & South & East & West \\
\hline $15^{\circ}$ slope & 177.7 & 445.8 & 315.0 & 315.0 \\
$30^{\circ}$ slope & 66.3 & 539.8 & 304.5 & 304.5 \\
$45^{\circ}$ slope & 9.8 & 596.7 & 289.0 & 289.0 \\
Level Ground & 321.5 & & & \\
\hline
\end{tabular}

Each west slope winter range was associated with a prominent east-west ridge that projected farther west than adjacent ridges, maximizing the availability of south aspects. The "spaces" between west slope winter ranges were associated with the north and northwest aspects of these prominent ridges where minimal interception of solar radiation prevented snowmelt. Apparently, the reduction in snow depth caused by the increased surface area of steep slopes in these "spaces" was not singularly adequate to permit mule deer to consistently occupy those areas.

During midwinter, mule deer on the west slope were not able to substantially exploit areas of flat terrain at the lower limits of their winter ranges. Snow accumulation in these flat areas, which primarily occurred within the $457-508 \mathrm{~mm}$. precipitation zone, was usually great enough to preclude use by deer during much of the winter and formed a physical barrier to exploitation of drier precipitation zones further west on the Gallatin Valley floor. 

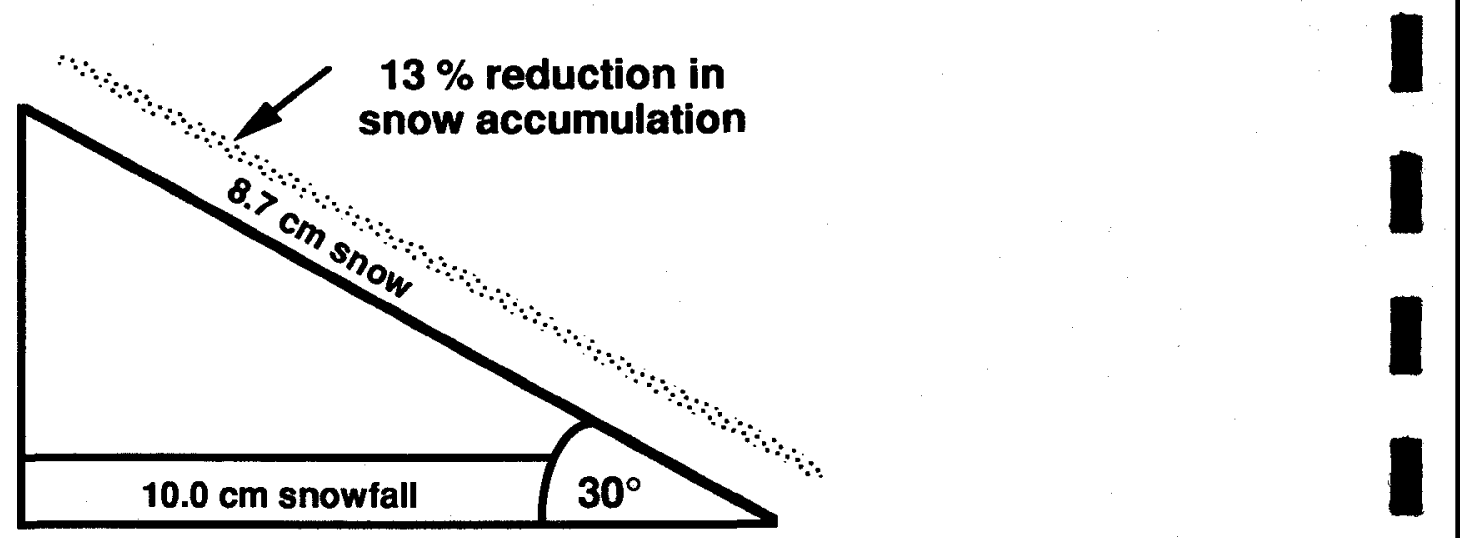

$30^{\circ}$ slope

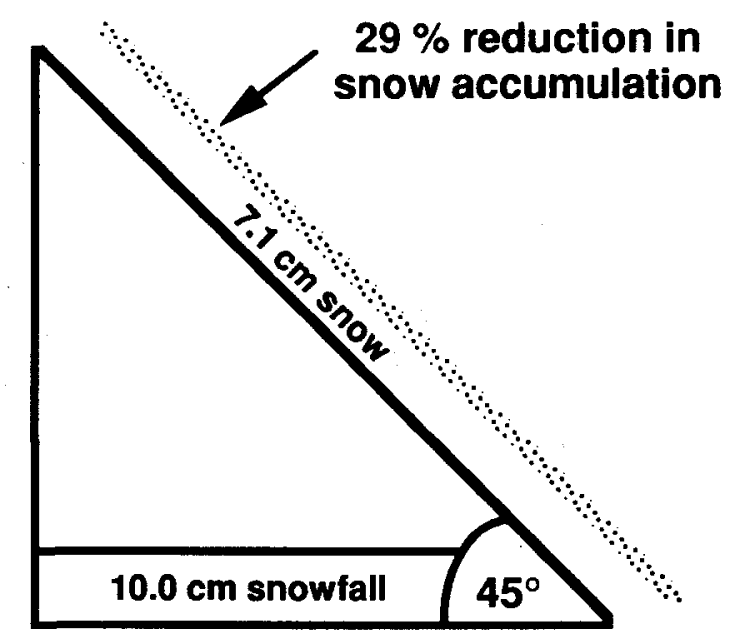

I

I
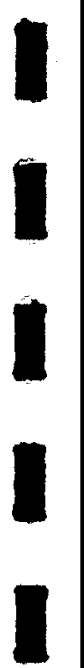

I

\section{$45^{\circ}$ slope}

Figure 5.2. Hypothetical reduction in snow accumulation on the greater surface area of $30^{\circ}$ and $45^{\circ}$ slopes compared to level ground. 
The distribution of temperature regimes along the west slope of the Bridger Mountains during winter also enhanced the ability of mule deer to successfully occupy those winter ranges. The upper portion of each winter range was normally above the temperature inversion that commonly occurred in the Gallatin Valley. The higher average temperatures combined with other factors cited above further increased snow melt and provided a favorable environment for conservation of energy by deer.

Mule deer populations associated with west slope winter ranges occurred within climatic/precipitation zones that could only be successfully occupied when deer employed a specialized strategy. This involved exploiting specific micro-environments where snow accumulation was reduced by the interaction of several abiotic factors. As will be discussed later, this strategy of winter habitat use significantly affected demographic characteristics and dynamics of the three populations.

Mule deer on east slope winter ranges encountered very different environments. With progressively decreasing snowfall at lower elevations, deer were able to easily move below the level of restrictive snow depth and exploit large, open, undulating expanses of winter habitat within the drier precipitation zones. All four east side and north end winter ranges contained relatively large proportions of gentle terrain compared to west slope ranges. The east side winter ranges were only locally dissected by numerous second or third order drainages that formed some steep-sided ridges and areas of rough "breaks". Spaces void of deer between east slope winter ranges were gentle, concave basins that provided virtually no topographic diversity and were generally dominated by large blocks of agricultural land.

Along the east slope, the $508-762 \mathrm{~mm}$ precipitation zone that figured so importantly in the winter ecology of deer on the west slope was uninhabitable because the abiotic characteristics that created favorable micro-environments (i.e. snowfree areas) were absent. The 457-508 $\mathrm{mm}$ precipitation zone that occupied the upper portions of those winter ranges was the same zone that occupied the valley floor at the lower edge of west slope winter ranges. By January, however, deer inhabiting the east and north slopes were usually distributed below this zone and exploiting areas of even lower snow accumulation in the $356-406$ and $406-457 \mathrm{~mm}$ precipitation zones.

Average winter air temperatures on the Livingston, Brackett Creek, and Battle Ridge winter ranges were lower than recorded for west slope ranges. This occurred despite the windier conditions that prevailed and prevented formation of temperature inversions along the east slope. As noted earlier, however, east side ranges were also affected more by arctic air masses. Steep southerly aspects where ambient temperatures were raised by solar heating were less available.

The South 16-Mile winter range was characterized by higher winter/spring temperatures than occurred on either west or east slope winter ranges. This resulted 
from the lowest mean elevation and reduced influence of temperature inversions that affected west slope ranges and the arctic air masses that influenced the east slope.

Climate and topography on east slope winter ranges influenced more generalized patterns and strategies of habitat use. During most winters, deer remained widely distributed across all available winter habitat and "keyed in" on specific micro-environments only when conditions were abnormally severe. This "generalist" strategy of winter habitat use affected the demographic characteristics of these populations in several ways that will be discussed later.

Throughout the Bridger Range, occurrence of winter habitat was determined by a hierarchy of factors. The broad distributional limits of winter habitat were primarily determined by the distribution of snow cover. Secondarily, within these limits, physical site characteristics determined the specific location, size, and shape of each winter range and patterns of deer dispersion within it. Vegetation composition and structure were only third order factors determining winter habitat use in each unit.

Spring, Summer, and Autumn

Distribution of deer during spring, summer, and autumn in all PHUs centered in areas characterized by higher precipitation zones closest to winter range (Fig. 5.1). By definition, environmental characteristics that described mule deer winter range provided poor quality summer ranges. Winter ranges were generally dry and rather uniform habitats that were capable of supporting relatively few deer yearlong. During summer, most deer were required to move, usually to higher elevations where diverse, mesic habitats provided high quality forage and other resources that supported reproduction and relatively high deer densities on small individual home ranges.

Summer ranges within PHUs 1, 2, and 7 spanned the Bridger Divide. Here, the spatial distribution of major vegetation types tended to occur in relatively narrow zones as a result of marked changes in elevation and precipitation over a short distance. Vegetation types on east slope ranges were broadly distributed because of more gradual changes in topographic relief and precipitation.

Seasonal Elevational Relationships

Winter

Median elevations of all deer groups observed during helicopter surveys in west slope PHUs during early and late winter were consistently higher than those recorded in PHUs 3, 4, and 6 (Fig. 5.3). During early winter, the medians varied from 1,800 to $1,950 \mathrm{~m}$ in the former and from 1,585 to $1,675 \mathrm{~m}$ in the latter. Medians in late winter decreased by 90 to $120 \mathrm{~m}$ in PHUs 1 and 2 and increased $30 \mathrm{~m}$ in PHU 7. Elevations of deer observations in PHUs 3 and 6 remained unchanged over winter. In PHU 4, the 


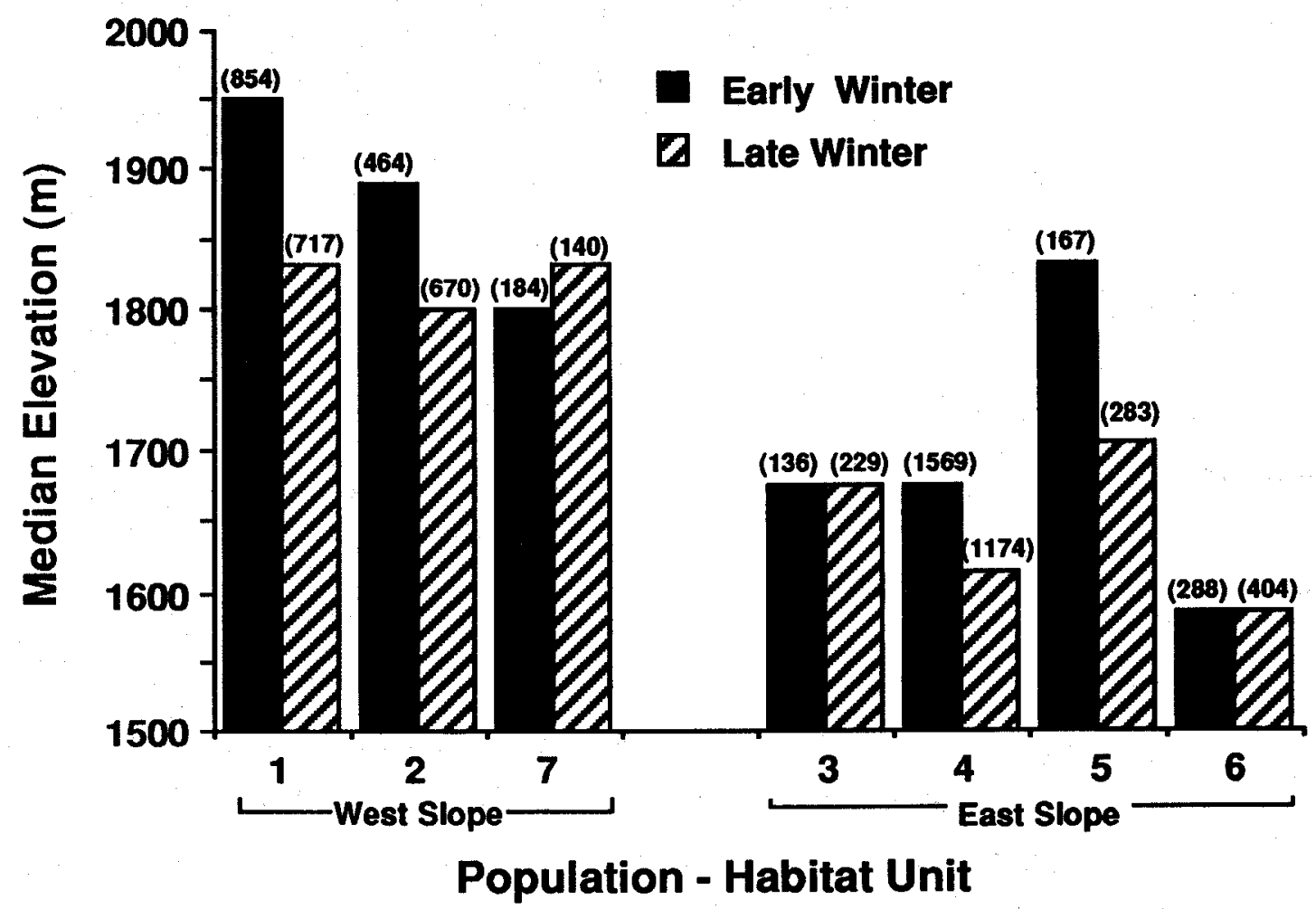

Figure 5.3 Median elevation of all groups of deer observed during helicopter surveys in early and late winter on three west slope and four east slope PHUs, 1976-1986. Number of deer groups in parentheses.

median elevation used by deer declined from 1,675 to $1,615 \mathrm{~m}$ between early and late winter.

Median elevations at which deer were observed in PHU 5 during early and late winter were higher than other east slope units; in fact, the early winter median fell within the range of median values recorded along the west slope (Fig. 5.3). This occurred because the winter range centered along Battle Ridge, a prominent east-west escarpment. Unlike other east slope ranges, deer in PHU 5 made less use of flat terrain, apparently because snow accumulations often became excessive at the $125-170 \mathrm{~m}$ higher elevation. However, major physical characteristics of the PHU 5 winter range, including precipitation pattern, availability of steep slopes, and forest cover, were more typical of east rather than west slope winter ranges.

Annual over-winter shifts in elevation for deer in PHUs 1 and 4, are shown in Fig. 5.4. Median elevations at which deer occurred during early winter in PHU 1 varied considerably between years from $1,675 \mathrm{~m}$ in $1975-76$ to $2,195 \mathrm{~m}$ in 1980-81. Late winter elevations were more stable, varying only from 1,735 to $1,920 \mathrm{~m}$ between years. 


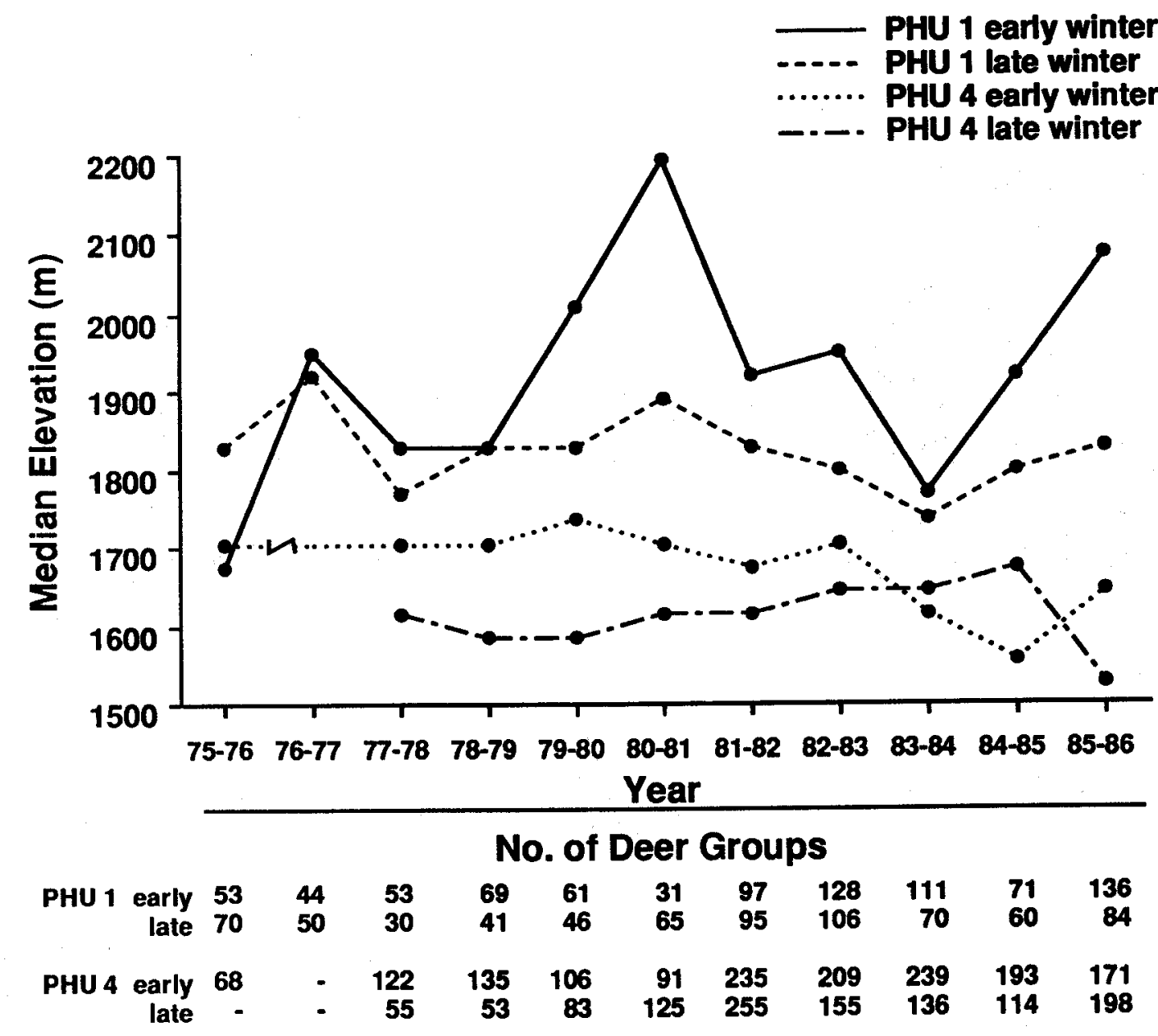

Figure 5.4. Median elevation of deer groups observed during helicopter surveys in early and late winter on PHUs 1 and 4, 1976-1986.

The greatest over-winter changes generally occurred during mild, open conditions (1980-81 and 1985-86) when deer remained at higher elevations in early winter. Little overwinter change occurred during particularly severe winters (e.g. 1977-78 and 1978-79) because deer had concentrated at lower elevations prior to the early winter surveys.

Other factors disrupted this general pattern during some years in PHU 1. Deer use of relatively low elevations during early and late winter surveys in 1983-84 corresponded to the only periods of deep snow during an otherwise mild winter (Fig. 5.4). In 1975-76, early winter distribution centered at substantially lower elevation than recorded for late winter. A brief period of light snow and moderately cold temperatures in January 1976 appeared to cause a greater than expected concentration of deer on the 
lower footslopes. This may have reflected some "conditioning" of deer during the previous, very severe 1974-75 winter when all deer were concentrated within the "core" winter range. Based on that experience, deer may have "over-reacted" to the first severe weather during the subsequent winter of 1975-76.

Median elevations at which deer were observed during early winter in PHU 4 ranged from 1,555 to $1,735 \mathrm{~m}$. This was lower and less variable than recorded for PHU 1. The difference was apparently related to the absence of steep southerly aspects at higher elevations above the winter range on PHU 4. Steep aspects in conjunction with forest cover above the winter range in PHU 1 allowed deer to remain at higher elevations when relatively open conditions occurred in early winter.

Over-winter decrease in elevation of deer varied less in PHU 4 than PHU 1 (Fig. 5.4). However, deer in PHU 4 were occasionally higher in late winter than early winter. In 1983-84 and 1984-85, periods of severe weather causing concentration in December and January were followed by exceptionally mild, open conditions that allowed deer to range higher in elevation. The lowest median elevation recorded for late winter occurred during the very mild $1985-86$ winter when deer made extensive use of early plant growth at low elevations.

The distribution of three primary deer group types by elevation during early winter in PHU 1 is shown in Fig. 5.5. Female and mixed groups were distributed approximately "normally" by elevation across the winter range. Male groups occurred predominantly at lower elevations, particularly $1585-1704 \mathrm{~m}$. Of all groups that contained yearling or older males, $71 \%$ were mixed; the remainder $(29 \%)$ were male-only groups. Male groups contained proportionately more mature $(\geq 2$ year) than yearling males.

Female groups in PHU 1 occurred at higher elevations than male groups. Mixed groups occupied an intermediate position but could not be distinguished from the other two (Table 5.2, Fig. 5.5). Mean and median elevations of mixed and male groups were very similar. Mean and median for females were at least 42 and $30 \mathrm{~m}$ higher, respectively. A Kruskal-Wallis test indicated a significant difference (Table 5.2) in distributions among the three group types; a non-parametric multiple comparison test (Dunn 1964, Zar 1984:200) did not. However, both tests conducted on pooled data from all three west slope PHUs indicated significant differences.

Distribution of the three groups in PHU 4 during the same years followed a different pattern (Fig. 5.6). Male groups occurred at significantly higher elevations than female and mixed groups (Table 5.2). Distribution of female and mixed groups was not different. These same statistical relationships were evident from tests using pooled data for PHUs 3, 4, 5, and 6. 


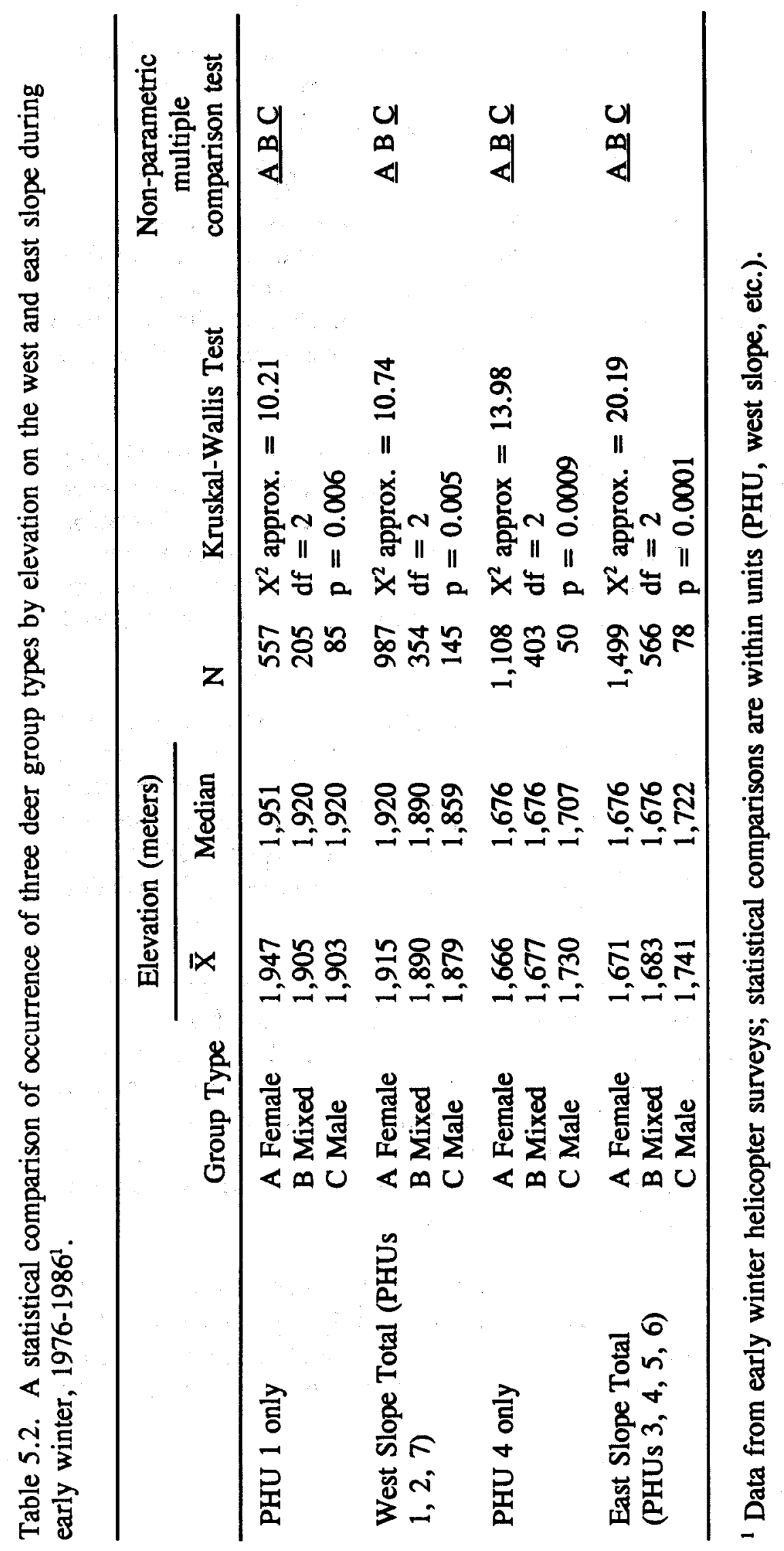




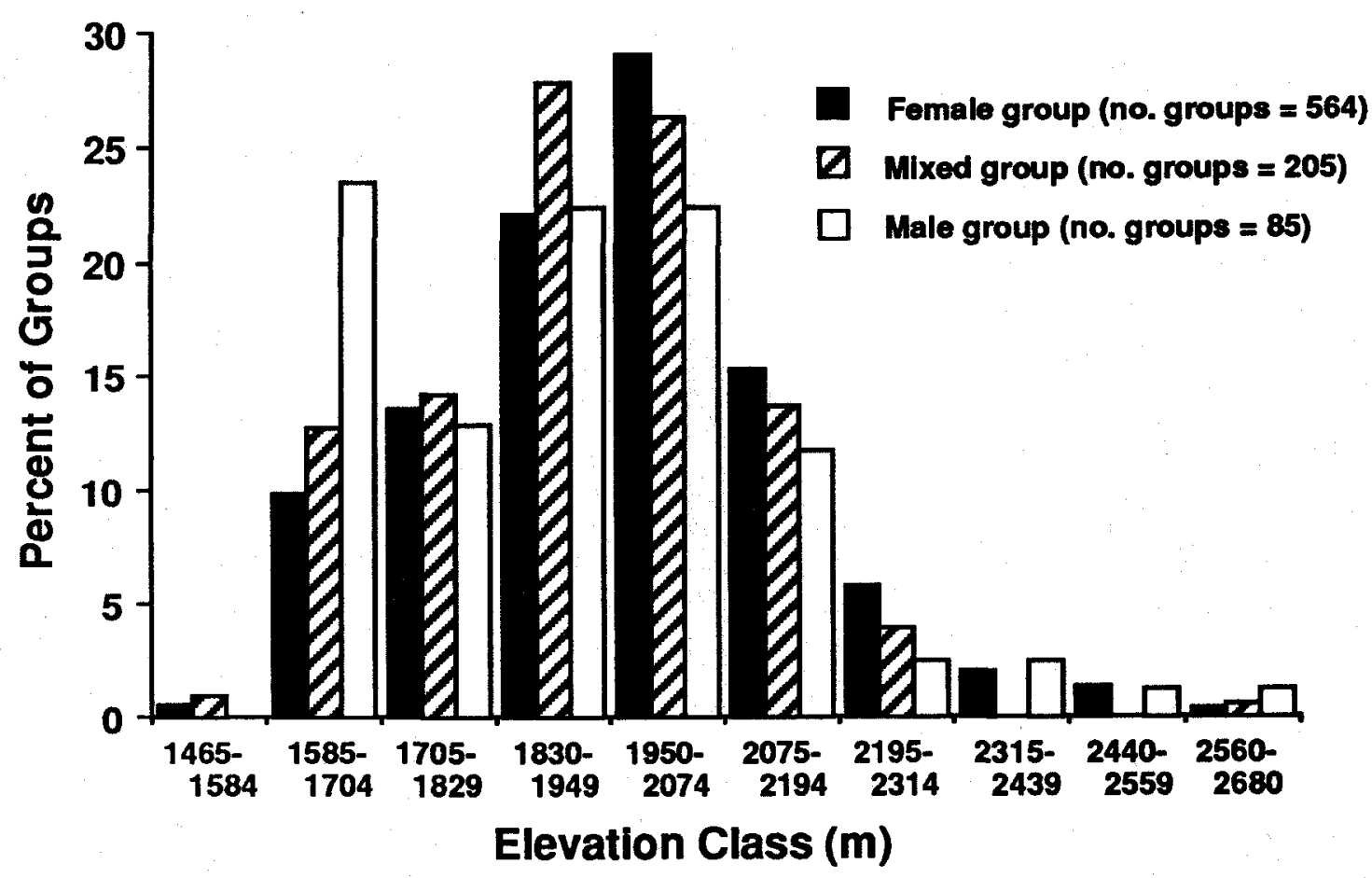

Figure 5.5. Percent of female, male, and mixed deer groups recorded at various elevations in PHU 1 during early winter helicopter surveys 1976-1986.

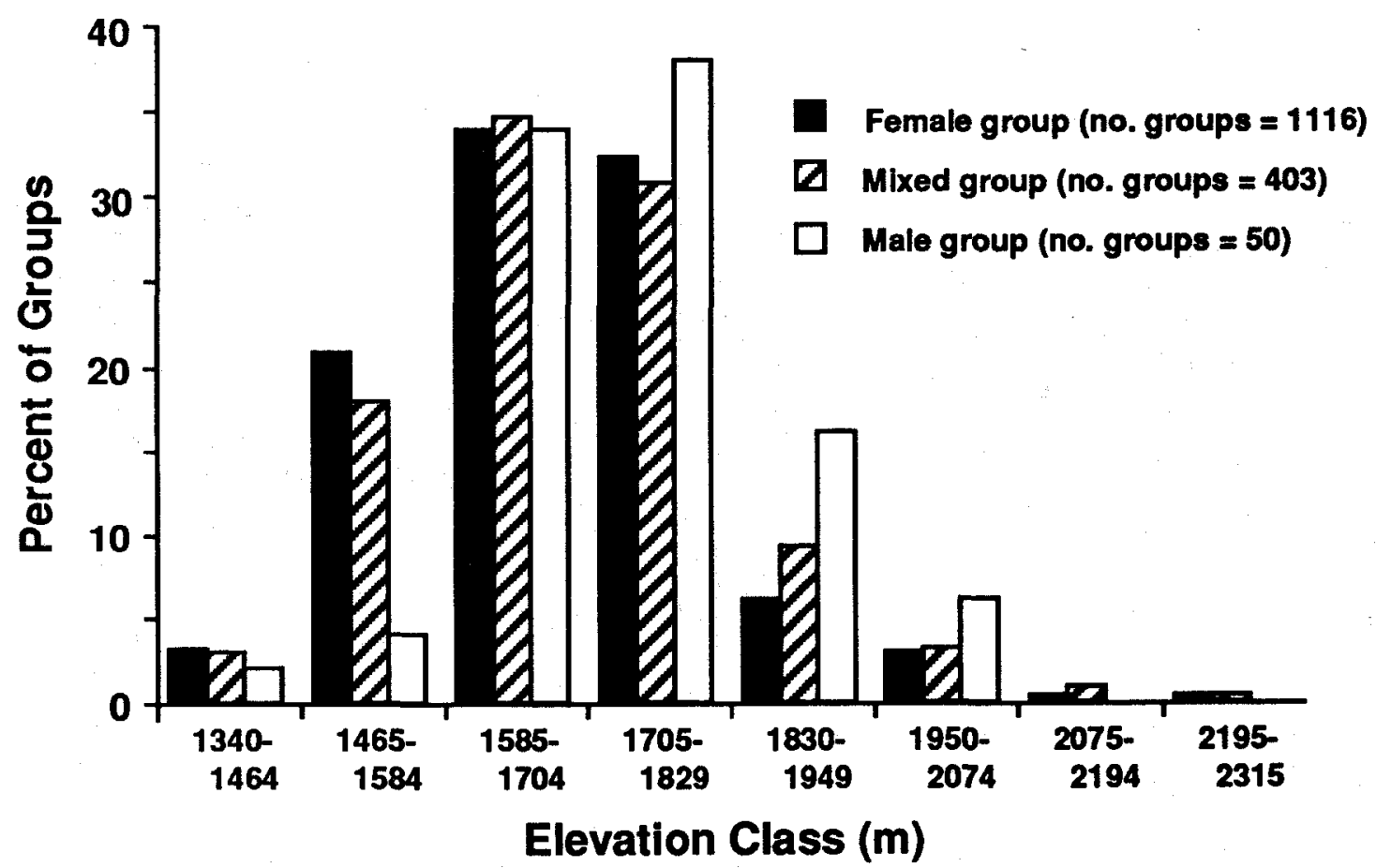

Figure 5.6. Distribution of female, male, and mixed deer groups by elevation category during early winter helicopter surveys in PHU 4, 1976-1986.

60 
Most female and mixed groups in PHU 4 were distributed between 1,585 and $1,704 \mathrm{~m}$ (Fig. 5.6). The largest percentage of male groups occurred between 1,705 and $1,829 \mathrm{~m}$, and males strongly outnumbered females above $1830 \mathrm{~m}$. Male-only groups comprised $11 \%$ of all groups containing yearling or mature males.

The two sexes overlapped considerably in elevational distribution in all units during early winter. At that time, the majority of yearling and mature males were associated with females in mixed groups at intermediate elevations. Some breeding may also have been occurring at the time data were collected in some years. This would increase the proportion of mixed groups and minimize opportunity for detection of any sexual segregation that may have occurred in early winter. Generally, female groups tended to stratify at higher elevations than males on the west slope, whereas this order was reversed on the east slope (Fig. 5.7).

Whenever possible, sexual segregation would seem to enhance resource partitioning (McCullough et al. 1989). However, opportunity for segregation may be limited on mountain foothill winter ranges where all deer are often forced to concentrate on restricted habitat. Segregation would be more likely to occur in early winter following the breeding season when deer were more widely distributed than in mid-late winter when maximum concentration occurred.
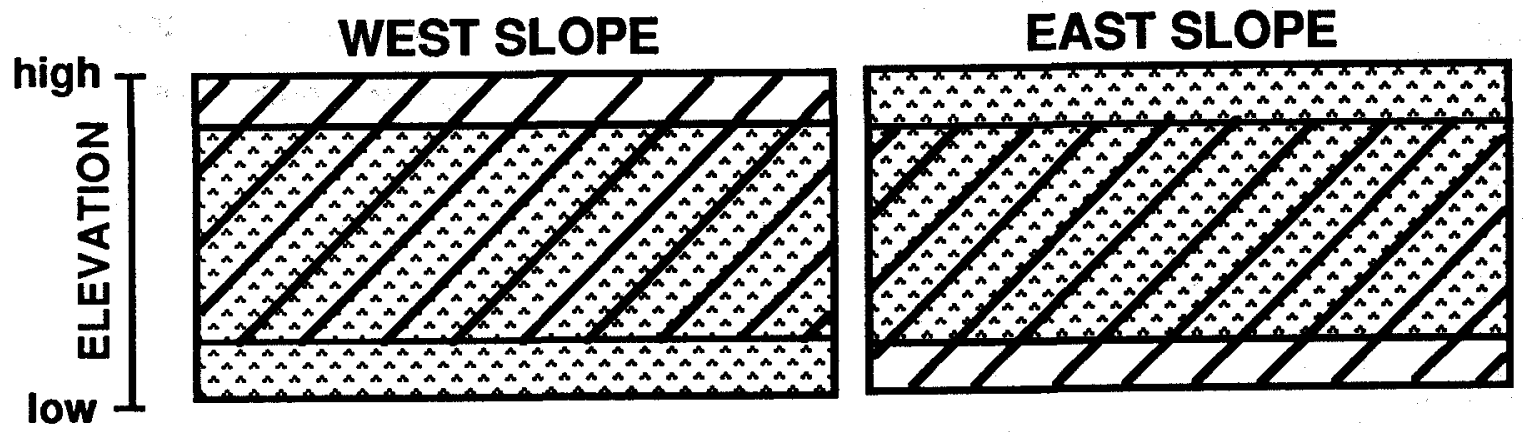

Female $Z$ Male Mixed

Figure 5.7. A conceptual comparison of the early winter distribution by elevation of female, male, and mixed groups of mule deer on the west and east slopes of the Bridger Mountains. 
The stratification of male groups at low elevations on the west slope may have been more evident had rutting been completed in all years by the time aerial surveys were conducted. In the absence of overriding factors, male use of low elevation sites could reflect their tendency to avoid upper elevation timbered habitats preferred by females. The contrasting use of relatively higher elevations on winter range by males in PHU 4 was consistent with female preference for extensive snow-free steppe habitats at lower elevations on that area.

There were no detectable differences in elevational distribution between groups of adult females with fawns $(\mathrm{N}=368)$ and adult females without fawns $(\mathrm{N}=178)$ in either PHU 1 (Kruskal-Wallis $\mathrm{x}^{2}$ approximation $=0.574, \mathrm{df}=2, \mathrm{P}=0.566$ ) or PHU $4\left(\mathrm{x}^{2}\right.$ approximation $=1.19, \mathrm{df}=2, \mathrm{P}=0.234, \mathrm{~N}=876$ and $\left.\mathrm{N}=214\right)$ in early winter.

\section{Summer}

There were no significant differences in elevation between summer activity centers for radio and neck-collared deer on the west slope (Table 5.3). There also was no significant difference between collar types for adult females on the east slope; sample size for males was too small to test for differences.

Table 5.3. Comparison of elevational distribution of radio and neck-collared female and male mule deer during summer on the east and west slopes of the Bridger Mountains.

\begin{tabular}{ccccccc}
\hline Slope & Sex & $\begin{array}{c}\text { Collar } \\
\text { Type }\end{array}$ & $\mathrm{N}$ & $\begin{array}{c}\overline{\mathrm{X}}(\mathrm{m}) \\
\text { Elevation }\end{array}$ & $\mathrm{Z} \mathrm{Value}^{1}$ & $\operatorname{Pr}>/ \mathrm{Z} /$ \\
\hline \multirow{2}{*}{ West } & Female & Radio & 61 & 2,168 & 0.478 & 0.633 \\
& & Neck & 62 & 2,169 & & \\
& Male & Radio & 16 & 2,239 & 1.066 & 0.286 \\
& & Neck & 46 & 2,152 & & \\
\hline \multirow{2}{*}{ East } & \multirow{2}{*}{ Female } & Radio & $68^{2}$ & 1,889 & 1.381 & 0.167 \\
& & Neck & 105 & 1,854 & & \\
& \multirow{2}{*}{ Male } & Radio & 2 & 1,908 & -- & -- \\
& & Neck & 23 & 1,925 & & \\
\hline
\end{tabular}

'Wilcoxon approximation.

${ }^{2}$ Excludes two radio-collared females that summered off the study area. 
Overall, during summer the sexes were distributed similarly with respect to elevation in four of the five PHUs where samples were adequate for comparison (Table 5.4). In PHU 5, activity centers of males averaged $200 \mathrm{~m}$ higher $(P=0.026)$ than females.

Table 5.4. Elevation $(\mathrm{m})$ of summer activity centers for marked female and male mule deer in seven PHUs in the Bridger Mountains.

\begin{tabular}{|c|c|c|c|c|c|c|c|c|}
\hline PHU & Sex & $\mathbf{N}$ & $\begin{array}{l}\text { Median } \\
\text { Elevation }\end{array}$ & $\begin{array}{c}\bar{X} \text { Elevation } \\
\pm S x\end{array}$ & Min & $\operatorname{Max}$ & Z Value' & $\operatorname{Pr}>/ Z I$ \\
\hline 1 & $\begin{array}{l}\mathbf{F} \\
\mathbf{M}\end{array}$ & $\begin{array}{l}90 \\
51\end{array}$ & $\begin{array}{l}2,216 \\
2,195\end{array}$ & $\begin{array}{l}2,212 \pm 214 \\
2,176 \pm 291\end{array}$ & $\begin{array}{l}1,646 \\
1,524\end{array}$ & $\begin{array}{l}2,652 \\
2,701\end{array}$ & 0.678 & 0.498 \\
\hline 2 & $\begin{array}{l}\mathbf{F} \\
\mathbf{M}\end{array}$ & $\begin{array}{l}23 \\
11\end{array}$ & $\begin{array}{l}1,928 \\
2,134\end{array}$ & $\begin{array}{l}2,032 \pm 207 \\
2,177 \pm 262\end{array}$ & $\begin{array}{l}1,768 \\
1,768\end{array}$ & $\begin{array}{l}2,358 \\
2,621\end{array}$ & 1.529 & 0.126 \\
\hline 7 & $\begin{array}{l}\mathbf{F} \\
\mathbf{M}\end{array}$ & $\begin{array}{r}10 \\
-\end{array}$ & $\begin{array}{c}2,095 \\
-\end{array}$ & $2,089 \pm 102$ & $\begin{array}{c}1,945 \\
-\end{array}$ & $\begin{array}{c}2,242 \\
-\end{array}$ & & \\
\hline $\begin{array}{l}\text { TOTAL WEST } \\
\text { SLOPE }\end{array}$ & $\begin{array}{c}\mathbf{F} \\
\mathbf{M}\end{array}$ & $\begin{array}{r}123 \\
62\end{array}$ & $\begin{array}{l}2,195 \\
2,195\end{array}$ & $\begin{array}{l}2,168 \pm 218 \\
2,176 \pm 284\end{array}$ & $\begin{array}{l}1,646 \\
1,524\end{array}$ & $\begin{array}{l}2,652 \\
2,701\end{array}$ & & \\
\hline 3 & $\begin{array}{l}\mathbf{F} \\
\mathbf{M}\end{array}$ & $\begin{array}{r}27 \\
1\end{array}$ & $\begin{array}{l}1,890 \\
1,829\end{array}$ & $1,902 \pm 177$ & 1,615 & 2,195 & & \\
\hline 4 & $\begin{array}{l}\mathbf{F} \\
\mathbf{M}\end{array}$ & $\begin{array}{l}85 \\
11\end{array}$ & $\begin{array}{l}1,829 \\
1,934\end{array}$ & $\begin{array}{l}1,889 \pm 232 \\
1,968 \pm 205\end{array}$ & $\begin{array}{l}1,463 \\
1,494\end{array}$ & $\begin{array}{l}2,438 \\
2,196\end{array}$ & 1.302 & 0.193 \\
\hline 5 & $\begin{array}{l}\mathbf{F} \\
\mathbf{M}\end{array}$ & $\begin{array}{r}27 \\
6\end{array}$ & $\begin{array}{l}1,768 \\
1,951\end{array}$ & $\begin{array}{l}1,768 \pm 179 \\
1,981 \pm 184\end{array}$ & $\begin{array}{l}1,494 \\
1,737\end{array}$ & $\begin{array}{l}2,256 \\
2,225\end{array}$ & 2.221 & 0.026 \\
\hline 6 & $\begin{array}{l}\mathbf{F} \\
\mathbf{M}\end{array}$ & $\begin{array}{r}34 \\
7\end{array}$ & $\begin{array}{l}1,838 \\
1,829\end{array}$ & $\begin{array}{l}1,853 \pm 121 \\
1,824 \pm 51\end{array}$ & $\begin{array}{l}1,585 \\
1,768\end{array}$ & $\begin{array}{l}2,103 \\
1,890\end{array}$ & 0.661 & 0.509 \\
\hline $\begin{array}{l}\text { TOTAL EAST } \\
\text { SLOPE }\end{array}$ & $\begin{array}{c}\mathbf{F} \\
\mathbf{M}\end{array}$ & $\begin{array}{r}173 \\
25\end{array}$ & $\begin{array}{l}1,829 \\
1,890\end{array}$ & $\begin{array}{l}1,868 \pm 199 \\
1,924 \pm 172\end{array}$ & $\begin{array}{l}1,463 \\
1,494\end{array}$ & $\begin{array}{l}2,438 \\
2,225\end{array}$ & & \\
\hline
\end{tabular}

' Wilcoxon approximation of $Z$ value.

For adult females, median elevations of activity centers ranged higher, from 1,928 to 2,216 m, in the three west slope PHUs compared to 1,768 to $1,890 \mathrm{~m}$ in four PHUs on the east slope (Table 5.4). Mean elevations were $300 \mathrm{~m}$ higher $(\mathrm{Z}=10.06, \mathrm{P}=$ 0.000) for the three west slope PHUs.

Median elevations for males were 2,134 and 2,195 $\mathrm{m}$ in PHUs 1 and 2, respectively. For PHUs 3, 4, 5, and 6 the medians were lower, varying from 1,829 to $1,951 \mathrm{~m}$. The mean elevation for 62 males on the west slope was $252 \mathrm{~m}$ higher $(\mathrm{Z}=$ $4.382, \mathrm{P}=0.000$ ) than that for 25 males on the east slope (Table 5.4). 
Females in PHUs 1, 2, and 7 that crossed the Bridger Divide $(\mathbf{N}=33)$ used summer home ranges averaging $104 \mathrm{~m}$ lower $(\mathrm{Z}=2.534, \mathrm{P}=0.011)$ than those which remained west of the divide $(N=90)$. In contrast, females that crossed barrier ridges $(\mathrm{N}=28)$ in PHUs 3, 4, 5 and 6 used summer home ranges at elevations averaging 291 $\mathrm{m}$ higher $(\mathrm{Z}=0.964, \mathrm{P}=0.000)$ than those that did not make crossings $(\mathrm{N}=145)$.

Divide crossing males had activity centers at similar elevation to noncrossers during summer $(Z=0.187, P=0.852, N=15$ and 47$)$ in PHUs 1 and 2. Numbers of males in PHUs 3, 4, 5, and 6 were too small for statistical comparison. However, the average activity center for three marked males that crossed barrier ridges was 260 $\mathrm{m}$ higher than for 22 males that did not exhibit that movement.

\section{Influence of Barrier Ridges}

The main Bridger Divide and two secondary ridges were particularly important in distribution and movements of some deer in each of the seven PHUs.

Among adult females marked in PHUs 1, 2, and 7, only 34, 32, and 30\%, respectively, crossed the Bridger Divide during seasonal movements. Twenty-two percent of the adult males marked in PHU 1 crossed the divide which ranged from 2,250 to $2,945 \mathrm{~m}$ and averaged $2,560 \mathrm{~m}$ in elevation. Distances between the divide and the upper boundary of winter ranges on the west slope varied from 2.6 to $4.0 \mathrm{~km}$. The divide was generally oriented perpendicular to the vector of seasonal movement in each unit and split yearlong ranges approximately in half (Figs. 5.8, 5.9, and 5.10).

No marked deer associated with PHUs 3, 4, and 5 crossed the Bridger Divide in interseasonal movement. However, distances between the divide and winter ranges exceeded $16 \mathrm{~km}$. Although the Bridger Divide was included in PHU 6 (Fig. 5.11), it did not constitute a barrier because the principal vectors of seasonal movement were oriented southeasterly, away from or parallel to the divide.

Bangtail Ridge was oriented perpendicular to movement vectors in PHUs 3 and 4 (Figs. 5.12 and 5.13). Although $300 \mathrm{~m}$ lower and a much less formidable barrier to deer movement than the Bridger Divide, fewer than one third of the deer crossed this ridge, which was located $7 \mathrm{~km}$ from the two winter ranges.

Elkhorn Ridge, averaging about $170 \mathrm{~m}$ lower than Bangtail Ridge, formed the boundary between PHUs 5 and 6 (Figs. 5.14 and 5.11). Less than $11 \%$ of the marked females in either unit crossed the ridge. These generally remained on or near the summit. However, this ridge was more than $12 \mathrm{~km}$ from winter ranges in both PHUs.

Overall, approximately half of the summer range in PHUs $1,2,3,4$, and 7 occurred on the opposite side of a barrier ridge from winter range. Based on distribution of activity centers, areas distal to these ridges did not appear to be exploited to the same 


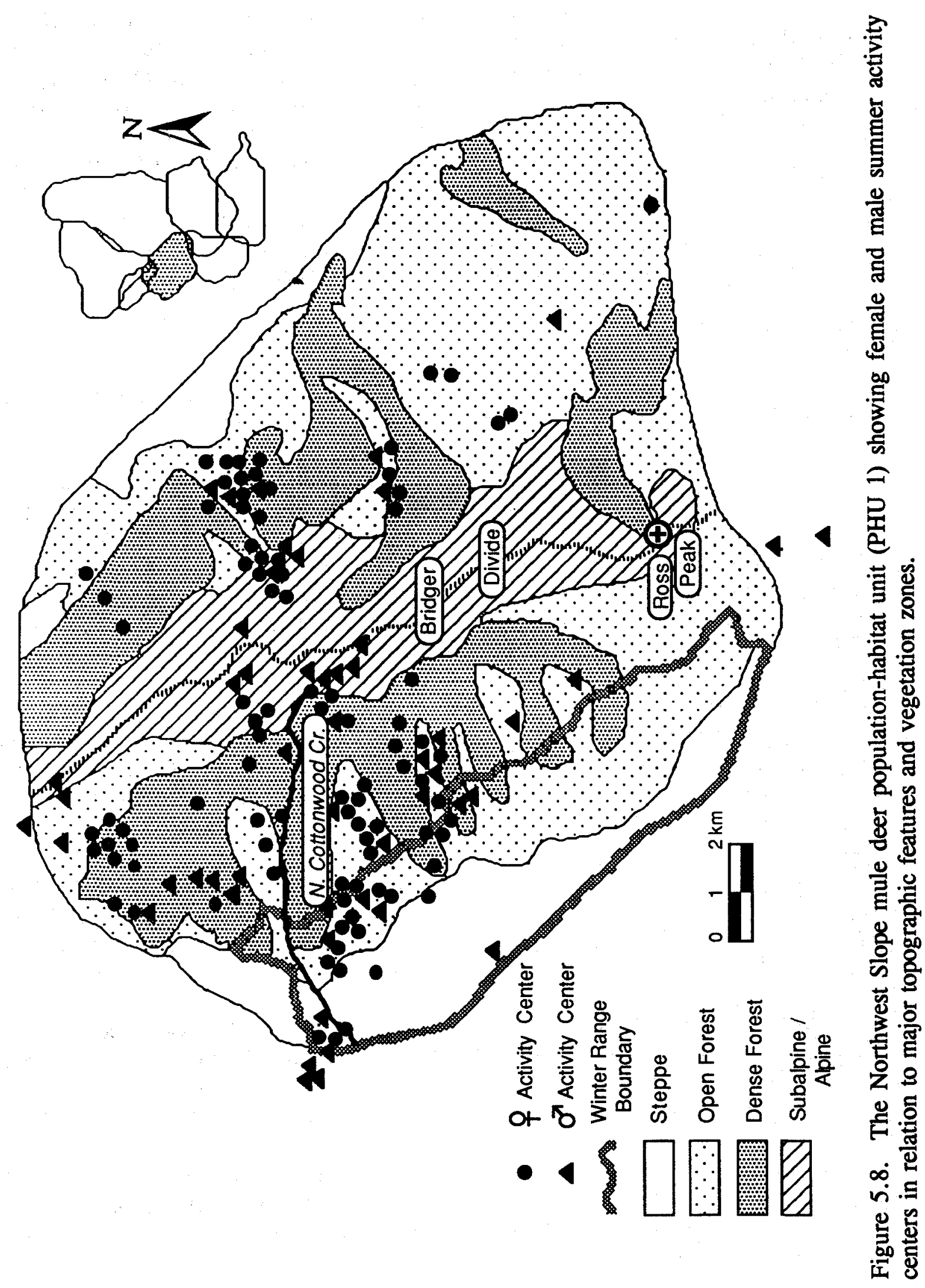




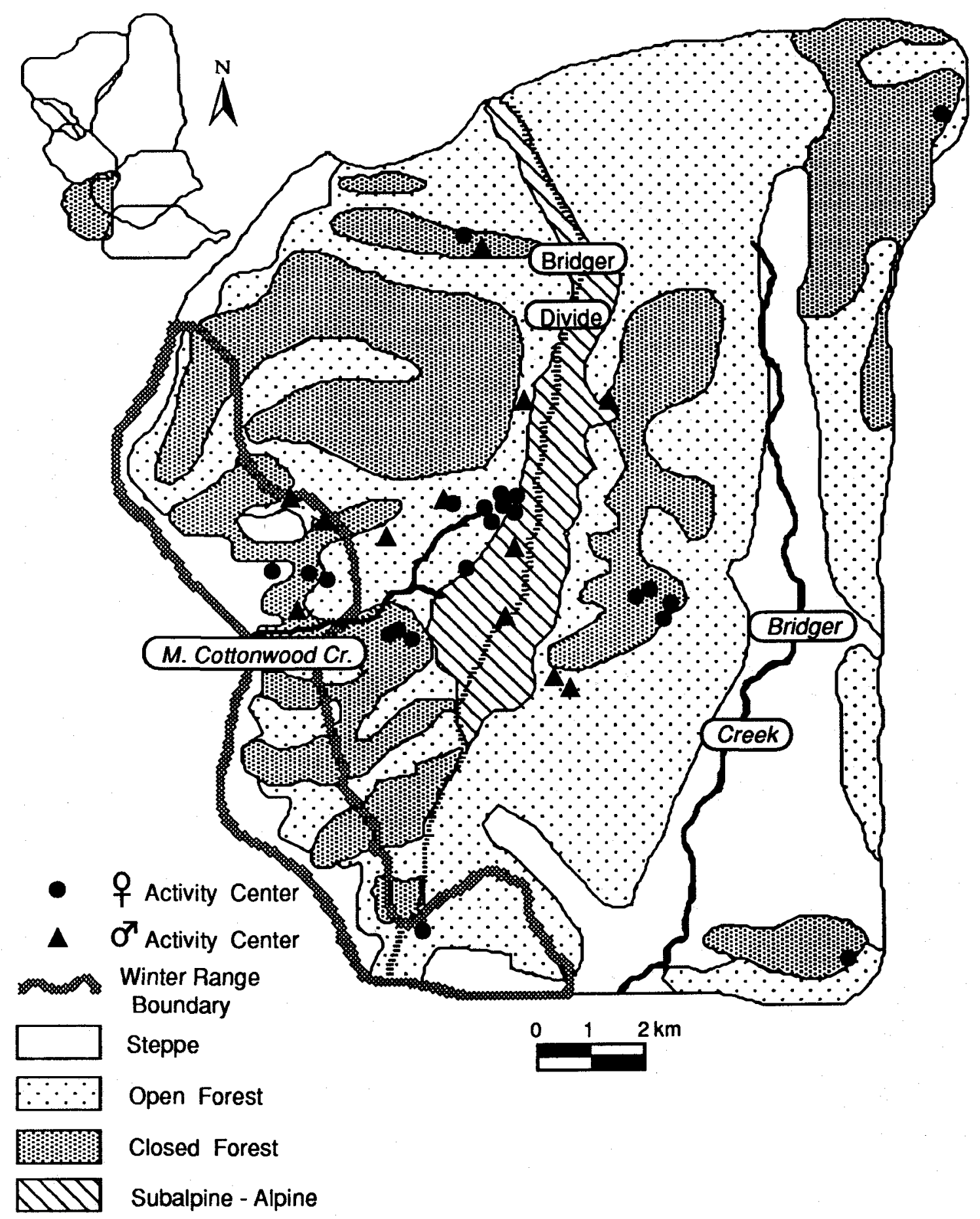

Figure 5.9. The Southwest Slope mule deer population-habitat unit (PHU 2) showing female and male summer activity centers in relation to major topographic features and vegetation zones. 


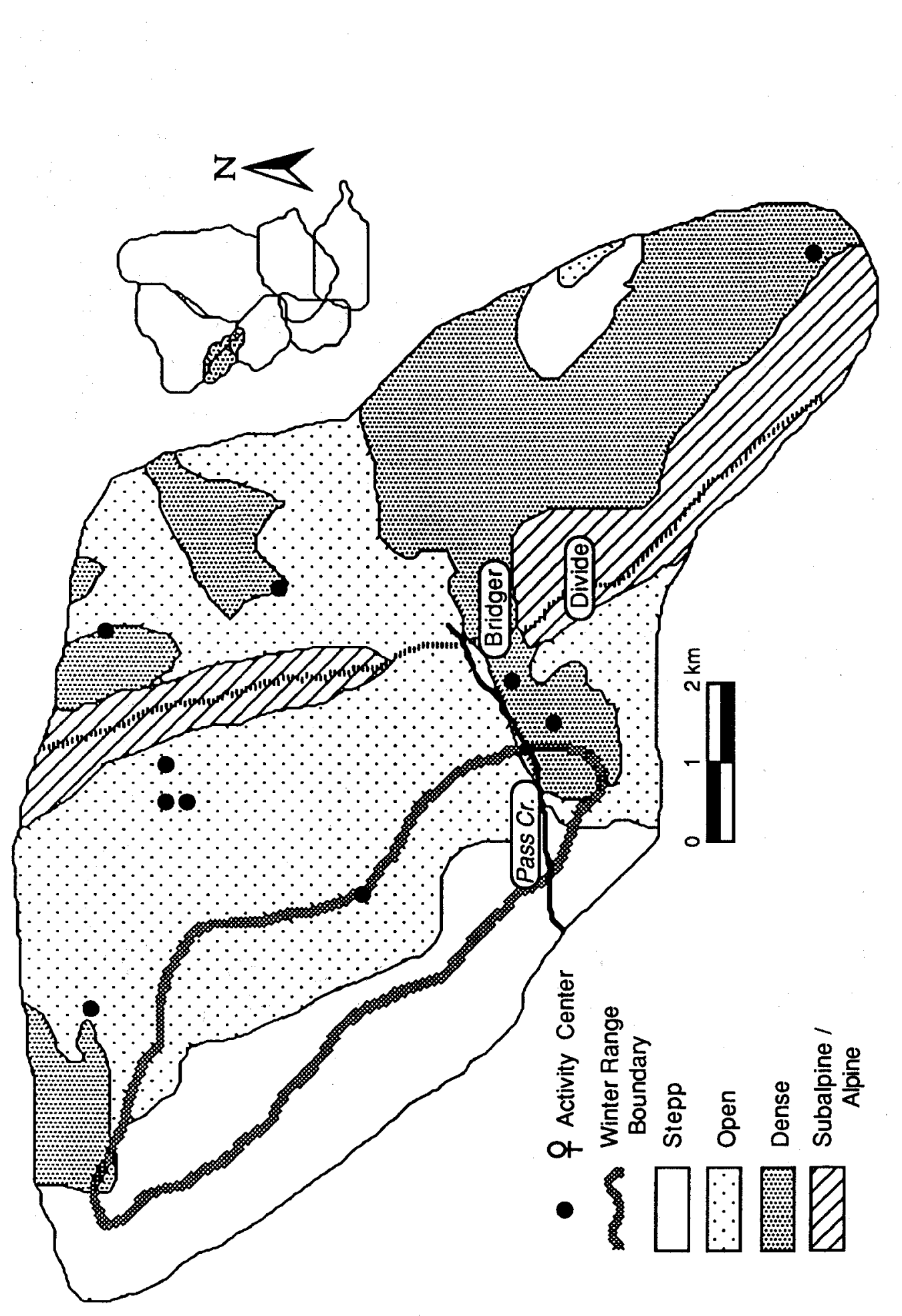

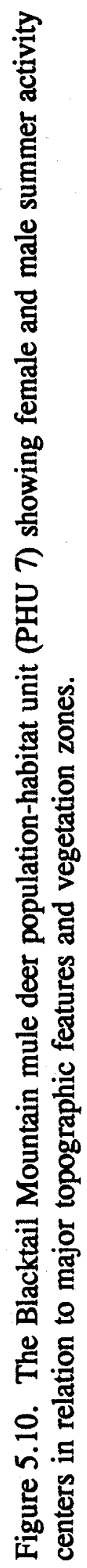
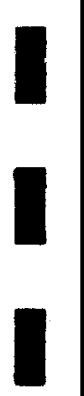

I

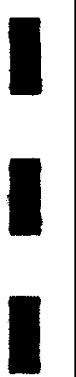

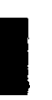

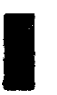

I
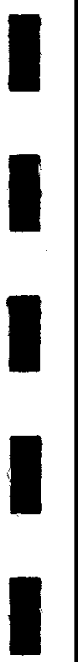


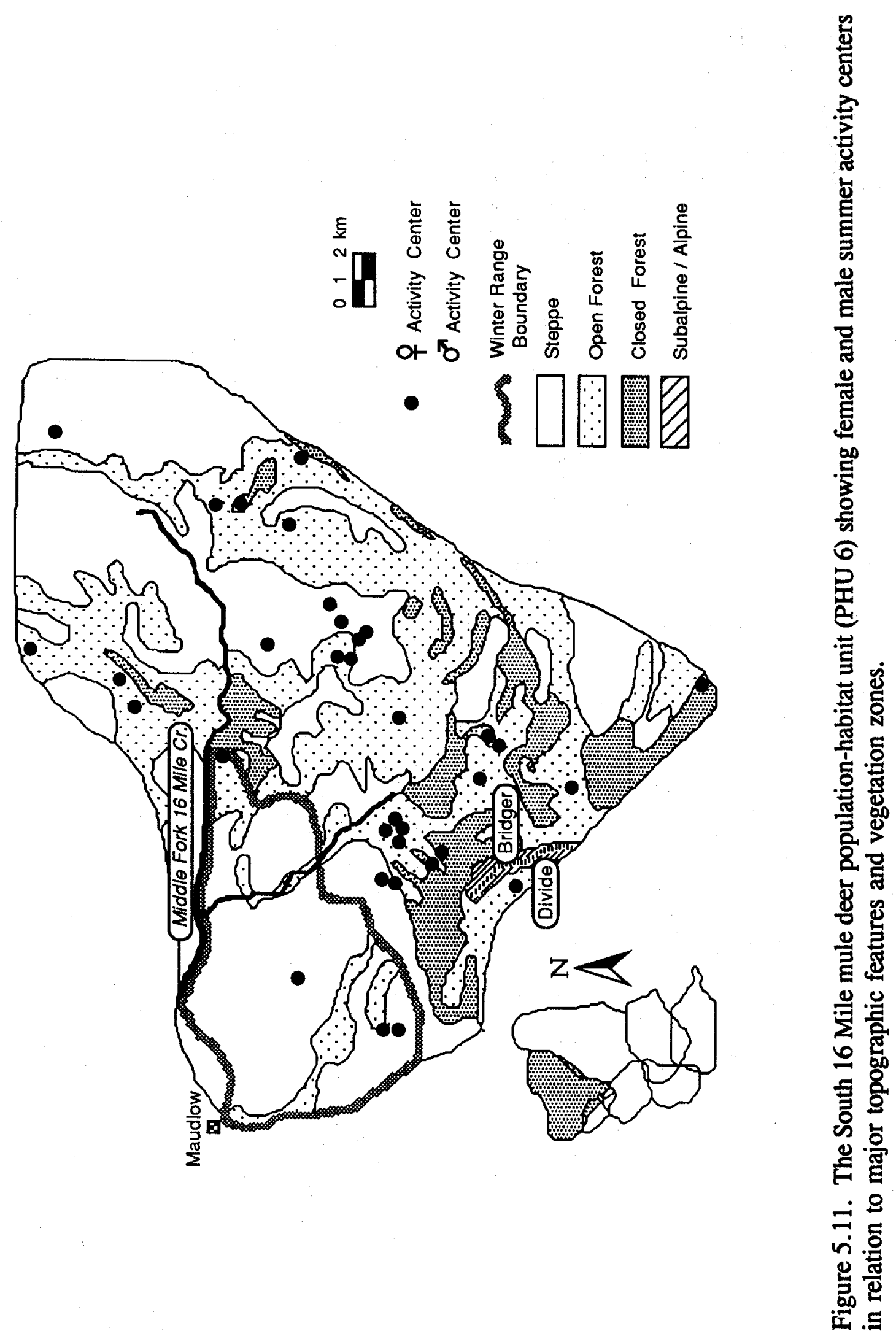




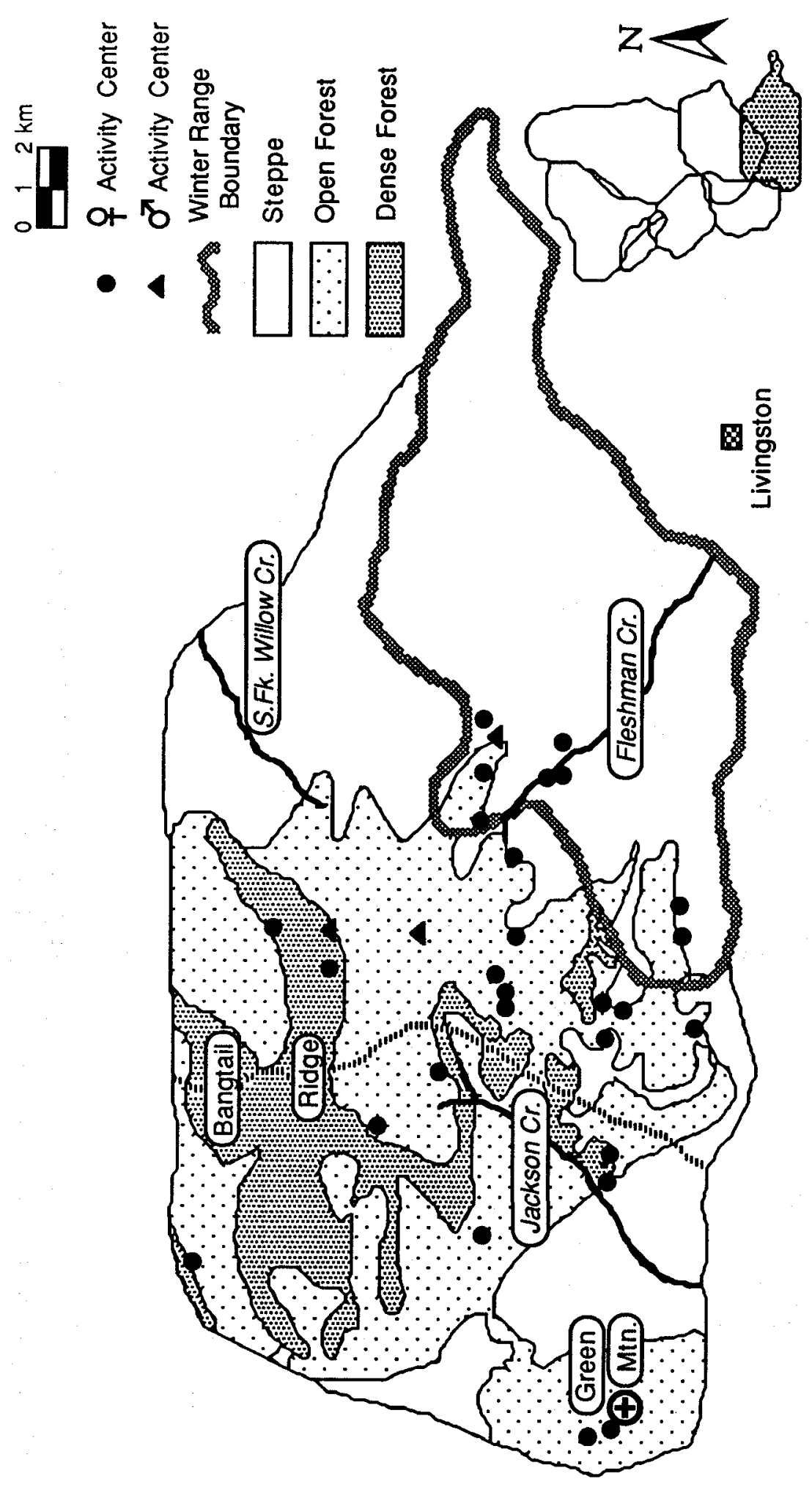

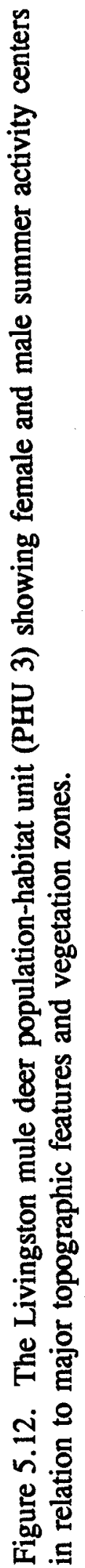




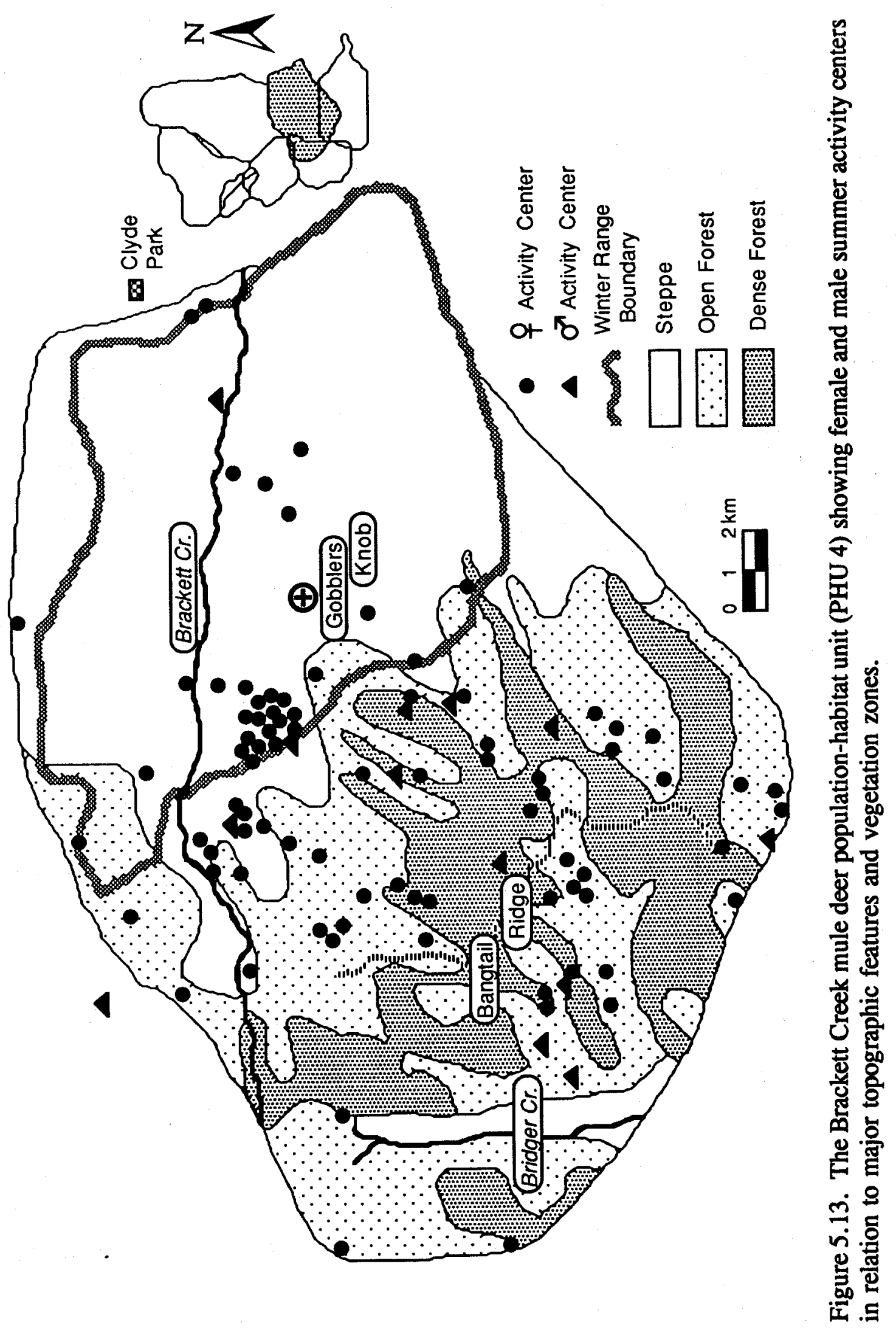




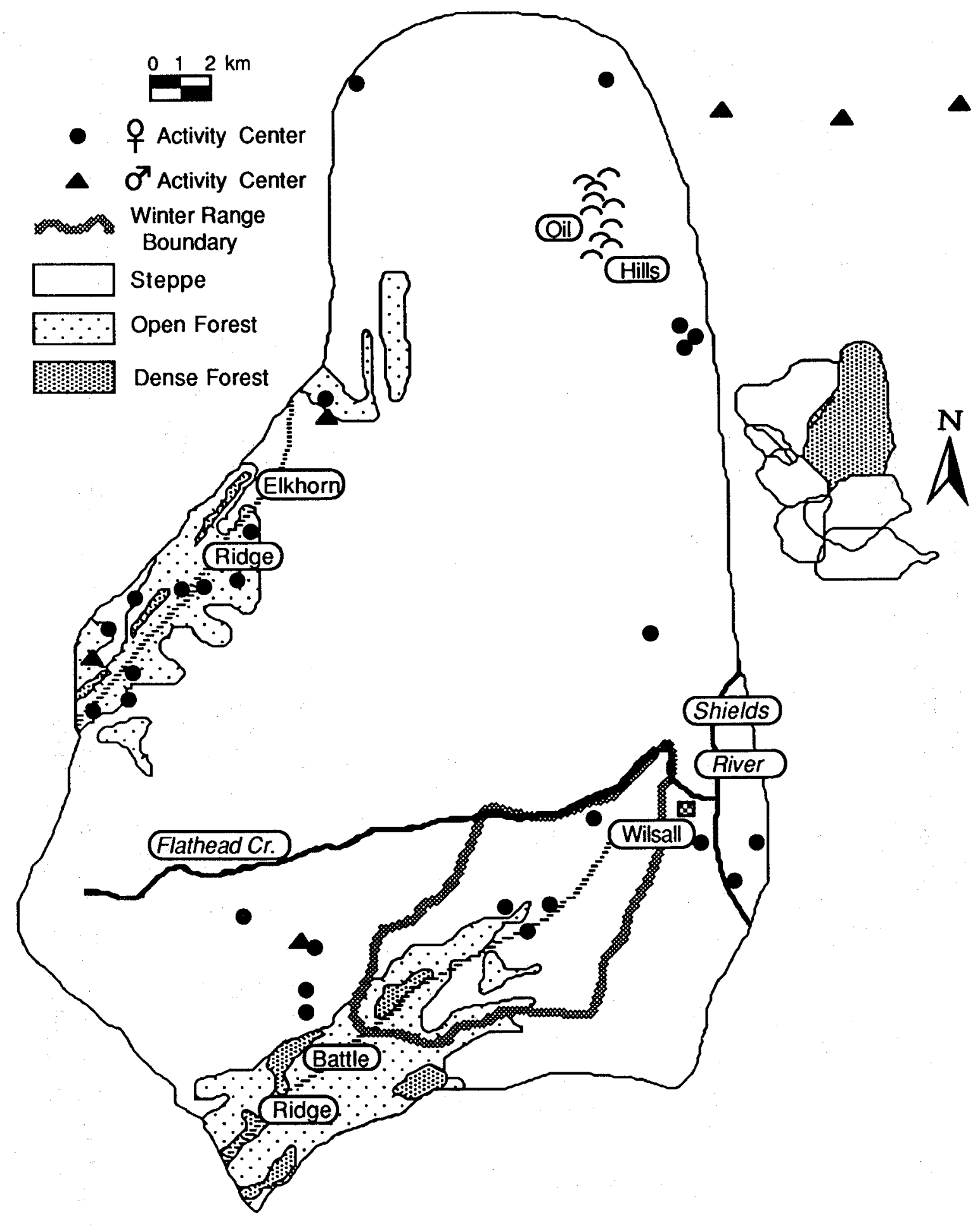

Figure 5.14. The Battle Ridge mule deer population-habitat unit (PHU 5) showing female and male summer activity centers in relation to major topographic features and vegetation zones. 
extent as summer habitats on the side nearest the winter range. This may partially explain why zones of overlap between PHUs were often associated with the more distant slopes of barrier ridges.

Elevation and relief undoubtedly contributed to the effectiveness of barrier ridges oriented perpendicular to movement vectors. However, distance between ridges and winter ranges was significantly related to the percentage of deer that crossed (Fig. 5.15). This relationship apparently described the dispersion of summer activity centers within PHUs.

About $2 \%$ of all radio-collared females had other tendencies resulting in long seasonal movement out of the Bridger Mountains. These involved crossing major divides at distances up to $130 \mathrm{~km}$ from their winter range.

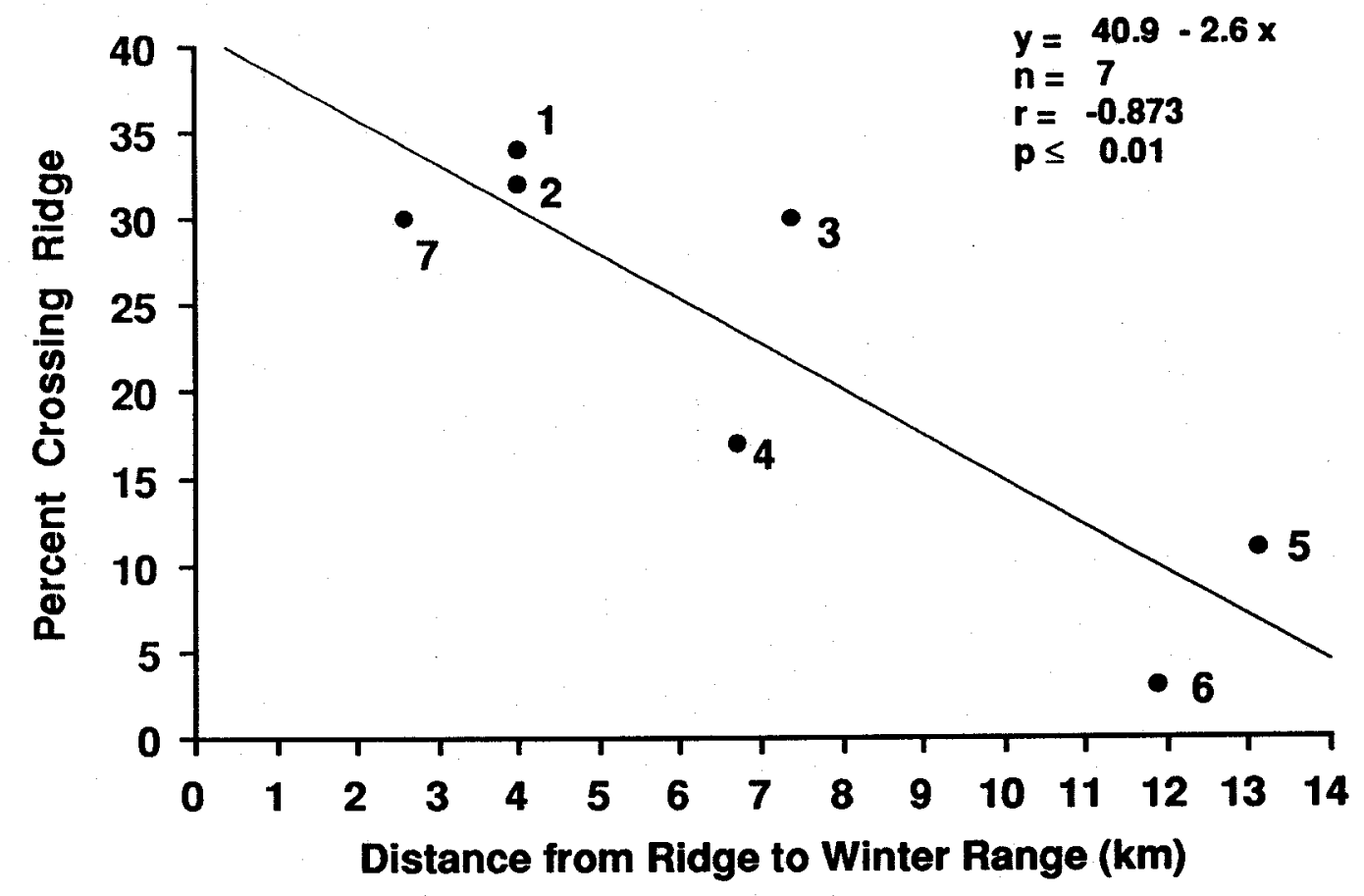

Figure 5.15. Relationship between percent females crossing barrier ridges and distances from winter ranges for seven PHUs. 
Deer Distribution and Habitat Use in Relation to Vegetation

\section{General Patterns}

When snow did not limit distribution, mule deer used nearly all available vegetation in the Bridger Range. Differences in use or preferences for zones and "types" apparently were related more to vegetation structure than to specific plant species.

Overall, steppe, which comprised $60 \%$ of the total habitat available to deer during summer, accounted for only $27 \%$ of 389 activity centers. Conversely, montane forest, comprising $38 \%$ of the area, held $67 \%$ of all summer activity centers. Subalpine-alpine vegetation accounted for only $6 \%$ of the activity centers; this was not significantly different from expected based on availability.

The greatest use and closest association of deer with steppe vegetation occurred in PHUs along the east slope, where 33-74\% of adult female activity centers for summer occurred in that zone (Figs. 5.11-5.14). The highest percentage occurred in PHU 5 in which the steppe zone predominated. However, in all east slope units, especially PHUs 3 and 4, many of the activity centers in steppe occurred near the forest border or in localized aggregations. Dispersion of activity centers in PHU 5 was "doughnut" shaped, the "hole" corresponding to the broad expanse of steppe in the center of the unit. Most activity centers occurred along the outer rim. Those along the east edge were associated with riparian or irrigated agricultural habitat. Steppe and montane forest were closely interspersed across much of PHU 6, and activity centers were more evenly distributed.

Only $12-15 \%$ of the adult females monitored in PHUs 5 and 6 centered their summer activity within winter range boundaries. This compared to $30-36 \%$ in PHUs 3 and 4. Apparently, greater availability of alfalfa fields and riparian draws within winter range in the latter provided better summer habitat than the native shrub-grasslands that predominated winter ranges in PHUs 5 and 6.

Summer distribution of adult females in PHUs 1, 2, and 7 occurred primarily in open and closed canopy montane forest (Figs. 5.8, 5.9, and 5.10). Although 10-20\% of the activity centers occurred within the general boundaries of winter ranges, only 0$7 \%$ were in steppe. Less than $12 \%$ of all activity centers in PHUs 1 and 2 , and none of those in PHU 7, occurred in the open, high elevation subalpine-alpine zone.

Data were sufficient to compare distribution between males and females only in PHU 1 (Fig. 5.8). There, more males than females centered their summer activity in the subalpine-alpine zone. Also, the proportion of male activity centers in steppe was nearly twice that for females. The majority of male activity centers occurred in montane forest where they were distributed either along the lower boundary or in loose aggregations in areas receiving minimal use by adult females. 
Seasonal Deer Distribution and Habitat Use in Relation to Vegetation Characteristics in PHUS 1 and 4

The relative occurrence of vegetation zones, subzones, and specific vegetation cover types in PHUs 1 and 4 are described in Appendix Tables A9 and A10. Seasonal deer use and selection (use relative to availability), implied from comparison of area of vegetation within scan circles centered on deer locations with expected values generated for scan circles centered on random points in the two units, is shown in Tables 5.5 and 5.6. Expected values for spring, summer, and autumn were determined from random locations distributed throughout the PHUs; those for winter were distributed within the winter range boundary. Vegetation "types" that occupied significantly $(P<0.01)$ more area within deer scan circles, implying selection, are marked with $(+)$ in the tables; types that covered significantly less area within deer scan circles than random circles, implying no selection or avoidance, are marked with (-).

Winter -- From December through April, mule deer in PHU 1 were usually confined to about $32 \mathrm{~km}^{2}$ of suitable winter habitat located between 1,675 and 2,200 m along the steep mountain front. Winter range comprised about $17 \%$ of the total unit area. Steppe covered $72 \%$ and montane forest $28 \%$.

For adult females, steppe accounted for $51 \%$ of the area of scan circles associated with relocations during winter. This was less than expected (Table 5.5). Within steppe, the agricultural subzone was significantly less represented than expected. Riparian and shrub-grassland subzones were used in proportion to availability. However, shrub-grassland accounted for $47 \%$ of the scan circles while riparian and agriculture comprised only $4 \%$. Important individual cover types included bitterbrush, intermediate grassland, dry grassland, juniper savannah, and dry sagebrush.

During winter, montane forest comprised $49 \%$ of female scan circles. This was significantly more than expected. Use was restricted to mid-elevation closed canopy forests; other forest zones were not available. All six forest cover types available in winter were associated with female deer relocations. Both Douglas fir-dry and Douglas fir/moist CTs were important within mid-elevation closed canopy forest.

Use of major vegetation categories by adult males in PHU 1 was similar to that by adult females $\left(\mathrm{X}^{2}=1.2, \mathrm{df}=8, \mathrm{P}=0.95\right)$. Steppe and montane forest accounted for 54 and $46 \%$ of the vegetation associated with male relocations. Steppe was associated with male relocations less than expected, montane forest more than expected. Within the steppe, males made little use of agriculture. Use of riparian and shrub-grassland was as expected, although the latter accounted for $49 \%$ of the area of scan circles associated with winter relocations. Bitterbrush was the most important individual cover type. Other important types used by males in the shrub-grassland 


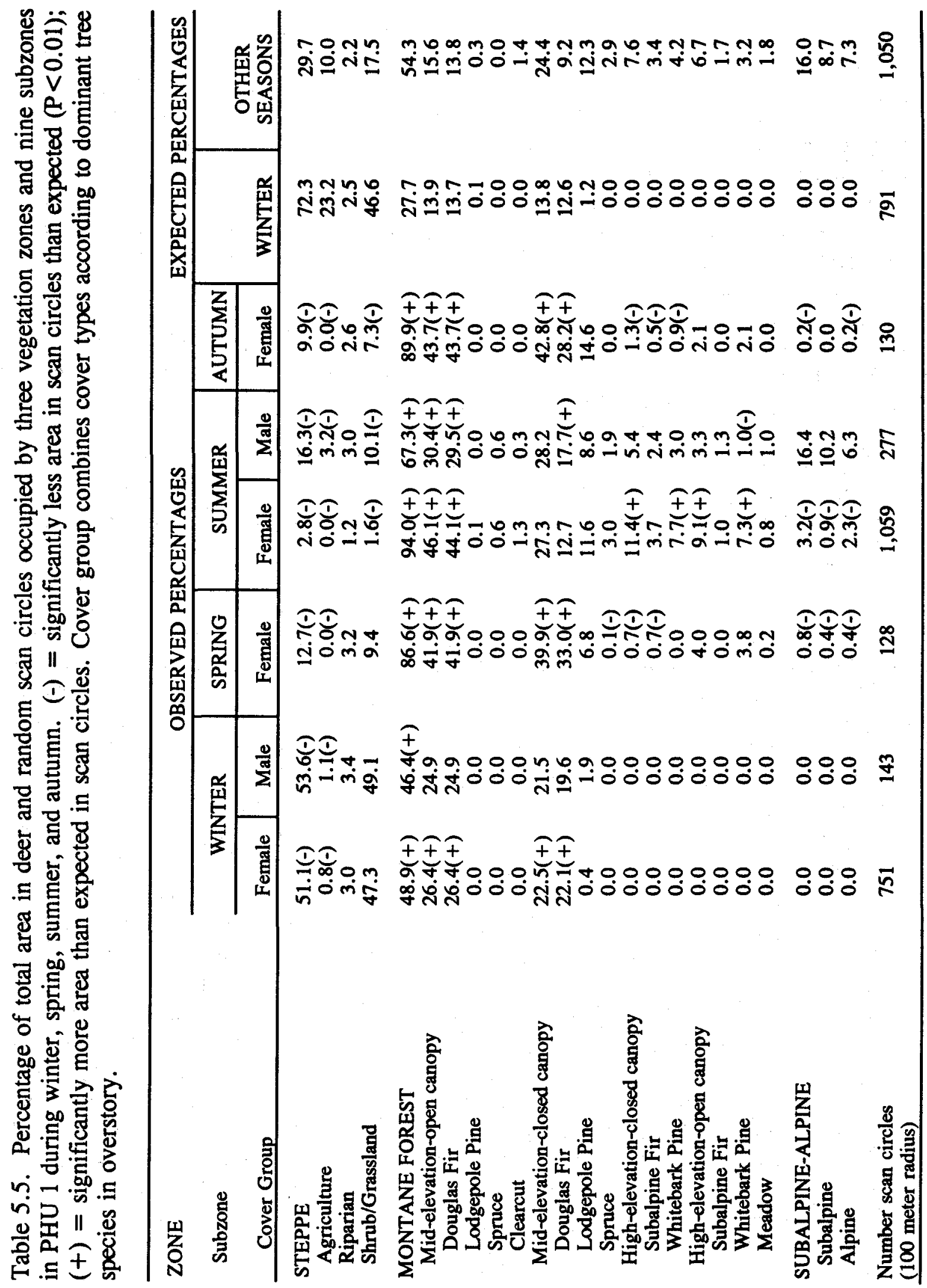


Table 5.6. Percentage of the total area in deer and random scan circles occupied by two vegetation zones and six subzones in PHU 4 during winter and summer. $(-)=$ significantly less occurrence in scan circles than expected $(\mathrm{P}<.01) ;(+)=$ significantly greater occurrence than expected. Cover group combines cover types according to dominant tree species in overstory.

\begin{tabular}{lcccc}
\hline ZONE & \multicolumn{2}{c}{ OBSERVED PERCENTAGES } & \multicolumn{2}{l}{ EXPECTED PERCENTAGES } \\
Subzone & WINTER & SUMMER & & \\
& & & & \\
Cover Group & Female & Female & WINTER & SUMMER \\
\hline STEPPE & 95.6 & $51.1(-)$ & 94.8 & 67.8 \\
Agriculture & $11.4(-)$ & $4.7(-)$ & 17.4 & 9.7 \\
Riparian & $1.9(-)$ & 7.2 & 5.2 & 4.6 \\
Shrub/Grassland & $82.3(+)$ & $39.2(-)$ & 72.2 & 53.6 \\
MONTANE FOREST & 4.4 & $48.9(+)$ & 5.2 & 32.2 \\
Mid-elevation-open canopy ${ }^{1}$ & 3.9 & $28.7(+)$ & 3.5 & 17.0 \\
Douglas Fir & 3.9 & $28.7(+)$ & 3.5 & 17.0 \\
Mid-elevation-closed canopy & 0.5 & 17.9 & 1.7 & 12.2 \\
Douglas Fir & 0.5 & 11.9 & 1.7 & 9.2 \\
Lodgepole Pine & 0.0 & $6.0(+)$ & 0.0 & 3.1 \\
High-elevation-open canopy & 0.0 & 2.3 & 0.0 & 2.9 \\
Subalpine Fir & 0.0 & 0.7 & 0.0 & 0.7 \\
Meadow & 0.0 & 1.6 & 0.0 & 2.2 \\
Number Scan Circles & 288 & 656 & 797 & 688 \\
(100 Meter Radius) & & & & \\
\hline Includes minor areas of clearcuts & & &
\end{tabular}

subzone included dry grassland, intermediate grassland, dry sagebrush, and juniper savannah.

Use of mid-elevation open and closed canopy forests by males was not different than expected. The most important individual cover types in the mid-elevation forests were Douglas fir-dry and Douglas fir-moist.

From late December to early April, mule deer in PHU 4 typically were restricted to winter range located between 1,435 and $1,870 \mathrm{~m}$. Winter range comprised approximately $135 \mathrm{~km}^{2}$ or $36 \%$ of PHU 4 . Open, rolling steppe covered $95 \%$ of the winter range and $96 \%$ of the area of scan circles around deer locations (Table 5.6). Use of agriculture and riparian subzones was minor and less than expected while shrub-grassland comprised $82 \%$ of scan circles, significantly more $(P \leq 0.01)$ than the $72 \%$ expected. Important cover types were dry grassland, dry sagebrush, juniper savannah, and moist sagebrush. 
Montane forest covered only 5\% of the winter range in PHU 4 and was used approximately as expected by deer. Use was primarily confined to Douglas fir types, especially the Douglas fir-Moist CT in open mid-elevation forest.

Like numerous other studies of mule deer in the Northern Rockies, our findings indicate that snow was the most important factor influencing habitat selection and use during winter (Loveless 1969, Gilbert et al. 1970). On PHU 1, deer were "hemmed in" by deep snow above and below the winter range and forced to rely on a composite of topographic, climatic, and vegetative microsites that enabled the population to successfully occupy the area. Although steppe was extremely important, accounting for about half of all winter deer use, total use was less than expected within winter range boundaries. Use of shrub-grassland, though important, was not different than expected even though bitterbrush, big sagebrush, juniper, various forbs, and grasses that provided the bulk of winter forage for deer occurred predominantly on this type. Also, preference for specific cover types within shrub-grassland was apparently influenced more by physical site characteristics that reduced snow accumulation than by vegetative composition. Cover types with greater than expected occurrence in scan circles characteristically occupied steep south aspects. Riparian and agricultural types generally were located where snow accumulation prevented deer use during much of the winter.

Forested habitats accounted for the remaining half of the area used by deer on winter range in PHU 1 and apparently were preferred. Relatively open Douglas fir stands seemed to be particularly important. Dominated by large, old-age trees distributed loosely on southwesterly and westerly aspects at upper elevations within the winter range, these stands appeared to provide an optimal combination of the most favorable attributes of forest and steppe. Trees were common enough to create favorable foraging sites by reducing snow depths under the canopies but not so dense as to limit diversity and productivity of an abundant shrub/grass/forb understory. The tree trunks, as well as rock outcrops scattered through the stands, seemed to act as solar "radiators" that promoted snow melt and plant greenup. Both Steerey (1979) and Youmans (1979) noted extensive deer use of these sites for feeding and bedding, especially on sunny days following heavy snowfall.

Douglas fir stands with closed canopies occurred as narrow "stringers" of timber on northerly aspects along steep draws and canyons at middle to lower elevations on winter range. These stands accumulated $20-23 \%$ less snow than adjacent open sites (Youmans 1979) and were preferred by deer for shelter and security over the entire spectrum of conditions encountered in winter. Use was especially heavy when snow conditions precluded deer use of shrub-grassland on adjacent open slopes. During such periods, deer remained sedentary and restricted feeding to short forays under dense canopy where a simple and relatively unproductive understory provided limited forage.

Moen and Evans (1971) reported that a conifer canopy with its load of intercepted snow acted as a reflector of infrared radiation. Thus, during cold clear 
periods, mule deer use of dense timber stands on PHU 1 may minimize radiant and convective heat loss. Radiant energy reflected downward by the canopy may also prevent or reduce snow crusting and in turn reduced energy expenditure of deer locomotion (Moen and Evans 1971). Ozoga and Gysel (1972) and Moen (1976) indicated that use of dense, mature timber was advantageous to deer in winter because it provided a narrow temperature range, warmest average temperatures, lowest wind flow, and least hazardous snow conditions.

During winter, deer appeared to preferentially use forest cover on PHU 1 even in the absence of snow (Youmans 1979). Steery (1979) reported similar selection for forested types on the winter range in PHU 2 during both mild and severe winters. This pattern could reflect deer preference for habitats offering opportunity for energy conservation, greater security, visual isolation from other deer, or utilization of certain forage plants. It is also possible that, if available, deer prefer to forage in areas of moderate snow cover during winter. Bruns (1977) found evidence that portions of sage (Artemisia cana) beneath the snow contained higher levels of moisture, protein, calcium, phosphorus, and less crude fiber than parts above the snow.

Youmans (1979) described apparent snow-related differences in winter habitat use among deer associated with the three subunits identified on the winter range in PHU 1 (Fig. 4.11). The north and south units constituted physiographically similar west to southwest exposures with north-facing subslopes and declivities of $26-30^{\circ}$. The middle unit was predominately southerly in exposure with $28-35^{\circ}$ slopes and had more heterogeneous topography than the other two units. Forest cover types were more common in the north and south units while steppe communities dominated the middle unit. During the early portion of severe winters when snow was deep but powdery, north and south unit deer were more mobile than middle unit deer and extensively used all available habitats including deciduous communities along creek bottoms down to the valley floor. By mid winter when heavy, crusted snow prevailed, mobility and home range size were reduced on the north and south units as deer became confined to certain conifer stands similar to a "yarding" situation. At the same time, the middle unit with more heterogeneous topography and steep south aspects often experienced snow melt and green-up of plants on certain microsites. With greater ease of movement and access to forage, deer mobility and habitat use remained relatively stable throughout winter.

We concluded that mule deer in PHU 1 were able to occupy that environment successfully by exploiting vegetation types that accentuated the more important influence of various abiotic factors in reducing snow accumulations. This pattern of winter habitat use was consistent with that of deer occupying deep snow environments where a strategy of energy conservation is more appropriate to survival than foraging (Youmans 1979, Dusek 1987).

By early April, activity of deer on PHU 1 increased sharply with use of early growth of forbs and grasses that became available on lower slopes and the adjacent valley 
floor. During this period, when deer emphasized foraging and shared common feeding areas, local deer densities were greater than at any other time of the year.

As noted earlier, environmental characteristics on winter range in PHU 4 contrasted sharply with PHU 1. Winter range in PHU 4 consisted of relatively gentle to rolling terrain, was more than four times larger, received less snowfall, and experienced more wind and slightly lower air temperatures. Thus, winters were relatively "open" during most years. Also, because the area was located on the drier side of the orographic precipitation pattern, conditions usually became progressively drier (less snowfall, snow depth and persistence) with decreasing elevation to the east. This allowed deer to move eastward below the montane forest zone onto the relatively flat expanses of steppe where snow conditions seldom became prohibitive of deer movement.

Steppe accounted for practically all vegetation used by deer in PHU 4 during winter. Within the steppe, shrub-grasslands were used significantly more by deer than expected. This group of cover types represented essentially all vegetation cover types available to fulfill the resource requirements of deer on the area in winter. Steep southerly aspects were extremely limited, and nearly all occurred within the shrub-grasslands. Cover types of individual importance included juniper savannah and dry sagebrush. The former was associated with steep southerly slopes which could indicate that its importance was related more to physical site characteristics than vegetation composition. The dry sagebrush cover type occurred predominantly on mid to lower portions of the winter range where it was largely available during most winters. The dry grassland type also received substantial use because of its occurrence on broad windswept ridgetops adjacent to stands of dry sagebrush on the lower half of the winter range.

Agricultural types received relatively minor use, but more than in PHU 1. Numerous fields occurred along the eastern edge of the PHU 4 winter range where snow depth was usually minimal. Use of riparian cover was very minor during winter, probably because these habitats were limited to small areas along narrow drainage bottoms and accumulated snow.

In PHU 4, forest cover types were largely unavailable to deer in winter. In the absence of steep slopes of southerly aspect, snow generally accumulated to prohibit deer use of timber cover by early winter. Consequently, forest cover accounted for only $4 \%$ of habitat used in winter compared to $49 \%$ in PHU 1.

South aspects and conifer-timber stands that significantly abetted energy conservation by deer in the Bridger Mountains overall were sparsely distributed on winter range in PHU 4. Although some conservation of energy may always be achieved through changes in physiology and behavior, very few sites were available to provide relief from excessive snow and radiant heat loss during occasional severe winters. Under 
such conditions, deer were forced to seek widely separated sites offering accessible forage.

An overwinter survival strategy emphasizing foraging in PHU 4 was supported by comparison of habitat use and food habits. Under severe conditions in 1978-79, grassland and shrub types respectively accounted for 44 and $36 \%$ of cover types use by marked mule deer (Nyberg 1980). With mild conditions in 1979-80, these same types accounted for 15 and $67 \%$ of total use, respectively (Rosgaard 1981). Use of agricultural, riparian, and forested types was generally low and similar during both winters. Analysis of food habits showed that dry grass, forbs, and shrubs accounted for 33 , 19, and $48 \%$, respectively, of deer use at feeding sites during 1978-79 (Nyberg 1980). A year later, grass comprised only $4 \%$ as use of forbs and shrubs increased to $28 \%$ and $68 \%$, respectively (Rosgaard 1981). These data indicate that deer continued to forage extensively under severe conditions, shifting only from the more protected, low-lying swales and gradual slopes dominated by shrub types to grasslands situated on ridgetops that were blown free of snow. Food habits changed accordingly with availability.

Rosgaard (1981) documented somewhat greater availability of important browse species on winter range in PHU 4 as compared with the Armstrong area in PHU 1. On PHU 4, big sagebrush, bitterbush and skunkbush sumac were estimated to collectively provide about $4.45 \mathrm{~kg} /$ deer $/$ day, or about $33 \%$ more than the $3.3 \mathrm{~kg} /$ deer/day estimated for PHU 1 (Buscis 1974). Although a significant quantity of forbs and grasses was also potentially available to deer on PHU 1 (Morton 1976), comparative data were not available for PHU 4.

Survival of deer in northern environments during winter depends on a delicate balance between energy intake, energy expenditure, and conservation of fat and protein reserves required to supplement nutritional deficiencies (Wallmo et al. 1977, Mautz 1978, Torbit et al. 1985). The contribution of each of these factors to winter survival may vary depending on the distribution and availability of resources in a particular environment.

On the east side of the Bridger Range, gentle topography and drier climate provided a large area of winter habitat consisting of shrub-grasslands and some agricultural fields. Deer could remain widely distributed across winter range in PHU 4 during most years. Such broad dispersion of individuals/family groups would seem to favor efficient allocation of forage whereas consistent aggregation of deer in specific vegetation communities, as occurred in PHU 1 dictated an energy conservation strategy.

In interpreting habitat usage during winter, it became evident that for every advantage a given habitat factor provided deer, a corresponding potential disadvantage associated with the same factor could be found. For example, more snow (greater precipitation) increased energy costs for deer and limited availability of winter forage 
while simultaneously providing for occurrence of conifer forest cover that created ideal sites and opportunities for energy conservation. Lower average snowfall was often associated with more available winter range and forage at lower energy cost, but less precipitation also resulted in lower species diversity and absence of conifer cover. This, in turn, required increased deer mobility to obtain resources and restricted the number and distribution of sites suitable for energy conservation under severe conditions.

Spring - Analysis of selection and use of vegetation during spring was limited to adult females that used distinct spring ranges located between winter and summer ranges in PHU 1. Females that moved directly from winter to summer home ranges $(37 \%$ of all females monitored in PHU 1 and essentially all in PHU 4) were excluded.

The data (Table 5.5) indicated that association of deer with steppe vegetation declined sharply as soon as forest cover types above winter range were free of snow and provided green plant growth. Agricultural fields were unused while use of riparian cover types was very minor. Use of shrub-grassland was not significantly different from expected, and only two cover types, dry grassland and intermediate grassland, were associated with deer locations.

Montane forest comprised $87 \%$ of the area of female scan circles in spring, significantly more than expected (Table 5.5). Deer activity was heavily concentrated in mid-elevation forest subzones and Douglas fir cover types. Use of lodgepole pine types within mid-elevation closed canopy forest was not different from expected. Some use of whitebark pine cover types within high elevation open canopy forest was recorded. Persistent snow cover through late spring prevented use of high elevation closed canopy forest and the subalpine-alpine zone.

Selection of vegetation in spring was influenced primarily by snow cover and progression of "greenup" to higher elevations. Large aggregations of deer, which had foraged collectively on early plant growth along lower slopes on winter range, rapidly disbanded to small groups as greenup advanced to upper slopes and ridges. Concomitantly, deer selectively used both open and closed canopy stands in the mid-elevation forest. This occurred despite continued availability of succulent forage on steppe cover types at lower elevations. The forested sites offered lower quantities of succulent forage in earlier stages of growth. Pac (1976) reported that dry weight protein levels of important forage plants on the area declined significantly through the progressive stages of plant development.

Delayed snow melt and plant development on high elevation summer range in PHU 1 resulted in a "bottleneck" in deer distribution and habitat use that involved up to two-thirds of the deer population. Such a "bottleneck" was not as evident or prolonged in PHU 4 where overall lower elevation and relatively gentle relief apparently permitted snowmelt and plant development to proceed more rapidly across this unit. 
Bloom dates of common purple lilac have been used as standardized indicators of plant phenology (Caprio 1966). Data from a network of lilac monitoring stations near the study area and across Montana were used to estimate plant development in PHUs 1 and 4 (Fig. 5.16, Table 5.7).

By 11 June, blooming would have occurred on approximately $54 \%$ of PHU 4, corresponding approximately to the area below $1,828 \mathrm{~m}$. By the same date, lilacs would have reached or exceeded early bloom phase on only $14 \%$ of PHU 1 . Similarly, by 29 June, lilacs would normally have reached or exceeded bloom stage on $95 \%$ of PHU 4, but only $72 \%$ of PHU 1. At the highest elevations in PHU 1, bloom phase would not have occurred until $17 \mathrm{July}$.

More rapid progression of snowmelt and plant development enabled deer to move earlier and more directly to summer home ranges in PHU 4 than in PHU 1.

Summer - From July through early October, mule deer were distributed throughout PHU 1 at elevations ranging from 1,585 to $2,685 \mathrm{~m}$. Deer used all vegetation zones and subzones including 25 of 28 individual cover types.

Steppe received relatively little use, especially by adult females (Table 5.5). As in other seasons, steppe occurred less than expected in scan circles around locations of both females and males.

Summer habitat use by adult females centered in montane forest which predominated in scan circles to a greater extent than during other seasons. Mid-elevation open canopy forest and both open and closed high elevation forest were used to a greater extent than expected while mid-elevation closed canopy forest was used as expected. Mid-elevation open canopy forest alone accounted for $46 \%$ of all vegetation associated with female locations. This was a higher proportion than for any other season and consisted almost entirely of Douglas fir cover types. The Douglas Fir-Dry CT, which predominated in open mid-elevation forest, accounted for most of the use.

Use of closed canopy mid-elevation forest by adult females declined from spring but ranked second overall. Summer was the only season in which this subzone occurred at less than expected proportions in scan circles. Use of Douglas fir cover types declined to $13 \%$, also lower than for other seasons. The only cover type of importance was Douglas Fir-Moist. Use of lodgepole pine cover types increased substantially over spring, but occurrence in scan circles did not exceed availability. Use of the spruce type was also about as expected.

High elevation closed canopy forest accounted for $11 \%$ of the area of female scan circles; open canopy forest comprised $9 \%$. This was greater than recorded for other seasons. Within these subzones, whitebark pine was of greatest importance and selected for, while use of subalpine fir was relatively minor and not different from expected. 

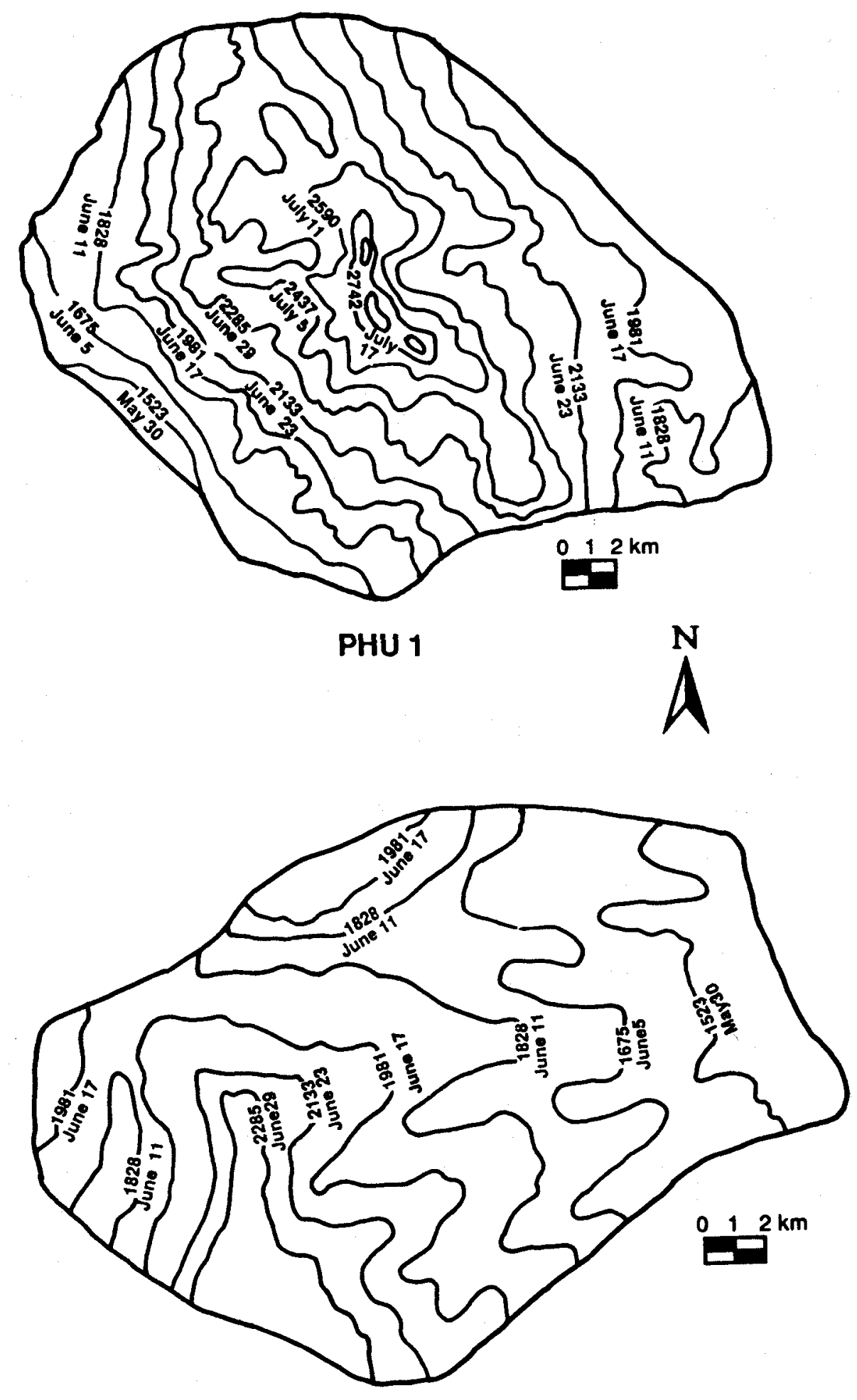

PHU 4

Figure 5.16. Phenological progression of plant development across PHU 1 and PHU 4. Dates are estimated lilac bloom dates at $152 \mathrm{~m}(500 \mathrm{ft})$ contour intervals. 
Table 5.7. Percent surface area of PHUs 1 and 4 that occurs below $152 \mathrm{~m} \mathrm{(500} \mathrm{ft)}$ contour intervals and estimated dates when lilacs begin to bloom at each elevation.

\begin{tabular}{c|c|c|c|c}
\hline \multicolumn{2}{c|}{ Elevation } & \multicolumn{2}{c|}{$\begin{array}{c}\text { Area Below Given } \\
\text { Elevation }\end{array}$} & $\begin{array}{c}\text { Estimated } \\
\text { Lilac Bloom Date }\end{array}$ \\
\hline Meters & Feet & PHU 4 & PHU 1 & \\
\hline 1523 & 5000 & 7 & 0 & $5 / 30$ \\
1675 & 5500 & 25 & 6 & $6 / 5$ \\
1828 & 6000 & 22 & 8 & $6 / 11$ \\
1981 & 6500 & 19 & 26 & $6 / 17$ \\
2133 & 7000 & 14 & 16 & $6 / 23$ \\
2285 & 7500 & 8 & 16 & $6 / 29$ \\
2437 & 8000 & 5 & 12 & $7 / 5$ \\
2590 & 8500 & 0 & 12 & $7 / 11$ \\
2742 & 9000 & 0 & 5 & $7 / 17$ \\
\hline
\end{tabular}

The subalpine-alpine zone received little, and less than expected use by adult females. Its 3\% occurrence in female scan circles indicated use similar to the steppe zone in summer.

There were significant differences in use of zones and subzones between sexes $\left(\mathrm{X}^{2}\right.$ $=126.1, \mathrm{df}=2, \mathrm{P}=0.00$ for three zones, $\mathrm{X}^{2}=163.1, \mathrm{df}=8, \mathrm{P}=0.00$ for nine subzones). Both steppe and subalpine-alpine zones were used comparatively more by adult males than females (16\% vs $3 \%$ in each case), while montane forest received greater use by females ( $94 \%$ vs $67 \%$ for males) (Table 5.5$)$. Within the steppe, the greatest difference was in shrub-grassland which accounted for $10 \%$ of all summer use by males compared with less than $2 \%$ for adult females. Much of the difference in use of montane forest was for mid-elevation open canopy timber which comprised $30 \%$ of male scanning circles compared with $46 \%$ for females. Although both made relatively minor usage of high elevation forests, use by males was only one-third (open canopy) to one-half (closed canopy) of that recorded for females.

For adult males, like females, montane forest was by far the most important vegetation zone and highly selected. Among subzones, only mid-elevation open canopy forest was selected; mid-elevation closed forest and high elevation open and closed canopy forest were all used approximately in proportion to availability. Within mid-elevation open canopy forest, Douglas fir, especially the Douglas fir-Dry CT, was more closely associated with buck locations than other timber types. In the closed canopy subzone, Douglas fir-Moist and Lodgepole pine-Shrub were important cover types. 
During summer, mule deer in PHU 4 were distributed throughout two vegetation zones, six subzones, and 17 of 18 individual cover types. The subalpine-alpine zone and high elevation closed canopy montane forest subzone did not occur. Relocations, which included only adult females, varied from 1,555 to $2,320 \mathrm{~m}$ elevation.

In contrast to PHU 1, steppe was an important component of summer habitat used by deer in PHU 4 . Covering $68 \%$ of the unit, steppe made up slightly more than half of the area of scan circles (Table 5.6). Use was, however, significantly less than expected. Within the steppe, summer deer use centered in the shrub-grassland subzone while agricultural fields and riparian cover were of relatively minor importance. Use of shrub-grassland centered in the moist sagebrush, intermediate grassland, and dry grassland cover types. In the agricultural subzone, use occurred primarily in alfalfa fields adjacent to riparian cover.

Use of montane forest was approximately $50 \%$ less than in PHU 1 . Nonetheless, the zone was significantly selected. Most of the use centered in the mid-elevation open canopy subzone and Douglas fir cover types. Mid-elevation closed canopy forest, consisting mostly of three Douglas fir and two lodgepole pine cover types, received relatively minor use. High-elevation open canopy forest, which occurred at the highest elevations in PHU 4, received only very minor use as expected.

Patterns of vegetation use during summer appeared related to availability of succulent forage. Topographic diversity and associated vegetation complexity within mid to high- elevation montane forest provided numerous options for deer to locate succulent forage within the confines of small home ranges throughout the summer.

Forest cover types with open canopies, especially Douglas fir types located on south and west aspects of steep-sloped ridges, were preferred throughout the season. These types had predominantly herbaceous understories comprised of at least 11 species of grass, 64 forbs, and 10 shrubs (Pac 1976). Annual production of forage was also greater in more open forest cover types (Fig. 5.17), and variation in forage production between years was low (Table 5.8).

North and east aspects of the same ridges typically were covered by closed canopy stands of Douglas fir, lodgepole pine, subalpine fir, and whitebark pine. Such stands located at mid elevations ranked second in importance for use by deer, but that usage was not significantly different than expected. Stands at high elevations received less total use but apparently were preferred. Closed canopy stands were characterized by less diverse; shrub-dominated understories (at least 3,33, and 9 species of grasses, forbs, and shrubs, respectively). Annual forage production was substantially less than on adjacent types with more open canopies (Fig. 5.17). 


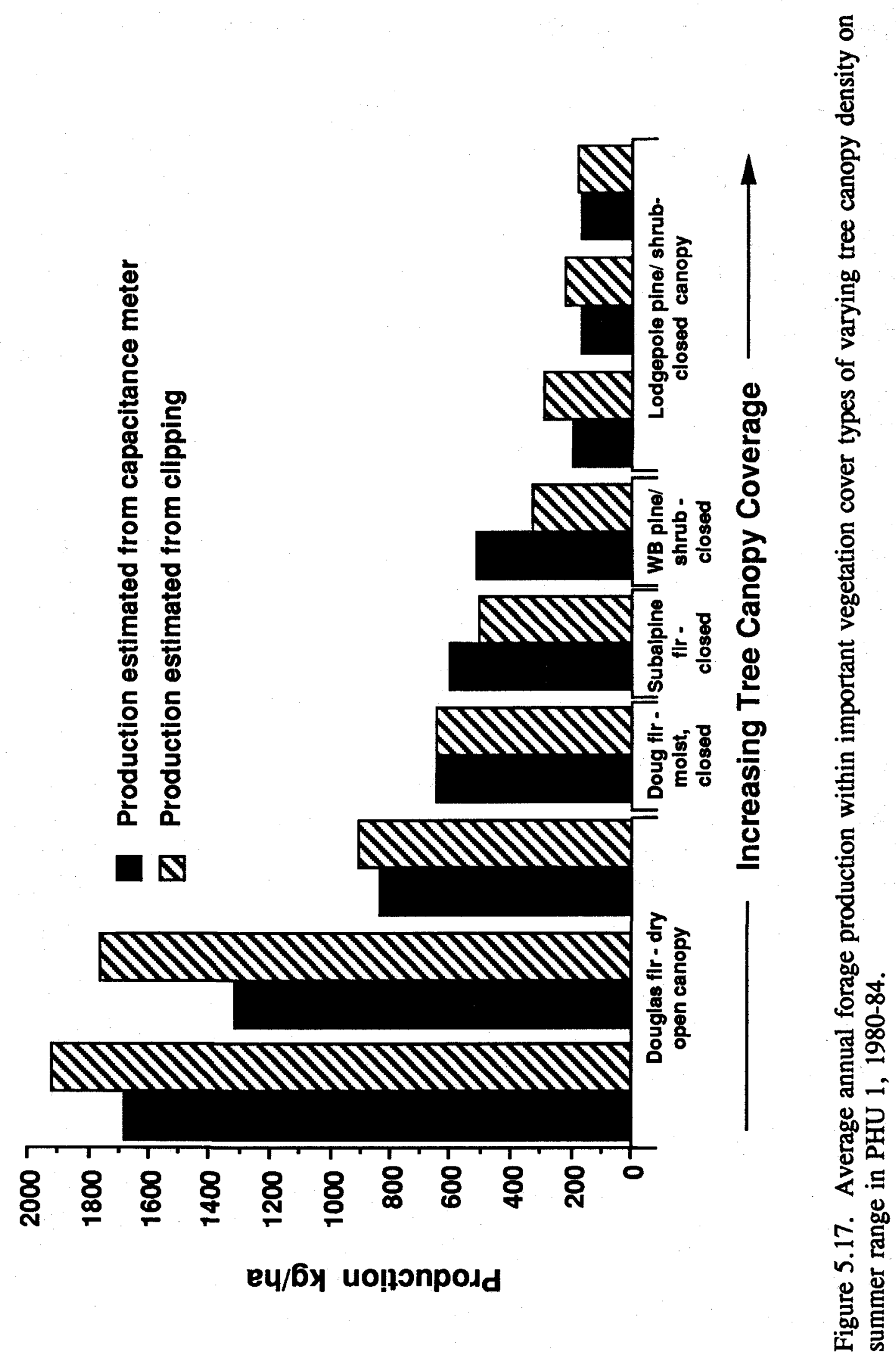


Table 5.8. Capacitance meter readings indicative of relative forage production at permanently marked points along nine transects located on summer range in PHU 1, 1980-1984.

\begin{tabular}{lrrrrr}
\hline \multicolumn{1}{c}{ Plot } & 1980 & \multicolumn{1}{c}{1981} & 1982 & \multicolumn{1}{c}{1983} & \multicolumn{1}{c}{1984} \\
\hline Lower Cottonwood & 1951 & 1625 & 1582 & 1640 & 1654 \\
Lower Mill & 1505 & 1258 & 1161 & 1330 & 1345 \\
Upper Tom Reese & 790 & 825 & 875 & 985 & 749 \\
Lower Johnson & 710 & 634 & 597 & 670 & 683 \\
Upper Mill & 667 & 469 & 629 & 692 & 607 \\
Upper Cottonwood & 658 & 566 & 370 & 363 & 695 \\
Lower Tom Reese & 329 & 222 & 218 & 153 & 160 \\
Upper Johnson & 171 & 163 & 170 & -- & -- \\
Flathead Pass & 171 & 156 & 181 & 171 & 185 \\
\hline
\end{tabular}

Shortages of succulent forage resulting from delayed development of plants on high elevation summer ranges led to significant spring/early summer use of habitats located between winter and summer home ranges by deer summering at high elevations and east of the Bridger Divide in PHU 1. Much of this occurred during parturition and early fawn-rearing.

In late August-early September, desiccation and early frosts reduced the availability of succulent herbaceous forage in most habitats. Pac (1976) and Steerey (1979) documented late summer shifts in habitat use from open forest with grass-forb understories to more heavily timbered stands in which shrubs predominated. In addition to providing a source of browse, the closed canopy stands provided limited supplies of green forage for a longer period than more open types. Hammond (1980) reported lower production, delayed phenological development, and prolonged nutritional value for forbs growing under timber as compared with open stands.

Slightly later, coincident with the first killing frosts in September, some adult females from high elevation montane forest moved higher and extensively used lower reaches of the subalpine-alpine zone. At least some plants in the dense herbaceous understory associated with subalpine vegetation remained green well into September. Late summer/early autumn shifts in habitat use apparently marked the beginning of seasonal transition in food habits from predominantly forbs to browse.

Because of differences in availability, usage of major vegetation zones and subzones by deer in PHUs 1 and 4 was difficult to compare. In general, patterns of selection were similar for vegetation types common to both areas. In summer, statistical results indicated that adult females tended to avoid steppe on both areas. However, because of its wide distribution and relative abundance in PHU 4, steppe was extremely 
important in habitat complexes used by deer in that unit whereas it received only minor use and was of little importance in PHU 1. Use of steppe in PHU 4 may also have been high as a result of close juxtaposition of open steppe with more preferred timbered habitats. Long, narrow fingers of steppe on south aspects extended further into the montane forest along the gradually inclining easterly slopes than on the steep west side of the Bridger Range. Also, where it occurred, deer use of cover types within the steppe zone focused on mesic sites that provided succulent forage and shrubby hiding cover.

Similar to the pattern in PHU 1, adult females in PHU 4 extensively used the montane forest zone and displayed preference for mid-elevation forest types with open canopies. Use of the mid-elevation closed canopy forest ranked third in importance after the shrub-grassland subzone and the mid-elevation open canopy forest. The preference for montane forest on both PHUs was apparently related to topographic and vegetative complexity, and diversity that provided numerous options for deer to fulfill all of their resource needs throughout summer on relatively small home ranges. The relatively stable annual production of forage in forested cover types may have been particularly important to adult females from June through mid-August. Forested sites also provided more opportunity for visual isolation from other does during fawning and early fawn rearing than more open habitats.

Compared to PHU 1, changes in distribution and habitat use related to shortages of succulent forage rarely occurred during early summer in PHU 4. Presumably, plant phenology had sufficiently advanced to provide adequate supplies of succulent forage during the early lactation period. Mean elevation of summer home ranges on PHU 4 was $374 \mathrm{~m}$ lower than PHU 1. However, use of habitat located outside the boundaries of summer home ranges during late summer was more prevalent in PHU 4, perhaps because of the lower elevation and less complex topography. Late summer accessory areas (see Chapter 6) were apparently utilized by some deer that required alternate sources of succulent forage after desiccation limited availability of preferred forage within their normal summer home ranges.

The distribution and availability of vegetation types preferred by deer throughout the Bridger Range during summer was related to the interaction of topography, temperature, and precipitation. For example, the broader and more gentle terrain at middle elevations on the east slope of the Bridger Range resulted in greater surface area within the 508-762 $\mathrm{mm}$ precipitation zone. This zone was closely correlated with occurrence of highly preferred open canopy Douglas fir forests within the seven mule deer population-habitat units $(r=0.86, p<0.02)$. Those types covered about $373 \mathrm{~km}^{2}$ within the four east slope population/habitat units compared to $183 \mathrm{~km}^{2}$ in the three west slope units.

Adult females in both PHUs remained widely distributed on small individual summer home ranges in an apparent effort to occupy preferred habitats for as long as possible. This pattern was apparently consistent with a strategy of selective foraging 
during summer. Adult males were more widely distributed across all available habitats and used steppe and subalpine-alpine habitat more and montane forests less than females. Although a preference for similar forest cover types was observed for both sexes, there was at least some spatial separation between adult males and females within types during summer.

Autumn - As in spring, use and selection of vegetation during autumn was determined only in PHU 1 from relocations of radioed adult females that used autumn accessory areas located between their summer and winter ranges $(58 \%$ of all radio-collared females monitored in the unit, see Chapter 6). Most deer in PHU 4 remained on summer home ranges through late autumn when they moved directly to winter ranges.

Montane forest comprised $90 \%$ of the vegetation in scan circles centered on deer locations (Table 5.5). Nearly all of this was accounted for by mid-elevation open and mid-elevation closed subzones which were used in about equal proportions and highly selected. Because all deer monitored had moved from summer home ranges, neither the subalpine-alpine zone nor high elevation forest subzones were of importance. Use of steppe increased from summer but, as for other seasons, was significantly less than expected.

Overall, patterns of use and selection of vegetation in autumn were closely similar to spring, with mid-elevation forest and Douglas fir cover types predominating. Use of lodgepole pine in the mid-elevation closed canopy zone increased to an annual peak but remained less than expected. These types may have helped satisfy a greater need for security during the hunting season; however, total use of closed canopy mid-elevation forest was slightly lower in autumn than spring when security should not have been a factor. It is also possible that patterns of use on both seasonal ranges simply reflected availability in areas of traditional use rather than forage/cover preferences.

Autumn use of steppe by radioed females was limited to shrub-grassland and riparian subzones. Agriculture did not occur in association with any female locations.

Intermittent storms and severe weather in autumn were often accompanied by sudden changes in habitat use, including food habits. For example, heavy snowstorms in October 1975 forced some deer in PHU 1 to move from shrubby habitats on north exposures to south and west aspects dominated by mid-elevation open canopy forests (Pac 1976). Concomitantly, foraging shifted from primarily browse to dried forbs of low nutritional quality. During a period of heavy snow and cold in late November, deer moved even lower, in the vicinity of the winter range, and a diet again predominated by browse of different species. This variability was reflected in an overall autumn diet averaging $45 \%$ browse, $42 \%$ forbs, $11 \%$ grasses, and $4 \%$ lichens, (Wilkins 1956, Schwarzkopf 1973, Hamlin 1974). 
Freeland and Janzen (1974) indicated that detrimental effects may accrue to herbivores subjected to rapid fluctuations in diet without ample time for rumen microflora to adapt to secondary plant compounds or toxins. In PHU 1, fawns and some females entering winter with minimal fat reserves (Hamlin 1974) may be vulnerable to early winter mortality in some years as a result of additional physiological stress from diet fluctuations during autumn. Bertram and Rempel (1977) reported fawn mortality associated with use of autumn "holding areas" by a migratory mule deer population in California.

Generally, deer in PHU 4 were not subjected to such abrupt changes in distribution and use of vegetation types in autumn. Apparently the relatively gentle topographic relief, lower average elevation of summer ranges, and lower average snowfall resulted in less specialized patterns of movement and habitat use in that unit.

Food Habits and Forage Relationships

Early deer studies in the Bridger Mountains (Wilkins 1956, Schwarzkopf 1973) emphasized food habits and range use. After 1973, food habits were not studied consistently by season or year but determined opportunistically from rumens obtained during the hunting season and winter-spring period when most natural mortality occurred. Only three rumens were collected during summer. Because of this, we generally describe summer food habits primarily from results reported previously by others.

\section{$\underline{\text { Seasonal Trends }}$}

Wilkins (1957) reported that forbs, browse, and grass constituted 77,19 , and $3 \%$, respectively, of the volume of rumen samples collected during summer in PHU 1. Common salsify (Tragopogon dubius), alfalfa (Medicago sativa), balsamroot sunflower, and fewflower aster (Aster modestus) were important forbs. Important browse species included antelope bitterbrush and thin-leaved huckleberry (Vaccinium membranaceum). Results from summer feeding site examinations were very similar to rumen samples (Wilkins 1957).

Schwarzkopf (1973) discussed summer food habits determined from examination of 27 feeding sites on the same area during summers 1971 and 1972. Forbs, browse, and grass accounted for 83,14 , and $3 \%$ of the use, respectively. Hamlin (1974) reported similar results for summer 1973. Nuttal violet (Viola nuttallii), yellow columbine (Aquilegia flavescens), false dandelion (Agoseris glauca), dogtooth lily (Erythronium grandiflorum) and Hayden clover (Trifolium haydenni) were important forbs. Redshoot gooseberry (Ribes setosum) and Bebb willow (Salix bebbiana) were important browse species.

Only limited data were available on summer food habits of mule deer populations along the east slope of the Bridger Mountains. Nyberg (1980) reported that browse, 
forbs, and grass accounted for 69,24 , and $7 \%$ of all instances of plant use recorded at five feeding sites in PHU 4.

During autumn, diet composition on the west slope shifted toward browse as indicated by rumen analysis (Table 5.9). Forty-four samples contained 37, 39, and $20 \%$ browse, forbs, and grass. Lichen accounted for the remaining 3\%. Important browse plants included Oregon grape (Berberis repens), antelope bitterbrush, and snowberry. The forb component was dominated by alfalfa, asters, and side-bells wintergreen (Pyrola secunda). Several species of Graminae and elk sedge were predominant among grass-like plants. Our autumn sample indicated substantially less utilization of browse and greater use of forbs than reported by Wilkins (1957). However, Wilkins' sample was collected on the shrub-dominated footslope.

A comparatively small sample of rumens collected during autumn on the east slope indicated greater use of browse and grass and less use of forbs than observed in west slope diets (Table 5.9). Important species on the east slope included Oregon grape, skunkbush sumac (Rhus trilobata), rose (Rosa sp.), and alfalfa.

In winter, mule deer diet based on forage class composition appeared similar between the west and east slopes of the Bridger Mountains (Table 5.10). Rosgaard (1981), however, indicated that winter diet on PHU 4 varied from year to year in relation to environmental conditions that affected deer habitat use and forage availability. Overall, browse species were most important followed by grass and then forbs. Important browse species on the west slope included big sagebrush, Rocky Mountain juniper (Juniperus scopulorum), Douglas fir, and antelope bitterbrush. Big sagebrush, Rocky Mountain juniper, limber pine, and willow predominated on the east slope. Important forbs on the west slope included alfalfa and the seedheads of showy sunflower (Helianthus laetiflorus), while alfalfa and Hoods phlox (Phlox hoodii) were important on the east slope. The occurrence of alfalfa in the winter diet on the west slope was partially influenced by the use of that species for trap bait.

During spring, diet composition on the west slope was $51 \%$ browse, $42 \%$ grass, and $9 \%$ forbs (Table 5.11). Important plant species remained similar to those utilized in winter. On the east slope, spring diet consisted of 24,64 , and $13 \%$ browse, grass, and forbs, respectively. Use of big sagebrush and Rocky Mountain juniper declined sharply from winter while use of antelope bitterbrush and black cottonwood (Populus trichocarpa) increased. Clover (Trifolium sp.) was the most important forb.

Overall, our data on food habits supported the conclusions of Coblentz (1970) and Suring and Vohs (1979) that deer preferred green herbaceous forage. Heavy use of browse occurred only in the absence of green, herbaceous forage and during winter. 
Table 5.9. Mule deer food habits on the west and east slope of the Bridger Mountains during autumn, 1972-1986.

\begin{tabular}{|c|c|c|}
\hline & $\begin{array}{l}\text { WEST SLOPE } \\
\text { (44 RUMENS) }\end{array}$ & $\begin{array}{l}\text { EAST SLOPE } \\
\text { (7 RUMENS) }\end{array}$ \\
\hline SPECIES & $\%$ Volume/\% Frequency & \\
\hline $\begin{array}{l}\text { Abies lasiocarpa } \\
\text { Artemisia tridentata } \\
\text { Berberis sp. } \\
\text { Ceanothus velutinus } \\
\text { Juniperus communis } \\
\text { Penstemon fruticosus } \\
\text { Populus trichocarpa } \\
\text { Prunus virginiana } \\
\text { Pseudotsuga menziesii } \\
\text { Purshia tridentata } \\
\text { Rhus trilobata } \\
\text { Ribes setosum } \\
\text { Rosa sp. } \\
\text { Symphoricarpos albus } \\
\text { Symphoricarpos } \\
\text { occidentalis } \\
\text { Symphoricarpos sp. } \\
\text { TOTAL BROWSE }\end{array}$ & $\begin{array}{l}0.005 / 11.4 \\
0.026 / 31.8 \\
0.115 / 63.6 \\
0.025 / 22.7 \\
0.016 / 27.3 \\
0.009 / 4.5 \\
0.023 / 52.3 \\
0.048 / 25.0 \\
0.005 / 4.5 \\
0.011 / 4.5 \\
0.023 / 9.1 \\
0.022 / 15.9 \\
0.374 / 100.0\end{array}$ & $\begin{array}{l}0.122 / 28.6 \\
0.019 / 14.3 \\
0.030 / 14.3 \\
0.021 / 28.6 \\
0.152 / 28.6 \\
0.072 / 14.3\end{array}$ \\
\hline $\begin{array}{l}\text { Antennaria racemosa } \\
\text { Aster conspicuus } \\
\text { Aster sp. } \\
\text { Balsamorrhiza sagittata } \\
\text { Chrysopsis villosa } \\
\text { Cirsium sp. } \\
\text { Heuchera parviflora } \\
\text { Medicago sativa } \\
\text { Penstemon sp. } \\
\text { Pyrolia secunda } \\
\text { Rumex occidentalis } \\
\text { Tragopogon dubius } \\
\text { TOTAL FORBS } \\
\end{array}$ & $\begin{array}{l}0.006 / 11.4 \\
0.023 / 6.8 \\
0.037 / 22.7 \\
0.012 / 6.8 \\
0.009 / 2.3 \\
0.018 / 15.9 \\
0.010 / 9.1 \\
0.064 / 13.6 \\
0.007 / 9.1 \\
0.025 / 9.1 \\
0.005 / 14.3 \\
0.013 / 2.3 \\
0.388 / 95.5 \\
\end{array}$ & $0.195 / 85.7$ \\
\hline $\begin{array}{l}\text { Carex geyeri } \\
\text { Graminae } \\
\text { TOTAL GRASS }\end{array}$ & $\begin{array}{l}0.032 / 11.4 \\
0.143 / 68.2 \\
0.196 / 86.4\end{array}$ & $0.255 / 85.7$ \\
\hline Lichen & $0.034 / 31.8$ & $0.007 / 14.3$ \\
\hline Other & $0.008 / 11.4$ & $0.002 / 0.0$ \\
\hline
\end{tabular}


Table 5.10. Mule deer food habits on the west and east slope of the Bridger Mountains during winter, 1972-1986.

\begin{tabular}{|c|c|c|}
\hline \multirow[b]{2}{*}{ SPECIES } & $\begin{array}{l}\text { WEST SLOPE } \\
\text { (36 RUMENS) }\end{array}$ & $\begin{array}{l}\text { EAST SLOPE } \\
\text { (50 RUMENS) }\end{array}$ \\
\hline & $\%$ Volume/\%Frequency & $\%$ Volume/\% Frequency \\
\hline Amelanchier alnifolia & $0.005 / 5.6$ & \\
\hline Artemisia tridentata & $0.172 / 75.0$ & $0.254 / 88.0$ \\
\hline Berberis sp. & $0.008 / 30.6$ & $0.012 / 4.0$ \\
\hline Juniperus scopulorum & $0.157 / 88.9$ & $0.122 / 84.0$ \\
\hline Pinus contorta & $0.015 / 8.3$ & \\
\hline Pinus flexilis & & $0.052 / 36.0$ \\
\hline Populus trichocarpa & & $0.005 / 4.0$ \\
\hline Prunus virginiana & $0.005 / 13.9$ & \\
\hline Pseudotsuga menziesii & $0.119 / 80.6$ & $0.022 / 40.0$ \\
\hline Purshia tridentata & $0.074 / 38.9$ & \\
\hline Rosa sp. & & $0.017 / 10.0$ \\
\hline Salix sp. & & $0.035 / 10.0$ \\
\hline Spiraea betulifolia & $0.005 / 2.0$ & \\
\hline Symphoricarpos albus & & $0.005 / 4.0$ \\
\hline Symphoricarpos sp. & $0.008 / 8.3$ & \\
\hline TOTAL BROWSE & $0.591 / 100.0$ & $0.575 / 100.0$ \\
\hline Antennaria rosea & $0.007 / 10.0$ & \\
\hline Antennaria sp. & & $0.006 / 8.0$ \\
\hline Artemisia frigida & & $0.010 / 8.0$ \\
\hline Aster sp. & & $0.007 / 6.0$ \\
\hline Cirsium sp. & $0.008 / 2.8$ & \\
\hline Erigeron sp. & $0.006 / 8.3$ & \\
\hline Helianthus laetiflorus & $0.024 / 2.8$ & \\
\hline Heuchera sp. & $0.008 / 2.8$ & \\
\hline Lomatium sp. & $0.007 / 5.6$ & \\
\hline Medicago sativa & $0.026 / 11.1$ & $0.029 / 16.0$ \\
\hline Phlox hoodii & $0.017 / 22.0$ & \\
\hline TOTAL FORBS & $0.146 / 72.2$ & $0.126 / 66.0$ \\
\hline Agropyron spicatum & $0.006 / 2.8$ & \\
\hline Graminae & $0.025 / 8.3$ & \\
\hline TOTAL GRASS & $0.240 / 83.3$ & $0.262 / 86.0$ \\
\hline Detritus & & $0.011 / 4.0$ \\
\hline Other & $0.023 / 19.4$ & $0.037 / 36.0$ \\
\hline
\end{tabular}


Table 5.11. Mule deer food habits on the west and east slope of the Bridger Mountains during spring, 1972-1986.

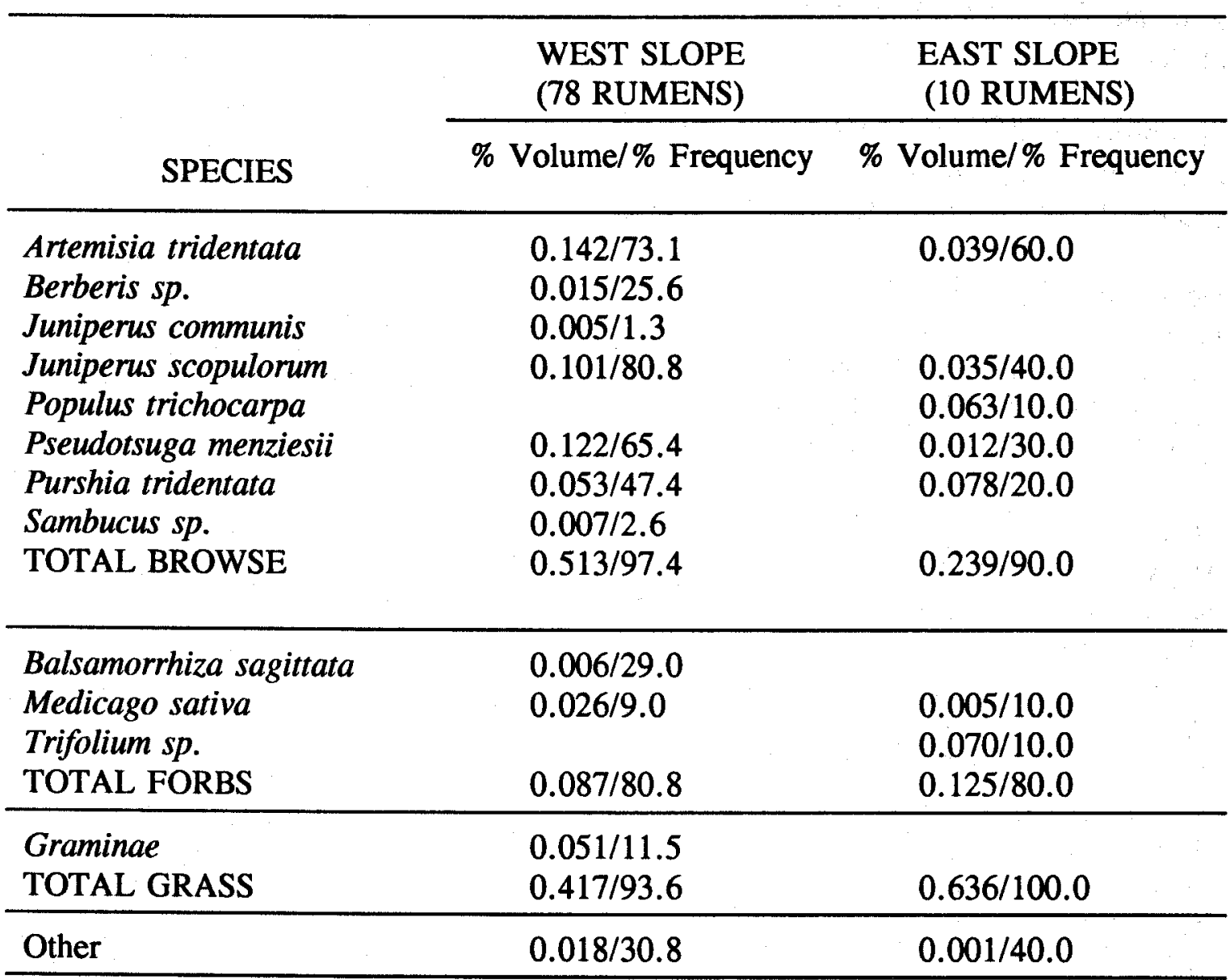

Summary

1. Throughout the Bridger Range, the broad distributional limits of winter habitat were determined by the distribution of snow cover. Within these limits, physical site characteristics determined the location, size, and shape of each winter range. Vegetation composition and structure were third order factors influencing winter habitat use.

2. Winter ranges associated with PHUs on the west slope were small and linearly oriented along the steep mountain footslope. They occurred within substantially higher precipitation zones than the larger, elliptical winter ranges located along the east slope and north end of the Bridger Range.

3. The occurrence of winter ranges on the west slope was closely tied to the distribution of steep south aspects which had a larger surface area and absorbed 
more solar radiation and thus reduced snow accumulation compared to level ground. Snow accumulation on the flat valley floor adjacent to the steep mountain footslope was usually great enough to preclude use by deer during winter.

4. In contrast, mule deer on the east slope were able to move out of the deep snow zone onto the gentle, undulating expanses of winter habitat in the drier precipitation zones created by the mountain-induced "rainshadow effect".

5. Generally, deer wintering in west slope PHUs were distributed at higher elevations compared to deer in east slope PHUs. In PHU 1 on the west slope, the distribution of adult male groups was skewed to lower elevations compared to adult female and mixed groups. Male groups occurred at higher elevations than female and mixed groups in PHU 4 on the east slope.

6. In summer, both sexes were distributed at significantly higher elevations in west slope PHUs compared to east slope PHUs. Generally, deer distributions in spring, summer, and autumn centered in areas with higher precipitation zones closest to winter range.

7. Zones of overlap between PHUs were often associated with the distant slopes of barrier ridges oriented perpendicular to deer movement vectors.

8. In winter, deer on the west slope used steppe vegetation less and montane forest more than expected on the basis of availability. Open and closed canopy forests were preferred. Mule deer were able to successfully occupy winter range in PHU 1 by exploiting vegetation types that accentuated the more important influence of various abiotic factors that reduced snow accumulation. This pattern of habitat use was consistent with that of deer occupation of a harsh, deep snow environment where a strategy of energy conservation was more appropriate to survival than foraging.

9. On the east slope, steppe vegetation accounted for nearly all deer use in winter. Shrub-grasslands were most important. Deer had little opportunity to use conifer forest, and physical factors that abetted energy conservation by deer were more sparsely distributed. This environment favored an overwinter survival strategy that emphasized foraging. Differences in topography, climate, and vegetation were primary determinants of differences in overwinter strategy between east and west slope ranges.

10. During spring, delayed snowmelt and plant development on high elevation summer ranges used by west slope deer resulted in a "bottleneck" in deer distribution. This "bottleneck" was not as evident in east slope PHUs where lower elevation and gentle relief permitted snowmelt and plant development to 
proceed more rapidly, and deer could move more rapidly and directly to summer ranges.

11. In summer, the montane forest accounted for nearly all use by adult females in west slope PHUs. Douglas fir cover types were most important. Although adult males made proportionately greater use of steppe and subalpine-alpine zones, the montane forest was most important. On the east slope, steppe and montane forest each accounted for about $50 \%$ of summer habitat use by adult females. However, only the latter was used more than expected.

12. The montane forest was preferred by adult females in summer because it provided a relatively stable source of succulent forage. Vegetative and topographic complexity within the forest also provided visual isolation from other deer during fawn-rearing and security from predation.

13. During autumn, intermittent severe storms caused sudden changes in habitat use and food habits in west slope PHUs. Deer in east slope PHUs were not subjected to such abrupt changes in distribution and habitat use.

14. Forbs predominated in the summer diet. A gradual shift to an increasing importance of browse occurred from late summer through late winter. During spring, emerging grasses were important early in the season gradually shifting to forbs. 


\section{CHAPTER 6}

\section{DEER MOVEMENTS AND BEHAVIORAL RESPONSE TO THE ENVIRONMENT \\ Individual Movement Patterns}

Movements of individual deer varied along a continuum from yearlong/lifelong residency on one small area to long movements between seasonal home ranges. Specific individual patterns were difficult to categorize and describe. The two fundamental patterns, residency and migration, described by other investigators (Harestad et al. 1979, Schoen and Kirchoff 1985, Garrott et al. 1987, Kufeld et al. 1989) have been used or interpreted in a variety of ways, but none seemed to completely describe the variation we observed. Instead, we recognized three broad individual movement patterns based on the juxtaposition of a deer's seasonal home ranges.

Deer with indistinct seasonal ranges (ISR pattern) fell at one end of the continuum. A typical example is shown in Fig. 6.1. There may have been some tendency for locations recorded during one season to cluster in a particular part of the total home range. However, numerous relocations could occur with equal probability in any portion of the home range during any season making it impossible to distinguish seasonal boundaries.

Individual deer with distinct seasonal ranges (DSR pattern) occupied the other extreme of the continuum (Fig. 6.2). Winter and summer home ranges were distinct entities separated by a minimum of $2 \mathrm{~km}$ and a maximum of $127 \mathrm{~km}$. Intra-seasonal trips between home ranges were the exception and almost never occurred among deer with winter and summer ranges centered more than $5 \mathrm{~km}$ apart. As the distance between seasonal ranges increased, seasonal movements and distribution became more specialized and more closely resembled migration as characterized by Baker (1978).

The third category (Fig. 6.3) described deer with adjacent seasonal ranges (ASR pattern). Movements of deer displaying this pattern were characteristically intermediate to those of ISR and DSR deer. Winter and summer home ranges usually were readily identified but separated by less than $2 \mathrm{~km}$. Also, deer following this pattern tended to move back and forth between seasonal ranges more frequently than DSR deer. During very mild winters, ASR deer sometimes remained on their summer home ranges for much of the winter, temporarily resembling the sedentary behavior of ISR deer. The attitudinal migrant described by Harestead (1979) was similar to the ASR pattern. 


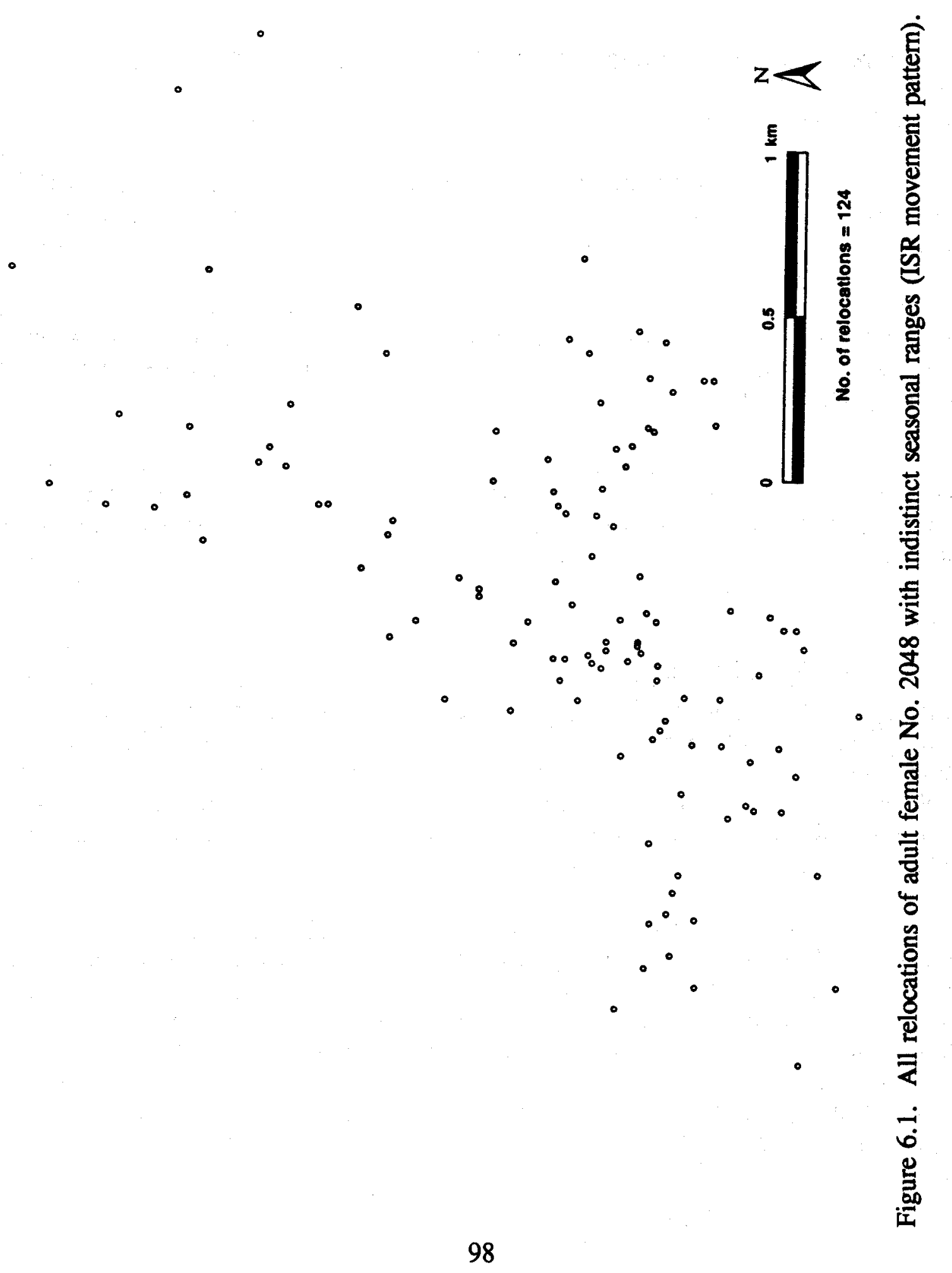



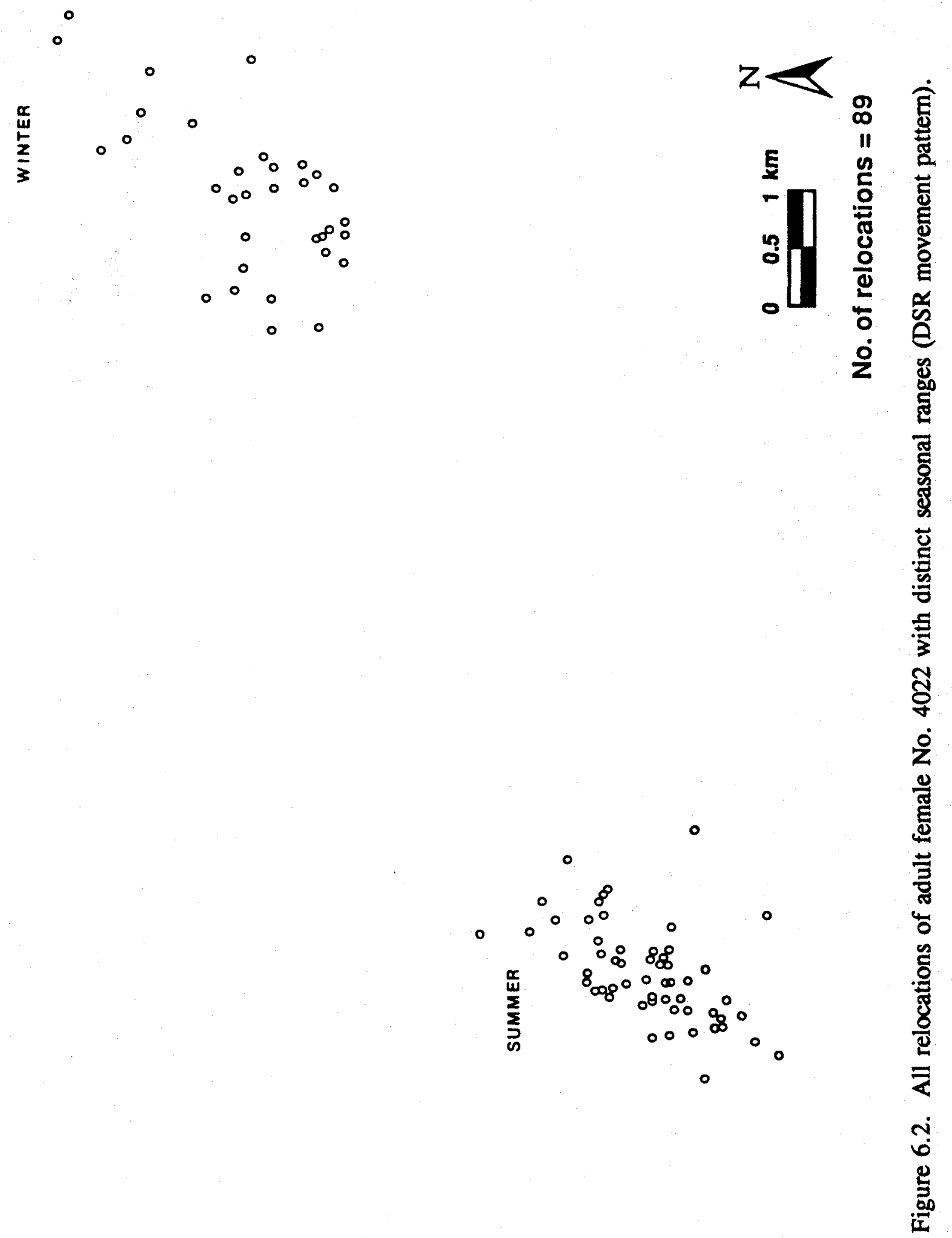

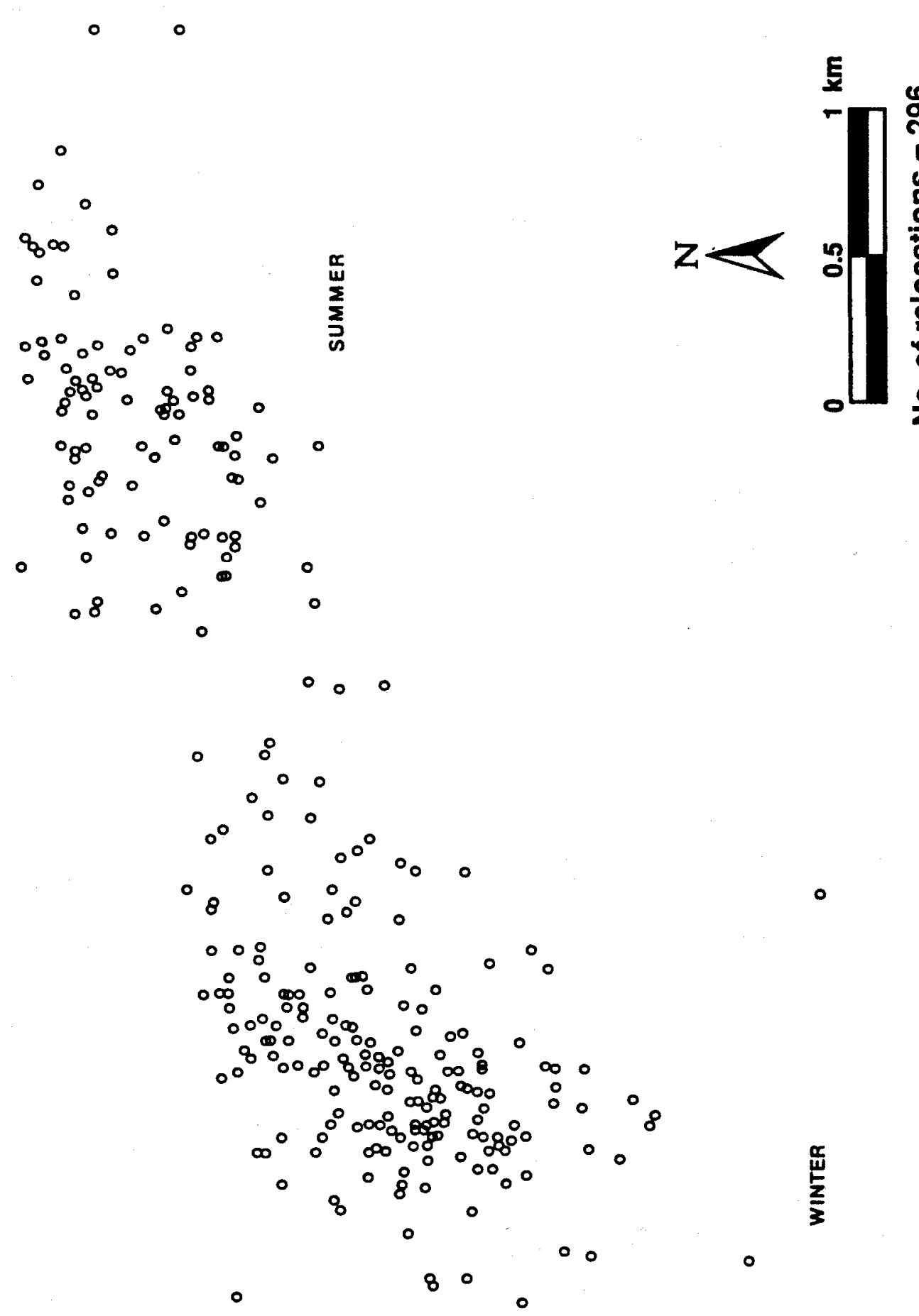

100 
Each deer radio-tracked for one complete biological year or longer was assigned to one of the three fundamental movement patterns (Table 6.1). Among a total sample of 131 adult females, we recognized $11 \%$ as ISR, $21 \%$ as ASR, and $68 \%$ as DSR. This is generally consistent with the common perception that mule deer in mountain environments tend to be migratory. However, migration was not a population phenomenon, but rather reflects one of several individual deer movement strategies.

Percentages of deer following the three movement patterns varied among the seven PHUs and between east (PHUs 3, 4, 5, and 6) and west slopes (PHUs 1, 2, and 7). Fewer females on the west slope displayed ISR and DSR patterns, and a greater percentage followed the ASR pattern as compared to the east slope. Also, the percentage of females in each movement category was more similar within PHUs 1, 2, and 7 than among PHUs 3, 4, 5, and 6. All three movement categories were represented in each of the three west slope PHUs. On the east slope, all three patterns occurred only in PHUs 4 and 5; only DSR deer were observed in PHU 6.

The percentage of females following the DSR pattern was consistently greater than that in the other two categories for each unit except PHU 7 where the percentage of ASR females was similar. In the three west slope units, ASR deer consistently outnumbered ISR deer. The reverse was true of the two east slope units where ASR deer occurred.

Small samples of radio-collared adult males prevented statistical comparison of movement patterns between the sexes. In PHU 1 where 11 males were classified, percentages of males and females classified as ASR and DSR were nearly identical (Table 6.1). Also, no males were classified as ISR compared to 3\% of females. Among an additional five males monitored in PHU 2, four were classified as DSR and one as ASR.

Seasonal Use of Accessory Areas

Accessory areas or habitats comprised local sites, usually outside of normal seasonal home ranges, that were used occasionally by deer either in addition to use of the normal range or between periods of use of summer and winter ranges. The use of seasonal accessory areas was responsible for much of the spatial and temporal variation which resulted in the continuum of individual deer movement patterns. Deer apparently moved to and used these alternate sites to satisfy temporary resource deficiencies on "normal" seasonal home ranges. Distances separating accessory areas from seasonal home ranges varied between 0.5 and $58.0 \mathrm{~km}$. The movement usually involved a distinct change in elevation.

Once individuals were monitored for sufficient time to identify these subtle specializations in habitat use, the factor or circumstance influencing the movement was usually evident. Thus, even though accessory areas were not occupied on an annual basis in the traditional manner that seasonal home ranges were used, their use was relatively predictable. Occasionally, the use of accessory areas modified the fundamental 


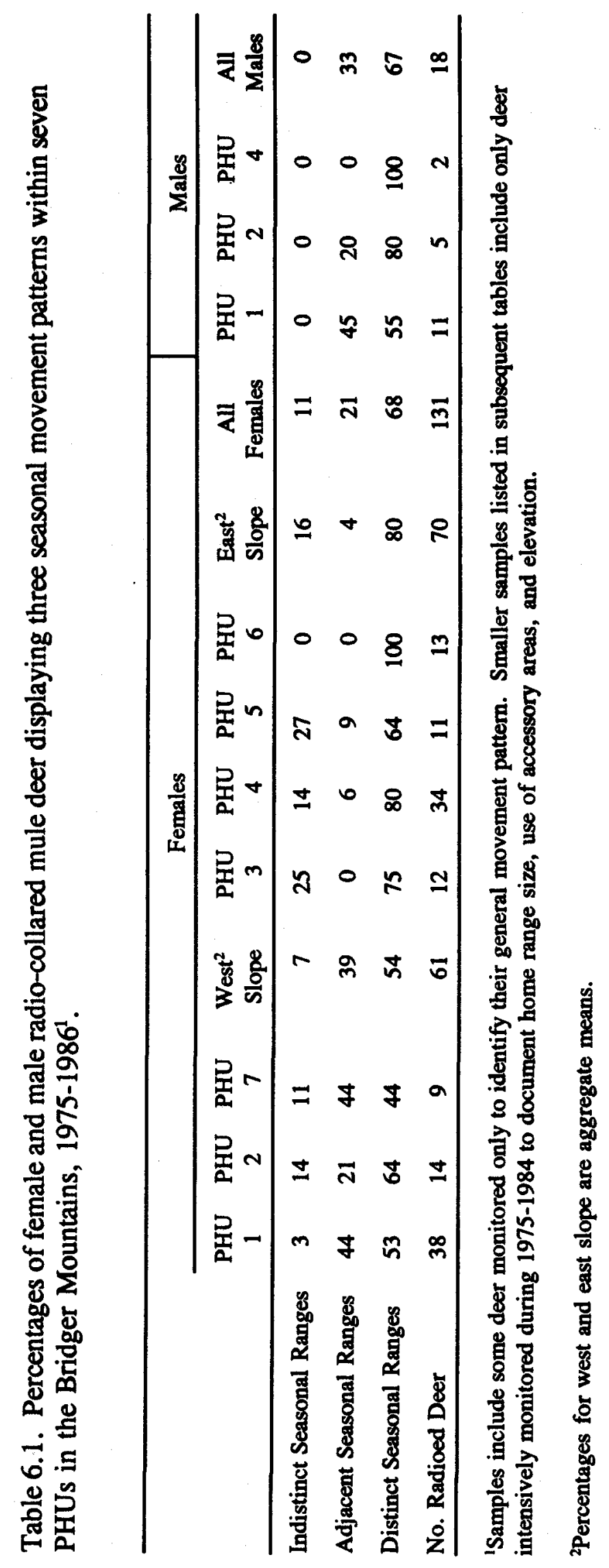


movement pattern of an individual to the point of making it difficult to distinguish it from another deer displaying an uncluttered version of the same type of movement pattern. By utilizing accessory areas during one or more seasons, a deer could display a total movement pattern as unique as an individual signature.

The five different types of accessory areas identified for adult females and their relative use by deer monitored in each PHU are listed in Table 6.2. Relative use of individual types varied between the west and east slopes.

Table 6.2. Relative use (\%) of five types of seasonal accessory areas (AA) by radio-collared adult females in seven PHUs in the Bridger Mountains.

\begin{tabular}{cccccccc}
\hline PHU & No. & Winter & Spring & Early Summer & Late Summer & Autumn \\
Females & AA & AA & AA & AA & AA \\
\hline 1 & 24 & 0 & 63 & 29 & 4 & 58 \\
2 & 14 & 0 & 57 & 36 & 0 & 50 \\
7 & 9 & 11 & 0 & 11 & 0 & 22 \\
West Slope & 47 & 2 & 49 & 28 & 2 & 49 \\
\hline 3 & 11 & 27 & 18 & 0 & 9 & 0 \\
4 & 15 & 20 & 40 & 7 & 13 & 27 \\
5 & 8 & 38 & 0 & 0 & 0 & 0 \\
6 & 13 & 0 & 38 & 0 & 31 & 15 \\
East Slope & 47 & 19 & 28 & 2 & 15 & 13 \\
\hline
\end{tabular}

\section{Winter Accessory Areas}

Use of accessory areas in winter occurred during periods of severe weather when unusually deep snow covered normal winter home ranges and restricted the availability of resources needed by deer, especially on higher, more marginal ranges. Individual female movement patterns incorporating winter accessory areas were relatively common in PHUs 3, 4 and 5 on the east slope and rare on the west slope (Table 6.2).

Adult female 4115 displayed an ISR movement pattern that included use of a typical winter accessory area in PHU 4 (Fig. 6.4). Throughout four years of surveillance, 4115 used a home range on the upper portion of PHU 4 winter range yearlong except for two visits to a winter accessory area initiated by severe weather and deep snow in late winter 1980 and 1982. In each case, she moved $5 \mathrm{~km}$ east and descended $135 \mathrm{~m}$ in elevation to the same small area of river breaks along the lower boundary of PHU 4 winter range. She remained on this accessory area for approximately 35 days in 1980 and 81 days in 1982, a more severe winter. To our knowledge, she never used the area during winters 1981,1983 , or 1984. 


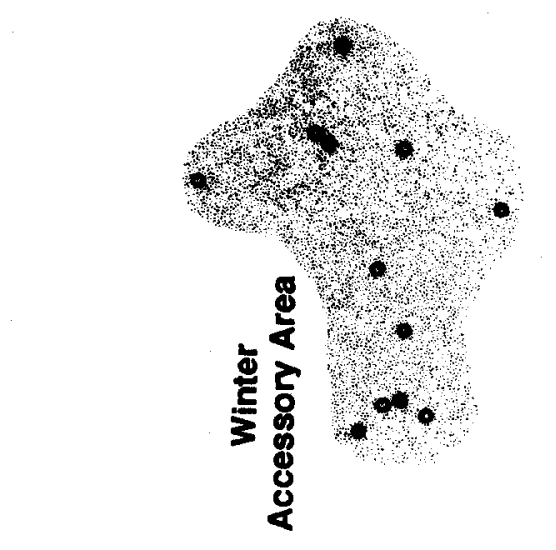

0

。
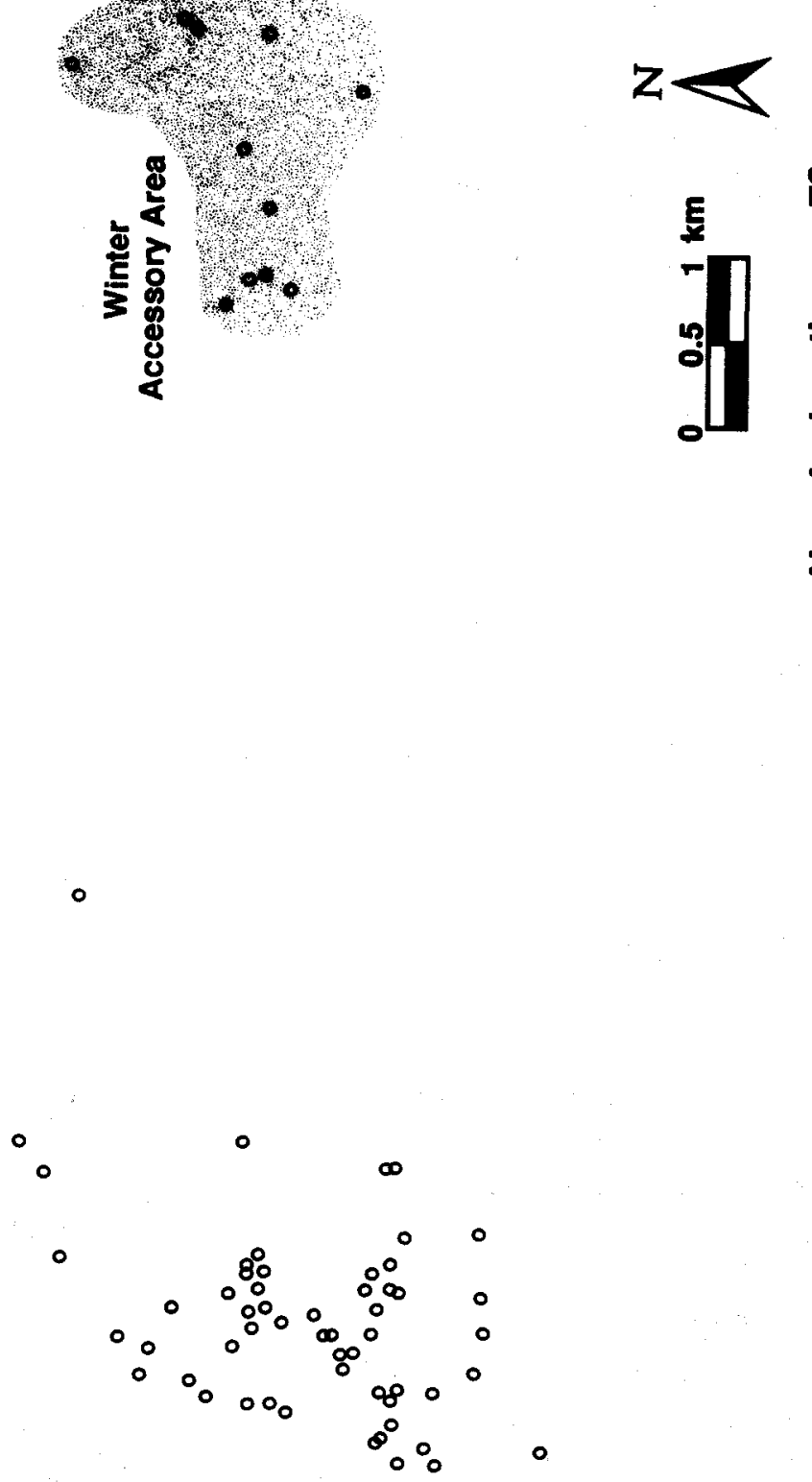

8

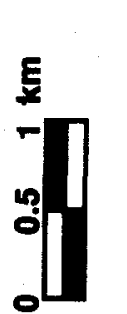

$R$

7

ㅊ

in E

을

車

i

卷

号

운

్ㅗㅀ

묵
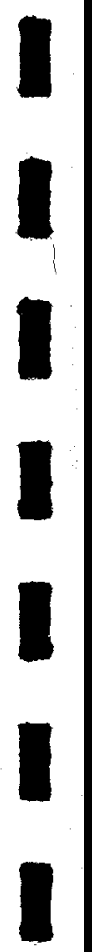

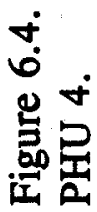


As in the above example, use of winter accessory areas was primarily associated with the ISR movement pattern. On the east slope, seven of nine females using such areas were ISR deer; the other two followed the DSR pattern. All seven ISR females occupied yearlong home ranges along the upper fringes of winter ranges. The single female observed using a winter accessory area on the west slope followed an ASR pattern. Her winter home range occurred on a marginal portion of the PHU 7 winter range. The winter accessory area was located in the PHU 6 winter range, $11.5 \mathrm{~km}$ from her winter home range. This was the greatest distance any deer moved to a winter accessory area; the minimum was $3.0 \mathrm{~km}$ by a DSR female in PHU 4.

No female used a winter accessory area during consecutive years. Overall, the 10 females observed to have such accessory ranges used them during $19(59 \%)$ of 32 winter seasons over which they were monitored. Despite the sporadic use, whenever use of an accessory area occurred, it was site specific. That is, the deer did not simply move to the nearest site offering more tolerable snow depths. Rather they moved directly and rapidly to the site (accessory area) used previously. In all cases, both the habitat they traversed and the accessory area supported generally higher densities of wintering deer than typically occurred in the vicinity of their home ranges. Apparently, knowledge of accessory areas was learned through previous experience or transmitted by older maternally-related deer in the same manner as location and use of normal seasonal ranges. Once learned, their location was retained in the memory of individuals and used whenever circumstances dictated. Time spent on these areas was quite variable but ranged from 31 to 87 days.

Winter accessory areas were lower in elevation than the corresponding home range. This difference averaged 170 and $60 \mathrm{~m}$, respectively, for ISR and DSR females on the east slope and $435 \mathrm{~m}$ for one ASR female on the west slope. The winter home range of the latter occurred at the second highest elevation $(1,934 \mathrm{~m})$ of all adult females monitored in the Bridger Mountains. On the east slope, adult females with winter accessory areas occupied home ranges located an average of $85 \mathrm{~m}$ higher than females lacking these areas. This was further evidence that use of accessory areas was a "strategy" necessary to cope with occasional resource deficiencies on more marginal home ranges where resources could quickly become limited or unavailable during severe winters.

Only 1 of 16 adult males monitored on the west slope used a winter accessory area. This individual, which followed a normal ASR movement pattern in PHU 1 , moved $1.5 \mathrm{~km}$ to an area on the valley floor located about $235 \mathrm{~m}$ below the elevation of its winter home range. It remained here for a maximum of 55 days during winter 1978.

Greater use of winter accessory areas by adult females on the east than west slope may have been related to the general absence of steep south aspects and conifer timber stands within east slope winter ranges. This restricted their opportunity to cope with or adjust to periodic accumulations of deep snow within their normal home ranges and 
forced them at times to temporarily abandon those ranges. In the more complex and vegetatively diverse terrain along the west slope, females could more easily find sites that offered reprieve from deep snow within the boundaries of their home ranges.

\section{Spring and Autumn Accessory Areas}

Spring and autumn accessory areas were similar in many respects. Both were typically located at intermediate elevations along movement corridors connecting individual seasonal home ranges of some deer following ASR and DSR movement patterns. In most cases, they were located relatively closer to winter $(0.5-5.0 \mathrm{~km})$ than summer home ranges. However, a few deer that traveled exceptionally long distances had accessory areas located approximately midway between their summer and winter ranges. The most extreme example involved an adult female that wintered in PHU 4, summered in Yellowstone National Park, and used a spring accessory area located 58.0 $\mathrm{km}$ from her winter range. Loft et al. (1989), Bertram and Rempel (1977), and Pac (1976) generally described "holding areas" that were similar to our spring and autumn accessory areas. Pac et al. (1988) referred to transitional ranges used during spring and autumn movement between winter and summer home ranges.

Deer using spring accessory areas moved onto those areas shortly after snowmelt when plant development had reached intermediate elevations where most such areas were located. They remained there until environmental conditions (especially snowmelt) along the remainder of the movement corridor permitted them to move directly to and occupy their summer home range.

Deer movement to autumn accessory areas was triggered by severe weather conditions and accumulation of snow on summer range. The extent to which deer tolerated snow on summer home ranges varied widely among individuals depending on when the snow occurred, the juxtaposition of their summer and winter ranges, and topographic characteristics along movement corridors.

Movements of one adult female (No. 1016) that included use of both spring and autumn accessory areas within a general DSR movement pattern in PHU 1 (Fig. 6.5) provide a typical example of the pattern and factors influencing use of these areas. During winter, 1016 used a home range centering around an elevation of $1,840 \mathrm{~m}$ along the northern edge of winter range in PHU 1. In mid-May 1976, she moved to a spring accessory area located $310 \mathrm{~m}$ higher and $3 \mathrm{~km}$ north of her winter home range. The area consisted of steep south and west aspects dominated by open stands of large Douglas fir trees with mixed bunchgrass/forb understory along the lower portion of a major canyon. After using the accessory area for 2-3 weeks, 1016 was relocated on $8 \mathrm{June}, 5.0 \mathrm{~km}$ to the east on her summer home range at an elevation of $2,340 \mathrm{~m}$. This move entailed crossing the main Bridger Range Divide at an elevation of $2,750 \mathrm{~m}$, and could only be accomplished following partial melting of the high elevation snow pack. 

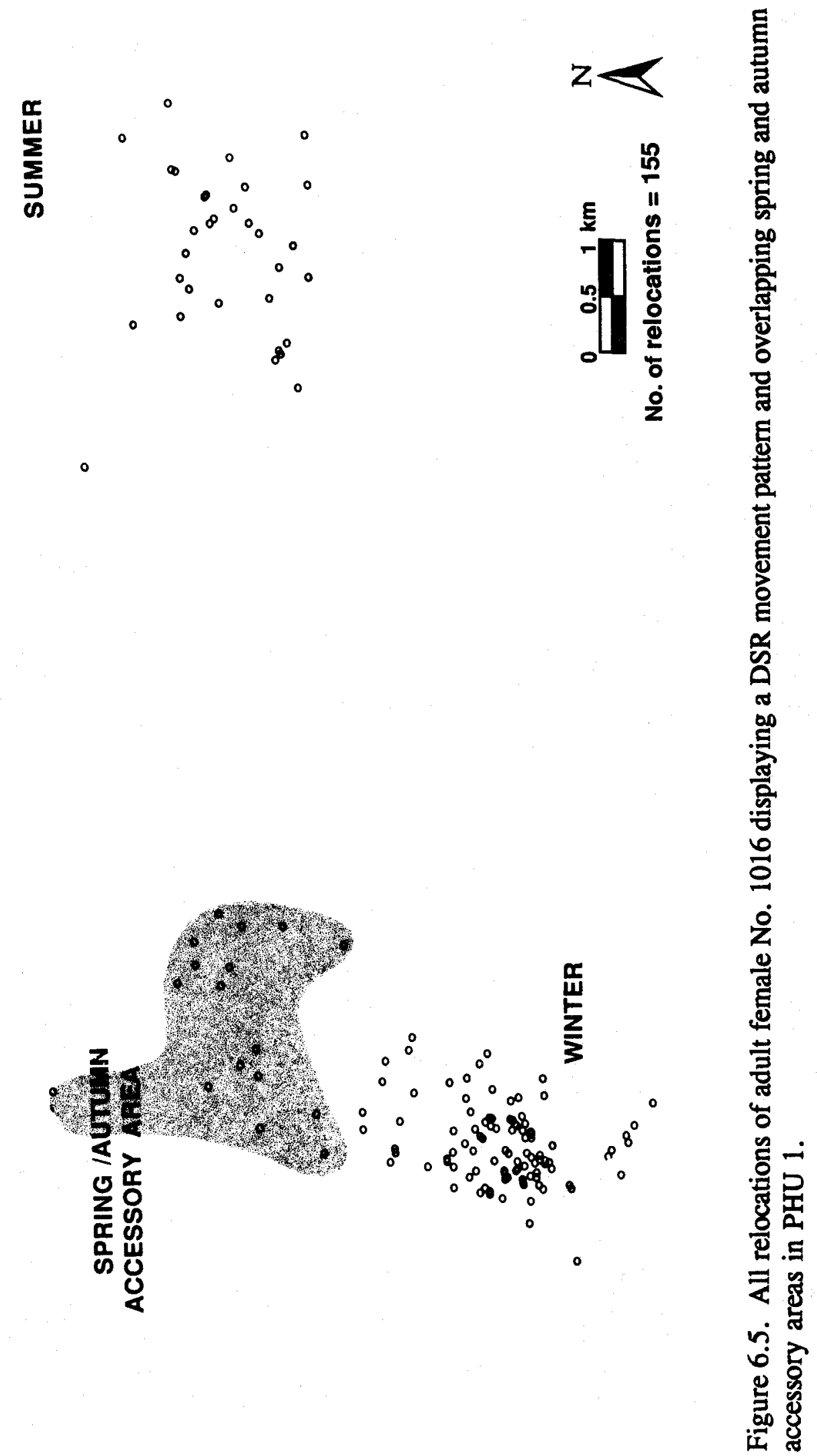
In autumn 1976, following a late October storm that left about $12 \mathrm{~cm}$ of snow on her summer home range, 1016 moved back across the Bridger Divide to an autumn accessory area located immediately adjacent to but about $125 \mathrm{~m}$ higher than the area used in spring. Although snow depth was somewhat greater where she crossed the Divide, the amount on the accessory area was very similar to that which triggered her move from summer range.

At the same time that 1016 moved, marked deer occupying higher-elevation summer home ranges on the west slope (above the autumn accessory range of 1016) were not disturbed by the storm. Apparently, in the absence of a high divide along movement corridors to winter range, these deer could tolerate storms and accumulations of snow later into autumn and winter.

With ensuing mild conditions, 1016 remained on the accessory area for about nine weeks before completing the move to her winter home range in late December. Thereafter, she remained on the winter range until early May, except for two brief visits ( $<1$ week) to the accessory area under very mild, open winter conditions.

In 1977, 1016 moved onto the accessory area by mid May and remained there until late June. She arrived on her summer home range about 24 June, approximately two weeks later than the previous year. Severe weather during autumn 1977 prompted her return to the autumn accessory area by mid-October, about two weeks earlier than in 1976. Continuing stormy conditions resulted in a shorter, four-week period of use of the accessory area and earlier movement to her winter home range by about 15 November.

Use of spring accessory areas was recorded in two of three PHUs on the west slope and involved about half (49\%) of all adult females monitored in those units (Table 6.2). Autumn accessory areas were used by deer in all three west slope PHUs and involved the same percentage of females as spring. In contrast, only 28 and $13 \%$, respectively, of all adult females monitored in PHUs along the east slope used spring and autumn accessory areas. None of the females monitored in PHU 5 used either autumn or spring accessory areas, and only spring accessory areas were used by females marked in PHU 3. Use of both spring and autumn accessory areas was evident only for some females in PHUs 4 and 6.

Overall, some individuals only used spring accessory areas, others only autumn, and some used both types. The latter comprised 61 and $36 \%$, respectively, of all females known to use at least one of these combinations on the west and east slope ranges. When one female used accessory ranges in both seasons, the areas often overlapped or were immediately adjacent to one another as in the case of female 1016 cited above.

Use of spring and/or autumn accessory areas by females on the west slope was most prevalent among individuals following the DSR movement pattern, especially those 
entailing movement across the Bridger Divide (Table 6.3). The proportion of DSR deer using spring/autumn accessory areas along the eastslope was less than half that recorded for DSR females on the west slope. None of the three females with ASR movement patterns on the east slope used spring/autumn accessory areas. Also, as on the west slope, DSR females that crossed barrier ridges between summer and winter home ranges along the east slope displayed greater use of spring/autumn accessory areas than those that did not have to cross a major ridge.

Table 6.3. Percent use of spring and/or autumn accessory areas among adult females with different types of movement patterns (see text).

\begin{tabular}{|c|c|c|}
\hline Movement pattern & West Slope & East Slope \\
\hline $\begin{array}{l}\text { ASR } \\
\text { DSR }\end{array}$ & $\begin{array}{l}37(19)^{1} \\
91(23)\end{array}$ & $\begin{array}{c}0(3) \\
42(33)\end{array}$ \\
\hline $\begin{array}{l}\text { Cross Barrier Ridges }{ }^{2} \\
\text { Non-Cross }\end{array}$ & $\begin{array}{l}90(10) \\
59(32)\end{array}$ & $\begin{array}{l}70(10) \\
27(26)\end{array}$ \\
\hline
\end{tabular}

'Sample size in parentheses $=$ number adult females

${ }^{2}$ Individuals that cross barrier ridges during movement to summer home range.

Use of accessory areas in spring typically occurred with greater regularity than use of winter accessory areas. The 23 west slope females known to use a spring accessory area were recorded using those areas during $91 \%$ of 65 deer-spring seasons. Only 4 of the 23 individuals failed to make use of their accessory areas during all consecutive years of monitoring. On the east slope, 13 females monitored during 34 deer-spring seasons used their spring accessory areas $82 \%$ of the time. Six of the 13 failed to use their spring area during consecutive years.

The incidence of use of autumn accessory areas was slightly lower than that in spring. The 23 females monitored on west slope ranges occurred on autumn accessory areas during $86 \%$ of 59 deer-autumn seasons. Seven of the 23 did not consistently use the areas. On the east slope, six females used their autumn areas during 57\% of 14 deer-autumn seasons. Only two of those used the areas during all consecutive years.

The length of time that spring and autumn accessory areas were occupied varied among PHUs, individuals, and years. Spring areas consistently were occupied for shorter periods of time than autumn areas in both PHUs 1 and 4. Deer generally spent between 21 and 38 days on spring areas in PHU 1 compared to 12 to 30 days for PHU 4. Autumn areas were occupied for 44 to 65 days on PHU 1 and 30 to 53 days in PHU 4. However, three yearling females and one 2-year old male in PHU 1 remained on their spring accessory areas until mid-July, nearly one month longer than five adult 
females using overlapping areas. All eventually moved across the Bridger Divide to summer in the same drainage east of the Divide. Two of the yearling females were also monitored in subsequent years and did not display extended use of spring accessory areas.

The average elevation of spring and autumn accessory areas was intermediate to the mean elevation of winter and summer home ranges in all seven PHUs (Table 6.4). All elevations within the home range and accessory area categories in Table 6.4 were lower on the east than on the west slope. However, there were some exceptions to these general patterns among individual deer, especially among those that seasonally crossed the Bridger Divide. Five of 10 adult females in PHUs 1, 2, and 7 that seasonally crossed the Divide used spring and/or autumn accessory areas located west of the divide. In each case, the accessory area was higher in elevation than the summer home range. One other adult female that seasonally traversed the 16-Mile Basin in PHU 6 used a spring accessory area centered $100 \mathrm{~m}$ lower in elevation than her winter home range. The spring area was located midway along a $12 \mathrm{~km}$ corridor connecting her winter and summer ranges.

Among all females with separate seasonal ranges, 87, 67 and $25 \%$ in PHUs 1 , 2 , and 7 and 29, 50, 0 and $46 \%$ in PHUs 3, 4, 5, and 6, respectively, used spring and/or autumn accessory areas. These data indicate considerable variation in use of accessory areas among females sharing similar habitats (adjacent PHUs) as well as between broadly different habitats (the east vs west slope PHUs).

There was a significant relationship between the percentage of females using spring and/or autumn accessory areas and the average elevational relief they encountered along movement corridors (Fig. 6.6). Females did not use accessory areas in PHU 5 where the average elevational difference between primary seasonal ranges was only 210 $\mathrm{m}$. From there, the percentage of females using spring and/or autumn areas increased to a maximum $82 \%$ in PHU 1 where elevational relief along all ASR and DSR movement corridors averaged $564 \mathrm{~m}$. Elevational relief was the only factor that adequately explained the confusing array of percentages pertaining to use of spring and autumn areas among the seven PHUs. The incidence of use of spring and/or autumn accessory areas did not appear to be related to linear distance separating winter and summer ranges ( $\mathrm{r}=$ -0.62 . $\mathrm{P}>0.05)$.

The average elevational relief along movement corridors of females that used spring and/or autumn accessory areas within west slope units was $583 \pm 177 \mathrm{~m}(\mathrm{~N}=$ 28) compared to $258 \pm 115 \mathrm{~m}(\mathrm{~N}=14)$ for females that did not use such areas. Comparable figures for east slope females were $470 \pm 238 \mathrm{~m}(\mathrm{~N}=14)$ and $290 \pm 112$ $\mathrm{m}(\mathrm{N}=22)$ for those using and not using accessory areas, respectively. 


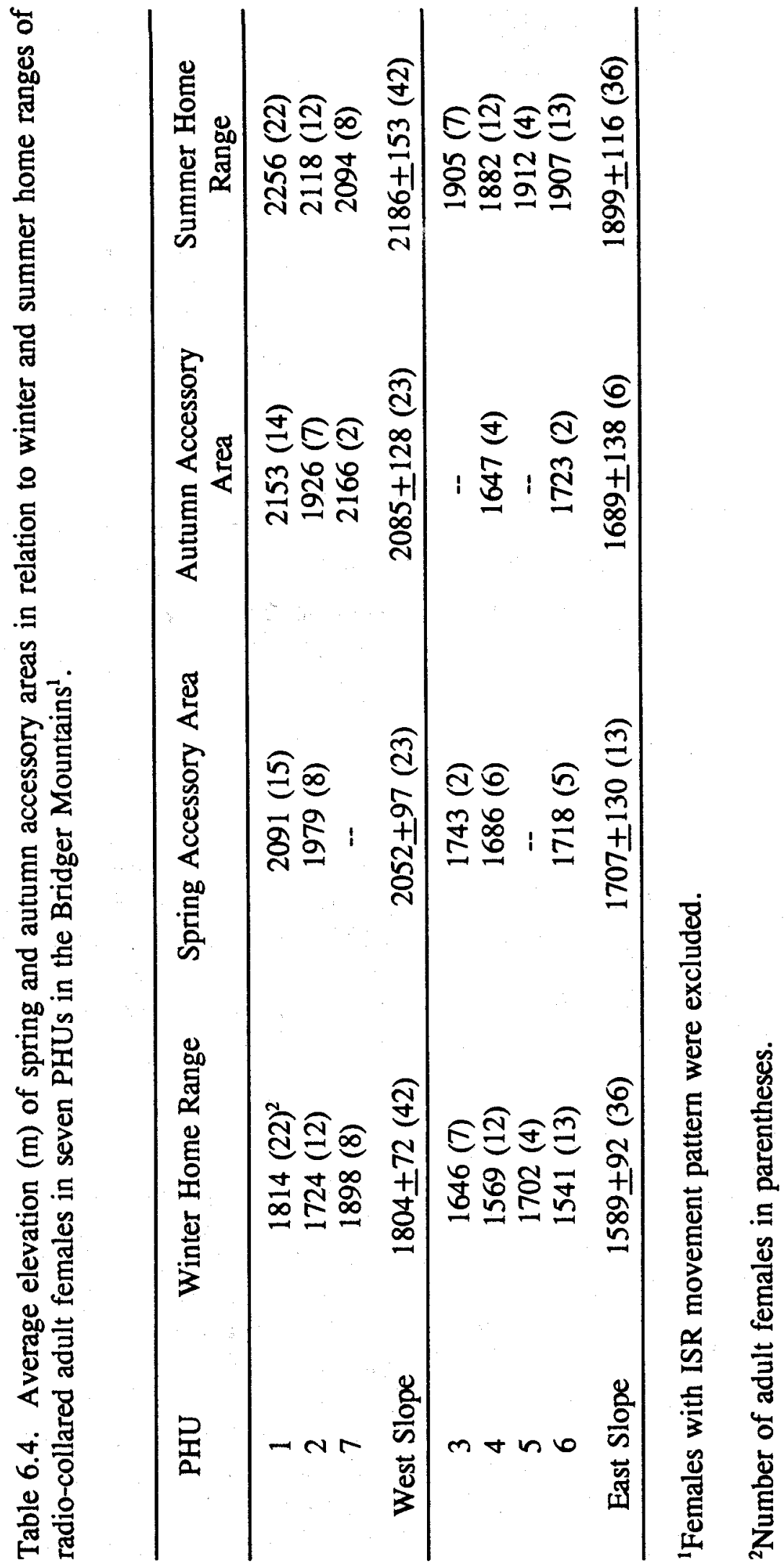




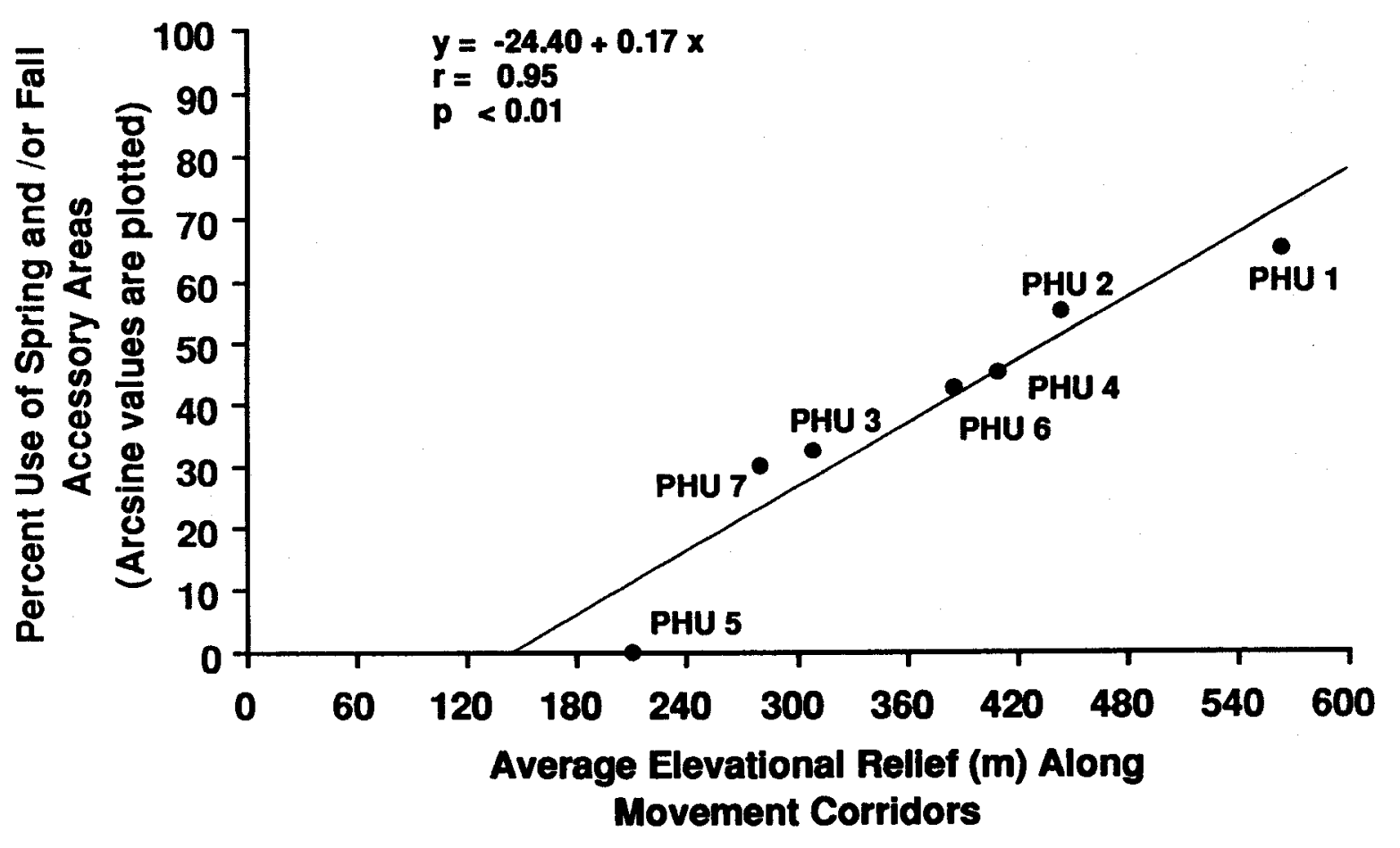

Figure 6.6. Relationship between average elevational relief $(\mathrm{m})$ along movement corridors and percent use of spring and/or autumn accessory areas by marked females in each of seven PHUs.

Incidence of use of spring and autumn accessory areas by males was determined from 16 radio-collared individuals on the west slope (11 in PHU 1, 5 in PHU 2). General patterns of use were similar to females (63\% vs. 67\%) except for less definitive use of autumn accessory areas by some bucks during the breeding season. Only 1 of the 10 males using accessory areas had adjacent seasonal home ranges, the remainder were DSR individuals including all eight of the bucks that seasonally crossed the Bridger Divide.

Spring accessory areas used by bucks were located between 0.5 and $4.0 \mathrm{~km}$. from winter home ranges. Autumn areas were more distant, ranging from 1.0 to $19.0 \mathrm{~km}$. Only 3 of 16 males used both types of areas. Two of these used spring and autumn areas that partially overlapped. The third, a 5 to 6 year old (No. 1240), followed a very large circular movement pattern that enclosed $166 \mathrm{~km}^{2}$ and included four or more distinct "seasonal" ranges. The spring and autumn accessory areas were located about $19 \mathrm{~km}$ apart and on opposite sides of the Bridger Range (Fig. 6.7).

Similar to females, spring and autumn ranges used by bucks were located at intermediate elevations. The average elevations of winter and summer home ranges for males were $1,770 \pm 71 \mathrm{~m}$ and $2,198 \pm 142 \mathrm{~m}$; for spring and autumn accessory areas, averages were 2,032 $\pm 204 \mathrm{~m}(\mathrm{~N}=7)$ and $2,153 \pm 174 \mathrm{~m}(\mathrm{~N}=7)$, respectively. The 


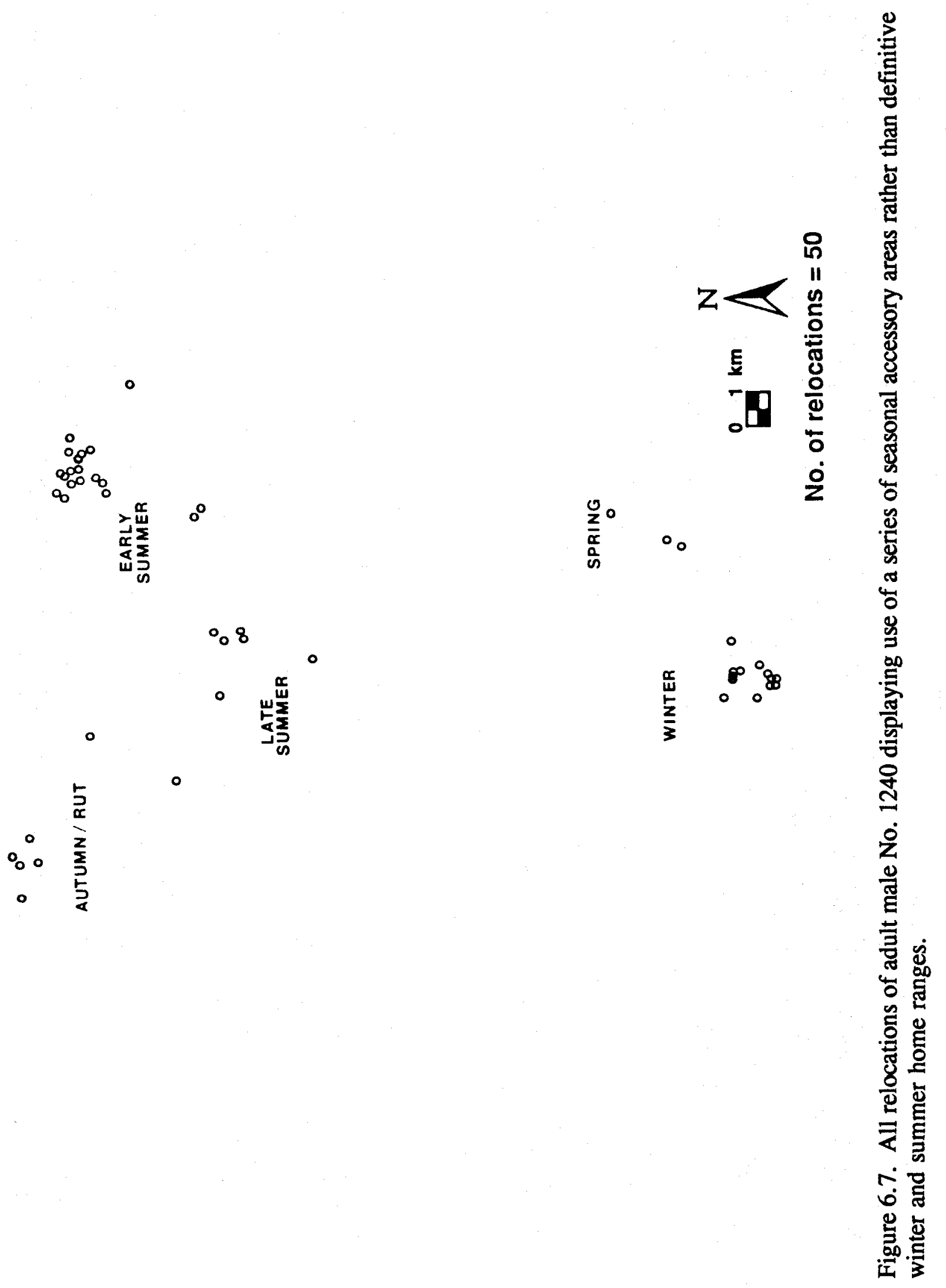


eight males crossing the Bridger Divide in late spring and autumn crossed at elevations ranging from 2,520 to $2,745 \mathrm{~m}$. Three of these used spring or autumn accessory areas on the west slope that were higher in elevation than their summer home ranges east of the divide. The average elevational difference between summer and winter home ranges of the 10 males that used spring and/or autumn accessory areas was $699 \pm 223 \mathrm{~m}$ compared to only $358 \pm 116 \mathrm{~m}$ among the six that did not use these areas.

Movements of 10 males, $\geq 3$ years of age, were radio-monitored at 7-10 day intervals during 1-3 rutting seasons. Six displayed what appeared to be rut-related movements that were tangential to the normal orientation of their movement corridors. These included some ASR individuals that normally occupied winter and summer home ranges along mountain footslopes, but temporarily moved several kilometers to higher elevations during the rut. Also, some crossed intervening ridges and moved into drainages not used during other seasons. However, only one of the six bucks displaying rut-related movements travelled more than $4.0 \mathrm{~km}$ beyond the normal travel corridor. The exception was male 1240 , described earlier as following a large circular movement pattern through the year (Fig. 6.7). During the rut, 1240 moved west of the Bridger Divide to an area approximately $7.0 \mathrm{~km}$ from that used in early autumn. Other year-long movements of this male were also anomalous, consisting of sequential use of a series of discrete areas along a circular path rather than the typical pattern of use of two distinct seasonal ranges located along a linear axis. This pattern was followed for two successive years before the buck was killed in late November 1981.

Four of 10 males monitored during the rut did not display any noticeable expansion in movements. Three had seasonal ranges on opposite sides of the Bridger Divide; the other used adjacent seasonal ranges located along the western edge of PHU 1.

In spring, ASR and DSR deer attempted to move off winter ranges as early as environmental conditions permitted. Some having summer home ranges at low-middle elevations moved early and directly. Others that contended with high elevation habitats or movement across high divides used the "stop-gap" measure of moving to spring accessory areas at intermediate elevations. Only ISR deer remained stationary on winter ranges. Because deer moved to summer ranges as soon as possible, spring accessory areas were generally occupied for shorter time periods than autumn accessory areas. Spring snow storms and cold temperatures resulting in persistent snow pack and blocking of movement corridors and passes across the divide resulted in prolonged use of spring areas in some years.

Deer that used autumn accessory areas were the first to leave summer home ranges situated at high elevations and/or across major mountain divides. Typically, however, they remained on autumn areas for as long as possible; perhaps to avoid congregating at high densities at lower elevations. Deer that did not use autumn accessory areas moved directly to winter ranges only at the "last minute" and as forced 
to move by accumulating snowpack. Mild open conditions during autumn prolonged use of summer ranges by these deer and use of autumn accessory areas by others. Conversely, extended periods of severe weather during autumn reduced periods of use of autumn accessory areas and accelerated movement and congregation of all deer on winter ranges.

All of this suggested that patterns of movement on and off the winter range, including use of autumn and/or spring accessory areas, represented a spacing mechanism that deer used to achieve a more desirable density distribution when environmental conditions prevented optimal dispersion.

\section{Early Summer Accessory Areas}

The fourth type of accessory area, which we term early summer accessory area, was used by $14(15 \%)$ of the 94 adult females that were intensively monitored during 1975-1984. All but one were located on the west slope (Table 6.2). In each case, the female moved to its summer home range as soon as possible in spring but subsequently moved again in early-mid June to an accessory area. Twelve moved to specific, low elevation sites located on or near the upper edge of their winter home ranges. The other two, one in PHU 2 and another in PHU 4, moved to accessory areas located farther from winter range and at higher elevation than their normal summer home ranges.

Use of early summer accessory areas by adult females appeared to be associated with parturition and early fawn-rearing. Eleven individual females moved to the accessory areas during each of 19 summer seasons when they had fawns. Two of these did not use the areas in years when they had no fawns. However, three females that demonstrated use of accessory areas during fawn-rearing in at least one year did not continue to use those areas during four subsequent summers when they had fawns. Also, one female moved to an early summer accessory area even though she was not observed with a fawn that summer.

Early summer movements of female 1136 , monitored through four consecutive spring-summer periods during 1978-1982, were typical of the 12 deer which moved downward in early summer to accessory areas along the upper part of winter range (Fig. 6.8). Female 1136 occupied distinct summer and winter home ranges separated by a minimum $0.6 \mathrm{~km}$. However, the average difference in elevation between the two ranges, $434 \mathrm{~m}$, was substantial.

In 1978, 1136 left her winter home range in late May and moved directly to her summer home range for the first two weeks of June. By 15 June, she had moved downward to an early summer accessory area located about $1.0 \mathrm{~km}$ to the west and about $185 \mathrm{~m}$ lower in elevation. She remained there for 8 to 13 days before moving $2.3 \mathrm{~km}$ east and $425 \mathrm{~m}$ higher to the upper portion of her summer home range. She remained 

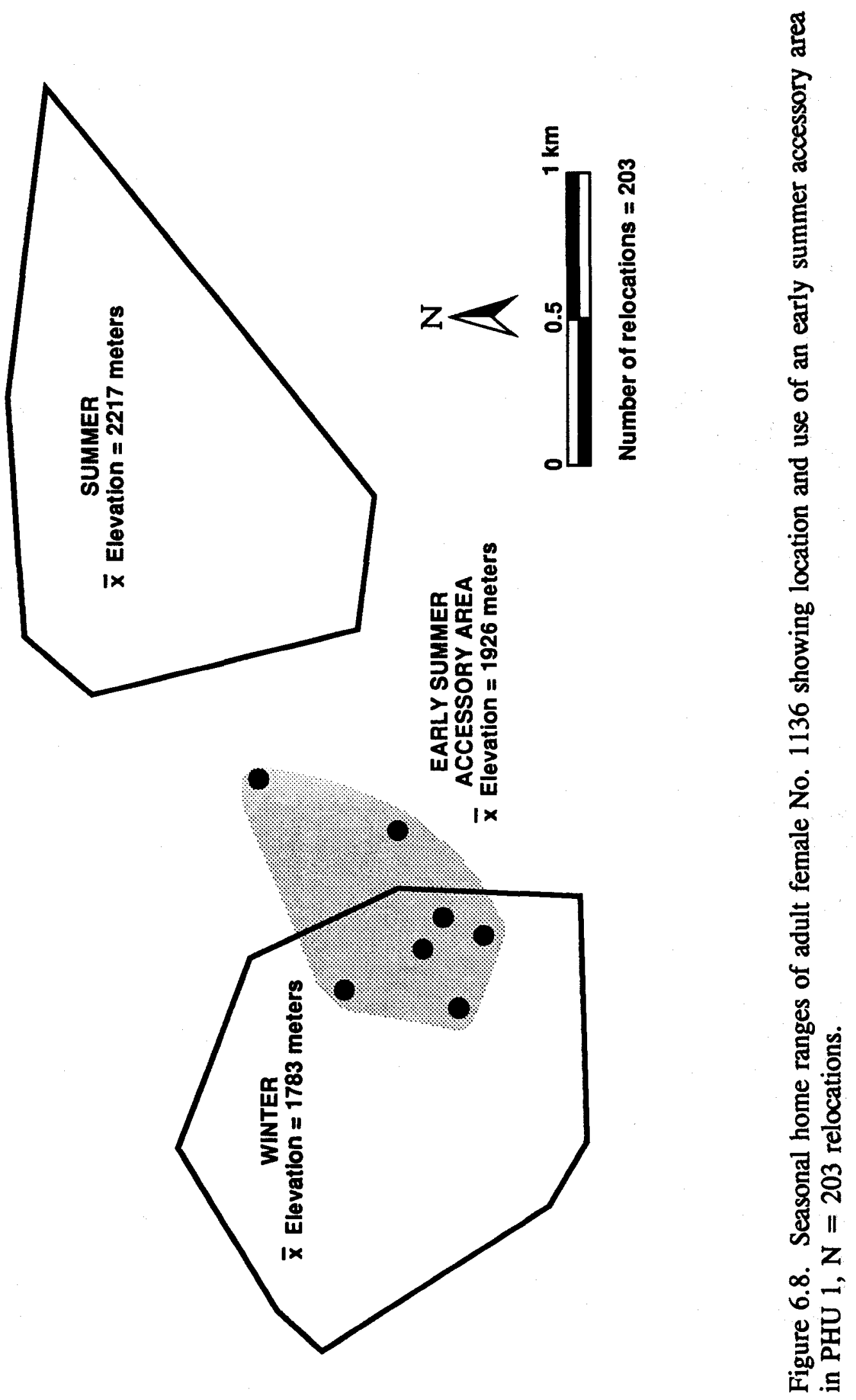
on the summer home range accompanied by two fawns until mid-November when she returned to her winter home range.

This same pattern of movement was followed in each of the next three years except that in summer 1980 she remained on the accessory area until mid-July, about two weeks longer than in other years. Also, in autumn 1980, she remained on summer range until late January. In each of the three summers, 1136 was accompanied by a single fawn. The overall average elevation of all relocations of this deer was $1,783 \mathrm{~m}$ in winter, 2,217 $\mathrm{m}$ on summer range, and $1,926 \mathrm{~m}$ on the early summer accessory area.

On the west slope, 12 of 13 adult females used early summer accessory areas that were located an average $421 \mathrm{~m}$ lower $(\mathrm{z}=10.92, \mathrm{P}=0.000)$ and $2.3 \mathrm{~km}(1.3-3.3 \mathrm{~km})$ away from their summer home ranges (Table 6.5). Nine of the 12 followed the ASR movement pattern, the remainder were DSR deer. The maximum distance separating winter and summer home ranges of an individual with this type of accessory area was $5.0 \mathrm{~km}$.

West slope females with early summer accessory areas normally occupied summer home ranges at significantly higher elevations $(\bar{X}=153 \mathrm{~m}, \mathrm{Z}=14.51, \mathrm{P}=0.000)$ than 34 other does that did not use such accessory areas (Table 6.6). The average elevation for all relocations $(\mathrm{N}=69)$ of the 12 females on their early summer accessory was $247 \mathrm{~m}$ lower $(\mathrm{Z}=8.64, \mathrm{P}=0.000)$ than the average for all early summer relocations $(\mathrm{N}=596)$ of the 34 does that used a single summer-long home range.

Table 6.5. Average elevation ( $\mathrm{m}$ ) of early summer accessory areas for twelve adult females on the west slope compared to average elevation of their summer home ranges ${ }^{1}$.

\begin{tabular}{ccccc}
\hline PHU & $\begin{array}{c}\text { Summer } \\
\text { Home Range }\end{array}$ & $\begin{array}{c}\text { Early Summer } \\
\text { Accessory Area }\end{array}$ & $\begin{array}{c}\text { Elevation } \\
\text { Change }\end{array}$ & N females \\
\hline 1 & $2362(353)^{2}$ & $1941(42)$ & 421 & 7 \\
2 & $2191(168)$ & $1779(25)$ & 412 & 4 \\
7 & $2102(21)$ & $1814(2)$ & 287 & 1 \\
West & $2299 \pm 189 \mathrm{~A}^{3}$ & $1878 \pm 199 \mathrm{~B}$ & 421 & 12 \\
\hline
\end{tabular}

${ }^{1}$ Excluding one deer that used an accessory area at higher elevation than its summer home range.

${ }^{2}$ Number of relocations in parentheses

${ }^{3}$ Value followed by different letters indicate significant differences according to Wilcoxon 2-sample test. 
Table 6.6. Comparison of average elevation ( $m$ ) of summer home ranges of adult females with and without early summer accessory areas (ESAA) on the west slope of the Bridger Mountains'.

\begin{tabular}{|c|c|c|c|c|c|}
\hline \multicolumn{3}{|c|}{ With ESAA } & \multicolumn{3}{|c|}{ Without ESAA } \\
\hline PHU & $\begin{array}{c}\text { No. } \\
\text { Females }\end{array}$ & $\overline{\mathrm{X}}$ Elevation & $\begin{array}{c}\text { No. } \\
\text { Females }\end{array}$ & $\overline{\mathrm{X}}$ Elevation & $\begin{array}{c}\text { Elevation } \\
\text { Difference }\end{array}$ \\
\hline 1 & 7 & $2362(353)^{2}$ & 17 & $2205(718)$ & 157 \\
\hline 2 & 4 & $2191(168)$ & 9 & $2078(464)$ & 113 \\
\hline 7 & 1 & $2101(21)$ & 8 & 2074 (141) & 27 \\
\hline West & 12 & $2299 \pm 189(542) A$ & 34 & $2146(1323) \mathrm{B}$ & 153 \\
\hline
\end{tabular}

'Excluding one deer that used an accessory area at a higher elevation than its summer home range.

${ }^{2}$ Number of relocations in parentheses

${ }^{3}$ Values followed by different letters indicate significant differences according to Wilcoxon 2-sample test.

Major vegetation cover types used on accessory areas in PHU 1 were types that were generally not preferred by adult females during summer (See Chapter 5). Shrub/grassland and mid-elevation closed canopy forest types accounted for $74 \%$ of the vegetation associated with female locations on accessory areas compared to only $29 \%$ for females remaining on their summer home ranges.

One female that annually used distinct summer and winter home ranges in PHU 2 also used an early summer accessory area, but in a different manner than the other 12 females on the west slope. During mid June of the first summer of observation, that 5 -year old female moved $2.1 \mathrm{~km}$ east across the Bridger Divide to an area $320 \mathrm{~m}$ higher than its summer home range. Two weeks later, she had returned to her normal summer home range in the company of two fawns. Use of the accessory area was not recorded during either of the following two summers; however, we were unable to ascertain the reproductive status either year.

Use of early summer accessory areas was not observed among the 10 females from PHUs 1, 2, and 7 that summered east of the Bridger Range Divide. Average elevation of those ranges was $2,139 \mathrm{~m}$, very similar to the average $2,126 \mathrm{~m}$ elevation for summer home ranges of the 24 females that summered west of the Divide and did not use accessory areas in early summer. 
Only 1 of the 47 adult females monitored on the east slope used an early summer accessory area. This ISR individual lived yearlong within the winter range on PHU 4. In the first two of the three years monitored, she ranged from mid May to mid June in a shrub-grassland draw located about $270 \mathrm{~m}$ higher and $6.0 \mathrm{~km}$ west of her normal home range. This accessory area apparently was not used during the third year, though she was known to have raised fawns that summer as well as in each of the preceding two years.

Overall, use of early summer accessory areas by the 14 females occurred during $63 \%$ of the 40 deer-summer seasons over which monitoring occurred. Only 5 of the 14 (36\%) used an accessory area during all consecutive years over which they were observed; the maximum was four consecutive years.

Time spent on early summer accessory areas varied among individuals and years. West slope females using these areas had previously occupied their summer home ranges for an average $18 \pm 11$ days $(\mathrm{N}=18$ time periods, 10 deer $)$ from mid May to early June. Average date of arrival on the early summer accessory area was 17 June \pm 12 days $(\mathrm{N}=23$ time periods, 13 deer). The average date of return to their summer home range was 17 July \pm 20 days $(\mathrm{N}=23$ time periods, 13 deer). The time females spent on early summer accessory areas corresponded closely to the 30-day period around fawning when dominant reproductive does are aggressive toward other deer (Ozoga et al. 1982). This may explain why adult females that used early summer accessory areas previously occupied their summer home ranges for about 18 days before the fawning period.

On the west slope, all females that used early summer accessory areas summered on high elevation ranges in relatively close proximity to winter ranges. These summer ranges supported relatively high deer densities. It is possible that the urge to leave winter ranges led females with nearby summer ranges to move as soon as those ranges "opened up" even though new growth at that elevation may not have advanced to the point where forage was capable of sustaining lactation. Thus, they were forced to move back to areas more favorable for fawning just prior to parturition.

Examples of "spacing" seemed evident in the ASR movement patterns of five adult females that concurrently used strongly overlapping winter and summer home ranges in PHU 1. Although the same habitats were exploited by all five, simultaneous relocations indicated that the distribution of use by individuals was localized, particularly during the early fawn-rearing period. To avoid undue complexity, the polarity of use among individuals is displayed for only two females (Fig. 6.9). In early June, deer No. 1077 (age 7 years) abandoned her summer home range which overlapped that of 1124 and descended $425 \mathrm{~m}$. in elevation to an early summer accessory area. She remained there with two fawns from 2 June through 7 July (relocation nos. 1-7). During that period, female 1124 (age 11 years) remained on the high elevation summer home range with her two fawns except for two relocations in June (nos. 1 and 3) at intermediate elevations above its winter home range. From mid July through late September (nos. 


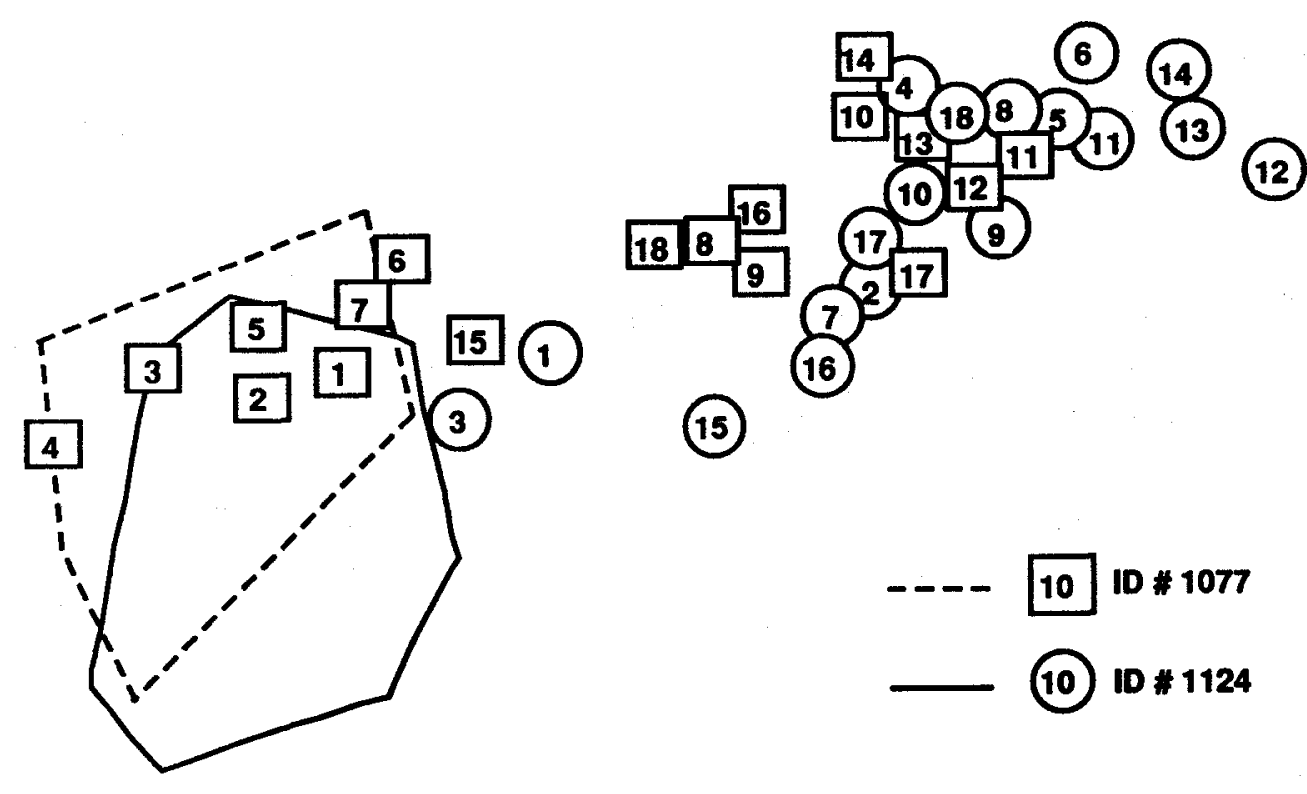

Figure 6.9. Consecutive weekly relocations between 1 June and 30 September 1978, for two adult females with overlapping seasonal home ranges. Relocations with same numbers were made on the same date about 10 minutes apart. Winter home ranges indicated by polygons.

8-18), spacing between these two individuals was much less pronounced as they commonly shared the same summer habitats.

Not shown in Fig. 6.9 were two other adult females (age 7 and 9 years) that spent the early fawn-rearing period on the high elevation summer home range they shared with female 1124. However, simultaneous relocations for each of these three does tended to be polarized within the total area inside their overlapping summer home ranges until midJuly. Reproductive status of the 9-year old female was unknown, and the 7-year old had twins. The fifth female (age 7 years) in this group had no fawns. It abandoned the high elevation summer home range between 22 June and 28 June and descended to an early summer accessory area included within the boundaries of its winter home range. This accessory area was adjacent to the accessory area used by no. 1077 (Fig. 6.9), but no overlap occurred.

Ozoga et al. (1982) reported that when suitable fawning sites were limited by high deer densities in preferred habitats, parturition territoriality forced younger subordinate members of matrilineal groups to shift use to more marginal sites. This occurred during 
the 4-week, post-partum period of aggression by dominant matriarchs. In our study, mean assigned age of adult females $(\mathrm{N}=12)$ using early summer accessory areas on the west slope was 7.8 compared to 6.5 for adult females $(\mathrm{N}=33)$ that did not use such areas.

Use of high elevation summer home ranges and low elevation early summer accessory areas by some adult females may have originated from the social interaction between subordinate and dominant individuals. When a young subordinate female was relegated to this type of movement pattern, she may have had little opportunity in subsequent years to achieve a more optimal pattern in a high density population with low turnover rates. This could explain the similarity in the mean age of descending and non-descending females.

These relationships between movement patterns, behavior, and habitat use indicate that mule deer may exhibit short-term territorial responses (Hamlin and Mackie 1989) similar to white-tailed deer (Ozoga et al. 1982) and black-tailed deer (Odocoileus hemionus columbianus) (Miller 1974) and may be less gregarious than indicated by de Vos et al. (1967).

Changes in distribution and use of accessory areas during parturition were much less frequent on the east slope of the Bridger Mountains. There, deer were able to escape the "bottleneck" of deer density on and around the winter range at an earlier date than on the west slope where significant "bottlenecks" sometimes occurred through the parturition period. As indicated earlier, the significantly lower average elevations and more gentle relief of east slope summer ranges resulted in more rapid plant development over the entire population unit. Thus, a greater proportion of the population may have had the opportunity to achieve optimal spacing before fawning.

Use of early summer accessory areas by adult males was limited to 2 of 16 individuals $(13 \%)$ on the west slope. However, the pattern of use was different from females. One used a summer home range in PHU 1 that included middle elevations used extensively by adult females. In mid June 1977 , this buck moved $4.0 \mathrm{~km}$. east of his summer home range to an area located $490 \mathrm{~m}$ higher and remained there for two weeks before returning. The other male (No. 1240) described earlier in Fig. 6.7 used a series of accessory areas including one in early summer.

\section{Late Summer Accessory Areas}

Late summer accessory areas were used by $8(9 \%)$ of the 94 adult females monitored. All but one occurred in PHUs 3, 4, and 6 (Table 6.2). This use coincided with desiccation and killing frosts which reduced the availability of green, succulent forage during late summer. Most deer were able to locate alternative sources of forage inside the boundaries of their summer home ranges. However, some individuals moved to late summer accessory areas located 5.0 to $14.0 \mathrm{~km}$. from their summer home ranges 
in an apparent response to shortages of succulent forage. The average date of movement on the east slope was September $25 \pm 13$ days $(\mathbf{N}=15)$. Late summer accessory areas often occurred in proximity to alfalfa fields or riparian communities or in areas of greater topographic complexity that offered more mesic sites than occurred on the summer home range.

Summer home ranges of females with late summer accessory areas were heavily grazed by cattle or sheep. They were generally located in areas of low topographic complexity and gentle relief that provided few alternative sources of forage. Hamlin and Mackie (1989) also found use of autumn accessory areas by mule deer with summer ranges in areas of low topographic relief and moderate to heavy grazing by cattle. Those deer moved to areas of higher relief and less cattle use.

Six of the seven late summer accessory areas on the east slope were located along the movement corridor connecting seasonal home ranges. The average elevation of these six areas was $225 \mathrm{~m}$ lower than the summer home range and $150 \mathrm{~m}$ above the winter home range.

The seventh east slope female used a late summer accessory area located $6.0 \mathrm{~km}$ west of its summer home range (Fig. 6.10). During three successive years, this female (No. 4026) abandoned her summer home range, located in upper Miles Creek, coincident with the arrival of more than 1,000 sheep in late August-early September. The accessory area, located in upper Slushman Creek, was about $140 \mathrm{~m}$ higher in elevation than her summer home range and consisted of lush grass-forb meadows interspersed with stands of mature timber that were essentially inaccessible to livestock. This area was occupied until mid-late October.

All adult females with late summer accessory areas on the east slope displayed DSR movement patterns except for one female with an ISR pattern in PHU 3. The latter moved to an alfalfa field located $5 \mathrm{~km}$ from its home range during September in three consecutive years.

The only adult female with a late summer accessory area on the west slope followed an ISR movement pattern in PHU 1. During 1980, she spent the entire year on her normal home range in lower Tom Reese Creek. For the next 4 years, during late July-early August, she moved $6.2 \mathrm{~km}$ east to an accessory area located east of the Bridger Divide in Frazier Creek. She remained on the accessory area until mid-October.

Overall, use of late summer accessory areas was recorded during $78 \%$ of 23 summer seasons of monitoring the eight females. Some used the areas during consecutive summers, others only in certain years.

Five (31\%) of 16 adult males monitored on the west slope used late summer accessory areas. Two moved from summer home ranges in the foothills to high elevation 
LATE SUMMER ACCESSORY AREA
SUMMER
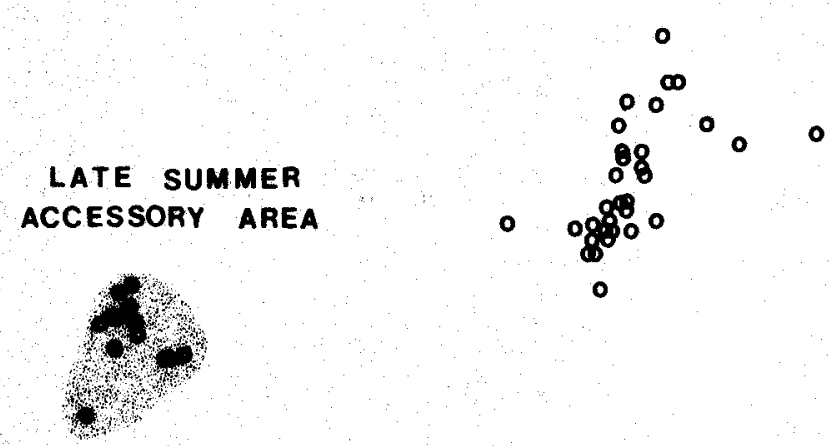

WINTER

$\circ$

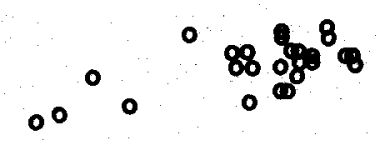

$80 \quad 0$

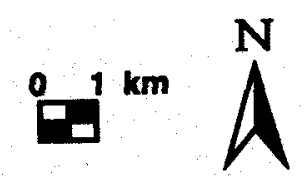

Figure 6.10. All relocations of adult female No. 4026 displaying a DSR movement pattern and a late summer accessory area in PHU 4.

basins in August. Two others moved lower to agricultural fields on the Gallatin Valley floor in mid-late summer. The fifth, described earlier (Fig. 6.7), used a series of seasonal accessory areas including one in late summer.

Spatial Relationships Between Males and Females

Distributional relationships between males and females within PHU 1 were compared based on their relative occurrence within $1 \mathrm{~km}^{2}$ grid-cells occupied by deer. A "cell" was considered deer habitat and included in the analysis for a particular season if it contained one or more telemetry relocations within the 10-year monitoring period. Relocations were primarily of mature deer, although limited numbers of relocations of yearlings were included.

During summer, cells were identified from 1,043 female and 289 male relocations. Seventy-nine cells were occupied. Mature males and females were recorded in 23 cells, males only in 24 , females only in 28 , and yearlings only in 4 cells. The distribution of mature males and females was significantly different $\left(X^{2}=13.48\right.$, df $=$ $1, \mathrm{p}=0.000$ ) 
Spatial separation of the sexes in summer was consistent with observed patterns of use of vegetation cover types. Although several important vegetation types were preferred by both sexes, about one third of all male relocations occurred in major vegetation zones which received minor use by females. However, general similarities in cover type use would not negate the conclusion that spatial separation of the sexes occurred in summer. Males were more widely distributed than females and made greater use of habitat at elevations above and below that used by females. They also occurred in aggregations within voids in the female distribution.

Sexual segregation was less evident during winter than summer. In winter, 741 female and 114 male relocations were recorded in 26 cells. Both mature males and females were observed in 11 cells, mature males only in 9 , mature females only in 4 , and yearlings only in 2. A continuity adjusted $\mathrm{X}^{2}$ (used because of low sample size), indicated no difference $\left(\mathrm{X}^{2}=1.28, \mathrm{df}=1, \mathrm{p}=0.258\right)$ in winter distribution of the sexes.

Use of vegetation types was also very similar, although other data on distribution by elevation in early winter indicated some sexual segregation occurred during periods when greater choice of habitats was possible. Opportunity for separation usually was reduced by greater concentration of deer in mid and late winter.

\section{Monthly Mobility}

Monthly average activity radii (MAAR) were calculated according to a procedure developed by Dusek and Wood (1986). MAAR provided indices of mobility useful for general comparisons between populations, habitats, sexes, and movement patterns. First, a geographic activity center (GAC) was calculated for each deer from all relocations for a particular month irrespective of year. We then calculated the activity radius (AR) or distance of each relocation to the monthly GAC. Monthly ARs were pooled for each deer movement category or population, and monthly averages (MAAR) were computed for all months and categories.

MAAR for adult females varied somewhat similarly in PHUs 1, 2, and 7 (Fig. 6.11). In each population, spring and autumn peaks corresponded to movement between seasonal ranges and were flanked by periods of lower and more stable MAAR during winter and summer.

Significant differences in MAAR between the three units (Fig. 6.11) resulted from variation in the timing of movement between seasonal ranges. In PHU 7, movement toward summer ranges during April-June resulted in a bimodal pattern of monthly mobility caused by the ASR individuals moving in April and DSR deer generally moving in June. Nearly all females in PHU 2 moved to summer ranges in May while spring movement in PHU 1 spanned May and June. 


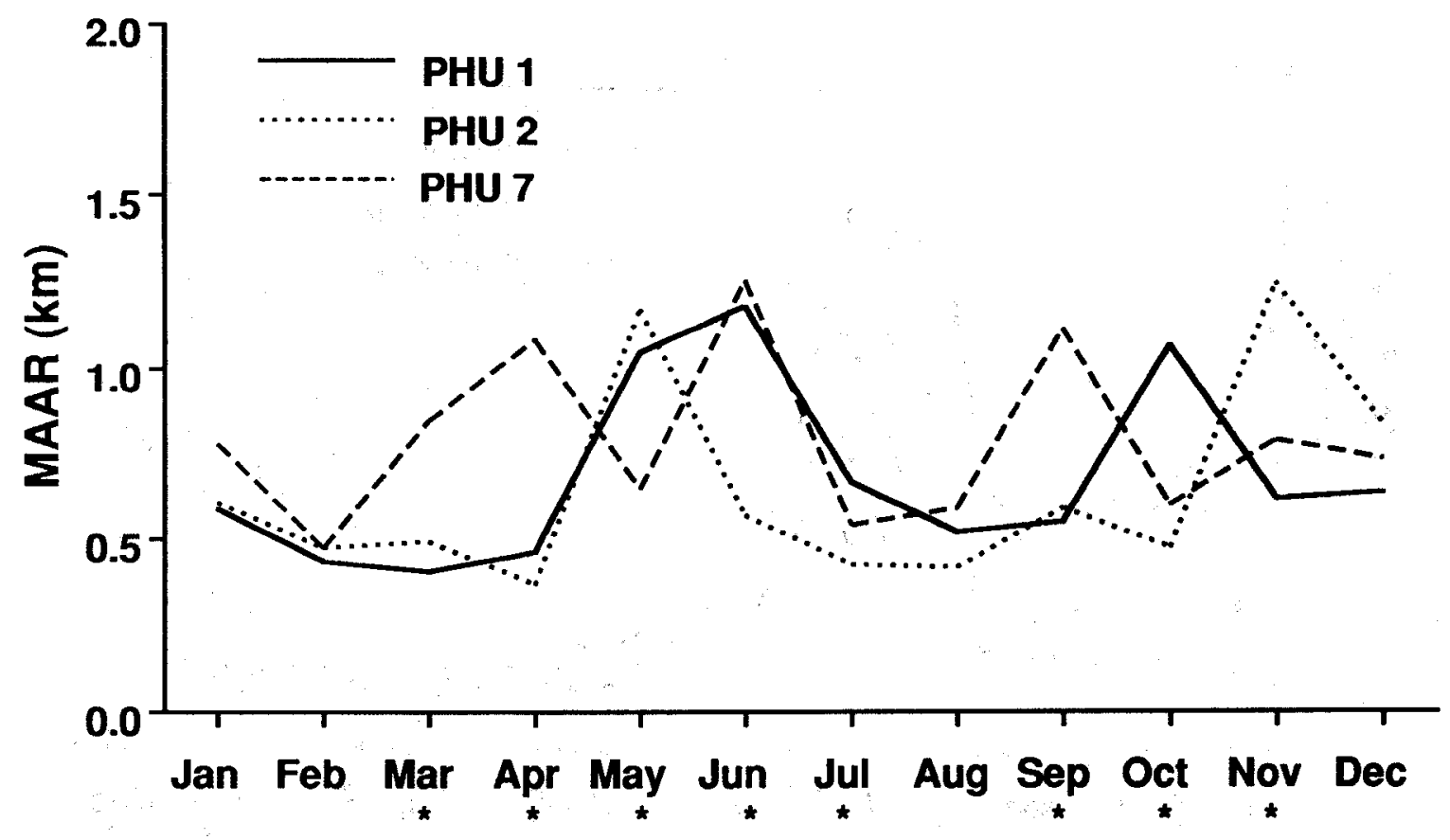

Number of Activity Radii

$\begin{array}{rrrrrrrrrrrrr}\text { PHU 1 } & 296 & 340 & 556 & 889 & 423 & 267 & 245 & 204 & 186 & 214 & 147 & 187 \\ \text { PHU 2 } & 144 & 122 & 92 & 136 & 140 & 164 & 154 & 131 & 118 & 128 & 106 & 84 \\ \text { PHU 7 } & 27 & 18 & 32 & 54 & 44 & 43 & 28 & 25 & 32 & 27 & 36 & 18\end{array}$

Figure 6.11. Monthly average activity radii for adult female mule deer in three west slope PHUs. Asterisk indicates significant difference in MAAR between three populations, $\mathrm{P} \leq 0.05$, one-way ANOVA.

Autumn movement to winter ranges in PHU 7 occurred as early as September for DSR deer with summer home ranges east of the Bridger Divide. However, nearly half of all deer in PHU 7 summered just above the winter range on the west slope (ASR deer) and gradually moved down during November and December. In PHU 1, the October peak in MAAR reflected movement toward the winter range by DSR individuals that crossed the Bridger Divide or summered at highest elevations on the west slope. A similar pattern occurred in PHU 2, though the peak in autumn movement occurred one month later.

Deer in the four PHUs on the east slope displayed greater variation in the magnitude of monthly movements (Fig. 6.12) than deer on the west slope (Fig. 6.11). Significant differences among east slope PHUs were more common during autumn and winter than during spring and summer. Mobility generally declined from January to March in all but PHU 6 where movement increased during March as some deer left the 


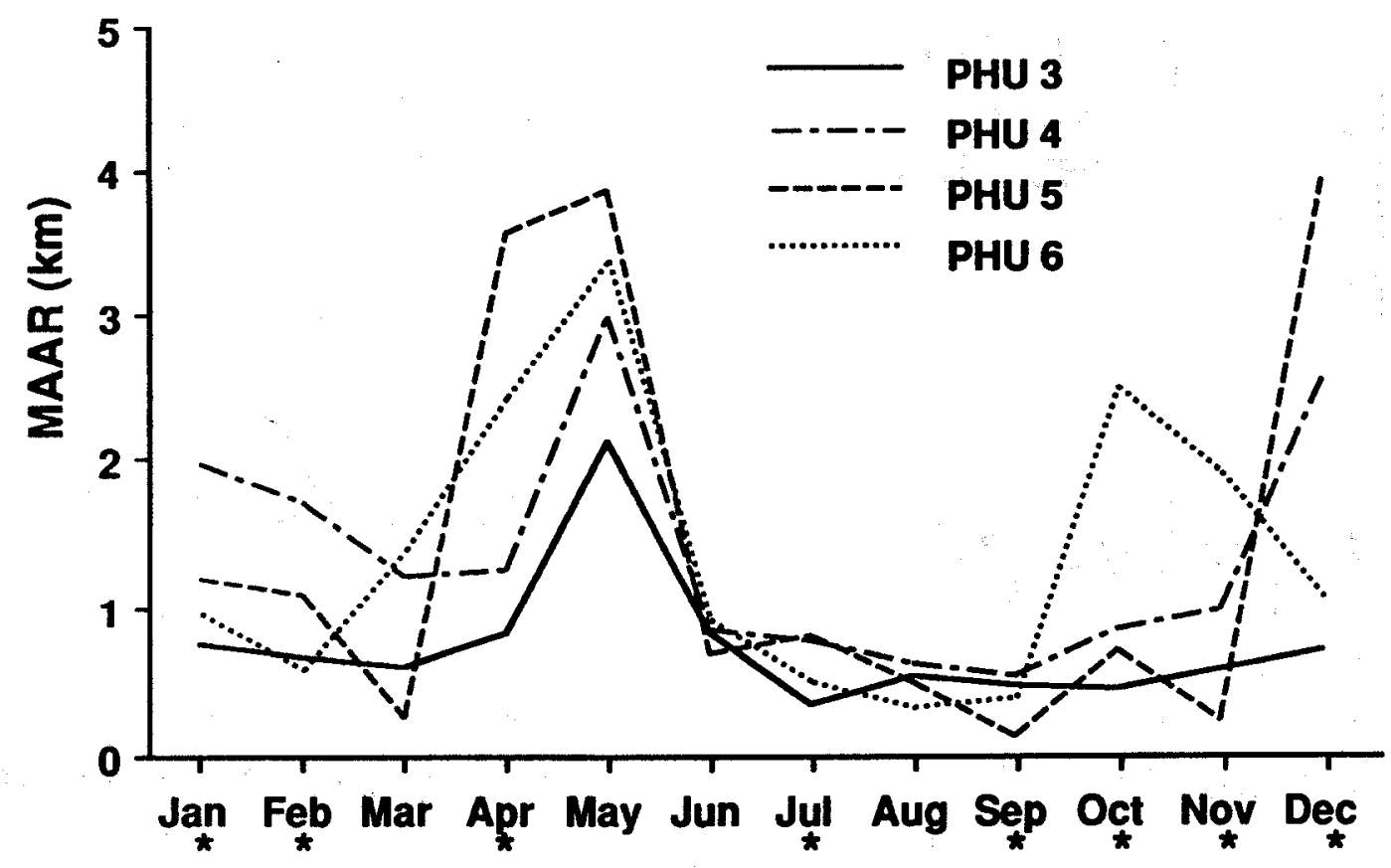

\section{Number of Activity Radii}

$\begin{array}{rrrrrrrrrrrrr}\text { PHU 3 } & 27 & 19 & 18 & 53 & 45 & 43 & 38 & 13 & 24 & 32 & - & 19 \\ \text { PHU 4 } & 98 & 115 & 89 & 92 & 146 & 92 & 103 & 98 & 100 & 97 & 93 & 64 \\ \text { PHU 5 } & 14 & 21 & 5 & 38 & 29 & 19 & 17 & 19 & 11 & 19 & 14 & 17 \\ \text { PHU 6 } & 27 & 25 & 53 & 75 & 62 & 52 & 49 & 36 & 38 & 37 & 50 & 25\end{array}$

Figure 6.12. Monthly average activity radii for adult female mule deer in four east slope PHUs. Asterisk indicates significant differences in MAAR between four populations, $P \leq 0.05$, one-way ANOVA test.

winter range earlier than deer in any other unit. However, larger MAARs associated with deer leaving the PHU 6 winter range spanned a three-month period and reached a peak in May. MAARs in the other three populations also peaked in May, but the period of increased activity associated with departure from the winter ranges was shorter than for PHU 6.

Summer months were characterized by a low and stable pattern of mobility common to all four east slope populations. Autumn was characterized by greater variation among units than occurred in spring. In PHU 3, the MAAR for October was similar to that for the preceding summer months while the other three populations experienced increased MAAR in October. This was particularly evident in PHU 6 where 
peak movement toward winter range occurred two months earlier than in other east slope populations.

MAAR for adult females were pooled and compared among the three west slope and four east slope units (Fig. 6.13). Females on the east slope had higher MAAR during winter (January-March) than summer (June-September months). In contrast, MAAR for west slope females were similar during the two seasons. During January-March, MAAR for adult females were more than twice as large on the east compared to the west slope (Fig. 6.13).

Increases in MAAR during April and May were associated with movement toward summer ranges which began and ended one month earlier on the east slope than on the west slope. Very similar levels of mobility were characteristic during June, July and August when most females were sedentary on summer home ranges. September was the

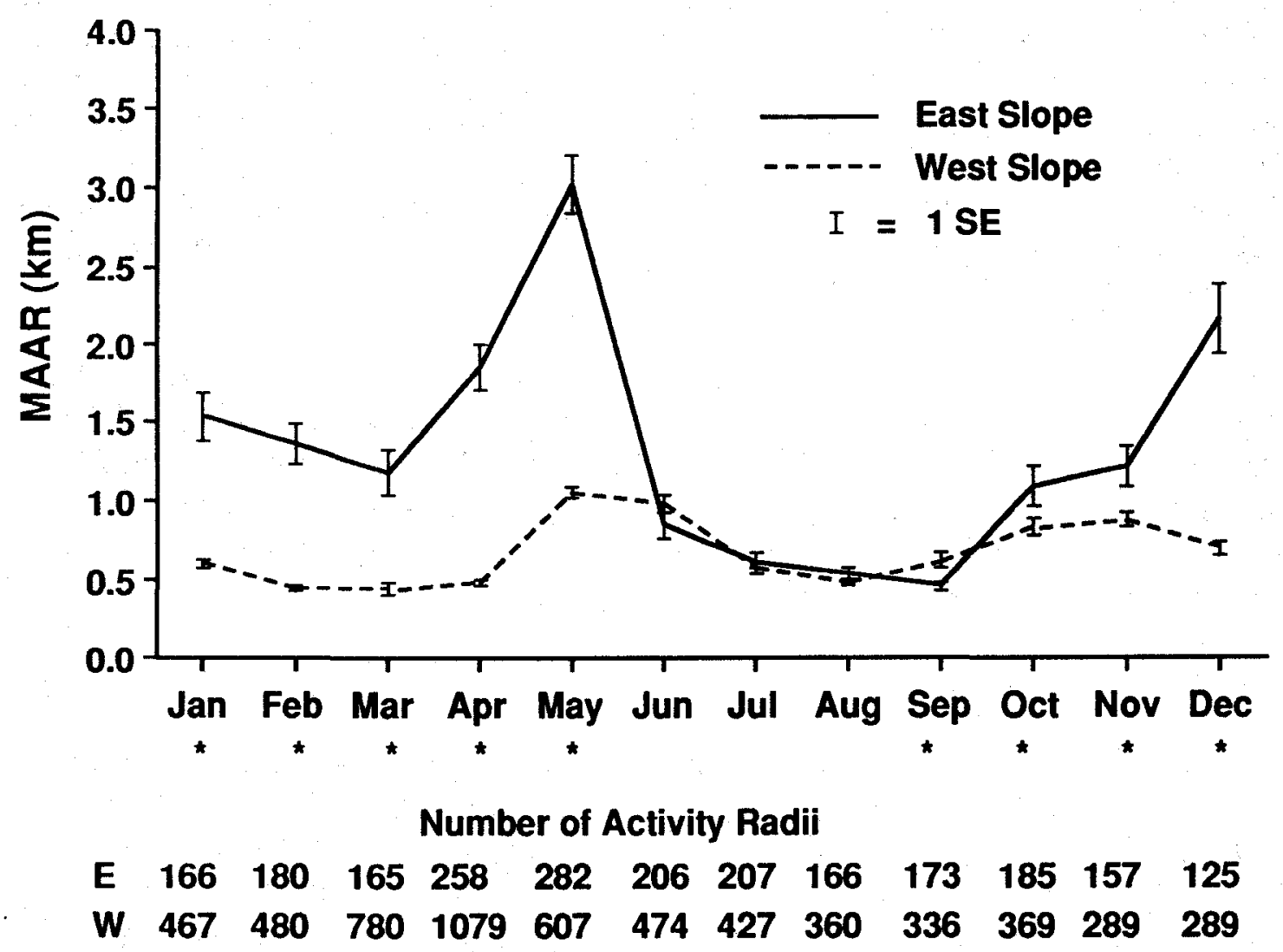

Figure 6.13. A comparison of monthly average activity radii for adult females on the West (PHU 1, 2, 7) and East (PHU 3, 4, 5, 6) slopes. Asterisk indicates significant differences in MAAR between areas, $P \leq 0.05$, one-way ANOVA. 
only month when the MAAR was significantly larger (1-way Anova, $F=6.43, P=$ 0.011 ) for west than for east slope females. This was related to early movement toward winter ranges by some individuals using summer habitats east of the Bridger Divide in PHUs 1, 2 and 7. During autumn, mobility levels began to diverge in October, peaking in November on the west slope and December on the east. In analysis, it was difficult to separate relative effects of weather, hunting, and breeding on deer mobility patterns during autumn. However, general observations indicated that weather patterns exerted primary influence.

Larger MAAR for east slope deer during spring and autumn reflected the greater distances separating seasonal ranges. Significantly lower monthly mobility during winter among west slope deer was related to the sedentary strategy of winter habitat use that best suited the greater snowfall that typically occurred on those ranges.

The similarity between MAAR for east and west slope females during summer may have been related to several factors. At least $75 \%$ of all females radio tracked in summer used montane forest habitats of generally similar structure and species composition. Most were also involved in fawn-rearing which would elicit similar resource requirements as indicated by preference for similar vegetation types. Such convergence in habitat use, movement, and activity patterns across the area would be less likely during other seasons when environmental constraints overrode deer preferences. Under the restricted conditions of winter, the differences in the physical and vegetative characteristics of east and west slope winter ranges resulted in divergent patterns of movement and habitat use.

During summer, some deer occupied distinctly different vegetation communities within the same population/habitat unit. For example, some adult females in PHU 4 exclusively used either the steppe or montane forest and others had home ranges that overlapped the ecotone between these two types. However, MAAR for June-September were not significantly different for adult females occupying vegetation communities with differences in structure and species composition (Table 6.7).

Variation in Mobility Between Sexes

Patterns of monthly mobility in adult males and females were compared only in PHU 1 (Fig. 6.14). Males were significantly more mobile than females during February, March, April, August, November, and December. Most differences were among deer with the ASR movement pattern. Bucks with adjacent seasonal ranges had significantly larger MAAR $(P \leq 0.01)$ than females (Fig. 6.15) during all months except May, June, September, and October $(\mathrm{P}>0.07)$.

The greater mobility of ASR males may have been related to a higher frequency of intra-seasonal movement to their summer home ranges during intermittent periods of mild weather in winter and early spring. Summer home ranges of ASR males were 
Table 6.7. Monthly average activity radii (MAAR) for adult females occupying different vegetation types during summer in PHU 4.

\begin{tabular}{lcc|ccccccc}
\hline & Steppe & \multicolumn{2}{c|}{$\begin{array}{c}\text { Steppe-Forest } \\
\text { Ecotone }\end{array}$} & \multicolumn{2}{c|}{ Montane Forest } & \multicolumn{2}{c}{ ANOVA } \\
\hline \multicolumn{1}{c}{ Month } & $\mathrm{N}^{1}$ & MAAR+Sx & $\mathrm{N}$ & MAAR+Sx & $\mathrm{N}$ & MAAR+Sx & F-Value & Pr > F \\
\hline June & 35 & $0.88 \pm 1.18$ & 12 & $0.31 \pm 0.18$ & 45 & $0.94 \pm 1.28$ & 1.46 & 0.24 \\
July & 40 & $0.62 \pm 0.34$ & 16 & $0.80 \pm 1.06$ & 47 & $0.84 \pm 1.12$ & 0.74 & 0.48 \\
August & 31 & $0.48 \pm 0.36$ & 15 & $0.39 \pm 0.32$ & 52 & $0.76 \pm 1.07$ & 1.78 & 0.17 \\
September & 34 & $0.47 \pm 0.41$ & 17 & $0.53 \pm 0.32$ & 49 & $0.56 \pm 0.30$ & 0.68 & 0.51 \\
No. Females & 5 & & 3 & & 7 & & & \\
\hline
\end{tabular}

${ }^{1} \mathrm{~N}=$ Number of activity radii

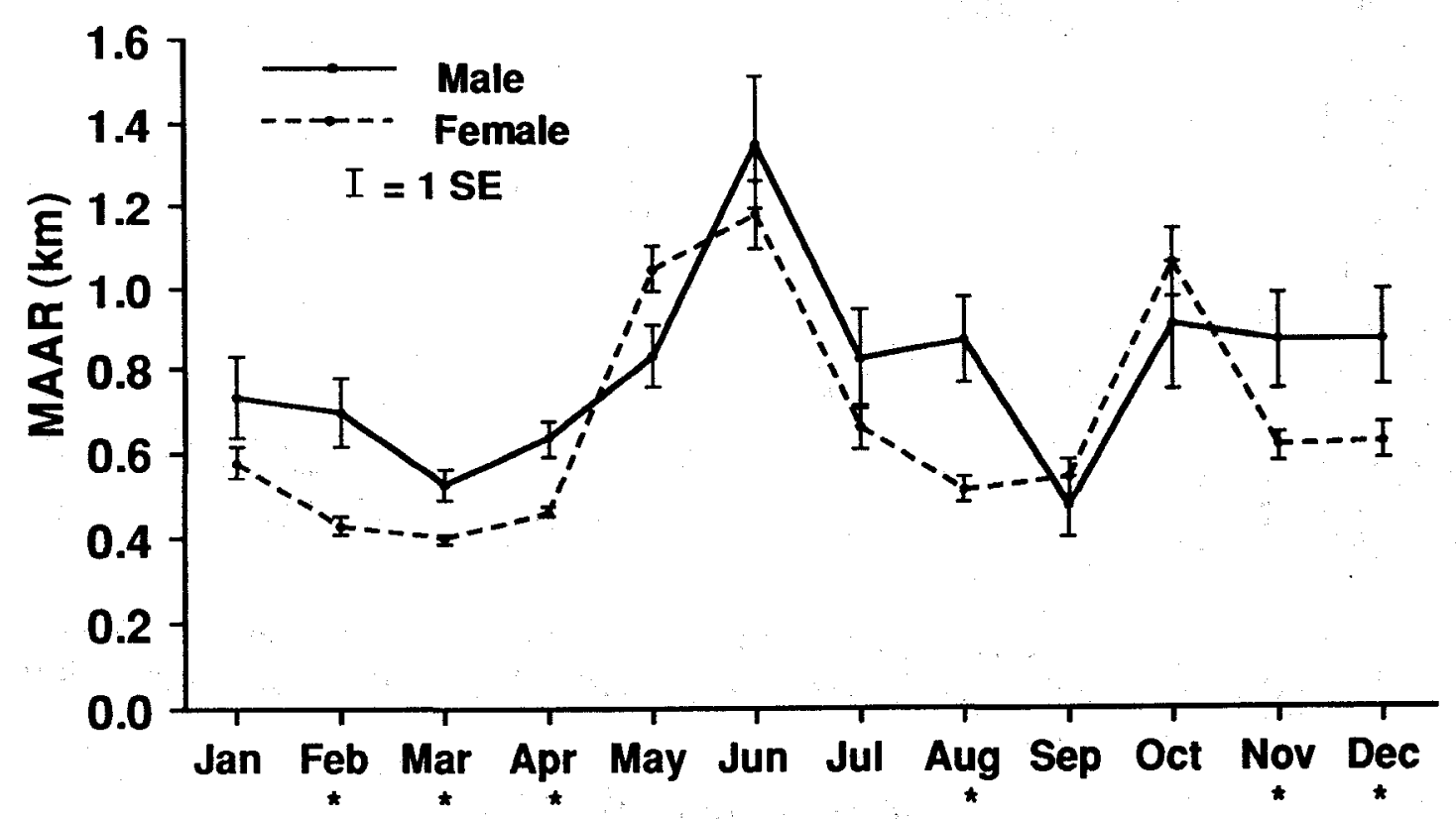

Number of Activity Radii

$\begin{array}{lrrrrrrrrrrrr}\text { Males } & 43 & 73 & 103 & 144 & 105 & 65 & 68 & 50 & 42 & 52 & 32 & 31 \\ \text { Females } 296 & 340 & 556 & 889 & 423 & 267 & 245 & 204 & 186 & 214 & 147 & 187\end{array}$

Figure 6.14. A comparison of monthly average activity radii between females and males in PHU 1. Asterisk indicates significant differences in MAAR between sexes, $P \leq 0.05$, one-way ANOVA. 
located in the lower portions of major canyons immediately adjacent to the upper winter range boundary. These areas were more likely to become accessible during periods of snow melt than the summer home ranges of ASR females which were predominantly located in the middle to upper portions of nearby canyons at elevations averaging $150 \mathrm{~m}$ higher than ASR males.

Four of the six ASR bucks made extensive use of early and late summer accessory areas located $2-4 \mathrm{~km}$. from their summer home ranges. These movements resulted in significantly larger MAAR for males during July and August (Fig. 6.15). Significantly larger MAAR for ASR males during November and December was apparently related to their greater activity and movement during the breeding season.

DSR males and females had very similar MAAR $(P>.09)$ during all months except May (Fig. 6.16). The larger MAAR $(P=0.04)$ for $D S R$ females during May resulted from earlier departure from the winter range.

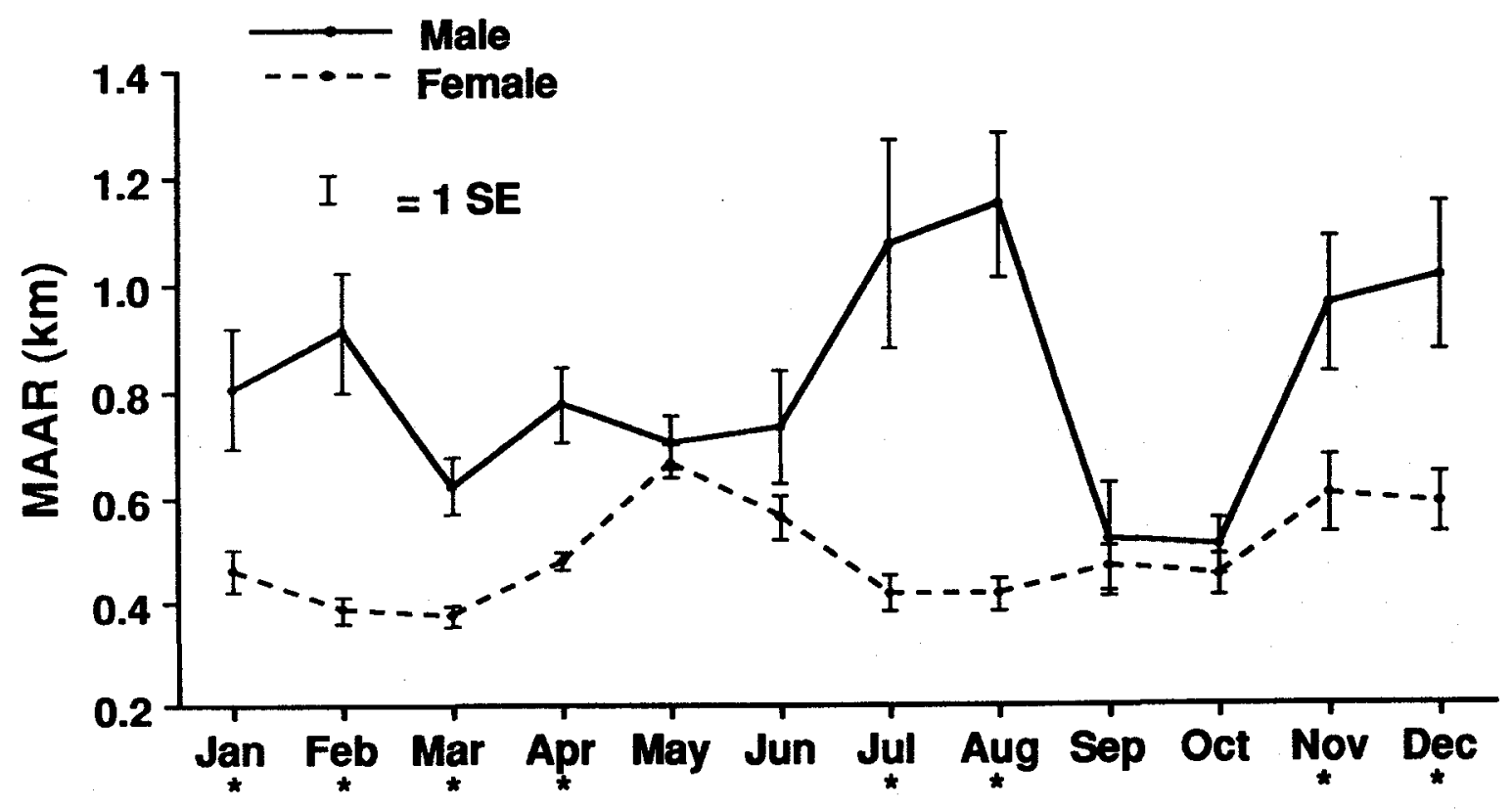

\begin{tabular}{rrrrrrrrrrrrr} 
& \multicolumn{11}{c|}{ Number of Activity Radii } \\
Male & 35 & 48 & 64 & 66 & 65 & 35 & 38 & 33 & 27 & 33 & 22 & 24 \\
Female & 83 & 101 & 154 & 256 & 148 & 76 & 66 & 52 & 46 & 60 & 43 & 56
\end{tabular}

Figure 6.15. A comparison of monthly average activity radii for males and females with adjacent seasonal ranges (ASR) in PHU 1. Asterisks indicate significant differences in MAAR between sexes, $\mathrm{P} \leq 0.05$, one-way ANOVA. 


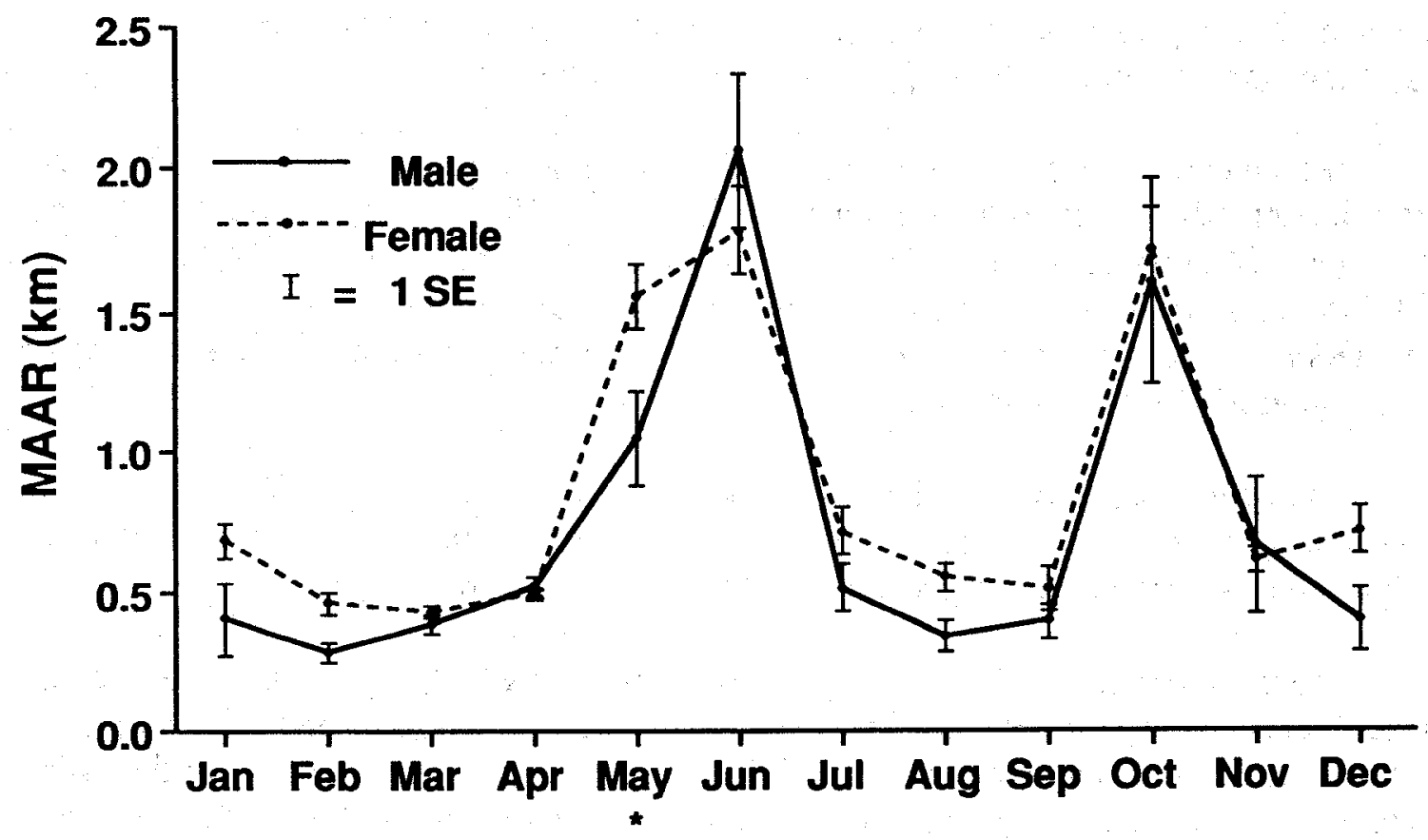

Number of Activity Radii

$\begin{array}{ccccccccccccc}\text { Male } & 8 & 25 & 39 & 78 & 40 & 30 & 30 & 17 & 15 & 19 & 10 & 7 \\ \text { Female 144 } & 135 & 254 & 409 & 189 & 126 & 120 & 99 & 90 & 101 & 69 & 83\end{array}$

Figure 6.16. A comparison of monthly average activity radii for males and females with distinct seasonal ranges (DSR) in PHU 1. Asterisk indicates significant differences between sexes, $\mathrm{P} \leq 0.05$, one-way ANOVA.

Seasonal Home Range Size and Mobility

Temporal variation in movement of individual deer prevented use of standardized calendar dates to define seasons for analysis of seasonal home range size and mobility. Instead, the entire set of relocations for each individual was plotted to logically identify its seasonal movement pattern. Each relocation was then classified and assigned a code indicating the seasonal home range represented. Only $0.5 \%$ of all relocations could not be classified and were excluded.

Mean seasonal maximum convex polygons and average activity radii (AAR) were computed only for deer following ASR and DSR movement patterns. Yearlong home range size was estimated only for ISR deer which, by definition, did not have identifiable seasonal ranges. Calculations aggregated all relocations of individuals over all years on a particular seasonal range. The average winter home range in PHUs 1, 2, and 4 aggregated relocations for 5.5 (range 2-10) years, whereas the average summer range 
included 3.2 (range 2-9) years. Averages for PHUs 3, 5, 6, and 7 aggregated 3.1 (range 2-4) years for winter and 2.9 (range 2-4) years for summer.

Estimates of seasonal home range size and mobility among the 7 PHUs were stratified according to intensity of sampling. Deer in PHUs 1, 2, and 4 were relocated an average 62 times/season overall (Tables 6.8 and 6.9), whereas deer in PHUs 3, 5, 6, and 7 were relocated an average of only 18 times/season (Table 6.10). Statistical comparisons of seasonal home range parameters were drawn only within sampling strata (e.g., among PHUs 1, 2, and 4).

The data, collectively, indicated a broad and variable spectrum of home range sizes and mobility among seasons, deer following different movement patterns, PHUs, and between west and east slope ranges (Tables 6.8, 6.9, and 6.10).

There were no consistent differences by season. In PHU 1, polygon home ranges of adult females were significantly smaller $(P=0.05)$ in summer than in winter, but seasonal AARs were not different $(P>0.36)$. In PHU 2, females following the ASR movement pattern had nearly identical polygon home ranges and AARs for summer and winter; whereas DSR females had significantly larger $(P<0.02)$ home ranges and AARs in summer than in winter. The only other significant seasonal differences occurred in PHU 6 (Table 6.10) where both polygon home range and AAR were smaller in summer as compared to winter.

There also were no detectable differences in home range size or mobility of adult males between seasons (Table 6.9) The only difference in home range parameters between males and females was a larger AAR for males in winter (Table 6.11).

Data were adequate to compare home range and mobility between females following ASR and DSR movement patterns only in PHU 1. During summer, convex polygons were similar in size $(P=0.13)$. AAR were also similar $(P=0.29)$. During winter, the two groups also used similar sized polygons $(P=0.06)$, but DSR deer exhibited larger AARs $(P=0.007)$.

Statistical comparison of seasonal home range size and mobility among PHUs was limited to DSR females in PHUs 1, 2, and 4 (Table 6.12). During summer, seasonal home range size and AAR were significantly larger in PHU 4 than PHU 2. Home range size and AAR were generally larger in PHU 4 than PHU 1, but differences were not significant. Deer in PHUs 1 and 2 had similar home range sizes, but AAR were significantly larger in PHU 1. In winter, like summer, home range size in PHU 4 was significantly larger than in PHU 2, but not as compared with PHU 1, even though the mean in PHU 1 was slightly more than half that for PHU 4. AARs differed significantly among all units in winter, being smallest in PHU 2 and largest in PHU 4. 
Table 6.8. Seasonal polygon home range size $\left(\mathrm{km}^{2}\right)$ and average activity radii $(\mathrm{Km})$ for adult female mule deer following three movement patterns in PHUs 1,2 , and $4(\bar{X}=$ 62 relocations/season/deer).

\begin{tabular}{|c|c|c|c|c|c|}
\hline PHU & $\begin{array}{c}\text { Movement } \\
\text { Pattern }\end{array}$ & No. Deer & $\begin{array}{c}\text { No. } \\
\text { Relocations }\end{array}$ & $\begin{array}{c}\text { Home Range } \\
\text { Size } \\
\overline{\mathrm{X}} \pm 1 \mathrm{SD} \\
\end{array}$ & $\mathrm{AAR} \pm 1 \mathrm{SD}$ \\
\hline \multicolumn{6}{|c|}{ Summer } \\
\hline 1 & $\begin{array}{l}\text { ASR } \\
\text { DSR }\end{array}$ & $\begin{array}{l}11 \\
10\end{array}$ & $\begin{array}{l}50 \pm 22 \\
46 \pm 24\end{array}$ & $\begin{array}{l}1.60 \pm 0.48^{*} \\
1.94 \pm 0.59^{*}\end{array}$ & $\begin{array}{l}0.54 \pm 0.17 \\
0.57 \pm 0.11\end{array}$ \\
\hline 2 & $\begin{array}{l}\text { ASR } \\
\text { DSR }\end{array}$ & $\begin{array}{l}3 \\
9\end{array}$ & $\begin{array}{l}55 \pm 33 \\
59 \pm 19\end{array}$ & $\begin{array}{l}0.89 \pm 0.18 \\
1.77 \pm 0.89 *\end{array}$ & $\begin{array}{l}0.35 \pm 0.05 \\
0.45 \pm 0.08 *\end{array}$ \\
\hline 4 & $\begin{array}{l}\text { ASR } \\
\text { DSR } \\
\end{array}$ & $\begin{array}{l}2 \\
9 \\
\end{array}$ & $\begin{array}{l}56 \pm 26 \\
45 \pm 15 \\
\end{array}$ & $\begin{array}{l}5.99 \pm 3.94 \\
3.14 \pm 1.28 \\
\end{array}$ & $\begin{array}{l}0.75 \pm 0.13 \\
0.68 \pm 0.21\end{array}$ \\
\hline \multicolumn{6}{|c|}{ Winter } \\
\hline 1 & $\begin{array}{l}\text { ASR } \\
\text { DSR }\end{array}$ & $\begin{array}{l}11 \\
12\end{array}$ & $\begin{array}{c}117 \pm 40 \\
85 \pm 61\end{array}$ & $\begin{array}{l}2.08 \pm 0.39 \\
2.77 \pm 1.01\end{array}$ & $\begin{array}{l}0.45 \pm 0.05 \\
0.54 \pm 0.08\end{array}$ \\
\hline 2 & $\begin{array}{l}\text { ASR } \\
\text { DSR }\end{array}$ & $\begin{array}{l}3 \\
7\end{array}$ & $\begin{array}{l}46 \pm 15 \\
60 \pm 6\end{array}$ & $\begin{array}{l}0.87 \pm 0.31 \\
0.84 \pm 0.28\end{array}$ & $\begin{array}{l}0.34 \pm 0.31 \\
0.29 \pm 0.05\end{array}$ \\
\hline 4 & $\begin{array}{l}\text { ASR } \\
\text { DSR } \\
\end{array}$ & $\begin{array}{l}1 \\
7 \\
\end{array}$ & $\begin{array}{l}30 \\
30 \pm 6 \\
\end{array}$ & $\begin{array}{l}5.15 \\
5.01 \pm 3.28 \\
\end{array}$ & $\begin{array}{l}0.84 \\
1.01 \pm 0.50\end{array}$ \\
\hline \multicolumn{6}{|c|}{ Yearlong } \\
\hline 1 & ISR & 1 & 104 & 3.76 & 0.62 \\
\hline 2 & ISR & 2 & $100 \pm 33$ & $2.33 \pm 0.56$ & $0.56 \pm 0.06$ \\
\hline 4 & ISR & 3 & $66 \pm 19$ & $11.60 \pm 4.99$ & $1.08 \pm 0.25$ \\
\hline
\end{tabular}

$*$ = summer home range size estimate is significantly different $(P \leq 0.05)$ than the comparable winter value for the same movement pattern. Test results based on Wilcoxon 2-sample test. 
Table 6.9. Seasonal polygon home range size $\left(\mathrm{km}^{2}\right)$ and average activity radii $(\mathrm{Km})$ for adult male mule deer with two movement patterns in PHU 1.

\begin{tabular}{lccccc}
\hline Season & $\begin{array}{c}\text { Movement } \\
\text { Pattern }\end{array}$ & $\begin{array}{c}\text { No. } \\
\text { Deer }\end{array}$ & $\begin{array}{c}\text { No. } \\
\text { Relocations }\end{array}$ & $\begin{array}{c}\text { Home Range Size } \\
\overline{\mathrm{X}} \pm \text { 1SD }\end{array}$ & $\begin{array}{c}\text { AAR } \\
\mathrm{X} \pm 1 S D\end{array}$ \\
\hline \multirow{2}{*}{ Summer } & ASR & 3 & $41 \pm 14$ & $3.09 \pm 1.06$ & $0.64 \pm 0.07$ \\
& DSR & 2 & $24 \pm 4$ & $1.37 \pm 0.43$ & $0.46 \pm 0.01$ \\
\hline \multirow{2}{*}{ Winter } & ASR & 5 & $47 \pm 18$ & $2.58 \pm 0.56$ & $0.62 \pm 0.06$ \\
& DSR & 3 & $39 \pm 6$ & $2.31 \pm 0.34$ & $0.55 \pm 0.10$ \\
\hline
\end{tabular}

Table 6.10. Seasonal polygon home range size $\left(\mathrm{km}^{2}\right)$ and average activity radii $(\mathrm{km})$ for adult female mule deer following three movement patterns in PHUs 3, 5, 6, and 7 ( $\overline{\mathrm{X}}=$ 18 relocations/season/ deer).

\begin{tabular}{|c|c|c|c|c|c|}
\hline PHU & $\begin{array}{c}\text { Movement } \\
\text { Pattern }^{2}\end{array}$ & $\begin{array}{l}\text { No. } \\
\text { Deer }\end{array}$ & $\begin{array}{c}\text { No. } \\
\text { Relocations }\end{array}$ & $\begin{array}{c}\text { Home Range } \\
\text { Size } \\
\overline{\mathrm{X}} \pm 1 \mathrm{SD}\end{array}$ & $\begin{array}{c}\text { AAR } \\
\overline{\mathrm{X}} \pm 1 \mathrm{SD} \\
\end{array}$ \\
\hline \multicolumn{6}{|c|}{ Summer } \\
\hline $\begin{array}{l}3 \\
5 \\
\\
6 \\
7\end{array}$ & $\begin{array}{l}\text { DSR } \\
\text { ASR } \\
\text { DSR } \\
\text { DSR } \\
\text { ASR } \\
\text { DSR } \\
\end{array}$ & $\begin{array}{r}7 \\
1 \\
3 \\
13 \\
5 \\
3 \\
\end{array}$ & $\begin{array}{l}17 \pm 4 \\
16 \\
21 \pm 7 \\
20 \pm 4 \\
22 \pm 4 \\
12 \pm 2 \\
\end{array}$ & $\begin{array}{l}1.66 \pm 0.89 \\
0.34 \\
3.21 \pm 0.95 \\
2.04 \pm 1.13^{*} \\
1.06 \pm 0.65 \\
0.88 \pm 0.37 \\
\end{array}$ & $\begin{array}{l}0.53 \pm 0.13 \\
0.37 \\
0.72 \pm 0.24 \\
0.63 \pm 0.19 * \\
0.41 \pm 0.09 \\
0.64 \pm 0.37 \\
\end{array}$ \\
\hline \multicolumn{6}{|c|}{ Winter } \\
\hline $\begin{array}{l}3 \\
5 \\
6 \\
7\end{array}$ & $\begin{array}{l}\text { DSR } \\
\text { DSR } \\
\text { DSR } \\
\text { ASR } \\
\text { DSR } \\
\end{array}$ & $\begin{array}{r}5 \\
1 \\
11 \\
5 \\
3 \\
\end{array}$ & $\begin{array}{l}13 \pm 2 \\
21 \\
17 \pm 5 \\
20 \pm 2 \\
22 \pm 2\end{array}$ & $\begin{array}{l}1.28 \pm 0.49 \\
2.77 \\
3.70 \pm 1.80 \\
0.85 \pm 0.35 \\
0.95 \pm 0.52 \\
\end{array}$ & $\begin{array}{l}0.61 \pm 0.12 \\
0.65 \\
0.96 \pm 0.34 \\
0.42 \pm 0.11 \\
0.46 \pm 0.15\end{array}$ \\
\hline \multicolumn{6}{|c|}{ Yearlong } \\
\hline $\begin{array}{l}3 \\
5 \\
7\end{array}$ & $\begin{array}{l}\text { ISR } \\
\text { ISR } \\
\text { ISR }\end{array}$ & $\begin{array}{l}4 \\
3 \\
1\end{array}$ & $\begin{array}{l}21 \pm 8 \\
28 \pm 14 \\
44\end{array}$ & $\begin{array}{l}2.92 \pm 1.47 \\
9.17 \pm 3.02 \\
17.29\end{array}$ & $\begin{array}{l}0.72 \pm 0.13 \\
1.45 \pm 0.09 \\
1.42\end{array}$ \\
\hline
\end{tabular}

* = summer home range size estimate is significantly different $(P \leq 0.05)$ than the comparable winter value for the same movement pattern. Test results based on Wilcoxon 2-sample test. 
Table 6.11. Comparison of estimates of seasonal home range size and mobility between adult females and males in PHU 1.

\begin{tabular}{|c|c|c|c|c|}
\hline $\begin{array}{l}\text { Season } \\
\text { Sex }\end{array}$ & $\begin{array}{l}\text { No. } \\
\text { Deer }\end{array}$ & $\begin{array}{c}\overline{\mathrm{X}} \text { No. } \\
\text { Relocations }\end{array}$ & $\begin{array}{c}\text { Polygon HR Size } \\
\begin{array}{c}\left(\mathrm{km}^{2}\right) \\
\overline{\mathrm{X}} \pm 1 \mathrm{SD}\end{array}\end{array}$ & $\overline{\mathrm{X}} \begin{array}{c}\mathrm{AAR} \\
\frac{ \pm 1 \mathrm{SD}}{(\mathrm{km})}\end{array}$ \\
\hline & SUMM & & & \\
\hline Female & 21 & $48 \pm 23$ & $1.77 \pm 0.55 \mathrm{~A}^{1}$ & $0.55 \pm 0.14 \mathrm{~A}$ \\
\hline \multirow[t]{2}{*}{ Male } & 5 & $34 \pm 14$ & $2.40 \pm 1.23 \mathrm{~A}$ & $0.57 \pm 0.11 \mathrm{~A}$ \\
\hline & WINTE & & & \\
\hline Female & 23 & $99 \pm 54$ & $2.44 \pm 0.84 \mathrm{~A}$ & $0.50 \pm 0.08 \mathrm{~A}$ \\
\hline Male & 8 & $44 \pm 15$ & $2.48 \pm 0.48 \mathrm{~A}$ & $0.60 \pm 0.08 \mathrm{~B}$ \\
\hline
\end{tabular}

${ }^{1}$ Different capital letters indicated a significant difference $(P<.05)$ between sexes within a season (Wilcoxon 2-sample test).

These data indicate that home range parameters expressed as means for areas such as the Bridger Mountains must be interpreted with caution. Variation among individuals, apparently related to characteristics of occupied environments, was the rule. Variation among PHUs was most evident in winter, especially in AARs. Deer associated with PHUs on the east slope exhibited generally larger home ranges than deer on the west slope; however, some significant differences in home range size and mobility also occurred between adjacent PHUs of generally similar habitat.

Such variation indicates that seasonal home range size and mobility represent adaptations of deer to a combination of factors that are often unique to individual deer and the habitats they occupy. PHUs comprise large aggregations of individual deer with movement patterns representing the entire spectrum of habitat use strategies they must employ to successfully occupy each unit under all environmental conditions.

Researchers have expended significant effort measuring and discussing home range characteristics of deer. Wood (1986) reviewed home range sizes reported for mule deer in major habitats across the west, and indicated that significant variation in methodology obstructed meaningful comparisons. This, in combination with the broad natural spectrum of movement patterns within and between populations and the small sample sizes inherent in studies of wild populations, indicated that opportunities for meaningful comparison of home range size between areas will not improve in the near future. Comparison might be more meaningful if the proportions of deer following different movement patterns within populations and habitats were determined. 


\begin{tabular}{|c|c|c|c|c|c|}
\hline 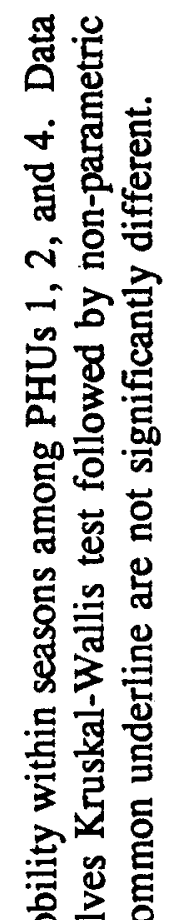 & $\underset{3}{\stackrel{\underline{I}}{\mathbf{Z}}}$ & 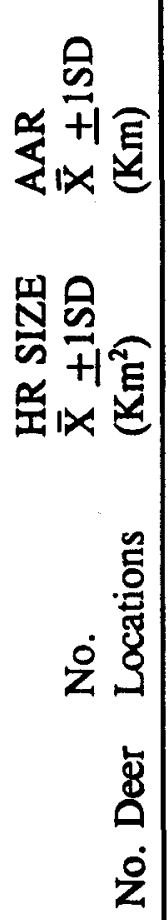 & 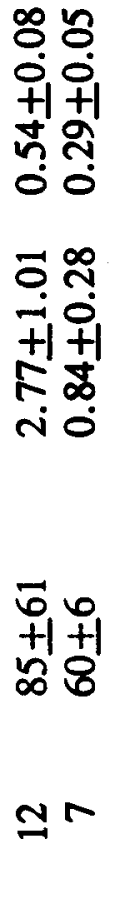 & 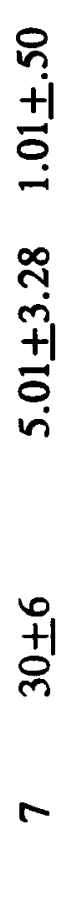 & $\begin{array}{l}\text { 에 } \\
\text { 메 } \\
\text { 히 } \\
\text { 에 } \\
\text { 메 } \\
\text { 메 }\end{array}$ \\
\hline 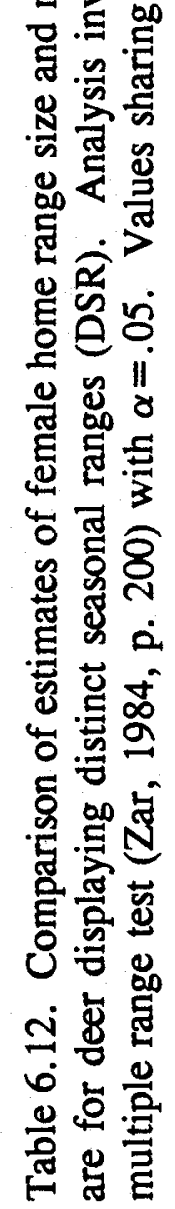 & 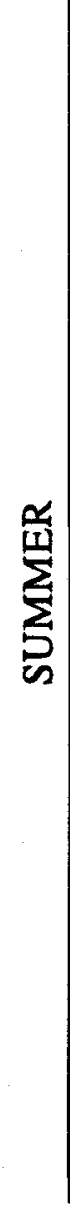 & 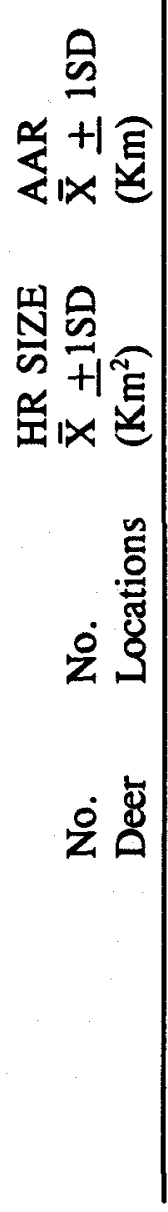 & 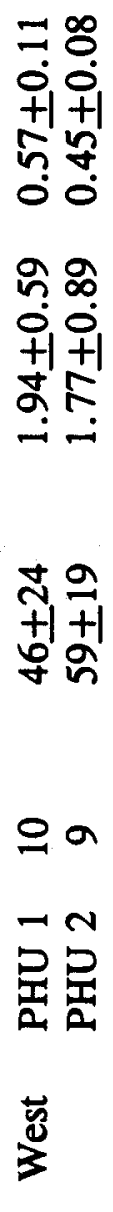 & $\begin{array}{l}\bar{N} \\
0 \\
+1 \\
\infty \\
0 \\
0 \\
\infty \\
\stackrel{+}{+} \\
+1 \\
\dot{+} \\
\dot{+}\end{array}$ & 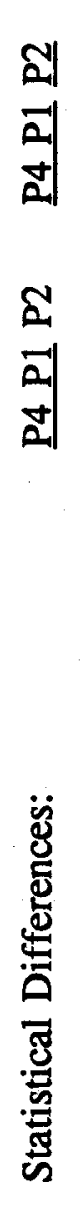 \\
\hline
\end{tabular}


Distance and Timing of Movements Between Seasonal Ranges

There were no significant differences in the distances traveled between seasonal ranges by either males or females within PHUs (Table 6.13). There was, however, at least one difference in distances traveled by adult females among PHUs (Kruskal-Wallis $\mathrm{X}^{2}$ approximation $=86.24, \mathrm{df}=6, \mathrm{P}=0.0001$ ). These and results of nonparametric multiple comparisons tests (Dunn 1964) indicated that females in PHUs 1, 2, and 7 traveled significantly $(\alpha=0.05)$ shorter distances between winter and summer ranges than females in PHUs 4, 5 and 6. Females in PHU 3 could not be distinguished from either group. Test results for adult males (Kruskal-Wallis $\mathrm{X}^{2}$ approximation $=39.49$, $\mathrm{df}=5, \mathrm{P}=0.0001$ ) were similar.

Table 6.13. Distances $(\mathrm{km})$ between winter and summer activity centers for marked female and male mule deer in seven PHUs in the Bridger Mountains ${ }^{1}$.

\begin{tabular}{|c|c|c|c|c|c|c|c|c|}
\hline PHU & Sex & $\mathbf{N}$ & Median & $\overline{\mathrm{X}} \pm S \mathrm{X}$ & Min & Max & $Z^{2}$ & $\operatorname{Pr}>\mid Z I$ \\
\hline 1 & $\begin{array}{l}\mathbf{F} \\
\mathbf{M}\end{array}$ & $\begin{array}{l}86 \\
47\end{array}$ & $\begin{array}{l}5.4 \\
5.1\end{array}$ & $\begin{array}{l}5.3 \pm 3.3 \\
5.6 \pm 3.3\end{array}$ & $\begin{array}{l}0.4 \\
1.4\end{array}$ & $\begin{array}{l}16.0 \\
18.4\end{array}$ & 0.518 & 0.605 \\
\hline 2 & $\begin{array}{l}\mathbf{F} \\
\mathbf{M}\end{array}$ & $\begin{array}{l}20 \\
12\end{array}$ & $\begin{array}{l}5.0 \\
4.8\end{array}$ & $\begin{array}{l}6.2 \pm 3.7 \\
4.4 \pm 2.1\end{array}$ & $\begin{array}{l}1.1 \\
1.5\end{array}$ & $\begin{array}{r}17.2 \\
7.8\end{array}$ & 1.304 & 0.192 \\
\hline 7 & $\begin{array}{l}\mathbf{F} \\
\mathbf{M}\end{array}$ & $\begin{array}{l}9 \\
-\end{array}$ & 2.8 & $3.7 \pm 3.3$ & 0.9 & $\begin{array}{c}11.4 \\
-\end{array}$ & - & - \\
\hline $\begin{array}{l}\text { Total West } \\
\text { Slope }\end{array}$ & $\begin{array}{l}\mathbf{F} \\
\mathbf{M}\end{array}$ & $\begin{array}{r}115 \\
59\end{array}$ & $\begin{array}{l}4.9 \\
4.9\end{array}$ & $\begin{array}{l}5.3 \pm 3.4 \\
5.4 \pm 3.1\end{array}$ & $\begin{array}{l}0.4 \\
1.4\end{array}$ & $\begin{array}{l}17.2 \\
18.4\end{array}$ & & \\
\hline 3 & $\begin{array}{l}\mathrm{F} \\
\mathrm{M}\end{array}$ & $\begin{array}{r}20 \\
3\end{array}$ & $\begin{array}{l}7.5 \\
7.2\end{array}$ & $\begin{array}{l}8.5 \pm 3.8 \\
6.0 \pm 3.2\end{array}$ & $\begin{array}{l}4.4 \\
2.4\end{array}$ & $\begin{array}{r}16.8 \\
8.5\end{array}$ & 0.867 & 0.386 \\
\hline 4 & $\begin{array}{l}\mathbf{F} \\
\mathbf{M}\end{array}$ & $\begin{array}{l}63 \\
10\end{array}$ & $\begin{array}{l}11.1 \\
11.9\end{array}$ & $\begin{array}{l}12.8 \pm 15.9 \\
10.8 \pm 3.2\end{array}$ & $\begin{array}{l}2.2 \\
5.7\end{array}$ & $\begin{array}{r}126.7 \\
15.4\end{array}$ & 0.281 & 0.779 \\
\hline 5 & $\begin{array}{l}\mathrm{F} \\
\mathrm{M}\end{array}$ & $\begin{array}{r}22 \\
6\end{array}$ & $\begin{array}{l}15.4 \\
20.7\end{array}$ & $\begin{array}{l}13.8 \pm 6.8 \\
19.7 \pm 6.9\end{array}$ & $\begin{array}{l}1.9 \\
8.7\end{array}$ & $\begin{array}{l}26.6 \\
27.3\end{array}$ & 1.764 & 0.078 \\
\hline 6 & $\begin{array}{l}\mathbf{F} \\
\mathbf{M}\end{array}$ & $\begin{array}{r}30 \\
6\end{array}$ & $\begin{array}{l}11.6 \\
14.5\end{array}$ & $\begin{array}{l}11.7 \pm 4.6 \\
14.7 \pm 4.5\end{array}$ & $\begin{array}{c}5.1 \\
10.3\end{array}$ & $\begin{array}{l}23.3 \\
21.7\end{array}$ & 1.358 & 0.174 \\
\hline $\begin{array}{l}\text { Total East } \\
\text { Slope }\end{array}$ & $\begin{array}{l}\mathbf{F} \\
\mathbf{M}\end{array}$ & $\begin{array}{r}135 \\
25\end{array}$ & $\begin{array}{l}11.1 \\
12.1\end{array}$ & $\begin{array}{l}12.1 \pm 11.6 \\
13.3 \pm 6.2\end{array}$ & $\begin{array}{l}1.9 \\
2.4\end{array}$ & $\begin{array}{r}126.7 \\
27.3\end{array}$ & & \\
\hline
\end{tabular}

' Radio-collared and neck-banded individuals were pooled. Data pertain to individual deer with spatially distinct winter and summer home ranges.

${ }^{2}$ Wilcoxon approximation of $\mathrm{Z}$-value. 
Median distances traveled by adult females on the west slope ranged from $2.8 \mathrm{~km}$ in PHU 7 to $5.4 \mathrm{~km}$ in PHU 1 (Table 6.13). By comparison, medians for adult females in PHUs 4, 5, and 6 varied from 11.1 to $15.4 \mathrm{~km}$. The median for females in PHU 3 was $7.5 \mathrm{~km}$. Minimum and maximum distance for females along the west slope were 0.4 and $17.2 \mathrm{~km}$, respectively, compared to 1.9 and $126.7 \mathrm{~km}$ for the east slope.

Median distances for adult males on the west slope were $4.8 \mathrm{~km}$ in PHU 2 and $5.1 \mathrm{~km}$ in PHU 1. Medians for males in PHUs 4, 5, and 6 varied from 11.9 to 20.7 $\mathrm{km}$. The median distance of $7.2 \mathrm{~km}$ for males in PHU 3 was intermediate. Minimum and maximum distances along the west slope were 1.4 and $18.4 \mathrm{~km}$, respectively, compared to 2.4 and $27.3 \mathrm{~km}$ on the east slope.

Mean dates of arrival and departure from winter home ranges in PHU 1 during 1975-83 were 20 December and 11 May (Table 6.14). For PHU 4, means were 23 January and 25 April. Adult females in PHU 1 remained on winter ranges for an average of 139 days. This was significantly longer (Wilcoxon $Z=2.95, P=0.003$, $\mathrm{N}=40$ and 21) than the 97 day mean for females in PHU 4 (Table 6.14).

In PHU 1, females that crossed the Bridger Divide spent an average of 44 more days on the winter range than females that summered west of the divide (Wilcoxon $Z=$ $2.56, \mathrm{P}=0.01, \mathrm{~N}=18$ and $\mathrm{N}=23$ ). Average date of arrival on the winter range was 27 November for the former compared to 12 January for other deer. Dates of departure from the winter range for the two groups were only nine days apart. During spring, some individuals from both groups utilized habitats located between winter and summer home ranges for an average of 46 days.

Females that crossed Bangtail Ridge in PHU 4 spent about the same amount of time on the winter range as deer that did not cross the ridge (Wilcoxon $Z=0.493, P$ $=0.62, \mathrm{~N}=11$ and $\mathrm{N}=10$ ). However, individuals that crossed the ridge more commonly used habitats located between winter and summer ranges. These habitats were occupied during spring for an average of $\mathbf{3 0}$ days.

Mean dates of arrival and departure from summer home ranges in PHU 1 were 15 June and 31 October, respectively. These dates were 17 May and 12 December for PHU 4 (Table 6.14). Adult females in PHU 1 remained on summer ranges for an average 137 days, significantly less (Wilcoxon $\mathrm{Z}=4.30, \mathrm{P}=0.000, \mathrm{~N}=59$ and $\mathrm{N}=$ 24) than the 206 day mean for females on PHU 4.

Females in PHU 1 that did not cross the Bridger Divide during seasonal movements spent an average of $\mathbf{5 2}$ more days on summer home ranges than females that crossed the divide (Wilcoxon $Z=3.86, P=0.0001, N=36$ and $N=23$ ). Average date of arrival on summer home ranges was 13 June for divide crossers compared to 17 June for other deer. However, departure dates from summer home ranges were more 


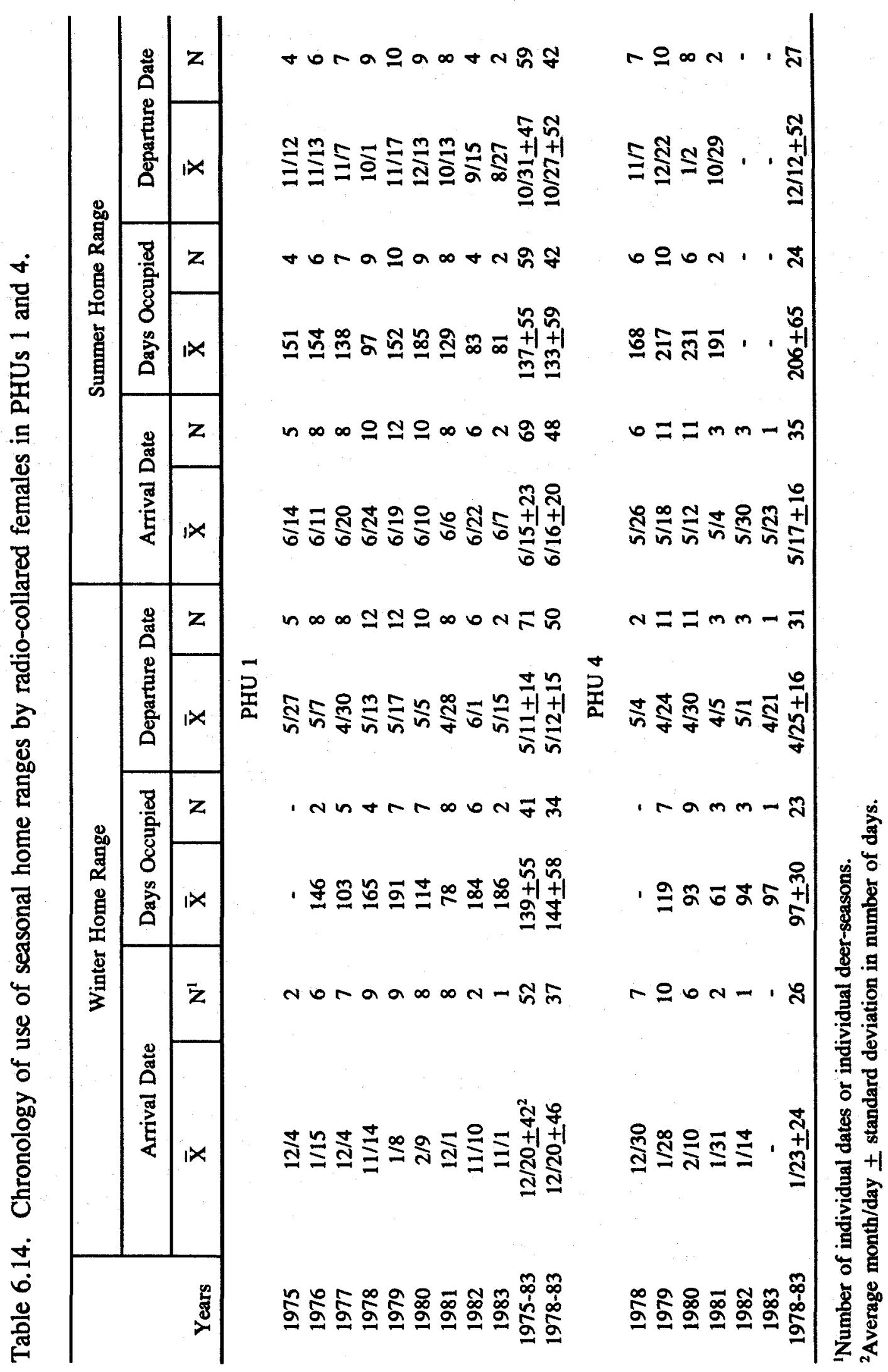


widely separated. On the average, divide crossers left summer ranges on 13 October while other deer did not leave until 23 November.

For PHU 4, females that did not cross Bangtail Ridge spent an average of 232 days on summer home ranges. This was longer (Wilcoxon $\mathrm{Z}=2.05, \mathrm{P}=0.04, \mathrm{~N}=$ 14 and $N=10$ ) than the 170 day average for females that crossed the ridge.

Emigration

Emigration was defined as abandonment of a traditionally used home range with subsequent movement to a new location outside the boundaries of a PHU. The probability of return to the traditional home range and movement pattern was low.

Direction and relative distance of movement of 34 emigrants from natal/original home ranges is shown in Fig. 6.17. Thirty of these deer were tagged with individually color-coded neck collars and four with radio-transmitter collars. All deer emigrating from the three west slope PHUs were males except for one female from PHU 1. The sex ratio of emigrants from the four east slope PHUs was 9 females: 10 males.

Emigration vectors for west slope deer were bimodally distributed along a north-south axis (Fig. 6.17), particularly in PHU 1 where sample size was largest (Raleigh test, $\mathrm{Z}=5.25, \mathrm{P}<0.05, \mathrm{~N}=12$ ). The bimodal pattern may have been related to the orientation of the high Bridger Divide which may have presented a formidable barrier to deer emigrating through unfamiliar habitat. Emigration in a westerly direction across the broad, inter-mountain valley was also infrequent and suggested that emigrants may have been reluctant to leave the general familiarity of mountain habitats.

In PHU 1, vectors delineating movements between seasonal home ranges of deer that maintained fidelity were also non-randomly distributed $(\mathrm{Z}=49.80, \mathrm{P}<0.05, \mathrm{~N}$ $=140$ ). However, these vectors radiated outward in northeasterly to southeasterly directions and generally did not intersect the vectors of emigrating deer.

Emigration vectors from the east slope PHUs radiated in more directions compared to the west slope. In PHU 4, vector angles were uniformly distributed around a circle $(Z=2.00, P>0.05, N=11)$. This may reflect the absence of major topographic barriers within unit boundaries. Greater representation of females among emigrants on the east slope also contributed to the uniform distribution of vector directions. Females emigrated in all directions except east. Males generally moved in northwesterly and southerly directions. 


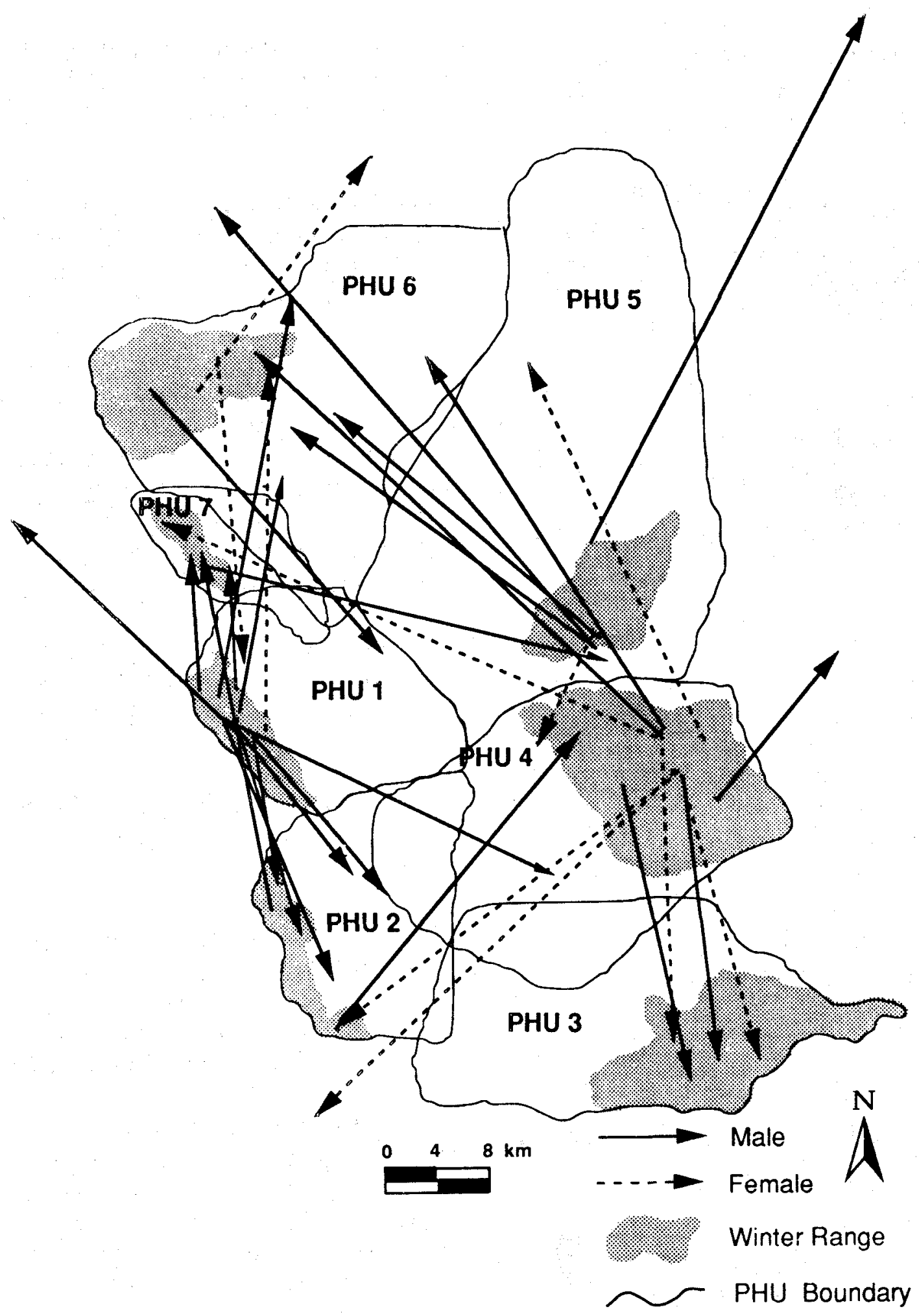

Figure 6.17. Direction and relative distance of movement of 24 male and 10 female mule deer that emigrated to other PHUs or to areas outside the Bridger study area. 
In contrast to deer that emigrated, vectors delineating seasonal movements of deer that maintained fidelity in PHU 4 were non-randomly distributed $(Z=46.29, P<0.05$, $\mathrm{N}=92$ ) in westerly to southwesterly directions. Only 2 of 11 emigrants from PHU 4 moved in similar directions.

Only three deer moved from east slope into west slope populations units; all were females. Four males and one female from the west slope emigrated into east slope units. Forty-seven and $32 \%$ of emigrants from west and east slope units moved to locations outside the Bridger Mountain complex. All other emigrants remained on the east or west slope but moved to other PHUs.

Age at time of emigration was known for 27 of 34 individuals. The fate of the other seven was not known for several years prior to observation at the "new" location, so age at time of emigration could not be ascertained precisely. The 10 male emigrants from the west slope included seven yearlings, one 2-year old, and two 3-year olds. The only female emigrant from the west slope was 9 years old. Male emigrants from the east slope included seven yearlings and two 2-year olds. Only one of seven females was a yearling. The others included three 2-year-olds, two 3-year-olds, and one 5-year-old.

The 15 emigrants from west slope PHUs dispersed an average of $17.6 \pm 7.2 \mathrm{~km}$ compared to $25.8 \pm 8.8 \mathrm{~km}$ for 19 emigrants from east slope units. Males $(\mathrm{N}=24)$ moved an average of $21.3 \pm 9.4 \mathrm{~km}$ (range $8.0-40.3 \mathrm{~km}$ ) which was similar to the 24.3 $\pm 7.9 \mathrm{~km}$ (range 8.7-36.3 km) for females $(\mathrm{N}=10)$.

Dates when deer emigrated were determined for only six individuals. Three males and one female dispersed during June or July. One deer of each sex moved to an entirely different winter range during December.

In addition to the 34 deer that emigrated to locations outside their PHU boundaries, four females and one male moved to different home ranges within their PHU boundary. All four females were 3 years old when dispersal occurred. Two moved 3.3 and $6.8 \mathrm{~km}$ to new winter home ranges, and two moved 5.0 and $6.5 \mathrm{~km}$ to new summer home ranges. A 5-year old male moved $7.7 \mathrm{~km}$ to a different winter home range.

Three other adult females temporarily moved outside of their PHU. These included one that normally ranged within PHU 2, but twice, when 10 and 13 years old, was observed on winter range in PHU 4, $31 \mathrm{~km}$ to the east. Another, marked initially as a yearling, consistently used the PHU 1 winter range from 1978 to 1985, except for 1980, when, as a 3-year old, she wintered $13 \mathrm{~km}$ north in PHU 7. The third, marked with a radio as a 2-year old, ranged in PHU 6 from 1982 through 1987 except for 1986, when it wintered in PHU 7. 
These examples indicated that $3(8 \%)$ of 37 deer that left their natal PHUs eventually returned to original home ranges. All three were females and represented $23 \%$ of the sample of 13 female emigrants.

The "plasticity" of deer movement patterns caused difficulty in quantification of the ultimate effect of emigration on population dynamics. At least some deer that fit our definition of emigration when two or more years of age, returned to home range sites used earlier. Thus, categorization of deer as emigrants was somewhat subjective, unless they were radio-tagged at birth and radio-tracked continuously throughout life.

Two marked males were known to have immigrated to the Bridgers from other mountain ranges. One had been tagged as a 6-month old fawn on the east slope of the Crazy Mountains during winter 1985 and was hit by a car one year later, $47 \mathrm{~km}$ to the west in PHU 5. The second, a 2-year-old buck killed by a hunter in PHU 3 during autumn 1983, had been marked in the Boulder River drainage $45 \mathrm{~km}$ to the southeast in March 1982.

Summary

1. Movements of individual deer were categorized according to three fundamental patterns. Indistinct seasonal ranges (ISR) described yearlong use of one small area. Adjacent seasonal ranges (ASR) referred to readily identifiable winter and summer home ranges separated by less than $2 \mathrm{~km}$. Intraseasonal trips between home ranges were common. Distinct seasonal ranges (DSR) described identifiable winter and summer home ranges separated by more than $2 \mathrm{~km}$. Intraseasonal trips between home ranges were uncommon. Percentages of deer following ISR, ASR, and DSR movement patterns varied among the seven PHUs in relation to the characteristics of the local environment.

2. Individual deer used five types of accessory areas to satisfy temporary resource deficiencies that occurred on "normal" seasonal home ranges. By utilizing accessory areas, a deer could display a total movement pattern as unique as an individual signature. The frequency of use of different types of accessory areas was related to the characteristics of the occupied habitat. Use of these areas achieved more optimal dispersion of deer and more complete use of available habitat.

3. The spatial distribution of adult males was significantly different than adult females in summer but not winter.

4. Adult females on east slope winter ranges were significantly more mobile than their west slope counterparts. This apparently reflected differences in strategy of winter habitat use. Mobility during summer was similar among females on west and east slope ranges when fawn-rearing elicited similar resource requirements. 
5. Polygon home range sizes and indexes of mobility exhibited a variable spectrum among seasons, deer movement patterns, PHUs, and between west and east slope ranges. Home range parameters expressed as means must be interpreted with caution. Variation was the rule and represented adaptations of individual deer to the unique environments they occupied. PHUs comprise large aggregations of individual deer with movement patterns reflecting the entire spectrum of habitat use strategies required to successfully occupy each unit under all environmental conditions.

6. Females and males in west slope PHUs traveled significantly shorter distances between winter and summer home ranges than their counterparts in east slope PHUs.

7. Adult females in PHU 1 remained on winter ranges for a significantly longer time period than females in PHU 4. Adult females in PHU 1 remained on summer ranges for significantly less time than females in PHU 4.

8. A total of 34 deer ( 24 males, 10 females) emigrated from their natal PHU. Only one of 15 emigrants from west slope PHUs was a female; emigrants from east slope PHUs included 9 females and 10 males. Forty-seven and 32\% of emigrants from west and east slope PHUs moved to locations outside the Bridger Mountain complex. 


\section{CHAPTER 7}

\section{SOCIAL STRUCTURE}

Social structure refers to the manner in which members of a population are positioned in space and time relative to one another. Social behavior consists of characteristic motor actions and communications by which group members interact, influence each others actions, and coordinate overall group activity (Morrison and Menzel 1972, Hirth 1977). Some aspects of social organization and behavior are inherent attributes of the species, others are products of adaptation to the environments occupied.

Knowledge of interactions between sociality and use of habitat resources has long been recognized as essential to understanding population ecology and dynamics of deer (Dasmann and Taber 1956, Geist 1981). Geist (1981) discussed aspects of behavior, but not specifically social organization, in Rocky Mountain mule deer. Recently, Hamlin and Mackie (1989) defined social organization and behavioral attributes of Rocky Mountain mule deer in a timbered "breaks" environment in the northern Great Plains of Montana. Other studies (Linsdale and Tomich 1953, Dasmann and Taber 1956, Miller 1970, Miller 1974) have focused on the black-tailed subspecies. Because little is known of social organization of mule deer in mountain-foothill environments and to help interpret population-habitat relationships, we analyzed social organization generally within the study area and comparatively between environments of PHUs 1 and 4. Data were available from observation of 11,319 social groups containing 66,777 deer on the west slope (PHUs 1, 2, and 7) and 8,775 groups containing 66,267 deer on the east slope (PHUs 3, 4, 5, and 6). PHU 1 was represented by 8,015 groups and 49,016 deer while 4,792 groups including 37,728 deer were recorded in PHU 4.

Most observations during May-November, when deer were widely scattered on timbered summer range, were recorded in the course of aerial monitoring using a Piper SuperCub. These were supplemented by on-the-ground observations in the course of other field work. During December-April, data were derived from full-coverage helicopter surveys supplemented by monitoring surveys using the SuperCub and periodic observations on winter ranges. We recorded and analyzed data only for social groups believed to be complete and independent of other deer located nearby. When some group disruption occurred, as during helicopter surveys, it should have been consistent across all PHUs. 
Data were recorded and analyzed in relation to four major social groups that were readily distinguished. Doe groups included at least one adult doe but no mature males. Buck groups consisted of at least one mature male but no adult females. Mixed groups contained both adult does and mature bucks. Yearling male groups included at least one yearling male with no adult does or mature bucks. Doe, buck, and mixed groups often included fawns and/or yearling males. Yearling male groups occasionally included fawns.

Social organization for most deer species centers in the family group (deVos et al. 1967). In mule deer, this may be either a milk group consisting of the doe and her new fawn(s) or a maternal group that would also include the previous year's offspring (Linsdale and Tomich 1953). Our data cited earlier (Chapter 4) as well as data from Hamlin and Mackie (1989) indicated that by winter, maternal groups could include females from at least three generations. With maternally-related groups of females constituting the core of mule deer society, other social groups (buck, mixed, and yearling male) were of secondary importance in occurrence and persistence (Fig. 7.1).

Some classification problems occurred during early (June) and late (January) stages of the antler cycle and during October and November when use of heavy cover coincided with hunting seasons. However, groups of unknown sex and age followed a similar trend in both populations. Unclassified groups were slightly more common in PHU 1 compared to PHU 4 during all months because of greater use of timbered habitats.

\section{Maternal Doe Groups}

Composition and size of doe groups was fundamentally influenced by the reproductive effort. Throughout the study area, the majority of adult does were solitary or with newborn fawns during June and July (Fig. 7.2). Does observed with other adult females declined by half from June through July on the west slope and remained unchanged on the east slope. Apparently, adult females on the west slope sought isolation at a later date; it may follow that fawning dates were also later.

During June and July, more than $80 \%$ of doe and/or mixed groups contained one adult female (Fig. 7.3). Hamlin and Mackie (1989) reported that does without fawns typically remained in or joined groups rather than remaining solitary during early summer. Less than $5 \%$ of adult females were associated with yearling or mature males during the early fawn-rearing period.

During late summer and early autumn (August-October), the incidence of solitary adult does steadily declined while groups including fawns steadily increased (Fig. 7.2) with completion of the weaning process. Also, groups consisting of two or more does with fawn(s) became increasingly more common as maternally-related females regrouped. 

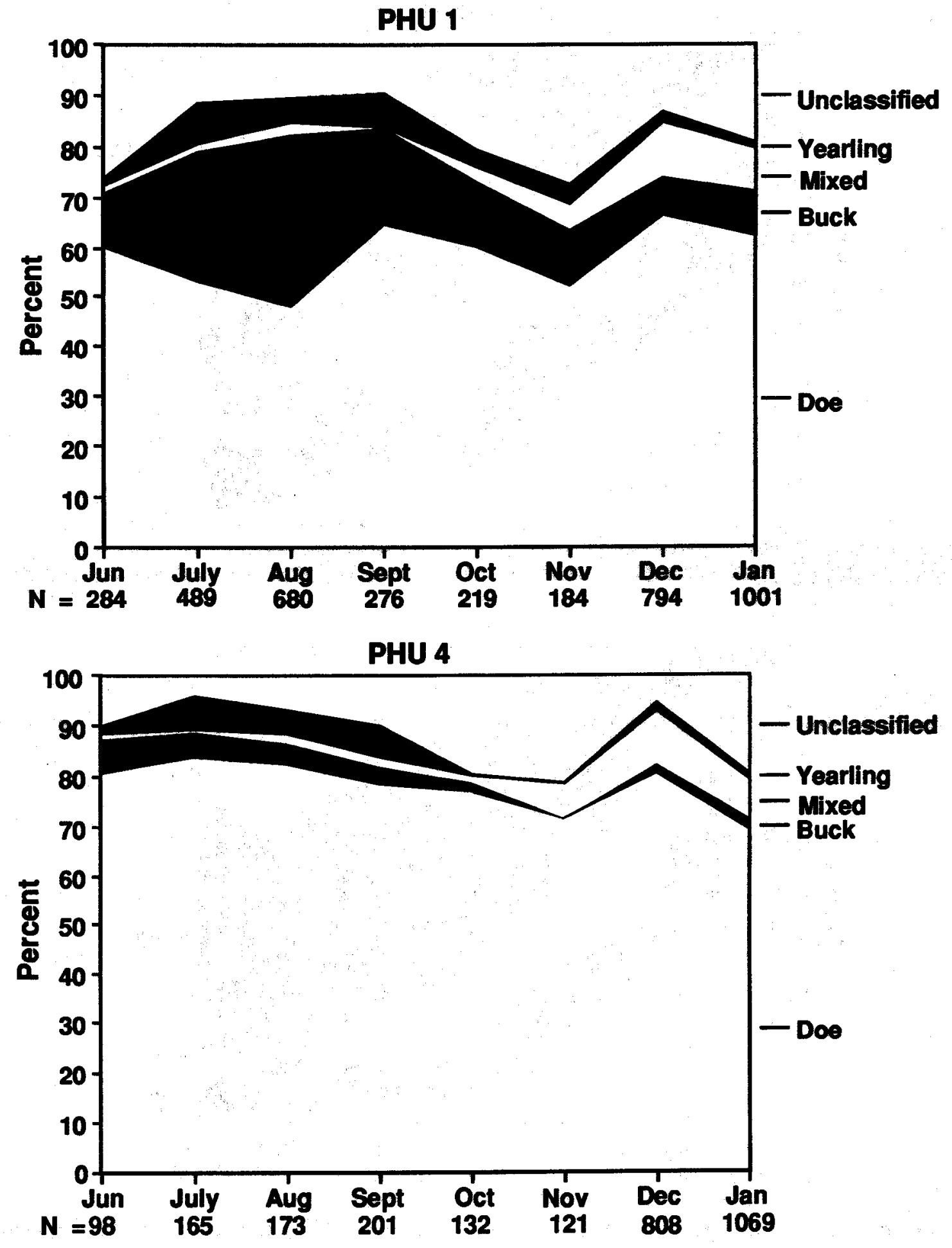

Figure 7.1. Percent distribution by month of four social group types of mule deer in PHUs 1 and 4. $\mathbf{N}=$ number of groups. 


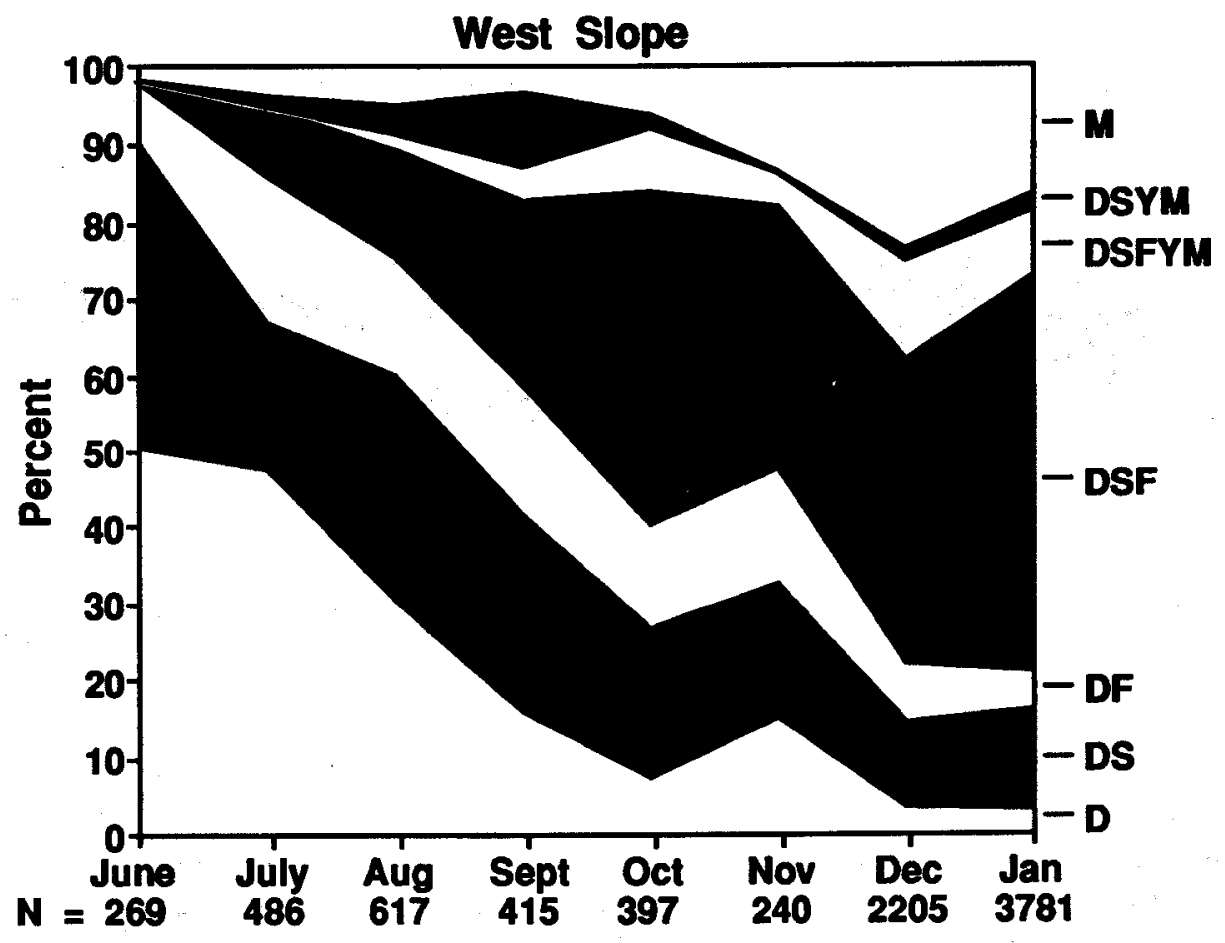

East Slope

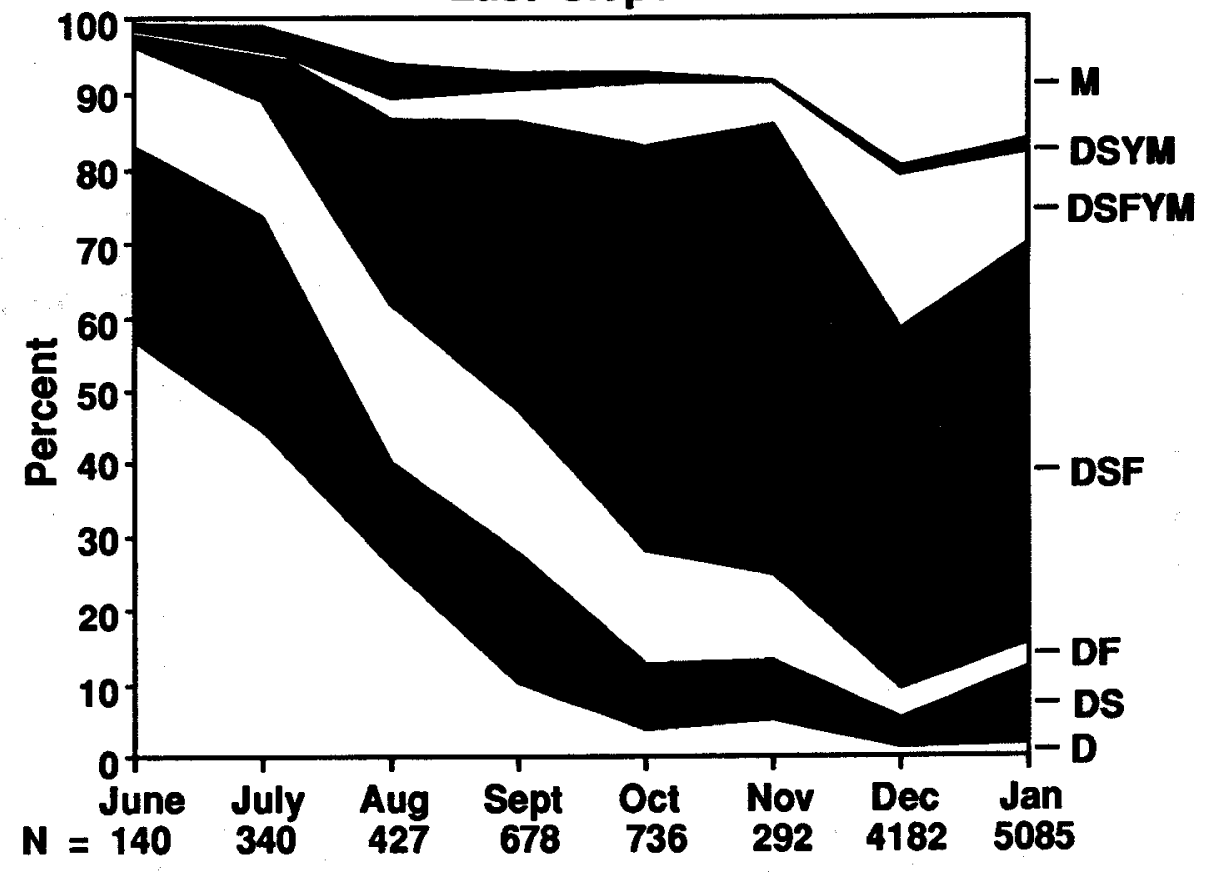

Figure 7.2. Percentage of adult females observed alone (D) and in other social groups by month on west and east slope ranges. Groups of more than one adult doe = DS; one adult doe and fawn = DF; more than one adult doe and fawns = DSF; one or more does, fawns, and yearling males = DSFYM; one or more does and yearling males = DSYM; and mixed groups $=\mathbf{M}$. $\mathbf{N}=$ number of adult females. 


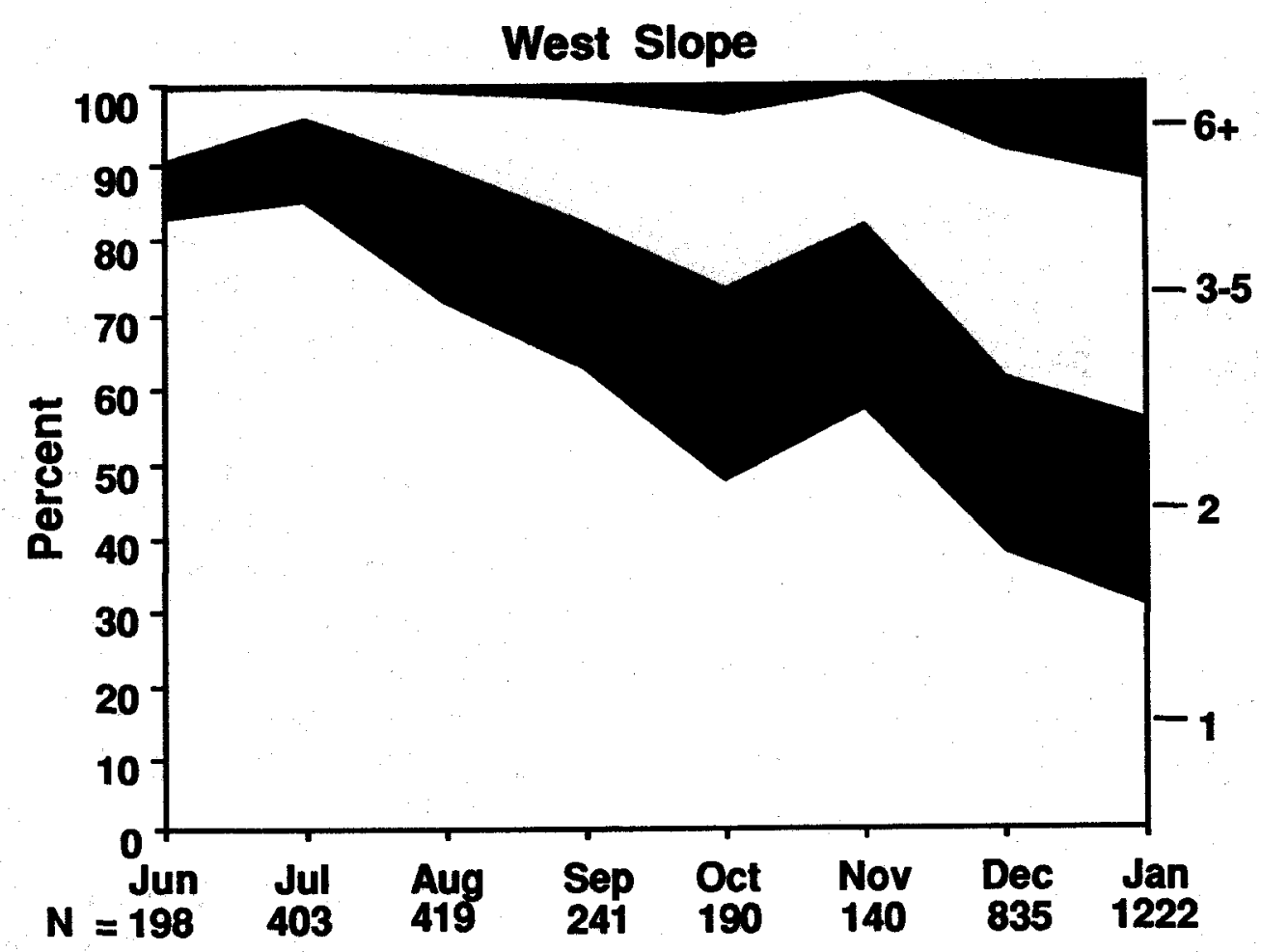

East Slope

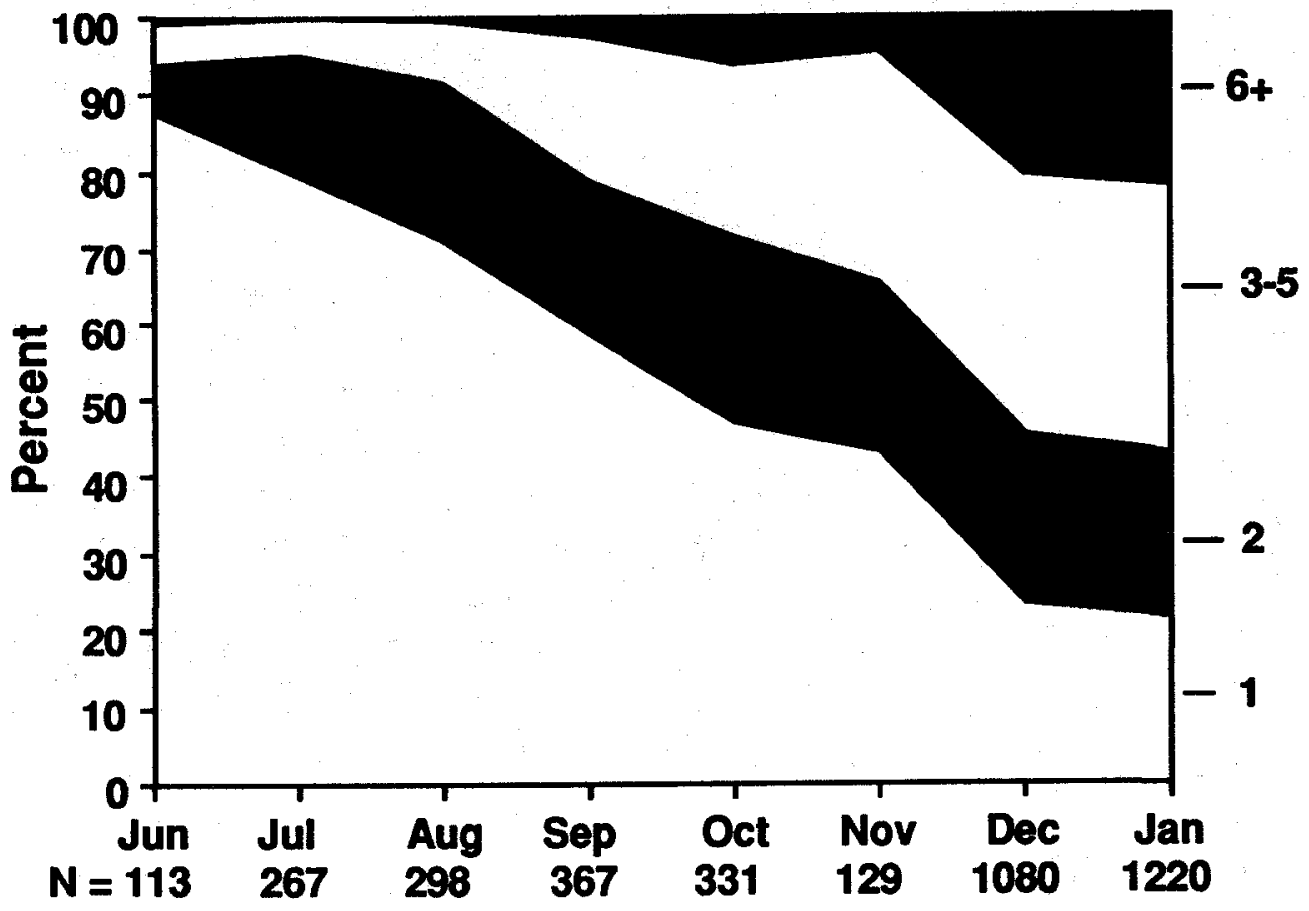

Figure 7.3. Percentage of groups observed by month that included $1,2,3-5$, and $6+$ adult females on the west and east slopes of the Bridger Mountains. $\mathbf{N}=$ number of completely classified groups. 
However, some adult females and their fawns remained apart from other does throughout summer and autumn.

Association between does (with or without fawns) and yearling males increased from a minimum in June to $10-14 \%$ during September-October (Fig. 7.2). No more than $7 \%$ of the adult does were associated with mature bucks during any one month from June-October. Groups including only one adult female declined to about $47 \%$ by October on both west and east slopes (Fig. 7.3).

Doe group characteristics, particularly on the west slope, were apparently influenced by breeding season activity in November (Fig. 7.2). Solitary females increased and groups with two or more does and their fawn(s) declined. This was a reversal of trend from the preceding five months. The percentage of does associated with mature bucks in mixed groups was twice that recorded in October. Courtship and chasing of adult females in estrous apparently contributed to temporary disruption of social groups. This was not evident on the east slope where the lower number of mature bucks may have resulted in less disruption of social groups.

By December, adult females on the west and east slopes were more closely associated with yearling and mature males than any other month. This was related to continuation of breeding activity and congregation of groups on winter range. By January, association between adult does and yearling and mature males declined, although 27 and $31 \%$ of all does on the west and east slopes, respectively, were still accompanied by bucks (Fig. 7.2). On west and east slope ranges, solitary does reached a minimum in December and January while groups with 3-5 and 6 or more females peaked (Fig. 7.3).

The influence of reproductive success on reformation of matrilineal groups was described by Hamlin and Mackie (1989). We presented similar data in Chapter 4 indicating females with fawns banded together at a later date. Reproductive success continued to influence the size of doe groups during early winter on both PHUs (Fig. 7.4). Mean female group size was largest when average fawn:female ratios were lowest and vice-versa. However, the mean number of females per group observed during each annual survey was higher on PHU 4 than on PHU 1 despite higher fawn:female ratios on the former area during 7 of 11 years. In other words, the same relationship between reproduction and female group size operated in both populations although it occurred at a consistently higher spectrum of group sizes on PHU 4.

Mature Buck Groups

Buck social structure was the antithesis of that described for adult does during summer and autumn. Mature males occurred together most often during June-October (Fig. 7.5). Solitary bucks were more prevalent on the west slope, although they never constituted more than $35 \%$ of all bucks observed by month during June-October on either 


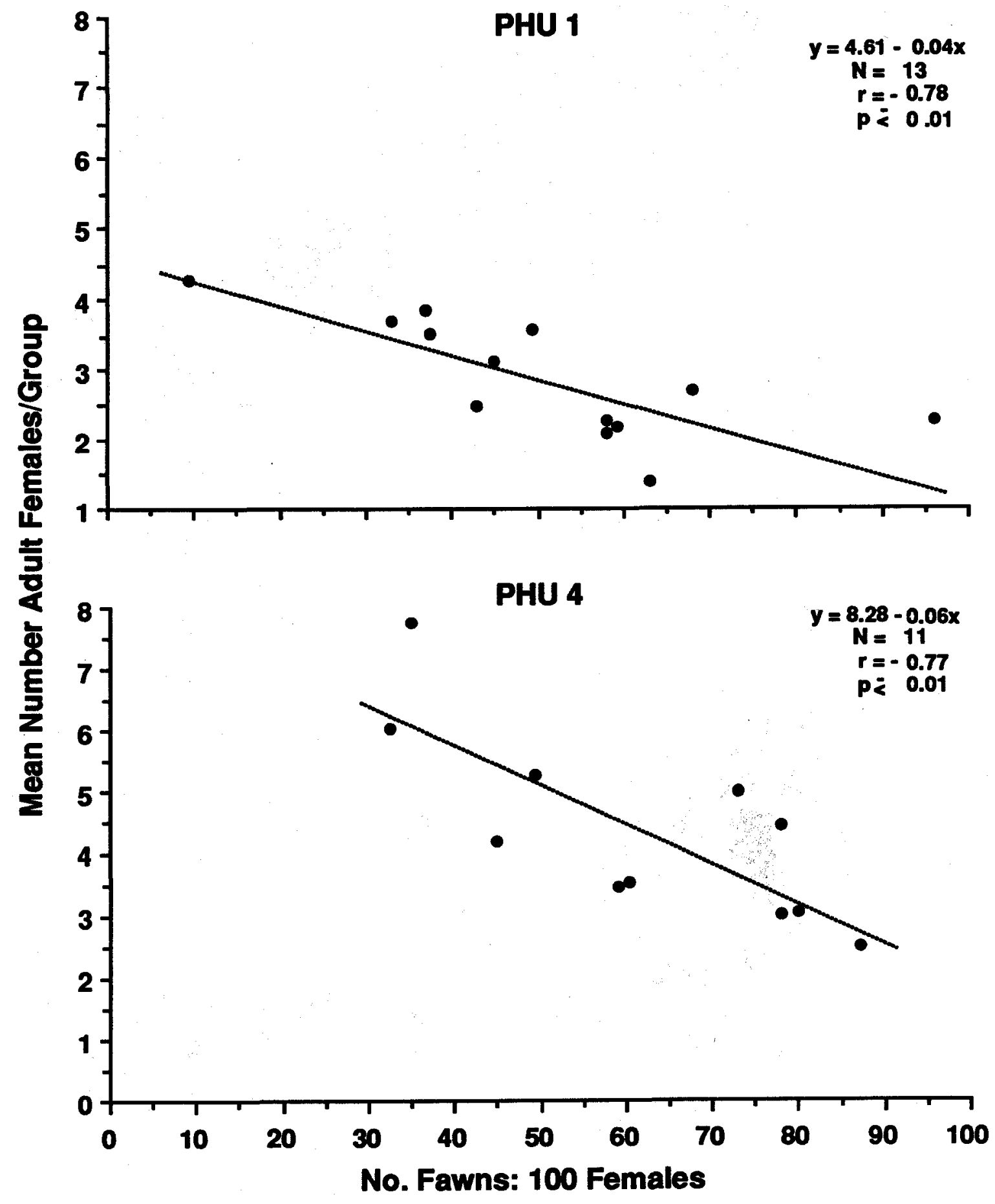

Figure 7.4. Relationship between mean numbers of adult females observed per group during December-January helicopter surveys and fawn:female ratio in early winter, PHUs 1 and 4, 1973-1985. 

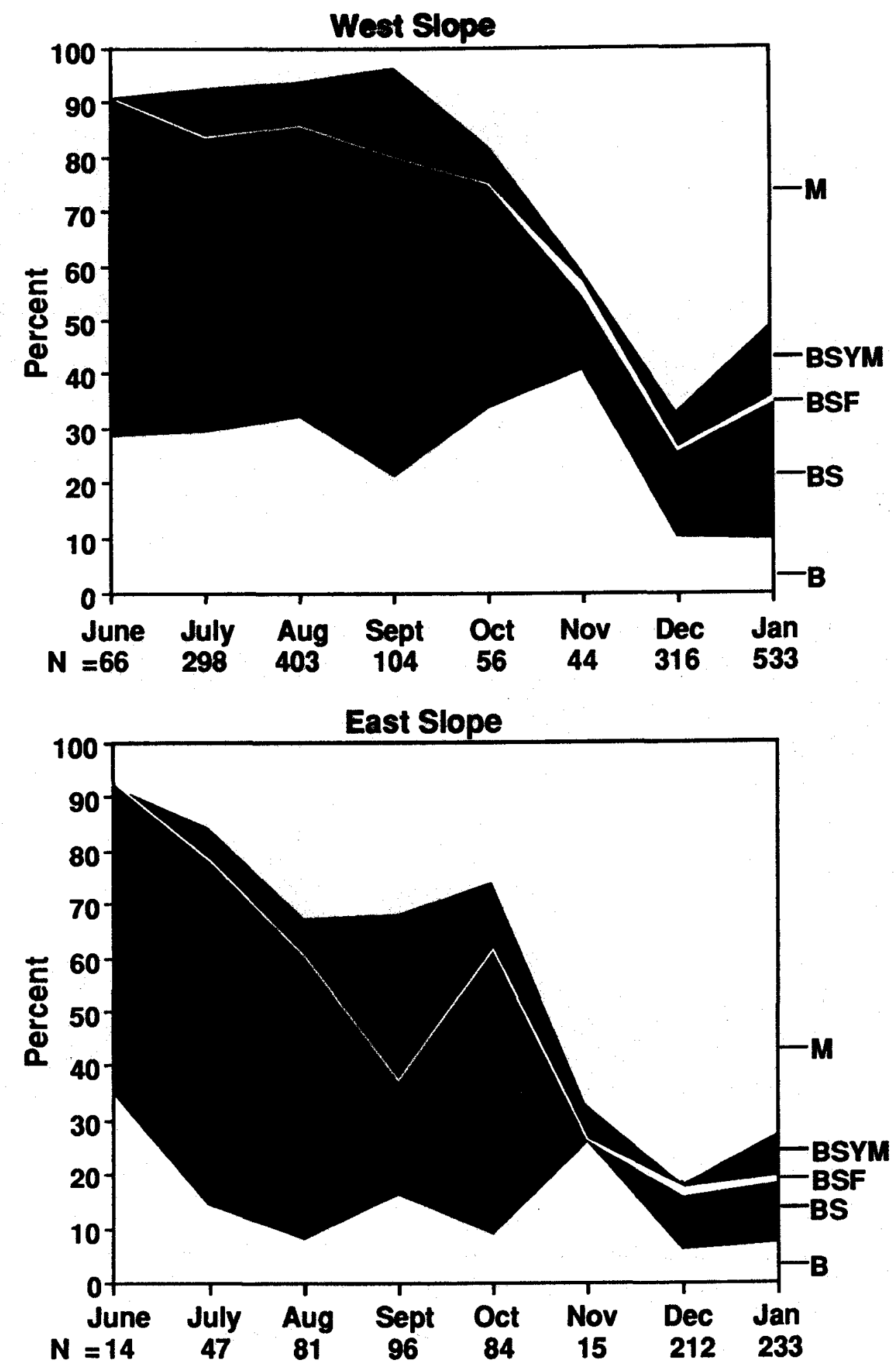

Figure 7.5. Percentage of mature bucks observed alone (B) and in other social groups on west and east slopes of the Bridger Mountains. Groups of more than one mature buck = BS; mature bucks and fawns = BSF; one or more mature bucks and yearling males $=\mathbf{B S Y M}$; and mixed groups $=\mathbf{M}$. $\mathbf{N}=$ number of mature bucks. 
area. Association between mature bucks and yearling males increased to a peak in September; the magnitude of this peak was twice as large on the east slope. Mature bucks associated with adult does in mixed groups more commonly on the east slope throughout summer and autumn.

Mature males were least sociable with other males during the November rut when most bucks were alone or in the company of adult does. Among all social groups including mature bucks, 93\% contained only one mature male (Fig. 7.6). Association between mature bucks and yearling males also reached a minimum on both areas during the rut in November and December (Fig. 7.5). By late December and January with movement toward winter ranges at the conclusion of the breeding season, groups with two or more mature males began to increase (Fig. 7.6). During all months (JuneJanuary), mature buck groups were less common in PHU 4 than in PHU 1 (Fig. 7.1).

The social structure of the two sexes complimented one another by potentially reducing competition for forage and space. This relationship was most evident during parturition and early fawn rearing when productive females experienced significant physiological demands and specialized resource requirements.

\section{Mixed Groups}

Mixed groups were considerably less definitive than either doe or buck groups. They represented temporary associations that occurred in relation to specific activities or in response to environmental factors. Mixed groups were comparatively uncommon during June-October when does sought isolation to raise fawns and bucks associated with one another (Fig. 7.1). Observations of mixed groups increased in November with the onset of the breeding season and peaked in December-January when weather conditions forced deer to congregate on limited winter habitat.

\section{Yearling Male Groups}

Yearling male groups represented "social drifters" that, given opportunity, preferred to associate with adult females or mature bucks. An early summer (June-July) peak in yearling males that were solitary or in the company of other yearling males occurred on both slopes (Fig. 7.7). On the west slope, association between yearling males and adult does with fawns increased steadily through October then declined in November when groups of one or more yearling males increased sharply. In contrast, on the east slope, yearling males were more frequently observed in the company of does and/or fawns during November than any previous month. Higher proportions of mature bucks in populations on the west slope may have limited the ability of yearling males to associate with adult does during the breeding season. By December and January, yearling males were primarily found in doe or mixed groups. Post-rut association of yearling males with mature bucks increased by January, particularly on the west slope. 

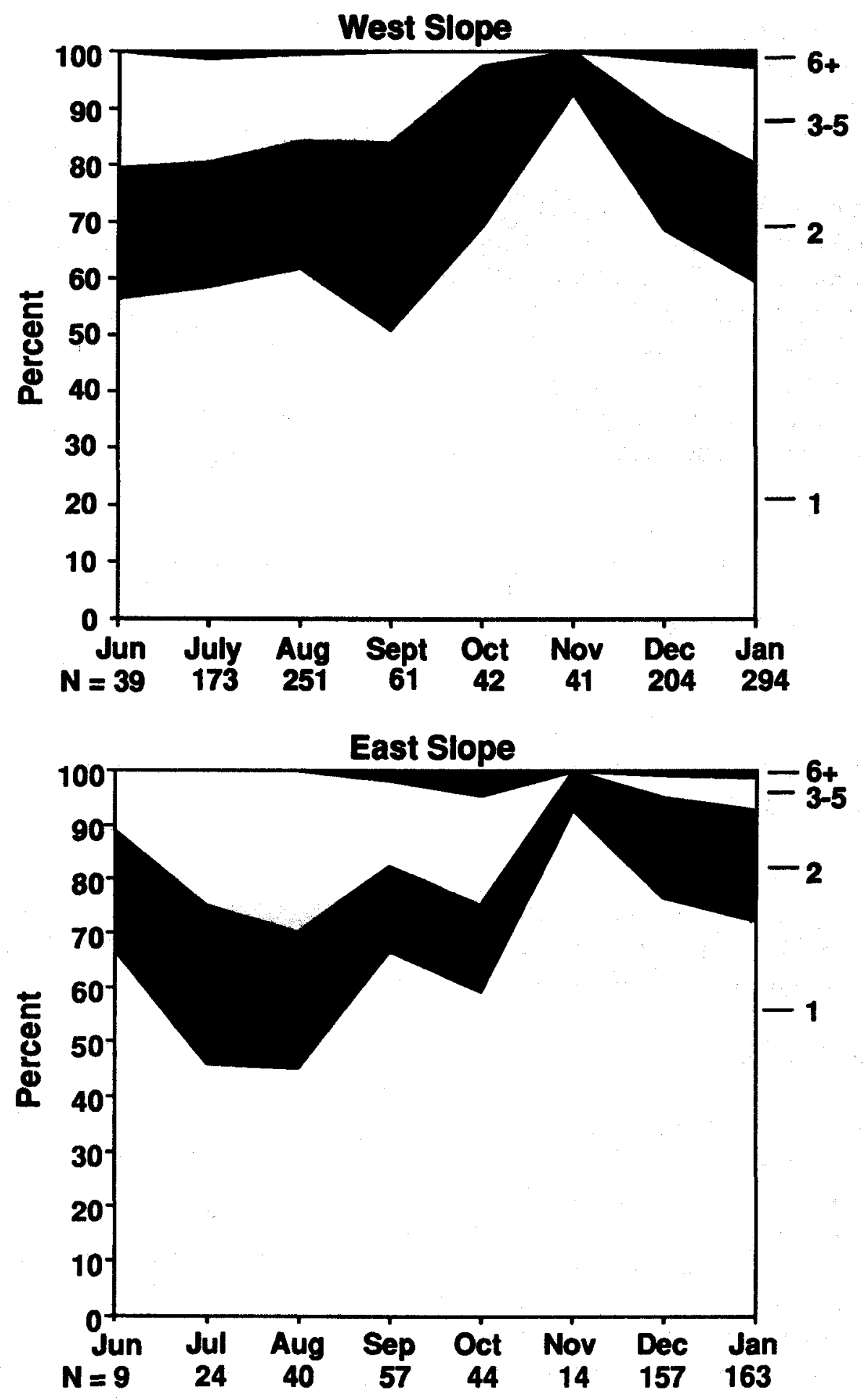

Figure 7.6. Percent of groups observed by month that included 1, 2, 3-5, and 6 or more mature males ( $\geq 2.5$ years) on the west and east slopes of the Bridger Mountains. N $=$ number of completely classified groups. 

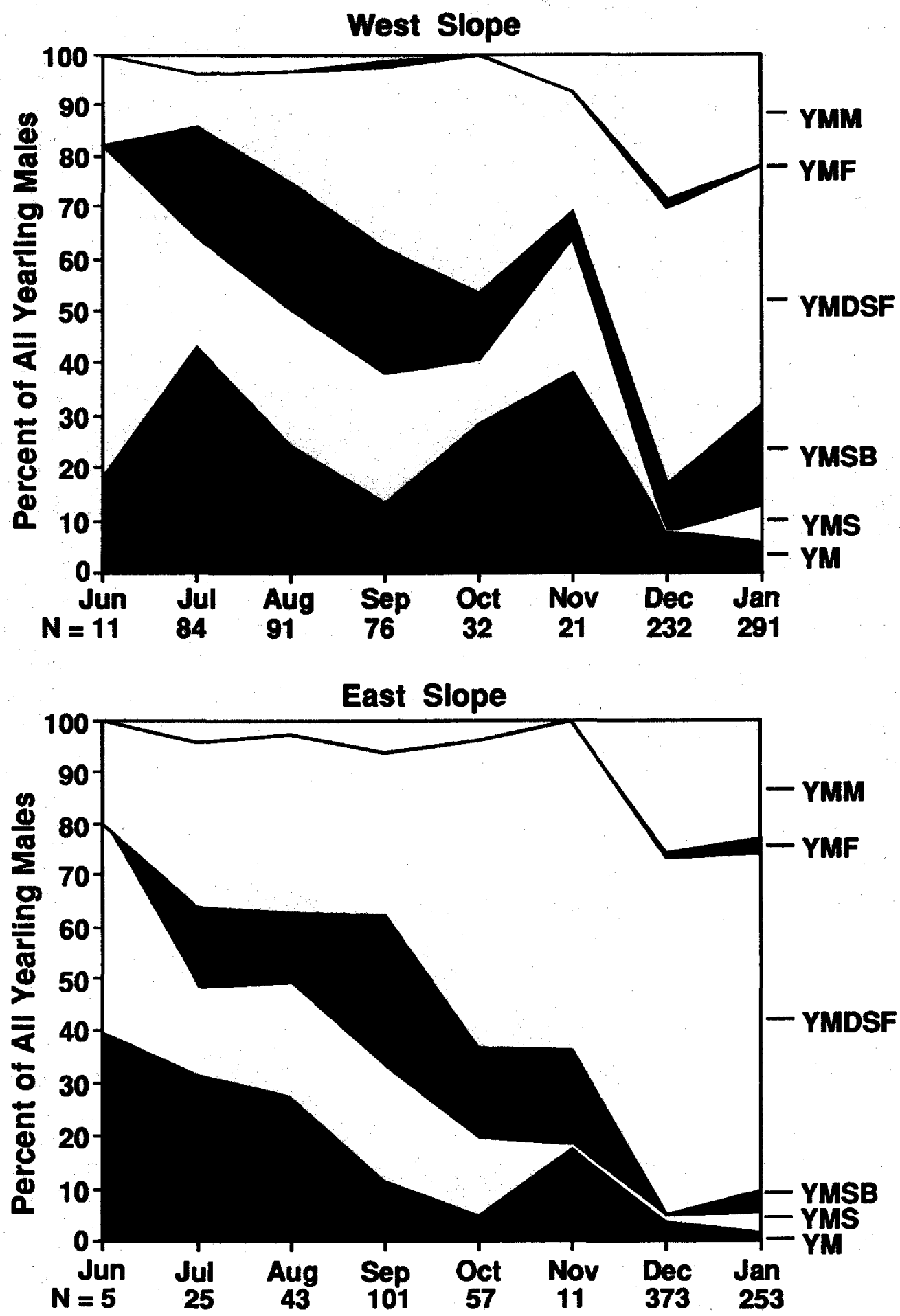

Figure 7.7. Percentage of yearling males observed alone (YM) and in other social groups on the west and east slopes of the Bridger Mountains. Groups of more than one yearling male = YMS; yearling male and mature buck = YMSB; yearling male(s) and does and fawns = YMDSF; yearling males and fawns = YMF; and yearling male(s) in mixed groups $=\mathbf{Y M M}$. $\mathbf{N}=$ number of yearling males. 
Monthly and Seasonal Changes in Group Size

Monthly changes in size of the four social groups were similar in populations on the west and east slope (Fig. 7.8). Yearling male groups were generally the smallest and varied least between months. Buck groups were only slightly larger than yearling groups during most months and minimal in November. Doe groups gradually increased in size through January, although temporary decline (west) or leveling off (east) occurred in November. Mixed groups were largest during all months, but were relatively uncommon until December when deer congregated on winter ranges.

Trends in monthly mean size of all groups were similar for west and east slope populations during June-August (Fig. 7.9). Beginning in September, however, mean group sizes began to increase and diverge with larger groups occurring on the east slope through April.

A distinct peak in group size occurred during mid-winter (February) on the east slope. On the west slope, group size peaked two months later in April when deer were particularly concentrated in a narrow zone of open footslopes that provided new, green forage. May was the only month when group size on the west slope was noticeably larger than the east slope average. Larger group sizes on the west slope during May were associated with a longer period of use of winter ranges. On the east slope, concentrations of deer on the winter range had disbanded by May as individuals moved toward their summer ranges.

Frequency distribution of group size classes by season for PHUs 1 and 4 are shown in Fig. 7.10. During summer, $75-78 \%$ of all groups in each population included only one or two deer, and there were no significant differences in group size class distribution between the two populations.

By autumn, significantly more groups in the larger size classes were observed on PHU 4 where $49 \%$ of groups included four or more deer compared to 32\% on PHU 1. This trend continued through winter.

In spring, $67 \%$ of all groups on the Northwest Slope contained four or more deer compared to $59 \%$ in winter. Groups of ten or more deer increased from $20-27 \%$. On PHU 4, the percentage of groups in the larger size classes declined as deer moved off winter range at an earlier date than on the west slope. The net result was a convergence of group size distributions $(P=0.18)$ for the two populations during spring (Fig. 7.10).

Habitat Factors Influencing Group Size and Distribution

In both populations, group size in summer was small and relatively uniform across habitats of varying cover density (Figs. 7.11 and 7.12). Behavioral requirements 


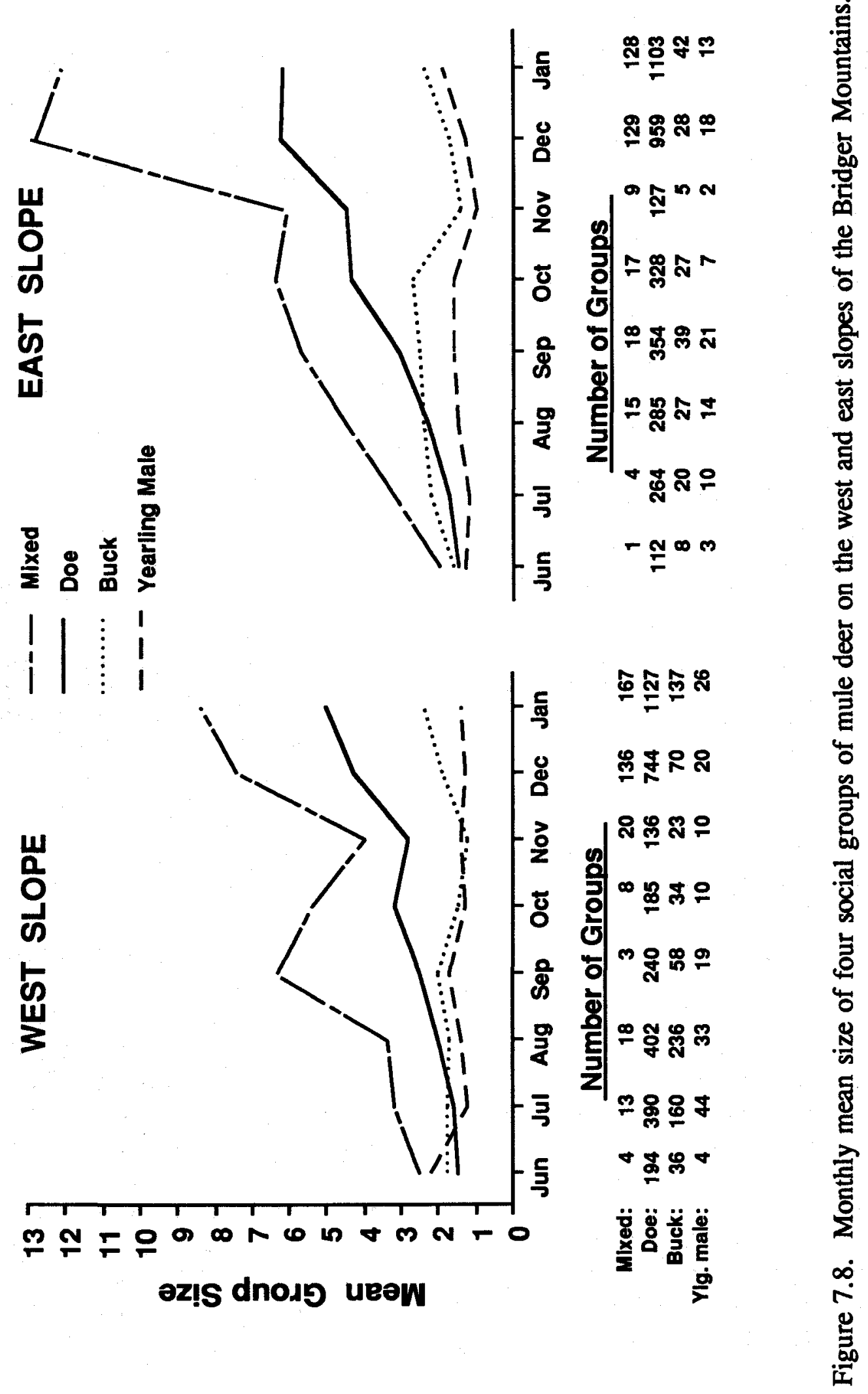




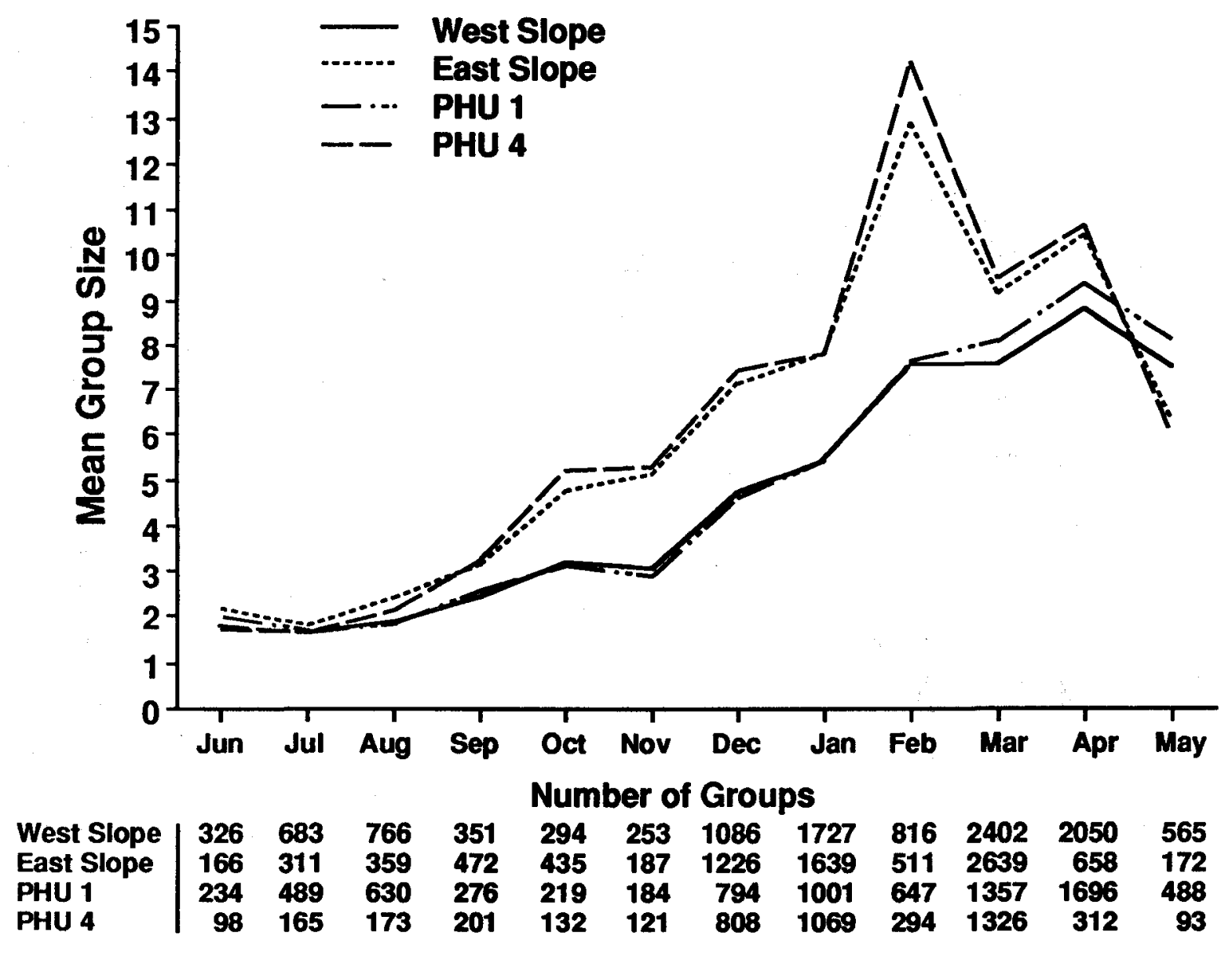

Figure 7.9. Monthly trends in mean group size among four study units within the Bridger Mountains.

of maternal does for isolation from other adult deer during fawn-rearing apparently overrode any potential influence of cover density on group size.

Stratification between the sexes in relation to group characteristics and dispersion was more evident during summer than other seasons. This resulted in habitat partitioning among the sexes (Fig. 7.13). On the west slope, adult females were distributed differently $\left(\mathrm{N}=2,433, \mathrm{X}^{2}=331.3, \mathrm{df}=3, \mathrm{P}=0.000\right)$ than mature males among the major vegetation zones. Adult females were most frequently observed in the montane forest while mature bucks predominated in the subalpine-alpine zone. Although adult females and yearling males were also distributed differently $\left(\mathrm{N}=1,827, \mathrm{X}^{2}=8.8 \mathrm{df}\right.$ $=3, P=0.032$ ), visual inspection of Fig. 7.13 indicated that these two distributions were more similar than any other pair combination. Yearling males and mature bucks were differently distributed $\left(\mathrm{N}=1,094, \mathrm{X}^{2}=131.5\right.$, $\left.\mathrm{df}=3, \mathrm{P}=0.000\right)$. 


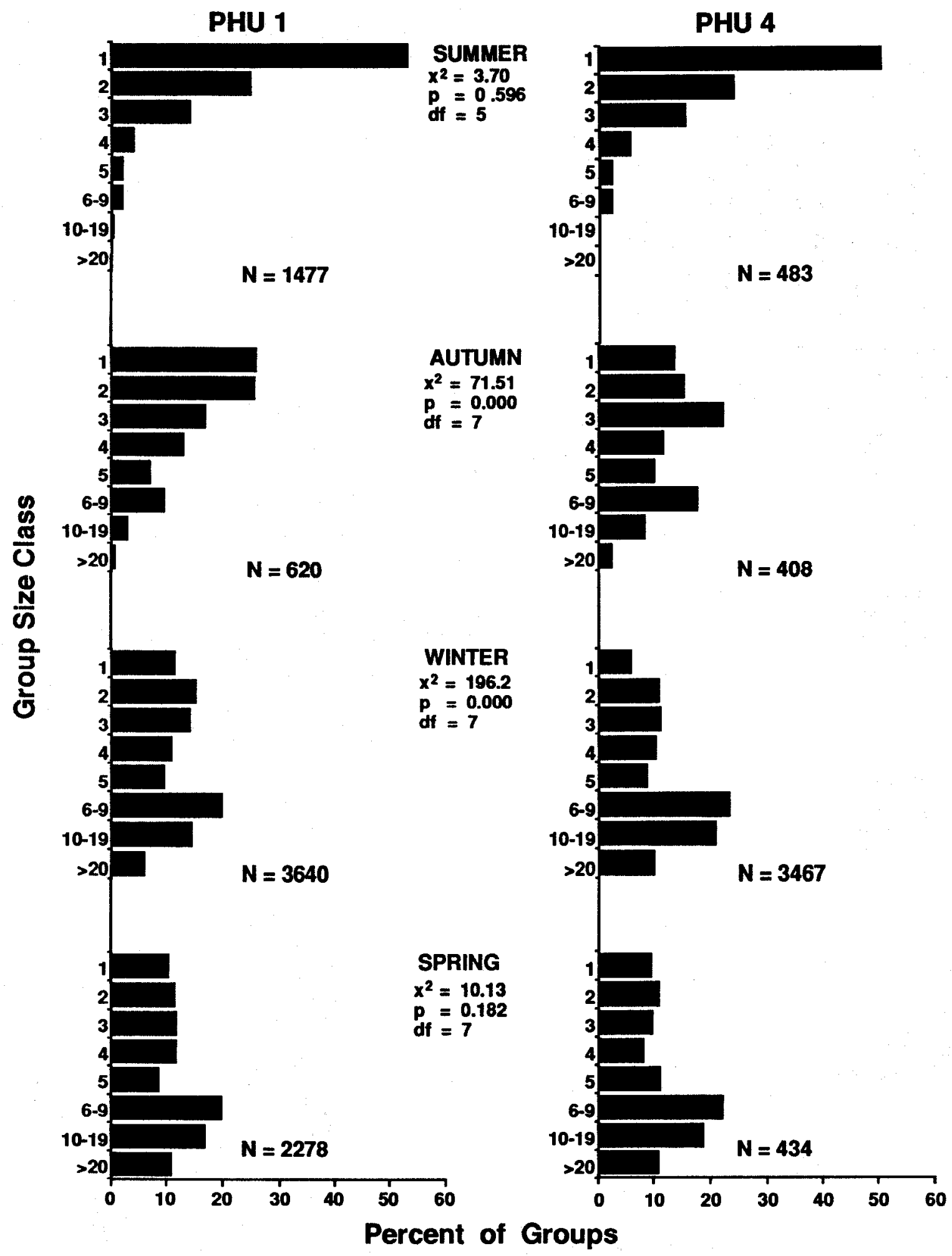

Figure 7.10. Frequency distribution of group size classes by season for PHUs 1 and 4 . $\mathbf{N}=$ number of groups observed by season. 


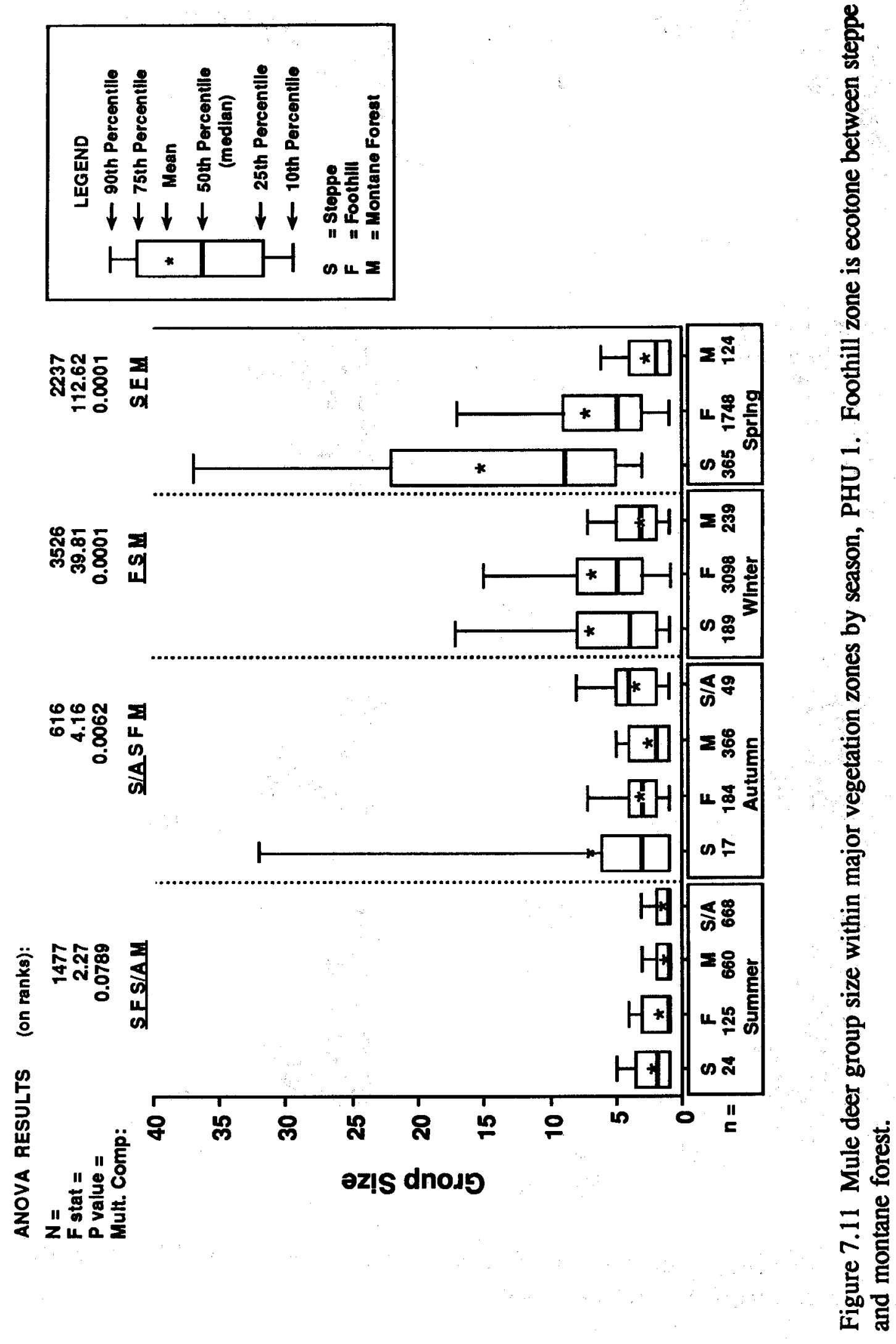




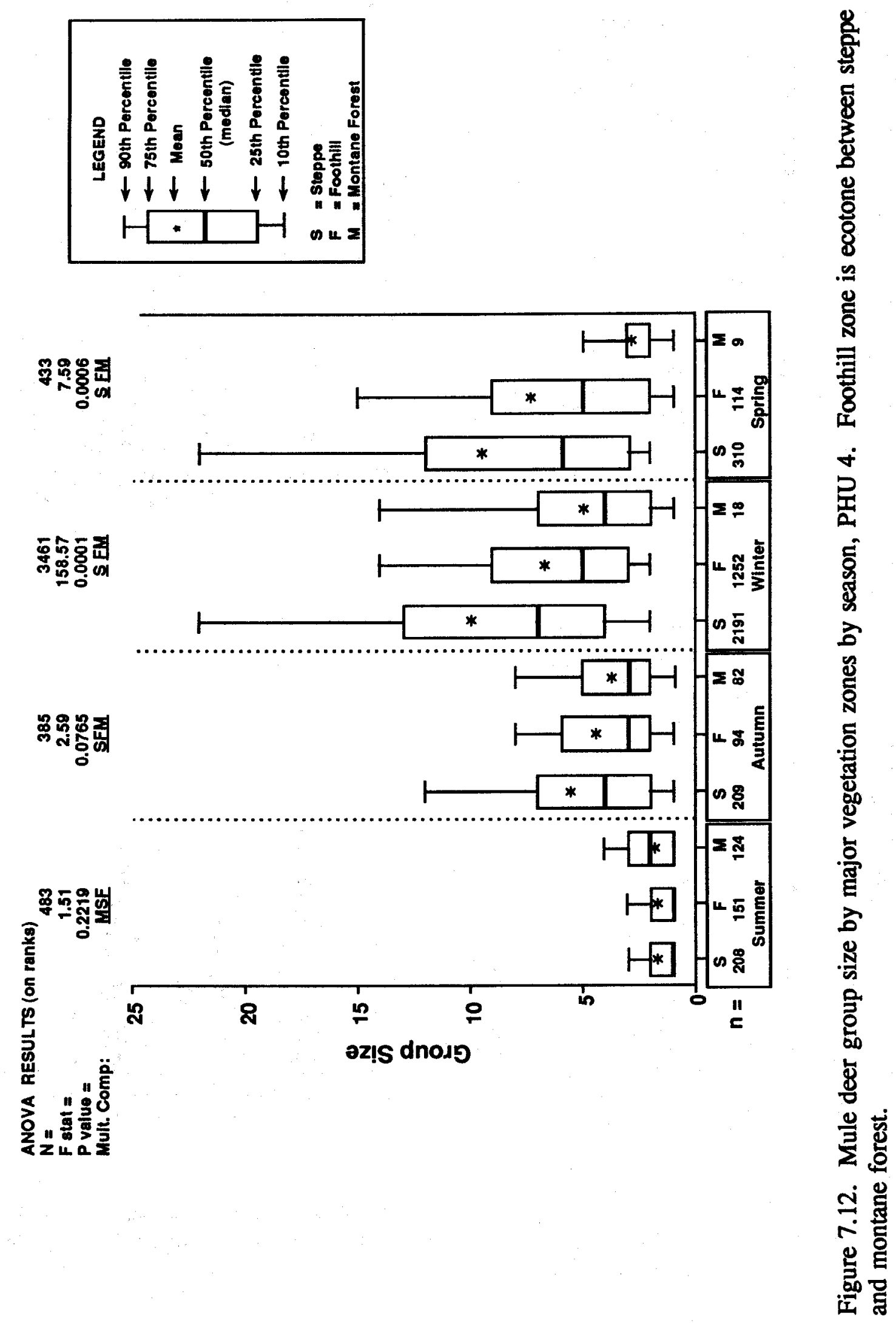



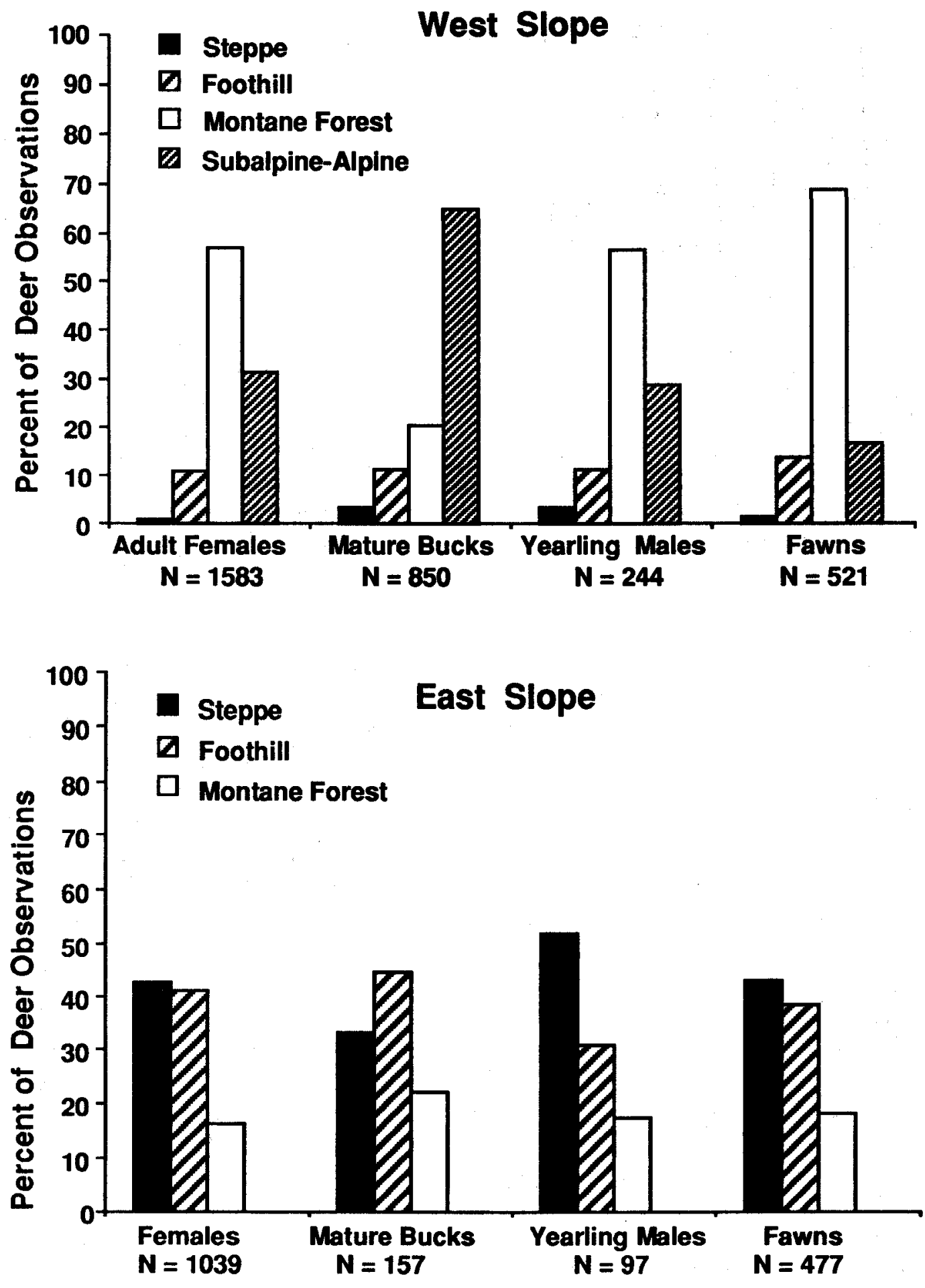

Figure 7.13. Relative occurrence of adult females, mature bucks, yearling males and fawns within vegetation zones during summer (16 June-15 September) on the west and east slopes of the Bridger Mountains. 
Surprisingly, fawns were distributed differently than adult females $(N=2,104$, $\mathrm{X}^{2}=41.4, \mathrm{df}=3, \mathrm{P}=0.000$ ) on the west slope. Compared to adult females, fawns were more frequently observed in the montane forest and less frequently seen in the subalpine-alpine zone. Frequency of observations were similar in the steppe and foothill zones. For all observations by major habitat type during summer on the west slope, 38, 42,40 , and 18 fawns: 100 does were recorded in the steppe, foothill, montane forest, and subalpine-alpine. However, the montane forest accounted for nearly $70 \%$ of all fawns observed. This reflected differential dispersion and habitat use between productive and non-productive adult females as also reported for mule deer in the Missouri River breaks (Hamlin and Mackie 1989). Fawns were also distributed differently than mature bucks $\left(\mathrm{N}=1,371, \mathrm{X}^{2}=363.1, \mathrm{df}=3, \mathrm{P}=0.000\right)$ and yearling males $\left(\mathrm{N}=765, \mathrm{X}^{2}=\right.$ 20.0 , df $=3, P=0.000$ ).

Along the east slope, pairwise comparisons indicated fewer differences in the distribution of the sex and age classes across the vegetation zones (Fig. 7.13). However, adult females were distributed differently $\left(\mathrm{N}=1,196, \mathrm{X}^{2}=6.6, \mathrm{df}=2, \mathrm{P}=0.037\right)$ than mature bucks. Adult females were more commonly observed in the steppe zone and less frequently seen in the montane forest compared to mature males. Yearling males were distributed differently than mature bucks $\left(\mathrm{N}=254, \mathrm{X}^{2}=8.6, \mathrm{df}=2, \mathrm{P}=\right.$ 0.014). Yearling males were observed more commonly in the steppe and less frequently in the foothills than mature bucks. Similar numbers of each were recorded in the montane forest.

During autumn, forage desiccation and snowfall became primary influences on habitat use, overriding behavioral preference for small group sizes and maximum dispersion. These factors became even more important in subsequent months as accumulating snow cover increasingly restricted deer on winter range and group size became increasingly more responsive to cover density in a manner similar to that described for white-tailed deer by Hirth (1977).

Group sizes were largest in open shrub-grasslands and smallest in forested habitats (Figs. 7.11 and 7.12). In the foothill and subalpine-alpine, cover densities were similar to one another and group sizes were intermediate to the other zones. The foothill zone represented the ecotone between steppe and forest. The high elevation subalpine-alpine zone occurred in PHU 1 and was absent from PHU 4.

\section{Summary}

1. Mule deer society centered in maternally-related groups of females. Other social groups (buck, mixed and yearling male) were of secondary importance in occurrence and persistence.

2. Composition and size of doe groups was fundamentally influenced by the reproductive effort. Maternal does sought isolation from other deer during fawn- 
rearing in summer. By early autumn, maternally related females began to regroup. Female group size gradually increased to a peak in late winter or spring. Mean female group size was largest when average fawn:female ratios were lower and vice-versa.

3. Buck social structure was the antithesis of that described for adult does during summer and autumn. Mature bucks were most sociable with each other during June-October and least sociable during the rut in November.

4. Social structure of the sexes complimented one another by reducing competition for forage and space. This was most evident during parturition and early fawn rearing when females experienced significant physiological demands and specialized resource requirements.

5. Mixed groups of adult does and mature bucks represented temporary associations that occurred in relation to specific activities or in response to environmental factors.

6. Yearling male groups represented "social drifters" that, given opportunity, preferred to associate with adult females or mature bucks.

7. Monthly mean size of all groups was small and similar during June-August for deer on west and east slope ranges. Group sizes began to increase and diverge in September with larger groups on the east slope. Group size peaked in February on the east slope and in April on the west slope.

8. Observations of deer by vegetation zone during summer indicated that the distribution of males and females by vegetation zone was significantly different in both west and east slope PHUs. 


\section{CHAPTER 8}

\section{REPRODUCTION AND MORTALITY}

Reproduction, Fawn Mortality, and Recruitment

\section{Conception and Birthdates}

Growth curves developed by Hudson and Browman (1959) were used to predict ages of fetuses recovered from reproductive tracts of 39 females during winter-spring 1972-1988. Back-dating suggested conception occurred between 16 November and 7 January with a median date of 6 December. Median breeding dates for mature $(\mathbf{N}=32)$ and yearling females $(\mathrm{N}=7)$ were 5 December and 13 December, respectively. Breeding spanned a 52 day period with $75 \%$ occurring between 16 November and 14 December. This was 18 days longer than reported for mule deer in the Missouri River Breaks of northcentral Montana where $75 \%$ of the conception dates fell between 21 November and 1 December (median $=24$ November) (Hamlin and Mackie 1989).

Assuming a gestation period of 203 days (Robinette et al. 1973), parturition occurred from 6 June through 26 July with a median of 26 June. By comparison, the median birth date in the Missouri River Breaks was 16 June (range $=6$ June-15 July). Robinette et al. (1977) reported later fawning on high elevation summer ranges similar to the Bridger Mountains which were more than 1,000 meters higher than the Missouri River Breaks.

Comparatively later and more varied conception and birth dates in the Bridgers could have developed in several ways. A significant number of females could have failed to conceive in the first estrus cycle. Also, fetal development in the last trimester of gestation may have been slower during periodic severe winters. Another explanation could relate to greater variation in the timing of the first estrus cycle between years and/or individual females. Both Verme (1965) and Robinette et al. (1973) indicated that females on a higher nutritional plane gave birth earlier or had a shorter gestation period than females on a lower plane. Hamlin and Mackie (1989) inferred that a threshold birth weight may exist and that gestation could be longer for females on lower nutrition.

Pregnancy, Ovulation, and Fetal Rates

No instances of pregnancy were recorded among 12 fawns for which reproductive status was determined (Table 8.1). In a sample of mule deer killed on highways 
Table 8.1. Potential productivity of mule deer in the Bridger Mountains. Data are from 50 reproductive tracts collected during 1972-1988; 38 (76\%) of which were from the west slope.

\begin{tabular}{|c|c|c|c|c|c|c|}
\hline Age & No. Females & $\begin{array}{c}\text { No. } \\
\text { Pregnant }\end{array}$ & $\begin{array}{c}\text { Fetuses: } 100 \\
\text { Preg. Females }\end{array}$ & $\begin{array}{l}\text { Fetuses: } 100 \\
\text { Females }\end{array}$ & $\begin{array}{l}\text { Ovulation } \\
\text { Rate }^{1}\end{array}$ & $\begin{array}{c}\text { Fertilization } \\
\text { Rate (\%) }\end{array}$ \\
\hline$<1$ & 12 & 0 & 0 & 0 & 0 & - \\
\hline$>1<2$ & 8 & 7 & 114 & 114 & 1.33 & 86 \\
\hline$>2<8$ & 24 & 24 & $158^{2}$ & 158 & 2.00 & 79 \\
\hline$\geq 9$ & 18 & 14 & $114^{3}$ & 89 & 1.85 & 62 \\
\hline \multicolumn{7}{|l|}{ Total } \\
\hline$\geq 11 / 2$ & 50 & 45 & 138 & 127 & 1.83 & 75 \\
\hline ] & is were bas & on 36 repro & ctive tracts & & & \\
\hline
\end{tabular}

throughout Montana during 1976-1981, only 1 of 26 females 6-11 months of age was pregnant (Pac 1979). The pregnant fawn, which weighed $41.8 \mathrm{~kg}$., was killed 3 March 1981 in agricultural-riparian habitat in the Gallatin Valley west of the study area. Compared to most fawns in late winter, this individual was in superior physical condition. It contained a single fetus weighing $28 \mathrm{~g}$. The fetal crown-rump measurement $(102 \mathrm{~mm})$ indicated that conception occurred about 24 December.

Reports of pregnancy in free ranging mule deer fawns are extremely rare. A full term fetus was recovered from a yearling killed on 15 July in Utah (Jensen and Robinette 1955). Nellis et al. (1976) also reported a fetus recovered from a mule deer fawn in Idaho. Robinette et al. (1955) found no pregnancies among 107 fawns in Utah; however, 7 of 167 sets of ovaries from yearlings contained pigmented scars. Similar indirect evidence of occasional fawn breeding has been reported for New Mexico (Anderson et al. 1970) and Arizona (Swank 1958).

Among 50 yearling and older females examined in the Bridger Mountains, 90\% were pregnant (Table 8.1 ). Pregnancy rates were $88 \%$ for 8 yearlings, $100 \%$ for 24 females 2-8 years of age, and $78 \%$ for 18 females 9-14 years of age.

Fetal rates among females 2-8 years of age were noticeably higher than for yearlings and 9-14 year olds. However, the overall fetal rate for females $\geq 1.5$ years in the Bridger Range was lower than reported for other populations in Montana (Table 8.2). In-utero productivity reported for the Missouri Breaks (Hamlin and Mackie 1989) probably was minimal because many of the reproductive tracts were recovered during years of severe drought when other population parameters indicated suppressed 
Table 8.2. Comparison of potential productivity among mule deer females $\geq 1.5$ years from five studies in Montana.

\begin{tabular}{|c|c|c|c|c|c|}
\hline Source & $\begin{array}{l}\text { No. } \\
\text { Females }\end{array}$ & $\begin{array}{c}\mathscr{\%} \\
\text { Pregnant }\end{array}$ & $\begin{array}{l}\text { Fetuses: } 100 \\
\text { Preg. Female }\end{array}$ & $\begin{array}{c}\text { Fetuses: } \\
100 \\
\text { Females }\end{array}$ & $\begin{array}{l}\text { Ovulation } \\
\text { Rate }\end{array}$ \\
\hline Bridger Mountains & 50 & 90 & 138 & 127 & 1.83 \\
\hline $\begin{array}{l}\text { Moiese Bison Range (Nellis } \\
\text { 1968) }\end{array}$ & 151 & 89 & 167 & 150 & 1.68 \\
\hline $\begin{array}{l}\text { Missouri Breaks (Hamlin and } \\
\text { Mackie 1989) }\end{array}$ & 39 & 97 & 155 & 151 & 1.70 \\
\hline $\begin{array}{l}\text { Rosebud/Garfield Counties } \\
\text { (Eustace 1971) }\end{array}$ & 19 & 100 & 190 & 190 & - \\
\hline $\begin{array}{l}\text { Statewide Highway Collection } \\
\text { (Pac 1979) }\end{array}$ & 129 & 85 & 155 & 131 & 1.69 \\
\hline
\end{tabular}

reproduction. Both pregnancy and fetal rates from the statewide collection may have been minimized by greater than average representation of less productive yearling females.

Ovulation rates were generally high and similar among prime and old females; both were higher than recorded for yearlings. However, fertilization rates decreased progressively from $86 \%$ among yearlings to $79 \%$ in prime-aged females and $62 \%$ in the oldest age classes (Table 8.1). The fertilization rate of $75 \%$ for females $\geq 1.5$ years was substantially lower than reported for other populations in Montana (Nellis 1968, Hamlin and Mackie 1989) and elsewhere (Robinette et al. 1955). This suggested relatively high rate of failure in fertilization/implantation and/or high intrauterine fetal mortality. Because females were collected in various stages of pregnancy, it was impossible to determine directly either the total number of fetuses implanted or total intrauterine loss.

Four of 50 reproductive tracts provided evidence of fetal resorption or abortion. Three were females aged 12-14 years. The fourth was 6 years old. All were in relatively poor condition when collected from winter range in PHU 1 during late April and early May. The uteri of three including the 6-year old were larger than those in non-pregnant does at the time, but no fetuses were found. Two sets of ovaries contained 1-2 corpora lutea of pregnancy. The ovaries of the 6-year old were not recovered. The fourth female contained one normal fetus and the remnant of a resorbed fetus. One of her ovaries had atrophied and the other contained two corpora lutea of pregnancy. 
Forty-eight percent of the females $\geq 1.5(\mathrm{~N}=42)$ carried twin fetuses. No triplets were recorded. Yearling $(N=7), 2-8$ year olds $(N=23)$, and 9-14 year old females $(N=12)$ produced 14,65 , and $33 \%$ twin litters, respectively.

The fetal sex ratio was 84 males: 100 females $(N=57$ fetuses) which was not significantly different than a 1:1 ratio $\left(\mathrm{X}^{2}=0.218, \mathrm{P}=0.64\right)$.

\section{$\underline{\text { Litter Size }}$}

The proportion of adult females observed with twin litters was significantly higher in east as compared with west slope populations during summer $\left(X^{2}=4.960, P=\right.$ 0.026 ) and autumn $\left(X^{2}=18.518, P=0.000\right.$ ) (Fig. 8.1). Proportions were similar for the two areas during early winter $\left(X^{2}=0.614, P=0.433\right)$ and late winter $\left(X^{2}=0.531\right.$, $P=0.466$ ). During spring after most juvenile mortality had occurred, the percentage of twin litters observed on the east slope was significantly higher $\left(X^{2}=4.793, P=\right.$ 0.029 ) than on the west slope. This resulted from a sharp drop in twins observed between late winter and spring on the west slope while little change occurred on the east slope.

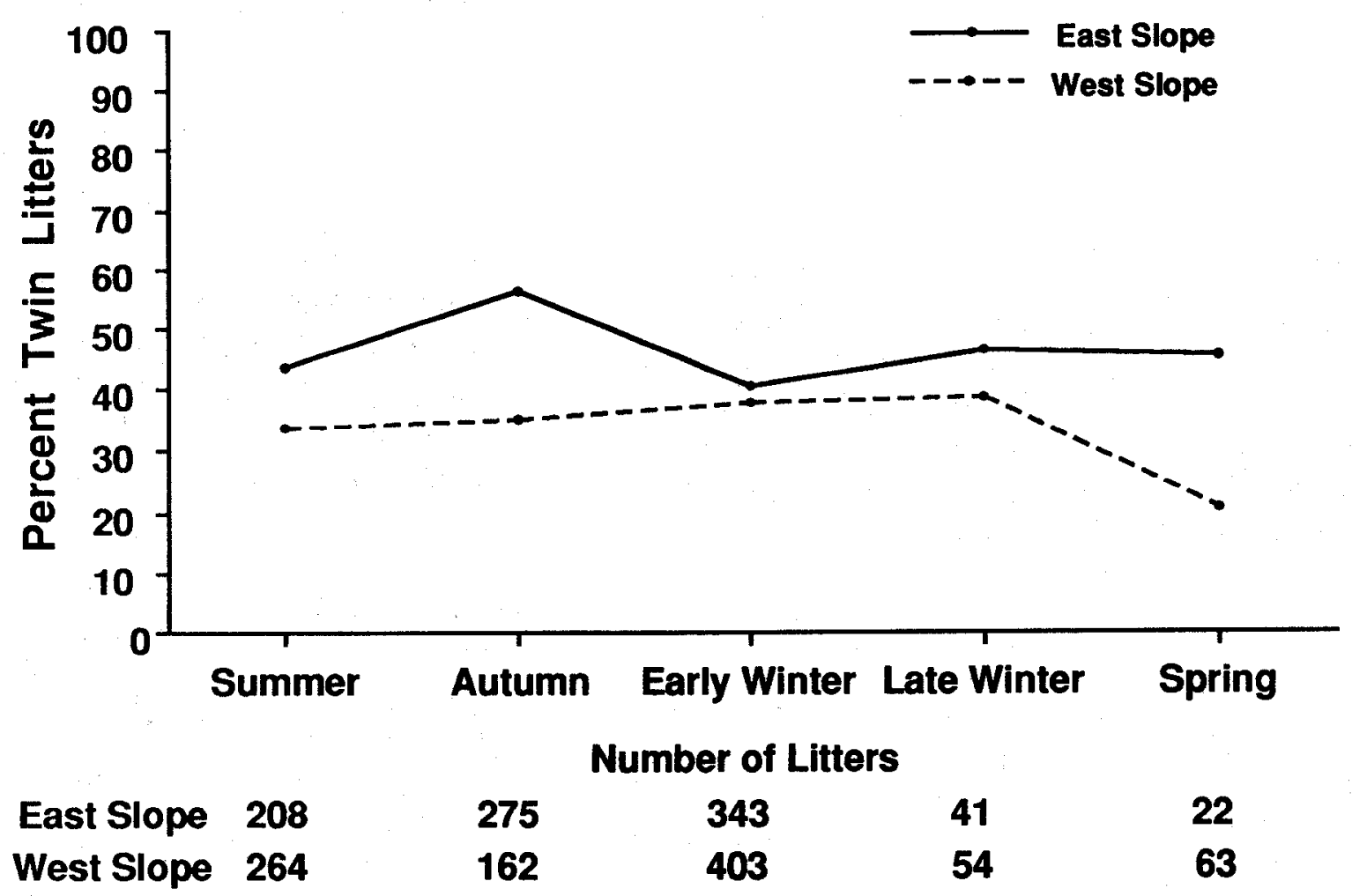

Figure 8.1. Percent twin litters observed by season on the east and west slope of the Bridger Mountains. 
Triplets comprised only 2 of 264 litters observed on the west slope and 3 of 208 litters on the east slope. By early winter, the incidence of triplets increased to 5 and $8 \%$ of litters observed on the two areas, respectively. We could not determine if the higher percentage in winter was real, related to better observability, or the result of either "adoption" or misclassification.

Some differences in reproductive performance were recorded among marked adult females in PHU 1 that followed different movement strategies. Females $(\mathbf{N}=31)$ that did not cross the Bridger Divide during summer produced an average of $0.90 \pm 0.82$ fawns during 49 reproductive seasons. This included 39,33 , and $29 \%$ with 0,1 , and 2 fawns, respectively. Slightly greater fawn production $(1.00 \pm 0.76)$ was recorded for 17 adult females that summered east of the Bridger Divide (29 reproductive seasons). They included 28,45 , and $28 \%$ with 0,1 , and 2 fawns, respectively.

By spring, the discrepancy between the two groups was even greater. Females $(\mathrm{N}=43)$ that remained on the west slope successfully reared an average $0.24 \pm 0.52$ fawns during 75 seasons while "divide crossers" $(\mathrm{N}=22)$ reared $0.60 \pm 0.78$ fawns during 35 seasons. Apparently, the benefits of summering in diverse, mesic habitats east of the Bridger Divide outweighed the longer time females on the west slope spent on summer home ranges.

Radio-collared females summering west of the divide included some individuals that used low elevation, early summer accessory areas during parturition (see Chapter 6). Seven of these deer produced an average $1.23 \pm 0.93$ fawns during a total of 13 reproductive efforts. This included 31,15 , and $54 \%$ with 0,1 , and 2 fawns. Eight females that did not use early summer accessory areas produced an average of $1.00 \pm$ 0.68 fawns during 14 seasons that included 21,57 , and $21 \%$ with 0,1 , and 2 fawns.

Movement patterns involving greater distance or specialization did not result in comparatively lower reproductive performance. In fact, adult females that crossed the Bridger Divide appeared more successful in rearing fawns to recruitment than those living yearlong on the west flank of the Bridger Ridge. Within limits, the costs of specialization may be more than offset by benefits gained from a different, proven successful strategy of habitat use.

\section{Fawn Mortality}

Annual fawn mortality rates (Fig. 8.2) were derived from arithmetic models of populations on the Armstrong segment of PHU 1 and PHU 4 (Tables 8.3 and 8.4). Over 14 years, the mean annual rate for PHU 1 was $73 \pm 11 \%$. During a comparable 9-year (1979-87) period within those 14 years, fawn mortality averaged $69 \pm 9 \%$ for PHU 1 and $65 \pm 13 \%$ in PHU 4. Minimum and maximum rates were 55 and $97 \%$ in the former and 35 and $84 \%$ in the latter. Compared to PHU 1 , mortality was generally lower on PHU 4 during 1979-1981 and higher during 1983-1986. Rates were similar in 1982 


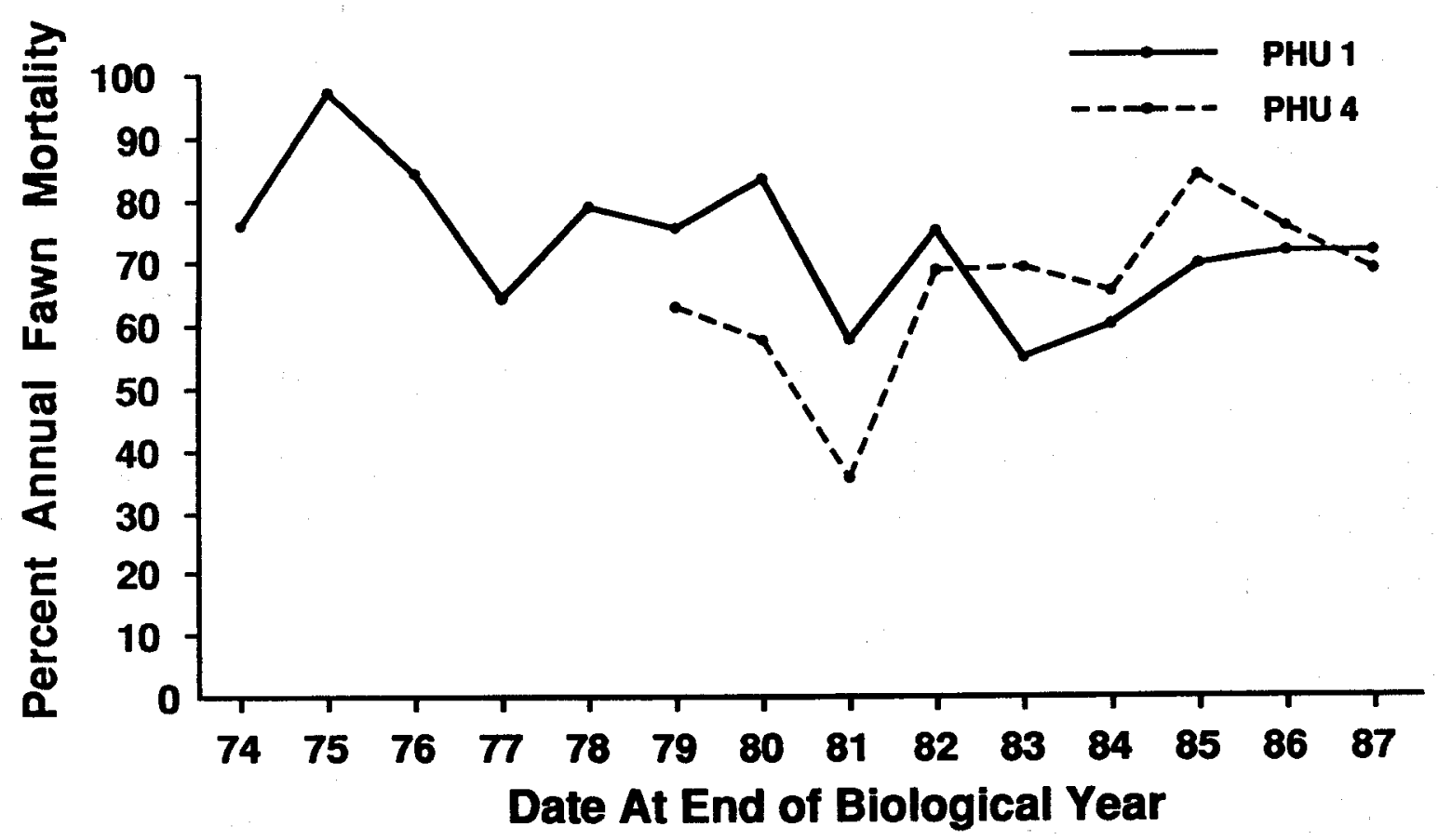

Figure 8.2. Comparison of annual fawn mortality rate in PHUs 1 and 4.

and 1987. During some biological years (e.g. 1979-80) mortality rates differed by as much as $26 \%$ between populations. Over all years, annual mortality rates were less variable in PHU 1.

Annual fawn mortality rates ranging from 55 to $65 \%$ were associated with moderate to substantial increases in deer numbers in PHU 1. Occasionally, total population size increased slightly despite annual fawn mortality as high as $84 \%$.

Generally, however, fawn mortality rates in excess of $75 \%$ were associated with declines in population size. The relationship between annual fawn mortality and population trend was more variable in PHU 4, primarily because of periodically higher adult mortality.

The temporal distribution of fawn mortality during the biological year in PHU 1 is shown in Fig. 8.3. On the average, fawn mortality rates were higher and less variable between 1 June and 1 December than between 1 December and 31 May. An average of $75 \%$ of total annual losses occurred during the earlier period.

The highest recorded rate of fawn mortality for 1 June-1 December occurred in 1975 immediately following the highest recorded winter mortality (Fig. 8.3). Thus, the 1975 cohort was born to females in extremely poor physical condition. Additionally, plant development was extremely late with green forage not readily available until 1 June. Because of this, does had little time to recover condition before parturition and lactation. 
Table 8.3. Modeled population estimates for mule deer on the Armstrong segment of PHU 1, Bridger Mountains, 1973-1986.

\begin{tabular}{|c|c|c|c|c|c|}
\hline Date & Total & Adults & Fawns & Females & Males \\
\hline $\begin{array}{l}\text { June } 1,1973 \\
\text { December } 1,1973 \\
\text { May 31, } 1974\end{array}$ & $\begin{array}{l}408 \\
262 \\
231\end{array}$ & $\begin{array}{l}243 \\
202 \\
191\end{array}$ & $\begin{array}{r}165 \\
60 \\
40\end{array}$ & $\begin{array}{r}160 \\
150 \\
141 \\
\frac{20}{161}\end{array}$ & $\begin{array}{l}83 \\
52 \\
50 \\
\frac{20}{70}\end{array}$ \\
\hline $\begin{array}{l}\text { June } 1,1974 \\
\text { December } 1,1974 \\
\text { May 31, } 1975\end{array}$ & $\begin{array}{l}410 \\
258 \\
162\end{array}$ & $\begin{array}{l}231 \\
213 \\
157\end{array}$ & $\begin{array}{r}179 \\
45 \\
5\end{array}$ & $\begin{array}{r}161 \\
153 \\
115 \\
\frac{3}{118}\end{array}$ & $\begin{array}{c}70 \\
60 \\
42 \\
\frac{2}{44}\end{array}$ \\
\hline $\begin{array}{l}\text { June } 1,1975 \\
\text { December } 1,1975 \\
\text { May } 31,1976\end{array}$ & $\begin{array}{l}308 \\
180 \\
170\end{array}$ & $\begin{array}{l}162 \\
151 \\
147\end{array}$ & $\begin{array}{r}146 \\
29 \\
23\end{array}$ & $\begin{array}{r}118 \\
115 \\
111 \\
\frac{9}{120}\end{array}$ & $\begin{array}{l}44 \\
36 \\
36 \\
\frac{14}{50}\end{array}$ \\
\hline $\begin{array}{l}\text { June } 1,1976 \\
\text { December 1, } 1976 \\
\text { May 31, } 1977\end{array}$ & $\begin{array}{l}311 \\
200 \\
200\end{array}$ & $\begin{array}{l}170 \\
150 \\
150\end{array}$ & $\begin{array}{r}141 \\
50 \\
50\end{array}$ & $\begin{array}{r}120 \\
120 \\
120 \\
\frac{20}{140}\end{array}$ & $\begin{array}{l}50 \\
30 \\
30 \\
\frac{30}{60}\end{array}$ \\
\hline $\begin{array}{l}\text { June } 1,1977 \\
\text { December 1, } 1977 \\
\text { May 31, } 1978\end{array}$ & $\begin{array}{l}352 \\
212 \\
160\end{array}$ & $\begin{array}{l}200 \\
148 \\
128\end{array}$ & $\begin{array}{r}152 \\
64 \\
32\end{array}$ & $\begin{array}{r}140 \\
130 \\
116 \\
\frac{5}{121}\end{array}$ & $\begin{array}{l}60 \\
18 \\
12 \\
\frac{27}{39}\end{array}$ \\
\hline $\begin{array}{l}\text { June } 1,1978 \\
\text { December } 1,1978 \\
\text { May 31, } 1979\end{array}$ & $\begin{array}{l}307 \\
258 \\
168\end{array}$ & $\begin{array}{l}160 \\
145 \\
132\end{array}$ & $\begin{array}{r}147 \\
113 \\
36\end{array}$ & $\begin{array}{r}121 \\
121 \\
113 \\
\frac{14}{127}\end{array}$ & $\begin{array}{l}39 \\
24 \\
19 \\
\frac{22}{41}\end{array}$ \\
\hline $\begin{array}{l}\text { June } 1,1979 \\
\text { December } 1,1979 \\
\text { May } 31,1980\end{array}$ & $\begin{array}{l}312 \\
221 \\
160\end{array}$ & $\begin{array}{l}168 \\
141 \\
136\end{array}$ & $\begin{array}{r}144 \\
80 \\
24\end{array}$ & $\begin{array}{r}127 \\
117 \\
112 \\
\frac{8}{120}\end{array}$ & $\begin{array}{l}41 \\
24 \\
24 \\
\frac{16}{40}\end{array}$ \\
\hline $\begin{array}{l}\text { June } 1,1980 \\
\text { December } 1,1980 \\
\text { May } 31,1981\end{array}$ & $\begin{array}{l}302 \\
214 \\
194\end{array}$ & $\begin{array}{l}160 \\
135 \\
134\end{array}$ & $\begin{array}{r}142 \\
79 \\
60\end{array}$ & $\begin{array}{r}120 \\
115 \\
114 \\
\frac{30}{144}\end{array}$ & $\begin{array}{l}40 \\
20 \\
20 \\
\frac{30}{50}\end{array}$ \\
\hline
\end{tabular}


Table 8.3. Continued.

\begin{tabular}{|c|c|c|c|c|c|}
\hline Date & Total & Adults & Fawns & Females & Males \\
\hline $\begin{array}{l}\text { June } 1,1981 \\
\text { December } 1,1981 \\
\text { May 31, } 1982\end{array}$ & $\begin{array}{l}339 \\
231 \\
171\end{array}$ & $\begin{array}{l}194 \\
167 \\
135\end{array}$ & $\begin{array}{r}145 \\
64 \\
36\end{array}$ & $\begin{array}{r}144 \\
128 \\
105 \\
\frac{18}{123}\end{array}$ & $\begin{array}{l}50 \\
39 \\
30 \\
\frac{18}{48}\end{array}$ \\
\hline $\begin{array}{l}\text { June } 1,1982 \\
\text { December } 1,1982 \\
\text { May } 31,1983\end{array}$ & $\begin{array}{l}304 \\
218 \\
202\end{array}$ & $\begin{array}{l}171 \\
148 \\
142\end{array}$ & $\begin{array}{r}133 \\
70 \\
60\end{array}$ & $\begin{array}{r}123 \\
120 \\
114 \\
\frac{30}{144}\end{array}$ & $\begin{array}{l}48 \\
28 \\
28 \\
\frac{30}{58}\end{array}$ \\
\hline $\begin{array}{l}\text { June } 1,1983 \\
\text { December } 1,1983 \\
\text { May } 31,1984\end{array}$ & $\begin{array}{l}347 \\
263 \\
219\end{array}$ & $\begin{array}{l}202 \\
173 \\
161\end{array}$ & $\begin{array}{r}145 \\
90 \\
58\end{array}$ & $\begin{array}{r}144 \\
140 \\
128 \\
\frac{29}{157}\end{array}$ & $\begin{array}{l}58 \\
33 \\
33 \\
\frac{29}{62}\end{array}$ \\
\hline $\begin{array}{l}\text { June } 1,1984 \\
\text { December } 1,1984 \\
\text { May } 31,1985\end{array}$ & $\begin{array}{l}382 \\
263 \\
211\end{array}$ & $\begin{array}{l}219 \\
185 \\
162\end{array}$ & $\begin{array}{r}163 \\
78 \\
49\end{array}$ & $\begin{array}{r}157 \\
145 \\
125 \\
\frac{24}{149}\end{array}$ & $\begin{array}{l}62 \\
40 \\
37 \\
\frac{25}{62}\end{array}$ \\
\hline $\begin{array}{l}\text { June } 1,1985 \\
\text { December } 1,1985 \\
\text { May } 31,1986\end{array}$ & $\begin{array}{l}370 \\
239 \\
213\end{array}$ & $\begin{array}{l}211 \\
175 \\
168\end{array}$ & $\begin{array}{r}159 \\
64 \\
45\end{array}$ & $\begin{array}{r}149 \\
141 \\
137 \\
\frac{22}{159}\end{array}$ & $\begin{array}{l}62 \\
34 \\
31 \\
\frac{23}{54}\end{array}$ \\
\hline $\begin{array}{l}\text { June } 1,1986 \\
\text { December } 1,1986 \\
\text { May } 31,1987\end{array}$ & $\begin{array}{l}387 \\
234 \\
212\end{array}$ & $\begin{array}{l}213 \\
168 \\
163\end{array}$ & $\begin{array}{r}174 \\
66 \\
49\end{array}$ & $\begin{array}{l}159 \\
151 \\
146\end{array}$ & $\begin{array}{l}54 \\
17 \\
17\end{array}$ \\
\hline
\end{tabular}


Table 8.4. Modeled population estimates for mule deer in PHU 4, Bridger Mountains, 1978-1986.

\begin{tabular}{|c|c|c|c|c|c|}
\hline Date & Total & Adults & Fawns & Females & Males \\
\hline $\begin{array}{l}\text { June } 1,1978 \\
\text { May } 31,1979\end{array}$ & $\begin{array}{l}3745 \\
1833\end{array}$ & $\begin{array}{l}1988 \\
1399\end{array}$ & $\begin{array}{r}1757 \\
434\end{array}$ & $\begin{array}{r}1504 \\
1238 \\
217 \\
1455\end{array}$ & $\begin{array}{l}484 \\
161 \\
217 \\
378\end{array}$ \\
\hline $\begin{array}{l}\text { June } 1,1979 \\
\text { May } 31,1980\end{array}$ & $\begin{array}{l}3690 \\
1995\end{array}$ & $\begin{array}{l}1833 \\
1209\end{array}$ & $\begin{array}{r}1857 \\
786\end{array}$ & $\begin{array}{r}1455 \\
1126 \\
393 \\
1519\end{array}$ & $\begin{array}{r}378 \\
83 \\
393 \\
476\end{array}$ \\
\hline $\begin{array}{l}\text { June } 1,1980 \\
\text { May } 31,1981\end{array}$ & $\begin{array}{l}3684 \\
2424\end{array}$ & $\begin{array}{l}1995 \\
1332\end{array}$ & $\begin{array}{l}1689 \\
1092\end{array}$ & $\begin{array}{r}1519 \\
1200 \\
546 \\
1746\end{array}$ & $\begin{array}{l}476 \\
132 \\
546 \\
678\end{array}$ \\
\hline $\begin{array}{l}\text { June } 1,1981 \\
\text { May } 31,1982\end{array}$ & $\begin{array}{l}4224 \\
2057\end{array}$ & $\begin{array}{l}2424 \\
1491\end{array}$ & $\begin{array}{r}1800 \\
566\end{array}$ & $\begin{array}{r}1746 \\
1319 \\
\frac{283}{1602}\end{array}$ & $\begin{array}{l}678 \\
172 \\
\frac{283}{455}\end{array}$ \\
\hline $\begin{array}{l}\text { June } 1,1982 \\
\text { May } 31,1983\end{array}$ & $\begin{array}{l}4036 \\
2122\end{array}$ & $\begin{array}{l}2057 \\
1516\end{array}$ & $\begin{array}{r}1979 \\
606\end{array}$ & $\begin{array}{r}1602 \\
1318 \\
303 \\
1621\end{array}$ & $\begin{array}{l}455 \\
198 \\
\frac{303}{501}\end{array}$ \\
\hline $\begin{array}{l}\text { June } 1,1983 \\
\text { May } 31,1984\end{array}$ & $\begin{array}{l}4099 \\
2303\end{array}$ & $\begin{array}{l}2122 \\
1622\end{array}$ & $\begin{array}{r}1977 \\
681\end{array}$ & $\begin{array}{r}1621 \\
1435 \\
340\end{array}$ & $\begin{array}{l}501 \\
\frac{187}{341}\end{array}$ \\
\hline $\begin{array}{l}\text { June } 1,1984 \\
\text { May } 31,1985\end{array}$ & $\begin{array}{l}4456 \\
1904\end{array}$ & $\begin{array}{l}2303 \\
1548\end{array}$ & $\begin{array}{r}2153 \\
356\end{array}$ & $\begin{array}{r}1775 \\
1358 \\
178\end{array}$ & $\begin{array}{l}528 \\
190 \\
178\end{array}$ \\
\hline $\begin{array}{l}\text { June } 1,1985 \\
\text { May } 31,1986\end{array}$ & $\begin{array}{l}3941 \\
2003\end{array}$ & $\begin{array}{l}1904 \\
1506\end{array}$ & $\begin{array}{r}2037 \\
497\end{array}$ & $\begin{array}{r}1536 \\
1382 \\
248\end{array}$ & $\begin{array}{l}368 \\
\frac{124}{249}\end{array}$ \\
\hline $\begin{array}{l}\text { June } 1,1986 \\
\text { May } 31,1987\end{array}$ & $\begin{array}{l}4076 \\
2268\end{array}$ & $\begin{array}{l}2003 \\
1620\end{array}$ & $\begin{array}{r}2073 \\
648\end{array}$ & $\begin{array}{l}1630 \\
1459\end{array}$ & $\begin{array}{l}373 \\
161\end{array}$ \\
\hline
\end{tabular}




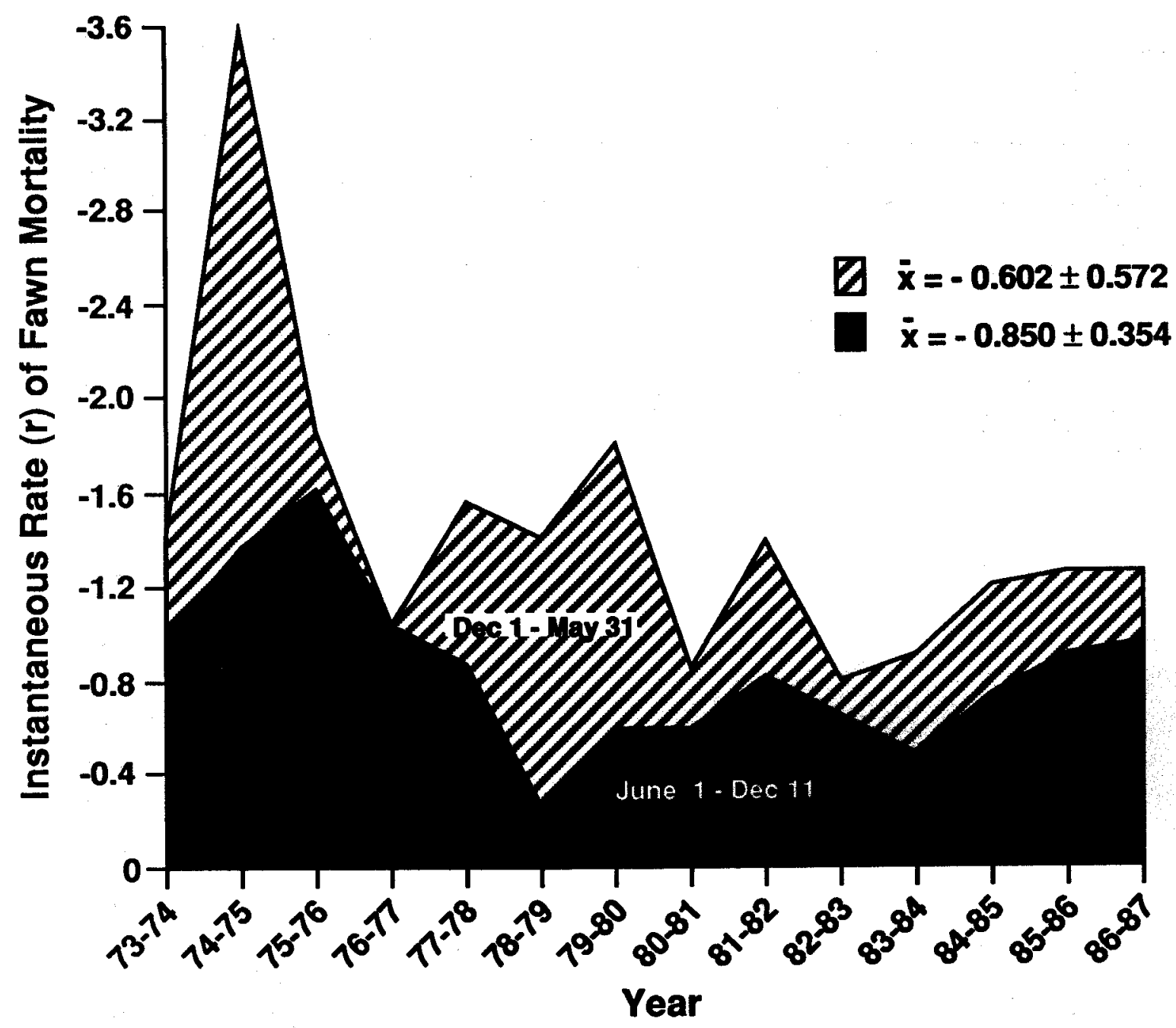

Figure 8.3. Instantaneous rate (r) of fawn mortality in PHU 1 during the first and second half of each biological year 1973-74 through 1986-87.

Despite the situation in 1975, there was no correlation between estimated fawn mortality during the period 1 June-1 December and severity of the preceding winter over a 13-year period $(r=0.02)$. The lowest rate of fawn mortality for the summer-autumn period was recorded in 1978 following a winter of above average severity. However, the adult female segment primarily consisted of prime-aged (2-8 year old) individuals that displayed high in utero fetal rates. Adult females entered that winter in relatively good physical condition as a result of very mild conditions the two previous winters. In addition, an early spring in 1978 provided females opportunity to partially recover condition before onset of lactation.

The highest recorded rates of overwinter (1 December-31 May) fawn mortality occurred during 1974-75 and 1978-79, years with relatively severe winters. However, 
mortality was also higher than expected during the latter half of 1979-80, a winter of below average severity. This was probably explained by the depletion of physical condition among adult females during the two previous (1977-78 and 1978-79) winters, both of which were above-average in severity. The lowest rates of fawn mortality through winter-spring occurred in years of mild conditions (1975-76, 1976-77, 1980-81, and 1982-83).

Instantaneous rate (r) of fawn mortality estimated from the PHU 1 model (Table 8.3) for the period 1 December-31 May was significantly related to an index of severity for the same winter (Fig. 8.4). However, large residuals for some years reduced the predictive accuracy of this relationship. For example, much greater than expected mortality was recorded during winter 1974-75 when about $97 \%$ of all fawns that entered winter died. Severe conditions occurred primarily during February-May, preventing the emergence of new green forage and extending the period of negative energy drain beyond the limits of fawn survival. In contrast, the most severe winter recorded during the study, 1978-79, was marked by significantly less mortality because severe conditions occurred during early-mid winter when deer were in reasonably good physical condition.

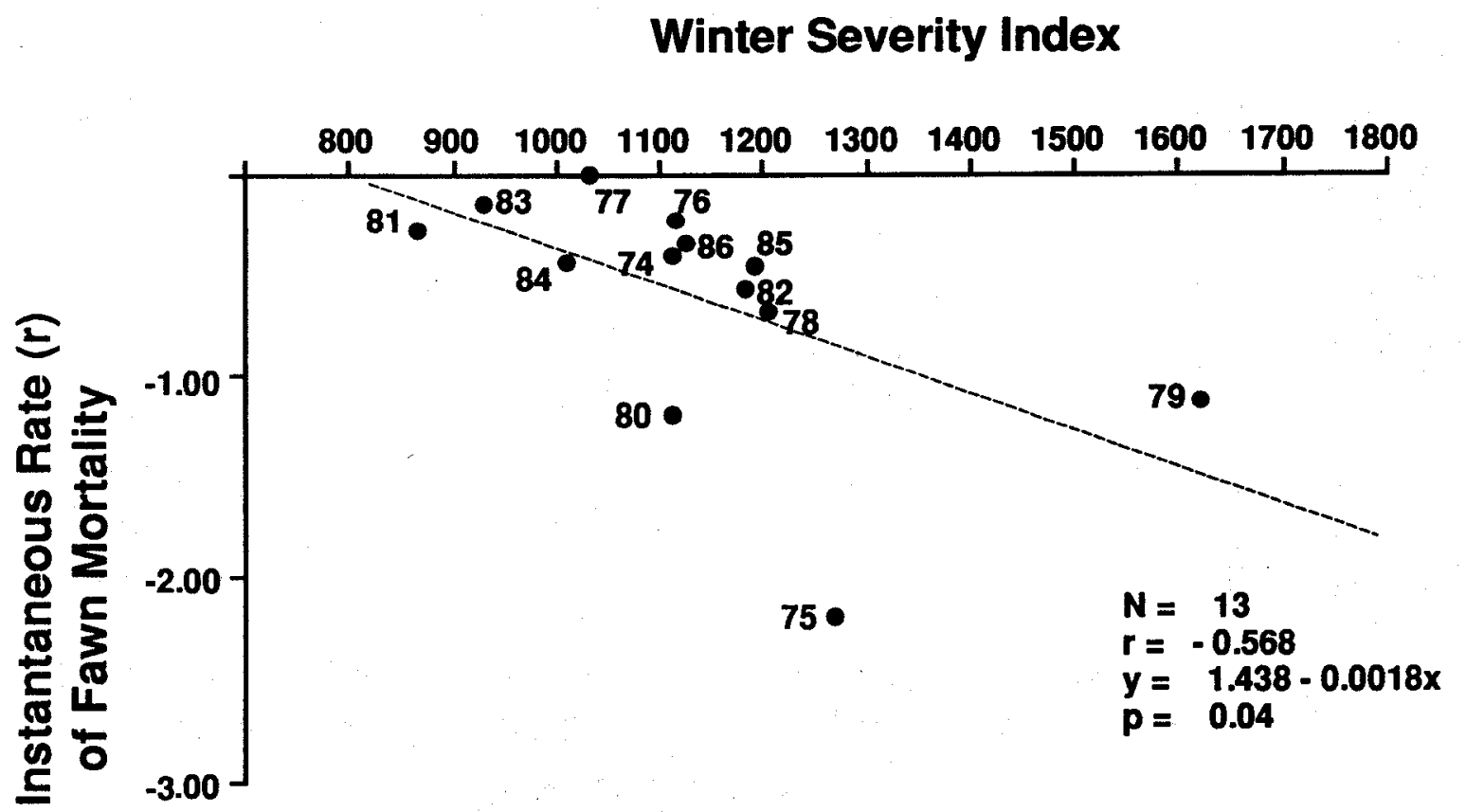

Figure 8.4. Relationship between overwinter fawn mortality and winter severity in PHU 1. Year listed represents ending date of biological year. 
The fawn mortality rate for 1979-80 was similar to 1978-79 despite a lower winter severity index. Again, however, the 1979 cohort appeared to have been predisposed to greater mortality as a result of the previous severe winter.

Mortality was less than expected and nearly nonexistent over the mild 1976-77 winter (Fig. 8.4) because that cohort was born to adult females in apparently good condition coming out of the very mild winter of 1975-76.

Overwinter fawn mortality rates calculated from change in fawn:adult ratios between early and late winter in PHU 1 were also significantly correlated with winter severity indexes $(\mathrm{N}=13, \mathrm{r}=0.593, \mathrm{P}=0.035)$. For $\mathrm{PHU} 4$, changes in ratios were not significantly correlated with winter severity indexes (Fig. 8.5). Fawn mortality usually ranged between 20 and $40 \%$ during winters in the low to mid-range of severity. A major increase in winter severity during 1978-79 resulted in only a moderate increase in overwinter mortality (55\%). Compared with PHU 1, the lower elevation and more rapid plant development across PHU 4 in spring may have resulted in a shorter energy deficit period that minimized fawn mortality.

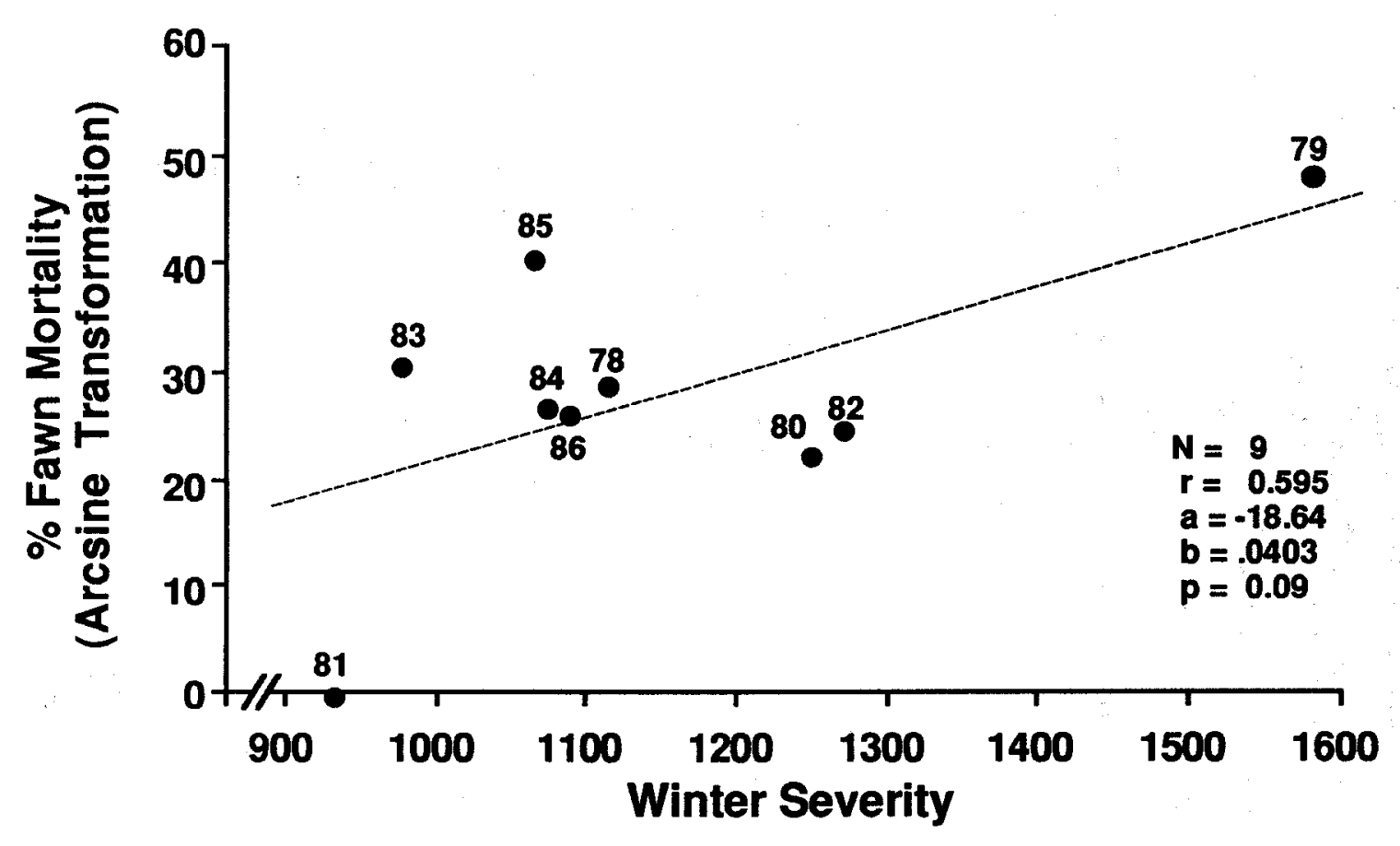

Figure 8.5. Relationship between overwinter fawn mortality and winter severity in PHU 4. 
High fawn survival in PHU 4 during the 1980-81 winter (Fig. 8.5) probably resulted from interaction of several factors. Some females doubtless survived the severe 1978-79 winter in such poor condition that they experienced substantial post-partum fawn loss. These does, in particular, had opportunity to regain physical condition prior to the 1979-80 winter which was near average in severity. They apparently also wintered in above average condition to give birth to a strong 1980 cohort. These fawns survived the mildest winter recorded during the study with virtually no over-winter mortality.

Comparison of overwinter fawn mortality rates between PHU 1 and PHU 4 (Fig. 8.6) shows that PHU 1 was characterized by higher mortality in seven of nine winters. During four of the seven years $(1979,1980,1981$, and 1984), mortality was higher in PHU 1 even though winter severity indexes were similar for the two units. Mortality was higher in PHU 4 only during 1983 and 1985 . In general, mortality of fawns in PHU 4 through winter-spring was poorly explained by winter severity. Apparently, some combination of factors permitted fawns on Brackett Creek to experience lower and less variable mortality rates across a spectrum of severity (SI 900-1300), the same spectrum that resulted in steadily increasing fawn mortality in PHU 1. However, higher than average fawn mortality was occasionally recorded in PHU 4 during winters of below average severity as in 1984-85. Routine field notes and observations indicated relatively high incidence of coyote predation though overall effect was not quantified. Several local ranchers expressed concern about coyote predation on deer that year.

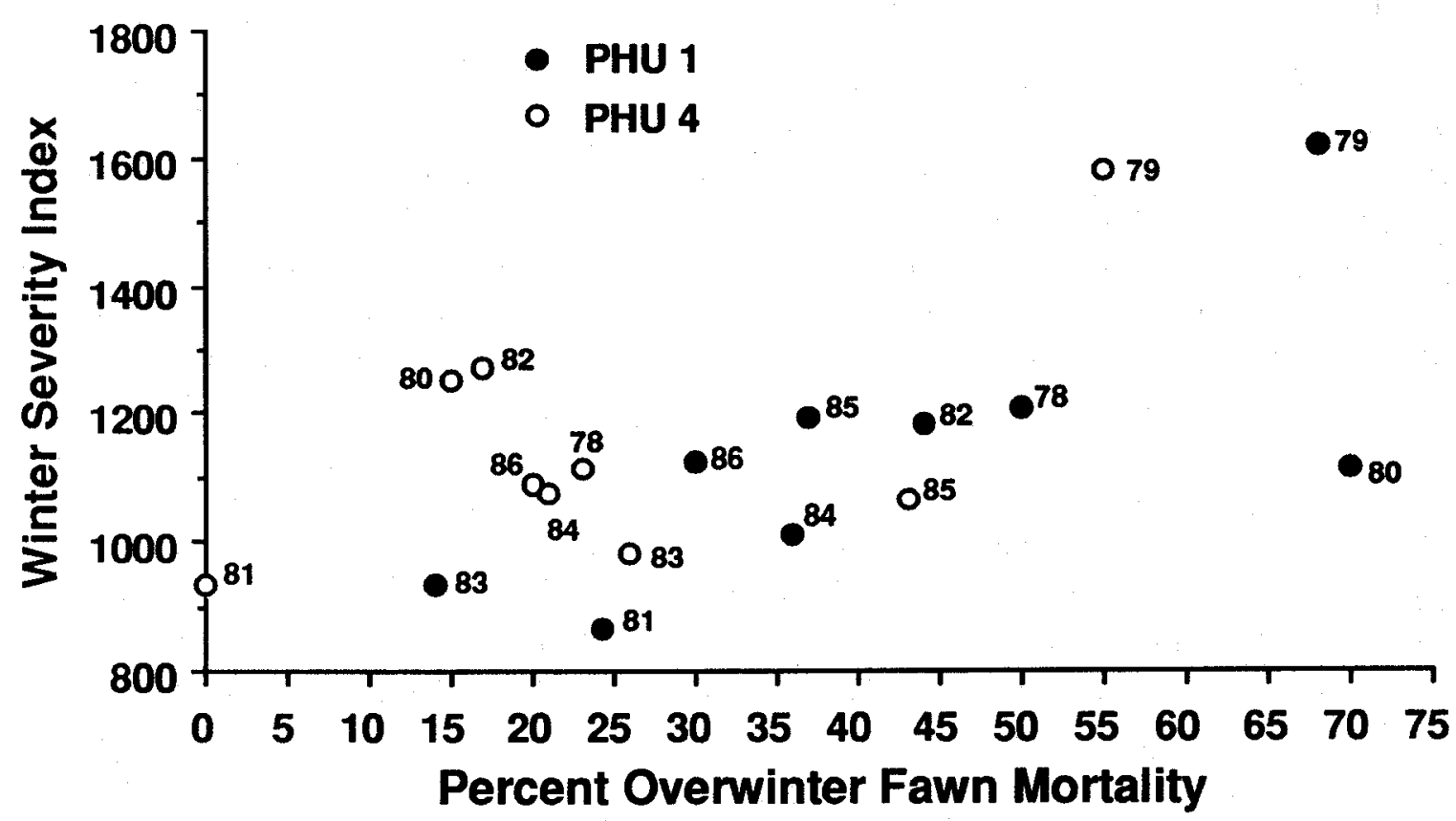

Figure 8.6. Comparison of overwinter fawn mortality relative to winter severity in PHUs 1 and 4, 1978-1986. 
Some differences in overwinter fawn mortality rates were also documented among subunits of deer on PHU 1. During the very severe 1978-79 winter $(S I=1620)$, only $2(17 \%)$ of 12 fawns tagged on the north subunit during January survived to May while 6 of $13(46 \%)$ survived in the middle subunit. Three fawns were marked in the south subunit during late January and February, and two survived. White et al. (1987) indicated that fawn weights varied significantly among segments of the winter range they studied. Differences in weight and their subsequent influence on over-winter survival could be related to variation in the quality of summer ranges occupied by those segments.

Differences in fawn survival between subunits were less apparent during the near average winter of 1981-82 $(\mathrm{SI}=1182)$. Despite a small sample marked on the north subunit, Youmans (1979) indicated that environmental characteristics and habitat use patterns were generally similar for deer associated with north and south subunits while both differed from the middle subunit. In 1981-82, four of seven (57\%) fawns marked in the middle subunit during early January survived compared to 6 of 13 (46\%) fawns marked during the same time period in the south subunit.

The magnitude and timing of fawn mortality was difficult to predict. This resulted from the complex of factors that interacted to affect survival of a fawn cohort on a particular area. These included factors that operated during the first year of life as well as environmental conditions that influenced adult female physical condition several years preceding the birth of a cohort.

Proximate causes of fawn mortality in winter were difficult to ascertain because carcasses were usually consumed, scavenged, or decayed before discovery. Documented deaths of marked fawns were adequate for discussion only on the Armstrong area. Male fawns died primarily of winter-related malnutrition (Fig. 8.7). Unknown natural deaths accounted for $21 \%$ while $8 \%$ were study related. No male fawns were included in the confirmed predation category while $16 \%$ of the marked females were predator kills. Unknown natural deaths accounted for the greatest proportion of female fawn deaths while only $32 \%$ died of winter-related malnutrition, etc. The percentage of female fawns dying of study related causes was nearly equal to that of males.

Because most fawns were marked only with observation collars, dates of death were rarely ascertained. Deaths were confirmed to the nearest 2-week period for only 15 male and 10 female fawns during the winters of 1978, 1979, and 1982. By the end of February, only $13 \%$ of marked male fawns had died compared to $50 \%$ of females. Most of the remainder (73\% of males and 50\% of females) died between 15 March and 30 April.

\section{Fawn Recruitment}

Fawn recruitment by marked females in east and west slope populations is compared in Fig. 8.8. On the west slope, the reproductive status was recorded for 145 


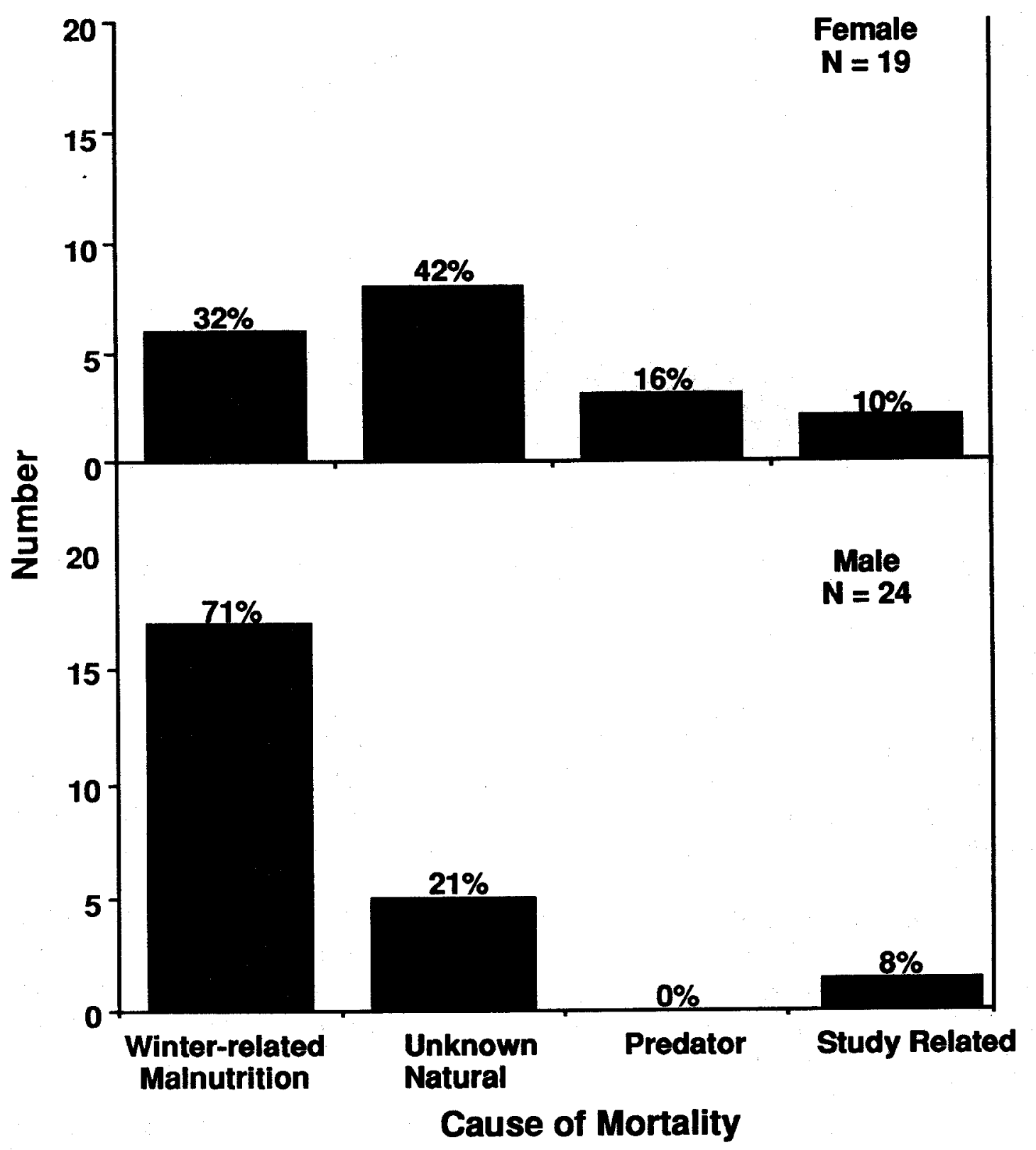

Figure 8.7. Causes of overwinter mortality of fawns marked in PHU 1. 


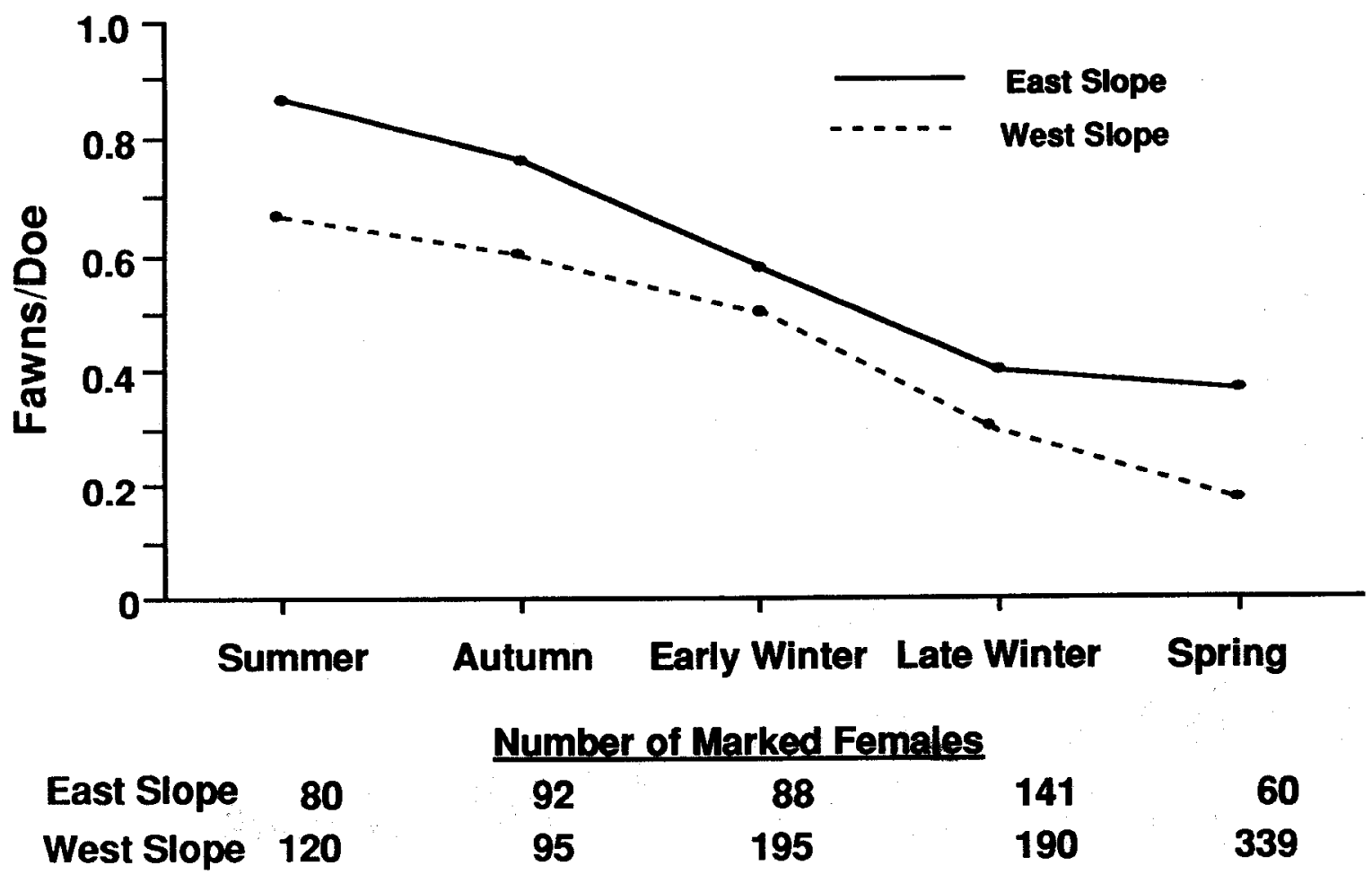

Figure 8.8. Average number of fawns/doe by season for marked adult females on the east and west slopes.

individually marked females observed during one or more seasons from 1973 through 1986 (PHU $1=116$, PHU $2=19$, PHU $7=10$ ). For the east slope, data were determined for 91 females during 1978-1986 (PHU $3=14$, PHU $4=44$, PHU $5=13$, PHU $6=20$ ). Reproductive rates were undoubtedly conservative because of low observability of deer in the rugged timbered terrain.

Observed recruitment rates were higher for females in east slope populations through all seasons. The greatest difference occurred during summer when recruitment by east slope females averaged $20 \%$ higher and during spring when fawn recruitment was nearly $50 \%$ higher than recorded for females on the west slope. Differences were less during early and late winter.

Populations on east and west slopes exhibited declining recruitment from summer through spring. From summer to early winter, the rate of decline was greater among east slope females. Between early winter and spring, fawn survival declined more rapidly on the west slope. These data are long-term averages presented only to portray and compare general trends between the two areas. The pooled samples for each area 
spanned a wide range of environmental conditions over a minimum of nine consecutive years. However, data for the east slope in spring were somewhat biased in favor of years with above-average conditions for fawn survival and thus maximized reproductive differences.

Differences in reproductive output on west and east slopes were also indicated by age specific rates of fawn production/recruitment of marked females derived from pooled observations in three west slope and four east slope PHUs (Fig. 8.9).

Age-specific rates for east slope females during summer-autumn were equal to or greater than those on the west slope in all but age class 9-10. There was, however, considerable variation in rates among age classes within both groups. As expected, yearling females made no contribution to production while 2-year olds had low and

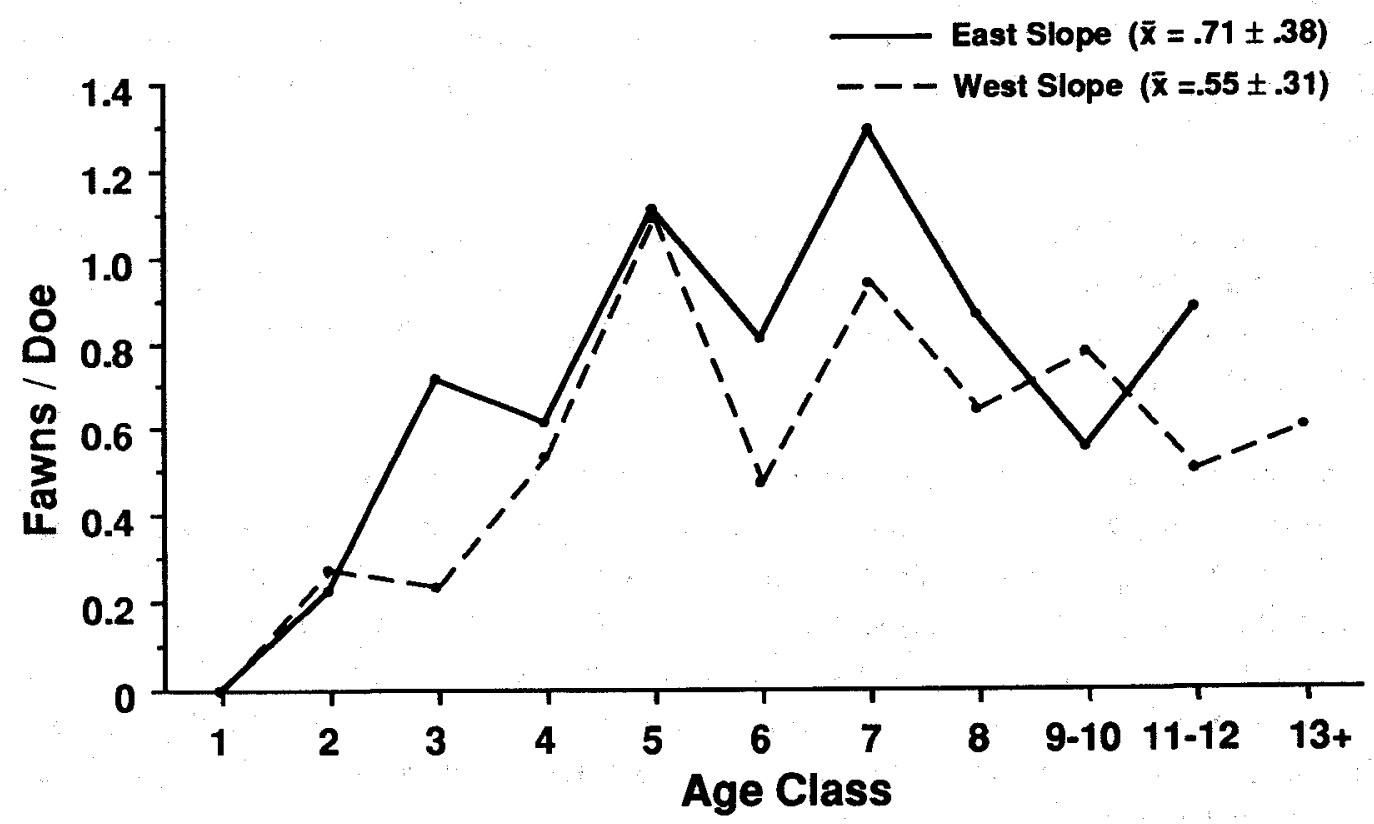

Number of Reproductive Seasons

$\begin{array}{rrrrrrrrrrrr}\text { East } & 4 & 13 & 14 & 21 & 19 & 26 & 17 & 15 & 9 & 8 & - \\ \text { West } & 6 & 11 & 17 & 15 & 23 & 21 & 16 & 25 & 31 & 20 & 10\end{array}$

Figure 8.9. Mean age specific reproductive rates for marked females on the east and west slope ranges during summer and autumn. Data are for 51 and 80 marked females on the two areas, respectively. 
similar reproductive rates on both areas. Rates for 3-year olds were 3-fold greater on the east slope. Among older deer, peaks in reproduction were usually followed by significant setbacks for the subsequent age class. Following the peak in productivity at age class 5 on the west slope, rates declined sharply to age class 6 before recovering to a secondary peak at age class 7 . On the east slope, the peak at age 7 was followed by a sharp two-year decline spanning age classes 8 and 9-10. The magnitude of this decline was equal to that which occurred one year after the peak in production at age 5 on the west slope.

Age-specific recruitment rates of females on the west slope were generally lower and less variable by winter and spring (Fig. 8.10). Rates for some age classes $(1,2,3$, and 4) were slightly higher during winter or spring than for earlier seasons. This appeared related to larger sample sizes and more efficient observability when deer were concentrated in more open habitats. The $\mathbf{0 . 1 0}$ fawns/doe recorded for yearlings during winter was probably an error in assignment of fawns to females.

The greatest decline in age-specific recruitment among west slope females from summer-autumn to winter occurred in age classes $5,7,8$, and 9 , which had the highest initial productivity, and among the oldest age class (Fig. 8.10). Rates apparently declined the least in age classes 2, 3, 4 and 6.

By spring, recruitment rates displayed little age-specific variation for west slope females older than two years (Fig. 8.10). Proportionately, the greatest overall decline in rates between summer to spring was recorded among 2-, 5-, and 7-year olds. Rates declined the least among 3- and 6-year old females.

Seasonal comparison of age-specific reproductive rates on the east slope was limited to summer-autumn and winter (Fig. 8.11). Higher rates during winter for age classes 1,2 , and 8 apparently resulted from observational factors similar to those described for the west slope. During winter, reproductive rates declined among most age classes. As on the west slope, greatest declines occurred in age classes that had highest initial productivity (5 and 7) and were oldest (11-13). However, 3- and 4-year olds apparently experienced proportionately greater declines in recruitment rates through winter than recorded for west slope females.

The most striking characteristic pertaining to age-specific productivity on the east slope during winter was the continued variation in rates among age classes. Much of the variation in recruitment among age classes of females on the west slope had diminished by winter. Unfortunately, sample sizes were not adequate to determine age-specific rates during spring for east slope females. Generally, however, age-specific data supported other findings indicating lower and less variable fawn recruitment rates on the west slope. 


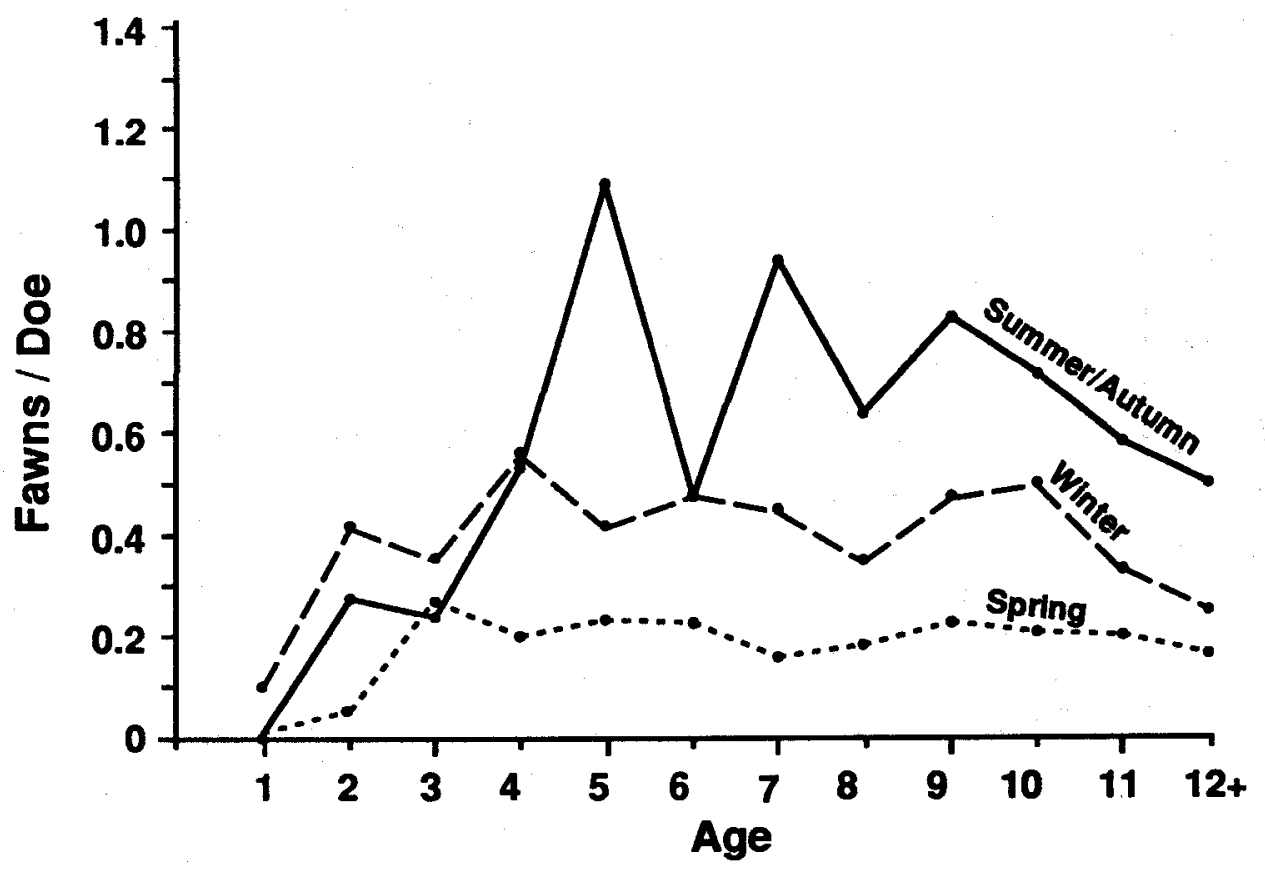

\begin{tabular}{rrrrrrrrrrrrr} 
& \multicolumn{1}{c}{} & \multicolumn{1}{c|}{ Number of Reproductive Seasons } \\
Summer/Autumn & $\mathbf{6}$ & $\mathbf{1 1}$ & $\mathbf{1 7}$ & $\mathbf{1 5}$ & $\mathbf{2 3}$ & $\mathbf{2 1}$ & $\mathbf{1 6}$ & $\mathbf{2 5}$ & $\mathbf{1 7}$ & $\mathbf{1 4}$ & $\mathbf{1 2}$ & $\mathbf{1 8}$ \\
Winter & $\mathbf{1 0}$ & $\mathbf{2 4}$ & $\mathbf{2 8}$ & $\mathbf{2 3}$ & $\mathbf{4 3}$ & $\mathbf{3 1}$ & $\mathbf{3 7}$ & $\mathbf{4 6}$ & $\mathbf{4 2}$ & $\mathbf{3 2}$ & $\mathbf{3 3}$ & $\mathbf{3 6}$ \\
Spring & $\mathbf{1 4}$ & $\mathbf{2 2}$ & $\mathbf{3 0}$ & $\mathbf{2 5}$ & $\mathbf{3 5}$ & $\mathbf{3 1}$ & $\mathbf{3 8}$ & $\mathbf{3 8}$ & $\mathbf{2 7}$ & $\mathbf{3 4}$ & $\mathbf{2 0}$ & $\mathbf{2 5}$
\end{tabular}

Figure 8.10. Comparison of summer-autumn, winter and spring age-specific fawn recruitment rates on the west slope. Data are for 80 marked females in summer-fall, 111 in winter, and 117 in spring.

The variable, alternate-year pattern of reproductive output among females in successive age classes on our study area, as exemplified by recruitment through summerautumn, may have been influenced by the high cost of successfully rearing fawns in a comparatively severe environment. Energy demands associated with lactation and fawn rearing apparently adversely affected reproductive success of some individuals the following year. This was indicated by the reproductive status of 55 marked females $\geq$ 2 years of age which provided 85 two-year reproductive histories on the west slope. Females reared fawns through weaning during both years in 37 (44\%) of the cases, reared fawns in alternate years in $34(\mathbf{4 0 \%})$ of the cases, and failed to wean fawns in both years in $14(16 \%)$ cases.

Similar data for east slope females indicated a more consistent pattern of reproductive success. Marked females $(\mathrm{N}=36$ ) provided 61 two-year case histories. Females successfully reared fawns during both years in $36(59 \%)$ of those cases, reared fawns in alternate years in $19(31 \%)$ cases, and failed during both years in $6(10 \%)$ cases. 


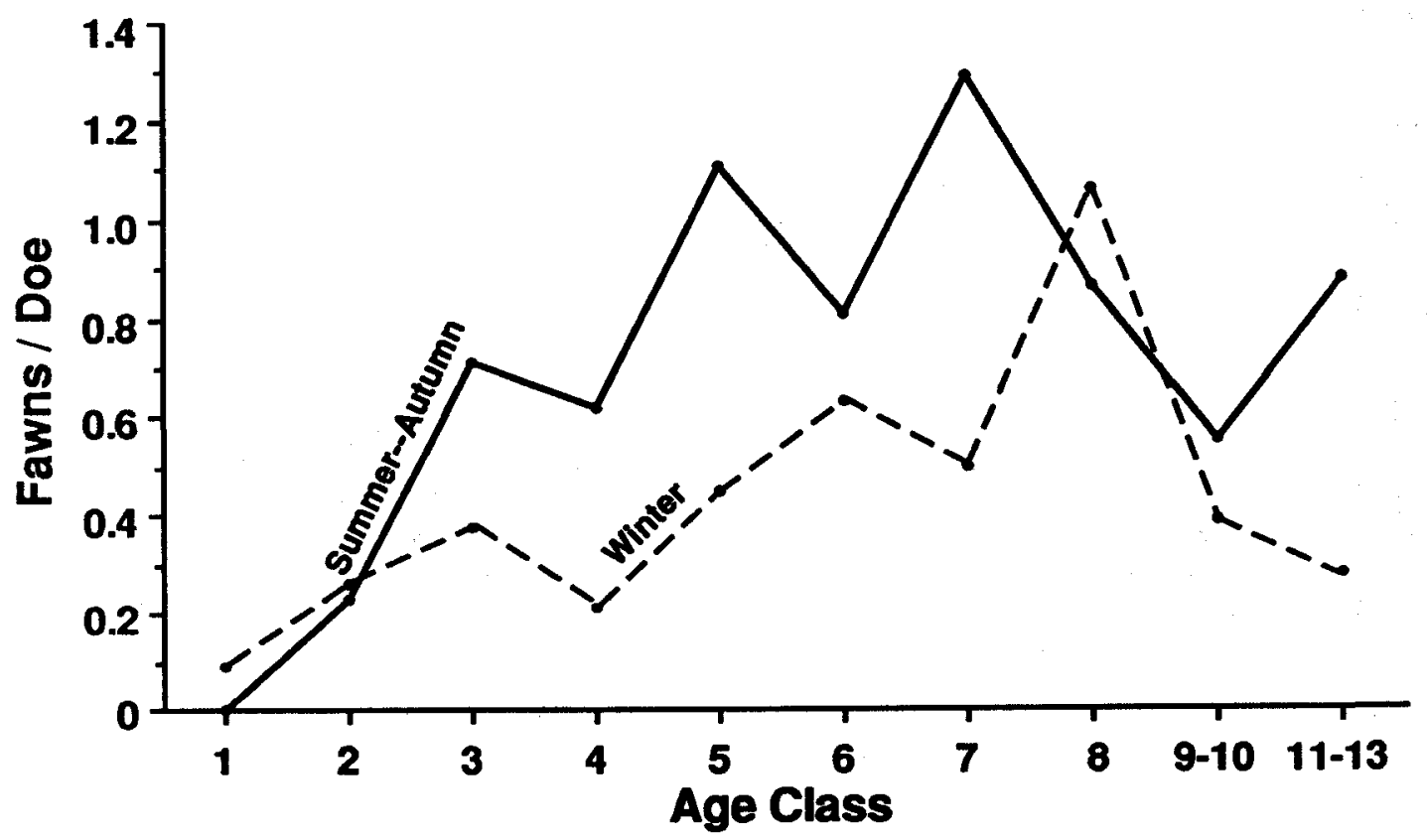

Number of Reproductive Seasons

$\begin{array}{rrrrrrrrrrr}\text { Sum-Autumn } & 4 & 13 & 14 & 21 & 19 & 26 & 17 & 15 & 9 & 8 \\ \text { Winter } & 11 & 23 & 32 & 28 & 42 & 22 & 36 & 16 & 18 & 11\end{array}$

Figure 8.11. Comparison of age-specific reproductive rates of marked females between summer-autumn and winter for mule deer on the east slope. Data are for 51 and 66 females during the two seasons, respectively.

Recruitment to spring in PHU 1 averaged 33.4 \pm 13.1 fawns: 100 adult females (Fig. 8.12). Annual recruitment varied between 4:100 and 53:100. Comparison of recruitment between PHUs 1 and 4 was limited to 1978-1987 when both areas were surveyed annually in spring. For these 10 years, the PHU 4 population averaged 49.6 \pm 18.9 fawns: 100 adult females compared to $37.2 \pm 10.4$ for PHU 1. The maximum on PHU 4 was also substantially greater, $91: 100$ vs. 53:100 in PHU 1. Both peaked in 1981. The ratio for PHU 1 was at the maximum again in 1983 while recruitment in PHU 4 declined substantially to slightly less than recorded for PHU 1.

Minimum recruitment rates in the two populations during 1978-1987 were similar but occurred in different years (Fig. 8.12). The minimum for PHU 1 was 21 fawns: 100 adult females in 1980 at the end of a four-year period of declining recruitment on the west slope. In 1980, recruitment increased sharply in PHU 4 after a decline the previous year. The minimum for PHU 4 occurred in 1985 after a three-year period of stable, near-average recruitment on the east slope. That same year, the population in PHU 1 was experiencing the third of a gradual four-year decline to near-average recruitment. 


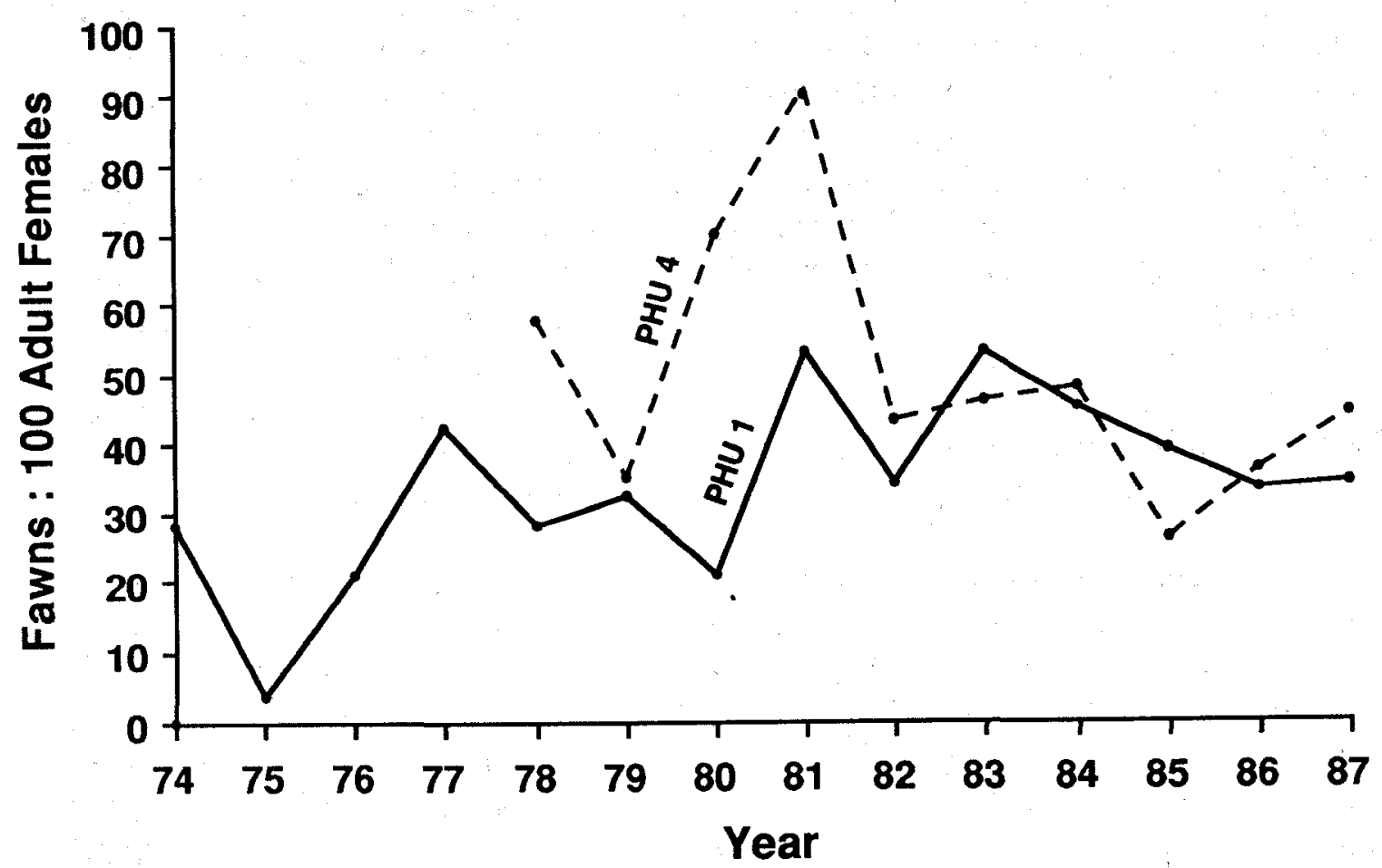

Figure 8.12. Relative recruitment (fawns: 100 adult females) to spring in PHUs 1 and 4. Data derived from population modeled estimates.

The coefficient of variation for spring recruitment ratios on PHU 4 was $38 \%$ compared to $28 \%$ for PHU 1.

\section{Fawn Sex Ratios}

The sex ratio of fawns in west slope populations became distorted in favor of males by the time of recruitment at one year of age; little change was apparent for east slope populations (Table 8.5). During the second year of life of individuals initially marked as fawns, males declined substantially in both populations. However, in contrast to east slope populations, males continued to outnumber females on the west slope.

Table 8.5. Sex ratios (male:female) at four age intervals on the west and east slope.

\begin{tabular}{llccc}
\hline & in-utero & 6 months & 1 year & 2 years \\
\hline West & $84: 100$ & $157: 100$ & $200: 100$ & $125: 100$ \\
Sample (N) & $26: 31$ & $83: 53$ & $46: 23$ & $25: 20$ \\
East & $84: 100$ & $92: 100$ & $92: 100$ & $55: 100$ \\
Sample (N) & $26: 31$ & $56: 61$ & $47: 51$ & $24: 44$ \\
\hline
\end{tabular}


On the west slope, documented losses of females between one and two years of age were limited to one hunter kill, one winter kill (malnutrition), and one trap mortality. On the east slope, two females were killed by hunters, one emigrated, and four disappeared. The 21 marked yearling males lost on the west slope included 11 emigrants, 2 hunter kills, 1 winter kill, 1 trap mortality, and 6 that disappeared of unknown cause. Among 23 marked yearling males lost on the east slope, 7 were emigrants, 3 hunter kills, 2 winter kills, 1 road kill, and 10 that simply disappeared. Emigration of yearling males was the most important factor influencing the sex ratio among 2-year olds on both areas. Emigration and immigration were somewhat compensating within the Bridger complex because an emigrant from one PHU often became an immigrant to another. However, at least 32 and $47 \%$ of all emigrants from east and west slope PHUs, respectively, left the Bridger ecosystem.

Trapped samples of yearlings provided additional evidence of differences in juvenile sex ratios between west and east slope populations. Over all years, 80 yearlings were trapped on the west slope with a sex ratio of 167 males: 100 females. This compared to 29 males: 100 females among 103 yearlings handled on the east slope. The documented fates of a sample of marked fawns discussed above indicated that emigration was the most important cause of loss for males between one and two years of age throughout the Bridger Mountains. The principle effects of emigration/immigration would have already occurred by the time yearlings were trapped. Thus, the total loss of males was apparently relatively high or immigration was less influential on the east slope. By contrast, any emigration losses of yearling males on the west slope were apparently offset by immigration.

Both the fawn and yearling trap samples indicated variation in the sex ratio of successive cohorts in the Armstrong segment of PHU 1 (Table 8.6). Although small trap samples limited statistical significance, data obtained during the years 1977-78, 1978-79, and 1981-82 suggested fawn sex ratios skewed toward males in and following very severe winters and more even ratios in mild winters. Hamlin and Mackie (1989) indicated similarly skewed sex ratios toward males following severe winters in the Missouri River Breaks.

Sex ratios at six months (Table 8.5) may have been biased as reported by Garrott and White (1982) and Mattfield et al. (1974). However, the four trapping methods employed over 13 years on the west slope all indicated a preponderance of male fawns in the trap sample (Table 8.7). These data also reinforced indications of an increasing male component from six months to one year. The helicopter drive trap and cannon net were generally used later in winter/spring than the other two methods and apparently accounted for the greater number of males captured.

A high percentage of all fawns marked on the east slope was captured using the helicopter drive trap. This sample showed a preponderance of females in direct contrast to the predominance of males among fawns captured by the same method on the west 
Table 8.6. Relationship between winter severity and sex ratio (M:F) of marked fawns in PHU 1 at 12 and 18 months of age. Proportion of fawn cohort size sampled at recruitment in parentheses.

\begin{tabular}{cccc}
\hline Cohort Year & $\begin{array}{c}\text { Winter Severity } \\
\text { Index }\end{array}$ & $\begin{array}{c}\text { Cohort Sex Ratio at } \\
12 \text { months }\end{array}$ & $\begin{array}{c}\text { Cohort Sex Ratio at } \\
18 \text { months }\end{array}$ \\
\hline $1976-77$ & 1032 & $0: 1(.02)$ & $4: 4(.16)$ \\
$1977-78$ & 1206 & $5: 1(.19)$ & $12: 3(.47)$ \\
$1978-79$ & 1620 & $8: 4(.33)$ & $3: 0(.08)$ \\
$1979-80$ & 1113 & $2: 0(.08)$ & $1: 0(.04)$ \\
$1980-81$ & 865 & $2: 1(.05)$ & $11: 8(.28)$ \\
$1981-82$ & 1182 & $9: 8(.47)$ & $1: 2(.08)$ \\
$1982-83$ & 930 & $0: 1(.02)$ & - \\
$1983-84$ & 1009 & -- & -- \\
$1984-85$ & 1191 & - & $6: 4(.20)$ \\
\hline
\end{tabular}

Table 8.7. Sex ratio of fawns captured by four trapping methods on west and east slopes of the Bridger Mountains.

\begin{tabular}{|c|c|c|c|c|c|}
\hline Trapping Method & Years Employed & $\begin{array}{l}\% \text { Total } \\
\text { Fawns } \\
\text { Captured }\end{array}$ & $\begin{array}{l}\text { No. } \\
\text { Males }\end{array}$ & $\begin{array}{l}\text { No. } \\
\text { Females }\end{array}$ & Sex Ratio \\
\hline \multicolumn{6}{|c|}{ West Slope } \\
\hline Helicopter drive-trap & $1974,1979,1982,1983$ & 12 & 13 & 3 & $433 / 100$ \\
\hline Corral trap & $1975,1978-82$ & 22 & 16 & 13 & $123 / 100$ \\
\hline Cannon net & $1975,1978,1979,1981$ & 12 & 11 & 5 & $220 / 100$ \\
\hline Clover trap & 1977-1982, 1986 & 54 & 43 & 29 & $148 / 100$ \\
\hline Total & & & 83 & 50 & $166 / 100$ \\
\hline \multicolumn{6}{|c|}{ EAST SLOPE } \\
\hline Helicopter drive-trap & $\begin{array}{l}1979,1980,1982,1983, \\
1986\end{array}$ & 89 & 46 & 59 & $77 / 100$ \\
\hline Cannon net & 1978 & 11 & 10 & 3 & $333 / 100$ \\
\hline Total & & & 56 & 62 & $90 / 100$ \\
\hline
\end{tabular}


slope. Although the sample of fawns caught with a cannon net on the east slope indicated substantially more males than females, this method was used only for one year and may not be comparable to the trend established over five years by the much larger helicopter drive net sample.

We share the frustration expressed by other authors in interpreting juvenile sex ratios relative to other studies. Robinette et al. (1977) and Clutton-Brock et al. (1982) discussed conflicting evidence pertaining to the influence of maternal condition on the sex ratio at birth. Similarly, some studies of juvenile mortality during winter indicated greater losses among females in roe deer (Capreolus capreolus) (Borg 1970), white-tailed deer (Free et al. 1964), and mule deer (Robinette et al. 1957b). Others show heavier loss of males among saiga (Saiga tatarica) (Bannikov et al. 1961), white-tailed deer (Free et al. 1964), black-tailed deer (Brown 1961, Longhurst 1956, Taber and Dasmann 1954), and mule deer (Nellis 1968). Robinette et al. (1957b) also indicated that sex ratio might vary with range condition and/or winter severity.

There seems to be general agreement in studies among sexually dimorphic mammals, including mule deer, that male offspring receive greater parental investment through the time of weaning than females (Glucksman 1974, Short 1970, Defries et al. 1959, Dittus 1979, Clutton-Brock et al. 1982, and others). Males of a species are born heavier, grow faster, and have greater lactation demand as demonstrated for caribou (Rangifer tarandus) calves (McEwan 1968, McEwan and Whitehead 1971). For mule deer, Robinette et al. (1973) demonstrated greater weights for males both at birth and at weaning. This potentially provided males with a head start on growth and development during the first year of life after which they generally became independent of their mothers. These gains were offset by greater maternal investment in female offspring which, after weaning, generally remained with the matriarchal group. We agree with Clutton-Brock et al. (1982) that selection would favor maternal females who invested more heavily in sons before weaning and more heavily in daughters after weaning because early growth has a greater effect on the reproductive success of the male. Access to quality habitat during adulthood probably increases the reproductive success of females because lactation has such high energetic costs.

Differentially greater early growth of males could increase their opportunity to survive their first year of life in a comparatively demanding environment such as the west slope of the Bridger Mountains. On the east slope, the less specialized movement patterns and more generalized habitat use strategies were, on the average, less demanding and female fawns were at a lesser disadvantage. In addition, east slope deer spent significantly more time on summer ranges. This may have allowed female fawns to continue growth in autumn, offsetting the earlier gains by males. On the west slope, "bottle-necks" in distribution often occurred by mid-October resulting in locally high deer densities in the vicinity of the winter range. This placed fawns in a high density, potentially competitive situation soon after weaning. Under those conditions, any 
advantages gained from faster growth rates of male fawns could be particularly important in giving them a survival advantage over females entering winter.

Fawn Mortality in Relation to Adult Density

In recent years, the most widely accepted theory of ungulate population control is based on a weather-forage complex that operates through a density-dependent feedback loop affecting juvenile production and mortality (Caughley 1976, 1979; Peek 1980). Time lag effects have been identified in association with the feedback loop. This relationship generally assumes a more or less determinant carrying capacity that best applies to stable environments.

Applied to mule deer populations in environments such as PHU 1, the theory would predict increasing annual fawn mortality with numbers of adult deer in the population. When no time lags were incorporated, we found no significant correlation $(\mathrm{N}=14$ years, $\mathrm{r}=-0.339, \mathrm{P}=0.25$ ). With a one-year time lag (Fig. 8.13), the relationship approached statistical significance $(\mathrm{r}=0.558, \mathrm{P}=0.05)$. However, the correlation coefficient was reduced to $r=-0.205(\mathrm{P}>0.50, \mathrm{~N}=12)$ if one data point representing 1975 was omitted. In addition, the regression line between fawn mortality

\section{Number of Adults in PHU 1 ( Year $\mathbf{N}_{\tau}$ )}

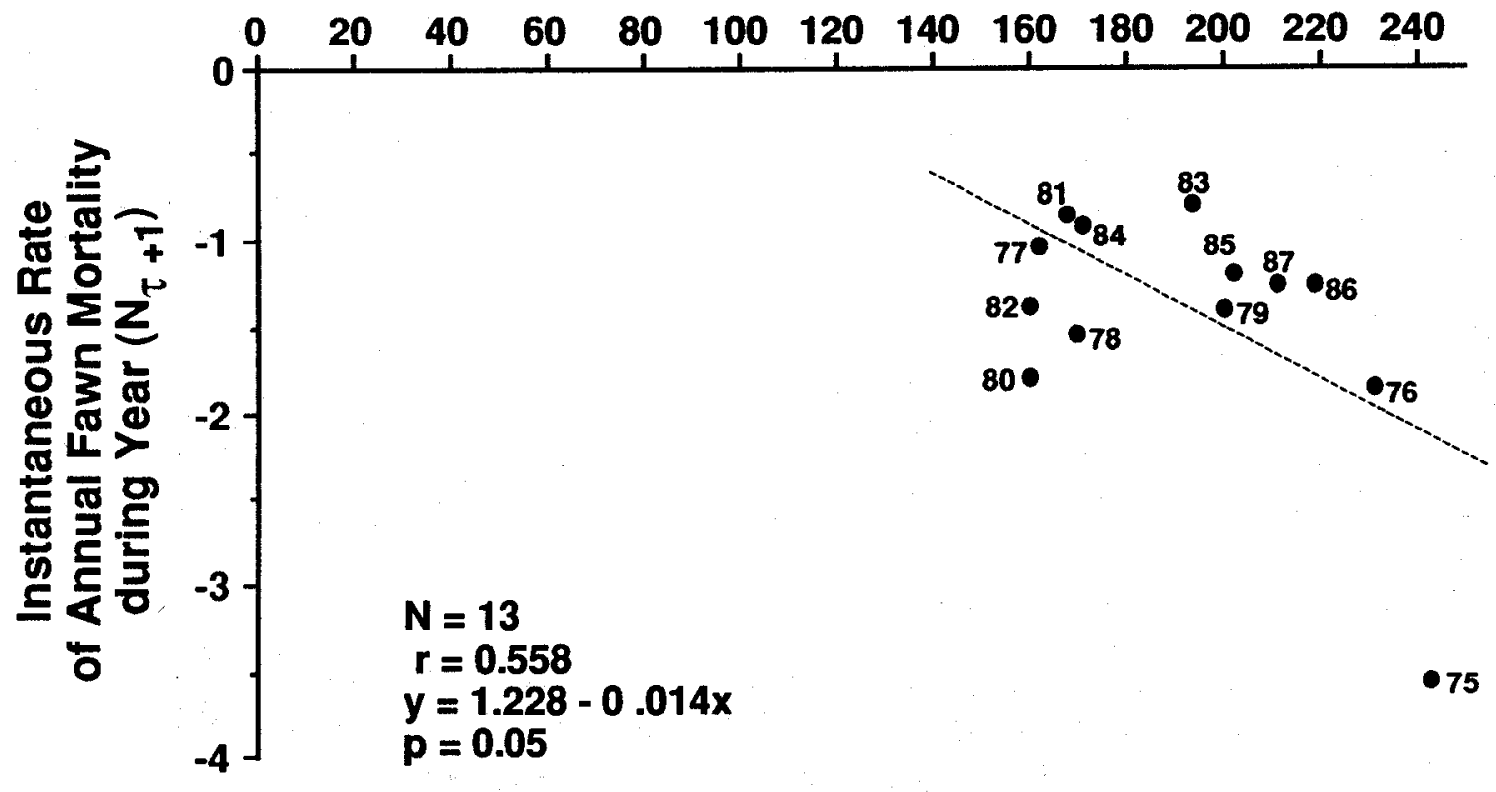

Figure 8.13. Relationship between annual instantaneous rate (r) of fawn mortality during year $\left(\mathbf{N}_{t+1}\right)$ and number of adults at beginning of previous year $\left(\mathrm{N}_{\mathfrak{l}}\right)$ in PHU 1 . 
and numbers of adults had little predictive value because of the large residuals associated with many data points. For example, nearly equal rates of mortality occurred at both the lowest and second highest densities of adults (1976 and 1980, respectively). Poor correlations also occurred between annual rates of fawn mortality and numbers of adult females with a one year time lag $(\mathrm{N}=13, \mathrm{r}=-0.430, \mathrm{P}=0.15)$.

For PHU 4, correlations between instantaneous rates of annual fawn mortality and numbers of adult deer were similarly not significant $(\mathrm{N}=9, \mathrm{r}=-0.429, \mathrm{P}=0.27$ ). Incorporating a one-year time lag made little improvement in this relationship $(\mathbf{N}=\mathbf{8}$, $r=-0.543, P=0.16$ ).

Figure 8.14 plots a theoretical maximum sustained yield (MSY) curve for PHU 1. This assumes maximum recruitment (yield) at the lowest observed adult density and minimum recruitment at maximum observed adult density. Observed data points poorly fit the theoretical MSY curve. At the lowest observed adult densities, 160-170 deer, the number of fawns recruited spanned much of the documented range of variation. Overall, lower recruitment than predicted by the MSY curve frequently occurred at the lower range of adult densities. Recruitment was often greater than predicted at above average adult densities. Across the entire range of adult densities, the MSY curve reasonably predicted recruitment in only six of 14 years (Fig. 8.14).

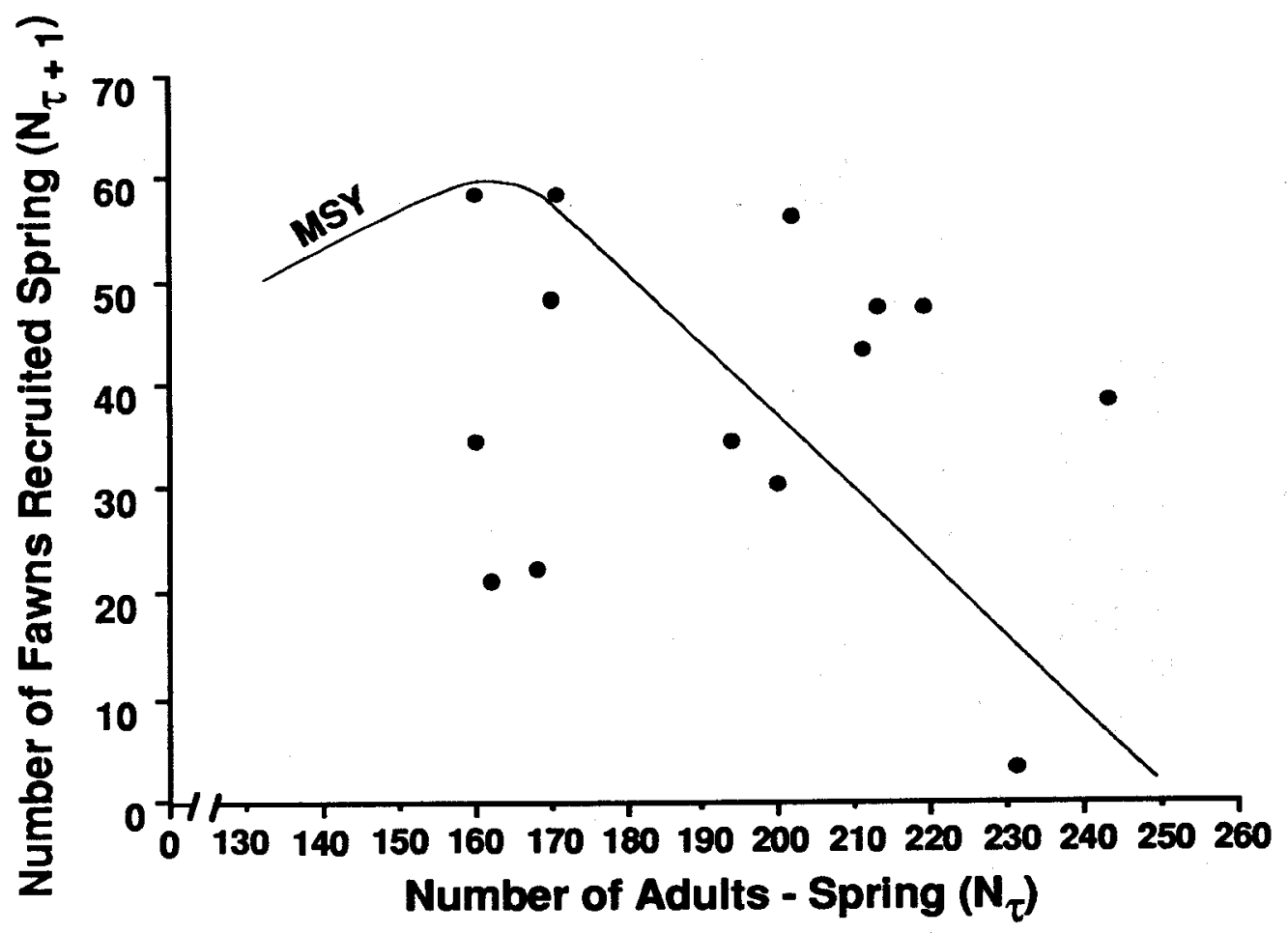

Figure 8.14. Yield in number of fawns recruited in spring $\left(\mathrm{N}_{t+1}\right)$ plotted against the number of adults in the previous spring population $\left(\mathrm{N}_{\mathbf{V}}\right.$ ) for PHU 1 . 
In this mountain-foothill environment, fawn recruitment rates were often controlled by factors other than adult density. The poor fit to theoretical concepts of density dependent population control may be at least partially explained by the variable nature of mountain environments. Density independent factors affecting fawn survival may frequently over-ride any underlying relationship between recruitment and animal density.

\section{Adult Mortality}

Annual and seasonal estimates of adult mortality were derived from arithmetic models of mule deer populations in PHUs 1 and 4 (Tables 8.3 and 8.4). The models were developed from several data sets that included population estimates for spring 19741987 on PHU 1 and 1979-1987 on PHU 4. Annual variation in these estimates was compared and reconciled with annual mortality rates calculated from samples of marked deer (Table 8.8). Changes in population composition were further evaluated using data from comprehensive aerial classifications of deer by sex and age during early and late winter. Additionally, winter mortality patterns on PHU 1 were monitored annually by carcass searches of the principal winter range in early May. Collectively, these data provided a reasonable range of estimates from which we derived final estimates of annual and seasonal mortality that best fit population estimates and trends in composition during prior and subsequent seasons and years.

Table 8.8. Annual mortality rates determined from samples of marked adult females and males in PHUs 1 and 4.

\begin{tabular}{|c|c|c|c|c|c|c|c|c|}
\hline \multirow[b]{3}{*}{ Year } & \multicolumn{4}{|c|}{ PHU 1} & \multicolumn{4}{|c|}{ PHU 4} \\
\hline & \multicolumn{2}{|c|}{ Female } & \multicolumn{2}{|c|}{ Male } & \multicolumn{2}{|c|}{ Female } & \multicolumn{2}{|c|}{ Male } \\
\hline & $\begin{array}{c}\text { No. } \\
\text { Marked }\end{array}$ & $\begin{array}{c}\% \\
\text { Mortality }\end{array}$ & $\begin{array}{c}\text { No. } \\
\text { Marked }\end{array}$ & $\begin{array}{c}\% \\
\text { Mortality }\end{array}$ & $\begin{array}{c}\text { No. } \\
\text { Marked }\end{array}$ & $\begin{array}{c}\% \\
\text { Mortality }\end{array}$ & $\begin{array}{c}\text { No. } \\
\text { Marked }\end{array}$ & $\begin{array}{c}\% \\
\text { Mortality }\end{array}$ \\
\hline 1975 & 39 & 30.8 & 13 & 38.5 & - & - & - & -- \\
\hline 1976 & 32 & 12.5 & 21 & 19.0 & - & - & - & -- \\
\hline 1977 & 31 & 0 & 18 & 33.3 & -- & -- & - & -- \\
\hline 1978 & 44 & 13.6 & 15 & 93.3 & - & - & - & -- \\
\hline 1979 & 59 & 6.8 & 11 & 63.6 & 19 & 15.8 & 10 & 60.0 \\
\hline 1980 & 78 & 11.5 & 22 & 40.9 & 84 & 22.6 & 10 & 50.0 \\
\hline 1981 & 78 & 5.1 & 18 & 50.0 & 69 & 10.1 & 7 & 42.9 \\
\hline 1982 & 81 & 27.2 & 12 & 41.7 & 62 & 19.6 & 4 & 50.0 \\
\hline 1983 & 84 & 15.5 & 24 & 41.6 & 45 & 24.2 & 2 & 100.0 \\
\hline 1984 & 75 & 18.7 & 15 & 60.0 & 98 & 11.5 & 13 & 76.9 \\
\hline 1985 & 54 & 20.4 & 6 & 83.3 & 85 & 23.5 & 3 & 66.7 \\
\hline 1986 & 38 & 7.9 & 1 & 100.0 & 65 & 20.3 & 1 & 100.0 \\
\hline 1987 & 48 & 16.7 & 10 & 70.0 & 107 & 25.7 & - & - \\
\hline
\end{tabular}


Hunting regulations were relatively consistent during much of the study period. Either sex hunting occurred throughout the five-week general deer hunting season in 1974 and for the first two weeks of the season in 1975 . From 1976 through 1986, any mule deer buck was legal while antlerless deer were hunted on limited numbers of special permits issued through a drawing.

\section{Annual and Seasonal Mortality Rates}

Total annual mortality of adult females in PHU 1 ranged from 0 to $28.6 \%$ and averaged $12.1 \%$ (Fig. 8.15). Rates exceeded $15 \%$ in only 4 of 14 years. By contrast, annual mortality of adult females in PHU 4 ranged from 10.0 to $24.3 \%$ and averaged $17.6 \%$; rates exceeded $15 \%$ during six of nine years. Differences between the two populations were greatest during 1979-1981 when both populations were recovering from declines experienced in the mid-late 1970s. Rates were very similar during 1984-1987 when populations were relatively stable.

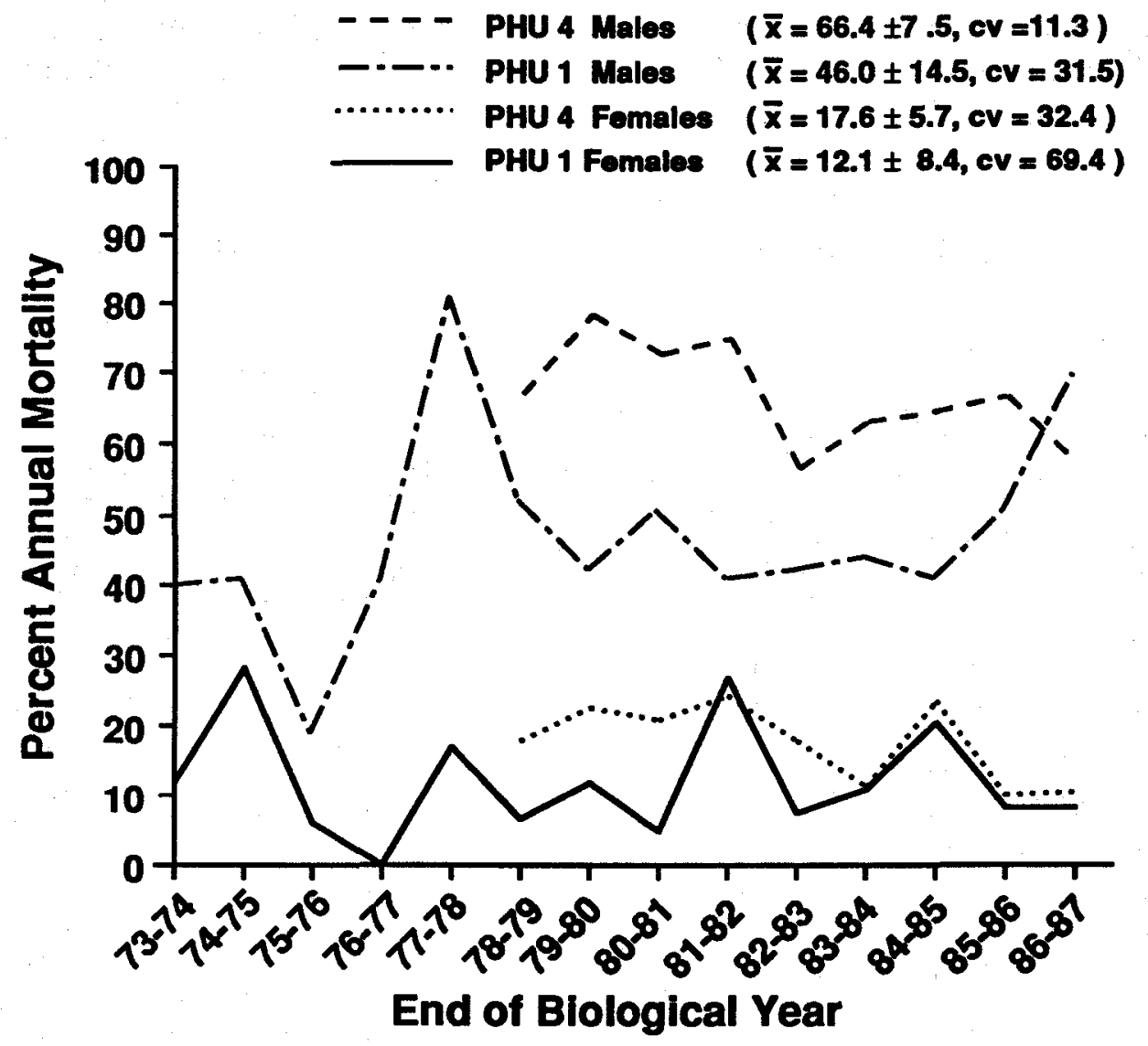

Figure 8.15. Percent annual mortality for adult mule deer in PHUs 1 and 4. Data derived from population models (Tables 8.3 and 8.4). 
Annual mortality rates for adult males were substantially higher than for adult females. Also, except for 1987, rates for males in PHU 4 were greater than rates in PHU 1 during comparable years. In PHU 4, rates ranged from 56.5 to $78.0 \%$ and averaged $66.4 \%$ during $1979-1987$. For PHU 1, rates varied from 18.2 to $80.0 \%$ and averaged $46.0 \%$ during 1974-1987. They exceeded 55\%, the low for PHU 4, during only 2 of 14 years (1978 and 1987).

Annual mortality rates computed from data for marked deer in the two populations are listed in Table 8.8. During most years when reasonable samples were available, mortality rates among marked deer were comparable to rates derived from population models (Fig. 8.15). For females, mortality rates of marked deer in PHU 1 differed by less than $3.5 \%$ from final modeled rates during 9 of 13 years; in the remaining four years, divergence varied from 6.6 to $8.5 \%$. For PHU 4, marked and modeled rates varied less than $4.7 \%$ during 5 of 9 years and between 6.5 and $15.2 \%$ in the other four years. The better fit between rates from the model and marked females for PHU 1 doubtless reflected greater proportions of marked deer in that population through the years.

Numbers of males marked in PHU 1 were sufficient to interpret annual mortality rates only during 1975-1984 (Table 8.8). Rates derived for marked males and from the model differed by less than $6.7 \%$ during 7 of 10 years and $12.3-16.9 \%$ in the other three years. Samples of males marked in PHU 4 were not adequate to compute mortality rate for any year.

On both areas, the greatest discrepancy between rates for modeled and marked populations occurred during years when the marked samples had not recently been replenished. Thus, existing marked samples were comprised of comparably older deer subject to greater mortality than the population as a whole.

Seasonally, mortality among adult females in PHU 1 averaged $4.8 \%(0-11.1 \%)$ during summer-autumn (Table 8.9). Hunter harvest estimates (Appendix Table B1) indicated that hunting of females accounted for $2.2 \pm 1.7 \%$ or slightly less than half of this; the remainder accrued from natural causes. Confirmed losses of 20 marked females included 10 shot by hunters, 1 crippling loss, 2 predator kills, 1 emigration, and 6 deaths from undetermined natural causes.

Winter-spring mortality averaged $7.3 \%(0-23.6 \%)$ among adult females in PHU 1. Winter-related malnutrition accounted for $37(58 \%)$ of the 64 confirmed deaths, 10 (16\%) were attributed to predation, and $3(5 \%)$ were accidental. The remaining 14 died of undetermined natural causes.

Less than $10 \%$ of all known natural mortalities during winter and spring occurred during the first three months (Fig. 8.16). Mortality increased sharply from February through March and peaked in April. Deaths were recorded as late as May. Of the 43 
Table 8.9. A comparison of rates of recruitment and annual and seasonal mortality of adult females in PHU 1. Data from population model (Table 8.3).

\begin{tabular}{|c|c|c|c|c|}
\hline \multirow[b]{2}{*}{ Year } & \multirow{2}{*}{$\begin{array}{c}\text { Annual } \\
\text { Yearling } \\
\text { Female } \\
\text { Recruitment" }\end{array}$} & \multicolumn{3}{|c|}{ Mortality $^{\mathbf{b}}$} \\
\hline & & $\begin{array}{c}\text { Annual } \\
(6 / 1-5 / 31)\end{array}$ & $\begin{array}{c}\text { Summer-Fall } \\
(6 / 1-11 / 30)\end{array}$ & $\begin{array}{c}\text { Winter-Spring } \\
(12 / 15 / 31)\end{array}$ \\
\hline $1973-74$ & 0.125 & 0.119 & 0.063 & 0.056 \\
\hline $1974-75$ & 0.019 & $0.286^{c}$ & $0.050^{c}$ & $0.236^{c}$ \\
\hline $1975-76$ & 0.076 & 0.059 & 0.025 & 0.034 \\
\hline $1976-77$ & 0.167 & 0.000 & 0.000 & 0.000 \\
\hline $1977-78$ & 0.036 & $0.171^{\mathrm{c}}$ & $0.071^{c}$ & $0.100^{c}$ \\
\hline $1978-79$ & 0.116 & 0.066 & 0.000 & 0.066 \\
\hline $1979-80$ & 0.063 & $0.118^{c}$ & $0.079^{c}$ & 0.039 \\
\hline $1980-81$ & 0.250 & 0.050 & 0.042 & 0.008 \\
\hline $1981-82$ & 0.125 & $0.271^{c}$ & 0.111 & $0.160^{c}$ \\
\hline $1982-83$ & 0.244 & 0.073 & 0.024 & 0.049 \\
\hline $1983-84$ & 0.201 & 0.111 & 0.028 & 0.083 \\
\hline $1984-85$ & 0.153 & $0.204^{c}$ & 0.076 & 0.127 \\
\hline $1985-86$ & 0.148 & 0.081 & 0.054 & 0.027 \\
\hline $1986-87$ & 0.151 & 0.082 & 0.050 & 0.031 \\
\hline Mean & 0.134 & 0.121 & 0.048 & 0.073 \\
\hline Range & $0.019-0.250$ & $0.000-0.286$ & $0.000-0.111$ & $0.000-0.236$ \\
\hline
\end{tabular}

a Recruitment expressed as: number of yearling females $5 / 31$ number adult females previous $6 / 1$

${ }^{b}$ Mortality expressed as:

number of adult females lost during the period number of adult females $6 / 1$ at start of biological year

${ }^{\mathrm{c}}$ Mortality during period exceeded annual recruitment 


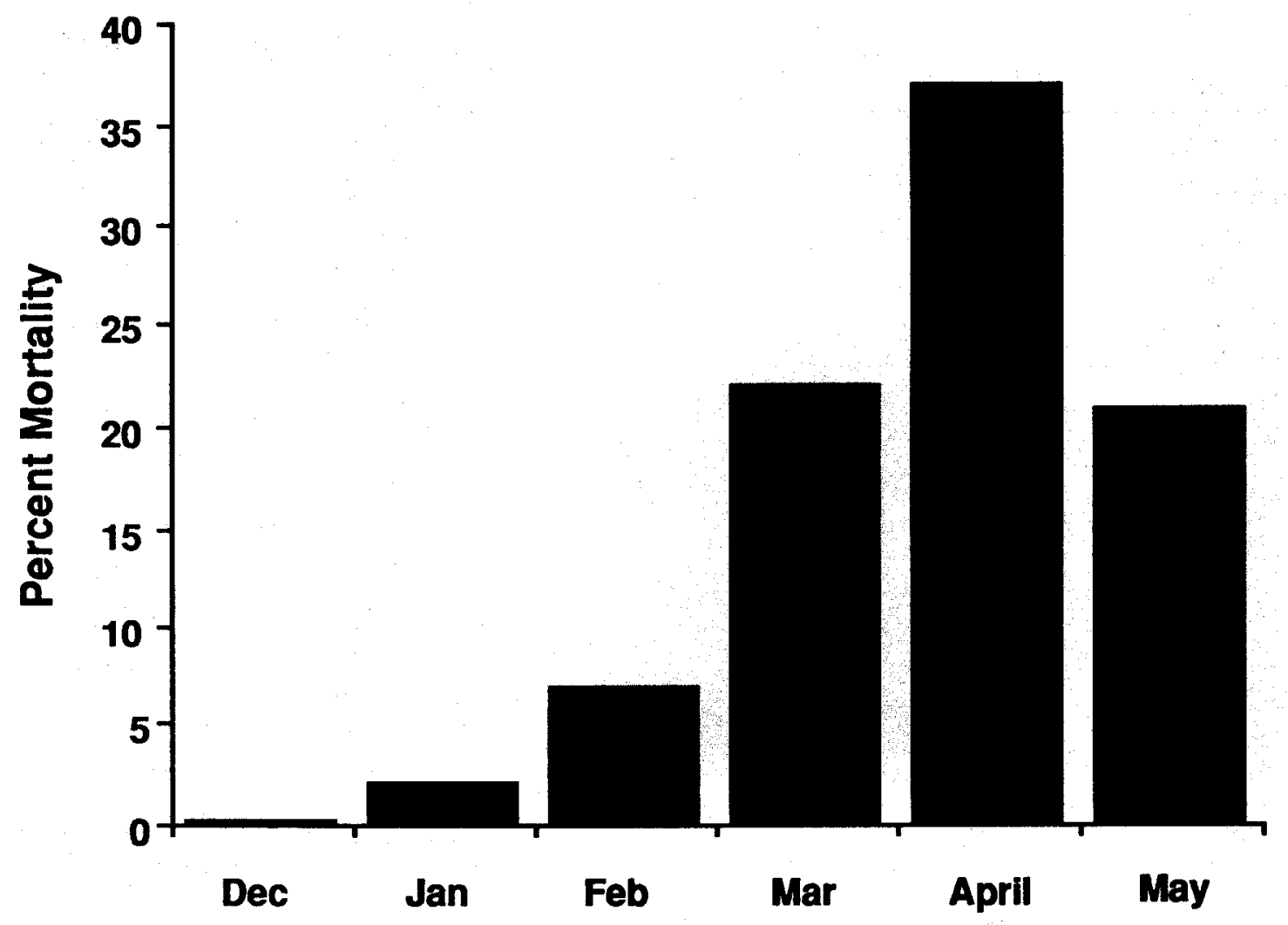

Figure 8.16. Monthly distribution of deaths of 43 marked adult females in PHU 1 during winter and spring.

deaths of marked females, winter-related malnutrition, predation, undetermined cause, and accidents accounted for $63,16,14$, and $7 \%$, respectively. Females older than 10 years tended to die earlier in the period than younger does. Forty-two percent of 33 females $>10$ years and only $20 \%$ of 10 females $<10$ years died before April.

Mortality of adult males occurred primarily in summer-autumn when rates averaged $40.4 \%$ (14.3-70.0\%) (Table 8.10). Confirmed losses of 55 marked males during the period indicated that hunting accounted for $82 \%$ of the total. This included four fatally wounded during hunting season and located later. The remaining $18 \%$ (N $=10$ ) of the losses resulted from emigration. 
Table 8.10. A comparison of rates of recruitment and annual and seasonal mortality of adult males in PHU 1. Data from population models (Table 8.3).

\begin{tabular}{|c|c|c|c|c|}
\hline \multirow[b]{2}{*}{ Year } & \multirow[b]{2}{*}{$\begin{array}{l}\text { Annual Yearling } \\
\text { Male Recruitment }\end{array}$} & \multicolumn{3}{|c|}{ Mortality } \\
\hline & & $\begin{array}{c}\text { Annual } \\
(6 / 1-5 / 31)\end{array}$ & $\begin{array}{c}\text { Summer-Autumn } \\
(6 / 1-11 / 30)\end{array}$ & $\begin{array}{l}\text { Winter-Spring } \\
(12 / 1-5 / 31)\end{array}$ \\
\hline $1973-74$ & 0.241 & $0.398^{c}$ & $0.374^{c}$ & 0.024 \\
\hline $1974-75$ & 0.029 & $0.400^{c}$ & $0.143^{c}$ & $0.257^{c}$ \\
\hline $1975-76$ & 0.318 & 0.182 & 0.182 & 0.000 \\
\hline $1976-77$ & 0.600 & 0.400 & 0.400 & 0.000 \\
\hline $1977-78$ & 0.450 & $0.800^{c}$ & $0.700^{c}$ & 0.100 \\
\hline $1978-79$ & 0.564 & 0.513 & 0.385 & 0.128 \\
\hline $1979-80$ & 0.390 & $0.415^{c}$ & $0.415^{c}$ & 0.000 \\
\hline $1980-81$ & 0.750 & 0.500 & 0.500 & 0.000 \\
\hline 1981-82 & 0.360 & $0.400^{c}$ & 0.220 & 0.180 \\
\hline $1982-83$ & 0.625 & 0.417 & 0.417 & 0.000 \\
\hline $1983-84$ & 0.500 & 0.431 & 0.431 & 0.000 \\
\hline $1984-85$ & 0.403 & 0.403 & 0.355 & 0.048 \\
\hline $1985-86$ & 0.371 & $0.500^{c}$ & $0.452^{c}$ & 0.048 \\
\hline $1986-87$ & 0.463 & $0.685^{c}$ & $0.685^{c}$ & 0.000 \\
\hline Mean & 0.433 & 0.460 & 0.404 & 0.056 \\
\hline Range & $0.029-0.750$ & $0.182-0.800$ & $0.143-0.700$ & $0.000-0.257$ \\
\hline \multicolumn{2}{|c|}{ "Annual recruitment expressed as: nun } & \multicolumn{2}{|c|}{$\frac{\text { number of yearling males } 5 / 31}{\text { number of adult males previous } 6 / 1}$} & \\
\hline \multicolumn{4}{|c|}{${ }^{\mathrm{b}}$ Mortality expressed as: } & \\
\hline \multicolumn{5}{|c|}{ number of adult males lost durine the period } \\
\hline \multicolumn{4}{|c|}{ c Mortality during period exceeded annual recruitment } & \\
\hline
\end{tabular}


Harvest surveys extrapolated to PHU 1 from data compiled at the hunting unit level indicated that, on average, $54.0 \pm 18.0 \%$ of the total adult male population in PHU 1 was shot annually from 1975-1987 (Appendix Table B1). Although perhaps less precise than other estimates, these data supported those for marked deer indicating that hunting accounted for most deaths of adult males.

Mortality rate for males during winter-spring was relatively low, averaging only $5.6 \%(0-25.7 \%)$. Thirteen confirmed losses of marked bucks included nine cases of winter-related malnutrition, one each attributed to emigration and accident, and two undetermined natural deaths.

Mortality rates of adults in PHU 4 during summer-autumn and winter-spring were not computed separately from annual rates. Annual mortality rates of adult females averaged 0.176 in PHU 4 (Table 8.11) compared to 0.121 in PHU 1 (Table 8.9).

Table 8.11. A comparison of annual rates of recruitment and mortality of adult females and males in PHU 4. Data from population model (Table 8.4.)

\begin{tabular}{ccc|cc}
\hline & \multicolumn{2}{c}{ Females } & \multicolumn{2}{c}{ Males } \\
\cline { 2 - 5 } Year & $\begin{array}{c}\text { Annual } \\
\text { Recruitment }^{\mathrm{a}}\end{array}$ & $\begin{array}{c}\text { Annual } \\
\text { Mortality }\end{array}$ & $\begin{array}{c}\text { Annual } \\
\text { Recruitment }^{\mathrm{b}}\end{array}$ & $\begin{array}{c}\text { Annual } \\
\text { Mortality }^{\mathrm{b}}\end{array}$ \\
\hline $1978-79$ & 0.144 & $0.177^{\mathrm{c}}$ & 0.448 & $0.667^{\mathfrak{c}}$ \\
$1979-80$ & 0.270 & 0.226 & 1.040 & 0.780 \\
$1980-81$ & 0.359 & 0.210 & 1.147 & 0.723 \\
$1981-82$ & 0.162 & $0.243^{\mathrm{c}}$ & 0.417 & $0.746^{\mathfrak{c}}$ \\
$1982-83$ & 0.189 & 0.177 & 0.666 & 0.565 \\
$1983-84$ & 0.210 & 0.115 & 0.681 & 0.627 \\
$1984-85$ & 0.100 & $0.235^{\mathrm{c}}$ & 0.337 & $0.640^{\mathfrak{c}}$ \\
$1985-86$ & 0.162 & 0.100 & 0.677 & 0.663 \\
$1986-87$ & 0.199 & 0.105 & 0.869 & 0.568 \\
\hline Mean & 0.199 & 0.176 & 0.698 & 0.664 \\
Range & $0.100-0.359$ & $0.100-0.243$ & $0.337-1.147$ & $0.565-0.780$ \\
\hline
\end{tabular}

- Annual recruitment expressed as:

number of yearlings $31 \mathrm{May}$ number of adults previous 31 May

b Mortality expressed as:

number of adults lost during year number of adults previous 31 May

c Mortality exceeded annual recruitment 
Confirmed losses of marked females $(\mathrm{N}=32)$ in PHU 4 included 20, 3, 6, 2, and 1 lost from hunting, crippling loss, emigration, accidents, and predation, respectively. An additional 18 known deaths occurred in winter-spring. Winter-related malnutrition ( $\mathrm{N}=11)$, predation $(\mathrm{N}=4)$, unknown natural death $(\mathrm{N}=2)$, and accident $(\mathrm{N}=1)$ were the recorded causes. However, it should be noted that records of natural mortality were underrepresented compared to hunting loss because of logistical constraints in documenting the former.

Harvest data for PHU 4 (Appendix Table B2) indicated that an average $3.1 \pm$ $2.6 \%$ of all adult females were killed annually from 1978-1986. These estimates were accurate because antlerless hunting was regulated by permit and each recipient received a detailed questionnaire. Similar to PHU 1, these data indicate that hunting was a relatively minor component of total annual mortality among adult females.

Among 22 confirmed losses of marked adult males, 18 (82\%) occurred during summer-autumn and the remainder in winter-spring. Losses during summer-autumn included 13 to hunting and 5 cases of emigration. In winter-spring, two bucks died of winter-related malnutrition, one of unknown natural causes, and another was killed by a vehicle.

Based on estimated harvests (Appendix Table B2), an average of $39.5 \pm 12.2 \%$ of the total adult male population was killed annually from 1978 to 1986 . This was substantially less than the average total annual mortality rate of $66.4 \%$ (Table 8.11). Factors other than hunting apparently contributed significantly to annual turnover of adult males in PHU 4.

\section{Adult Mortality/Recruitment Relationships}

Annual mortality of adult females in PHU 1 exceeded annual recruitment of yearling females during 5 of 14 years (Table 8.9). Summer-autumn mortality never exceeded the long-term average rate of recruitment of females; however, on an annual basis, it was sufficient to reduce the female segment during 1974-75, 1977-78, and 197980. These years were characterized by the lowest annual recruitment of females during the 14-year study.

Mortality during winter-spring exceeded annual recruitment and reduced the female population during 1974-75, 1977-78, and 1981-82. These were three of the four winters with the highest severity indexes recorded. However, winter-spring losses were greater than long-term average female recruitment only during 2 of 14 years (1974-75 and 1981-82). Combined summer-autumn and winter-spring mortality exceeded annual recruitment in 1984-85.

The adult male population in PHU 1 was numerically smaller than the female segment, and annual recruitment of males was proportionally higher (Table 8.10). 
Therefore, as compared to females, the male segment could sustain higher mortality rates before experiencing population declines. Despite this, annual mortality of adult males exceeded annual recruitment during seven of 14 years and long-term average recruitment during 5 of 14 years. Summer-autumn mortality, primarily hunting loss, was sufficient to reduce the male segment during 1973-74, 1974-75, 1977-78, 1979-80, 1985-86, and 1986-87. Male mortality rate in winter-spring exceeded annual recruitment only during the very severe winter of 1974-75.

Recruitment-mortality relationships for adult deer in PHU 4 were evaluated only on an annual basis (Table 8.11). Mortality of females exceeded annual recruitment during 1978-79, 1981-82, and 1984-85, years of lowest recorded recruitment of females in PHU 4 during the study. The long-term average recruitment rate was exceeded by annual mortality during four of nine years. Male mortality in PHU 4 was greater than annual recruitment during the same three years as for females. The long-term average recruitment rate for males was exceeded by annual mortality during three of nine years.

\section{Age-Specific Survival Rates}

Age-specific survival rates were determined from 99 females and 80 males marked in PHU 1 and 100 females and 30 males in PHU 4. Only individuals aged to a specific year class at time of capture or after death were included. Because all deer were captured during January-April, computation of age-specific survivorship was initialized on 1 June.

Adult females -- Among all age classes, survival of adult females in PHU 1 was equal to or greater than survival in PHU 4 (Fig. 8.17). Overall, age specific survival rates for females in PHU 1 were high with minimal variation through age 8. Survival declined slightly to age 9 but increased again for 10-year olds before generally declining among females older than 10. Rates of decline were most pronounced between ages 11-12 and 13-14. However, these were separated by a "plateau" of equal survivorship for 12 and 13 year olds.

Yearling female survival in PHU 4 was only $4 \%$ less than in PHU 1 . However, the rate for 2-year old females was $19 \%$ lower. Except for the peak in survival for 3year old females in PHU 4, the two survivorship curves generally paralleled one another through age class 9. They diverged at age class 10 when survival of females in PHU 4 continued to decline.

The differences in age specific survival rates had a significant effect on numbers of females expected in older age classes in the two populations. For example, starting with 1,000 yearling females in each population, on average only 74 would survive to age class 12 in PHU 4 compared to 322 in PHU 1. 


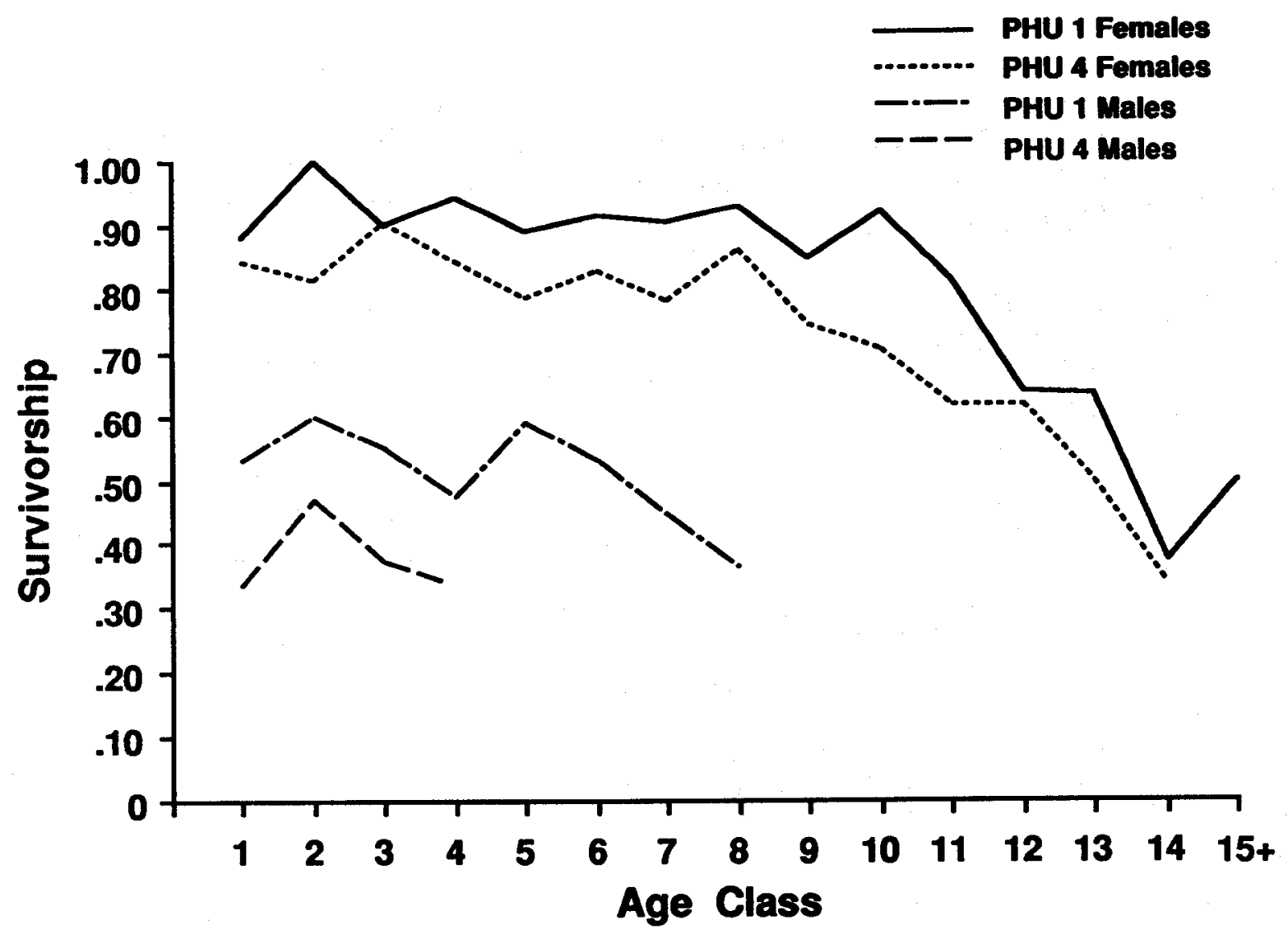

$\begin{array}{rllllllllllllllll}\text { Sample } & \text { PHU 1 F } & 17 & 34 & 49 & 53 & 55 & 57 & 64 & 69 & 71 & 62 & 59 & 47 & 27 & 15 & 6 \\ \text { Size: } & \text { PHU 4 F } & 19 & 48 & 53 & 50 & 46 & 47 & 59 & 50 & 39 & 27 & 21 & 13 & 10 & 3 & - \\ & \text { PHU 1 M } & 32 & 40 & 31 & 21 & 17 & 15 & 9 & 11 & - & - & - & - & - & - & - \\ & \text { PHU 4 M } & 21 & 15 & 8 & 6 & - & - & - & - & - & - & - & - & - & - & -\end{array}$

Figure 8.17. Age specific survival rates for adult females and males in PHUs 1 and 4.

Determination of the precise causes of deer mortality and the relative role of hunting and natural losses by age class was particularly challenging. Confirmed losses in PHU 1 probably approximated a more representative cross section of deer fates because the relatively small study area permitted better documentation of natural mortality. Also, its reputation as a research area among landowners and hunters may have increased reports of carcasses and rate of tag returns compared to PHU 4.

Hunting was the principal confirmed cause of death of marked females age 1-4 in PHU 1 (Table 8.12). Winter related malnutrition and undetermined natural causes accounted for the remainder of confirmed losses. In PHU 4, the opposite occurred with 
Table 8.12. Number of losses by age category for adult females and adult males marked in PHUs 1 and 4.

\begin{tabular}{|c|c|c|c|c|c|}
\hline \multicolumn{3}{|c|}{ Females } & \multicolumn{3}{|c|}{ Males } \\
\hline $\begin{array}{c}\text { Age } \\
\text { Category }\end{array}$ & Hunting & Natural & $\begin{array}{c}\text { Age } \\
\text { Category }\end{array}$ & Hunting & Natural \\
\hline \multicolumn{6}{|c|}{ PHU 1} \\
\hline $\begin{array}{l}1-4 \text { years } \\
5-8 \text { years } \\
9-12 \text { years } \\
13-15+\text { years }\end{array}$ & $\begin{array}{l}5 \\
2 \\
2 \\
2\end{array}$ & $\begin{array}{r}3 \\
13 \\
32 \\
25\end{array}$ & $\begin{array}{l}1 \text { year } \\
2-4 \text { years } \\
5-8 \text { years } \\
9+\text { years }\end{array}$ & $\begin{array}{r}2 \\
30 \\
12 \\
1\end{array}$ & $\begin{array}{r}13 \\
4 \\
4 \\
2\end{array}$ \\
\hline \multicolumn{6}{|c|}{ PHU 4} \\
\hline $\begin{array}{l}1-4 \text { years } \\
5-8 \text { years } \\
9-12 \text { years } \\
13-15+\text { years }\end{array}$ & $\begin{array}{l}6 \\
8 \\
7 \\
2\end{array}$ & $\begin{array}{l}9 \\
7 \\
6 \\
5\end{array}$ & $\begin{array}{l}1 \text { year } \\
2-4 \text { years } \\
5-8 \text { years } \\
9+\text { years }\end{array}$ & $\begin{array}{r}1 \\
10 \\
2 \\
--\end{array}$ & $\begin{array}{c}8 \\
1 \\
0 \\
--\end{array}$ \\
\hline
\end{tabular}

natural causes accounting for more of the confirmed total losses in age classes 1-4. More than half of those (five of nine) resulted from emigration, primarily of 2-year olds. Other natural losses were equally divided between predation and accidents.

Natural mortality significantly outnumbered hunting loss in age categories 5-8 for adult females in PHU 1. They included eight cases of winter-related malnutrition, four undetermined natural deaths, and one accident. On PHU 4, hunting and natural losses were nearly equal (Table 8.12) with no winter malnutrition losses recorded. Instead, there were four cases of predation and one case each of accidents, emigration, and undetermined natural death.

Among adult females in PHU 1, hunting accounted for only two mortalities each in age categories 9-12 and 13-15+. Natural losses among 9-12 year olds included 13 related to winter malnutrition, 11 undetermined natural deaths, 5 predator kills, 2 accidental deaths, and 1 emigration. Winter-related malnutrition, predation, undetermined natural death, and accidents accounted for $14,6,4$, and 1, respectively, of 25 total losses recorded for females in the 13-15 + age category.

On PHU 4, hunting losses $(N=7)$ outnumbered the six cases of winter malnutrition which comprised all of the confirmed natural mortalities in 9-12 year olds. In the 13-15 + age category, five cases of winter-related malnutrition were recorded compared to only two hunting losses. 
Age-specific survival curves for adult females in the two populations were similar to the general patterns described for mammals (Caughley 1966). They did not exhibit the "spike" in mortality described for 6-year old females in a northcentral Montana mule deer population (Hamlin and Mackie 1989). That spike was hypothesized as the average outcome of cumulative reproductive stress resulting from a strategy of maximum reproductive output each year in a variable environment. Adult females in the Bridger Mountains exhibited a high and stable plateau of survivorship that extended well into the older age classes.

Adult males - Survival rates for adult males were much lower than for females (Fig. 8.17). Additionally, age-specific survival rates for adult males in PHU 1 were higher than rates recorded for males in PHU 4 across all comparable age classes. However, the pattern of fluctuation in male survival by age class was similar for both populations. Rates increased between age 1 and 2 years and then consistently declined to age class 4 .

Few males lived more than four years in PHU 4, precluding evaluation of survivorship of older males in that population. In PHU 1, survival increased to a secondary peak at age 5 and then consistently declined through age classes 6-9.

The difference in age specific survival rates for males had a significant effect on numbers expected in older age classes of the two populations. Beginning with 1000 yearling males in each population, only $333,156,59$, and 20 would survive to age class $2,3,4$, and 5, respectively, in PHU 4. This compared with 531, 319, 175, and 83 survivors to the same age classes in PHU 1.

Confirmed losses of marked males by age class (Table 8.12) indicated that hunting had a relatively minor influence on survival of yearlings in both populations. In PHU 1, natural losses of yearling males included eight cases of emigration, four of winter related malnutrition, and one undetermined natural death. In PHU 4, these losses were emigration (4), winter-related malnutrition (2), and accidents (1).

Natural causes accounted for only $16 \%$ (8 of 50 ) and $8 \%$ ( 1 of 13 ) of all confirmed losses of males 2-8 years of age in PHU 1 and PHU 4, respectively. Losses in PHU 1 included three cases of winter-related malnutrition, three of emigration, and one each related to accidents and undetermined natural cause. Only one male, a 3-year old, died of undetermined natural cause in PHU 4. In PHUs 1 and 4, hunting accounted for 84 and $92 \%$, respectively, of all confirmed losses of males aged 2-8 years.

Only three males $\geq 9$ years of age were confirmed losses in PHU 1. One was killed by a hunter, and two died of malnutrition. None of the males marked in PHU 4 survived to this age category.

Male survival curves for both populations (Fig. 8.17) were strongly influenced by non-hunting losses in age class 1; survival of older males was influenced primarily 
by hunting mortality. The high mortality in all age classes truncated survival curves and precluded development of a "plateau" of survivorship that normally characterized middle age classes. This was particularly apparent for males in PHU 4.

\section{Adult Mortality-Winter Severity Relationships}

Overwinter mortality rates for adult females and males in PHU 1 were positively correlated with an index of winter severity when one data point (for 1979) was omitted from the 13-year data set for each sex (Fig. 8.18). Adult mortality rates for winter 1979 which had the highest severity index recorded during the study, fell well below those predicted by regression. This resulted from interaction of age structure and winter severity on adult mortality rate. The preceding winter, 1978, was characterized by the third highest severity index recorded. Thus, a winter of above average severity (1978) was followed immediately by a very severe winter (1979). This was the only time during our study that severe winters occurred back-to-back. All other winters of above average severity $(1974-75,1981-82,1984-85)$ were flanked by $2-3$ mild winters.

The adult female segment entering winter 1977-78 included limited numbers of deer older than 11 years of age as a result of above average survival during the mild winters of 1975-76 and 1976-77. The 10\% (Arcsine $=18.43$ ) overwinter mortality rate for adult females during 1977-78 largely removed these vulnerable, older-aged females. With the population purged of females most vulnerable to loss, mortality during the subsequent severe winter, 1978-79, was much lower than expected.

Similar circumstances apparently influenced differences in adult male mortality between these two years. However, the male segment may be more consistently vulnerable to winter mortality under severe conditions than females even though it is usually characterized by a younger age structure. Our survivorship data indicated that yearling males were more likely to die during severe winters than yearling females. Also, males older than six years appear to be more vulnerable to winter mortality than comparably aged females, apparently as a result of depleted physical condition following the rut. The male population in PHU 1 included significant numbers of yearlings and/or adults $\geq 6$ years during all three severe winters $(1975,1978$, and 1982) when overwinter mortality varied from 10 to $26 \%$ (Arcsine values $=18-30$ ) (Fig. 8.18).

We recorded no overwinter male mortality during the six mildest winters while female mortality ranged from 0-8\% (Arcsine = 16.74). If the outlying 1978-79 data point is included in the regression equation for each sex, the relationship remains significant for adult males $(\mathrm{N}=13, \mathrm{r}=0.699, \mathrm{p}=0.01)$ but not for adult females $(\mathrm{N}$ $=13, \mathrm{r}=0.444, \mathrm{p}=0.15$ ).

The relative position of the 1975 data point for both sexes (Fig. 8.18) indicated that mortality was greater than expected that winter. This was related to the relatively high proportion of older, vulnerable individuals of both sexes in the population entering 

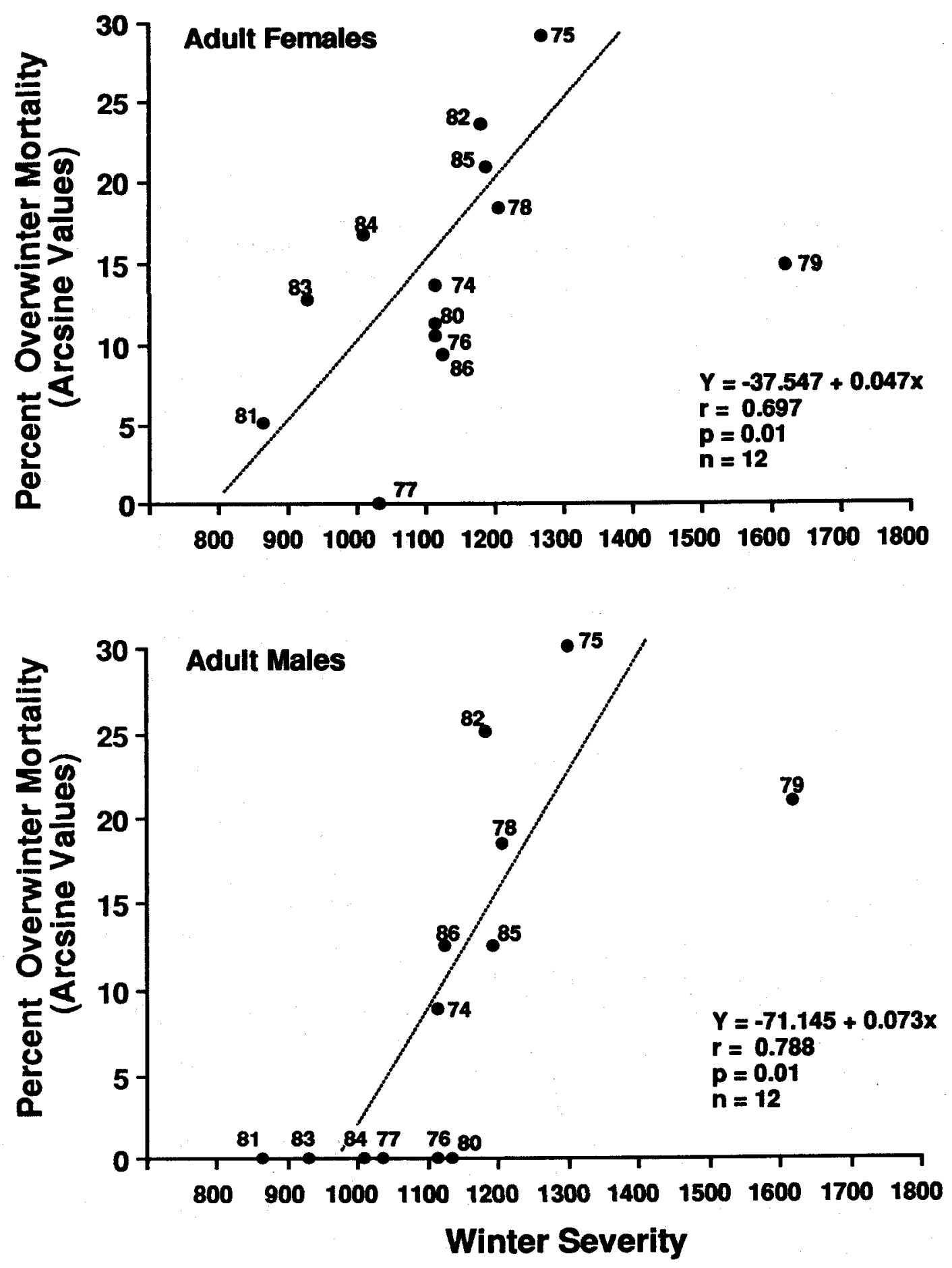

Figure 8.18. Relationship between overwinter mortality rates and winter severity for adult females and males in PHU 1. The 1979 data point was excluded from the regression (see text). 
winter that year. However, the timing of severe conditions during the winter season was also important. Thus, although the cumulative severity index $(S I=1,270)$ was only slightly greater than 1978 (SI $=1,206)$, severe conditions were concentrated during late winter and spring in 1975 , the time when deer normally are in the poorest physical condition. This combination of factors resulted in the highest recorded overwinter mortality rate for both sexes and the only year when deaths related to winter-related malnutrition were documented among 2-5 year old deer.

Adult Mortality-Density Relationships

Females - Mortality rate of adult females in PHU 1 during summer and autumn was not significantly correlated with number of adults in the population on 1 June $(\mathrm{N}=14, \mathrm{r}=$ $0.506, p=0.07$ ). This relationship was undoubtedly influenced by hunting mortality which comprised a part of total mortality during the period. Because hunting mortality rate was influenced by factors such as hunting regulation and weather that often operated independently of deer density, we can only conclude that adult female mortality during summer and autumn generally varied within a relatively narrow range of $0-11 \%$ across the spectrum of adult numbers $(160-243)$ that occurred during the study.

Overwinter mortality rates for adult females were significantly correlated $(\mathbf{N}=$ $14, r=-0.605, p=0.02$ ) with numbers of adult deer in the population at the onset of winter (Fig. 8.19). However, it should be noted that overwinter mortality rates

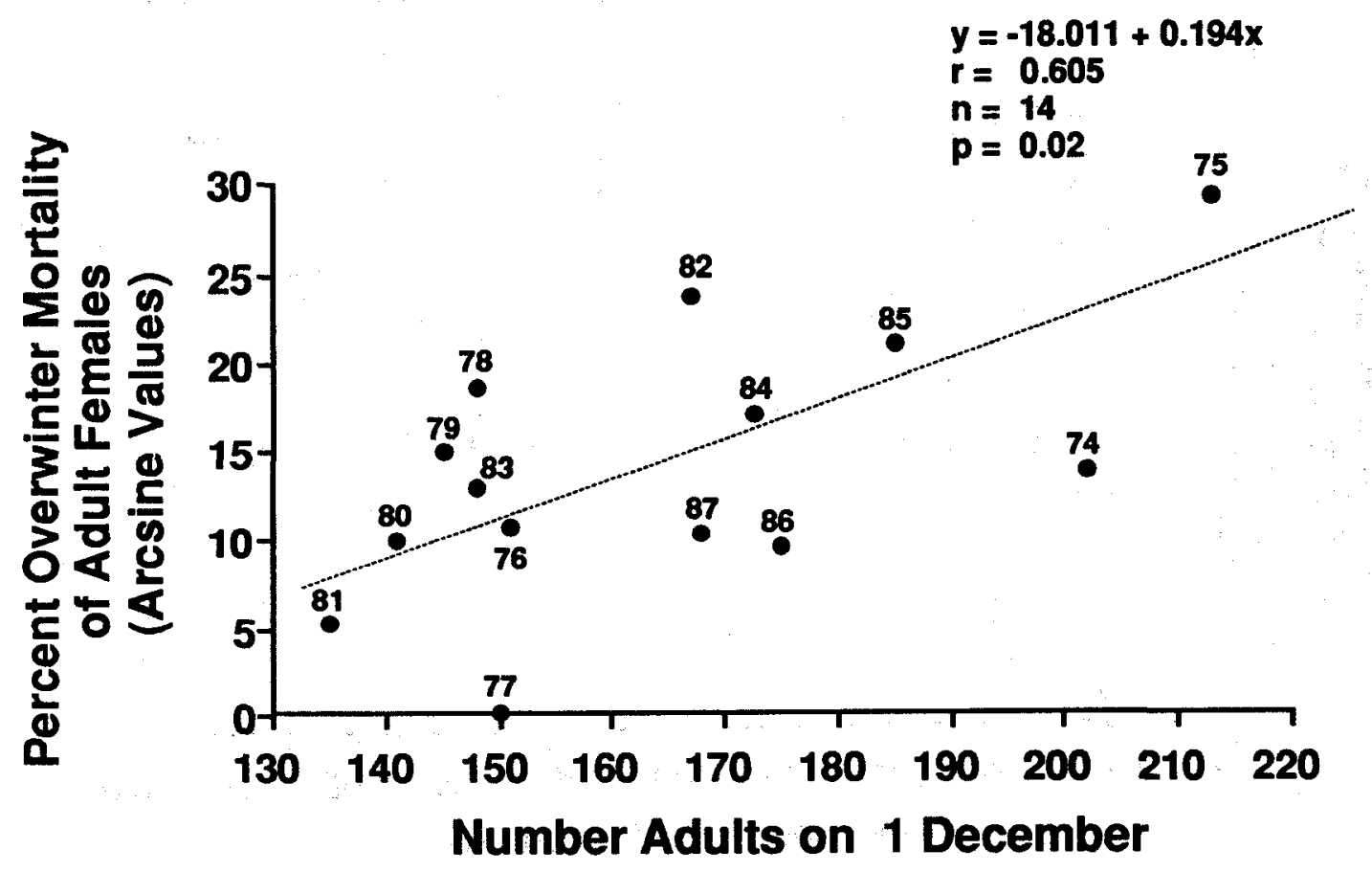

Figure 8.19. Relationship between overwinter mortality rate of adult females and number of adults in PHU 1 on 1 December. 
exhibited substantial variation at all densities. Mortality ranged from 0 to $10 \%$ (Arcsine $=18.43$ ) at the lower end of observed densities $(135-150), 3-16 \%$ (Arcsine $=9.97$ 23.58) at the mid-range (150-185) and 6-24\% (Arcsine $=14.18-29.33$ ) at the highest densities (185-215). During the four years (1975, 1978, 1982, and 1985) of highest over-winter mortality ( $\geq 10 \%)$, adult deer numbers in early winter ranged from 148-213.

On an annual basis, female mortality rates were significantly correlated with number of adult females in the Armstrong population on 1 June (Fig. 8.20). However, mortality rates generally clustered more closely along the regression line at the lower range of adult female numbers; rates were more variable and less linear at moderate to high numbers.

Although Figs. 8.19 and 8.20 implied a relationship between deer density and seasonal/annual mortality, other factors such as winter severity, population age structure, and habitat use interacted to also influence mortality patterns and rates.

The winter habitat use strategy employed by deer in PHU 1 emphasized energy conservation. This favored survival of adults entering winter with adequate fat reserves. Prime-aged females (1-10 years) were relatively immune to winter-related malnutrition, the predominant cause of natural mortality in the population. Thus, females aged 11-16 years comprised the segment which exerted the greatest influence on mortality-density relationships. These older females, characterized by sub-optimal body reserves, tended to accumulate (i.e. increase in number/proportion) in the age structure during mild

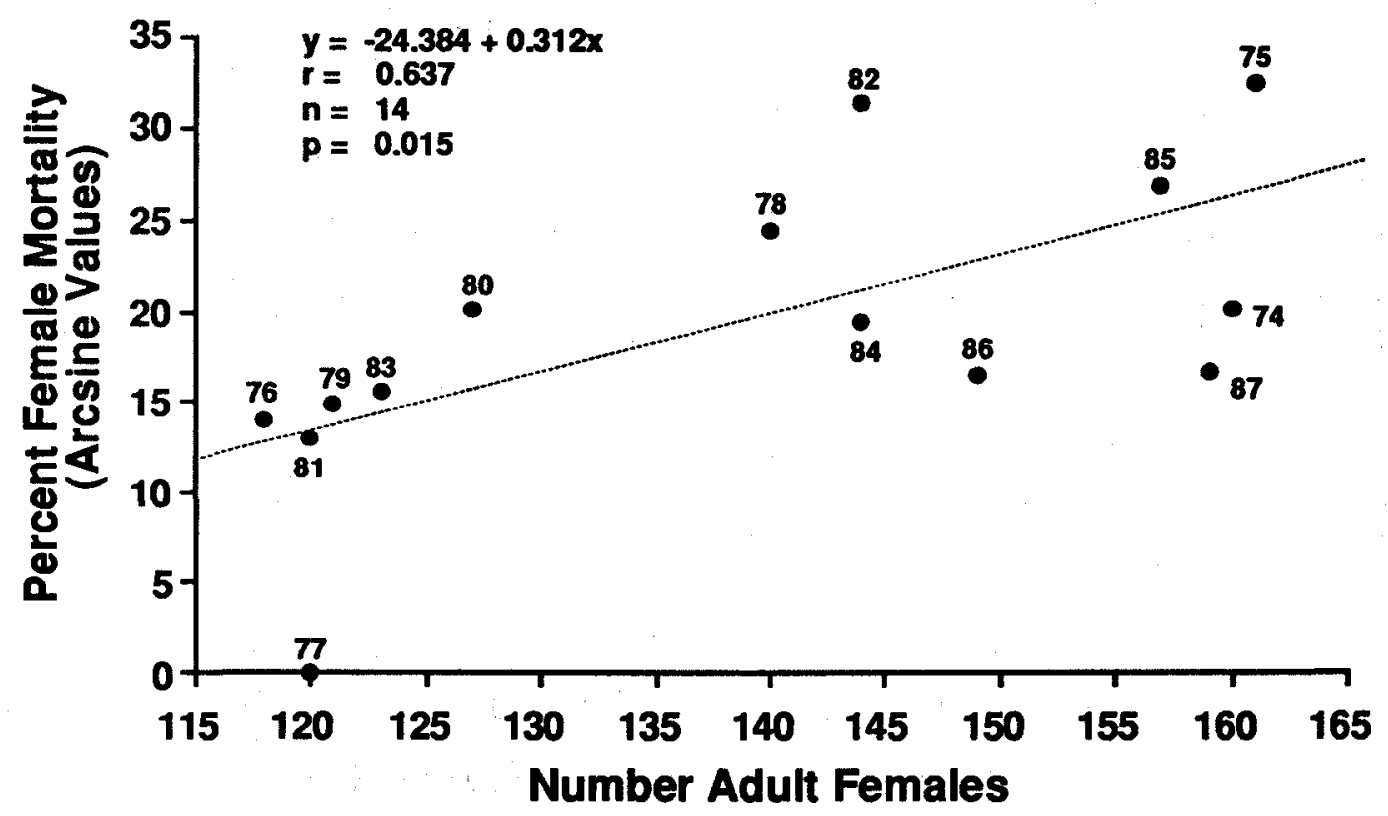

Figure 8.20. Relationship between annual mortality rate of adult females and number of adult females in PHU 1 on 1 June. 
winters. After two to four years of mild conditions usually accompanied by increasing total adult female numbers, populations entered severe winters such as 1975, 1978, 1982, and 1985 somewhat "heavy" with older deer predisposed to mortality. The result invariably was above average seasonal and annual mortality in the female segment, confined primarily to 11-16 year old individuals that lacked the fat reserves to withstand prolonged energy deficit associated with more severe winters. This mortality combined with high overwinter fawn losses resulted in general population declines. The smaller, trimmed populations that typically followed severe winters experienced low female mortality rates. This was not because female or total adult densities were low, but rather because the vulnerable segment was absent and mild winters usually followed severe.

In a population characterized by extended longevity of adult females such as PHU 1 , restoration of the vulnerable, old age segment requires no more than 2-3 years of successive mild winters because substantial numbers of 8,9 , and 10 year old females are usually available to move into the 11 year and older age classes. Also, not all older deer were vulnerable or died under severe conditions. If mild winters continue after the vulnerable segment is re-established, density can remain high in conjunction with relatively low mortality. This scenario occurred in 1974 and 1987 (Fig. 8.20). The classic combination of high density and high mortality occurred only when significant numbers of vulnerable females entered a severe winter as occurred in 1975 and 1985. High mortality also occurred at moderate density when significant numbers of vulnerable females were present as in the severe winters of 1978 and 1982.

In contrast with the Armstrong population segment of PHU 1, annual mortality rates for adult females in PHU 4 were not significantly correlated with numbers of adult females $(\mathrm{N}=9, \mathrm{r}=0.231, \mathrm{p}>0.50)$ or total adults $(\mathrm{N}=9, \mathrm{r}=0.432, \mathrm{p}=0.26)$ at the beginning of the biological year. Losses from a variety of causes including emigration, predation, accidents, hunting, and winter-related malnutrition contributed to overall higher mortality of females aged 1-10 years on PHU 4. This prevented accumulation of a significant number of females aged 11-16 years. Adult female mortality in PHU 4 was less synchronized to a particular cause or time of year. The lowest and highest observed adult female densities were associated with peak mortality rates ( 23 and $24 \%$, respectively). Mortality was equally unrelated to adult female density during all other years.

Males - Annual mortality rate of males in the Armstrong segment of PHU 1 was not significantly correlated with either total adult males $(\mathrm{N}=14, \mathrm{r}=0.076, \mathrm{p}>0.50)$ or total adults $(\mathrm{N}=14, \mathrm{r}=0.178, \mathrm{p}>0.50)$ on 1 June. Annual mortality rate of males in PHU 4 was also not significantly correlated with either total adult males ( $N=9, r=$ $-0.031, \mathrm{p}>0.50)$ or total adults $(\mathrm{N}=9, \mathrm{r}=0.252, \mathrm{p}>0.50)$.

In PHU 1, male mortality rate during summer and autumn was not correlated with numbers of adults $(\mathrm{N}=14, \mathrm{r}=-0.004, \mathrm{p}>0.50)$ or numbers of adult males $(\mathrm{N}=14$, $r=-0.057, p>0.50$ ). Similarly, during winter and spring, we found no significant 
relationship between mortality rates and number of adults $(\mathrm{N}=14, \mathrm{r}=0.474, \mathrm{p}=$ 0.09 ) or numbers of adult males $(\mathrm{N}=14, \mathrm{r}=0.476, \mathrm{p}=0.08)$ present on 1 December.

In both populations, hunting was the principle factor influencing the survival of males $\geq 2$ years of age. Although male survivorship was higher in PHU 1, few males in either population reached age classes $>5$ years that were vulnerable to winter-related malnutrition.

Summary

1. Pregnancy rates for mule deer in the Bridger Mountains were $88 \%$ for yearlings, $100 \%$ for $2-8$ year olds, and $78 \%$ for $9-14$ year olds.

2. Ovulation rates varied from 1.33 for yearlings, 2.00 for $2-8$ year olds, and 1.85 for females 9 years and older.

3. Fetal rate was 1.14 for yearlings, 1.58 for $2-8$ year olds, and 1.14 for females 9 years and older.

4. Yearling, 2-8 year olds, and 9-14 year old females produced 14,65 , and $33 \%$ twin litters, respectively.

5. Classification counts and age-specific reproductive data for marked females indicated generally lower reproductive output for west slope PHUs.

6. Annual fawn mortality rates averaged $73 \pm 11 \%(\mathrm{~N}=14$ years) in PHU 1 and $65 \pm 13 \%(\mathrm{~N}=9$ years $)$ in PHU 4. During these same periods, recruitment to spring averaged 33.4 \pm 13.1 fawns: 100 adult females in PHU 1 and $49.6 \pm 18.9$ fawns: 100 adult females in PHU 4.

7. Fawn mortality rates were higher and less variable between 1 June and 1 December than between 1 December and 31 May.

8. Overwinter fawn mortality rate was significantly correlated with an index of winter severity in PHU 1, but not significant in PHU 4.

9. The sex ratio of fawns in west slope PHUs became distorted in favor of males by the time of recruitment; little change was apparent for east slope PHUs.

10. Fawn recruitment rates were often controlled by factors other than adult density. When no time lags were incorporated, correlations between annual rates of fawn mortality and numbers of adult deer were not significant. With a one-year time lag, the relationship approached significance $(P=0.05)$. 
11. Annual mortality rates of adult females in PHU 1 averaged $12.1 \%$ (range 0$28.6 \%$ ) compared to $17.6 \%$ (range 10-24.3\%) in PHU 4. Hunting accounted for a relatively small portion of total annual female mortality in both PHU 1 and 4.

12. Annual mortality rates for adult males averaged $46.0 \%$ (range $18.2-80.0 \%$ ) in PHU 1 and 66.4\% (range 56.5-78.0\%) in PHU 4. Hunting was the major cause of documented deaths of adult males in both PHUs, although it appeared that natural loss of males was also important in PHU 4.

13. Age-specific survival rates were higher for both adult females and males in PHU 1 than in PHU 4. For both populations, survival of adult males was much lower than for females.

14. Overwinter mortality rates for adult females and males were positively correlated with an index of winter severity.

15. In PHU 1, overwinter and annual mortality rates of adult females were significantly correlated to numbers of deer in the population. However, the influence of winter severity, age structure, and habitat use on mortality patterns are also discussed. 


\section{CHAPTER 9}

\section{POPULATION COMPOSITION, SIZE, AND TREND}

Sex and age ratios and adult age structure are descriptive of the cumulative effect of all factors influencing natality and mortality. The relative importance of each individual factor is constantly changing and accounts for the dynamic nature of these data on a seasonal or annual basis. The purpose of this chapter is not to specifically discuss the effect of individual factors on population composition, but rather to describe the culmination of differences in the dynamics of individual mule deer populations occurring in the Bridger Range.

Sex and Age Composition

Sex and age composition varied between populations and between years in each population. Numbers and ratios of mule deer classified in PHUs 1 and 4, our principle study areas, during early and late winter each year are listed in Tables 9.1 and 9.2. Mean sex and age ratios for these two populations are compared with similar data for the five less intensively studied populations in Fig. 9.1. Early and late winter classifications in all seven population units were obtained through full-coverage aerial surveys of the winter range in all units though surveys were conducted during fewer years in PHUs 2 , $3,5,6$, and 7. Our discussion focuses on data for PHUs 1 and 4 because these units best represent long term trends in population composition relative to environmental characteristics of west and east slope ranges, respectively.

Females consistently predominated in both populations during early winter (Table 9.1). However, PHU 1 averaged 26 males:100 females (range 8-40:100) compared to only 11 males: 100 females (range 5-15:100) in PHU 4. Lower and more stable ratios in the latter unit apparently resulted from consistently high annual losses of adult males. Annual losses of males in PHU 4 were attributed to a combination of hunting and emigration, while hunting was the principle cause of mortality in PHU 1.

Average male:female ratios in other west slope populations were similar to PHU 1 (Fig. 9.1). Likewise, all four east slope populations had lower average ratios than west slope units. The greater variability among east than west slope populations was at least partially related to differences in sampling intensity. Yearlings comprised an average 42\% (range 8-77\%) of all adult males in PHU 1 and 60\% (range 36-73\%) in PHU 4. 


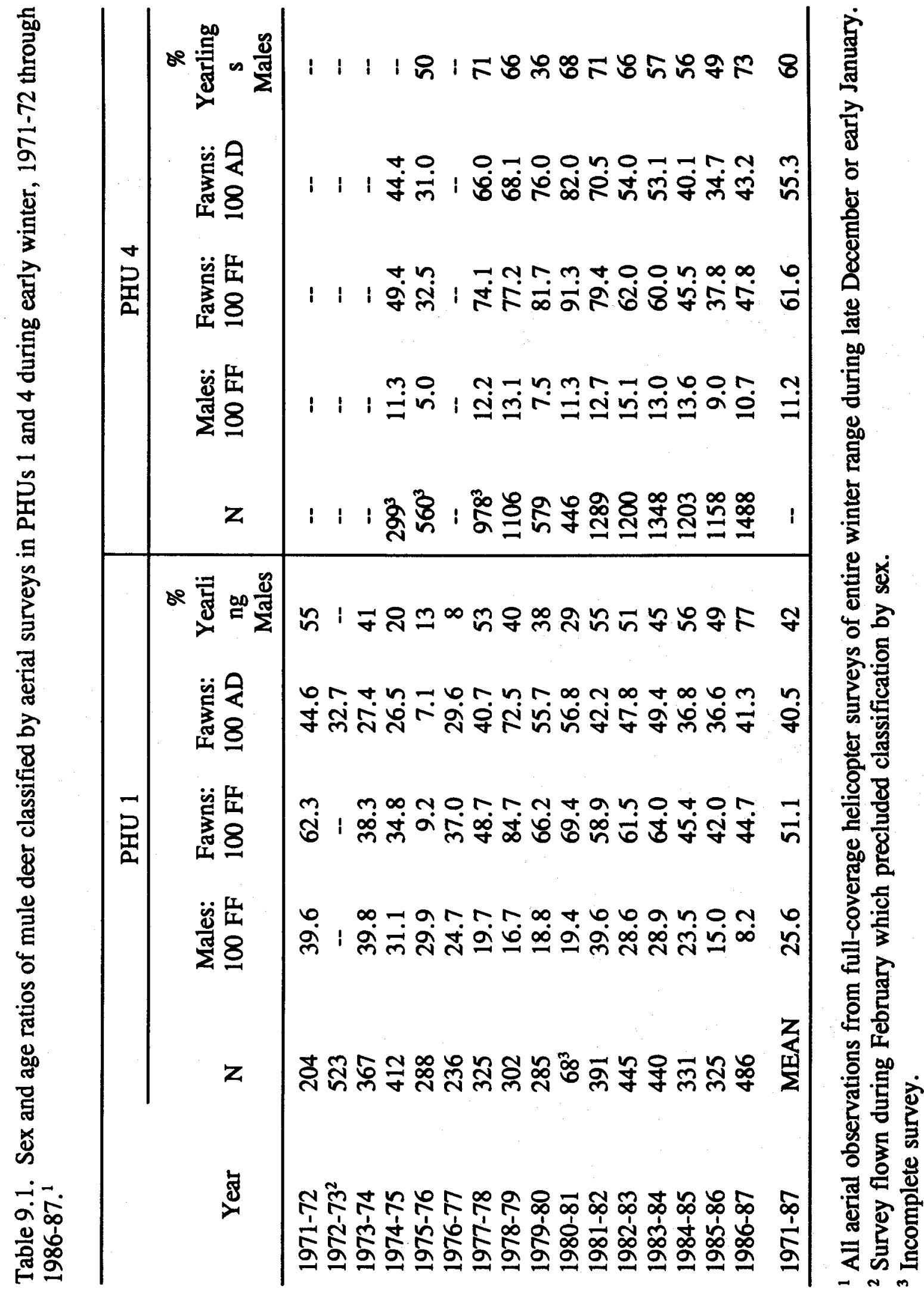


Table 9.2. Age ratios of mule deer classified by aerial surveys in PHUs 1 and 4 during late winter/early spring, 1972-1987.'

\begin{tabular}{ccc|cc}
\hline & \multicolumn{2}{c|}{ PHU 1 } & \multicolumn{2}{c}{ PHU 4 } \\
\cline { 2 - 5 } Year & N & $\begin{array}{c}\text { Fawns: } \\
\text { 100 AD }\end{array}$ & N & Fawns: \\
\hline 1972 & 352 & 29.9 & -- & 100 AD \\
$1973^{2}$ & 523 & 32.7 & --- & --- \\
1974 & 256 & 19.0 & -- & -- \\
1975 & 600 & 9.4 & -- & -- \\
1976 & 266 & 6.1 & -- & -- \\
1977 & 281 & 34.4 & -- & 51.2 \\
1978 & 288 & 30.3 & 449 & 30.5 \\
1979 & 249 & 39.9 & 1172 & 64.6 \\
1980 & 325 & 46.4 & 1017 & 97.4 \\
1981 & 362 & 63.1 & 1212 & 58.9 \\
1982 & 488 & 46.1 & 1697 & 40.4 \\
1983 & 455 & 41.3 & 1608 & 41.7 \\
1984 & 565 & 33.6 & 1590 & 22.5 \\
1985 & 407 & 29.2 & 1413 & 27.7 \\
1986 & 528 & 28.8 & 1583 & 35.9 \\
1987 & 348 & 29.4 & 1469 & 47.1 \\
$1972-1987$ & & 32.5 & & \\
\hline
\end{tabular}

${ }^{1}$ All aerial observations from full coverage helicopter surveys of entire winter range during late March or early April.

${ }^{2}$ Survey flown only in February.

${ }^{3}$ Incomplete survey.

Fawn:female ratios in early winter averaged 51:100 and 62:100 in PHUs 1 and 4 , respectively (Table 9.1). The minimum ratio in PHU 1 was 9:100 for 1975-76 when the ratio for PHU 4 was 33 fawns: 100 females. The maximum ratio recorded in PHU 1 was 85:100 in 1978-79. That for PHU 4, 91:100, was recorded two years later. Fawn:female ratios were generally higher in PHU 4 during 1975-1982 whereas similar ratios prevailed in the two populations during 1982-1987.

Average fawn:female ratios varied considerably among the seven PHUs in early winter (Fig. 9.1). However, different sampling intervals made direct comparison difficult. The highest mean value was recorded in PHU 5 during a comparatively short four-year sampling period. The second highest average was recorded in PHU 4 over 12 

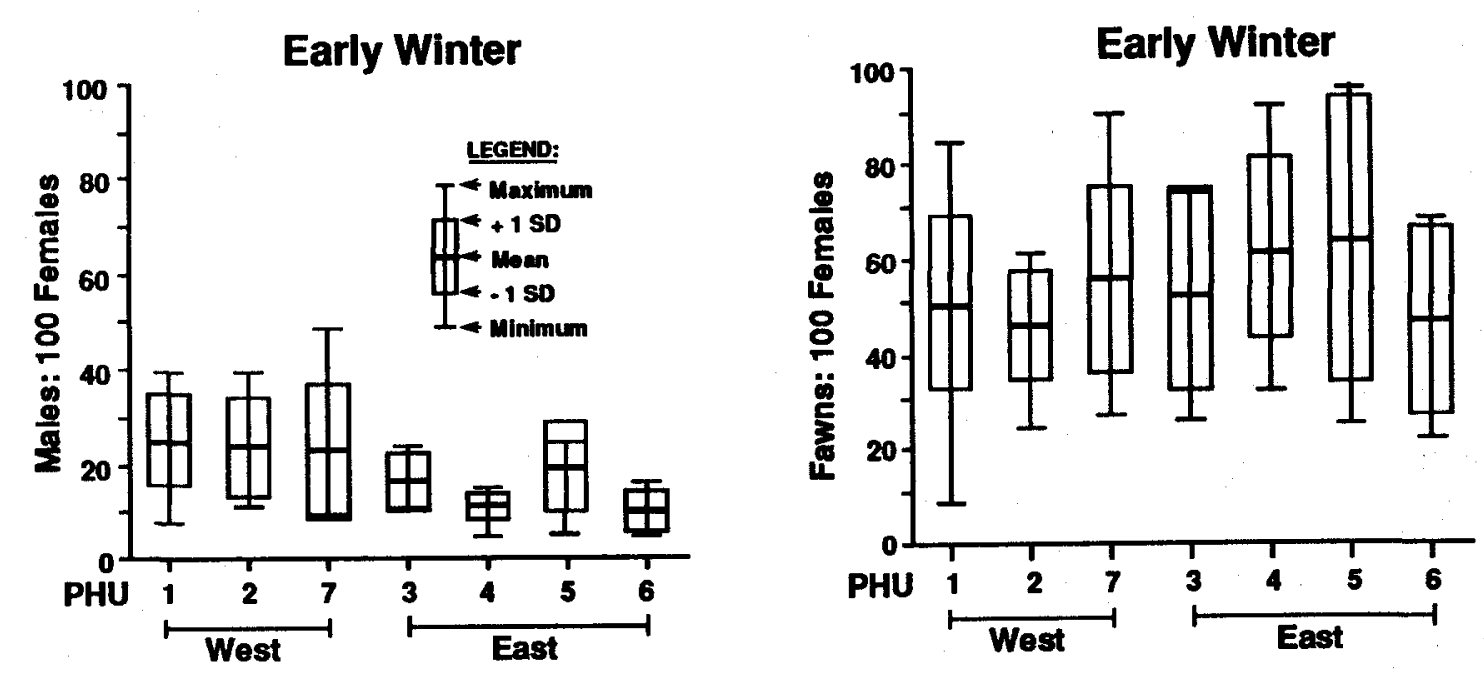

No. Yrs. $\begin{array}{lllllll}15 & 10 & 7 & 4 & 12 & 4 & 6\end{array}$

$\begin{array}{llllllll}\text { No. Yrs. } & 15 & 10 & 7 & 4 & 12 & 4 & 6\end{array}$
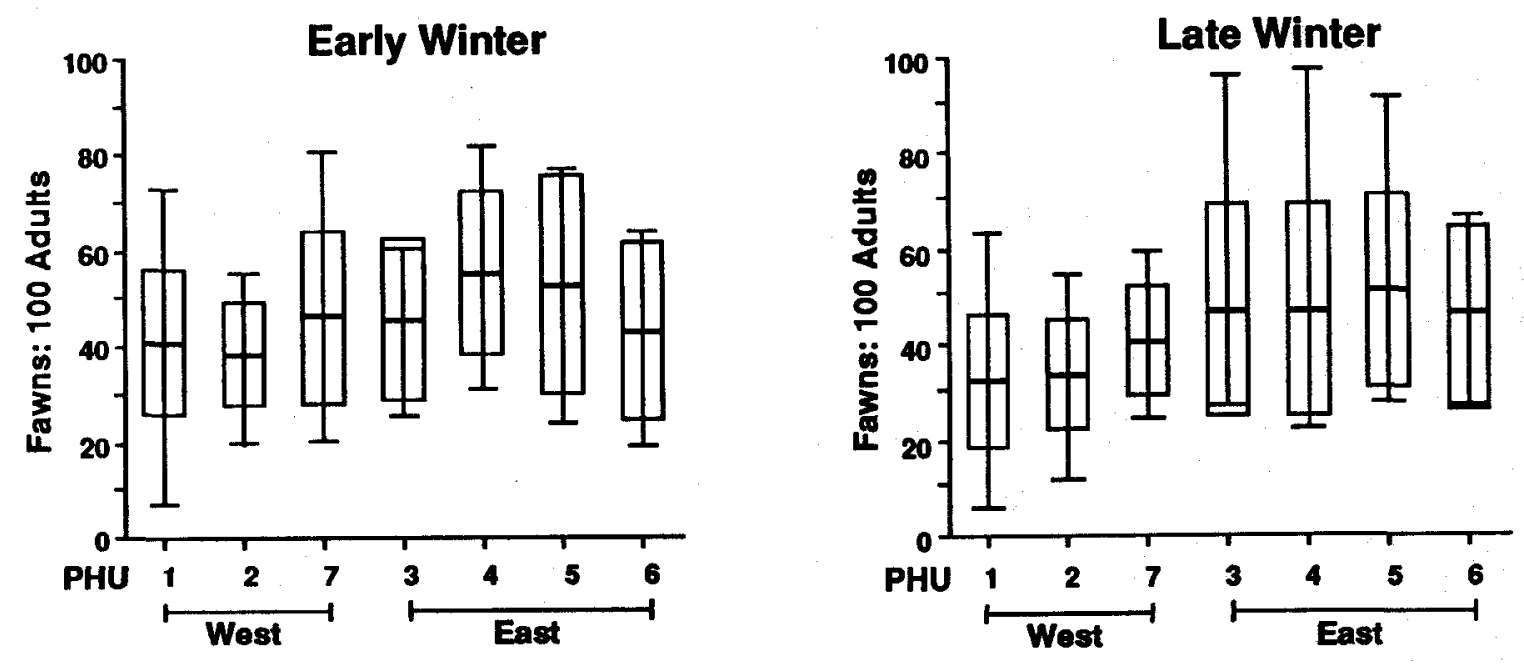

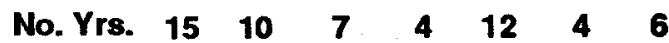

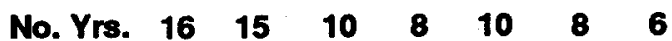

Figure 9.1. Sex and age ratios for mule deer in seven PHUs during early and late winter in the Bridger Mountains, 1971-1986. Data are means \pm 1 SD, and range for each PHU for number of years listed. 
years. Mean values were lowest in PHUs 2 and 6. Over a 10-year period, rates in PHU 2 were less variable than in other populations.

In late winter, we observed an average 33 fawns: 100 adults in PHU 1; the range was 6-63 fawns: 100 adults (Table 9.2). Late winter fawn:adult ratios averaged 47:100 (range 23-97) in PHU 4. These ratios were highest in both populations during the early 1980s, declined sharply in 1982, and remained comparatively low through 1987. Extremely low fawn:adult ratios were recorded in PHU 1 in late winter during the mid 1970s.

Sampling dates or intervals during late winter were more comparable among adjacent PHUs on the west and east slopes (Fig. 9.1). This reduced some of the variation in fawn:adult ratios between adjacent population units and tended to emphasize the higher average ratios that characterized east slope PHUs. Annual variation in late winter ratios was generally greater within each of the four east slope populations.

Adult Age Structure

Age structure was determined primarily from deer trapped during 1972-1986. Supplementary data were obtained from deer harvested by hunters during 1979-1986 when we requested that recipients of antlerless permits return lower jaws.

Both data sets were potentially biased. Although some trapping methods may have influenced relative proportions of fawns and adults captured (Garrott and White 1982), we did not detect age-related trapping bias among adult deer. Aging of livetrapped individuals by eruption-wear methods was often conducted under less than ideal conditions. However, multiple handlings of many marked individuals indicated reasonable age assignments. Also, substantial numbers of marked individuals were recovered after death, allowing verification of age by cementum analysis. Also, the relative distribution of cohort sizes within annual trap samples was generally comparable to other data for a population. Logical patterns in the flow of cohorts through successive annual trap samples also reinforced our confidence in the accuracy of these samples.

Most harvested deer, including yearlings, were aged by both eruption-wear and dental cementum methods. However, samples from individual populations were often small and unevenly distributed across years, particularly on the west slope. For example, $33 \%$ of the total harvest sample for the west slope was collected in 1986.

Pooled samples of all adult females trapped in PHU 1 and all three west slope PHUs show an older age structure than the harvest sample for these areas (Fig. 9.2). Apparently, younger females were harvested at a proportionately greater rate than they occurred in the population. This was particularly evident for yearling females, although age classes 2,3 , and 4 also were more strongly represented in the harvest sample. 

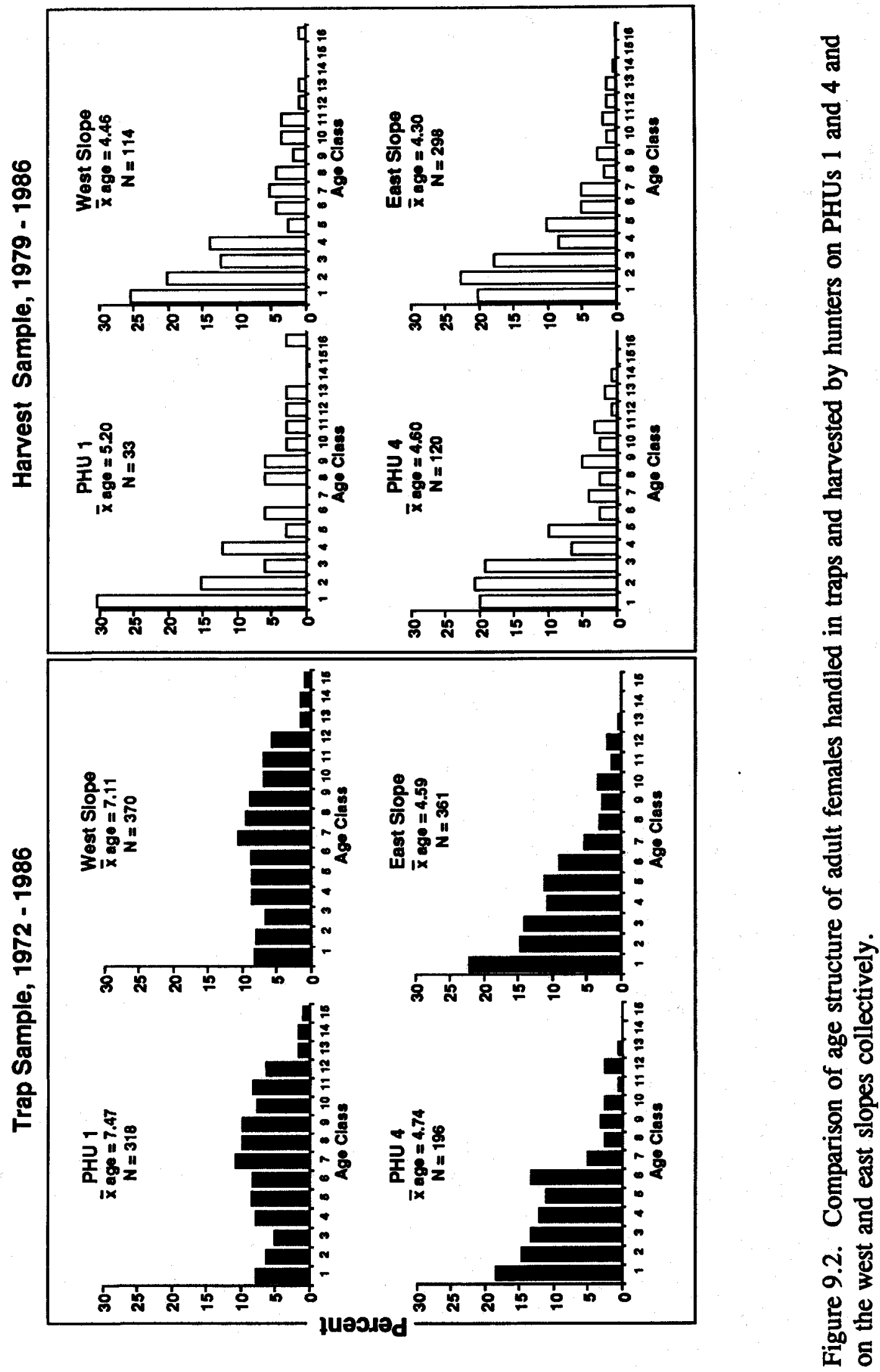
Hamlin and Mackie (1989) reported that yearlings and females older than nine years were more vulnerable to hunting than does aged 3-8 years.

More comparable sample sizes on the east slope may have minimized differences in age distributions between trapped and harvested females. Proportions of yearling females were similar in both samples while 2- and 3-year olds were more numerous in the harvest.

Trap samples apparently provided the best comparison of differences in age structure. These data, combined over all years, provide insight into some of the basic differences between west and east slope populations (Fig. 9.2).

On the average, the adult female segment in PHU 1 was characterized by individual cohorts that were proportionately small in size but remained relatively intact for many years. The pyramidal age structure of deer in PHU 4 was indicative of proportionally higher recruitment and lower adult survival over time. On the west slope, the average female was 2.5 years older than its counterpart on the east slope; also, $15.2 \%$ of all females were 11 years or older compared to only $3.6 \%$ on the east slope.

Female age distributions from samples trapped on the west and east slopes were significantly different $\left(X^{2}=61.69, \mathrm{df}=2, \mathrm{P}<0.001\right)$ for three age categories $(1$ and $2,3-9,10-15)$. Similar results were obtained from a comparison of adult female age distributions reconstructed from age-specific mortality rates in PHUs 1 and $4\left(\mathrm{X}^{2}=\right.$ $15.51, \mathrm{df}=2, \mathrm{P}<0.001$ ) (see Chapter 8).

Age data from harvested adult males were inadequate for comparison with the trap sample. The shape of the male age structure was essentially pyramidal in both west and east slope populations (Fig. 9.3) because hunters consistently selected for older, large antlered males. Male longevity was greater on the west slope, although few individuals lived more than seven years. Males older than three years seldom occurred in east slope populations.

Age structure in PHU 1 was characterized by significant temporal variation (Figs. 9.4 and 9.5). In early winter 1973-74, the adult female segment included comparatively strong cohorts in age classes $1,3,4,7,11$, and 12 (Fig. 9.4). With minor exceptions, most of these cohorts were relatively intact one year later at the beginning of the very severe 1974-75 winter. Mortality that winter removed nearly all fawns, some yearlings and prime-aged adults, and most females older than 11 years. This was reflected in a female age structure consisting largely of individuals aged 3-6 years by early winter 1975-76. 

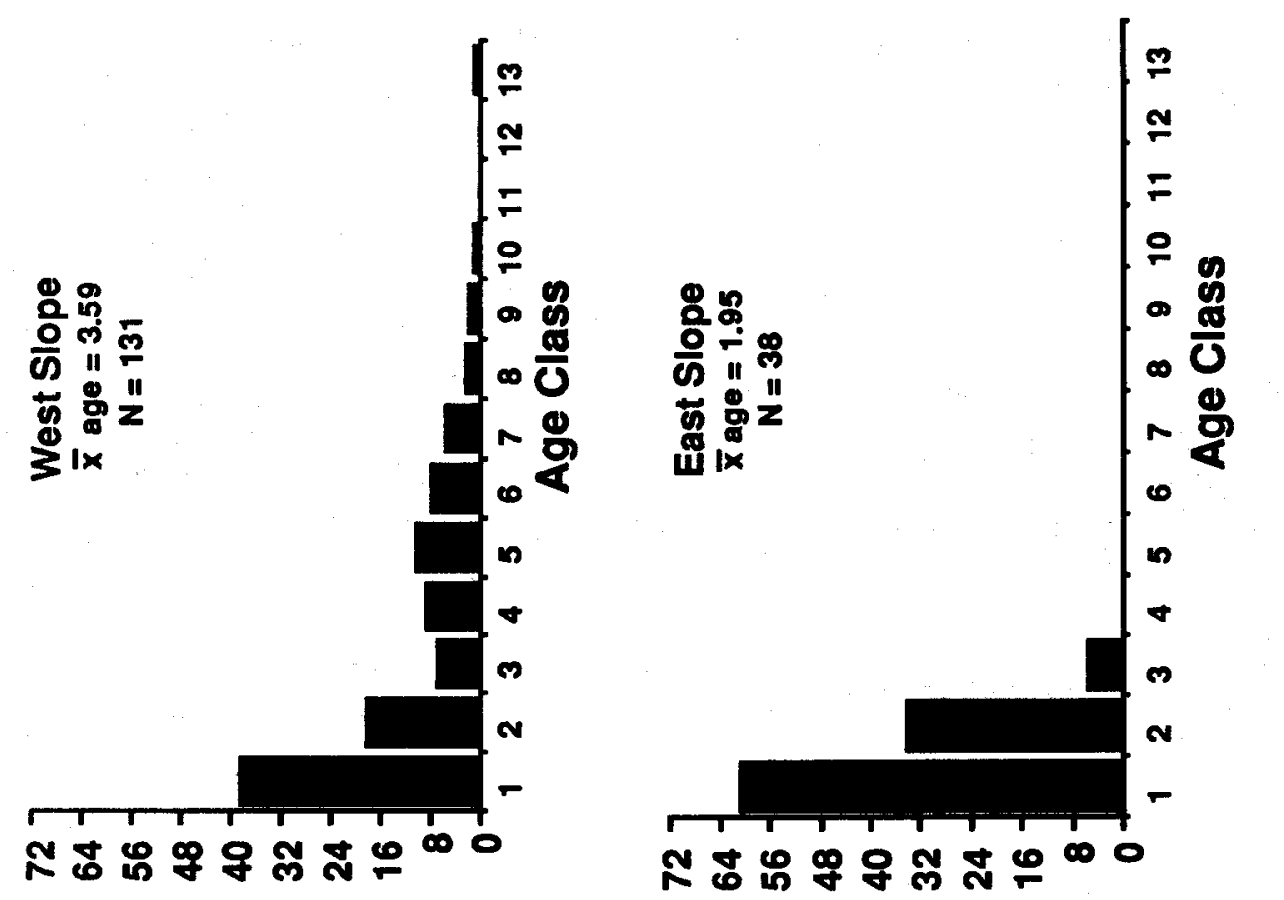

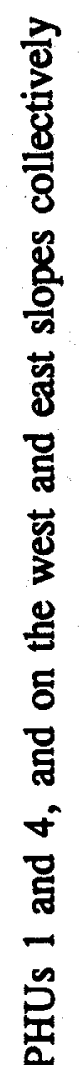

fuәวग्d

14ว2ม्d

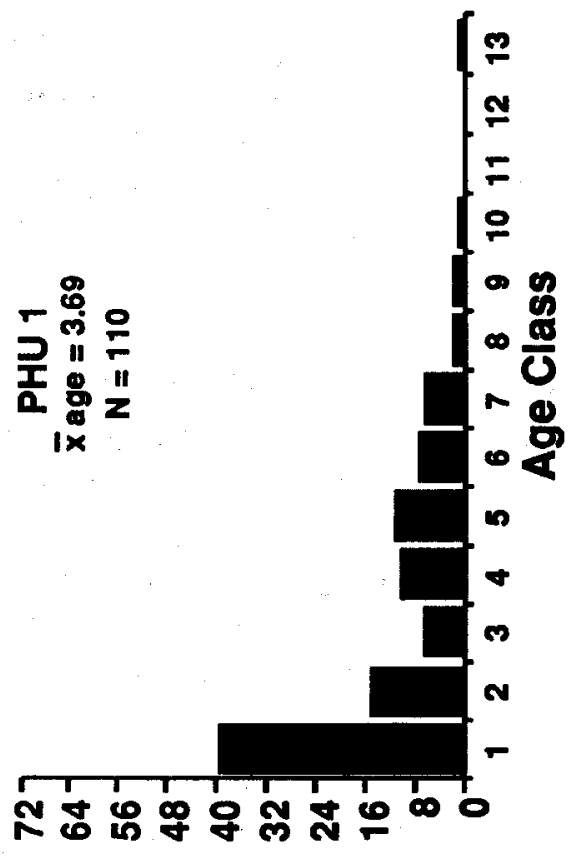

นบองมอd

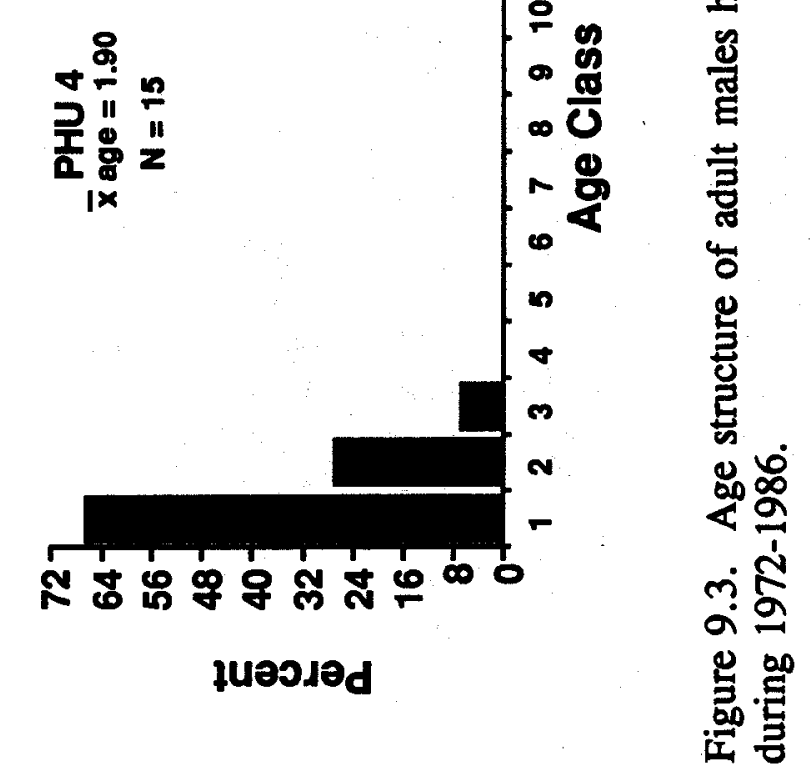




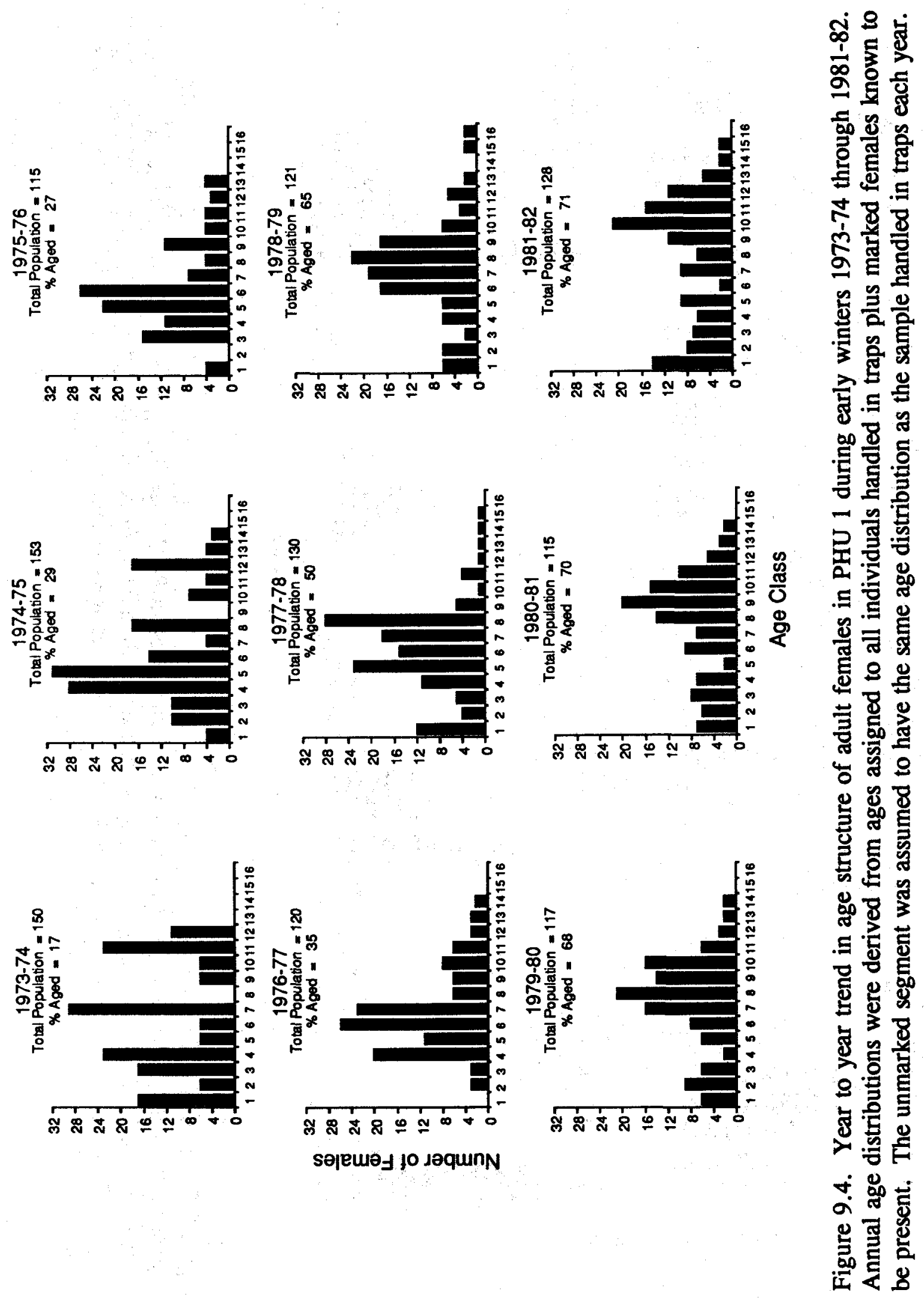




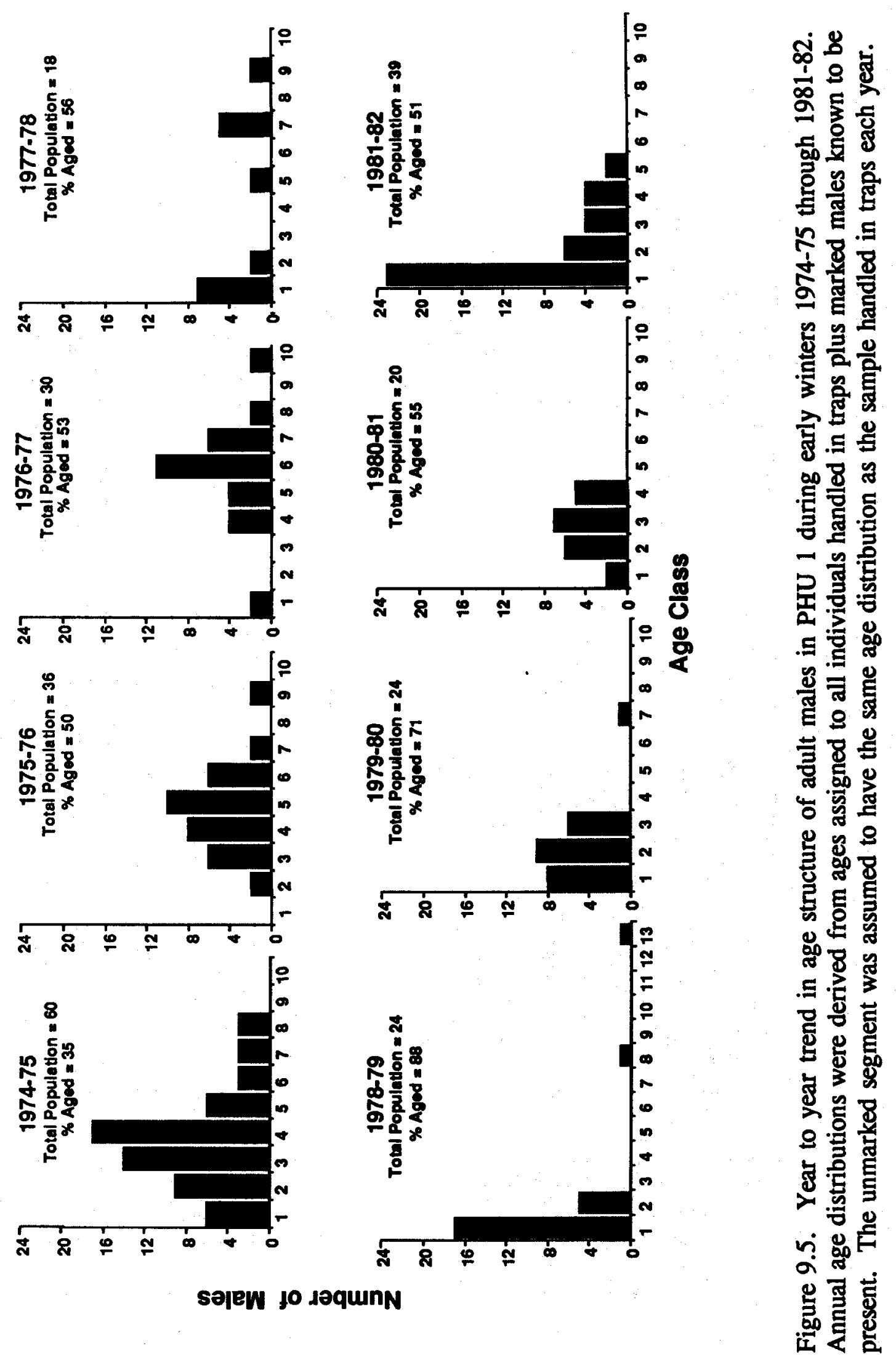


Age structure of females during January 1976-77 showed little change in the size of individual cohorts because of low adult mortality during the previous year. However, the absence of yearlings was a delayed effect of the severe 1974-75 winter. Fawns born in spring 1975 apparently experienced extensive losses during early summer. Although no yearlings were recorded in the 1976-77 trap sample, other data indicated that small numbers were present.

During the severe 1977-78 winter, the female population included strong cohorts in the middle age classes and limited numbers older than 10 years. Overwinter loss accounted for $10 \%$ of adult females and removed individuals in older, more vulnerable age classes. This contributed to generally lower than expected overwinter mortality of adult females during the subsequent severe winter of 1978-79. Poor fawn survival during the period was reflected in small yearling cohorts during both 1978-79 and 1979-80 (Fig. 9.4). Adult female survival remained high through $1979-80$ and 1980-81, although fawn survival was below average through spring 1980 .

As the population entered the severe winter of 1981-82, substantial numbers of females $\geq 10$ years of age were again present, and overwinter mortality of adult females was higher than in any year since 1974-75. Most of the loss occurred among 11-15 year old females. A strong yearling cohort during 1981-82 signalled the beginning of a period of above average fawn survival in six of seven years during the period 1981-1987. However, suspension of intensive trapping after 1981-82 precluded annual collection of age structural data during that period.

Annual age structure of adult males in PHU 1 was calculated for eight years beginning in 1974-75 (Fig. 9.5). High adult mortality in all age classes, coupled with periods of low recruitment, resulted in greater instability in annual age structure among males than females.

In January 1974-75, a "full" male age structure entered winter. The absence of yearlings and the occurrence of only a few 2-year olds in 1975-76 reflected significant mortality of fawns and yearlings, and loss of more than half of all males older than six years the previous winter. Losses of 3-6 year old males were primarily related to hunting in autumn 1975.

High neonatal mortality in the 1975 cohort resulted in scarcity of yearlings in 1976-77. Thus, the 1974-75 winter caused significant losses in three successive cohorts, and nearly all males in the 1976-77 population were 4-8 years of age. Mild weather conditions throughout autumn and winter 1976-77 minimized hunting success and natural mortality.

The sharp reduction in all males in the population in early winter 1977-78 resulted from harvest of about $70 \%$ of all males older than three years. A combination of severe weather, early migration, onset of the rut, and high hunter turnout contributed 
to substantial harvest in November 1977. The few 7-9 year old bucks that survived the hunting season perished the following winter.

The full impact of loss of three consecutive cohorts as a result of the catastrophic winter of 1975 did not completely unfold until early winter 1978-79. By that time, the male segment had been nearly "wiped out" by high adult mortality combined with several years of poor recruitment (Fig. 9.5). Except for a few individuals, all males were yearling or 2-year olds in early winter 1978-79. Substantial losses of fawns and some yearling males were again recorded that winter as indicated by poor yearling male recruitment to early winter $1979-80$.

High mortality of fawns occurred again in winter 1979-80 as evidenced by the small yearling male age class in 1980-81. By 1981-82, yearling recruitment increased substantially, and other data indicated this trend generally continued through 1987. Relatively high recruitment in conjunction with consistently high harvest rates resulted in the age structure retaining an acute pyramidal shape from 1982-1987. Under such exploitation, individual cohorts were essentially removed in five years. However, with fewer age classes male population stability became more vulnerable to reduction in juvenile recruitment.

Periodicity in fawn survival in the population was responsible for peaks and troughs in age structure of both sexes. Rates and patterns of adult mortality were primarily influenced by the movement of variably sized cohorts into vulnerable age classes. High rates of natural mortality only occurred when chance dictated that a severe winter coincided with large cohorts in vulnerable age classes because prime-aged females seldom died during even the most severe winters. Extended longevity appeared to be a mechanism that maintained greater population stability in an environment where recruitment was comparatively low and moderately variable.

Comparison of age-structural data across units indicates that not only was there no typical age distribution across time within one population, but there also was variation in age distributions among individual populations during the same year (Fig. 9.6). For example, during 1979, age distributions for adult females in PHUs 1 and 4 were quite different. In the latter, the largest cohort consisted of yearlings. In PHU 1, yearlings were noticeably outnumbered by 7- and 8-year olds. Also, fewer age classes occurred in PHU 4. In 1982, PHU 1 contained more individuals in the young and old age classes than in the middle ages. This U-shaped distribution provided a sharp contrast with the pyramidal pattern in both PHUs 3 and 6 . The only noticeable difference between PHUs 3 and 6 was a larger yearling cohort in the latter.

Variation in legal harvest rates of adult females was not responsible for the differences in female age structure among PHUs. For example, estimated harvest rates in PHUs 1 and 6 averaged $2.2 \pm 2.1 \%$ and $1.5 \pm 1.3 \%$, respectively, during $1975-$ 1981. 


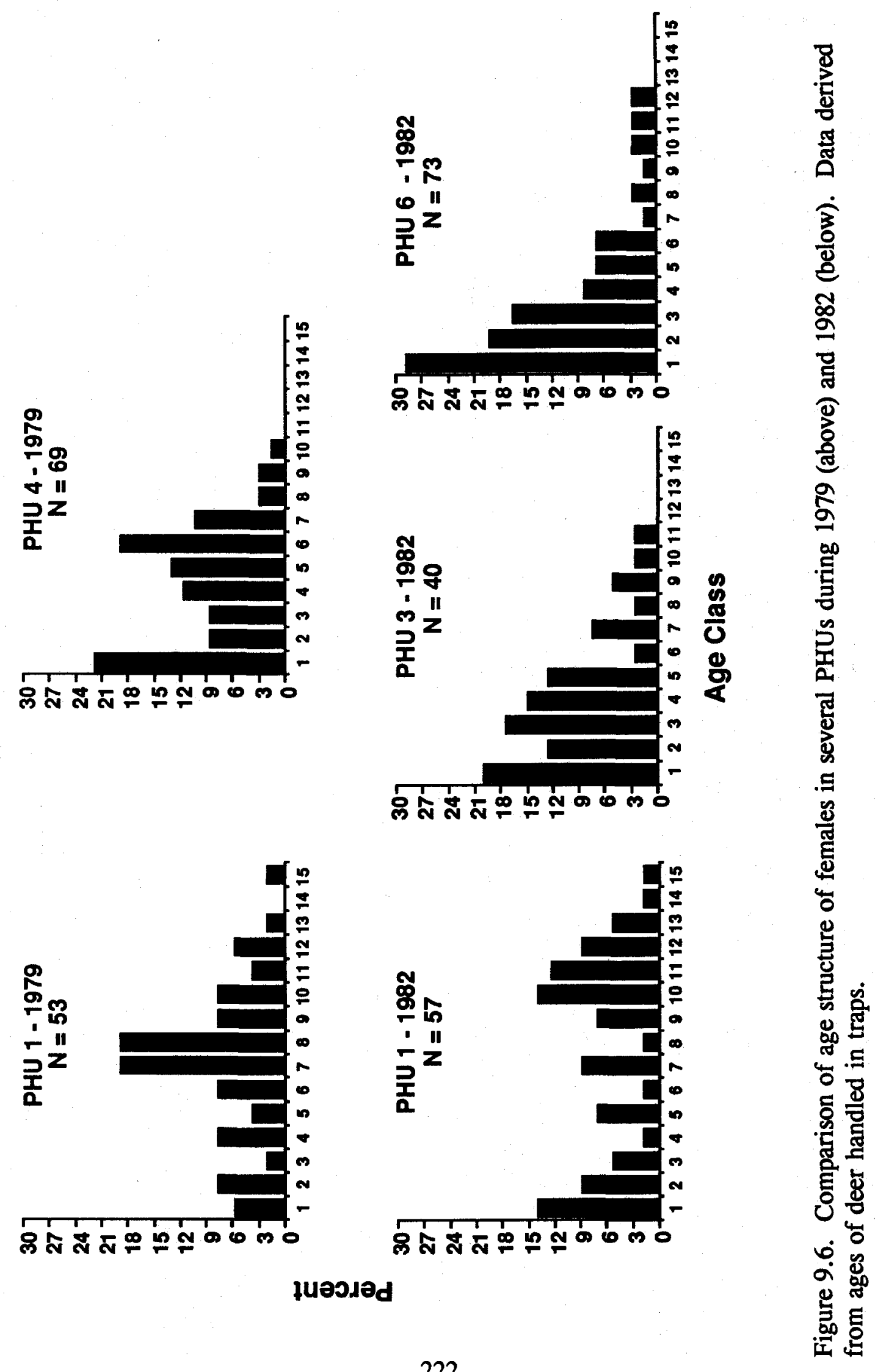


Population Size and Trend

Several data sets were used to estimate population size and trend. The most complete data were obtained for the Armstrong segment of PHU 1 based on observations along vehicle routes on winter range during April 1973 and 1975-1987 (Appendix Table C1.). During 14 years, $8.3 \pm 2.5$ surveys were conducted annually. Marked deer constituted $30-69 \%$ of estimated total populations during 1975-1983 and 12-22\% during 1984-1987. More than half of the estimated total population was observed on the average survey. A second set of Lincoln estimates for the area was derived from aerial surveys during mid-late March 1979-1987 (Appendix Table C2). Aerial estimates were slightly higher than vehicle survey estimates for the same years. However, mortality was often documented between the two survey periods. The third and final set of estimates of population size and composition was based on modeling using all available data on population size, composition, reproduction, and mortality (Table 8.3). The modeled data are presented as the best and final estimates of population size and trend, although they seldom varied significantly from values derived from vehicle and aerial surveys.

Population size and trend for PHU 4 during 1979-1987 was estimated from late winter aerial surveys (Appendix Table C3) and modeling (Table 8.4). Modeled estimates are graphically portrayed for comparison between PHUs 1 and 4 .

Aerial counting efficiencies (Mackie et al. 1981) were derived for west and east slope winter ranges. On the west slope, accuracy of full coverage counts was measured with marked samples during 12 late winter helicopter surveys (Appendix Table C2). The surveys counted an estimated $58.9 \pm 8.7 \%$ of the deer present.

During any particular survey, deer on the west slope occurred across a variety of vegetation from open shrub-grassland slopes to dense timber. Efficiency of counts was generally low when deer were disproportionately distributed in timbered habitats, particularly when the tree canopy was snow covered. Higher percentages were counted when deer were concentrated in large groups in sparsely timbered habitats at low elevations during deep, powder snow conditions. Considering that 50-65\% of west slope winter ranges was forested, overall counting efficiency was better than expected.

Counting efficiencies using marked samples were measured on four east slope winter ranges during 16 late winter aerial surveys (Appendix Table C3). Efficiency was higher $(\overline{\mathrm{X}}=67.2 \pm 13.0 \%)$ than on west slope ranges because deer were generally found in large groups on open, rolling shrub-grasslands. Counting was particularly efficient when surveys coincided with deer use of new vegetation and a ground cover of fresh snow. Counting efficiency was lowest during mild, snow-free periods prior to the initiation of plant growth in early spring. Under these conditions, deer were widely distributed and using more rugged, brushy, and timbered habitat at the upper margins of winter ranges. This was particularly noticeable on PHU 5 where deer had greater access to rugged terrain and forest cover than on other east slope winter ranges. 
Aerial counting efficiencies for our study areas were similar to the rate reported for mule deer in Colorado (Bartmann et al. 1986) and slightly lower than recorded in "breaks" habitat in north-central Montana (Hamlin and Mackie 1989). Our rates exceeded those reported for white-tailed deer (Beasom et al. 1986, Rice and Harder 1977). Precision of mule deer aerial surveys in the Bridger Mountains, as indicated by coefficients of variation, ranged from 9 to $13 \%$ for the west and east slope, respectively. Beasom (1979) found a significant negative correlation between coefficient of variation about mean estimated deer population size and the amount of total area censused by helicopter.

In all PHUs, but particularly 2, 3, 5, 6, and 7, helicopter surveys were flown during years when marked samples were unavailable. However, our data as well as Mackie et al. (1981), indicated that efficiency of full coverage surveys in a particular habitat was generally consistent from year to year under similar conditions. For years and winter ranges where marked samples were not available, we developed approximations of the number of deer on survey areas by referring to a three-point range expressed by the mean \pm 1 standard deviation of the aerial counting efficiencies measured from marked samples in other years in that habitat or a similar adjacent unit.

\section{PHU 1}

Estimated total number of mule deer in the Armstrong segment of PHU 1 (Fig. 9.7) declined substantially every year between June and December, primarily as a result of early fawn loss and hunting mortality of adults. Lower and more variable losses occurred between December and May as a result of winter-related mortality of fawns and adults.

Peak numbers occurred during the first year of study. Thereafter, deer numbers declined sharply through the severe winter of 1974-75. Numbers in early and late winter remained low through the subsequent year and increased slightly in 1976-77. During the next two years, early winter numbers (December) staged a comparatively sharp increase, although two consecutive severe winters reduced spring (May) populations to low levels through 1979-80. Another severe winter in 1981-82 also reduced the spring population to a comparatively low level. The population increased gradually during the next two years and stabilized during 1984-1987.

The most remarkable characteristic of the trend during 1973-1986 was the relatively high degree of stability compared to other Montana mule deer populations (Wood et al. 1989, Hamlin and Mackie 1989). Within any of the three seasonal periods, the largest estimated population was not more than 1.5-fold larger than the smallest (Fig. 9.7). The lowest May (160 in 1978) and highest June population estimate (408 in 1973) varied only 2.6-fold. During this period, the Missouri Breaks population varied 4.4-fold while numbers on an eastern Montana prairie fluctuated 5.2-fold. 


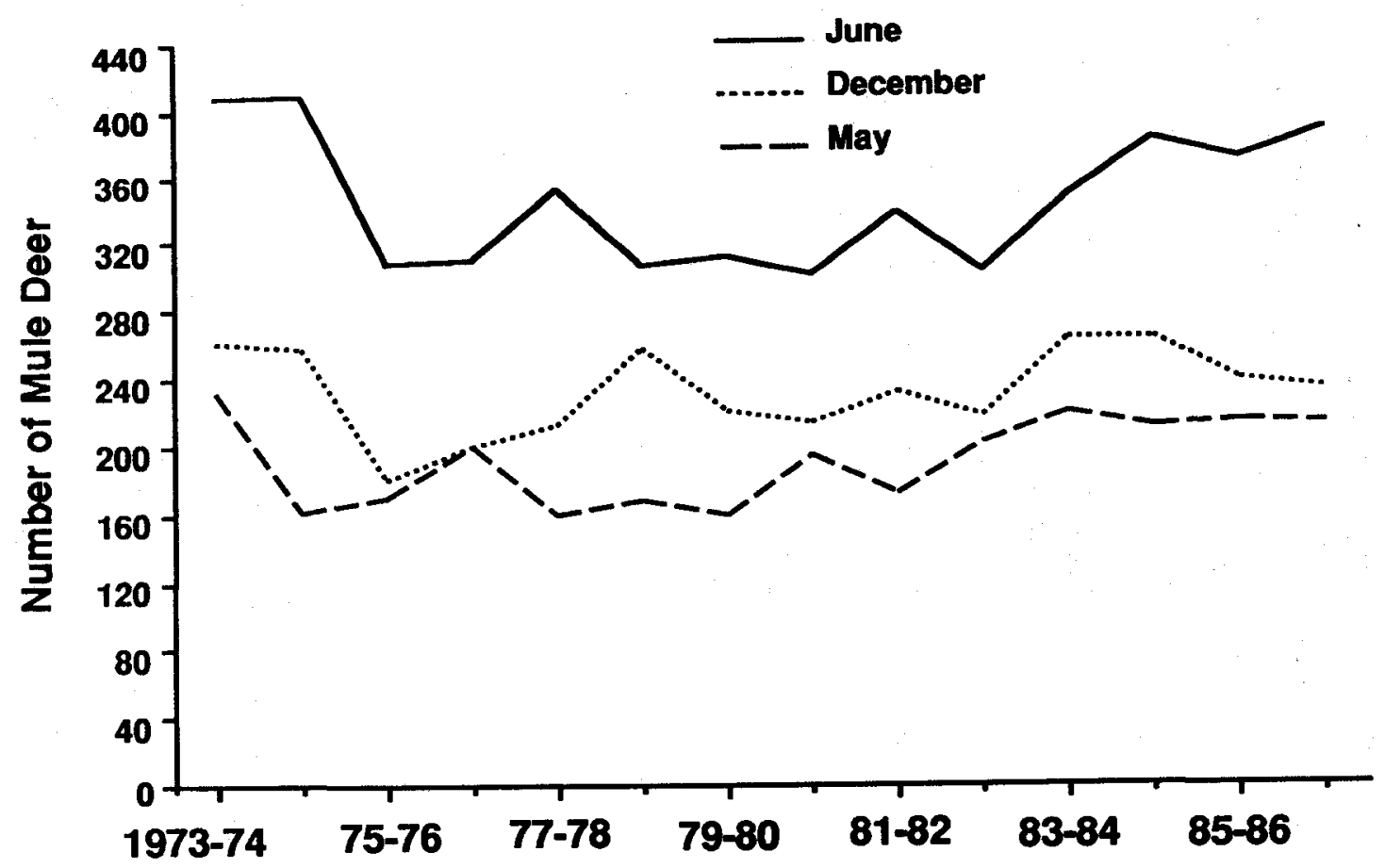

Figure 9.7. Estimated total number of mule deer in the Armstrong segment of PHU 1 at the beginning (June), middle (December), and end (May) of each biological year, 1973-1986.

Seasonal trends in numbers of adult females (Fig. 9.8) closely resembled, but were generally less variable than, trends in the total population. Female numbers varied less than 1.4-fold between high and low estimates for any season. Also, the highest number of females on the area at the beginning of a biological year (161 in 1974) was only 1.5 -fold greater than the minimum number estimated for the end of any biological year (105 in 1982). As noted earlier, in most years proportionately greater female mortality occurred during December-May.

Male numbers were lower and varied more widely than female numbers, both between and within seasons (Fig. 9.9). Trends in male numbers in December were most similar to trends for the following May. This resulted because, with the exception of 1974-75 and 1981-82, most of the annual loss of males occurred between June and December. Overall, numbers of males fluctuated 2.1- to 4.2-fold seasonally and about 7 -fold between the lowest May (12 in 1978) and highest June (83 in 1973) populations. The greatest divergence in seasonal trend curves for June, December, and May occurred in $1977-78$ when heavy hunting mortality $(80 \%)$ was combined with some winter mortality. 


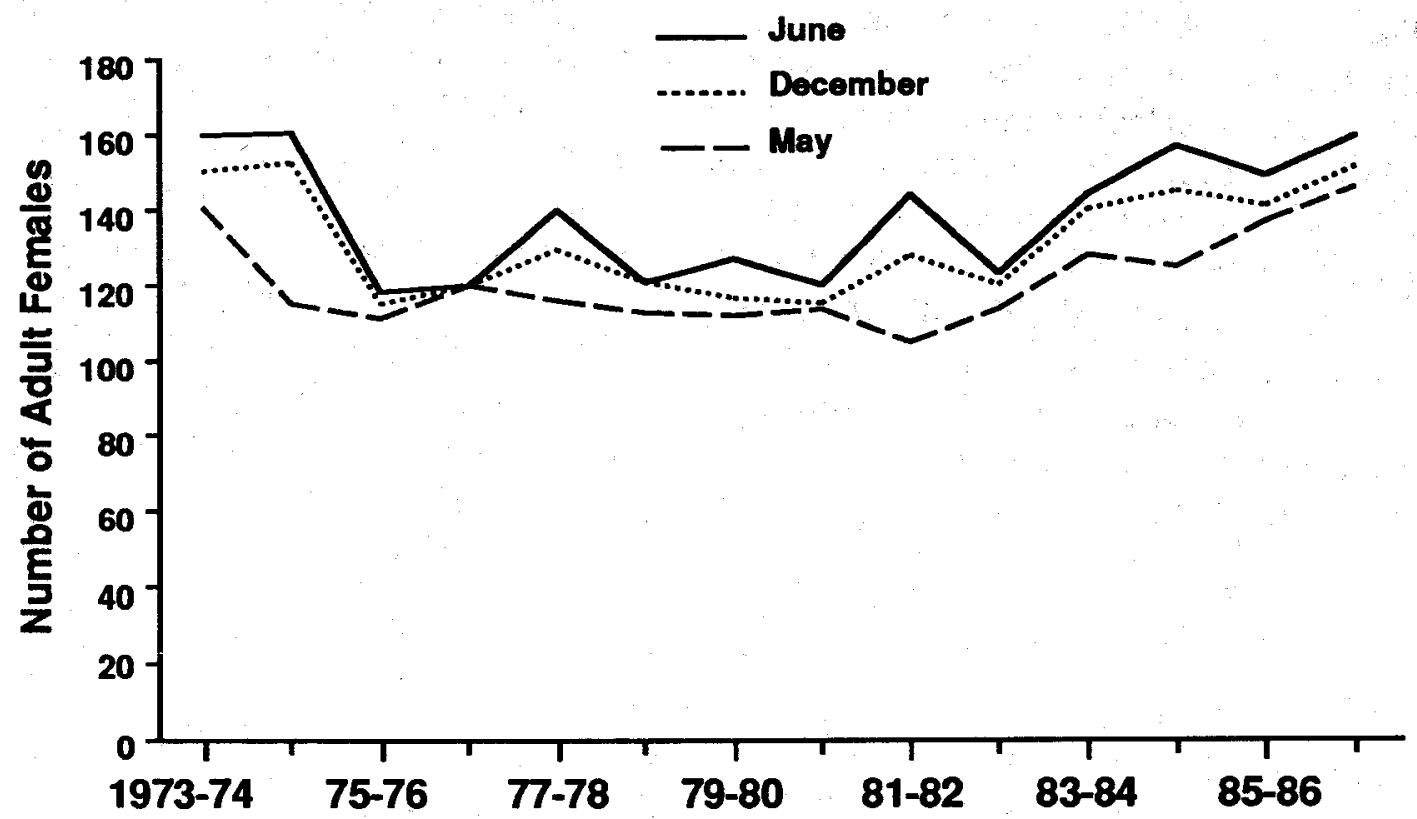

Figure 9.8. Estimated number of adult females in the Armstrong segment of PHU 1 during the beginning (June), middle (December), and end (May) of each biological year, 1973-1986.

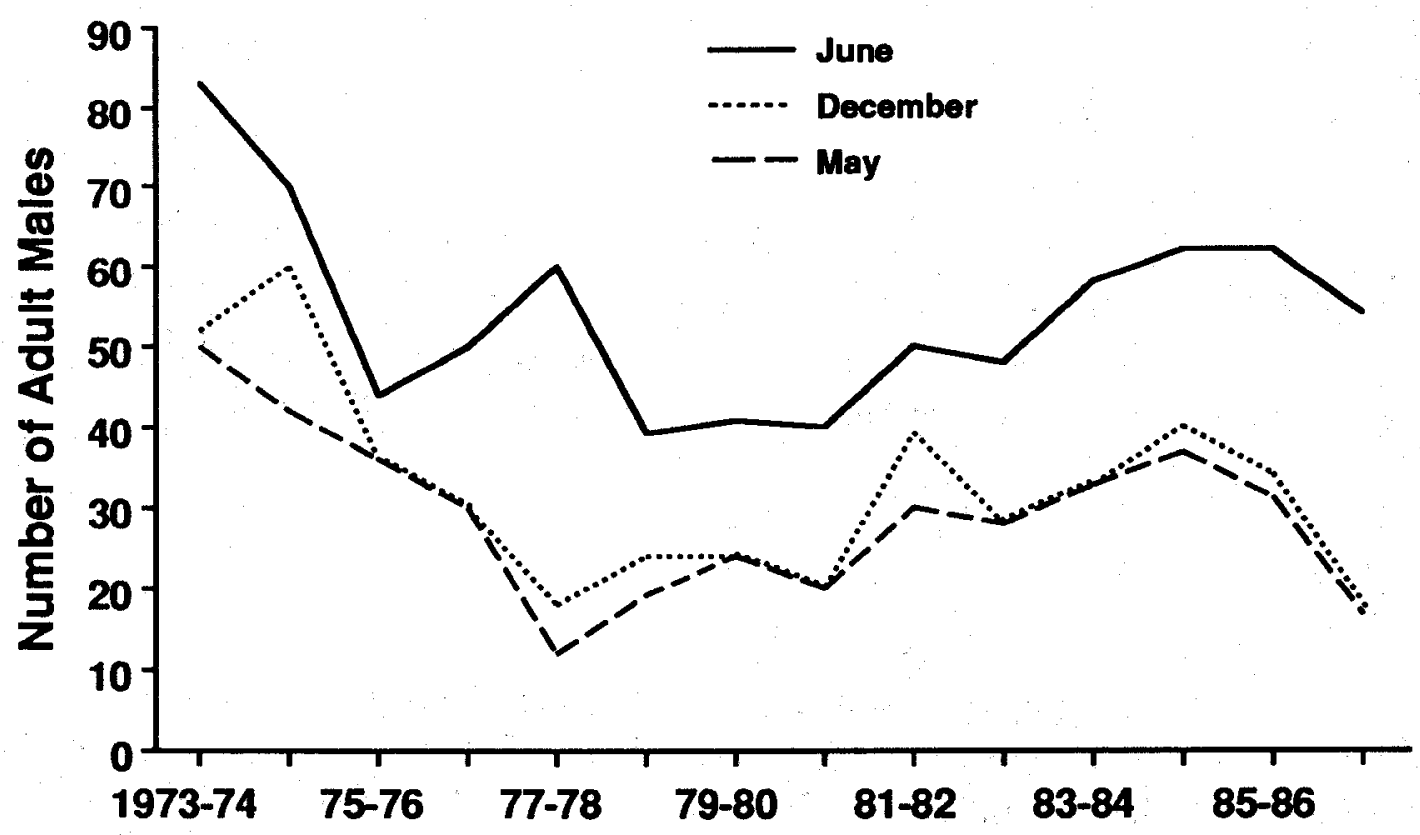

Figure 9.9. Estimated number of adult males in the Armstrong segment of PHU 1 during the beginning (June), middle (December), and end (May) of each biological year, 1973-1986. 
Trend in number of fawns in June (Fig. 9.10) displayed less variation (1.3-fold) than other seasons. In part, this was related to use of a constant in-utero fetal rate of $1.27 /$ adult female to calculate number of fawns born. Because of this, variation in fawn numbers in June corresponded directly to variation in number of adult females (Fig. 9.8). Losses of fawns between June and December were substantial. The sharp peak in the December curve during 1978-79 may have been related to improved physical condition of adult females following significant early losses of fawns in previous years. Variation in fawn numbers along the December curve was 3.9-fold, increasing to 12-fold along the May curve. The greatest fawn loss during any one year (97\%) occurred in 1974-75. Even during years of above average fawn survival, total fawn numbers as a proportion of the female population was quite low.

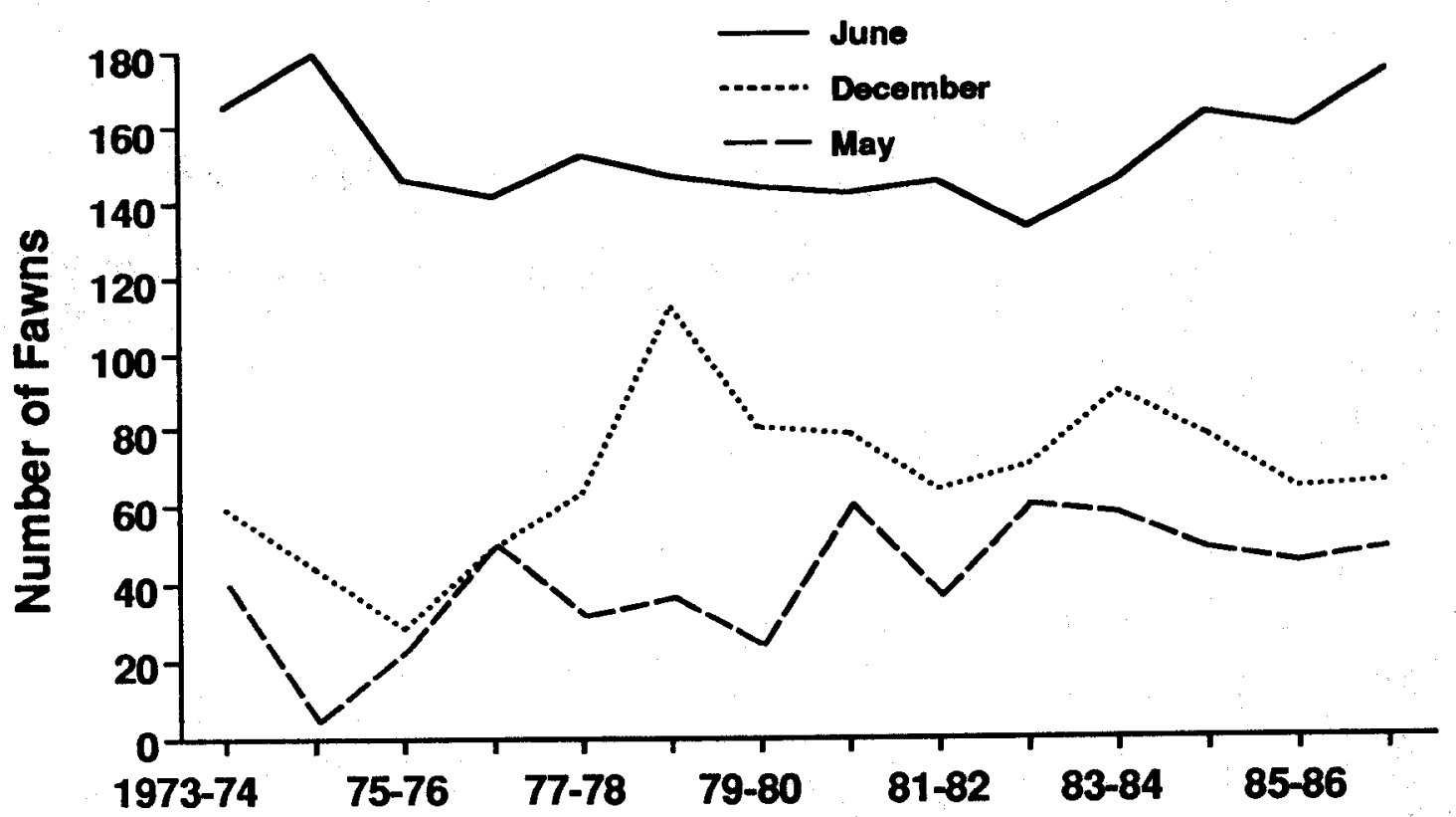

Figure 9.10. Estimated number of fawns in the Armstrong segment of PHU 1 during the beginning (June), middle (December), and end (May) of each biological year, 19731986.

\section{$\underline{\text { PHU } 4}$}

Estimated total numbers of mule deer in PHU 4 at the beginning (June) and end (May) of each biological year, 1978-1986, are shown in Fig. 9.11. Variability in total numbers was very similar to trends in PHU 1 , varying no more than 1.3 -fold between low and high estimates within any season. The lowest population at the end of a biological year $(1,833$ in 1979) and the highest population at the beginning $(4,456$ in 1984) varied 2.4-fold. Relative peaks in total numbers occurred in June 1981 and 1984 and followed by one year the peaks in total numbers on the May curve. 


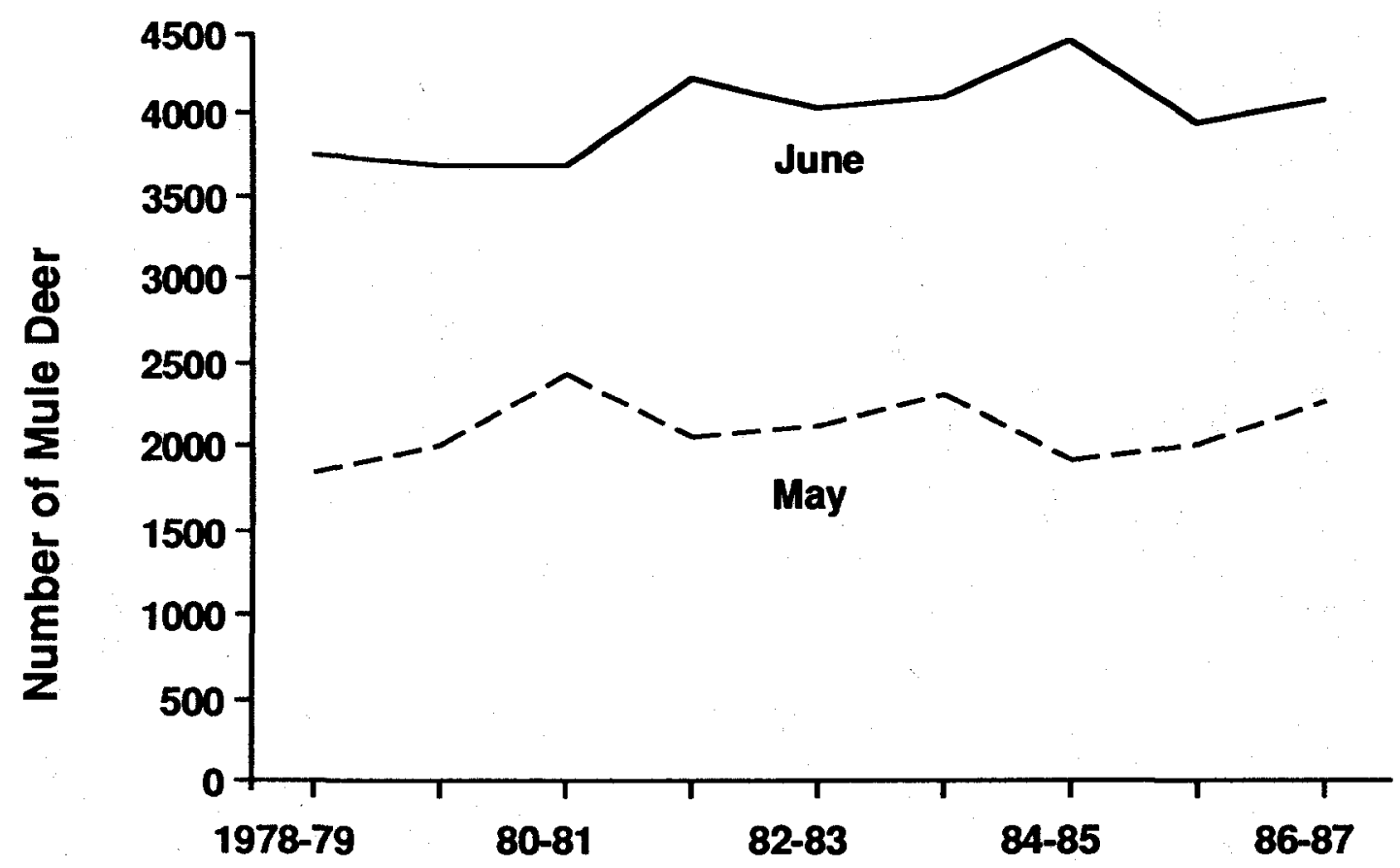

Figure 9.11. Estimated total number of mule deer in PHU 4 at the beginning (June) and end (May) of each biological year, 1978-1986.

The shape of the June curve for adult females (Fig. 9.12) closely resembled trend in total numbers. However, the May curve for adult females indicated gradual increasing numbers throughout the nine-year period. Within seasons, adult female numbers varied by 1.3 -fold. The maximum female population in June $(1,775$ in 1984) was only 1.6 -fold larger than the minimum population in May (1,126 in 1980).

Adult male numbers exhibited substantially more variation along both the June and May curves (Fig. 9.13) compared to females. Maximum estimated male numbers in June were 1.8 fold greater than the minimum; for May, this difference was 1.4 fold. During all years, male numbers were consistently reduced to comparatively low levels by May regardless of variation at the beginning of the year. This significant reduction accounted for the 8.2 fold difference between the lowest May population (83 in 1980) and highest June population (678 in 1981). Compared to adult males in PHU 1, males in PHU 4 displayed less variation particularly along the May curve. However, the June and May curves were consistently further apart for PHU 4.

Trend in number of fawns in June (Fig. 9.14) gradually increased, parallelling the May curve for adult females. Fawn numbers in June varied no more than 1.3 fold between low and high years. However, this variation was minimized by assumptions similar to those described for PHU 1. Limited data indicated that a slightly higher fetal rate, 1.50/adult female, was appropriate for PHU 4. Annual fawn losses were substantial 


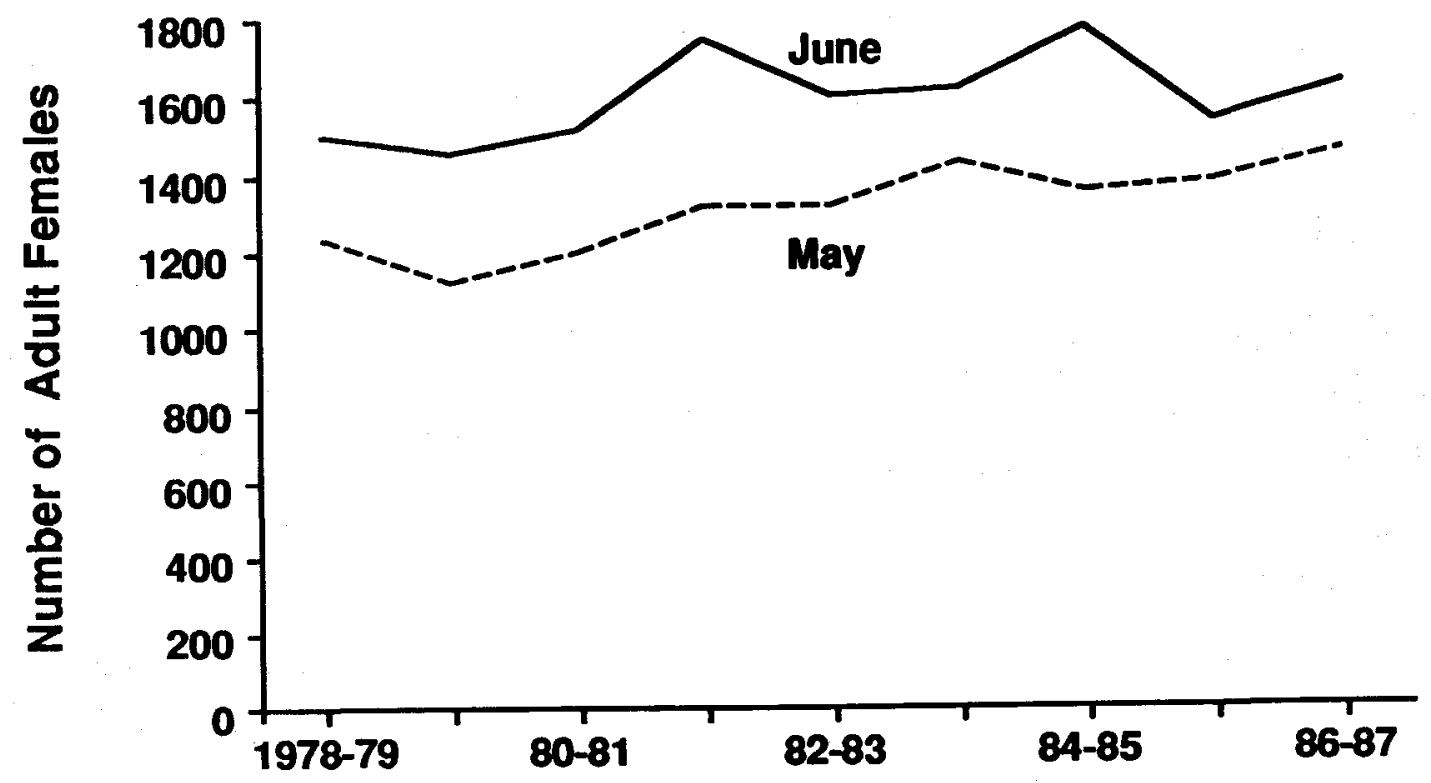

Figure 9.12. Estimated number of adult females in PHU 4 at the beginning (June) and end (May) of each biological year, 1978-1986.

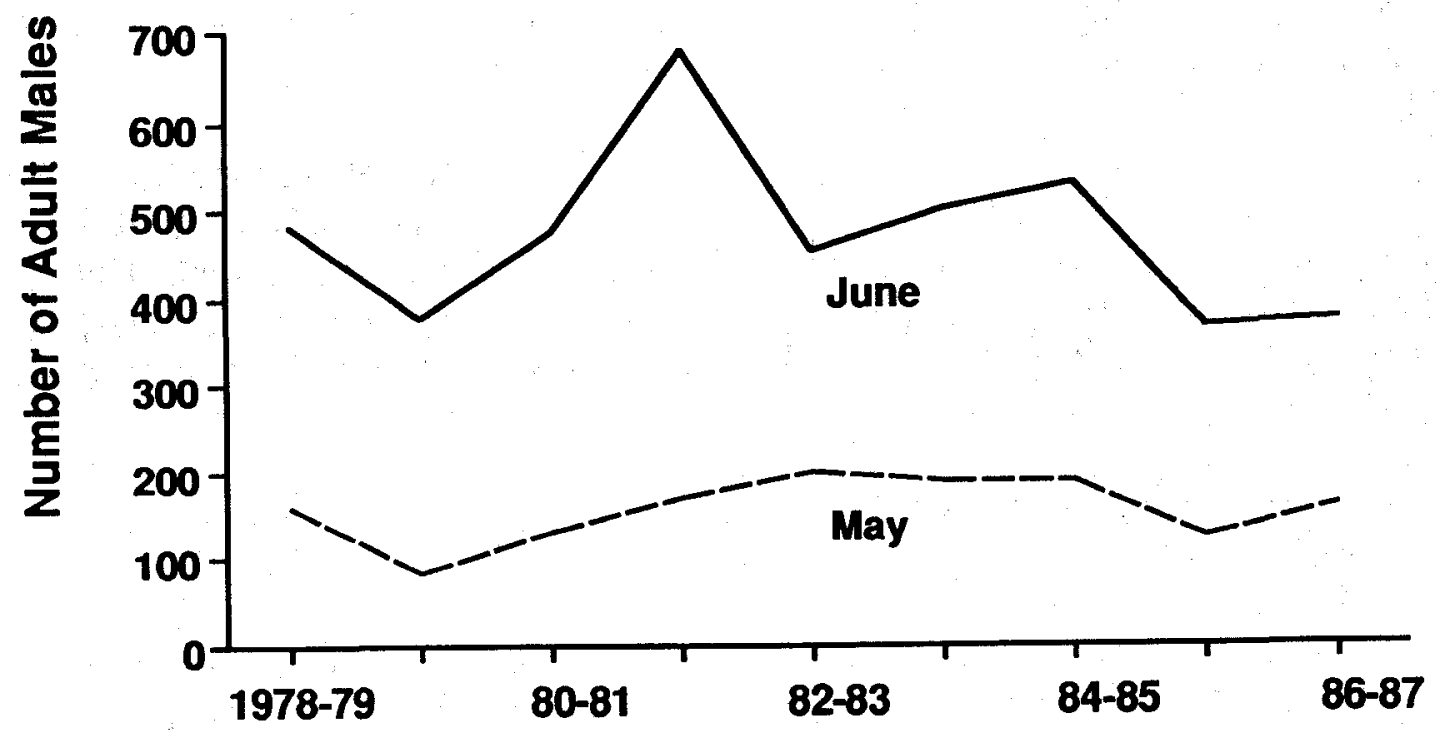

Figure 9.13. Estimated number of adult males in PHU 4 at the beginning (June) and end (May) of each biological year, 1978-1986. 


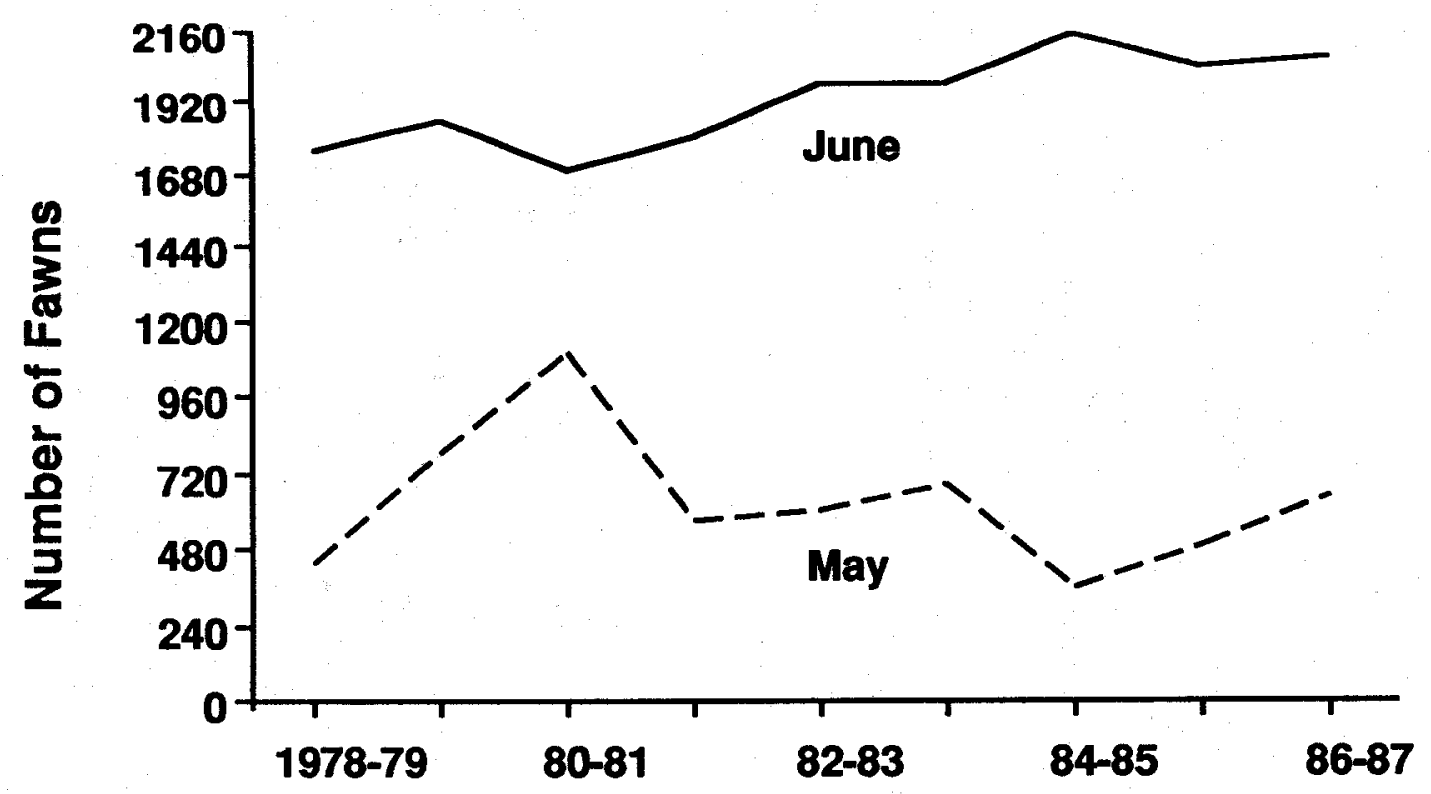

Figure 9.14. Estimated number of fawns in PHU 4 at the beginning (June) and end (May) of each biological year, 1978-1986.

and rather variable as indicated by the shape of the May curve. Maximum numbers of fawns in May exceeded minimum numbers by 3.1-fold. The peak in fawn numbers followed by one year the lowest recorded number of adult females in May (Fig. 9.12). A secondary peak in adult female numbers in 1983-84 preceded by one year the lowest number of fawns in May. Maximum number of fawns in June (2,153 in 1984) was more than six times greater than the minimum in May (356 in 1985). This difference occurred within one biological year, 1984-85.

Total Deer Numbers and Density in the Bridger Range

Approximate numbers of mule deer associated with the seven PHUs during late winter-early spring are listed in Table 9.3.

West slope populations were generally numerically smaller than those on the east slope. PHU 2 had the largest average population on the west slope followed by PHUs 1 and 7. In total, the three populations contained approximately 2,000 deer (Table 9.3).

On the east slope, deer numbers were largest on PHU 4, followed by PHU 6. Populations on PHU 3 and PHU 5 were noticeably smaller and comparable to the largest unit on the west slope. On average, the four east slope units collectively contained about 5,250 deer. Lower total populations were associated with the period spanning the mid- 


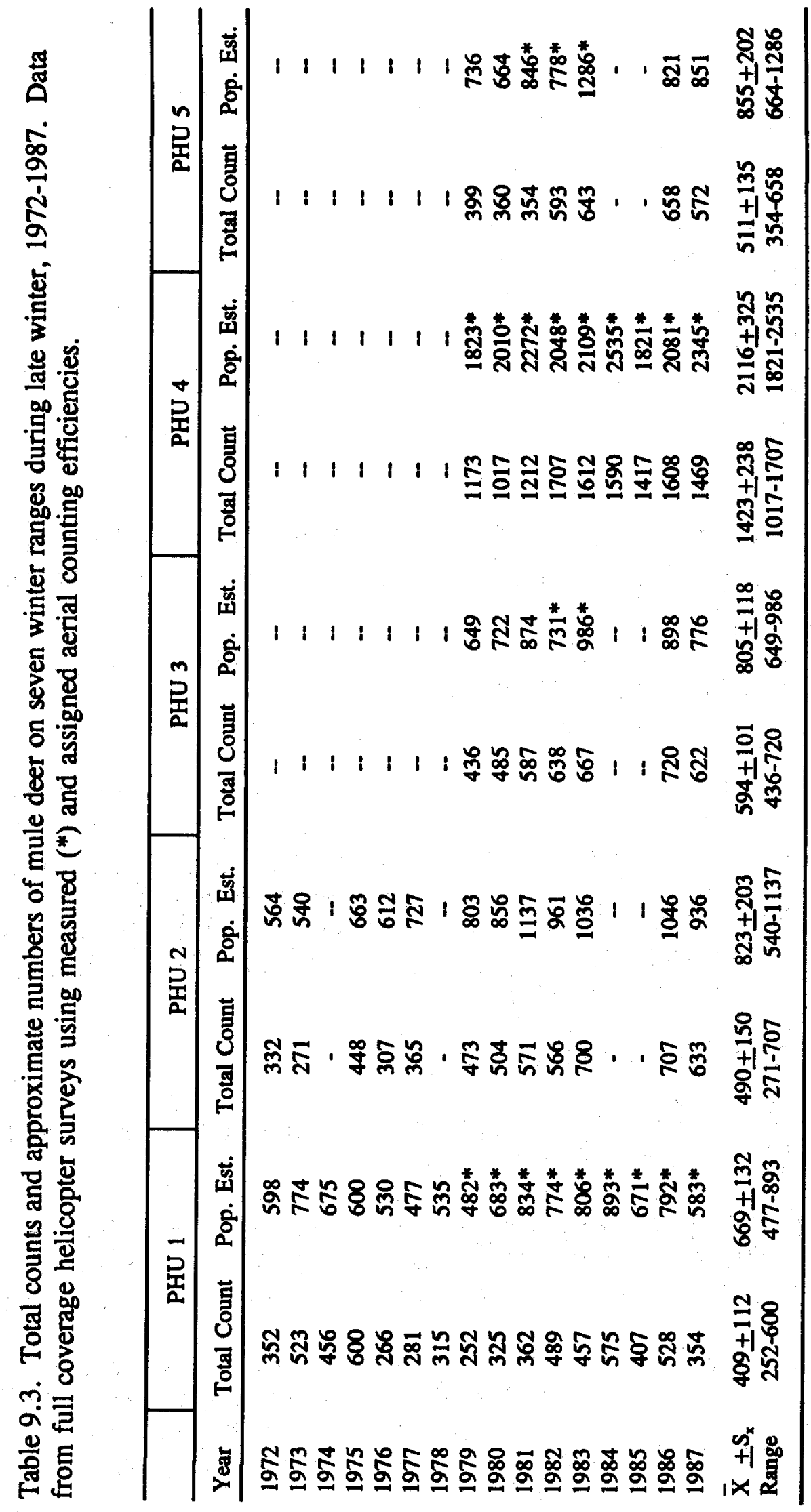




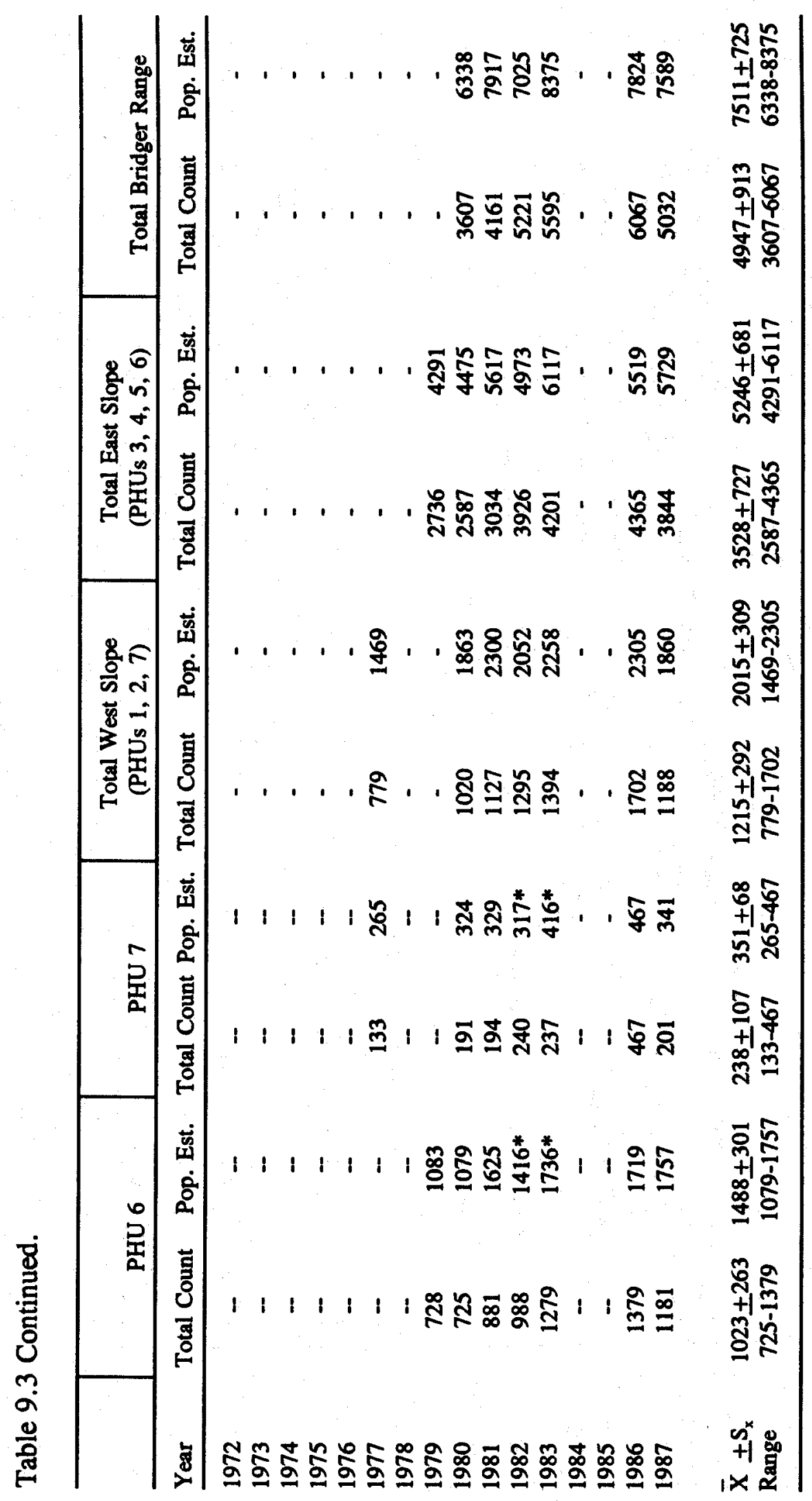


1970 s through the early 1980s. Larger populations occurred on all areas through most of the 1980s with peaks in 1983 and 1984.

All seven winter ranges were flown in late winter during six of eight years between 1980 and 1987, providing approximations of total mule deer numbers within the $1,966 \mathrm{~km}^{2}$ Bridger Mountain complex (Table 9.3). A low population of 6,338 was estimated in 1980; the peak was 8,375 in 1983. By 1987, numbers declined to 7,589. Approximate population sizes averaged 7,511 \pm 725 deer for the six years.

Using data in Table 9.3, we calculated deer density for yearlong and winter range in all seven PHUs (Table 9.4). Based on total yearlong habitat, densities were generally higher within west slope than east slope PHUs. Among individual units, however, densities varied greatly, reflecting the unique combination of habitat characteristics in each unit. For example, the highest and lowest mean deer densities occurred in immediately adjacent PHUs 4 and 5. Densities on the other two east slope units were intermediate. On the west slope, highest and lowest means were recorded in PHUs 7 and 1 , respectively.

Hamlin and Mackie (1989) reported an average density of 2.98 mule deer $/ \mathrm{km}^{2}$ (range 1.42-4.47/ $\mathrm{km}^{2}$ ) for "breaks" habitat in northcentral Montana. Similarly, Wood et al. (1989) found late winter-spring mule deer densities ranging from 0.6 to $2.0 / \mathrm{km}^{2}$ in prairie habitat in eastern Montana. Mean density in five of seven individual PHUs in

Table 9.4. Mule deer densities (No. adults $/ \mathrm{km}^{2}$ ) based on approximate numbers of deer in the seven PHUs in late winter.

\begin{tabular}{lrccc|cccc}
\hline & \multicolumn{3}{c}{ Yearlong Habitat } & \multicolumn{3}{c}{ Winter Range } \\
\hline & $\begin{array}{r}\text { Area }^{1} \\
\left(\mathrm{~km}^{2}\right)\end{array}$ & low & $\bar{X}$ & high & $\begin{array}{c}\text { Area } \\
\left(\mathrm{km}^{2}\right)\end{array}$ & low & $\bar{X}$ & high \\
\hline PHU 1 & 179.4 & 2.66 & 3.73 & 4.98 & 31.8 & 15.00 & 21.04 & 28.08 \\
PHU 2 & 157.8 & 3.42 & 5.22 & 7.21 & 25.2 & 21.42 & 32.66 & 45.12 \\
PHU 7 & 54.1 & 4.90 & 6.49 & 8.63 & 11.2 & 23.66 & 31.34 & 41.70 \\
\hline West Slope Total & 391.3 & 3.75 & 5.15 & 5.89 & 68.2 & 21.54 & 29.55 & 33.80 \\
\hline PHU 3 & 282.3 & 2.30 & 2.85 & 3.49 & 95.0 & 6.83 & 8.47 & 10.38 \\
PHU 4 & 314.7 & 5.79 & 6.72 & 8.06 & 134.6 & 13.53 & 15.72 & 18.83 \\
PHU 5 & 596.7 & 1.11 & 1.43 & 2.16 & 51.1 & 12.99 & 16.73 & 25.17 \\
PHU 6 & 381.1 & 2.83 & 3.91 & 4.61 & 72.2 & 14.95 & 20.61 & 24.34 \\
\hline East Slope Total & 1574.8 & 2.72 & 3.33 & 3.88 & 352.9 & 12.13 & 14.87 & 17.33 \\
\hline Bridger Range Total & 1966.1 & 3.22 & 3.82 & 4.26 & 421.1 & 15.05 & 17.84 & 19.89 \\
\hline
\end{tabular}

${ }^{1}$ Areas of overlap were partitioned among PHUs. 
the Bridger Mountains was larger. In fact, two Bridger units (PHUs 4 and 6) had mean densities more than twice the average for "breaks" habitat.

On winter range, the spectrum of mean deer densities showed less overlap between west (21-33 deer $\left./ \mathrm{km}^{2}\right)$ and east (8-21/ $\mathrm{km}^{2}$ ) slope units (Table 9.4). Average density for the three west slope winter ranges combined was twice that recorded for the four east slope ranges. During severe winters, density values reported in Table 9.4 doubled or even tripled as deer distribution became restricted. This phenomenon was more frequently observed on west than on east slope winter ranges.

When deer were distributed across their entire yearlong range in summer, ecological density (i.e. density within specific areas) varied substantially within individual PHUs. Pattern of density distribution was difficult to quantify but appeared related to the availability of preferred vegetation types.

Three major vegetation zones, steppe, montane forest, and subalpine-alpine, comprised $1,140,786$, and $40 \mathrm{~km}^{2}$, respectively, of the entire Bridger Mountain complex. Within the total study area, we determined the distribution of summer activity centers for 389 individual adult deer relative to these zones. Twenty-seven percent occurred in steppe, $67 \%$ were in montane forest, and $6 \%$ in the subalpine-alpine zone. We assumed this sample was representative of the distribution of summer home ranges within the entire Bridger study area. Thus, it was used to partition the average number of adult mule deer in the Bridger Range $(\overline{\mathrm{X}}=7,500)$ and calculate density within each of the three vegetation zones. Average densities were $1.8,6.4$, and $11.3 \mathrm{deer} / \mathrm{km}^{2}$ in steppe, montane forest, and subalpine-alpine zones, respectively.

Variable proportions of the three vegetation zones among individual PHUs apparently influenced the number of deer each unit would support. For example, this relationship explains the significantly lower densities recorded in PHU 5 compared to the adjacent PHU 4. Knowledge of the perimeter and vegetative composition of a PHU is a prerequisite to reasonably interpreting the number of mule deer associated with it or its potential to support deer.

Population Growth Rate

The maximum observed annual (spring-spring) instantaneous rate of population growth ( $r=\mathrm{LnN}_{t+1}-\mathrm{LnN}_{\mathbf{1}}$ ) in PHU 1 during 1973-1987 was $\mathrm{r}=0.19$ in 1980-81 (Fig. 9.15). This growth rate included harvest loss of adult males during a five-week buck season, limited legal losses of adult females under an antlerless permit system, and natural mortality of all sex and age classes. Rates of population change during the previous and subsequent year were $r=-0.05$ and $r=-0.13$, respectively. If no deer had been harvested during biological year 1980-81 and effects of other factors remained the same, the population growth rate would have increased to $r=0.31$. 


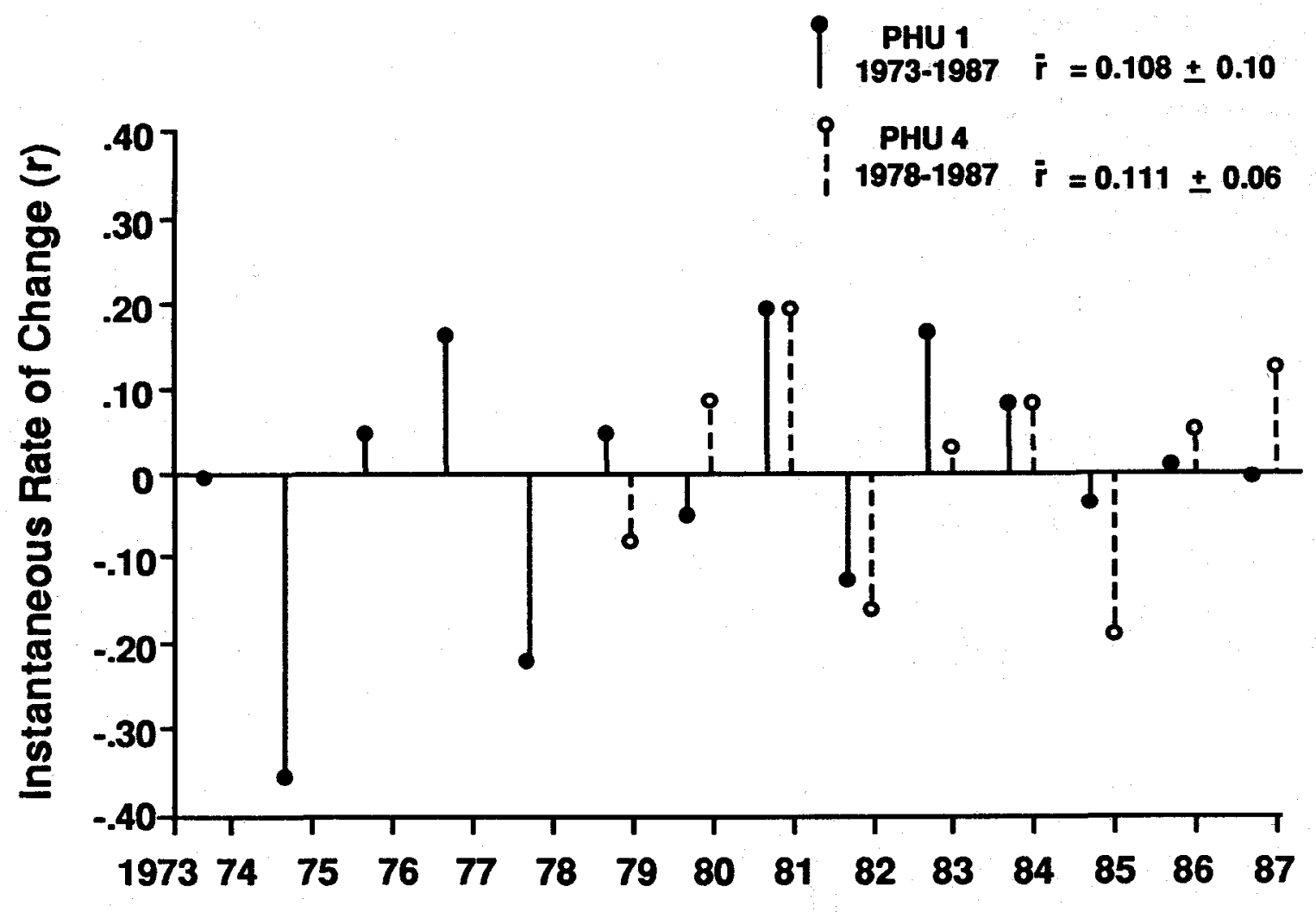

Figure 9.15. Instantaneous rate of change in mule deer numbers from May to May in PHUs 1 and 4, 1973-1987.

For PHU 4, the maximum observed growth rate (Fig. 9.15) was very similar (r $=0.20$ ) and also occurred during 1980-81. If no harvest had occurred on PHU 4 that year, the rate would have increased to $r=0.28$. In both populations, maximum growth rates coincided with years of highest recorded fawn recruitment.

Maximum observed population growth rates in the two populations were less than reported for a northcentral Montana mule deer population (Hamlin and Mackie 1989) and white-tailed deer on the George Reserve (McCullough 1983).

The largest instantaneous rates of decline $(-r)$ from spring-spring were $r=-0.36$ in PHU 1 and $\mathrm{r}=-0.19$ in PHU 4 (Fig. 9.15). During the period 1978-1980, one population increased while the other declined. In other periods (1982-1983 and 19841985), the direction of change was the same, but the magnitude of $r$ was different. Disregarding sign, $\overline{\mathrm{r}}$ was similar for PHUs 1 and 4 , though variability about the mean was less in the latter. 
Rates and direction of change in growth rates in PHU 1 are plotted against spring population size in Fig. 9.16. A very steep rate of decline occurred during 1974-75. This was associated with high early fawn losses followed by substantial mortality of all sex/age classes during the severe winter. During the next seven years, the population fluctuated around a lower level, coinciding with several severe winters. Although total numbers were already comparatively low, the population experienced additional declines on three occasions. During the last five years of study, the population "escaped" from the low level spiral to fluctuate at a higher equilibrium coincident with a period of relatively mild winters. Throughout the 14-year period, it was apparent that total deer numbers on PHU 1 fluctuated in response to factors other than just population level.

For PHU 4, the rate and direction of population change fluctuated in a "tight" spiral (Fig. 9.17). In contrast to PHU 1, a decline on PHU 4 was always followed by two years of population increase. This indicated greater resiliency in recovering from population setbacks.

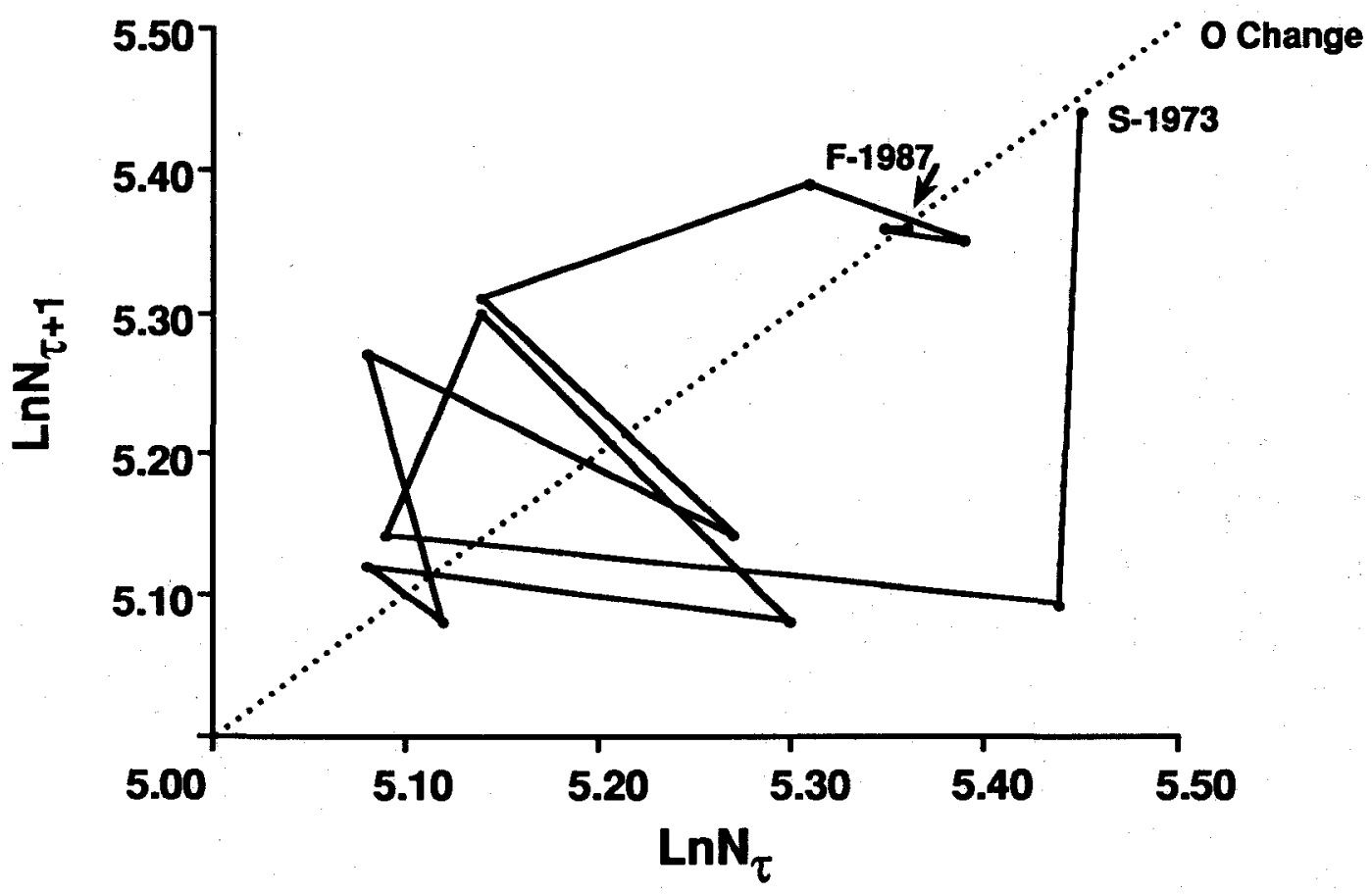

Figure 9.16. Rate and direction of change in population growth in relation to spring population size for the Armstrong segment of PHU 1, 1973-1987. 


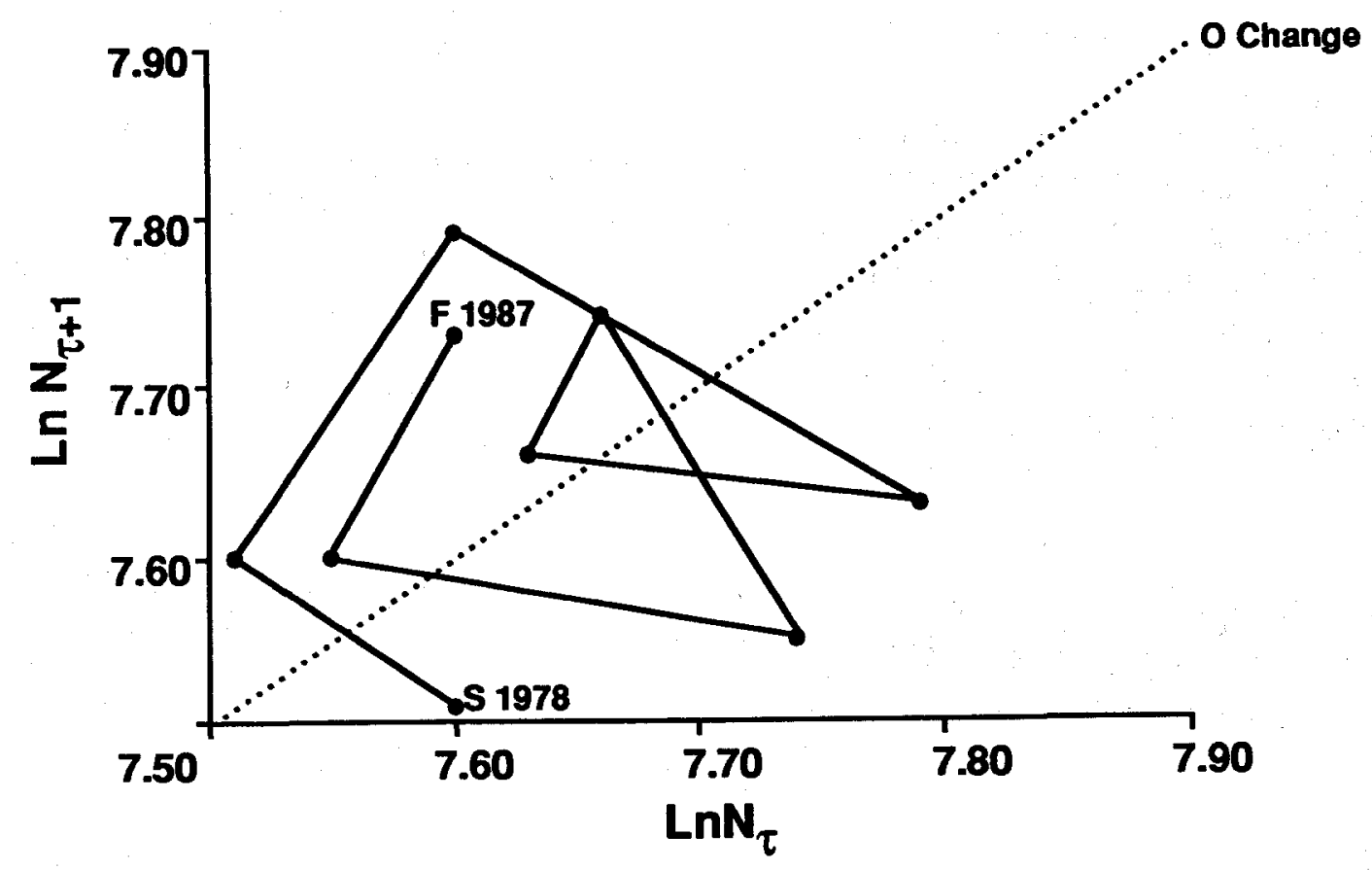

Figure 9.17. Rate and direction of change in population growth in relation to spring population size for PHU 4, 1978-1987.

Summary

1. Sex and age composition varied among PHUs and between years for individual PHUs. Comparisons focused on PHUs 1 and 4 which were most intensively studied and representative of trends in population size and composition along the west and east slopes, respectively.

2. In early winter, females consistently predominated in both PHUs. Male:female ratios were higher and more variable in PHU 1. Yearling males comprised a greater average percentage of adult males in PHU 4 than in PHU 1. Fawn:female ratios were generally higher in PHU 4 during 1975-1982, whereas ratios were similar in both populations during 1982-1987.

3. In late winter, average fawn:adult ratios were higher in PHU 4 than in PHU 1.

4. The adult female segment in PHU 1 was characterized by an older age structure than occurred in PHU 4. Variation in legal harvest rates of adult females did not account for these differences in age structure.

5. Although male longevity was greater on the west slope, the pyramidal shape of the male age distribution in west and east slope PHUs indicated that hunters selected for older, larger antlered males. 
6. High adult buck mortality in all age classes, coupled with periods of low recruitment, resulted in greater instability in annual age structure among males than females.

7. Adult female mortality rates were primarily influenced by the movement of variably sized cohorts into older age classes that were vulnerable to natural mortality.

8. Population trends in PHUs 1 and 4 were characterized by a high degree of stability compared to other Montana mule deer populations. Total numbers of mule deer declined substantially every year between June and December as a result of early fawn losses and hunting mortality of adults. Lower and more variable losses occurred between December and May as a result of winter-related mortality of fawns and adults.

9. Collectively, an average of 2,000 mule deer occurred in the three west slope PHUs. The four east slope PHUs contained about 5,250 deer. This resulted in an overall average of 7,000-7,500 mule deer in the Bridger Range.

10. Deer densities varied greatly among individual PHUs reflecting the unique combination of habitat characteristics in each unit. However, mean densities in five of seven individual PHUs in the Bridger Mountains were greater than reported for other Montana populations in prairie and "breaks" habitat.

11. Maximum observed population growth rates in PHUs 1 and 4 were less than reported for other Montana mule deer populations. Rate and direction of population change in PHU 4 fluctuated in a tight spiral where declines were followed by increases in the following year. In PHU 1, rates of population change exhibited both a high and low level spiral that coincided with periods when mild and severe winters prevailed. 
CHAPTER 10

\section{POPULATION-HABITAT RELATIONSHIPS}

This chapter and Chapter 11 address several important questions relating to population ecology and management of mule deer. These include:

- What constitutes a population and its habitat?

- How do mule deer populations develop?

- What factors determine mule deer distribution and use of habitat?

- What factors influence population size, composition and dynamics?

Definition of Population and Habitat

The term "population" is fundamental to the parlance and practice of ecology and wildlife management. Typically, however, it is only obscurely defined as "a group of individuals belonging to a single species" (Odum 1953) or as a group of individuals that share a common gene pool (Keeton 1972). Cole (1957) referred to a population as "a biological unit at the level of ecological integration where it is meaningful to speak of a birth rate, a death rate, a sex ratio, and an age structure in describing the properties of the unit."

Mayr (1970), like Cole, considered a population to be a level of integration occurring between the individual and the species, but suggested several uses. It could include individuals of several species or the totality of all individuals of a single species. However, he stated that usage of the term has been increasingly restricted to the community of potentially interbreeding individuals at a given locality. This interpretation has also been defined as a "deme", a term first proposed by Gilmour and Gregor (1939) and more specifically defined by Simpson (1953) and others to mean a local, interbreeding population.

Alternatively, Nicholson (1957) proposed that "population" be defined as "a group of interacting and interbreeding individuals which normally has no contact with other groups of the same species...that is to say...a discrete dynamic unit." Mayr (1970) concluded that local populations are selected for adaptation to the specific environment in which they live. 
Existing definitions of habitat are perhaps even more obscure than those concerning population. Odum (1953) described habitat simply as "the place where an organism lives." His definition included other organisms as well as the abiotic environment. Fretwell (1972) described it as "any portion of the surface of the earth (or in some cases a layer parallel to the surface) where a species is able to colonize and live (temporarily or permanently) at some density greater than zero". Both definitions include other organisms as well as the abiotic environment.

Other authors emphasized only the abiotic component of the environment of an organism or species. Thus, Whitaker (1970) defined habitat as "the kind of environment the organism occurs in as may be described by elevation, topographic position, etc., and in physical and chemical terms." Whittaker et al. (1973) termed it as "the complex of physical variables on the range where a species exists".

Adding even more confusion to habitat terminology is the concept of "niche." Whittaker (1970) defined niche as "the species' place in a community in relation to other species." Most authors include only the biotic component of the environment in the niche concept. As stated above, habitat may or may not include the biotic component.

Previous definitions of population and habitat have obstructed understanding of the two concepts and their relationship to one another. None completely fit mule deer population-habitat relationships observed on our study area. To some extent, this is expected whenever generalities are applied to specific situations.

The Population-Habitat Unit (PHU) Concept

When our studies began, all mule deer in the Bridger Mountains were generally considered one population. Earlier work (Wilkins 1957) and initial efforts associated with our study (Schwarzkoph 1973, Buscis 1974, Hamlin 1974, Morton 1976, Pac 1976, and Mackie et al. 1976) were directed toward one representative segment of that population. Subsequent investigation revealed that mule deer in the Bridger Mountains were distributed as discrete population-habitat units. Preliminary definitions of this concept were discussed in Mackie and Pac (1980), Pac and Mackie (1981), and Lonner and Pac (1990). Pac et al. (1988) also applied the concept to other mule deer populations in the Northern Rocky Mountains.

A PHU consists of an assemblage of deer bonded together by a web of individual movement and habitat use patterns radiating outward from a specific winter range. The traditional nature of these patterns is established and maintained through behavioral interactions typically associated with a matriarchal society. Life-long fidelity of individual deer and their offspring to site-specific seasonal home ranges ensured that each unit was associated with a definable and distinct habitat area. 
The habitat component of a PHU included a unique combination of environmental characteristics. These were organized under two major categories. Stable characteristics include geographic position (latitude, longitude), climate, topographic landform, and vegetation structure. Variable characteristics include weather, forage availability, periods of positive/negative energy balance, and other animals and man's activities as they influence fluctuations in habitat suitability.

To satisfy all seasonal and yearlong resource requirements, deer in each PHU displayed a diversity of behavioral strategies specifically adapted to the local environments they encountered. The collective sum of the "strategic choices" made by all deer in a PHU influenced the demographic characteristics and dynamics in the unit.

Diagnostic attributes of PHUs were not limited to environmental characteristics, deer distribution, movements, habitat use, and demographics. Genetic analysis revealed significant differences in the frequency of mitochondrial DNA (mtDNA) haplotypes between east and west slope PHUs. This implied that east and west slope units constituted separate breeding populations (demes). We speculate that the social order among mule deer maintained mtDNA frequencies that occurred among the original immigrants along the east and west slopes of the Bridger Mountains. Traditional movement and habitat use patterns and low rates of female dispersal maintained spatial organization within individual PHUs and the long-term integrity of adjacent units.

As applied to mule deer in the Bridger Mountains, the term "population" was no longer a conceptual abstraction. Our results were consistent with Nicholson's (1957) description of populations as discrete dynamic units, but we expanded the definition to imply behavioral, biological, and ecological unity with the local environment occupied. Additionally, we provided specific criteria for recognizing and defining both the population and habitat components for mule deer occupying Northern Rocky Mountain environments.

In our concept, the population delineates the complete ecological unit of habitat required to sustain it. Physical and biotic characteristics of the habitat determine the strategies of exploitation (behavioral and biological) employed by members of the population. Both habitat and strategy influence demographics and dynamics.

Other recent studies on mule deer (Hamlin and Mackie 1989, Wood et al. 1989) and white-tailed deer (Dusek et al. 1989) have provided additional data supporting broad application of this concept. Manlove et al. (1976), Ramsey et al. (1979), and Chesser et al. (1982) indicated that whitetail populations are genetically subdivided into demes over short distances. Cothran et al. (1983) hypothesized that white-tailed deer demes were related to a matriarchal society. More detailed investigations revealed demographic and genetic differences for white-tailed deer populations occupying different habitats in South Carolina (Dapson et al. 1979, Ramsey et al. 1979). 
We can speculate from our results that development of population-habitat units follows a predictable pattern from initial colonization through the latter stages of population growth and habitat exploitation. In mountain environments characterized by strong seasonality and periodic severe winters, successful mule deer colonizers must have selected home ranges that included suitable winter habitat. Most mountain ranges include significantly smaller proportions of winter than summer range. Pioneering individuals that localized in the lower elevation foothill zone would have had the greatest probability of survival. These deer probably displayed the ISR (indistinct seasonal ranges) movement pattern. This pattern represents a fundamental strategy requiring little specialization in seasonal movements or habitat use. Areas providing the basic requirements for over-winter survival were most common along the drier "rainshadow" side (east slope) of the Bridger Mountains and may represent the sites where successful occupation began.

Dispersal occurs during early summer when environmental conditions are most benign and adult females exhibit parturition territoriality. This time also provides emigrants with the best conditions for traveling through unfamiliar terrain and locating suitable home ranges in "new" habitat. Because all habitats are potentially available at this time of year, some immigrants will unknowingly settle in areas unsuitable for overwinter survival. If these deer fail to locate winter habitats at the onset of severe weather, mortality is probable.

Once colonizing deer became established, sufficient reproduction was necessary to ensure the perpetuation and expansion of the founding population. Although foothill areas often provided sufficient winter range, local habitats providing dependable sources of succulent forage throughout the summer are often in short supply. Habitats with these characteristics are the driving force behind successful reproduction and summer habitat selection by adult females (Wood et al. 1989, Hamlin and Mackie 1989, Dusek et al. 1989). ISR females occupying the foothill zone rapidly exploited the limited amount of reproductive habitat. This minimized the number of generations of females that established home ranges around ISR matriarchs. Semi-territorial behavior of maternal does during parturition resulted in dispersal of juvenile females away from ISR groups.

In the Bridgers, juvenile females seeking summer home ranges found extensive areas of mesic summer habitat at "middle" elevations above the foothill zone. Successful exploitation of montane forest habitats required only moderate specialization culminating in traditional movement patterns of the ASR (adjacent seasonal ranges) type. These "middle elevation" summer ranges provided plentiful reproductive habitats, but snow accumulation required seasonal movement back to winter home ranges in the foothill zone. The distance separating seasonal ranges was only a few kilometers and often involved simple, up-down movements. Winter home ranges of these ASR deer seasonally overlapped the yearlong home ranges of their ISR counterparts and began to 
increase the complexity of movement and habitat use patterns that characterized this developing population.

As summer habitats at middle elevations began to fill with matriarchal groups, juvenile females dispersing away from both ISR and ASR ranges had to travel further to locate suitable summer home range sites. Habitats now available were located primarily at elevations above the montane forest zone or in forests across mountain divides. Other individuals also moved downward in elevation and located summer home ranges in riparian valleys below the foothill zone. On the wet, windward slopes of the Bridger Mountains, prohibitive snow depths on these valley sites often resulted in movement back to suitable winter habitat in the foothills. The longer and more complex travels by these individuals resulted in the development of specialized traditional movement patterns of the DSR (distinct seasonal ranges) type.

The higher elevations and more distant location of summer ranges exploited by these deer also required greater refinements in the temporal and spatial arrangement of movement patterns. This increasingly complex web of movement patterns and accessory areas permitted members of the population to efficiently exploit all seasonal habitats in that locality. Successful patterns were perpetuated by the long lasting social bonds between mothers and their female offspring.

Ultimately, growth and expansion of the population became limited as members encountered and competed for space with individuals from other developing populations. Perimeters between adjacent populations overlapped on summer range areas where individuals from both populations intermingled. The traditional movements of matrilineal groups ensured that these behavioral boundaries would tend to "package" adjacent populations into discrete units we call PHUs. Obviously, these boundaries are not directly perceived by deer and could be freely penetrated by any individual that broke from tradition and moved into another PHU.

This process apparently produced the present-day juxtaposition and physical size of the seven PHUs in the Bridger Mountains. Nelson and Mech (1987) hypothesized that physical size of white-tailed deer demes in Minnesota may have been related to time since colonization. The largest habitat areas were encompassed by PHUs on the east slope and north end of our study area. If we assume that colonization occurred earlier in these areas, then populations had more time to expand their distribution. However, less specialized movement patterns that prevailed in the less complex habitats on the east slope could also have encouraged more rapid expansion. These conceptual relationships are displayed in Figure 10.1.

The smaller size of west slope PHUs may have resulted from later colonization and reduced potential for unimpeded expansion due to contact with deer from adjacent, better established east slope populations. A slower rate of development in west slope 


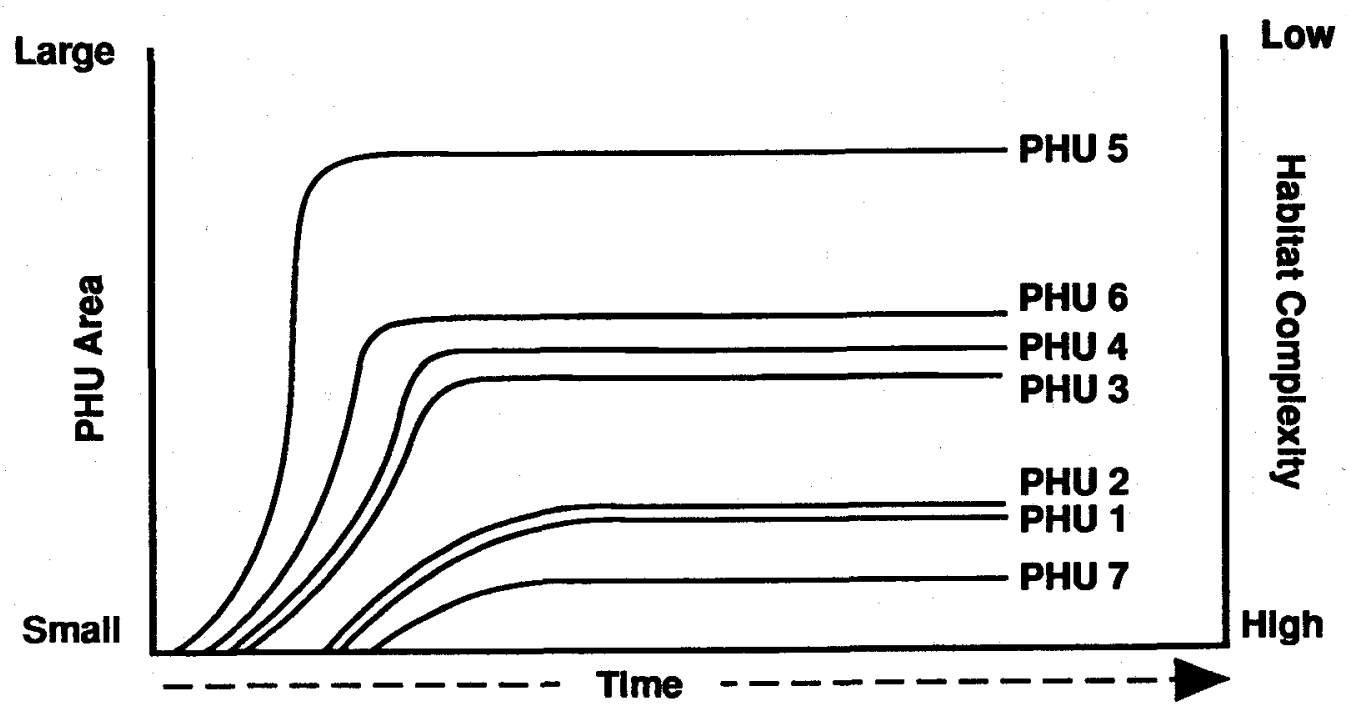

Figure 10.1. Rate and magnitude of development of seven PHUs across a spectrum of habitat complexity in the Bridger Mountains.

PHUs was probably related to development of more specialized patterns of habitat use and the lower recruitment associated with harsh, high elevation environments.

The inflection points along the conceptual curves in Figure 10.1 correspond to the establishment of PHU boundaries. Population-habitat relationships occurring prior to (left of) inflection points resemble the irruptive phase described by Leopold (1933) and Leopold et al. (1947). During this phase, populations expand rapidly in space as well as in local density. However, baring some catastrophic event, irruptive growth is a one time population phenomenon in an environment like the Bridger Mountains. Once a PHU is filled, only fluctuations in local density can occur; opportunities for spatial expansion associated with colonization and irruption no longer exist.

To this point, our discussion has considered only that portion of the curve depicting initial population development. In the following sections, we focus on population-habitat relationships within established PHUs. 
Deer Behavior and Habitat Use Among Established PHUs

Influence of Behavior

It has long been recognized that social behavior in mule deer centers on the family group (Russell 1932). However, the implications of this behavior to distribution and habitat use only gradually became known. Early tagging studies of mule and black-tailed deer (Leopold et al. 1951, Taber and Dasmann 1958, Ashcraft 1961, Gruell and Papez 1963, Zalunardo 1965, Robinette 1966, and Richens 1967) confirmed that deer habitually used the same winter and summer ranges and migration routes. Some investigators (Gruell and Papez 1963, Zalunardo 1965) recognized that seasonal movements of a family group were accomplished independently of other groups and that younger animals reaching maturity probably repeated learned patterns for life. Dasmann and Taber (1956) were the first to report that establishment of the home range was probably related to early experience with the mother. Later, Taber and Dasmann (1958) demonstrated that adult female black-tailed deer became aggressive during fawning, resulting in spacing of maternal does across occupied habitat and occasional dispersal of yearlings.

During the last 15 years, radio telemetry studies of mule and black-tailed deer distribution, behavior, and habitat use have confirmed and refined many of these early findings. In addition, numerous studies measured home range size and shape (Severson and Carter 1978, Steigers and Flinders 1980, Eberhardt et al. 1984, Schoen and Kirchoff 1985) and quantified fidelity to specific home range and movement patterns (Garrott et al. 1987, Kufeld et al. 1989).

Collectively, these studies established clearly what deer did. However, only recently have studies followed the recommendation of Sanderson (1966) and shifted toward determination of why animals display particular patterns of distribution, movements, and habitat use (Wood et al. 1989, Hamlin and Mackie 1989). This approach is based on an integration of knowledge concerning social behavior, resource requirements, and characteristics of the occupied environment to explain the "whys" of mule deer distribution, seasonal movements, and habitat use.

In this context, our results confirmed that distribution, movements, and habitat use of female mule deer in mountain environments are fundamentally based on individual behavioral patterns learned by association with successful matriarchs. Social structure and matrilineal behavior acted as mediating factors between the individual and its environment. Through this process, a female mule deer learned from its mother where to set up seasonal home ranges and how to use habitat in that locality. Related females usually shared overlapping home ranges. However, they possessed exclusive parturition territories (Ozoga et al. 1982) that developed in response to maternal aggression and the requirement for isolation during the fawning period. Adaptation to characteristics of the area used by individual deer resulted in differences in the size and shape of their home ranges. 
In the early stages of population development, young adult males may have been the first to colonize new habitats because of their inherently greater propensity for dispersal. Initially, they may have been broadly distributed across reproductive and maintenance habitats in summer. However, as populations became established, home range formation and habitat use of males increasingly centered on areas receiving limited use by productive females. Spatial segregation occurred because yearling males and mature males either removed themselves or were driven from reproductive habitat by maternal does during the fawn-rearing period. Yearling males temporarily joined groups of more tolerant, non-productive adult females or became loosely attached to groups of mature males with established habitat use patterns. Other yearlings permanently dispersed from natal PHUs. Habitat partitioning between the sexes and differences in social behavior resulted in complete use of all available habitats within a PHU and minimized competition for forage and space.

Numerous authors have indicated that males select habitat on the basis of foraging opportunities while females select habitat suitable for raising young (Geist 1981, Bowyer 1984, Clutton-Brock et al. 1987, Jakimchuk et al. 1987). This hypothesis is based on energetic requirements and the differing reproduction strategies that exist between the sexes in polygynous ungulates (Main and Coblentz 1990).

Based on our data, habitat selection must be interpreted within the constraints of traditional behavior. Habitat choice was not simply a random encounter between an individual and its environment. Schoen and Kirchoff (1985) concluded that "the composition of the home range determined the array of choices available to the individual and habitat selection was a function of the available choices. Areas outside of the home range represent unknown territory..." Therefore, precise understanding of habitat requirements and selection displayed by a specific population requires closely monitoring a representative sample of the existing array of individual strategies.

\section{Influence of Stable Habitat Characteristics}

Hamlin and Mackie (1989) concluded that habitat quantity and quality are heterogeneous in space and time. Spatial heterogeneity of major components of the habitat is primarily regulated by geographic position, climate, topographic landform, and vegetation structure. All of these characteristics are relatively fixed and change very slowly through time.

This generalization was especially applicable to PHUs occupying the diversity of environments encompassed by our study area. To simplify our discussion, we adopt the terminology of Wood et al. (1989) to describe three general categories of deer habitat. These are:

1) Reproductive habitat -- environments with resources necessary for adult survival and a high probability of reproductive success. 
2) Maintenance habitat - environments providing resources necessary for adult survival, but not for reproduction.

3) Non-habitat -- environments incapable of supporting deer.

Individual deer do not usually reside exclusively in any one category; consequently, yearlong movements may include habitats in two or three categories.

In the Bridger Mountains, reproductive habitat was generally synonymous with low to middle elevation montane forests on summer range or riparian agricultural inclusions within some winter ranges. All reproductive habitats shared common characteristics. They provided dependable sources of succulent forage throughout the parturition-lactation period. The array of forage species available was highly variable and less important than the attribute of succulence and corresponding high nutrition. Herbaceous plants predominated, although succulent stages of some shrubs and grasses were important. Other important attributes of reproductive habitat included the opportunity for isolation from other deer, security from predation, and avoidance of competition with other ungulates and livestock. These opportunities were enhanced by multi-layered vegetation stands in conjunction with topographic diversity. Higher deer density occurred where all of these essential components were available in close proximity.

Maintenance habitat includes both foothill winter ranges and high elevation portions of summer range. Winter-maintenance habitats occur on sites where the interaction of topography and local climate create a reprieve from deep snow accumulation. Consequently, the energetic costs of locomotion associated with a deer's daily routines will be reduced. Native forage supplies in winter-maintenance habitat include locally variable mixtures of browse, forbs, and grasses. Regardless of species composition, nutritional value of native winter forage is below the maintenance level for deer. Therefore, deer survival can only be achieved by balancing sub-maintenance diets with behavior that emphasizes conservation of energy reserves. Stands of coniferous timber and broken topography are important features that enhance energy conservation, particularly in deep snow environments. These same features also provide security from predators during the period of winter concentration on limited habitat when deer are particularly vulnerable.

Summer-maintenance habitat may occur throughout the Bridger Mountains, but especially at high elevations where plant development is slow and consequently provides inadequate amounts of succulent forage during parturition and early lactation. In addition, early autumn snow storms limit the period when these habitats can be occupied. Summer-maintenance habitats occasionally occur at low elevations as small inclusions of gentle, non-timbered breaks in rangeland basins. Availability and dependability of succulent forage is restricted on these sites. Risk of predation and/or competition with livestock may be comparatively greater in summer-maintenance habitats. 
In non-habitat, resources of value to deer are essentially absent. Non-habitat is relatively scarce in mountain-foothill environments and is limited to massive rock formations, alpine scree, or some low elevation basin bottoms with monotypic grasslands or dryland grain crops.

The juxtaposition of major habitat components and their relative quantity and quality within each PHU was influenced by the landform that characterized the unit. PHUs 1 and 5 provided the most striking contrast in relation to the influence of landform (Fig. 10.2) on the other stable habitat characteristics, their use by deer, and ultimately on deer demography and dynamics. In diagrammatic cross section, the landforms of the two adjacent units are nearly the antithesis of each other.

In PHU 1, the sharply convex land form included substantial changes in elevation and relief across a relatively short linear distance. These attributes resulted in a significant modification of the local climate. Orographically induced precipitation varied

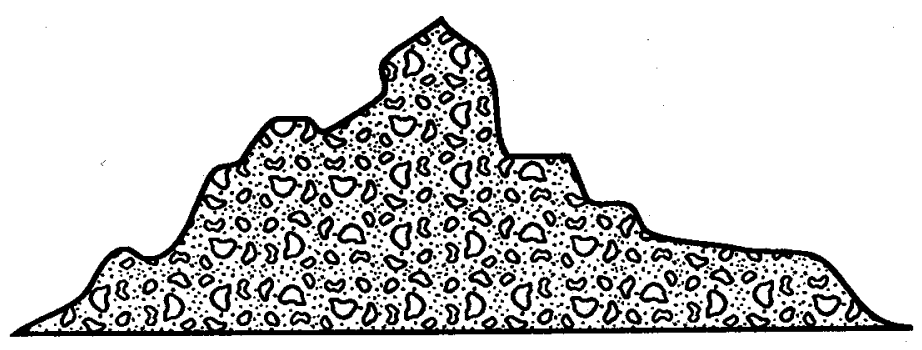

PHU 1

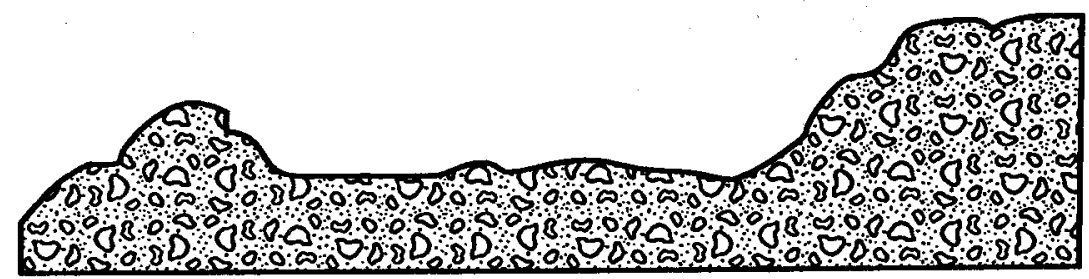

PHU 5

Figure 10.2. Diagrammatic cross-sections of the landforms in PHUs 1 and 5 in the Bridger Mountains. 
from 457-1270 $\mathrm{mm}$ across the unit. The pronounced changes in elevation and precipitation resulted in a diversity of vegetation zones that tended to be stratified in narrow, linear belts. Consequently, maintenance and reproductive habitat was often distributed in closely adjacent and distinct strata (Figure 10.3).

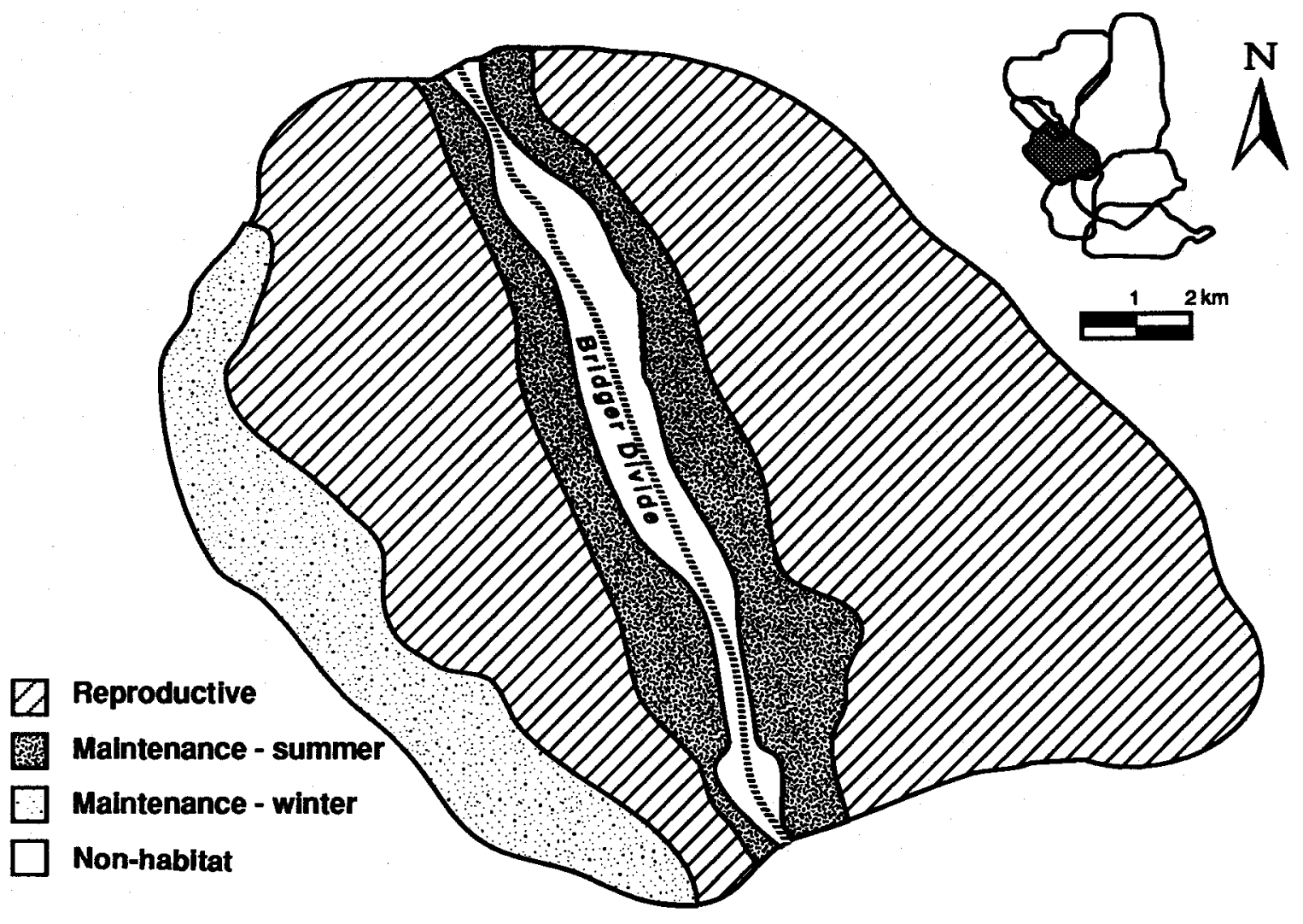

Figure 10.3. Distribution of reproductive, maintenance, and non-habitat within PHU 1.

Maintenance habitat in the foothill zone provided winter range for all members of the PHU 1 population. These same habitats also provided summer range for some mature males and unproductive females. During summer, larger numbers of mature males and unproductive females utilized a different strata of maintenance habitat located in the subalpine-alpine zone just below the Bridger Divide. Below this zone and separated by the high divide were two strata of montane forest that provided extensive areas of reproductive habitat used by the majority of adult females during summer. The only non-habitat in this PHU consisted of nearly vertical rock outcrops and scree slopes along the summit of the divide.

Collectively, landform, climate, and vegetation zones exerted a primary influence on the quantity, quality, and juxtaposition of habitat components important to deer. The spatial distribution of important habitats affected the type of movement pattern required 
to connect and use all essential components. In PHU 1, very few deer displayed ISR movement patterns because habitats accommodating both over-winter survival and reproduction were scarce. In contrast, ASR patterns were common because significant amounts of reproductive habitat were readily accessed in the montane forest located immediately above the steep band of foothill winter range.

Approximately half of all deer in PHU 1 employed DSR movement patterns. During spring and autumn, these individuals traveled through summer home ranges of ASR deer to reach reproductive habitats along the east side of the mountain crest or at more distant locations on the west slope.

The broad, concave landform of PHU 5 (Figure 10.2) encompassed only subtle changes in elevation and relief across a comparatively large linear distance. The entire unit occurred within the rainshadow created by high elevation terrain associated with the Bridger Mountain Divide. Annual precipitation across PHU 5 varied between 356-762 $\mathrm{mm}$, although only very limited portions of the area occurred within the higher precipitation classes. Correspondingly, diversity of vegetation was limited to steppe and predominantly open-canopy montane forest. The steppe was extensively distributed across a broad centrally located basin and included a substantial amount of non-habitat consisting of dry, monotypic rangeland and grain fields (Figure 10.4). A few islands of summer-maintenance habitat associated with rough breaks-type topography supported a few mature males and unproductive females during summer. Most of the maintenance habitat occurred along the ridge forming the southern border of the unit. Here, moderate slopes and secondary drainages supported stands of sagebrush, juniper and Douglas fir that provided winter range for the entire population. A few inclusions of reproductive habitat were located within the wintering area. The largest piece of reproductive habitat was situated at a considerable distance from the winter range along a ridge forming the northwest boundary of the PHU. There, Douglas fir stands interspersed with mesic pockets of aspen provided succulent forage for a significant number of adult females on a relatively small part of the entire unit.

In contrast to PHU 1, reproduction and maintenance habitats in PHU 5 occurred as small inclusions in a large matrix of non-habitat. This loose juxtaposition of important habitats explained why nearly two thirds of the deer in this unit employed DSR movement patterns. Average distances separating seasonal home ranges in PHU 5 were 3 -fold greater than in PHU 1. Only a small proportion of deer in PHU 5 displayed ASR patterns; however, ISR deer were relatively common.

A different set of landform, climate, and vegetation characteristics prevailed in PHU 4 where these factors came together in nearly optimum combination for deer exploitation. A large block of winter-maintenance habitat was situated directly adjacent to an even larger block of high quality reproductive habitat (Figure 10.5). Very little area in this unit was considered non-habitat. The DSR movement pattern predominated among $80 \%$ of the females in PHU 4 because of the large size of the contiguous blocks 


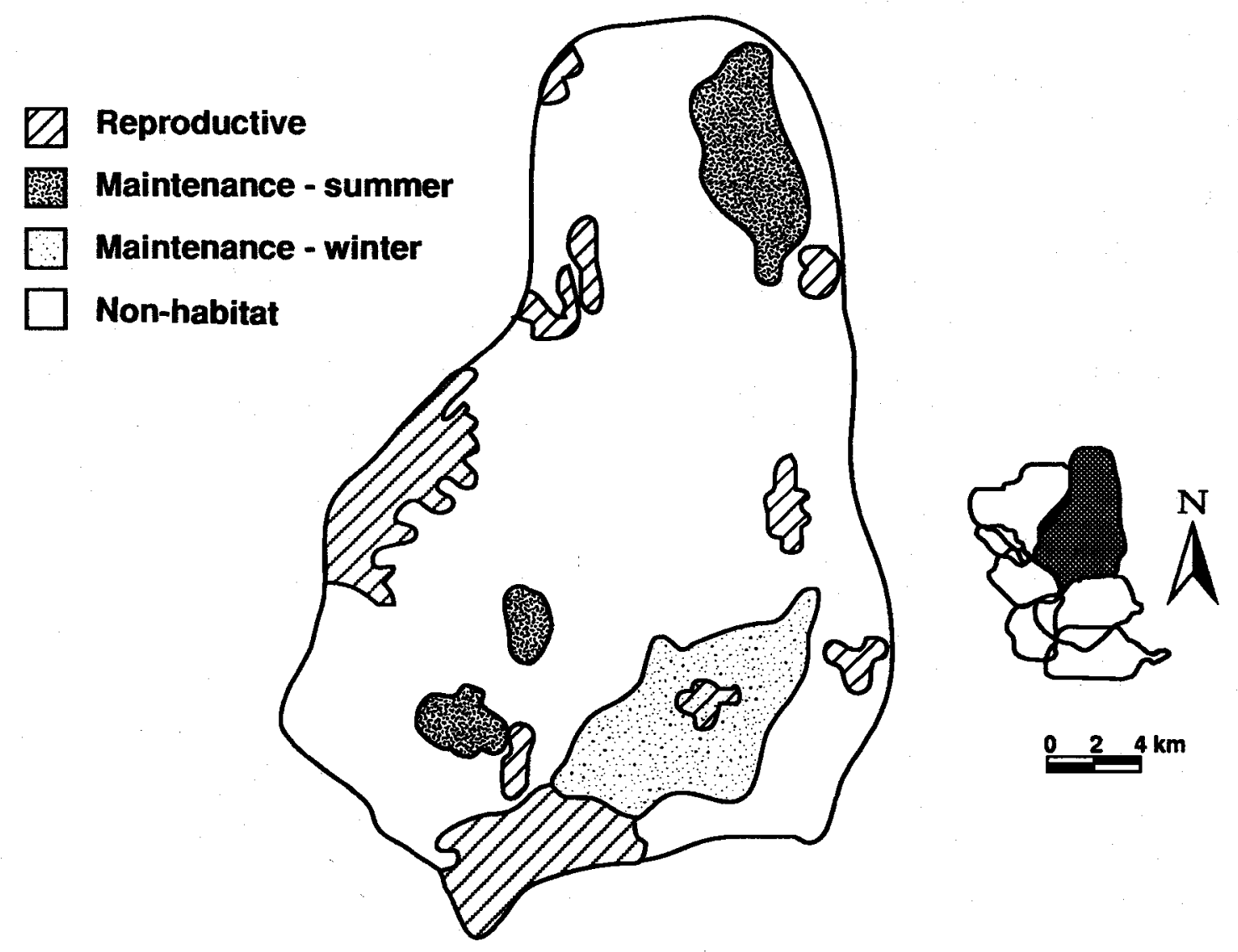

Figure 10.4. Distribution of reproductive, maintenance, and non-habitat within PHU 5.

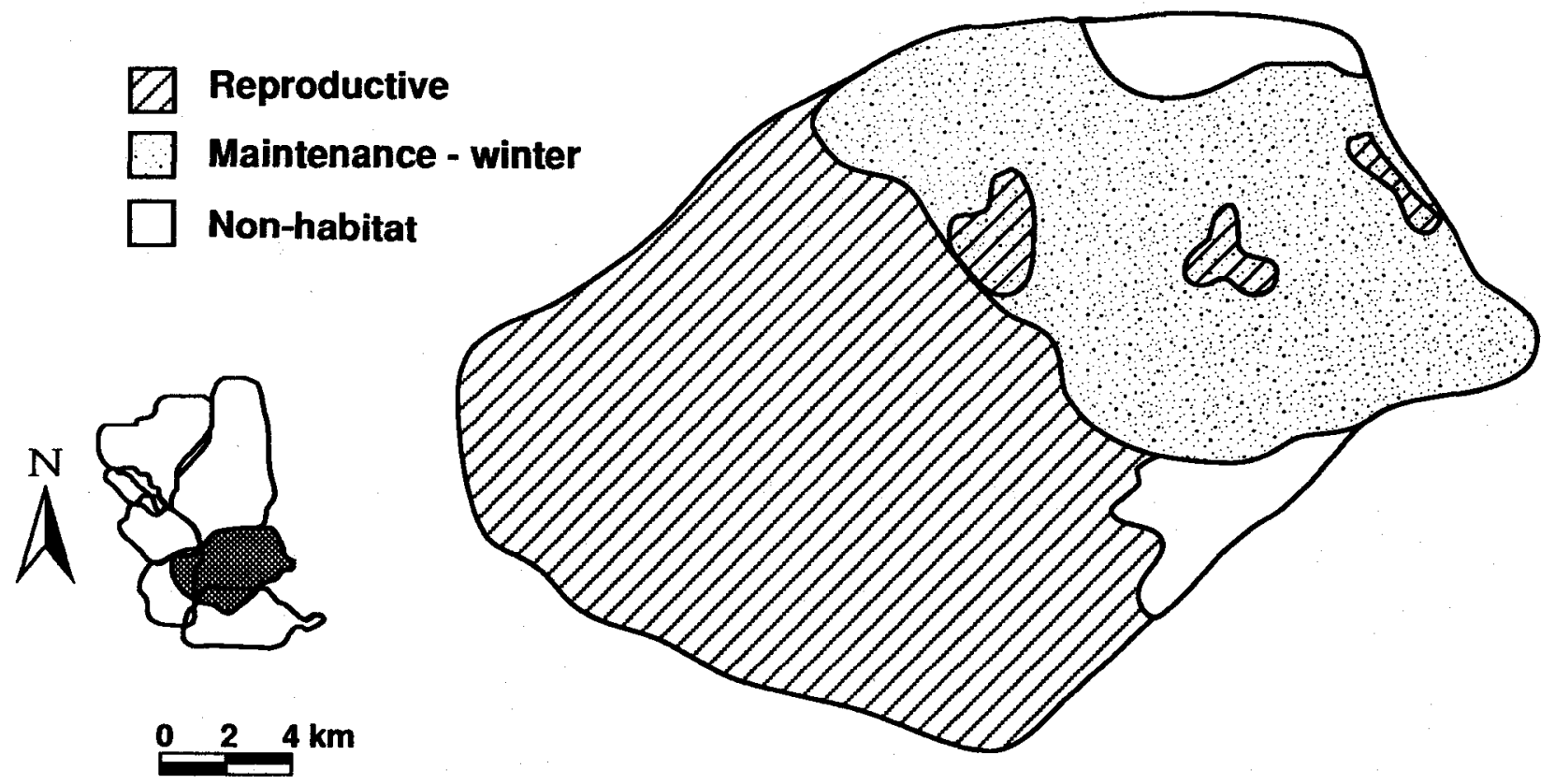

Figure 10.5. Distribution of reproductive, maintenance, and non-habitat within PHU 4. 
of maintenance and reproductive habitats. Most other deer displayed ISR patterns; only a few individuals had ASR patterns.

Deer-habitat relationships in other PHUs were generally similar to one of the three patterns portrayed in Figs. 10.3-10.5. Reproductive, maintenance, and non-habitats in PHUs 2 and 7 were similar to the stratified pattern described for PHU 1. However, maximum elevations were lower which tended to reduce the amount of summermaintenance and non-habitats. In PHU 6, the pattern was intermediate to that described for PHUs 4 and 5. Reproductive habitat was not as continuous as in PHU 4, and nonhabitat was significantly less prevalent compared to PHU 5. The pattern in PHU 3 was structurally and spatially similar to PHU 4; however, reproductive habitats apparently were of lower quality. Similarly, the array of movement patterns in PHUs 2, 3, 6, and 7 reflected the local distribution of reproductive, maintenance and non-habitats.

\section{Influence of Variable Habitat Characteristics}

Superimposed over stable habitat characteristics are a set of variable factors creating the dynamic environments that deer contend with on a daily, seasonal and annual basis. Included within this category are weather, other animals, man's activities that influenced fluctuations in habitat suitability, forage availability, and periods of positive/negative energy balance.

Weather and its variations are essentially local phenomena regulated by the geographic position, prevailing climate, and topographic landform of a specific area. The influence of weather was pervasive; it affected many physical and biotic aspects of the relationship between deer and their habitat.

For example, the distribution of snow significantly determined where suitable winter habitat occurred around the periphery of the mountain range. Snow depth and consistency interacting with low temperature were important in energy expenditure by deer during feeding, resting, and travel. These same factors affected vulnerability to predators, hunters, and various man-caused disturbances. On a daily basis, weather constantly caused adjustments in deer movements and habitat use.

Probably the most important effect of weather was its significant control over quantity and quality of available forage during all seasons of the year. While other factors could impact forage supplies on small, local areas, their role was significantly less important than the all-encompassing influence of weather.

On winter ranges, deer subsisted predominantly on native forage species. In winter, forage quality was generally below the nutritional maintenance requirement for deer because of normal changes in plant phenology that resulted in plant senescence (Morton 1976, Wallmo et al. 1977, Mautz 1978). In the Bridger Mountains, Morton (1976) indicated that total forage quantity was seldom limiting although the availability 
of particular species was regulated by snow accumulation. Browse species traditionally considered important (e.g., big sagebrush and antelope bitterbrush) supplied less than one-third of the forage required by the number of deer that occurred (Mackie et al. 1976, Hamlin 1977). The remainder of the requirement was supplied by juniper, Douglas fir, and various forbs and grasses often considered of poor forage quality. However, both composition of the total forage supply and food habits appeared relatively unchanged from prior years when up to twice as many deer used this winter range.

Forage conditions during spring-autumn were of paramount importance to the recovery of physical condition (Wallmo et al. 1977, Klein 1985, Garrott et al. 1987, Hamlin and Mackie 1989). Interaction between stable characteristics of the habitat and weather regulated the length of the effective growing season when green, high quality succulent forage was available. In mountain environments on our study area, forage production was significantly less variable than on a low elevation breaks habitat (Hamlin and Mackie 1989). The orographically induced precipitation associated with mountain environments apparently makes them much less susceptible to severe summer droughts. However, the initiation and phenological progression of plant growth occurred more slowly in high relief environments. This delayed the transition from low to high quality diets. Furthermore, summer home ranges were occupied for significantly shorter time periods.

Vegetation trend monitoring on winter range (Bucsis 1974, Mackie et al. 1976, Morton 1976, Hamlin 1977, Pac et al. 1984) indicated that quantity of winter forage supplies was not related to deer density. Quality of native forage species used in winter was consistently below maintenance levels, although some variation in nutritive value between years was observed for some species (Morton 1976). Some changes noted in crown area and density of important browse plants on the winter range (Pac et al. 1984) appeared related to normal successional trends that have occurred in the absence of fire.

Klein (1985) concluded that northern cervids have adapted to nutritionally inadequate winter forage by displaying behavior oriented toward energy conservation, winter growth dormancy, and accumulation of fat reserves during summer and autumn. Fat and protein reserves "buy time" for deer as a buffer against the inadequacies of winter forage and the severity of the winter environment (Torbit et al. 1985). Therefore, winter ranges should be viewed as holding areas for deer until summer ranges become available. Because deer physical condition is a product of the quality of all habitats used yearlong, Torbit et al. (1985) concluded that "seasonal ranges can no longer be considered to have isolated effects on herd performance."

In the severe winter environments typical of the Rocky Mountain region, deer must cope with a prolonged negative energy balance each year (Garrott et al. 1987). Our results indicate that the length of this period can vary substantially from one PHU to another because of differences in landform, elevation, relief, local weather, and their corresponding influence on plant development, and availability of high quality, succulent 
forage. Although we had no way of directly measuring the length of the period of negative energy balance, we did observe significant differences in the time periods that deer occupied their seasonal home ranges. Deer in PHUs 1, 2, and 7 spent up to 40 days longer on winter home ranges and about 70 days less on summer home ranges than their east slope counterparts. The length of time that high quality forage was available was set by the local environment. However, through their behavior, deer could maximize their use of succulent forage and optimize their accumulation of fat reserves. Consequently, the interface between stable and variable attributes of the habitat and the behavioral flexibility of the animals resulted in a characteristic energy flow between deer and their local environments. The type of behavioral specialization employed by individual deer to exploit this energy flow depended on the characteristics of each environment.

Incorporation of various kinds of accessory areas into movement and habitat use patterns was a visible consequence of this specialization in habitat usage. Use of accessory areas occurred in response to variable factors such as weather, forage conditions, and interactions with deer or other animals. Accessory areas represented subtle, yet critically important adjustments that allowed individual deer to continue optimal use of habitat in spite of changes in their local environment. While basic movement patterns (ISR, ASR, DSR) were descriptive of the stable arrangement of important habitats in a PHU, accessory areas were diagnostic of an individual's response to variable aspects of its environment.

Winter accessory areas were employed almost exclusively by deer with winter home ranges in habitats of low topographic complexity. These accessory areas were used only during severe weather when deep snow buried forage supplies and prohibitively increased the energy cost of using the normal winter home range. By moving to the accessory area, those conditions were alleviated. Vulnerability to predation may also have contributed to abandonment of the winter home range during severe conditions.

Spring and autumn accessory areas were used by deer that encountered substantial elevational relief along their movement corridors. These individuals were particularly susceptible to bottlenecks in seasonal distribution. In spring, this situation was partially alleviated by moving to accessory areas as soon as plant development occurred on these sites. This strategy maximized their ability to use high quality forage at the earliest possible time while minimizing intraspecific competition. These same factors explained their subsequent departure from spring accessory areas as soon as conditions became favorable for movement to their summer home ranges.

Deer moved to autumn accessory areas only when it was energetically advantageous or necessary to do so. For deer with both summer and winter home ranges on the same side of a mountain divide, movement to autumn accessory areas occurred only when deep snow forced the move. For deer with seasonal home ranges on opposite sides of a high mountain divide, movement to autumn accessory areas occurred when 
only minor amounts of snow accumulated on their summer home, ranges. Weather conditions on the high divide, rather than on the summer home range, dictated when these deer moved to autumn areas. Were it not for the topographic barrier, prevailing conditions on the summer home range would have potentially allowed continued occupation in an energetically advantageous manner for longer periods of time similar to deer that did not cross the divide.

When it became necessary to abandon their summer home ranges, deer in both situations optimized their habitat use strategy by using autumn accessory areas for the longest possible time period. This approach short-stopped their move to winter concentration areas where competition was greater for poorer quality forage. Also, deer probably were more vulnerable to predation on winter concentration areas than on autumn accessory areas.

Early summer accessory areas were used by some deer with high elevation summer home ranges. The time these areas were used closely corresponded to the period when maternal females displayed parturition territoriality. Aggression may have been intensified by limited supplies of succulent forage at high elevations in mid-June. Use of these areas contributed to the spacing of adult females across all habitats that provided succulent forage at a time when demand for this resource was exceptionally high. Subordinate does with summer home ranges that strongly overlapped those of dominant individuals may have been forced to move to early summer accessory areas at low elevations where succulent forage was available. However, security for newborn fawns may have been deficient on these areas.

Late summer accessory areas were associated with deer that had summer home ranges in habitats of low topographic and vegetative complexity. Movement to those areas coincided with pronounced reductions in forage quality on normal summer home ranges that was related to desiccation or killing frosts. By utilizing sources of succulent forage on accessory areas, these deer were able to continue to accumulate fat reserves in preparation for the energy deficient period during winter.

In the last 50 years, many studies have addressed mule deer population-habitat relationships from a variety of perspectives. Early publications focused on single factors (i.e. winter forage) thought to be of over-riding importance in this relationship (Rasmussen 1941, Leopold et al. 1951, Lack 1954). This approach emphasized winter range as constituting the primary habitat of relevance to the population. Gradually, the importance of other seasonal ranges was established (Julander et al. 1961, Wallmo et al. 1977). Recent investigations have provided a more complete understanding of the contribution of all seasonal ranges to the yearlong energetics required to sustain a population (Torbit et al. 1985, Garrott et al. 1987).

Early studies viewed seasonal movements and migration as collective responses by a population to snowfall and/or forage availability (Russell 1932, Leopold et al. 
1951). More recent interpretations suggest that seasonal migrations are instead driven and controlled by changes in energetic requirements and by the quantity and quality of forage within the year-round range of the animals (Garrott et al. 1987).

Historically, numerous authors concluded that deer did not display territorial behavior (Smith 1976, Coblentz 1977, Peek 1980). Recently, Ozoga et al. (1982), Dusek et al. (1989), and Hamlin and Mackie (1989) demonstrated that parturitionterritoriality was an important factor in distribution, home range formation, habitat use, and population dynamics. Essentially, behavior provided the "action-link" between the animal and its environment. A major advancement in understanding population-habitat relationships was achieved by utilizing behavioral concepts.

Our results, similar to Hamlin and Mackie (1989), demonstrated that deer responded to their environment as individuals, not as $1 / \mathrm{N}$. There were no "average" deer in the population. The behavioral and biological responses of individual deer represented the cornerstone to understanding both the population and habitat components of a PHU (Fig. 10.6).

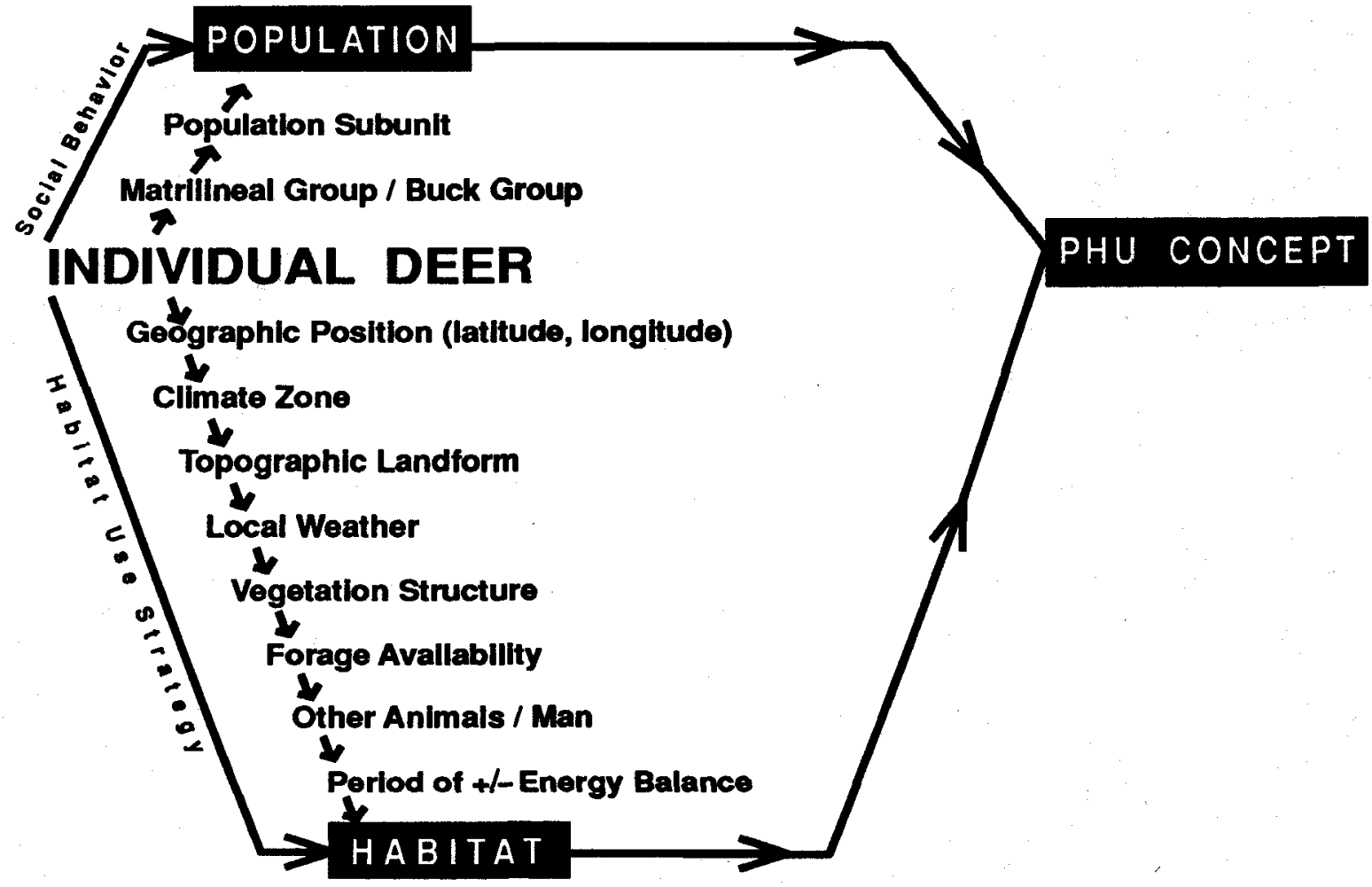

Figure 10.6. Integration of important factors in the PHU concept. 
The population component was defined by the mediating influence of social behavior. Individual deer were organized into matrilineal groups or buck groups. Aggregations or loose bands of matrilineal groups tended to form population subunits. These, in turn, comprised a discrete population associated with a particular PHU. A series of adjacent PHUs could be considered a meta-population. This term seems appropriate for the seven PHUs delineated with the Bridger Mountains.

The habitat component of a PHU was defined by the habitat use strategies of individual deer. These strategies integrated important attributes of their local environment. Collectively, a representative array of these strategies defined the relevant habitat for a particular population.

Only from a perspective based on the PHU concept can we find answers to the "whys" of mule deer distribution, movements, and habitat use. 


\section{CHAPTER 11}

\section{POPULATION DYNAMICS}

This chapter begins with a discussion of habitat factors that influenced size and composition of mule deer populations in the Bridger Mountains. Later, we examine the contributions of reproduction, mortality, emigration, and immigration to the temporal dynamics of populations. Adult females, adult males, and fawns responded differently to extrinsic (environment-related) and intrinsic (animal-related) factors. This occurred because of individual variation in social behavior, distribution patterns, habitat use, and physical condition. As suggested earlier, there were no "average" deer in the population. Demographics and dynamics represented the sum total of the performance and fates of all individual members. We conclude the chapter with our perspective of mule deer population regulation in the Bridger Mountains.

\section{Habitat Factors Affecting Population Size and Composition}

In northern Rocky Mountain environments, deer populations require both reproductive and winter-maintenance habitats. The amount and quality of reproductive habitat influenced the potential number of adult females associated with PHUs in the Bridger Mountains. These habitats were critical to successful fawn-rearing and allowed maternal does to recover physical condition at the same time. During summer, allocation of these habitats among maternal females was accomplished through behavioral mechanisms, especially parturition territoriality. Maternal aggression directed toward other deer at parturition resulted in segregation of adult males and some unproductive females into maintenance habitats.

These patterns were in sharp contrast to behavior during winter when deer aggregated in groups on restricted winter range. Specializations in behavior and habitat use during winter were directed toward energy conservation and survival rather than segregation and allocation of resources among individual deer.

Quantity and quality of winter-maintenance habitat appeared to exert comparatively less effect than amount and quality of reproductive habitat on total numbers of deer in a particular PHU. Rather, these habitats represented a "holding area" where deer congregated to survive the rigors of winter. Interrelationships between length and severity of the winter and deer energy reserves influenced rate of over-winter survival. Winter forage supplemented and reduced the rate of utilization of energy reserves. 
Without ample amounts of winter-maintenance habitat, few deer would survive yearlong. However, because deer are behaviorally and physiologically adapted to tolerate much higher deer densities in winter, total numbers of deer in a PHU will gradually reach a level dictated by the quantity and quality of summer reproductive habitat associated with a winter range. In the Bridger Mountains, varying quantity and quality of summer habitats resulted in widely varying numbers of mule deer associated with winter ranges. Those numbers could not be directly correlated with kinds and amounts of winter forage or other characteristics of winter ranges.

For example, the largest average number of deer associated with any $\mathrm{PHU}(2,100)$ occurred in PHU 4 where large units of reproductive and winter-maintenance habitat were directly adjacent (Fig. 10.5). In PHU 3, a much smaller population $(\overline{\mathrm{X}}=800$ ) was associated with a winter range of size and quality similar to PHU 4. Patchy reproductive habitat of lower quality was responsible for the smaller population. Another unit (PHU 2) similar in numerical size $(\overline{\mathrm{X}}=820)$ to PHU 3 was associated with a winter range only one third as large and located in a more severe environment. Total summer range in PHU 2 was also comparatively smaller, although reproductive habitats apparently were of higher quality than found in PHU 3. In PHU 5 (Fig. 10.4), a significant proportion of non-habitat contributed to the large physical size of the unit. The modest number of deer in PHU 5 was related to limited amounts of reproductive habitat. Population size in three other PHUs could be generally explained in a similar manner. Therefore, deer density was highest in PHUs with the greatest proportional occurrence of reproductive habitats. Mountain-foothill environments often include larger contiguous tracts of reproductive habitat compared to river breaks (Hamlin and Mackie 1989) or prairie environments (Wood et al. 1989).

Mule deer populations in the Bridger Mountains exhibited more stable trends than populations occupying more variable northern plains environments (Hamlin and Mackie 1989, Wood et al. 1989). This stability resulted from consistently high annual fawn losses largely offset by consistently low mortality among adult females. The adult male segment displayed greater annual variation compared to females. However, the impact of that variation on population trend was dampened by the numerical superiority and greater longevity of the female segment.

The relative availability of reproductive, winter-maintenance and summermaintenance habitats may have contributed to differences in adult sex ratios between PHUs on the east and west slope. However, sex ratios were influenced by a number of factors and the effect of habitat was difficult to ascertain. Further investigation is needed to test the hypothesis that high average male:female ratios in PHU 1 is related to greater availability of summer-maintenance habitats. These habitats were used almost exclusively by adult males and unproductive females.

In PHU 4, bucks may have been relegated in summer to small areas of temporarily vacant reproductive habitat or limited localities within the winter-maintenance 
habitat. Summer maintenance habitat was lacking. The limited buck habitats could become "filled" rather quickly. Young males wandering in search of the limited buck habitat would frequently encounter aggressive maternal females. Such encounters could lead to a greater incidence of male emigration from PHU 4. However, it is also possible that higher rates of predation could also have accounted for reduced survival of bucks.

Strategies of deer habitat use apparently affected the age composition of some populations. In west slope PHUs, a significant proportion of adult females survived to older age classes (10 years and older). Deer in these populations contended with a prolonged energy deficit during winter by conserving their energy reserves. The drain on adult female physical condition as a result of prolonged winters contributed, in turn, to characteristically high mortality in the subsequent fawn crop. Lactation stress associated with rearing young to weaning age constituted a further drain on physical condition (Short et al. 1969, Clutton-Brock et al. 1982, Hamlin and Mackie 1987). Early fawn loss relieved females from lactation stress and provided opportunity for recovery of condition. This probably contributed to an enhanced potential for survival during the subsequent winter. The potential for adult female survival apparently was more closely related to reproductive history than chronological age.

Adult females in east slope PHUs were typically younger and collectively constituted an age structure similar to those reported for other Montana mule deer populations (Hamlin and Mackie 1989). This younger age distribution apparently resulted from a combination of relatively high reproductive and mortality rates among adults. Because east slope populations spent significantly less time on winter ranges and followed a more generalized strategy of winter habitat use that included greater mobility associated with forage gathering, they apparently experienced shorter periods of energy deficit. Differences in female age structure between west and east slope populations were largely related to these natural factors because hunting mortality annually removed less than three percent of the females in either population during the study.

Age structure of adult males was significantly less stable. Lower natural longevity, higher hunting mortality, and periodically very low recruitment resulted in pronounced peaks and troughs in the male age structure. Compared with adult females, the loss of a single cohort through high fawn mortality had much greater impact on male numbers and age structure because the male segment usually contained less than half as many year classes as the female population.

A stable age distribution can develop and persist in a population only with relatively constant natality and mortality (Andrewartha and Birch 1954). Obviously, this concept was not applicable to mule deer populations in the Bridger Mountains or to most long-lived species (Miller 1976, McCullough 1979). Bayliss (1987) concluded that unstable age distributions and imbalanced sex ratios favoring females were not temporary aberrations in kangaroo populations, but "part and parcel of the boom and bust of juvenile recruitment in arid environments." We extend this generalization to mule deer 
populations occupying winter-variable environments. Hamlin and Mackie (1989) reached a similar conclusion for mule deer occupying an environment exhibiting substantial variation during both winter and summer.

\section{Reproduction and Juvenile Mortality in Mountain Environments}

Ovulation rates in the Bridger Mountains were higher than reported for other Montana mule deer populations (Nellis 1968, Eustace 1971, Pac 1979, Hamlin and Mackie 1989). However, the high ovulation rate was consistent with a pattern of fawn loss during summer which allowed females to recover physical condition and achieve high ovulation and conception rates during the autumn rutting season (Verme 1969). Females that successfully weaned fawns may not have fully recovered from the strain of nursing in the short time available before commencement of the rut, and may thus be less productive, at least initially. Clutton-Brock et al. (1982) concluded that red deer hinds with young put on little fat during the summer despite an abundance of food, and by autumn they were in substantially poorer condition than hinds without calves. Generally, this disparity in productivity among non-lactating and maternal does may virtually balance out (Verme 1967) resulting in an average rate that obscures the underlying relationship.

Although ovulation was high, fetal rates were lower than other Montana mule deer populations. Females $\geq 9$ years made up a significant proportion of the female segment in west slope PHUs. They produced only $56 \%$ as many fetuses as 2-8 year olds. In red deer, calf birth weights declined among hinds over 9 years of age and negatively impacted subsequent calf survival through summer. Although this may partially explain summer fawn losses on our west slope study area, age-specific reproductive data indicated substantial losses also occurred among fawns of prime-aged does.

Variation in female physical condition may also influence observed patterns of post-partum survival in Bridger Mountain populations. Non-lactating does that became pregnant were probably in better physical condition and better able to withstand energy deficit in winter than does which reared fawns prior to breeding. Such does might also be expected to give birth to heavier fawns that have a better chance for survival. Other studies have shown a close relationship between ungulate birth weight and probability for survival through the summer (Clutton-Brock et al. 1982).

Among successful mothers, lactation stress may reduce subsequent reproductive performance resulting in an apparent pattern of alternate-year post-partum reproductive success (Mundinger 1981). Our data on productivity of marked females during summerautumn indicated that this phenomena occurred in west slope populations. However, factors such as predation or annual variation in the length of energy deficits that also acted on fawn survival could obscure this pattern. 
Reduced reproduction and high rates of fawn loss are common in some deer populations in northern environments (Ransom 1967, Verme 1969, Fuller 1990). In some areas, this has been attributed to chronic malnutrition resulting from food shortages caused by overuse of the range (Verme 1969). In other environments, the length of the winter energy deficit has been considered the causative factor because mortality occurred in spite of adequate forage supplies that showed no evidence of overuse (Ransom 1967). This seems to be the case on our study area where mortality occurred when energy reserves were exhausted before plant growth raised forage quality above sub-maintenance levels.

Trends in annual fawn mortality generally preceded trends in total population size by one year. Annually, mortality removed about $73 \%$ of potential production in PHU 1 and $65 \%$ in PHU 4. These rates were comparable to those reported for other mule deer populations (Hamlin and Mackie 1989, Wood et al. 1989), although initial production was higher in those populations. Higher rates of annual mortality were reported for white-tailed deer during population declines (Wood et al. 1989, Fuller 1990).

Seasonally, fawn loss during summer-autumn accounted for an average $75 \%$ of total annual losses and removed $55 \%$ of potential productivity in west slope populations. Similarly high seasonal fawn mortality rates have been reported for mule deer elsewhere (Hamlin and Mackie 1989, Wood et al. 1989).

We were unable to specifically identify causes of natural mortality during summer-autumn. Much of the fawn loss may have been caused by poor adult female physical condition. These losses would have most likely occurred early in summer. However, our data only provided an estimate of overall fawn mortality rate through the entire six month summer-autumn period.

Other factors such as predation were known to occur throughout summer and autumn. The Bridger Mountains supported a diversity of effective predators including coyotes, mountain lions, and black bears. Their effect on early fawn loss, though not quantified, may have been significant in some habitats and could have occurred regardless of the physical condition of adult females and their fawns. Hamlin and Mackie (1989) reported that coyote predation was the major cause of death among fawns during summer. A confounding effect of several mortality factors operating in concert may explain why instantaneous rates of fawn loss for this period were not significantly correlated to severity of the previous winter. Losses attributed to hunting were insignificant and accounted for less than $4 \%$ of autumn fawn numbers in PHU 1 over a 12-year period.

Limited data suggested that social relationships among adult females during summer may have provided an additional mechanism that dampened reproductive output and limited potential for high annual rates of increase. On the west slope, long-lived 
adult females persisted at high density within areas of good quality reproductive habitat. Social competition apparently occurred among adult females in these habitats as evidenced by use of accessory areas during the 30-day period of maternal aggression. Where high adult densities prevailed, the youngest producing females may have been consistently relegated to poorer quality habitats where reproductive output was low. Some of these individuals may have acquired better reproductive resources later in life through attrition of dominant matriarchs. Dusek et al. (1989) concluded that reduced fawn-rearing success by two- and three-year old white-tailed does was related to increased social competition among females at high density in a river-bottom habitat with a relatively stable summer environment.

We speculate that dominant matriarchs are prone to occupy the best reproductive habitats. If so, the length of time they maintain dominance could influence trends in productivity within long-lived female populations such as PHU 1. Our data showed a substantial decline in fetal rates among females older than nine years. If significant numbers of older females retain their dominant social status in a population, an increasingly greater proportion of prime-aged females would be relegated to poorer quality reproductive habitats. Although prime-aged females are inherently more productive, they may be decidedly disadvantaged in rearing fawns in poorer quality habitat. This could explain the proportionately large fawn losses from summer to early winter among prime-aged females as indicated from age-specific rates.

It may be more than coincidental that the much higher than normal fawn crop in early winter 1978-79 was born to a female segment containing very few older-age individuals. During the previous severe winter, the population was "purged" of most older females. For a few years, the most productive age classes had exclusive use of the best reproductive habitats. However, these increases in productivity were not sustained to recruitment age because those cohorts suffered above average rates of over-winter mortality. An experimental removal of dominant matriarchs older than nine years might be conducted for several years to test if increases in productivity would be sustained.

Age of females occupying core reproductive habitats may have been more important in influencing productivity to early winter than total density of females at the start of summer. Adult female numbers on 1 June were not correlated $(r=-0.212)$ with the rate of fawn mortality during summer-autumn. Clutton-Brock et al. (1982) concluded also that calf mortality in summer was not related to population size.

Data were inadequate for comparison of in utero productivity and early fawn loss between the west and east slope deer. However, post-partum productivity of marked females was generally higher on the east slope throughout the biological year.

Fawn mortality during winter-spring was more readily documented. During that period in PHU 1, fawn losses accounted for about $25 \%$ of total annual mortality, significantly less than in summer-autumn. Over-winter fawn mortality rates averaged 
$39 \%$ and varied from $0-89 \%$. The mean was similar to rates reported elsewhere for mule deer (Hamlin and Mackie 1989, Wood et al. 1989) and significantly greater than recorded for white-tailed deer (Dusek et al. 1989). However, variation in over-winter fawn mortality rates $(\mathrm{CV}=0.62)$ was higher in PHU 1 than reported for other studies because survival over winter-spring was significantly correlated to an index of winter severity. Not surprisingly, large residuals in this relationship reduced its predictive value.

In PHU 4, the relationship between winter severity and fawn mortality was not significant. Overwinter mortality rates varied from $0-55 \%(N=9, \bar{X}=24 \%)$ which was less than PHU 1. A shorter period of energy deficit and a winter habitat use strategy that emphasized forage gathering may have minimized fawn losses caused by malnutrition during all but the most severe and prolonged winters in PHU 4.

Recent investigations (Pac, unpublished data) indicate that coyote predation may be a significant fawn mortality factor during winter-spring on east side ranges; winter mortality predominated on the west slope. This dichotomy in cause of mortality may contribute to the lack of a relationship between winter severity and fawn mortality on PHU 4. White et al. (1987) described similar differences in cause of fawn mortality on adjacent winter range segments.

We can speculate on other interactions operating less directly that may also contribute to higher over-winter fawn survival in east slope PHUs. Earlier average departure from winter ranges by adult females in conjunction with more rapid advancement of plant growth across the unit may have resulted in a better nutritional plane during the last trimester of pregnancy. This could have resulted in heavier fawns born earlier that may have resulted in higher growth rates during summer. Additionally, fawns in east slope populations remained on summer range for a longer time period than fawns on the west slope. Further investigation is required to test for differences in fawn weights in early winter on west and east slope ranges.

Other studies have identified numerous variables that interacted to influence overwinter juvenile survival. Clutton-Brock et al. (1982) concluded that birth date in red deer was significantly correlated to winter survival. Late-born calves were lighter at the onset of winter and more likely to die. Median birth dates on our west slope study area were later than reported by Hamlin and Mackie (1989). Calving dates were specifically later among old red deer hinds and generally later in higher density populations (CluttonBrock et al. 1982).

White et al. (1987) indicated that weight of mule deer fawns was the best predictor of over-winter survival. However, their data suggested that not all mortality selected for small-bodied fawns. Variability in body size parameters was greatest for fawns taken by predators. This indicated that they killed fawns regardless of their physical condition (Hamlin and Mackie 1989). 
Clutton-Brock et al. (1982) concluded that post-partum calf growth was more closely correlated with food availability of the hind during lactation than with her body condition at the start of gestation. On our study area, differences in the quality of reproductive habitats used during summer and the length of time reproductive habitat was occupied could exert a substantial effect on post-partum fawn growth rates. Thus, the probability of a fawn surviving winter may have been largely predetermined. For large fawns, survival probability was high in the absence of significant predation and if the length of the winter was not excessive.

Because of this relationship, intra-specific competition for forage on winter range was probably of secondary importance. All winter forage on our study area was of submaintenance quality (Morton 1976) and served to only slow down the slide toward exhaustion of energy reserves. Because the quantity of forage usually was not limiting, all deer may have had similar opportunity to reduce mobilization of their individual energy reserves. Correspondingly, we found no significant relationship $(N=14$ years, $r=-0.154$ ) between adult deer density at the onset of winter and the rate of over-winter fawn loss in PHU 1.

West slope populations exhibited lower average fawn recruitment rates in spring than east slope populations. Recruitment rates on the west slope were only half those reported for a mule deer population in a prairie environment (Wood et al. 1989). Recruitment in populations on the east slope of the Bridger Mountains was similar but less variable than reported for mule deer in a Missouri River breaks environment (Hamlin and Mackie 1989).

Yield, expressed as number of fawns recruited at one year of age, was poorly correlated with number of adults the previous spring. Mackie et al. (1990) provided further discussion of these data for our study area and other Montana deer populations. Generally, the lack of a dependable relationship between yield and density applied to populations occupying variable winter and/or summer environments characterized by significant energy deficit periods. Deer utilized non-cultivated forage plants during the entire year. Forage quantity was seldom limiting, although forage quality experienced seasonal declines to sub-maintenance values. Animal condition generally deteriorated substantially during annual energy deficit periods.

In all environments studied, deer density was only one of numerous factors influencing fawn survival. In the Bridgers, some factors that operated during the first year of a fawn's life included:

1) duration and quality of the energy surplus period

2) length and severity of the energy deficit period

3) age and physical condition of doe

4) weight of fawn and date of parturition

5) quality of summer and winter home ranges of doe 
6) population density

7) intensity of predation.

Other factors affecting fawn survival operated before parturition:

1) reproductive output of doe in previous year

2) physical condition of doe at onset of gestation

3) length and severity of energy deficit during gestation

4) winter habitat use strategy of doe

5) quality of seasonal home ranges of doe.

Factor interaction was dynamic; however, it appeared that length and severity of the energy deficit was most consistently important.

Mackie et al. (1990) and Dusek et al. (1989) described another Montana deer population that did display fawn recruitment rates inversely correlated with adult density. These white-tailed deer had access to high energy agricultural crops well into the period when mule deer in the Bridger Mountains were experiencing energy deficits. Consequently, animal condition was substantially less impacted by winter severity or summer droughts. This represented a completely different energetic relationship between deer and their environment than we have described for populations with little or no access to agricultural crops. In such relatively stable agricultural habitats, limitation of fawn recruitment at higher densities resulted from social competition among adult females (Dusek et al. 1989). Mortality related to energy deficits was minimized by a high nutritional plane maintained yearlong.

For our study area, density-related increases in fawn survival could possibly occur at densities lower than we observed. However, the range of densities recorded during our 15-year investigation appeared representative of fluctuations expected in that environment. As suggested by Mackie et al. (1990), it is unlikely that the public would support management actions that held deer populations below the lows we observed.

Adult Mortality in Mountain Environments

Mule deer in the northern Rocky Mountains are behaviorally and physiologically adapted to survive and reproduce in an environment where the period of energy surplus is of short duration. Even in the demanding environment of our study area, the energetic requirements for adult survival were generally met with relative ease except under unusually severe conditions. However, when energetic cost of reproduction was coupled to that of survival, the total exerted a significant effect on adult mortality patterns.

Adult females and males coped with these demands differently as revealed by sexlinked variation in distribution, habitat use, and social behavior. Many of these 
differences originated because their energetic investment in the reproductive effort peaked during different seasons.

\section{Adult Females}

Lactation during June-August represented the greatest energetic demand during the biological year. This demand coincided with a phenological peak in availability of high quality forage. Specializations in habitat use and social behavior among adult females focused on efficiently allocating resources and reducing intraspecific competition during this most critical time. Other authors have demonstrated that reproductively successful females select habitats suitable for birthing, rearing, and protecting offspring (Lent 1974), even when this may compromise foraging opportunities (Geist 1981, Jakimchuk et al. 1987). Selection of habitats with these characteristics could also lead to lower predation losses among adult females.

Our data for adult females suggested that mean annual rates of natural mortality can vary from one environment to another. For example, total mortality in PHU 1 on the west slope averaged $12 \%$ compared to $18 \%$ in PHU 4 on the east slope. During the same years, adult female harvest rates were essentially the same in both populations. Therefore, variation in total mortality between the two populations was largely a result of differences in rates of natural losses. Although these differences may not seem large, they resulted in substantially greater numbers of females surviving to older age classes in PHU 1.

During summer-autumn, adult female mortality from all causes in west slope populations averaged only about 5\% (range, 0-11\%). Natural mortality and hunting each accounted for about half of the losses. Total summer-autumn mortality averaged 2-4 fold higher among females in breaks and prairie mule deer populations (Hamlin and Mackie 1989, Wood et al. 1989). Mortality attributed to natural causes was low and similar among all three areas. Hunting accounted for the much larger remainder in the breaks and prairie populations.

Emigration represented another form of natural loss during the summer period. In west slope PHUs, female emigration was essentially non-existent. We speculate this resulted from a combination of factors. First, low recruitment provided little surplus after replacement of adult losses. Secondly, specialized habitat use patterns may have resulted in exceptionally strong bonding between members of matrilineal groups. Additionally, the summer maintenance habitats within PHUs could have functioned as dispersal sinks. Surplus animals were seldom plentiful enough to fill these localized sinks, so emigration beyond PHU boundaries was uncommon and unnecessary. Thus, west slope populations may require long periods of time to refill vacant habitat.

On the east slope, female emigration was relatively common. This was probably influenced by greater annual recruitment and surpluses of yearlings, less specialized 
habitat use strategies, and the relative absence of summer maintenance habitat/dispersal sinks in some east slope PHUs. We were unable to quantify the ultimate effect of emigration on the dynamics of the female segment. However, we suspect that emigration operated intermittently in relation to cohort size and other factors and probably was not offset by female immigration.

Hamlin and Mackie (1989) indicated that emigration of yearling females was more variable compared to males. On their study area, net female emigration occurred during the first years of increase following population declines and again during years when conditions were favorable for recruitment at high female density. This enhanced recovery from declines by refilling vacant habitats and maintained deer in these areas during favorable conditions at high densities.

Lactation demands ceased before the end of the energy surplus period in late summer. In the Bridgers, this allowed maternal females reasonable time to recover physically before the onset of the winter. This recovery contributed to the relatively low rate of winter mortality experienced by prime-aged (2-9 years) individuals. Among older females (10-16 years), winter losses increased.

During winter-spring, we documented an average mortality rate of $7 \%$ (range 0 $24 \%$ ) for adult females in west slope populations. Overwinter mortality was significantly related to winter severity. This was not surprising because the strategy of winter survival emphasized energy conservation. Utilization of energy reserves and potential for mortality increased with increasing winter severity.

Overwinter mortality of adult females averaged 5\% (range 0-12\%) and 6\% (range $1-25 \%$ ) in Montana prairie (Wood et al. 1989) and river breaks (Hamlin and Mackie 1989) populations, respectively. Winter-related malnutrition, which we define as total depletion of energy reserves, was the predominate cause of death in the Bridgers; coyote predation accounted for most adult female losses in the Missouri Breaks.

Overwinter and annual mortality rates of adult females in PHU 1 (Figs. 8.19 and 8.20) were significantly correlated with adult deer densities (see Chapter 8). This could be interpreted as the result of intra-specific competition for a limited forage resource and would imply that much of the natural loss could be replaced by legal harvest.

In Chapter 8, we provided another interpretation (p. 206-208). In summary, higher deer densities occurred in PHU 1 after mild winters because of above average survival of adults and fawns. After a few years of low mortality, greater numbers of adult females occur in older (10-16 years) age classes. This vulnerable segment invariably suffered high mortality during the next severe winter. Such mortality is not necessarily related to limited forage availability. Rather, it results from decreasing energy reserves and the inefficiency of maintaining physical condition that come with old age. Even at high densities, prime-aged (2-9 years) females experienced minimal natural 
mortality. The smaller, trimmed populations that typically followed severe winters invariably exhibited low female mortality rates regardless of the severity of the subsequent winter. This occurred because the populations consisted mostly of prime-aged animals and not because of low population density.

Because prime-aged females in this environment suffered very low rates of natural mortality, the legal harvest tended to be additive. The greatest opportunity for substituting harvest for natural mortality (compensation) is among females older than 10 years. Hunting losses, however, appeared to be biased toward the younger age classes.

Other investigators (McCullough 1979, 1990) might conclude that a consistently higher rate of harvest, particularly among adult females, would result in a substantial increase in the fawn recruitment rate. The validity of this conclusion as applied to Northern Rocky Mountain environments represents the pivotal issue of an ongoing debate (McCullough 1990, Mackie et al. 1990) concerning density-dependent compensation in deer populations.

Our data demonstrate not only limited opportunity for compensation in the adult female segment, but also that fawn recruitment patterns reflect the cumulative outcome of a number of interacting factors. Deer density represents only one of these variables and may often constitute a minor contribution to a broad ecological relationship that governs fawn production and survival in a particular environment. We consider our interpretations not as an indictment of current theory, but as part of a healthy process of providing alternative explanations to understanding deer populations in diverse, dynamic environments.

\section{Adult Males}

Peak energetic demands occurred during the rut in November and December which coincided with the beginning of the winter deficit period. This close temporal relationship between demand and deficit was unfortuitous for adult male survival, although necessary to the proper timing of the birth pulse. It contributed to their lower longevity which occurred naturally in the absence of hunting (Martinka 1978, Gavin et al. 1984, Kie and White 1985).

Lower natural longevity of males may also result from higher predation losses (McCullough 1979). Males occupy habitats where they can maximize body condition even if the risk of predation is greater in those areas (Jakimchuk et al. 1987, Main and Coblentz 1990).

Annual mortality rates of adult males on the west and east slopes averaged 46 and $66 \%$. Hunting was the predominant cause of mortality in both areas. Although data were limited, it appeared that the higher mortality rate on the east slope resulted from greater natural losses added to hunting mortality. 
Emigration apparently resulted in a significant net loss of yearling males from east slope populations. Earlier in this chapter, we speculated that this was related to habitat characteristics. Hamlin and Mackie (1989) indicated that more than $50 \%$ of yearling males emigrated each year. However, those losses were largely offset by immigration from surrounding areas as was apparently the case on our west slope study area.

Emigration of yearling males represented a consistent source of gene flow between adjacent PHUs. It also contributed to resource partitioning by maintaining male use of habitats peripheral to those used by adult females. Recent evidence (Pac, unpublished data) suggests that predation losses of all age classes of males may be greater than previously thought, particularly on the east slope. Continuing investigations will be directed to understanding the relative contributions of hunting, emigration, and predation to male mortality in the Bridger Mountains.

Mortality patterns during winter and spring indicated that yearling males and adults six years and older were particularly vulnerable during severe winters. Yearlings apparently emphasize body growth over accumulation of fat reserves while older males tend to be dominant breeders that arrive on winter ranges in very poor physical condition.

In PHU 1, male mortality rates during winter-spring ranged from 18-26\% when substantial numbers of yearlings and older males entered severe winters. However, during most years, hunting mortality was high and few males older than five years occurred in the population. Under these conditions, over-winter male mortality was lower, varying from $0-13 \%$.

Compared to adult females, few males reached the age when they were vulnerable to over-winter mortality. Therefore, legal harvest may have substituted for some bucks that could potentially have been lost to winter-related mortality had they lived to old age. In contrast, losses to predation may occur throughout the year and across all age classes of adult males regardless of their physical condition. These tend to be additive to hunter harvests.

Clutton-Brock et al. (1982) and others (Stirling 1975, Klein 1968) indicated that sex differences in mortality should be most pronounced in species where polygyny and sexual dimorphism are strongly developed. The larger sex usually experiences increased natural mortality during times of environmental stress. However, they recognized that many other factors contribute to these mortality patterns.

All studies indicating the importance of population density have focused on correlations between reproductive performance and the combined density of both sexes (Clutton-Brock et al. 1982). Botkin (1990) described other limitations of models commonly used to explain population growth. For example, he reported that logistic equations view all individuals as equally capable of reproduction, mortality, and growth. 
"A logistic individual decreases the availability of resources for its fellows regardless of how many others there are... A logistic moose responds instantaneously to changes in the size of the population; there is no history; no time lags; no seasons; a logistic moose has no fat."

Our data indicated that there were no "average" deer in the population. Social behavior, habitat use, and dynamics varied substantially between the two sexes. A separate set of variables influenced fawn production and survival. Models of population dynamics must consider these differences to improve over the relatively poor fit that currently exists between theoretical predictions and observed trends.

Patterns of fawn recruitment and adult mortality also varied among PHUs occupying different environments within our study area. The cumulative outcome of these differences was reflected in growth rate patterns (Figs. 10.16 and 10.17) that were characteristic of populations on the west and east slope. A west slope population (PHU 1) consistently exhibited low growth rates when exposed to severe winters. Initial declines were associated with mortality of fawns and old-aged adults. If severe conditions occurred in close temporal succession, then low recruitment prevailed even though adult density remained low. Population growth rates continued to fluctuate at a low level until winter conditions moderated and fawn survival improved. Consequently, growth rates rebounded and the population fluctuated at a higher equilibrium until environmental conditions again became unfavorable.

Growth rates in an east slope population (PHU 4) consistently fluctuated in a "tight" spiral where declines were usually followed by increases in the following year. This greater resiliency was primarily related to higher average recruitment that was not significantly correlated to winter severity. Additionally, the adult female segment was less vulnerable to substantial over-winter mortality because of its inherently younger age structure. Adult female mortality in this population was not synchronized to a single cause or set of circumstances as in PHU 1. In PHU 4, female mortality represented the influence of a number of factors. These were collectively sufficient to prevent the establishment of a sizeable segment of older aged females. Their absence contributed to the greater stability of population growth rates in PHU 4.

Population Regulation

Population regulation is usually divided into extrinsic and intrinsic processes. Extrinsic regulation can arise from a relationship between the animal and a limiting resource. For ungulates, this usually entails intraspecific competition for forage that operates in a density-dependent manner. However, a variety of other extrinsic factors have been considered such as other ungulates, predators, weather, and shelter. Intrinsic regulation occurs through the variable attributes of individual animals. These attributes have included territorial behavior, genetics, and physiological changes. We refer the reader to an extensive review of regulatory theory in Hamlin and Mackie (1989). 
In the past, proponents of various regulation theories tended to gravitate into opposing schools of thought. Whether extrinsic or intrinsic, most theories generally centered on single factors of control operating in a steady-state ecological system.

Botkin (1990) described the development of ecological theory during the latter part of the nineteenth century as becoming increasingly dependent on mathematical theory and models that arose from the physical sciences. These theories asserted that natural populations left alone would reach an equilibrium called carrying capacity. If disturbed, the population would diverge from carrying capacity but return to it after the disturbance was removed. This theoretical approach has pervaded all aspects of population biology.

The limitations of this approach have only recently been recognized by investigators conducting long-term research on large mammals in variable environments. For example, Hamlin and Mackie (1989) challenged the steady-state, balance of nature approach and proposed that deer populations vary in accordance with a "balance of the environment." Over time, favorable conditions that result in population growth are balanced by unfavorable conditions that result in decline. They concluded that this "channel" of variation is measurable and population fluctuations will remain within these bounds which are characteristic of a particular environment. These conclusions generally agree with Botkin (1990) who stated that ... "It is possible there can be balance without stability."

Caughley (1987) used the term "centripetal" to describe the variable ecosystem he studied in Australia. The term implied "that the forces causing temporal variation may be so powerful, continual and multi-directional that the equilibrium is seldom or never occupied." In the arid environment he studied, the system rose above randomness and achieved a tighter centripetality because of negative feedback loops. These included the interaction of pasture biomass and pasture growth and negative feedback from grazing by kangaroos.

Caughley (1987) concluded that environmental variability "can no longer be ignored as noise, it is now the signal." He indicated that concepts pertaining to ecological carrying capacity were largely an abstraction in environments with a coefficient of variation in annual rainfall in the realm of $30 \%$.

We agree with Caughley's conclusion that population dynamics in variable environments must be viewed from a different perspective. We also suggest that steadystate theories of regulation are not universally applicable to ungulate populations occupying so-called "temperate" environments of North America. We believe that environments in the Northern Rockies are more variable than previously believed. At a minimum, assessment of this variation must include both precipitation (summer drought) and winter severity. These two variables are instrumental in defining the periods of energy surplus and deficit. These variables can become additive in their effects on an ungulate population when both become unfavorable. 
Our data indicated that the "channel" of environmental variation in the Bridger Mountains was somewhat less than occurred in river breaks and prairie environments of the northern plains. However, variability and severity of conditions were often sufficient to invalidate the consistent application of steady-state theories of population regulation in this mountain environment.

Instead, regulation was accomplished through a variety of interactions between deer and their environment. Populations originate in new habitat through emigration of juveniles away from matrilineal groups. Once established, populations persist as discrete and definable population-habitat units. The mean density of deer in a PHU will be determined by stable characteristics of the habitat including geographic position, climate, topographic landform, and vegetation. All of these factors interact to determine the spatial heterogeneity of reproductive habitat, maintenance habitat, and non-habitat. Low deer density will occur in a PHU with minimal reproductive habitat even if maintenance habitat is plentiful. High density will prevail where large tracts of both habitat types occur in close proximity.

Social behavior centering on parturition-territoriality of matriarchs results in allocation of reproductive habitats among maternal females and relegates adult males and some unproductive does to peripheral areas in maintenance habitats during summer. This resource partitioning represents the basis for general distribution patterns and home range establishment. Traditional use perpetuates successful patterns. In contrast, deer behavior in winter emphasizes toleration of other deer in limited available habitats and conservation of energy reserves.

Variable characteristics of the habitat creates the dynamic environments that deer must contend with yearlong. These factors include weather, predators and other animals, and man's activities that influence habitat suitability and forage availability. The interaction of many of these factors defines the periods of positive and negative energy balance that characterized a particular environment. In the northern Rockies, the period of energy deficit can be severe and prolonged. The relatively shorter period of surplus in summer permitted deer to reproduce and recover physical condition before onset of the next deficit period.

Deer displayed a spectrum of behavioral strategies to successfully exploit these variable and complex environments. The collective sum of the "strategic choices" made by all deer in a PHU determined the demographic characteristics and dynamics of that population. 


\section{CHAPTER 12}

\section{MANAGEMENT RECOMMENDATIONS}

In northern Rocky Mountain environments, mule deer are distributed in discrete population-habitat units (PHUs). The population delineates the complete ecological unit of habitat required to sustain it. Characteristics of the habitat determine the strategy of exploitation employed by members of the population. Both habitat and strategy influence demographics and dynamics.

The PHU concept provides an ecological foundation for building a responsive approach to management. Big game managers have long recognized the need for improved alignment of natural herd units with the boundaries of administrative hunting units (Hunter and Yeager 1949, Longhurst et al. 1952). However, earlier approaches considered only seasonal distribution.

By using the PHU concept, a manager can determine where a population lives, why the population performs as it does, and how the habitat is distributed and used within the PHU. From this, it will also be possible to ascertain deer-habitat relationships and predict responses to habitat changes and impacts.

We recognize that data collection by management personnel are limited by money, time, and priority. Intensive data collection can only be justified for top priority populations. However, even management of moderate intensity will require basic information on population size, composition, seasonal distribution, and general habitat characteristics. A detailed discussion of population monitoring is summarized in earlier Montana Deer Study reports (Mackie et al. 1980, 1985) and will not be repeated here. Additionally, Hamlin and Mackie (1989) provided a detailed review of existing management theory and application. Our recommendations will specifically apply to the mountain environments of west-central and southwestern Montana, but may have general application elsewhere.

Population Management

1. We recommend that managers use a "tracking" harvest strategy (Caughley 1977) that reflects changes in population size and composition. This is most efficiently accomplished by annual population monitoring and issuing specific numbers of tags for harvest of antlerless deer. 
2. Maximum sustained yield (MSY) concepts are not applicable to management of mule deer populations in mountain environments. Net recruitment was poorly correlated to deer density. Other factors, such as severity of the energy deficit and predation, are instrumental in their influence on net recruitment.

3. Managers cannot assume that legal harvest will compensate for natural mortality among all sex and age classes. For adult females, there is limited potential for substitution of hunting for natural losses because the annual rate of natural mortality is low. Substitution would occur if the specific animal that was harvested was in poor condition and predisposed to die in the subsequent winter. Among adult males, natural mortality rates are higher so the opportunity for substitution is greater. The very high annual mortality of fawns to natural causes provides a significant potential for replacement of these losses with harvest. However, the logistics of applying this in the field situation may be impractical.

Compensation between hunting and natural mortality was limited because competition for food played a minor role in governing the dynamics of survival and mortality in this environment. In summer, competition for food was negated by behavioral spacing of individual home ranges and subsequent allocation of resources. In winter, all forage was of sub-maintenance value. Survival was governed by the adequacy of the energy reserves a deer brought to the winter range and the length and severity of the winter season. The reader should note that we are not saying that nutrition was unimportant to survival. Rather, competition for nutritious food was minimized throughout the year by the factors discussed above.

4. Management goals should be established for size and composition of important populations. The hunting season structure should be flexible enough so that annual adjustments can be made to achieve and maintain the management goal. Opportunity for adult female harvest is based on the annual surplus provided by net recruitment. In west slope populations, female fawn recruitment varied from $2-25 \%$ as a percentage of the female segment compared to $10-36 \%$ on the east slope. However, natural mortality rates of adult females also need to be considered because much of this will be additive to hunting harvest. When hunter harvest and natural mortality exceed recruitment, then the population will decline.

The adult male segment is numerically smaller than the adult female segment. Therefore, males can sustain higher mortality rates before experiencing decline because recruitment is proportionally higher. However, hunting loss was sufficient to cause declines in the adult male segment during 6 of 14 years on our west slope study area. Over-winter mortality resulted in a decline only during 1 of 14 years.

5. Harvest objectives should emphasize removal of a "thin slice" across the distribution pattern of all sex and age classes. In reality, this is extremely difficult to accomplish. Deer harvest was unevenly distributed across our study area (Figs. 12.1 and 
12.2) which encompassed the entire $2000 \mathrm{~km}^{2}$ Bridger Range. This resulted from a patchy hunter access pattern created by private land, heavily roaded public land, and roadless areas. Deer in some drainages were heavily harvested while others were essentially unexploited. These patterns in kill distribution did not vary significantly from one year to the next or between antlered and antlerless deer (Figs. 12.1 and 12.2).

In mountain environments, recruitment and female emigration rates are characteristically low. For drainages where deer have been heavily harvested, recolonization may occur very slowly. This problem becomes critical when it involves population segments with highly specialized movements to distantly located summer ranges. In numerous western Montana mountain ranges, entire population segments may have been essentially eliminated during the heavy harvest of the 1950 s and 1960 s. Clutton-Brock et al. (1982) cautioned that harvest of ungulate species that form matrilineal groups and exhibit low rates of female emigration must be carefully regulated with respect to its rate and distribution. "If they are over-culled in one locality and under-culled in another, they are likely to be slow to redistribute themselves and the total population will decline".

6. Special buck management strategies will be successful only if they are tailored to the ecological characteristics of specific populations. Some populationhabitat units may naturally provide better opportunities for production and availability of mule deer bucks. We have some evidence that the sex ratio in some populations can be biased toward males at recruitment under severe conditions. We speculate that habitat characteristics within some PHUs may result in lower net emigration of young males. However it may be difficult to "stock-pile" mature bucks because of high natural mortality rates.

Any buck management strategy that involves raising older, large-antlered males will require a substantial reduction in the current rate of harvest. Trade-offs in monetary expense and loss of hunter opportunity must be clearly understood and defined for the public before a buck management strategy is implemented. Only populations with the ecological potential for this form of management (i.e, sustaining relatively high buck:doe ratios and a full compliment of age classes) should be selected. A comprehensive population monitoring plan should be in place to evaluate the season effectiveness.

Habitat Management

1. Management of mule deer winter ranges should emphasize their importance as maintenance habitats where deer conserve energy. The location and occurrence of winter ranges are very site specific and relate to special conditions of climate and topography. Forage characteristics are often of secondary importance to topographic characteristics and/or conifer timber stands that ameliorate temperature and snow depth. Timber management should emphasize retention of conifer timber stands on winter ranges. 


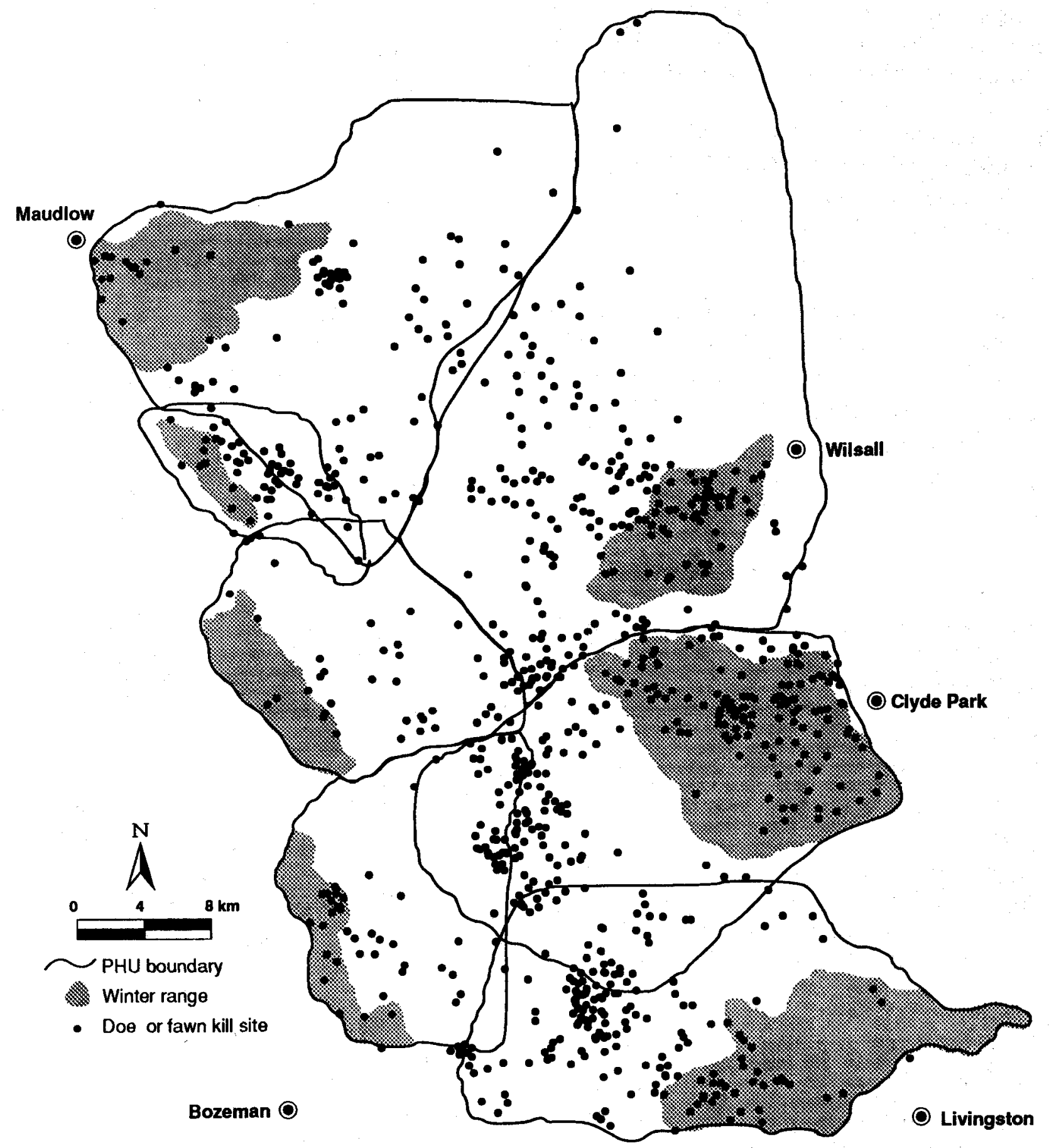

Figure 12.1. Distribution of mule deer does and fawns killed by hunters in seven PHUs during 1982-1985. 


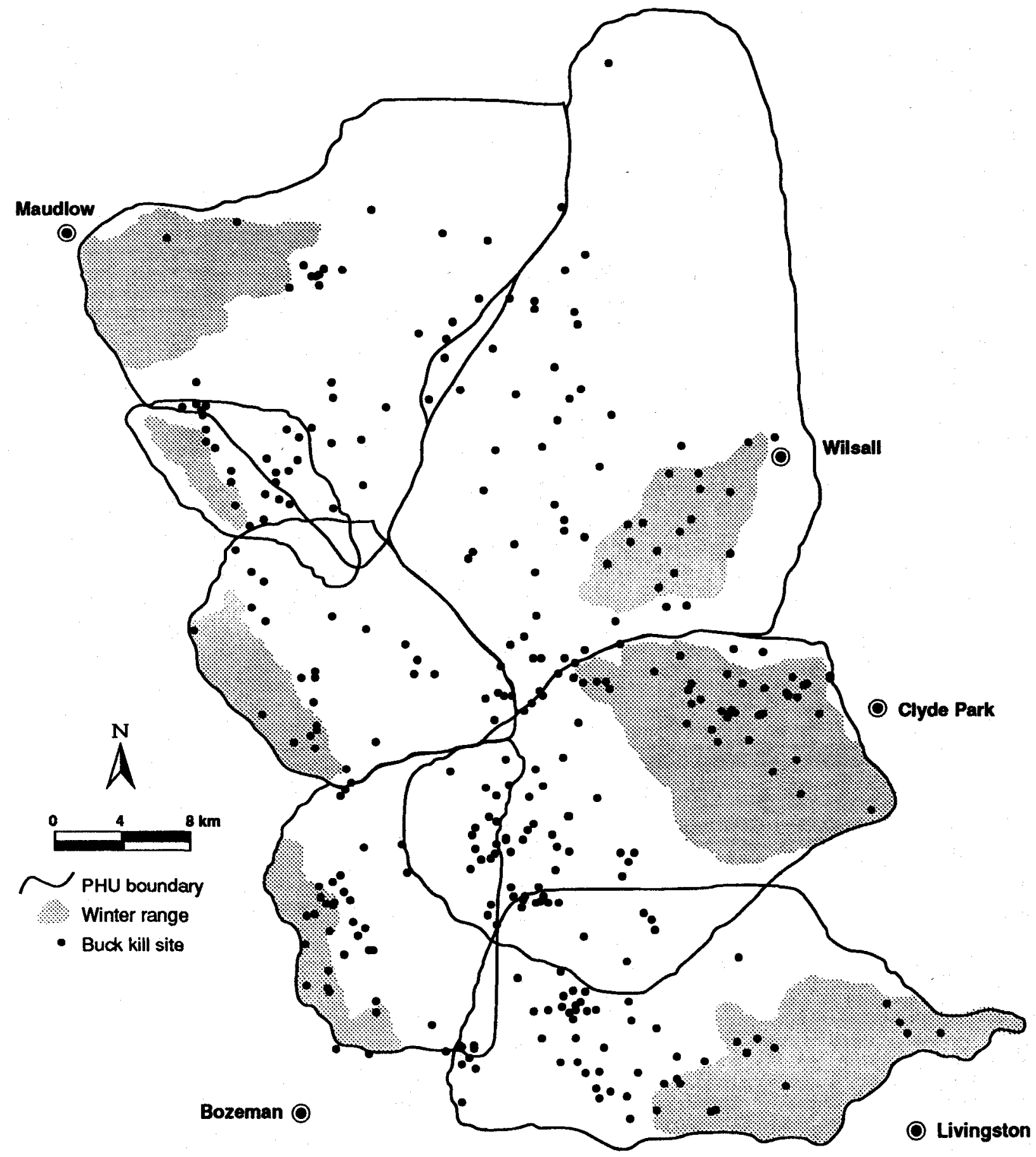

Figure 12.2. Distribution of mule deer bucks killed by hunters in seven PHUs during 1982-1985. 
2. Management should emphasize the out-right acquisition or use of conservation easements to secure important winter ranges. Rural housing developments are becoming an increasingly significant impact on many mule deer winter ranges in western Montana.

3. Management of mule deer summer range should emphasize perpetuation and enhancement of small-scale habitat diversity. Summer range characteristics will basically regulate the total numbers of deer associated with a particular PHU. The interaction between habitat diversity and mule deer social behavior will determine how many parturition territories are available. Maternal aggression toward other deer will result in the use of maintenance habitats by adult males and unproductive females, particularly at higher population densities. In mountain environments, the montane forest, especially mature or over mature (150-300 years) Douglas fir stands, provide critical reproductive habitats. These stands have irregular overstory canopies that promote a patchwork of understory diversity. High quality forage resources and security for fawn-rearing occur in an optimal combination in diverse and topographically complex montane forest communities. Removal of small scale habitat diversity through large scale cutting units will reduce the number of deer home ranges that can be supported.

Timber management should avoid large scale removal of these stands and insure that harvest strategies allow for regenerating stands to reach the age where these attributes are replaced in the system.

Where timber harvest is considered compatible with mule deer management, cutting units should focus on large, even-aged stands of lodgepole pine. Units should be small (1-5 acres) and irregularly shaped to maximize edge-effect. They should be loosely distributed across large stands to avoid reduction in habitat security. Dense, even-aged lodgepole stands are important habitat components providing security for mule deer during the autumn hunting season.

4. Access should be given priority consideration in management of mule deer populations and their habitats in mountain-foothill environments. Road construction often associated with timber management represents a "two-sided issue" for mule deer management. Some access is required and enjoyed by hunters and other recreationists. When the location and use of roads are carefully managed, they can improve mule deer harvest distribution. Conversely, when road networks are constructed in mountain environments without regard for deer management, they become a significant impact on habitat quality and hunter opportunity.

5. Habitat management criteria and objectives designed for elk are not applicable to mule deer. In mountain environments, mule deer habitat use is highly specialized and focused on traditional use of small $\left(<2.5 \mathrm{~km}^{2}\right)$ seasonal home ranges. This limited mobility compared to elk restricts their opportunity to respond to habitat changes or impacts. 
6. Current patterns of livestock grazing, particularly on winter range in the Bridger Mountains, do not appear to have a significant impact on habitat values for mule deer. The greatest potential for impact probably centers on summer ranges and on the quantity and quality of reproductive habitat. Currently, grazing in many mountain drainages is limited, and focuses primarily in drainage bottoms and areas of low topographic relief. Mule deer seem to prefer other areas with greater topographic complexity where vegetative diversity is prevalent. If summer-long livestock grazing were intensified over large areas of highly diverse Douglas fir stands, both the amount and quality of these areas as reproductive habitats for mule deer could decline.

7. The importance of accessory areas to mule deer occupying mountain environments must be recognized and incorporated into management plans. Five types of seasonal accessory areas were used by individual deer to satisfy temporary resource deficiencies experienced on normal seasonal home ranges. These areas represented subtle yet very important components of a successful habitat use strategy. Their existence became known only through intensive, long-term monitoring of individual deer. Often deer only used these areas for relatively brief time periods during a period of environmental stress.

These small areas could easily be eliminated through various habitat impacts as a result of poor management or because of a lack of knowledge of their existence. This loss would have dire consequences to the survival of some individual deer. Accessory areas can easily become sacrifice areas in the habitat trade-offs that occur between management agencies. Gradually as habitat alteration and resource extraction intensify, these seemingly subtle and unimportant losses can result in long-term declines in populations and the quality of their habitats. Preservation of diversity should be the "hallmark" of habitat management for mule deer. 


\section{Appendix A}

\section{ENVIRONMENTAL CHARACTERISTICS OF MULE DEER POPULATION- HABITAT UNITS IN THE BRIDGER MOUNTAINS, MONTANA}

Topographic, climatic, and vegetational characteristics of the Bridger Mountain study area and the seven deer population-habitat units (PHUs) were generally described in Chapters 3 and 4, respectively. This appendix provides additional data and discussion of environmental differences among PHUs.

Topography

In the Bridgers and among PHUs, topographic relief was directly related to elevation; the higher the area, the greater the relief and vice-versa. PHUs 1, 2, and 7, which straddle the main Bridger Divide, were higher in elevation (Table A1) and included more area in the three highest topographic relief classes than the other four units (Fig. A1). Among the latter, PHU 6 centered on a moderately high ridge that included Horsethief, Red Rock, and Hatfield Mountains. Thus, while slightly lower and with less relief than PHUs 1, 2, and 7, this unit was higher and rougher than PHUs 3, 4, and 5 along the east slope proper. PHUs 3 and 4, which extended eastward from the moderately low and gentle Bangtail Ridge across large, generally flat or rolling expanses, were almost identical in elevation and roughness and lowest overall.

Table A1. Mean and extreme elevations for yearlong and winter ranges for seven PHUs in the Bridger Mountains.

\begin{tabular}{lccc|ccc}
\hline & \multicolumn{3}{c}{ Yearlong Range } & \multicolumn{3}{c}{ Winter Range } \\
\cline { 2 - 7 } & Mean & Min. & Max. & Mean & Min. & Max. \\
\hline PHU 1 & 2,084 & 1,460 & 2,947 & 1,758 & 1,460 & 2,335 \\
PHU 2 & 1,935 & 1,521 & 2,793 & 1,745 & 1,521 & 2,190 \\
PHU 3 & 1,818 & 1,372 & 2,427 & 1,606 & 1,372 & 1,952 \\
PHU 4 & 1,822 & 1,411 & 2,433 & 1,611 & 1,411 & 2,079 \\
PHU 5 & 1,716 & 1,512 & 2,295 & 1,689 & 1,536 & 2,136 \\
PHU 6 & 1,857 & 1,366 & 2,555 & 1,586 & 1,366 & 1,951 \\
PHU 7 & 2,010 & 1,585 & 2,555 & 1,818 & 1,634 & 2,042 \\
\hline
\end{tabular}



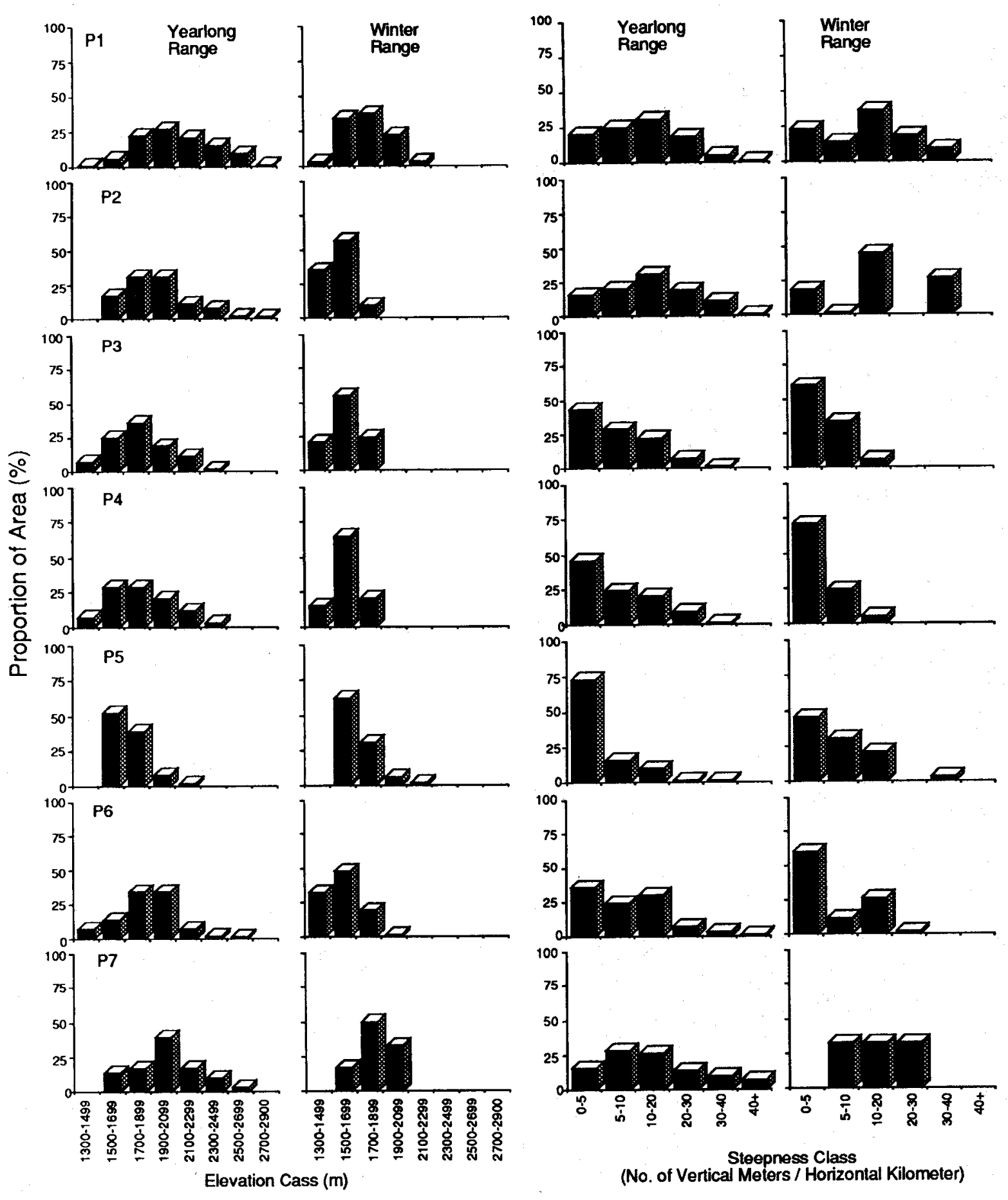

Figure A1. Proportion of surface area of yearlong and winter range in each PHU within each elevation and topographic relief class. Frequency distributions of elevational classes across each PHU were calculated from elevations recorded at $1-\mathrm{km}$ grid intervals on topographic maps. Topographic relief class was calculated as the relative amount of elevational change between $1 \mathrm{~km}$ grid points in an east-west orientation. 
Elevations were distributed somewhat normally over a relatively wide range in all but PHU 5 (Fig. A1). Most of PHU 5 fell within an elevational range of 1,500-1,699 m. The only substantial topographic relief occurred along Battle and Elkhorn Ridges. The remainder of the unit consisted of wide, flat valleys and low hills which resulted in lower average relief than other PHUs.

Winter ranges tended to be clumped within narrow elevational bands (Fig. A1). Winter ranges with the greatest elevation and relief (PHUs 1, 2, and 7) occurred along the west slope.

Mean elevation of winter range was much lower than the yearlong mean for all units except PHU 5 where elevation of the winter range was similar to that for yearlong range. Winter ranges of PHUs 3, 4, and 6 were almost identical in mean elevation as were yearlong ranges (Table A1). Topographic relief on winter range was nearly as great or greater than on yearlong range for PHUs 1, 2, and 7 (Fig. A1). Winter ranges in PHUs 3 and 4 had the least relief while those in PHUs 5 and 6 were intermediate.

The amount of each winter range comprised of steep (20-30 ) and very steep $\left(>30^{\circ}\right.$ ) slopes of southerly (SSE to WSW) aspect was also measured and compared (Table A2). Winter ranges along the west slope (PHUs 1, 2, and 7) had both the greatest total area and highest percentage of total area in these categories. The greatest total area of both steep - very steep southerly slope occurred in PHU 2. The greatest percentage of winter range on steep-very steep slopes was in PHU 7.

Although the total amount of area in steep-very steep southerly slopes on winter range in other PHUs may equal or exceed the total amount on west slope ranges, steepvery steep southerly slopes always comprised only a small percentage of the total winter range in PHUs 3 - 6 (Table A2). Of the four east slope winter ranges, PHU 3 contained the greatest amount of steep-very steep southerly slopes, while PHU 6 included the least. PHU 5 was generally similar to PHU 6, whereas PHU 4 was more similar to PHU 3.

Climate and Weather

\section{Temperature}

Temperature patterns and differences among PHUs in summer and fall (Table A3) were primarily functions of elevation. PHUs 1, 2, and 7 along the main Bridger Range were higher and comparatively cooler than their counterparts along the east slope.

Temperature patterns and differences during winter were more complex. Generally, higher temperatures prevailed at elevations near the mean on west slope (PHUs 1, 2 and 7) as compared with east slope ranges (PHUs 3, 4, 5 and 6). Winter temperatures on winter range in PHUs 1 and 2 in particular were significantly higher than on winter ranges in PHUs 3, 4, and 5 even though the latter were lower in 
Table A2. Availability of steep and very steep slopes of SSE-WSW aspect on winter range within seven PHUs in the Bridger Mountains.

\begin{tabular}{|c|c|c|c|c|}
\hline & \multicolumn{2}{|c|}{$\begin{array}{c}\text { Steep } \\
20-30^{\circ}+\end{array}$} & \multicolumn{2}{|c|}{$\begin{array}{c}\text { Very Steep } \\
>30^{\circ}+\end{array}$} \\
\hline & $\mathrm{km}^{2}$ & $\%$ & $\mathrm{~km}^{2}$ & $\%$ \\
\hline \multicolumn{5}{|c|}{ West Slope } \\
\hline PHU $1^{1}$ & 2.96 & 9.5 & 2.14 & 6.9 \\
\hline PHU 2 & 9.22 & 37.4 & 3.01 & 12.2 \\
\hline PHU 7 & 5.62 & 50.4 & .23 & 2.0 \\
\hline \multicolumn{5}{|c|}{ East Slope } \\
\hline PHU 3 & 4.57 & 4.8 & .96 & 1.0 \\
\hline PHU 4 & 3.11 & 2.3 & .77 & 0.6 \\
\hline PHU 5 & 1.60 & 3.1 & .06 & 0.1 \\
\hline PHU 6 & 1.02 & 1.4 & .12 & 0.2 \\
\hline
\end{tabular}

' Percentages for PHU 1 were based on a total winter range area that included $19.6 \mathrm{~km}^{2}$ of flat terrain used only during spring and early winter. If excluded, the percentage of primary winter range in steep and very steep categories would total $\mathbf{4 1 . 8 \%}$

elevation. This may have reflected the cooling influence of relatively shallow arctic air masses that sometimes covered the east side ranges without penetrating the Gallatin Valley to the west. Strong solar heating of the steep southerly aspects on PHUs 1 and 2 may also have contributed.

The frequent occurrence of downslope "chinook" winds along the east side rendered temperature inversions relatively rare along the Shields and Yellowstone River Valleys. There, midwinter temperatures did not decline rapidly with elevation from the relatively high weather stations on winter range to the near valley bottom location of the Livingston weather station. In contrast, along the west slope there was a $1.7^{\circ} \mathrm{C}$ difference in mean daily temperature during January between the weather station on winter range in PHU $2(1,645 \mathrm{~m})$ and the MSU station $(1,478 \mathrm{~m})$ and a $2.8^{\circ} \mathrm{C}$ difference between the Bozeman and Belgrade weather stations $(1,353 \mathrm{~m})$. Although mild "chinook" winds may have increased winter temperatures in the vicinity of Livingston (PHU 3), they were not sufficient to overcome other factors which resulted in overall lower temperatures on east slope winter ranges.

Temperatures on winter range in PHU 6 were significantly higher than other east slope as well as west slope ranges. Like the west slope, PHU 6 was generally protected from cooling by shallow arctic air masses that influenced lower temperatures on winter ranges along the east slope. However, the area was generally lower in elevation and less influenced by temperature inversions than west slope ranges. 


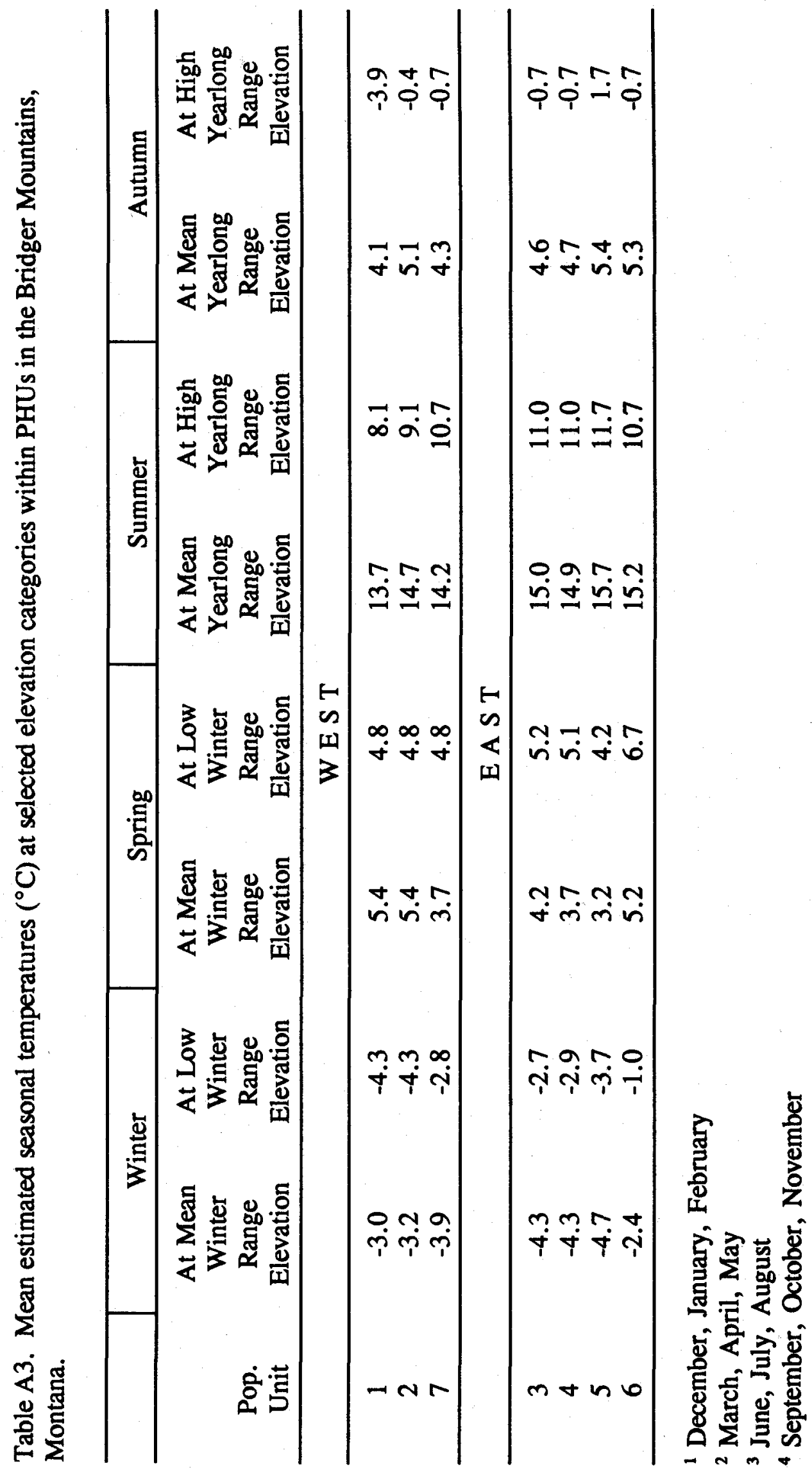


Among west slope ranges, PHU 7 which was highest in elevation, had the lowest mean winter temperature at mean elevation; higher temperatures prevailed in the lowest reaches of the area. In contrast, mean temperatures were warmer at mid elevations than at low elevations on winter ranges in PHUs 1 and 2.

In spring, the effects of temperature inversions and other factors diminished, and differences in mean temperatures between east and west side winter ranges were less. Also the temperature difference between middle and lower reaches of winter ranges in PHUs 1 and 2 became smaller. In general, temperature differences tended toward the summer-autumn pattern of primarily elevational effect.

Mean minimum and mean maximum daily temperatures at our weather stations (Table A4) indicated that winter ranges on the east slope were characterized by greater daily variation as well as generally lower temperatures than west slope winter ranges. This was influenced largely by differences in minimum daily temperatures. Mean minimum daily temperatures on winter ranges in PHUs 3 and 4 were significantly lower than those at stations of similar elevations in PHUs 1 and 2. Mean maximum daily temperatures were very similar between the stations during winter and spring months.

\section{Precipitation}

Mean annual precipitation, calculated by averaging the proportions of occurrence of midpoints of the precipitation classes over the total area of each unit, was significantly higher along the west slope (PHUs 1, 2, and 7) than for PHUs 3, 4, and 5 along the east slope or for PHU 6 on the north end (Fig. A2). PHU 1, with the highest overall and mean elevation, received the greatest precipitation annually. This was nearly twice the annual mean for PHU 5 which included extensive relatively flat, low elevation terrain within the rain shadow of PHU 1.

Perhaps of greater significance than the total, the proportion of each PHU within each of the annual precipitation classes differed considerably. Most of the area fell within the moderate-subhumid $(509-762 \mathrm{~mm}$ ) category (Fig. A2). Notably, however, PHUs 1, 2, and 7 included very little area receiving less than $508 \mathrm{~mm}$ annually while the low to semi-arid classes covered considerable area in PHUs 3, 4, and 6 and most of PHU 5 .

\section{Snow Depths and Coverage}

Daily snow depths calculated from measurements at our weather stations on winter ranges in PHUs 1, 2, 3, 4, and 7 during November-May 1978-1982 tended to vary directly with elevation, though other topographic factors were sometimes overriding (Table A5). For example, mean daily snow depth on PHU 3 winter range was less than all other areas due to the combined effects of relatively low elevation and precipitation and high chinook winds that sublimated and/or melted much of the relatively meager 


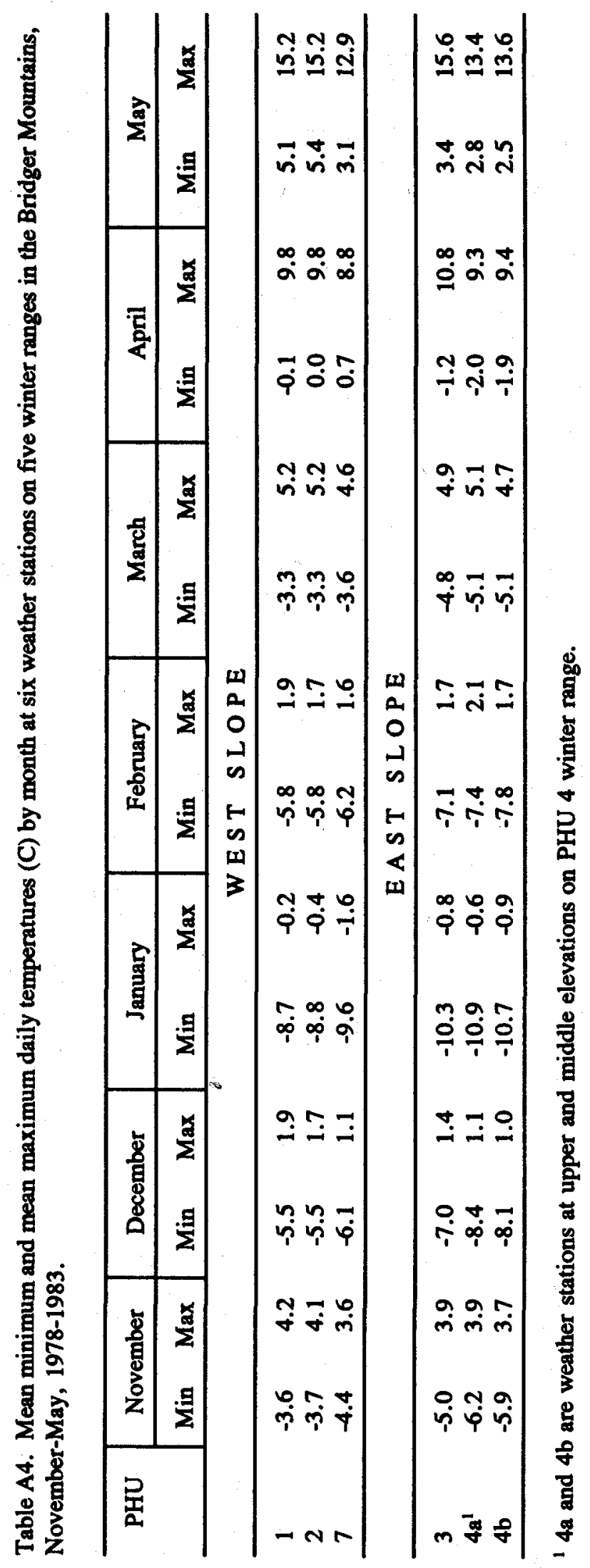




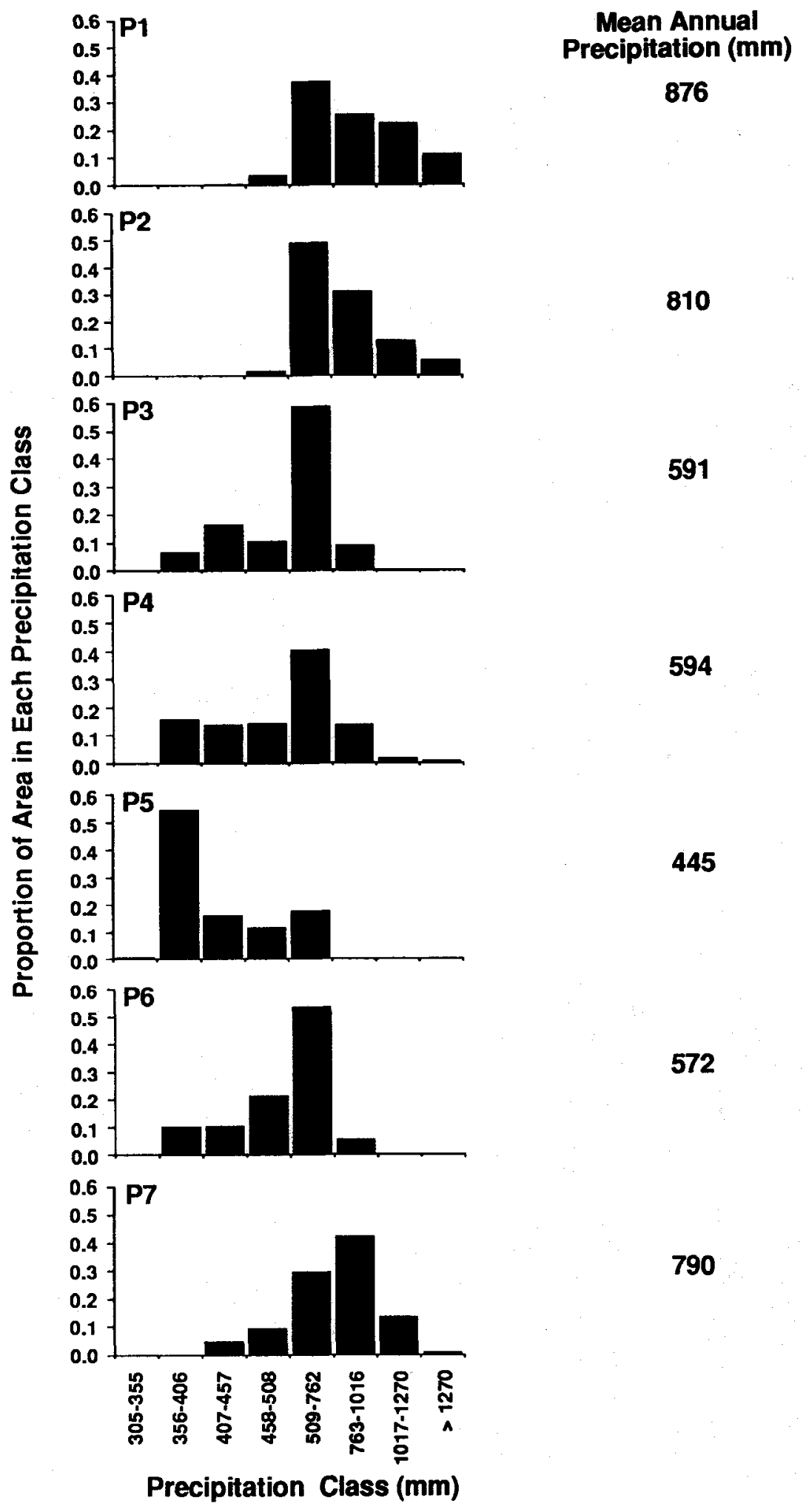

Precipitation (mm)

876

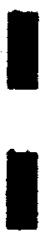

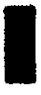

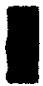

1

1

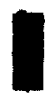

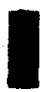

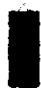

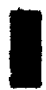

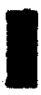

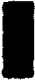

$\square$

Figure A2. Proportion of surface area of each PHU characterized by various precipitation classes. 
Table A5. Mean daily snow depths (dm) by month at six weather stations on five winter ranges in the Bridger Mountains, November through May, 1978-79 through 1982-83.

\begin{tabular}{|c|c|c|c|c|c|c|c|}
\hline PHU & November & December & January & February & March & April & May \\
\hline \multicolumn{8}{|c|}{ WEST S LOPE } \\
\hline 1 & 1.4 & 2.4 & 4.2 & 4.4 & 2.0 & 0.6 & 0.2 \\
\hline 2 & 1.6 & 2.4 & 4.2 & 4.6 & 2.0 & 0.6 & 0.2 \\
\hline 7 & 2.0 & 3.4 & 7.0 & 8.4 & 4.6 & 2.2 & 0.2 \\
\hline \multicolumn{8}{|c|}{ EAST SLOPE } \\
\hline 3 & 1.2 & 1.2 & 1.6 & 1.2 & 1.0 & 0.2 & 0 \\
\hline $4 a^{1}$ & 2.0 & 2.2 & 5.2 & 5.4 & 2.2 & 0.8 & 0.2 \\
\hline $4 b$ & 1.4 & 1.4 & 3.4 & 3.2 & 1.4 & 1.0 & 0.2 \\
\hline
\end{tabular}

$14 a$ and $4 b$ are weather stations at upper and middle elevations on PHU 4 winter range

snowfall. The PHU 3 winter range also included a greater proportion of area in steep southerly aspect than other east slope ranges.

Mean daily snow depth was greatest on winter range in PHU 7, the highest in elevation. Weather station 4a, on the upper edge of winter range in PHU 4, had the second highest snow depth although the site was lower and apparently drier than the station on winter range in PHU 1. This resulted from slope and aspect differences which provided more favorable conditions for snowmelt at the latter. Station $4 \mathrm{~b}$, located near the mean elevation of winter range in PHU 4, experienced substantially lower mean daily snow depths than the upper station during most of the study. Mean daily snow depths at the station on PHU 2 were almost identical to those on PHU 1, though the means obscured large differences in snowfall and depths that could occur on any given date.

Other indicators of snow conditions such as the mean number of days per month with at least $2.5 \mathrm{~cm}$ of snow on the ground (Table A6) and the mean percentage of ground covered by snow on days when measurements were recorded (Table A7) varied in the same manner as mean daily snow depth. Generally, areas of highest elevation or which lacked steep southerly aspect also had the most persistent snow coverage.

Wind

Mean wind speeds measured at weather stations were significantly greater on east as compared with west slope ranges (Table A8). On the east, wind speeds generally increased south of PHU 4 to the Livingston area which lies within the strong chinook wind zone that characterizes the upper Yellowstone River Valley. Winter ranges along the west slope were not subject to either chinook winds or to the moderate northerly to easterly winds that accompany the passage of arctic fronts through the area. Rather, 
Table A6. Mean number of days per month with at least $2.5 \mathrm{~cm}$ of snow on the ground at six weather stations on five winter ranges in the Bridger Mountains, November through May, 1978-79 through 1982-83.

\begin{tabular}{|c|c|c|c|c|c|c|c|}
\hline PHU & November & December & January & February & March & April & May \\
\hline \multicolumn{8}{|c|}{ WEST SLOPE } \\
\hline 1 & 8.8 & 17.4 & 21.0 & 21.8 & 13.8 & 7.2 & 2.0 \\
\hline 2 & 8.8 & 17.4 & 21.0 & 21.8 & 13.8 & 7.2 & 2.0 \\
\hline 7 & 12.6 & 20.4 & 24.8 & 28.2 & 21.0 & 12.6 & 2.2 \\
\hline \multicolumn{8}{|c|}{ E A S T S L OPE } \\
\hline 3 & 10.2 & 13.8 & 17.6 & 9.8 & 6.6 & 4.0 & 1.6 \\
\hline $4 a^{1}$ & 10.6 & 17.2 & 21.6 & 21.0 & 13.4 & 7.0 & 1.4 \\
\hline $4 b$ & 13.0 & 16.0 & 17.8 & 17.8 & 11.0 & 7.4 & 1.0 \\
\hline
\end{tabular}

$14 a$ and $4 b$ are weather stations at upper and middle elevations on PHU 4 winter range.

Table A7. Mean percent of ground covered by snow at five weather stations on four winter ranges in the Bridger Mountains by month, November through May, 1978-79 through 1982-83.

\begin{tabular}{cccccccc}
\hline PHU & November & December & January & February & March & April & May \\
\hline & & \multicolumn{7}{c}{ W E S T } & S L O P E & & & \\
\hline 1 & 51 & 54 & 73 & 66 & 54 & 47 & 8 \\
7 & 59 & 60 & 84 & 85 & 65 & 42 & 8 \\
\hline & & E A S T & S L O P E & & & \\
\hline 3 & 49 & 45 & 54 & 39 & 32 & 21 & 7 \\
$4 a^{1}$ & 52 & 64 & 76 & 63 & 54 & 37 & 8 \\
$4 \mathrm{~b}$ & 55 & 62 & 63 & 57 & 43 & 30 & 8 \\
\hline
\end{tabular}

1 $4 a$ and $4 b$ are weather stations at upper and middle elevations on PHU 4 winter range. 
Table A8. Mean weekly wind speeds $(\mathrm{km} / \mathrm{hr})$ at six weather stations on five winter ranges in the Bridger Mountains by month, November through May, 1978-79 through 1982-83.

\begin{tabular}{|c|c|c|c|c|c|c|c|}
\hline PHU & November & December & January & February & March & April & May \\
\hline \multicolumn{8}{|c|}{ WEST SLOPE } \\
\hline 1 & 3.23 & 4.09 & 2.67 & 3.27 & 3.64 & 3.96 & 3.80 \\
\hline 2 & 1.53 & 2.20 & 1.08 & 1.54 & 1.85 & 2.37 & 1.98 \\
\hline 7 & 3.77 & 4.15 & 3.78 & 3.57 & 4.65 & 4.84 & 4.52 \\
\hline \multicolumn{8}{|c|}{ EAST SLOPE } \\
\hline 3 & 9.38 & 9.12 & 9.12 & 9.75 & 8.80 & 10.15 & 9.53 \\
\hline $4 a^{1}$ & 5.83 & 7.55 & 6.81 & 6.32 & 5.95 & 6.42 & 6.68 \\
\hline $4 b$ & 7.03 & 9.78 & 7.98 & 7.66 & 7.77 & 9.62 & 9.33 \\
\hline
\end{tabular}

$14 \mathrm{a}$ and $4 \mathrm{~b}$ are weather stations at upper and middle elevations on PHU 4 winter range.

prevailing winds were west to southwesterly and increased directly with elevation on all three west slope winter ranges.

General Vegetational Characteristics of PHUs

Vegetational patterns and differences among the seven PHUs, based on relative occurrence of steppe, open canopy montane forest, closed canopy montane forest, and subalpine-alpine vegetation are shown in Appendix Table A9.

As expected, differences in topography and climate among PHUs were reflected in variation in vegetational patterns and coverage. PHUs 1,2 , and 7 , which straddled the main Bridger Range and were most similar in topography and climate, were most similar vegetatively. All were characterized by high amounts of open $( \pm 45 \%)$ and closed $( \pm 25 \%)$ montane forest and low amounts of steppe $(<22 \%)$. They also were the only units with significant $(>5 \%)$ representation of subalpine-alpine vegetation.

PHUs 3, 4, and 6 were also vegetatively similar. Steppe dominated at least half of each unit. Amounts of open $( \pm 33 \%)$ and closed $( \pm 12 \%)$ canopy montane forest were not significantly different. The subalpine-alpine zone was very minor and occurred primarily in areas of overlap with PHUs 1, 2, and 7.

PHU 5 was vegetationally unique, reflecting its low average elevation and minimal amount of mountain terrain. About $90 \%$ was dominated by steppe, $10 \%$ by open forest, and only $1 \%$ by closed canopy forest. No subalpine-alpine vegetation occurred. 
Table A9. Percentage of steppe, open and closed canopy montane forest, and subalpinealpine vegetation among population-habitat units overall and for winter range only.

\begin{tabular}{|c|c|c|c|c|}
\hline PHU & Steppe & $\begin{array}{c}\text { Open canopy } \\
\text { forest }\end{array}$ & $\begin{array}{c}\text { Closed canopy } \\
\text { forest }\end{array}$ & $\begin{array}{c}\text { Subalpine- } \\
\text { Alpine }\end{array}$ \\
\hline \multicolumn{5}{|c|}{ Total Unit } \\
\hline $\begin{array}{l}1 \\
2 \\
7\end{array}$ & $\begin{array}{l}14.5 \\
21.9 \\
21.4\end{array}$ & $\begin{array}{l}45.6 \\
51.5 \\
41.9\end{array}$ & $\begin{array}{l}25.5 \\
21.0 \\
26.7\end{array}$ & $\begin{array}{r}14.4 \\
5.6 \\
10.3\end{array}$ \\
\hline $\begin{array}{l}3 \\
4 \\
5 \\
6\end{array}$ & $\begin{array}{l}55.6 \\
51.2 \\
89.6 \\
52.0\end{array}$ & $\begin{array}{r}33.0 \\
32.3 \\
9.5 \\
37.1\end{array}$ & $\begin{array}{r}11.5 \\
16.3 \\
0.9 \\
10.0\end{array}$ & $\begin{array}{l}0 \\
0.2 \\
0 \\
0.9\end{array}$ \\
\hline \multicolumn{5}{|c|}{ Winter Range } \\
\hline $\begin{array}{l}1 \\
2 \\
7\end{array}$ & $\begin{array}{l}51.8 \\
32.5 \\
51.6\end{array}$ & $\begin{array}{l}33.6 \\
46.8 \\
38.8\end{array}$ & $\begin{array}{r}14.6 \\
20.7 \\
9.6\end{array}$ & $\begin{array}{l}-- \\
-- \\
--\end{array}$ \\
\hline $\begin{array}{l}3 \\
4 \\
5 \\
6\end{array}$ & $\begin{array}{l}94.2 \\
94.5 \\
83.4 \\
82.3\end{array}$ & $\begin{array}{r}5.9 \\
4.7 \\
15.2 \\
16.8\end{array}$ & $\begin{array}{l}0 \\
0.7 \\
1.4 \\
0.9\end{array}$ & $\begin{array}{l}-- \\
-- \\
-- \\
-\end{array}$ \\
\hline
\end{tabular}

Vegetational patterns and differences on winter ranges were generally similar to overall patterns (Table A9). Winter range within PHUs 1, 2, and 7 included substantially more montane forest than other units where winter range was dominated almost entirely by steppe.

Specific Vegetation Characteristics in PHUs 1 and 4

Table A10 compares the relative occurrence of vegetation zones, subzones, and specific cover types within PHUs 1 and 4 which were representative of the west and east slope. Zones were generally comparable to the broad vegetation types delineated across all PHUs, but relative and total amounts differ because of differences in mapping resolution. 
Table A10. Occurrence (\%) of major vegetation zones, subzones, and cover types (CT) on yearlong and winter ranges within PHUs 1 and 4.

\begin{tabular}{|c|c|c|c|c|}
\hline \multicolumn{5}{|l|}{ ZONE } \\
\hline \multirow{2}{*}{$\begin{array}{l}\text { SUBZONE } \\
\text { COVER TYPE (CT) }\end{array}$} & \multicolumn{2}{|c|}{ PHU 1} & \multicolumn{2}{|c|}{ PHU 4} \\
\hline & $\begin{array}{l}\text { Year- } \\
\text { long }\end{array}$ & Winter & $\begin{array}{l}\text { Year- } \\
\text { long }\end{array}$ & Winter \\
\hline STEPPE ZONE & 29.6 & 72.3 & 67.8 & 94.8 \\
\hline AGRICULTURE SUBZONE & 10.0 & 23.2 & 9.7 & 17.4 \\
\hline RIPARIAN SUBZONE & 2.2 & 2.5 & 4.6 & 5.2 \\
\hline Cottonwood-Aspen CT & 0.8 & 0.9 & 0.9 & 0.8 \\
\hline Riparian Shrub CT & 1.4 & 1.7 & 3.7 & 4.2 \\
\hline Marsh CT & 0.0 & 0.0 & 0.0 & 0.1 \\
\hline SHRUB-GRASSLAND SUBZONE & 17.4 & 46.6 & 53.5 & 72.2 \\
\hline Dry Sagebrush CT & 0.8 & 5.2 & 9.1 & 18.7 \\
\hline Moist Sagebrush CT & 0.5 & 3.1 & 10.1 & 11.7 \\
\hline Bitterbrush CT & 0.8 & 7.1 & 0.7 & 1.7 \\
\hline Juniper Savannah CT & 0.1 & 2.2 & 3.4 & 4.7 \\
\hline Dry Grassland CT & 8.0 & 4.1 & 26.9 & 33.0 \\
\hline Intermediate Grassland CT & 7.2 & 24.9 & 3.3 & 2.5 \\
\hline $\begin{array}{l}\text { MONTANE FOREST ZONE } \\
\text { MID ELEVATION - OPEN CANO }\end{array}$ & 54.2 & 27.7 & 32.1 & 5.2 \\
\hline SUBZONE & 15.6 & 13.9 & 17.0 & 3.5 \\
\hline Douglas Fir-Dry CT & 10.1 & 13.7 & 10.8 & 1.6 \\
\hline Douglas Fir-Moist CT & 3.6 & 0.1 & 6.1 & 1.8 \\
\hline Lodgepole Pine/Shrub CT & 0.3 & 0.1 & 0.0 & 0.0 \\
\hline Spruce CT & 0.1 & 0.0 & 0.0 & 0.0 \\
\hline Clearcut CT & 1.4 & 0.0 & 0.0 & 0.0 \\
\hline \multicolumn{5}{|c|}{ MID-ELEVATION-CLOSED CANOPY } \\
\hline SUBZONE & 24.4 & 13.8 & 12.2 & 1.7 \\
\hline Douglas Fir-Dry CT & 2.2 & 3.2 & 1.0 & 0.2 \\
\hline Douglas Fir-Moist CT & 7.0 & 9.4 & 8.1 & 1.5 \\
\hline Lodgepole Pine/Grass CT & 0.9 & 0.0 & 0.9 & 0.0 \\
\hline Lodgepole Pine/Shrub CT & 11.4 & 1.2 & 2.1 & 0.0 \\
\hline Spruce CT & 2.9 & 0.0 & 0.0 & 0.0 \\
\hline \multicolumn{5}{|l|}{ HIGH ELEVATION-OPEN CANOPY } \\
\hline SUBZONE & 6.7 & 0.0 & 2.9 & 0.0 \\
\hline Subalpine Fir CT & 1.7 & 0.0 & 0.7 & 0.0 \\
\hline Whitebark Pine/Grass CT & 1.6 & 0.0 & 0.0 & 0.0 \\
\hline Whitebark Pine/Shrub CT & 1.5 & 0.0 & 0.0 & 0.0 \\
\hline Moist Meadow CT & 0.0 & 0.0 & 2.2 & 0.0 \\
\hline Wet Meadow CT & 1.7 & 0.0 & 0.0 & 0.0 \\
\hline \multicolumn{5}{|c|}{ HIGH ELEVATION-CLOSED CANOPY } \\
\hline SUBZONE & 7.6 & 0.0 & 0.0 & 0.0 \\
\hline Subalpine Fir CT & 3.4 & 0.0 & 0.0 & 0.0 \\
\hline Whitebark Pine/Shrub CT & 4.2 & 0.0 & 0.0 & 0.0 \\
\hline SUBALPINE-ALPINE ZONE & 16.0 & 0.0 & 0.0 & 0.0 \\
\hline SUBALPINE SUBZONE & 8.7 & 0.0 & 0.0 & 0.0 \\
\hline Subalpine Fir-Open Canopy CT & 5.0 & 0.0 & 0.0 & 0.0 \\
\hline Subalpine Fir-Closed Canopy CT & 1.1 & 0.0 & 0.0 & 0.0 \\
\hline Subalpine Grassland CT & 2.5 & 0.0 & 0.0 & 0.0 \\
\hline ALPINE SUBZONE & 7.3 & 0.0 & 0.0 & 0.0 \\
\hline
\end{tabular}


The steppe zone, including the agricultural, riparian, and shrub-grassland subzones, comprised significantly more area in PHU 4 than PHU 1, both overall and on winter range. In both units, the shrub-grassland subzone covered most of the steppe; the riparian subzone was least represented.

The shrub-grassland subzone was dominated by mountain big sagebrush, bitterbrush, bluebunch wheatgrass, and Idaho fescue. Big sagebrush was widely distributed while bitterbrush, aromatic (skunkbush) sumac, and Rocky Mountain juniper typically were common on steep, rocky, south aspects. Bluebunch wheatgrass generally dominated drier sites while Idaho fescue predominated on more mesic areas. Within this framework, dry grasslands consisting largely of bluebunch wheatgrass and/or seral species that replace it under heavy livestock grazing dominated the steppe zone on PHU 4. In PHU 1, shrub-grasslands and grasslands dominated by Idaho fescue or Idaho fescue/bluebunch wheatgrass stands were about equal in occurrence to those dominated by drier shrub-grassland and grassland types.

We recognized four subzones within the montane forest. Cover types within subzones were combined on the basis of elevational interval and canopy coverage of trees as determined by air photo interpretation. The boundary between mid and high elevation forest was $2,300-2,400 \mathrm{~m}$, the approximate elevation at which whitebark pine and subalpine fir became important.

Montane forest covered approximately one-half of PHU 1 and about one-third of PHU 4. In PHU 1, closed canopy stands covered greater total area than open stands, whereas in PHU 4, open and closed canopy stands were about equally represented. Douglas fir was the dominant tree in mid elevation forest on both units, lodgepole pine ranked a distant second, and other trees (mostly spruce) were very minor in occurrence.

Most of the forest zone occurred at middle elevations $(1,800-2,300 \mathrm{~m})$. Because of elevational differences, high elevation forest covered about 14\% of PHU 1 and 3\% of PHU 4. In PHU 1, these forests were dominated by subalpine fir and/or whitebark pine with minor amounts of Douglas fir, spruce, and lodgepole pine. In PHU 4, they consisted mostly of scattered stands of subalpine fir in moist meadow areas.

Subalpine-alpine vegetation occurred only in PHU 1 on limestone ridges above $2,400 \mathrm{~m}$. It consisted largely of scattered, stunted subalpine fir and limber pine trees often associated with common juniper, Rocky Mountain clematis, and arnica extending up to about $2,700 \mathrm{~m}$. Interspersed with and extending above these stands are alpine areas consisting mostly of talus (scree) with some Hayden clover, sheep fescue, and shrubby cinquefoil. 


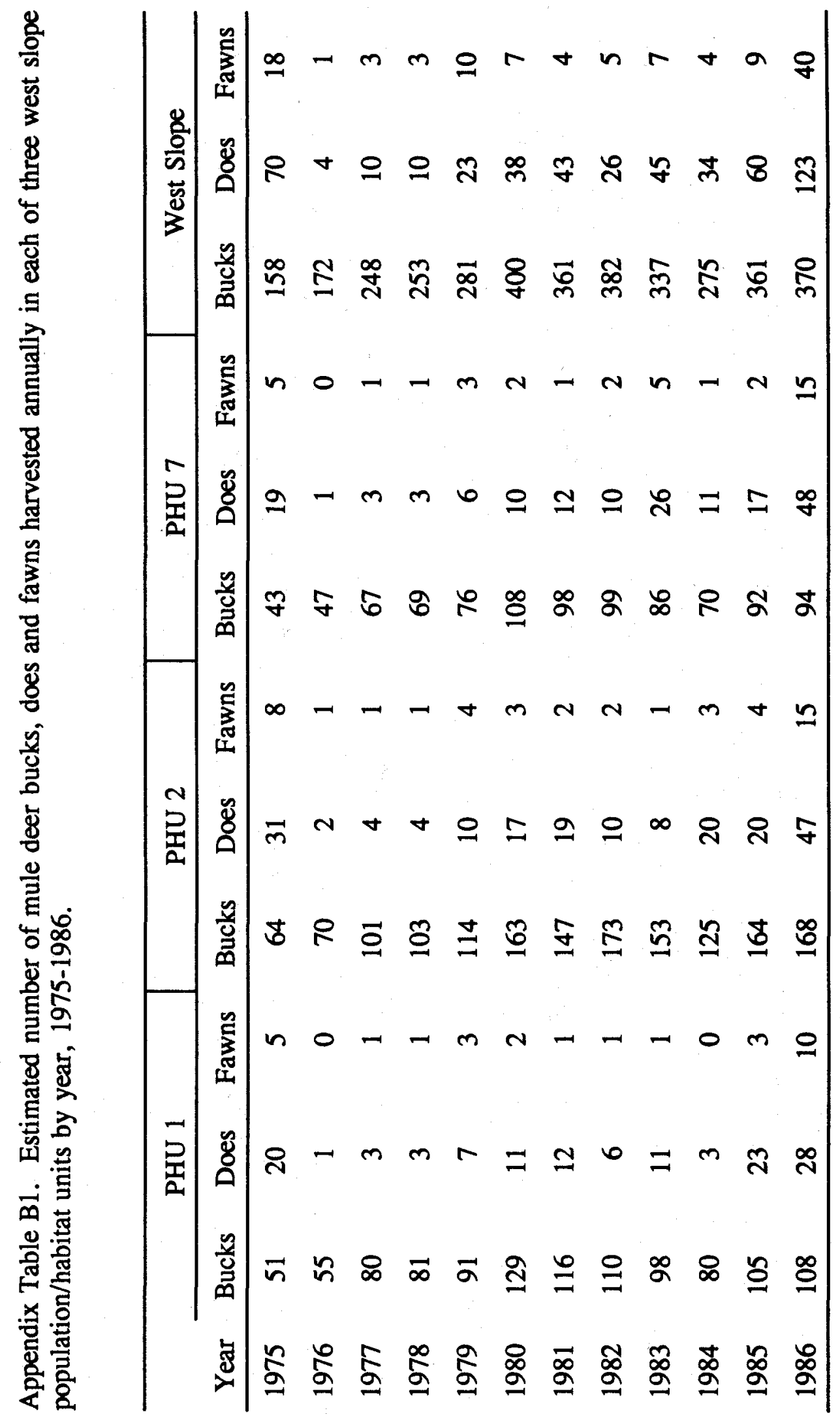




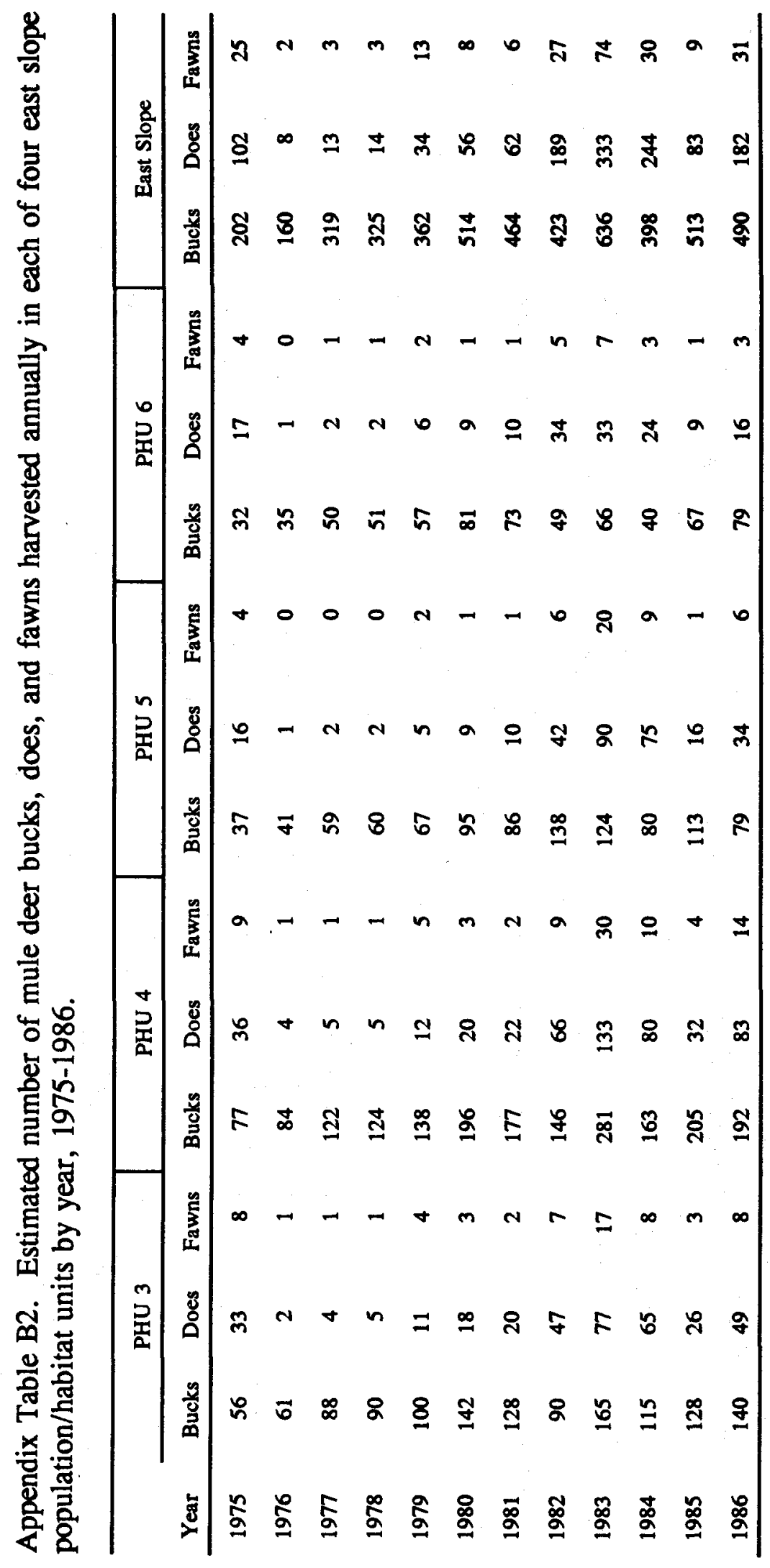


Appendix Table C1. Mark-recapture (Lincoln indexes) population estimates for mule deer on the Armstrong segment of PHU 1 during April, 1973-1987.

\begin{tabular}{cccccc}
\hline & $\begin{array}{c}\text { Population } \\
\text { Estimate } \\
\left(\overline{\mathrm{X}} \pm S_{\mathrm{x}}\right)\end{array}$ & $\begin{array}{c}\text { Number } \\
\text { of } \\
\text { Surveys }\end{array}$ & $\begin{array}{c}\text { Number Deer } \\
\text { Observed/Survey } \\
\left(\overline{\mathrm{X}} \pm \mathrm{S}_{\mathrm{x}}\right)\end{array}$ & $\begin{array}{c}\text { Marked } \\
\text { Observed/Survey } \\
\left(\overline{\mathrm{X}} \pm \mathrm{S}_{\mathrm{x}}\right)\end{array}$ & $\begin{array}{c}\text { Total } \\
\text { Number } \\
\text { Marked }\end{array}$ \\
\hline 1973 & $232 \pm 32$ & 7 & $153 \pm 32$ & $10 \pm 3$ & 18 \\
1974 & -- & 0 & -- & - & - \\
1975 & $150 \pm 28$ & 7 & $67 \pm 15$ & $25 \pm 4$ & 56 \\
1976 & $169 \pm 17$ & 3 & $132 \pm 5$ & $43 \pm 5$ & 55 \\
1977 & $201 \pm 45$ & 7 & $64 \pm 12$ & $22 \pm 6$ & 68 \\
1978 & $160 \pm 33$ & 8 & $66 \pm 22$ & $33 \pm 11$ & 80 \\
1979 & $140 \pm 11$ & 12 & $78 \pm 25$ & $54 \pm 17$ & 98 \\
1980 & $160 \pm 16$ & 8 & $83 \pm 27$ & $44 \pm 15$ & 85 \\
1981 & $170 \pm 20$ & 8 & $85 \pm 25$ & $36 \pm 11$ & 72 \\
1982 & $170 \pm 10$ & 14 & $86 \pm 22$ & $39 \pm 11$ & 77 \\
1983 & $217 \pm 12$ & 9 & $134 \pm 28$ & $40 \pm 9$ & 68 \\
1984 & $225 \pm 16$ & 7 & $162 \pm 41$ & $36 \pm 9$ & 50 \\
1985 & $203 \pm 19$ & 9 & $101 \pm 31$ & $13 \pm 4$ & 26 \\
1986 & $200 \pm 16$ & 7 & $123 \pm 23$ & $24 \pm 4$ & 41 \\
1987 & $217 \pm 41$ & 8 & $116 \pm 26$ & $15 \pm 3$ & 27 \\
\hline
\end{tabular}

'Maximum number of marked deer known to be on study area during surveys. 


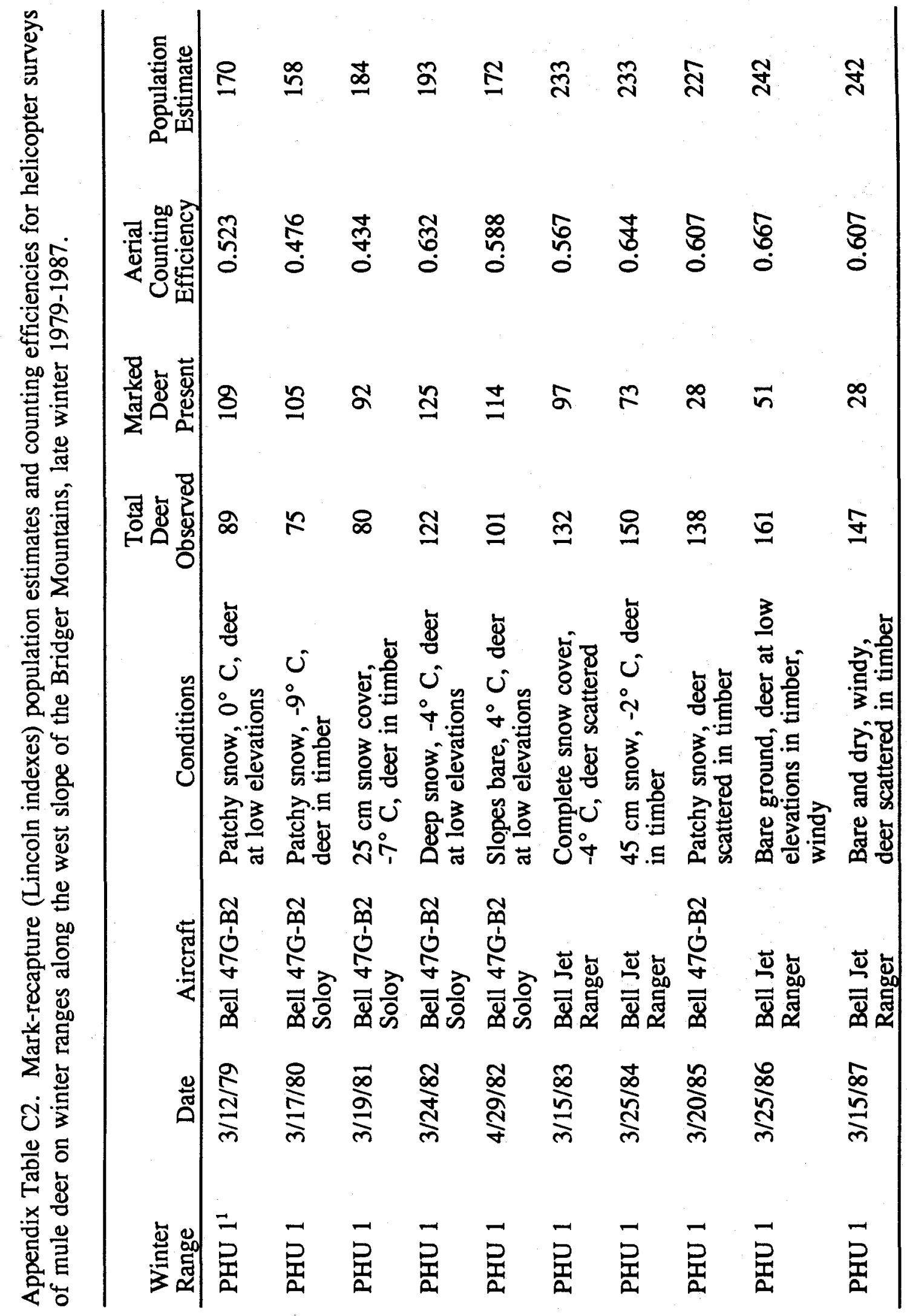




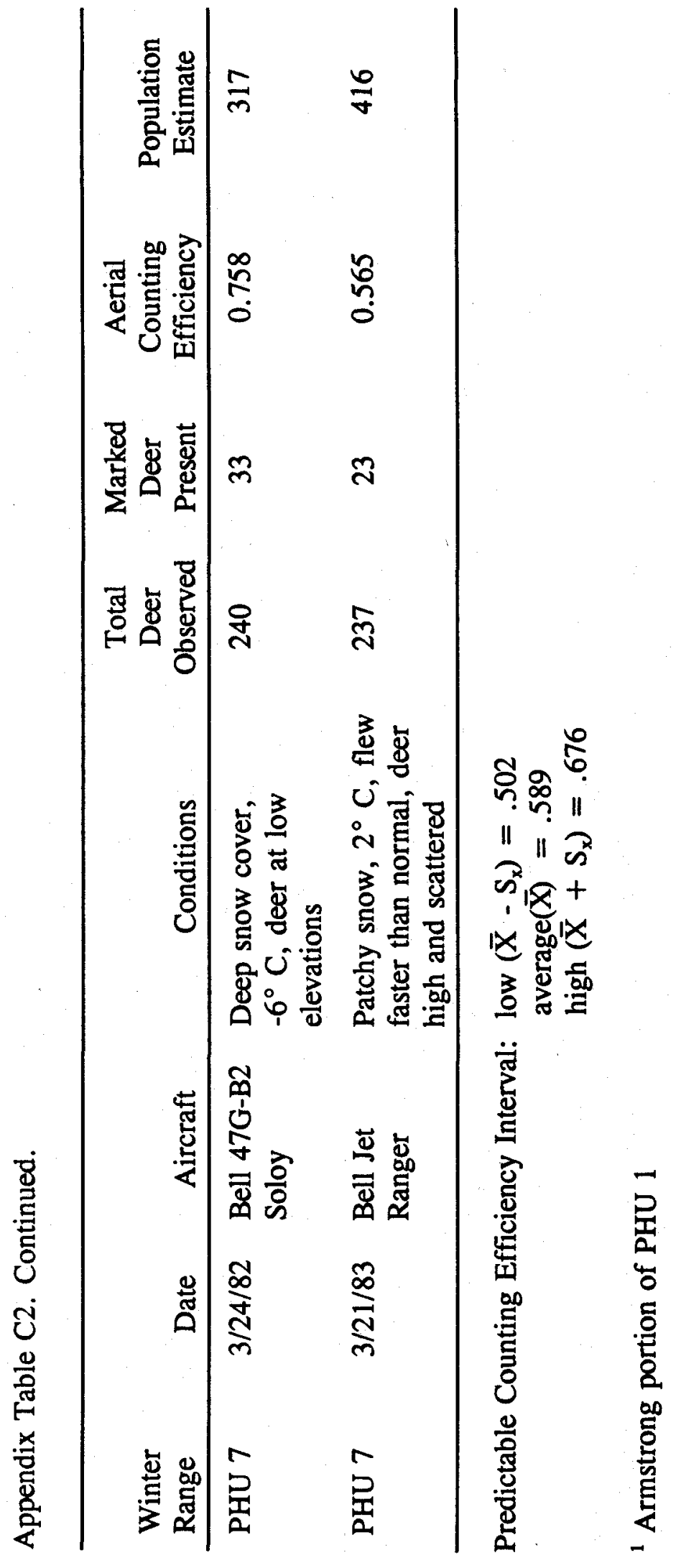




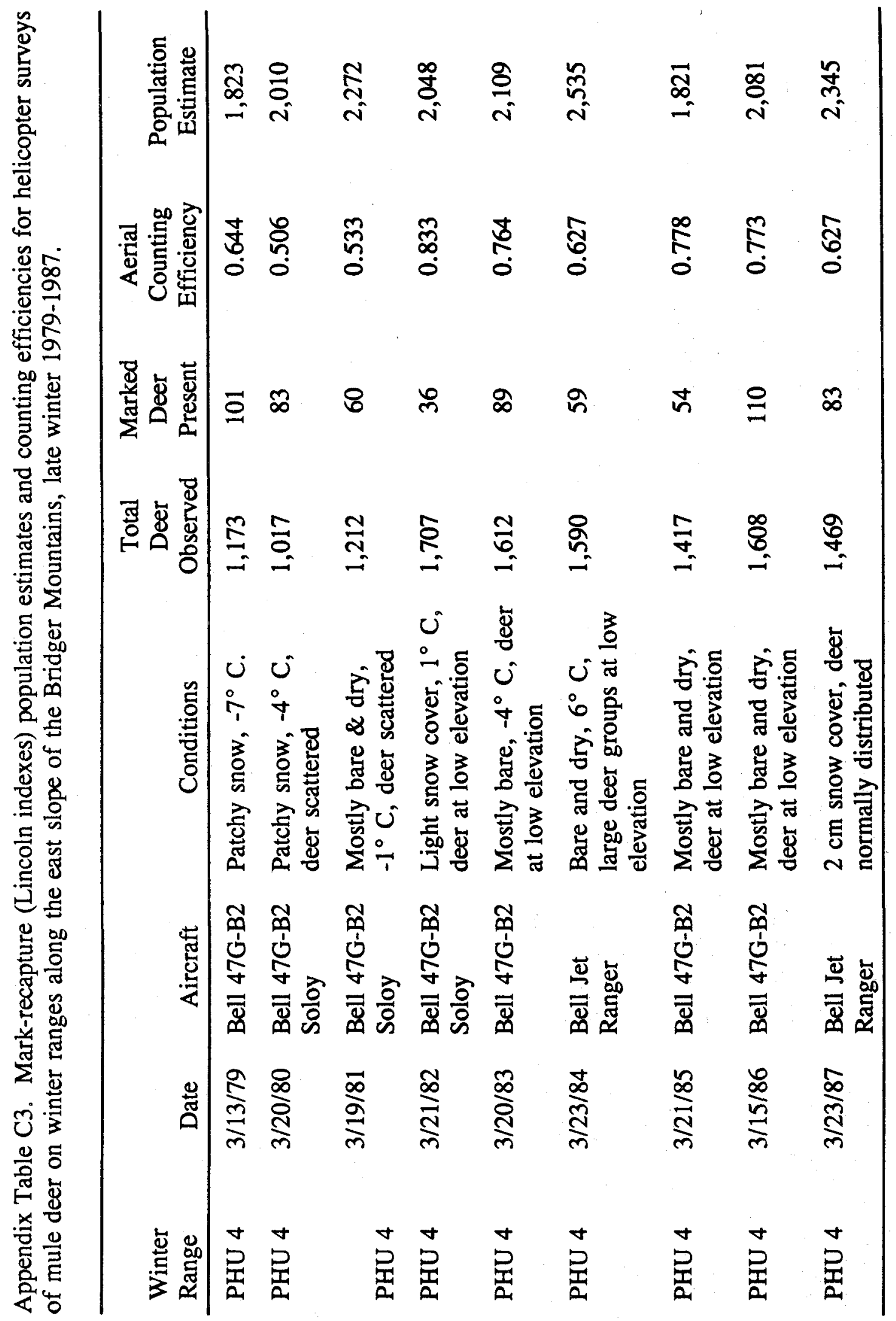




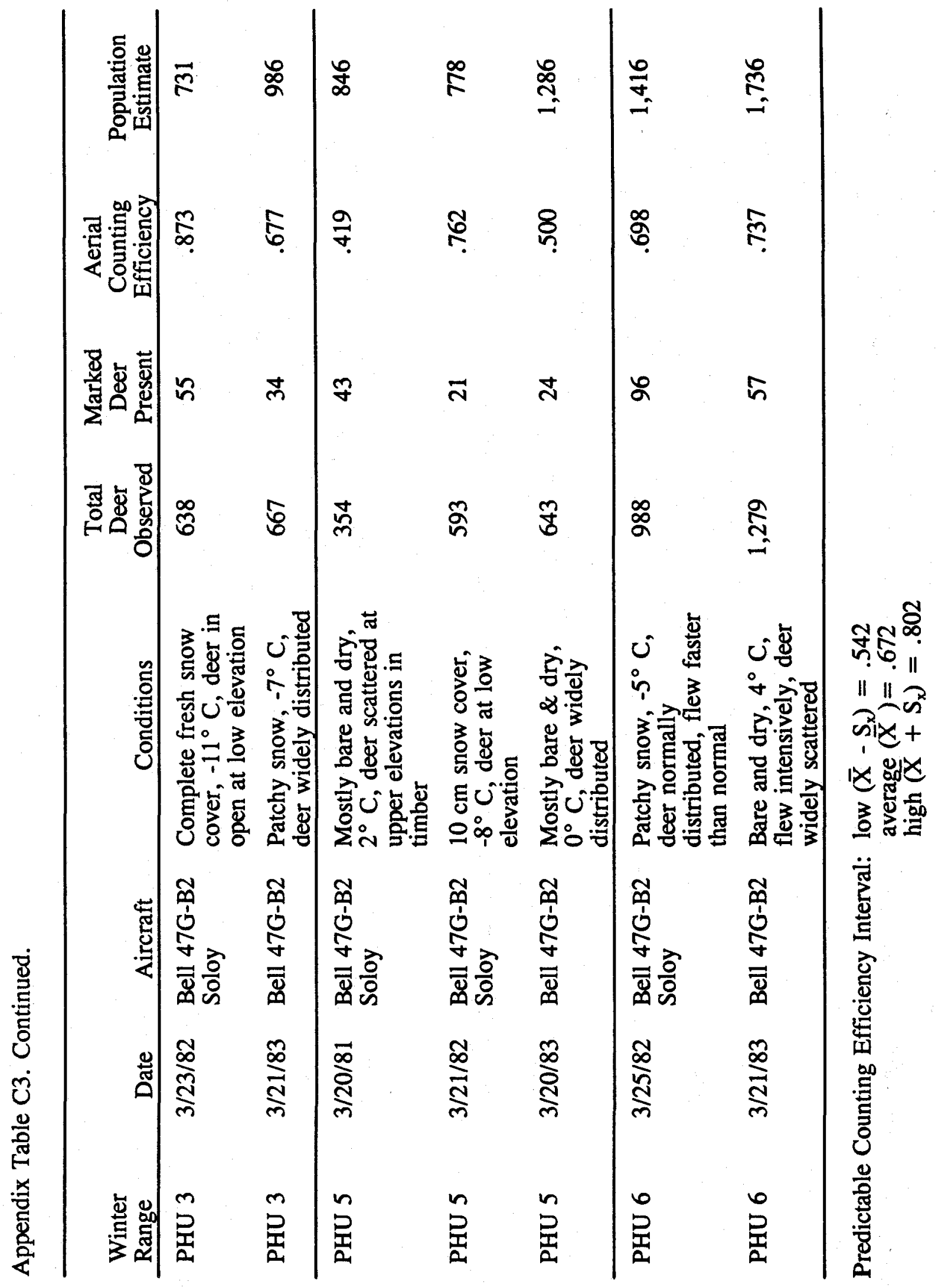




\section{LITERATURE CITED}

Anderson, A. E., W. A. Snyder, and G. W. Brown. 1970. Indices of reproduction and survival in female mule deer, Guadalupe Mountains, New Mexico. Southwestern Nat. 15(1):29-36.

Andrewartha, H. G., and L. C. Birch. 1954. The distribution and abundance of animals. Univ. of Chicago Press, Chicago.

Ashcraft, G. C., Jr. 1961. Deer movements of the McCloud Flats herds. California Fish and Game 47:145-152.

Avise, J. C., G. Giblin-Davidson, J. Laern, J. C. Patton, and R. A. Lansman. 1979. Mitochondrial DNA clones and matriarchal phylogeny within and among geographic populations of the pocket gopher, (Geomys pinetis). Proc. Natl. Acad. Sci. USA 76:6694-6698.

Baker, R. R. 1978. The evolutionary ecology of animal migration. Holmes and Meier Publ., Inc. New York, NY. 1012 pp.

Bannikov, A. G. 1967. Moose in the USSR and its explanation. Int. Congr. Game Biologists, August 22-27. Helsinki, VIII:273-276.

Barrett, M. W., J. W. Nolan, and L. D. Roy. 1982. Evaluation of a hand held net-gun to capture large mammals. Wildl. Soc. Bull. 10:108-114.

Bartmann, R. M., L. H. Carpenter, R. A. Garrott, and D. C. Bowden. 1986. Accuracy of helicopter counts of mule deer in pinon-juniper woodland. Wildl. Soc. Bull. 14:356-363.

Bayliss, P. 1987. Kangaroo Dynamics. Pp. 119-133 in G. Caughley, N. Shepherd, and J. Short, eds., Kangaroos: their ecology and management in the sheep rangelands of Australia. Cambridge Univ. Press, London, United Kingdom. 253 pp.

Beasom, S. L. 1979. Precision in helicopter censusing of white-tailed deer. J. Wildl. Manage. 43:777-780. 
, W. Evans, and L. Temple. 1980. The drive net for capturing western big game. J. Wildl. Manage. 44:478-480.

, F. G. Leon III, and D. R. Synatzske. 1986. Accuracy and precision of counting white-tailed deer with helicopters at different sampling intensities. Wildl. Soc. Bull. 14:364-368.

Bertram, R. C., and R. D. Rempel. 1977. Migration of the North Kings Deer Herd. California Fish and Game 63(3): 157-179.

Birkey, C. W. Jr., T. Maruyama, and P. Fuerst. 1983. An approach to population genetic and evolutionary genetic theory for genes in mitochondria and chloroplasts, and some results. Genetics:103:513-527.

Borg, K. 1970. On mortality and reproduction of roe deer in Sweden during the period 1948-1969. Viltrevy 7(2): 121-149.

Botkin, D. B. 1990. Discordant Harmonies: A new ecology for the twenty-first century. Oxford University Press. $241 \mathrm{pp}$.

Bowyer, R. T. 1984. Sexual segregation in southern mule deer. J. Mammal. 65:410-417.

Brown, E. R. 1961. The black-tailed deer of western Washington. Washington State Game Dept. Biol. Bull. No. 13, 124 pp.

Bruns, E. H. 1977. Winter behavior of pronghorns in relation to habitat. J. Wildl. Manage. 41(3): 560-571.

Bucsis, R. A. 1974. Ecological characteristics of the Armstrong mule deer winter range, Bridger Mountains, Montana. Unpubl. M.S. Thesis. Mont. State Univ., Bozeman. $104 \mathrm{pp}$.

Caprio, J. M. 1966. Pattern of plant development in the western United States. Montana Agricultural Experiment Station. Bull. No. 607. 42 pp.

Caughley, G. 1966. Mortality patterns in mammals. Ecology 47:906-918.

- 1976. Plant-herbivore systems. Pp. 94-113 in R.M. May (ed.), Theoretical ecology: principles and applications. Blackwell, Oxford.

- 1977. Analysis of vertebrate populations. John Wiley and Sons, New York, N.Y. 234 pp. 
- 1979. What is this thing called carrying capacity? pp. 2-8 in North American Elk: Ecology, Behavior, and Management (M.S. Boyce and L.D. Hayden-Wing, eds.), Univ. Wyoming Press, Laramie.

- 1987. Ecological Relationships. Pp. 159-187 in G. Caughley, N. Shepherd, and J. Short, eds., Kangaroos: their ecology and management in the sheep rangelands of Australia. Cambridge Univ. Press, London, United Kingdom. 253 pp.

, and J. Goddard. 1972. Improving the estimates from inaccurate censuses. J. Wildl. Manage. 36:135-140.

Cheatum, E. L. 1949. The use of corpora lutea for determining ovulation incidence and variations in fertility of the white-tailed deer. Cornell Vet. 39:282-291.

Chesser, R. K., M. H. Smith, P. E. Jones, M. N. Manlove, D. O. Straney, and R. Baccus. 1982. Spatial, temporal, and age-dependent heterozygosity of betahemoglobin in white-tailed deer. J. Wildl. Manage. 46:983-990.

Clover, M. R. 1954. A portable deer trap and catch-net. Calif. Fish and Game 40:367-373.

Clutton-Brock, T. H., F. E. Guinness, and S. D. Albon. 1982. Red deer-Behavior and ecology of two sexes. Univ. of Chicago Press, Chicago. 378 pp.

, G. R. Iason, and F. E. Guinness. 1987. Sexual segregation and density-related changes in habitat use in male and female red deer (Cervus elaphus). J. Zool. London 211:275-289.

Coblentz, B. E. 1970. Food habits of George Reserve deer. J. Wildl. Manage. $34: 535-540$.

. 1977. Comments on deer sociobiology. Wildl. Soc. Bull. 5:67.

Cole, L. C. 1957. Sketches of general and comparative demography. Cold Springs Harbor Sym. Quant. Biol., 22:1-15.

Cothran, E. G., R. K. Chesser, M. H. Smith, and P. E. Johns. 1983. Influences of genetic variability and maternal factors on fetal growth in white-tailed deer. Evolution 37(2):282-291.

Cronin, M. A. 1989. Molecular evolutionary genetics and phylogeny of cervids. PhD. dissertation. New Haven, CT, Yale Univ. 
Dapson, R. W., P. R. Ramsey, M. H. Smith, and D. F. Urbston. 1979. Demographic differences in contiguous populations of white-tailed deer. J. Wildl. Manage. 43:889-898.

Darling, F. F. 1937. A herd of red deer. London, Oxford Univ. Press. 225 pp.

Dasmann, R. F., and R. D. Taber. 1956. Behavior of Columbian black-tailed deer with reference to population ecology. J. Mammal. 37:143-164.

Davis, D. E., and R. L. Winstead. 1980. Estimating the numbers of wildlife populations. Pages $221-245$ in S. D. Schemnitz, ed. Wildlife management techniques manual, Fourth ed. The Wildl. Soc., Inc., Washington, D.C.

de Vos, A., P. Brokx, and V. Geist. 1967. A review of social behavior of the North American cervids during the reproductive period. Am. Midl. Nat. 77:390-417.

Defries, J. C., R. W. Touchberry, and R. L. Hays. 1959. Heritability of the length of the gestation period in dairy cattle. J. Dairy Sci. 42:598-606.

Dittus, W. P. J. 1979. The evolution of behaviors regulating population density and age-specific sex ratios in a primate population. Behavior 69:265:301.

Dunn, O. J. 1964. Multiple contracts using rank sums. Technometrics 6:241-252.

Dusek, G. L. 1987. Ecology of white-tailed deer in upland ponderosa pine habitat in southeastern Montana. Prairie Nat. 19:1-17.

, and A. K. Wood. 1986. An evaluation of the average activity radius as an estimator of monthly movements of deer. Proc. Mont. Acad. Sci. 46:19-26.

, R. J. Mackie, J. D. Herriges, Jr., and B. B. Compton. 1989. Population ecology of white-tailed deer along the lower Yellowstone River. Wildl. Monogr. 104:1-68.

Eberhardt, L. E., E. E. Hanson, and L. L. Cadwell. 1984. Movement and activity patterns of mule deer in the sagebrush-steppe region. J. Mammal. 65:404-409.

Eustace, C. D. 1971. Mule deer food habits and browse use study. Montana Fish and Game Dept. Job Final Report, Proj. W-130-R-1 and 2, Job. No. I-7.1. 25 pp.

Free, S., W. T. Hesselton, and C. W. Severinghaus. 1964. The gains and losses in a deer population for five sections of New York state. Proc. Northeast Wildlife Conf. Hartford, CT. 37 pp. 
Freeland, W. J., and D. H. Janzen. 1974. Strategies in herbivory by mammals: The role of plant secondary compounds. Amer. Natur. 108:269-289.

Fretwell, S. D. 1972. Populations in a seasonal environment. Princeton Univ. Press. $217 \mathrm{pp}$.

Fuller, T. K. 1990. Dynamics of a declining white-tailed deer population in northcentral Minnesota. Wildl. Monogr. 110:1-37.

Garrott, R. A., and G. C. White. 1982. Age and sex selectivity in trapping mule deer. J. Wildl. Manage. 46:1083-1086.

, _ R. M. Bartmann, L. H. Carpenter, and A. W. Alldredge. 1987. Movements of female mule deer in northwest Colorado. J. Wildl. Manage. 51(3): 634-643.

Gavin, T. A., L. H. Suring, P. A. Vohs, Jr., and E. C. Meslow. 1984. Population characteristics, spatial organization, and natural mortality in the Columbian white-tailed deer. Wildl. Monogr. 91:1-41.

Geist, V. 1981. Behavior: adaptive strategies in mule deer. Pages 157-223 in O.C. Wallmo, ed. Mule and black-tailed deer of North America. Univ. of Nebraska Press, Lincoln. 605 pp.

Gilbert, F. F. 1966. Aging white-tailed deer by annuli in the cementum of the first incisor. J. Wildl. Manage. 30:200-202.

Gilbert, P. F., O. C. Wallmo, and R. B. Gill. 1970. Effect of snow depth on mule deer in Middle Park, Colorado. J. Wildl. Manage. 34:15-23.

Gilmour, J. S. L., and J. W. Gregor. 1939. Demes: a suggested new terminology. Nature 144:333-334.

Glucksman, A. 1974. Sexual dimorphism in mammals. Biol. Rev. 49:423-475.

Gruell, G. E., and N. J. Papez. 1963. Movements of mule deer in northeastern Nevada. J. Wildl. Manage. 27:414-422.

Guinness, F. E., M. J. Hall, and R. A. Cockerill. 1979. Mother-offspring association in red deer. Animal Behav. 27:536-544.

Hamlin, K. L. 1974. Ecological relationships of mule deer in the Bridger Mountains, Montana, with special reference to daily and seasonal movements. M.S. Thesis, Montana State Univ., Bozeman. 65pp. 
- 1977. Population dynamics and habitat relationships of mule deer in the Bridger Mountains, Montana, 1955-1976. Ann. Conf. N.W. Section, TWS., Kalispell, MT Feb. 1977.

, and R. J. Mackie. 1989. Mule deer in the Missouri River Breaks, Montana: A study of population dynamics in a fluctuating environment. Fed. Aid in Wildl. Restor., Job Compl. Rept., Proj. W-120-R, Montana Department of Fish, Wildlife and Parks, Helena. 401 pp.

Hammond, G. R. 1980. Nutritional characteristics of the vegetation of clearcut and uncut sites on summer-fall elk range. M.S. Thesis, Montana State Univ., Bozeman. $65 \mathrm{pp}$.

Hann, W. J., and M. E. Jensen. 1987. Ecosystem classification handbook - Chapter 4: Ecodata sampling methods. Handb. 12/87 R-1 supplement 1. US Dept. of Agric. Forest Service, Northern Region, Missoula, MT:

Harestad, A. S. 1979. Seasonal movements of black-tailed deer on northern Vancouver Island. Ph.D. Thesis. Univ. British Columbia, Vancouver, Canada. 98pp.

Hawkins, R. E., W. D. Klimstra, and D. C. Autry. 1971. Dispersal of deer from Crab Orchard National Wildlife Refuge. J. Wildl. Manage. 35:216-220.

Hayne, D. W. 1949. Calculation of size of home range. J. Mammal. 30:1-18.

Hirth, D. H. 1977. Social behavior of white-tailed deer in relation to habitat. Wildl. Monogr. No. 53. 55 pp.

Horwich, R. H., S. J. H. Cogswell, J. Burrows, and N. Mitchell. 1982. Seasonal variation in mother-daughter groupings in Siberian ibex (Capra ibex siberica). Zoo. Biol. 1:345-354.

Hudson, P., and L. G. Browman. 1959. Embryonic and fetal development of the mule deer. J. Wildl. Manage. 23:295-304.

Hunter, G. N., and L. E. Yeager. 1949. Big game management in Colorado. J. Wildl. Manage. 13:392-412.

Jakimchuk, R. D., S. H. Ferguson, and L. G. Sopuck. 1987. Differential habitat use and sexual segregation in the Central Arctic caribou herd. Can. J. Zool. 65:534541.

Julander, O., W. L. Robinette, and D. A. Jones. 1961. Relation of summer range condition to mule deer herd productivity. J. Wildl. Manage. 25:54-60: 
Keeton, W. T. 1972. Biological Science (second edition). W.W. Norton Co. New York. $888 \mathrm{pp}$.

Kessler, L. G., and J. C. Avise. 1985. Microgeographic lineage analysis by mitochondrial genotype variation in the cotton rat (Sigmodon hispidus). Evolution 39:831-837.

Kie, J. G., and M. White. 1985. Population dynamics of white-tailed deer (Odocoileus virginianus) on the Welder Wildlife Refuge, Texas. The Southwestern Naturalist, 30:105-118.

Klein, D. R. 1968. The introduction, increase and crash of reindeer on St. Matthew Island. J. Wildl. Manage. 32:350-367.

- 1985. Population ecology: the interaction between deer and their food supply. Biol. Deer Prod. 22:13-22.

Kufeld, R. C., D. C. Bowden, and D. L. Schrupp. 1987. Estimating mule deer density by combining mark-recapture and telemetry data. J. Mammal. 68:818-825.

, and

- 1989. Distribution and movements of female mule deer in the Rocky Mountain Foothills. J. Wildl. Manage. 53:871-876.

Lack, D. 1954. The natural regulation of animal numbers. Clarendon Press, Oxford, London.

Lageson, D. R. 1989. Reactivation of a proterozoic continental margin, Bridger Range, Southwestern Montana. In: French, D.E. and Grabb, R.F., Geological Resources of Montana, Vol. I: Montana Geological Society Field Conference Guide Book. p. 279-298.

Leckenby, D. A., and A. W. Adams. 1986. A weather severity index on a mule deer winter range. J. Range Manage. 39:244-248.

Lent, P. C. 1974. Mother-infant relationships in ungulates, pp. 14-55 in: The behavior of ungulates and its relation to management, vol. I. V.C. Geist and F. Walther, eds., Morges, Switzerland, Inter. Union for the Conservation of Nature.

Leopold, A. 1933. Game Management. Charles Scribner's Sons, New York. 481 pp. , L. K. Sowls, and D. L. Spencer. 1947. A survey of over-populated deer ranges in the United States. J. Wild. Manage. 11:162-177. 
Lcopold, A. S., T. Riney, R. McCain, and L. Tevis, Jr. 1951. The Jawbone deer herd. Game Bull. No. 6, Calif. Fish and Game, 136 pp.

Linsdale, J. M., and P. Q. Tomich. 1953. A herd of mule deer: A record of observations made on the Hastings Natural History Reservation. Univ. of Calif. Press, Berkeley. 567 pp.

Loft, E. R., R. C. Bertram, and D. L. Bowman. 1989. Migration patterns of mule deer in the central Sierra Nevada. Calif. Fish and Game 75:1-19.

Longhurst, W. M. 1956. Population dynamics of deer. Calif. Agric., July, pp. 9-10.

, A. S. Leopold, and R. F. Dasmann. 1952. A survey of California deer herds. Calif. Fish and Game Bull. No. 6, 136 pp.

Lonner, T. N., and M. F. Pexton. 1983. GEOSCAN: A system of computer programs for quantifying animal distribution-habitat relationships. Montana Department of Fish, Wildlife and Parks, Bozeman. 459 pp.

, and D. F. Pac. 1990. Elk and mule deer use of whitebark pine forests in southwest Montana: An ecological perspective. Pp. 237-244 in: Proc. of Sympos. on Whitebark pine ecosystems: Ecology and management of a highmountain resource. U.S. Dept. of Agric., Forest Service, Intermount. Research Station, Gen. Tech. Rept. INT-270. 386 pp.

Loveless, C. M. 1967. Ecological characteristics of a mule deer winter range. Tech. Bull. No. 20. Colorado Game, Fish, and Parks Dept., Denver, 124 pp.

Lund, R. E. 1983. A user's guide to MSUSTAT -- An interactive statistical analysis package. CP/M Version. Research and Development Institute, Inc., Montana State University, Bozeman.

Lutgens, F. K., and E. J. Tarbuck. 1982. The atmosphere: an introduction to meteorology. Prentice-Hall, Inc., New Jersey, 478 pp.

Mackie, R. J. 1975. Evaluation of the key browse survey method. Paper presented at the Fifth Mule Deer Workshop, Albuquerque, New Mexico, February 1975. 17 pp. Available from author.

, and S. T. Stewart. 1976. Population ecology and habitat relationships of mule deer in the Bridger Mountains, Montana. Pp. 42-62 in Montana deer studies. Job Compl. Rept., P-R Proj. W-120-R, Study BG-1.4, J1. Montana Fish and Game Dept., Helena. 170 pp. 
, D. F. Pac, and H. E. Jorgensen. 1978. Population ecology and habitat relationships of mule deer in the Bridger Mountains, Montana. Pp. 83-128 in: Montana Deer Studies. Job Prog. Rept., Proj. W-120-R-9. Montana Department of Fish and Game, Helena. 217 pp.

, K. L. Hamlin, H. E. Jorgensen, J. G. Mundinger, and D. F. Pac. 1980. Management implications and recommendations. Pp. 192-205 in: Montana deer studies. Job Prog. Rept. Proj. W-120-R-11. Montana Department of Fish, Wildlife and Parks, Helena, 205 pp.

, and D. F. Pac. 1980. Deer and subdivisions in the Bridger Mountains, Montana. Proc. Ann. Conf. West. Assoc. Fish and Wildl. Agencies 60:517-526.

, K. L. Hamlin, and D. F. Pac. 1981. Census methods for mule deer. Pages 97-106 in F. L. Miller and A. Gunn, eds. Symposium on census and inventory methods for populations and habitats. For., Wildl., and Range Exp. Stn., Univ. Idaho Publ. 217, Moscow.

, G. L. Dusek, K. L. Hamlin, H. E. Jorgensen, D. F. Pac, and A. K. Wood. 1985. Management Recommendations, pp. 1-8 in: Montana deer studies. Job Prog. Rept. Proj. W-120-R-16. Montana Department of Fish, Wildlife and Parks, Helena. 132 pp.

, K. L. Hamlin, D. F. Pac, G. L. Dusek, and A. K. Wood. 1990. Compensation in free-ranging deer populations. Trans. 55th N.A. Wildl. and Nat. Res. Conf., pp 518-526.

Main, M. B., and B. E. Coblentz. 1990. Sexual segregation among ungulates: a critique. Wildl. Soc. Bull. 18:204-210.

Manlove, M. N., M. H. Smith, H. O. Hillestad, S. E. Fuller, P. E. Johns, and D. O. Straney. 1976. Genetic sub-division in a herd of white-tailed deer as demonstrated by spatial shifts in gene frequencies. Proc. of the S.E. Assoc. Game and Wildlife Commission 30:487-492.

Martinka, C. J. 1978. Ungulate populations in relation to wilderness in Glacier National Park, Montana. Trans. North Am. Wildl. Nat. Res. Conf. 43:351-357.

Mattfield, G. F., R. W. Sage, Jr., J. E. Wiley III, and D. F. Behrend. 1974. Seasonal difference in sex ratio of box-trapped deer. J. Wildl. Manage. 38:563-565.

Mautz, W. W. 1978. Sledding on a brushy hillside: the fat cycle in deer. Wildl. Soc. Bull. 6:88-90. 
Mayr, E. 1970. Populations, species, and evolution. The Belknap Press of Harvard Univ. Press. Cambridge, MS. 453 pp.

McCullough, D. R. 1979. The George Reserve deer herd: Population ecology of a Kselected species. Univ. of Michigan Press, Ann Arbor. 271 pp.

- 1983. Rate of increase of white-tailed deer on the George Reserve: A response. J. Wildl. Manage. 47:1248-1250.

. 1990. Detecting density dependence: Filtering the baby from the bath water. Trans. 55th N.A. Wildl. and Nat. Res. Conf., pp. 534-543.

, and D. H. Hirth. 1988. Evaluation of the Petersen-Lincoln estimator for a white-tailed deer population. J. Wildl. Manage. 52:534-544.

, and S. J. Newhouse. 1989. Resource partitioning between sexes in white-tailed deer. J. Wildl. Manage. 53:277-283.

McEwan, E. H. 1968. Growth and development of barren ground caribou. II. Postnatal growth rates. Can. J. Zool. 46:1023-1029

, and P. E. Whitehead. 1971. Measurement of the milk intake of reindeer and caribou calves using tritiated water. Can. J. Zool. 49:443-447.

Miller, F. L. 1974. Four types of territoriality observed in a herd of black-tailed deer. In The behavior of ungulates and its relation to management (V. Geist and F.R. Walther, eds.). 2:644-660. IUCN New Series Publ. No. 24. Morges, Switzerland: IUCN.

- 1970. Distribution patterns of black-tailed deer (Odocoileus hemionus columbianus) in relation to environment. J. Mammal. 51:248-260.

Miller, R. 1976. Models, metaphysics, and long-lived species. Bull. Ecological Soc. Amer. 57:2-6.

Moen, A. N. 1976. Energy conservation by white-tailed deer in the winter. Ecology 57:192-198.

Moen, A. N., and K. E. Evans. 1971. The distribution of energy in relation to snow cover in wildlife habitat. Pp 147-162 in: Proc. Symp. on snow and ice in relation to wildlife and recreation, Ames, IA. $280 \mathrm{pp}$.

Mohr, C. O. 1947. Table of equivalent populations of North American small mammals. Am. Midl. Nat. 37:223-249. 
Morrison, J. A., and E. W. Menzel, Jr. 1972. Adaptation of a free-ranging rhesus monkey group to division and transplantation. Wildl. Monogr. 31:1-78.

Morton, M. A. 1976. Nutritional values of major mule deer winter forage species in the Bridger Mountains, Montana. M.S. Thesis, Montana State University, Bozeman. 104 pp.

Mueggler, W. F., and W. L. Stewart. 1980. Grassland and shrubland habitat types of western Montana. U.S.D.A. Forest Service Gen. Tech. Rept. INT-66. 154 pp.

Mundinger, J. G. 1981. White-tailed deer reproductive biology in the Swan Valley, Montana. J. Wildl. Manage. 45:132-139.

Nellis, C. H. 1968. Productivity of mule deer on the national bison range, Montana. J. Wildl. Manage. 32:344-349.

, J. L. Thiessen, and C. A. Prentice. 1976. Pregnant fawn and quintuplet mule deer. J. Wildl. Manage. 40:795-796.

Nelson, M. E., and L. D. Mech. 1987. Demes within a northeastern Minnesota deer population. Pages 27-40 in B. D. Chepko-Sade and A. Halpin, eds. Proc. symp. on patterns of dispersal among mammals and their effects on the genetic structure of populations. Univ. Chicago Press, Chicago, Il.

Neu, C. W., C. R. Byers, and J. M. Peek. 1974. A technique for analysis of utilization-availability data. J. Wildl. Manage. 38:541-545.

Nicholson, A. J. 1957. The self-adjustment of populations to change. Cold Spring Harbor Sym. on Quant. Biol. 22:153-173.

Nyberg, H. E. 1980. Distribution, movements and habitat use of mule deer associated with the Brackett Creek winter range, Bridger Mountains, Montana. M.S. Thesis, Montana State Univ., Bozeman. 106pp.

Odum, E. P. 1953. Fundamentals of ecology. W.B. Saunders Co. Philadelphia. 384 pp.

Ozoga, J. J., and L. W. Gysel. 1972. Response of white-tailed deer to winter weather. J. Wildl. Manage. 36:892-896.

, and L. J. Verme. 1982. Physical and reproductive characteristics of a supplementally-fed white-tailed deer herd. J. Wildl. Manage. 46:281-301. 
, L. J. Verme, and C. S. Bienz. 1982. Parturition behavior and territoriality in white-tailed deer: impact on neonatal mortality. J. Wildl. Manage. 46:1-11.

Pac, D. F. 1976. Distribution, movements and habitat use during spring, summer and fall by mule deer associated with the Armstrong winter range, Bridger Mountains, Montana. M.S. Thesis, Montana State Univ., Bozeman. 120 pp.

- 1979. Statewide carcass collection. Montana Fish and Game Dept., Job Prog. Rept., Proj. W-120-R-10. 17 pp.

, and R. J. Mackie. 1981. Conflict for space. Montana Outdoors 12(2):13-16. , and H. E. Jorgensen. 1984. Relationships between mule deer and forest in southwestern Montana. In: Wallmo, O.C. and R.D. Taber (eds.), Fish and Wildlife relationships in old growth forests: Sym. of the NW Sect. for the Wildlife Soc., April 1982, Juneau, AK. Amer. Inst. of Fishery Res. Biol: 321328.

Pac, H. I., W. F. Kasworm, L. R. Irby, and R. J. Mackie. 1988. Ecology of the mule deer, Odocoileus hemionus, along the east front of the Rocky Mountains, Montana. Can. Field Nat. 102:227-236.

Peek, J. M. 1980. Natural regulation of ungulates (what constitutes a real wilderness?). Wildl. Soc. Bull. 8:217-227.

Pfister, R. D., B. L. Kovalchik, and S. F. Arno. 1977. Forest habitat types of Montana. Intermount Forest and Range Exp. Sta. and Northern region, USFS, Missoula, MT. 174 pp.

Ramsey, P. R., J. C. Avise, M. H. Smith, and D. F. Urbston. 1979. Biochemical variation and genetic heterogeneity in South Carolina deer populations. J. Wildl. Manage. 43:136-142.

Ransom, A. B. 1967. Reproductive biology of white-tailed deer in Manitoba. J. Wildl. Manage. 34:114-123.

Rasmussen, D. I. 1941. Biotic communities of the Kaibab Plateau. Ecol. Monog. 3:229-275.

Ray, A. A. 1982. SAS User's Guide. SAS Inst., Inc., Cary, North Carolina. 921 pp.

Rice, W. R., and J. D. Harder. 1977. Application of multiple aerial sampling to a mark-recapture census of white-tailed deer. J. Wildl. Manage. 41:197-206. 
Richens, V. B. 1967. Characteristics of mule deer herds and their range in northeastern Utah. J. Wildl. Manage. 31:651-666.

Robinette, W. L. 1966. Mule deer home range and dispersal in Utah. J. Wildl. Manage. 30:335-349.

, J. S. Gashwiler, D. A. Jones, and H. S. Crane. 1955. Fertility of mule deer in Utah. J. Wildl. Manage. 19:115-136.

, D. A. Jones, G. Rogers, and J. S. Gashwiler. 1957a. Notes on tooth development and wear for Rocky Mountain mule deer. J. Wildl. Manage. 21:134-153.

, J. S. Gashwiler, J. B. Low, and D. A. Jones. 1957b. Differential mortality by sex and age among mule deer. J. Wildl. Manage. 21:1-16.

, C. H. Baer, R. E. Pillmore, and C. E. Knittle. 1973. Effects of nutritional change on captive mule deer. J. Wildl. Manage. 37:312-326.

, N. V. Hancock, and D. A. Jones. 1977. The Oak Creek mule deer herd in Utah. Utah Div. Wildl. Res. Resource Publ. 77-15. 148 pp.

Robson, D. S., and H. A. Regier. 1964. Sample size in Petersen mark-recapture experiments. Trans. Amer. Fish Soc. 93:215-226.

Rosgaard, A. I., Jr. 1981. Ecology of the mule deer associated with the Brackett Creek winter range in the Bridger Mountains, Montana. M.S. Thesis, Montana State Univ., Bozeman. 76 pp.

Russell, C. P. 1932. Seasonal migration of mule deer. Ecol. Monog. Vol. II(1), 41 pp.

Sanderson, G. C. 1966. A study of mammal movements - a review. J. Wildl. Manage. 30:215-235.

Schoen, J. W., and M. D. Kirchoff. 1985. Seasonal distribution and home range patterns of sitka black-tailed deer on Admiralty Island, southeast Alaska. J. Wildl. Manage. 49:96-103.

Schwarzkopf, W. F. 1973. Range use and relationships of mule deer on the west slope of the Bridger Mountains, Montana. M.S. Thesis, Montana State Univ., Bozeman. $65 \mathrm{pp}$. 
Severson, K. E., and A. V. Carter. 1978. Movement and habitat use by mule deer in the northern Great Plains, South Dakota. Pages 466-468 in D. N. Hyder, ed. Proc. First Int. Rangelands Congr., Denver, Colorado. Soc. Range Manage.

Short, C. 1970. Morphological development and aging of mule and white-tailed deer fetuses. J. Wildl. Manage. 34:383-388.

Short, H. L., J. D. Newsom, G. L. McCoy, and J. F. Fowler. 1969. Effects of nutrition and climate on southern deer. Trans. N. Am. Wildl. Conf. 34:137145.

Simpson, G. G. 1953. The major features of evolution. Columbia Univ. Press, New York.

Smith, C. A. 1976. Deer sociobiology - some second thoughts. Wildl. Soc. Bull. 4:181-182.

Steerey, W. F. 1979. Distribution, range use and population characteristics of mule deer associated with the Schafer Creek winter range, Bridger Mountains, Montana. M.S. Thesis, MT State Univ., Bozeman, 119 pp.

Steigers, W. D. Jr., and J. T. Flinders. 1980. Mortality and movements of mule deer fawns in Washington. J. Wildl. Manage. 44:381-388.

Stirling, I. 1975. Factors affecting the evolution of social behavior in the pinnipedia. P. Reun. Cons. Int. Explor. Mer. 169:205-212.

Suring, L. H., and P. A. Vohs, Jr. 1979. Habitat use by Columbian white-tailed deer. J. Wildl. Manage. 43:610-619.

Swank, W. G. 1958. The mule deer in Arizona chaparral and an analysis of other important deer herds. Arizona Game and Fish Dept. Wildl. Bull. 3. 109 pp.

Taber, R. D., and R. F. Dasmann. 1954. A sex difference in mortality in young Columbian black-tailed deer. J. Wildl. Manage. 18:309-315.

Torbit, S. C., L. H. Carpenter, D. M. Swift, and A. W. Alldredge. 1985. Differential loss of fat and protein by mule deer during winter. J. Wildl. Manage. 49:80-85.

Verme, L. J. 1969. Reproductive patterns of white-tailed deer related to nutritional plane. J. Wildl. Manage. 33:881-887.

Wallmo, O. C., L. H. Carpenter, W. L. Regelin, R. B. Gill, and D. L. Baker. 1977. Evaluation of deer habitat on a nutritional basis. J. Range Manage. 30:122-127. 
White, G. C., R. A. Garrott, R. M. Bartmann, L. H. Carpenter, and A. W. Alldredge. 1987. Survival of mule deer in northwest Colorado. J. Wildl. Manage 51: 852859.

Whittaker, R. H. 1970. Communities and ecosystems. MacMillan Co., New York. $162 \mathrm{pp}$.

S. A. Levin, and R. B. Root. 1973. Niche, habitat, and ecotope. Amer. Nat. 107:321-338.

Wilkins, B. T. 1956. Range use, food habits, and agricultural relationships of the mule deer, Bridger Mountains, Montana. M.S. thesis. Montana State College, Bozeman. $34 \mathrm{pp}$.

- 1957. Range use, food habits, and agricultural relationships of mule deer, Bridger Mountains, Montana. J. Wildl. Manage. 21:159-169.

- 1958. Experimental range work-techniques. Mont. Dept. Fish and Game, Helena. Job Completion Report Project W-37-R-9, Job \#B2. 5 pp. Multilith.

Wood, A. K. 1986. Ecology of a prairie mule deer population. PhD. Thesis, Montana State Univ., Bozeman. 205 pp.

, R. J. Mackie, and K. L. Hamlin. 1989. Ecology of sympatric populations of mule deer and white-tailed deer in a prairie environment. Montana Department of Fish, Wildlife and Parks, Helena. 97 pp.

Youmans, H. B. 1979. Habitat use by mule deer of the Armstrong winter range. M.S. thesis, Montana State Univ., Bozeman. 66 pp.

Zalunardo, R. A. 1965. The seasonal distribution of a migratory mule deer herd. J. Wildl. Manage. 29: 345-351.

Zar, J. H. 1984. Biostatistical analysis. Second ed. Prentice-Hall, Inc., Englewood Cliffs, N.J. 718 pp. 